Guilherme Rosa Franzini

Tópicos de pesquisa em problemas de excitação paramétrica e de vibrações induzidas pelo escoamento

São Paulo 
Guilherme Rosa Franzini

\title{
Tópicos de pesquisa em problemas de excitação paramétrica e de vibrações induzidas pelo escoamento
}

Texto apresentado ao Departamento de Engenharia de Estruturas e Geotécnica da Escola Politécnica da USP como parte dos requisitos para a obtenção do título de Livre-Docente

\author{
Universidade de São Paulo - USP \\ Escola Politécnica \\ Departamento de Engenharia de Estruturas e Geotécnica
}

São Paulo

2019 
Autorizo a reprodução e divulgação total ou parcial deste trabalho, por qualquer meio convencional ou eletrônico, para fins de estudo e pesquisa, desde que citada a fonte.

\section{Catalogação-na-publicação}

\section{Franzini, Guilherme Rosa}

Tópicos de pesquisa em problemas de excitação paramétrica e de vibrações induzidas pelo escoamento / G. R. Franzini -- São Paulo, 2019. $343 \mathrm{p}$.

Tese (Livre-Docência) - Escola Politécnica da Universidade de São Paulo. Departamento de Engenharia de Estruturas e Geotécnica.

1.Dinâmica das estruturas 2.Excitação paramétrica 3.Interação fluido estrutura I.Universidade de São Paulo. Escola Politécnica. Departamento de Engenharia de Estruturas e Geotécnica II.t. 
Este trabalho é dedicado à Fabiana, amada esposa e maior incentivadora. 


\section{Agradecimentos}

Agradeço à Fabiana, minha amada esposa por todo o suporte, incentivo e paciência conferidos não só ao longo do desenvolvimento do texto mas em todos os aspectos da vida. Claro, não poderia esquecer de meus pais, Reinaldo e Maria, por todo o esforço para que eu tivesse as melhores formações pessoal e profissional possíveis. Sou grato a Deus, por todas as conquistas e pela oportunidade e saúde para trabalhar com ensino e pesquisa.

Aos funcionários e docentes do PEF, pela acolhida e suporte dados durante os quase cinco anos de convívio; aos professores Alfredo Neto, por toda a convivência diária de muita amizade, trabalho e, às vezes, partidas de videogame; Carlos Mazzilli, por todos os conselhos, confiança e todas as inúmeras oportunidades a mim oferecidas; Miguel Bucalem e João Cyro, pelo apoio, pelo convite para integrar a equipe de Mecânica das Estruturas I e II e por toda a ajuda oferecida ao longo de cinco anos; Edgard Neto, pela inestimável ajuda quando do meu início como docente; Eduardo Campello, Luis Bitencourt, Valério Almeida, Claudius Barbosa, pelos momentos de descontração, conversas (sérias ou não) e partidas de futebol; Celso Pesce, por todo o incentivo, apoio, discussões, conselhos, convites e por me incentivar a tomar o caminho por onde mais aprenderei; Alexandre Simos, pelos diversos convites e oportunidades de pesquisa; André Fujarra, antigo/atual mentor e a quem muito devo nesta jornada; Bruno Carmo, pelas conversas sempre produtivas e disposição em ajudar, Frédérick Gosselin, pelo convite e oportunidade para integrar seu grupo de pesquisa na condição de pesquisador visitante junto à École Polytechnique de Montréal.

Ao Conselho Nacional de Desenvolvimento Científico e Tecnológico (CNPq) pela bolsa de produtividade em pesquisa - nível 2, processo 310595/2015-0, à Fundação de Amparo à Pesquisa do Estado de São Paulo (FAPESP) pelo Auxílio à Pesquisa Regular, processo 2016/20929-2 e ao Fond de Recherche du Québec. Sem o apoio que essas agências ofereceram a mim e aos meus orientados, os resultados aqui obtidos não teriam sido alcançados.

A todos os meus orientados e orientadas. Muito obrigado pela confiança. Busquei fazer o meu máximo para que a formação de vocês tenha sido a melhor possível. Obrigado Agnes Brasil, Alice Lepique, Alex Wu, Amanda Vernabel, Alexandre Ravagnani, Arthur Cato, Bianca Teixeira, Beatriz Sato, Bruno Calidonna, Carolina Mondadori, Daniela Kawaguti, Daniel Pasetti, Daniel Tomin, Elvis Oliveira, Flávia Donatiello, Giovanna Campedelli, Giovanni Amaral, Guilherme Morita, Guilherme Rizkallah, Guilherme Vernizzi, Heloísa Castro, Igor Lourenço, Júlia Rizkallah, Lais Moraes, Letícia Madi, Lucas Bunzel, Michel Freitas, Pâmella Conte, Rafael Bernardes, Rafael Nagano, Rebeca Caramêz, Rodrigo Carneiro, Tatiana Ueno, Vinícius Vaguetti, Vitor Maciel e Ynaê Almeida. 
"You, me, or nobody is gonna hit as hard as life. But it ain't about how hard you hit, it's about how hard you can get hit and keep moving forward. How much you can take and keep moving forward. That's how winning is done." (Frase dita por Rocky Balboa a seu filho. Extraída do filme Rocky Balboa (2006), escrito e dirigido por Sylvester Stallone) 


\section{Resumo}

Este texto traz, de maneira integrada e sintetizada, tópicos de pesquisa em dinâmica das estruturas conduzidas pelo autor. Foco é destinado aos problemas de excitação paramétrica e em dois fenômenos de vibrações induzidas pelo escoamento, a saber, as vibrações induzidas pela emissão de vórtices (VIV) e o galloping. Os tópicos de pesquisa aqui descritos focam em contribuições na análise experimental e na modelagem matemática dos referidos problemas e em aplicações com vistas ao aproveitamento de energia e em supressão passiva por meio de elementos denominados absorvedores não-lineares de vibração.

No tocante à análise experimental, o texto traz a descrição de campanhas experimentais conduzidas com vistas ao estudo da resposta de um cilindro flexível vertical excitado por movimento imposto ao seu topo (o que induz a excitação paramétrica), por correnteza ou por ambas de maneira concomitante. Por meio de técnicas de análise experimental cujo desenvolvimento foi liderado pelo autor, contribuições referentes à composição modal da resposta e resultados qualitativos acerca da sincronização entre modos de vibrar são obtidas. Em particular, o texto apresenta os primeiros resultados experimentais existentes na literatura acerca da resposta de um cilindro flexível à solicitação combinada de movimento imposto ao topo e de correnteza.

Já no que diz respeito à supressão passiva via absorvedores não-lineares de vibração, estudos numéricos com foco na mitigação de excitação paramétrica, VIV e galloping são conduzidos e com contribuições inéditas ao estado-da-arte. Para o fenômeno de excitação paramétrica, mostra-se que o uso do tipo de absorvedor aqui estudado é capaz de limitar a resposta da estrutura principal mesmo em uma condição onde respostas ilimitadas são obtidas quando da ausência do supressor. Para os fenômenos de VIV e de galloping, os estudos indicam a eficiência do dispositivo para mitigação das oscilações, embora com a presença de erosão do plano de parâmetros de controle.

O texto é encerrado com a apresentação de contribuições do autor no tema de aproveitamento de energia a partir do fenômeno de VIV e via efeito piezoelétrico. Configurando uma outra contribuição inédita ao estado-da-arte, estudos numéricos mostram um pronunciado aumento da eficiência da coleta de energia quando o cilindro é liberado para oscilar nas duas direções do plano horizontal.

Palavras-chave: Dinâmica das estruturas, excitação paramétrica, interação fluido-estrutura. 


\section{Abstract}

This thesis shows some selected research topics on dynamics of structures developed by the author. Focus is placed on the following problems: parametric excitation and two flow-induced vibrations phenomena, namely, vortex-induced vibrations (VIV) and galloping. The contributions from of the research topics herein described concern both the experimental analyses and the mathematical modeling of the aforementioned problems as well as applications in energy harvesting and passive suppression using non-linear vibration absorbers (NVAs).

Considering the experimental analyses, the thesis brings the description of the experimental campaign carried out aiming at investigating the response of a vertical and flexible cylinder to either top-motion or current excitations. The response to simultaneous excitations is analyzed as well. By means of analyses methodologies developed by the author, contributions related to both the modal participation in the structural response and the synchronization between modal oscillations are assessed. Additionally, the thesis brings the first experimental results considering the response of a flexible cylinder to simultaneous excitation by the current and the imposed top motion.

Focusing on the passive suppression of parametric excitation and the mentioned flowinduced vibrations phenomena, new contributions to the literature are shown. The numerical results reveal that the presence of the NVA allows a limited structural response, despite the response of the system without the suppression being unbounded. For the VIV and the galloping phenomena, the use of the NVA can decrease the characteristic oscillation amplitudes of the main structure. It is worth emphasizing that sensitivity studies show the erosion of the plane of control parameters.

Finally, the thesis brings contributions related to the piezoelectric energy harvesting from VIV. Energy harvesting from the condition in which the cylinder subjected to VIV oscillates in the two directions of the horizontal plane is shown to be significantly more efficient than that in which the cylinder is constrained to oscillate in one direction. Key-words: Dynamics of structures, parametric excitation, fluid-structure interaction. 


\section{Lista de ilustrações}

Figura 1 - Representação esquemática dos tópicos de pesquisa aqui abordados. . . 34

Figura 2 - Curvas de transição do diagrama de Strutt obtidas para a equação de Mathieu não amortecida utilizando o método do balanço harmônico com três e com sete termos. . . . . . . . . . . . . . . . . . 38

Figura 3 - Cabo horizontal submetido à força de tração variável no tempo. . . . . 39

Figura 4 - Variação dos coeficientes $C_{m}=\left(1+C_{a}\right)$ e $C_{d}=\bar{C}_{D}$ com o número de Keulegen-Carpenter. . . . . . . . . . . . . . . . . . . . . . . 42

Figura 5 - Representações esquemáticas da separação do escoamento ao redor de um fólio e perfis de velocidade na camada limite. . . . . . . . . . . . 46

Figura 6 - Modelo bidimensional para a geração e desprendimento de vórtices. . . 47

Figura 7 - Variação dos coeficientes de arrasto médio $\bar{C}_{D}$ e de sustentação com o número de Reynolds. Os subscritos ()$_{f}$ e ()$_{p}$ indicam as parcelas de atrito e de pressão respectivamente. A área tracejada indica dispersão dos dados da literatura. . . . . . . . . . . . . . . . . . . . . 49

Figura 8 - Variações do número de Strouhal e do valor rms do coeficiente de sustentação com o número de Reynolds. . . . . . . . . . . . . . . . . . 50

Figura 9 - Amplitude de resposta como função da velocidade reduzida. VIV-1gl. . 52

Figura 10 - Frequência adimensional de oscilação como função da velocidade reduzida. VIV-1gl. . . . . . . . . . . . . . . . . . . . . . . 53

Figura 11 - Padrões de emissão de vórtices. . . . . . . . . . . . . . . . . . . . 54

Figura 12 - Variações da amplitude característica de oscilação como funções da velocidade reduzida e do número de Reynolds. . . . . . . . . . . . . . 55

Figura 13 - Amplitude de resposta e frequência adimensional de oscilação como funções da velocidade reduzida. VIV-2gl. . . . . . . . . . . . . . . 56

Figura 14 - Amplitude de resposta na direção cross-wise e ângulo de fase entre as oscilações nas direções cross-wise e in-line. . . . . . . . . . . . . . . 57

Figura 15 - Comparação entre resultados experimentais obtidos com cilindros rígidos montados em apoio elástico de dois graus de liberdade (círculos) e com cilindros flexíveis em balanço (demais marcadores). . . . . . . . . . . . 59

Figura 16 - Amplitude e frequências características de oscilação como função da velocidade reduzida. Experimentos com um modelo flexível com rigidez ortotrópica. . . . . . . . . . . . . . . . . . .

Figura 17 - Representação esquemática - fenômeno de VIV com um grau de liberdade para a estrutura. . . . . . . . . . . . . . . 
Figura 18 - Representação esquemática das forças hidrodinâmicas atuando em um cilindro sujeito ao VIV. O cilindro tem liberdade de oscilação somente na direção $Y \ldots \ldots$. . . . . . . . . . . . . . . . . . . . 68

Figura 19 - Corpo prismático sujeito ao fenômeno de galloping. Representação esquemática do problema. . . . . . . . . . . . . . . . . . . . 74

Figura 20 - Representação esquemática de experimentos com cilindros estacionários para obtenção das forças de arrasto e de sustentação. . . . . . . . . . . 74

Figura 21 - Forças aerodinâmicas decorrentes da incidência de escoamento e da movimentação do corpo. . . . . . . . . . . . . . . . . . . . 76

Figura 22 - Variação do coeficiente de força $C_{y}$ como função do ângulo de ataque. . 78

Figura 23 - Representação esquemática de um TMD . . . . . . . . . . . . . . . . . . 81

Figura 24 - Frequências e modos naturais não amortecidos como funções dos parâ-

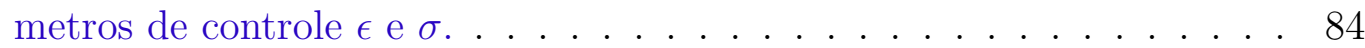

Figura 25 - Termos não nulos das matrizes de massa e de rigidez modal. . . . . . . 85

Figura 26 - Variação da grandeza $\hat{u}_{1} / p^{*}$ com os parâmetros de controle $\epsilon$ e $\sigma$. . . 87

Figura 27 - Defasagens entre força e deslocamento modais e fatores de amplificação dinâmica modais. Sistema sem amortecimento. . . . . . . . . . . . . . . 88

Figura 28 - Representação esquemática do fenômeno TET. . . . . . . . . . . . . . 90

Figura 29 - Exemplos de absorvedores não-lineares de vibração. . . . . . . . . . . . 92

Figura 30 - Representação esquemática de um CPVA. . . . . . . . . . . . . . . . . 93

Figura 31 - Exemplos de SIM para os problemas de supressão com VI-NES e NVA rotativo. . . . . . . . . . . . . . . . . . . 93

Figura 32 - Representação esquemática do dispositivo estudado em Benarous e Gendelman (2016). . . . . . . . . . . . . . . . . . . . . . . 94

Figura 33 - Representação esquemática do dispositivo estudado em Yang et al. (2018). 96

Figura 34 - Diagramas de bifurcação. As subfiguras a), b) c) e d) estão relacionadas a distintos valores da rigidez do NVA. . . . . . . . . . . . . . . . . 97

Figura 35 - Séries temporais de deslocamento do cilindro. A massa do NVA é 11\% da massa do cilindro. $R e=100 \ldots \ldots \ldots$. . . . . . . . . 98

Figura 36 - Série temporal de deslocamento do cilindro. A massa do NVA é 6,6\% da massa do cilindro. $R e=100 \ldots \ldots$. . . . . . . . . . . . 99

Figura 37 - Valores máximos de deslocamento do cilindro como função do número de Reynolds.

Figura 38 - Séries temporais de deslocamento do cilindro e do NVA. Condições iniciais triviais. $R e=106 . \ldots$. . . . . . . . . . . . . 100

Figura 39 - Séries temporais de deslocamento do cilindro e do NVA. Condições iniciais triviais e $\mu=0,03$. $R e=106$.

Figura 40 - Máximo deslocamento adimensional do cilindro como função da velocidade da correnteza incidente, parametrizado na massa do supressor. . . 102 
Figura 41 - Máximo deslocamento adimensional do cilindro como função da velocidade da correnteza incidente, parametrizado na rigidez do supressor.

Figura 42 - Amplitudes característica de oscilação do cilindro como função da velocidade reduzida.

Figura 43 - Séries temporais de deslocamento do cilindro e do supressor, de velocidade angular do supressor e dos coeficientes de arrasto e sustentação.

Figura 44 - Slow invariant manifold e a trajetória do cilindro obtida a partir do modelo de maior hierarquia. $\delta-\gamma$ representa a diferença entre a fase de resposta do cilindro e do supressor. . . . . . . . . . . . . . . . . 106

Figura 45 - Exemplos de resposta do cilindro e da esteira para uma particular configuração de NVA rotativo. Re =100 . . . . . . . . . . . . . . 107

Figura 46 - Resposta limitada em amplitude obtida para um determinado conjunto de parâmetros do NVA rotativo. . . . . . . . . . . . . . . . . . . . . 108

Figura 47 - Velocidade crítica para o fenômeno de galloping como função do amortecimento e da massa do NVA. . . . . . . . . . . . . . . . . . . . 109

Figura 48 - Máximo deslocamento adimensional do prisma como função da velocidade do escoamento incidente. $\beta=0,005, \xi_{\text {nes }}=0,05$ e $k_{\text {nes }}^{*}=0,02 . \quad$. 110

Figura 49 - Séries temporais de deslocamento do NVA com relação à estrutura principal, obtidas a partir de mudanças nos parâmetros que o definem. 111

Figura 50 - Séries temporais de deslocamento do NVA com relação à estrutura principal, obtidas a partir de mudanças nas suas condições iniciais. . 112

Figura 51 - Arranjo experimental e potência elétrica obtida como função da velocidade do vento.

Figura 52 - Rendimento da coleta de energia como função da frequência natural da estrutura $\delta$ e da taxa de amortecimento estrutural $\xi$. . . . . . . . . . 118

Figura 53 - Representação esquemática do problema estudado em Dai, Abdelkefi e Wang (2014) . . . . . . . . . . . . . . . . . . . . 119

Figura 54 - Correlação numérico-experimental. . . . . . . . . . . . . . . . . . . . . 119

Figura 55 - Representação esquemática de arranjo experimental. . . . . . . . . . . 120

Figura 56 - Representação esquemática de arranjo experimental. . . . . . . . . . . . 121

Figura 57 - Desvio padrão da tensão elétrica adimensional como função da velocidade reduzida. . . . . . . . . . . . . . . . . . . . 123

Figura 58 - Resultados experimentais. . . . . . . . . . . . . . . . . . . 125

Figura 59 - Representações esquemáticas do arranjo experimental. O carro de reboque movimenta-se da esquerda para a direita. O eixo $z$ tem a direção do modelo e sua origem no vínculo inferior. . . . . . . . . . . . . . . . 129

Figura 60 - Fotografias do arranjo experimental. . . . . . . . . . . . . . . . . . 130

Figura 61 - Resultado experimental do ensaio de decaimento com o modelo imerso. 132 
Figura 62 - Escalogramas $x^{*}(\xi, \tau)$ e espectros de amplitude $S_{x}(\xi, \hat{f})$. Os escalogramas ilustram apenas 10 instantes de tempo adimensional de medição. $f_{t}: f_{n, 1}=1: 3$ e $f_{t}: f_{n, 1}=1: 1 \ldots \ldots \ldots \ldots$

Figura 63 - Escalogramas $x^{*}(\xi, \tau)$ e e espectros de amplitude $S_{x}(\xi, \hat{f})$. Os escalogramas ilustram apenas 10 instantes de tempo adimensional de medição. $f_{t}: f_{n, 1}=2: 1$ e $f_{t}: f_{n, 1}=3: 1 \ldots \ldots \ldots \ldots \ldots \ldots \ldots \ldots \ldots \ldots$

Figura 64 - Diagramas de Strutt modais. Vermelho (triângulo): $f_{t}: f_{n, 1}=1: 1$; Verde (círculo): $f_{t}: f_{n, 1}=2: 1$; Azul (quadrado): $f_{t}: f_{n, 1}=3: 1$. Os resultados para $f_{t}: f_{n, 1}=1: 3$ estão dentro da região estável e não são visíveis. . . . . . . . . . . . . . . . . . . . . . . . 140

Figura 65 - Séries temporais de amplitude modal $\tilde{a}_{1}(\tau)$. . . . . . . . . . . . . 141

Figura 66 - Séries temporais de amplitude modal $\tilde{a}_{2}(\tau)$. . . . . . . . . . . . . 142

Figura 67 - Séries temporais de amplitude modal $\tilde{a}_{3}(\tau)$. . . . . . . . . . . . . . 144

Figura 68 - Espectros de amplitude $S_{x}(\xi, \hat{f})$ e $S_{y}(\xi, \hat{f}) .4<U_{r, 1}<8$. . . . . . . 147

Figura 69 - Espectros de amplitude $S_{x}(\xi, \hat{f})$ e $S_{y}(\xi, \hat{f}) .8<U_{r, 1}<14$. . . . . . 149

Figura 70 - Envelopes de amplitude característica de oscilação. $4<U_{r, 1}<8$. . . . . 151

Figura 71 - Envelopes de amplitude característica de oscilação. $8<U_{r, 1}<14$. . . . 153

Figura 72 - Exemplo de existência de dois regimes distintos de resposta. $U_{r, 1}=6,99.155$

Figura 73 - Trajetórias no plano horizontal. Os pontos vermelhos indicam a posição média de cada ponto para o qual a trajetória é exibida. $U_{r, 1}=6,99$. . 156

Figura 74 - Exemplo de existência de dois regimes distintos de resposta. $U_{r, 1}=11,57.157$

Figura 75 - Trajetórias no plano horizontal. Os pontos vermelhos indicam a posição média de cada ponto para o qual a trajetória é exibida. $U_{r, 1}=11,57$.

Figura 76 - Séries temporais de amplitude modal - direção cross-wise. Velocidades reduzidas modais $U_{r, 1} \approx U_{r, 2} \approx 4,20$.

Figura 77 - Séries temporais de amplitude modal obtidas a partir de dois experimentos distintos e caracterizados por velocidades reduzidas modais $U_{r, 1} \approx U_{r, 2} \approx 5,70 \ldots \ldots \ldots$. . . . . . . . . . . . . . . . . . . . . .

Figura 78 - Trajetórias nos planos modais $\tilde{a}_{x}^{2 k} \times \tilde{a}_{y}^{k}$. Velocidades reduzidas modais $U_{r, 1} \approx U_{r, 2} \approx 5,70$.

Figura 79 - Séries temporais de diferença de fase ${ }_{k}^{2 k} \phi_{y}^{x}(\tau)$. Velocidades reduzidas modais $U_{r, 1} \approx U_{r, 2} \approx 5,70 \ldots \ldots$. . . . . . . . . . . . 163

Figura 80 - Séries temporais de amplitude modal $\tilde{a}_{1}^{y}(\tau)$ e $\tilde{a}_{2}^{y}(\tau)$. . . . . . . . . . 164

Figura 81 - Séries temporais de diferença de fase ${ }_{1}^{2} \phi_{y}^{y}(\tau) . U_{r, 1}=6,99 \leftrightarrow U_{r, 2}=3,49$. 165

Figura 82 - Valores característicos das séries temporais de amplitude modal como funções da velocidade reduzida modal. . . . . . . . . . . . . . . 165

Figura 83 - Séries temporais de deslocamento e espectros de amplitude para um ponto localizado em $\xi=z / L_{0}=0,43$. (a), (b): "VIV puro"; (c)-(f) VIV com movimento imposto ao topo. $U_{r, 1} \approx 5,70$. 
Figura 84 - (a), (c) e (e): Amplitudes características de oscilação na direção crosswise $\hat{A}_{y}(\xi) ;(\mathrm{b}),(\mathrm{d})$ e (f): Espectro de amplitude na direção cross-wise $S_{y}(\xi, \hat{f}) . U_{r, 1} \approx 5,70$. e $A_{t} / L_{0}=1 \%$. . . . . . . . . . . . . 170

Figura 85 - (a), (c) e (e): Amplitudes características de oscilação na direção in-line $\hat{A}_{x}(\xi) ;(\mathrm{b}),(\mathrm{d})$ e (f): Espectro de amplitude na direção in-line $S_{x}(\xi, \hat{f})$. $U_{r, 1} \approx 5,70$. e $A_{t} / L_{0}=1 \% \ldots \ldots \ldots$. . . . . . . . . . . . . . . . . .

Figura 86 - Trajetórias no plano horizontal. (a), (d) e (g): "VIV puro"; (b), (e) e (h): $f_{t}: f_{n, 1}=2: 1, A_{t} / L_{0}=1 \%$; (c), (f) e (i): $f_{t}: f_{n, 1}=3: 1, A_{t} / L_{0}=1 \%$. $150<\tau=t f_{n, 1}<155 \ldots \ldots \ldots \ldots \ldots$. . . . . . . . . . . . . . . . . .

Figura 87 - Séries temporais de amplitude modal. $U_{r, 1} \approx 5,70$. (a), (b): "VIV puro"; (c)-(f) VIV concomitante com movimento imposto ao topo de amplitude $A_{t} / L_{0}=1 \%$.

Figura 88 - Série temporal de amplitude modal $\tilde{a}_{3}^{y}(\tau)$ e correspondente espectro de amplitude. $f_{t}: f_{n, 1}=3: 1 \ldots \ldots \ldots$. . . . . . . . . . . . . . . .

Figura 89 - Trajetórias no plano modal $\tilde{a}_{2}^{x} \times \tilde{a}_{1}^{y}$. a): "VIV puro"; (b), (c) VIV concomitante com movimento imposto ao topo de amplitude $A_{t} / L_{0}=1 \% .179$

Figura 90 - Valores característicos de amplitude modal como funções da velocidade reduzida modal $U_{r, k} \ldots \ldots \ldots$. . . . . . . . . . . . . 180

Figura 91 - Representações esquemáticas. . . . . . . . . . . . . . . . . . . 186

Figura 92 - Séries temporais de amplitude modal adimensional $n=2, A_{t} / L_{0}=1 \%$. 191

Figura 93 - Configurações deformadas instantâneas. Os marcadores indicam os máximos deslocamentos observados. . . . . . . . . . . . . . . . . . . 193

Figura 94 - Exemplos de séries temporais de amplitude modal - MOR unimodal. . 194

Figura 95 - Séries temporais de amplitude modal adimensional. $n=2,15, A_{t} / L_{0}=1 \% .195$

Figura 96 - Mapas de amplitude pós-crítica. . . . . . . . . . . . . . . . 196

Figura 97 - Valores característicos das séries temporais de amplitude modal como funções de $\epsilon_{k}\left(\omega_{1} / \omega_{n, k}\right)^{2}$ para $\Omega / \omega_{n, k}=2 \ldots$. . . . . . . . . . 197

Figura 98 - Curvas de resposta em frequência para $A_{t} / L_{0}=1 \%$. . . . . . . . . 198

Figura 99 - Comparação entre os modelos de ordem reduzida e dados experimentais. 200

Figura 100-Comparação entre os modelos de ordem reduzida e dados experimentais.201

Figura 101-Representação esquemática - fenômeno de VIV com dois graus de liberdade para a estrutura. . . . . . . . . . . . . . . . . . . . 202

Figura 102 - Representação esquemática das forças hidrodinâmicas atuando em um cilindro sujeito ao VIV-2gl. . . . . . . . . . . . . . . . . . . . . . . . . 204

Figura 103 -Estudo de sensibilidade da resposta do modelo obtido com relação aos parâmetros de calibração. Condição VIV-2gl. . . . . . . . . . . . . . . . 207

Figura 104-Representação esquemática do problema. Cilindro rígido sujeito à excitação paramétrica dotado de um NVA rotativo. O versor i é horizontal e orientado da esquerda para a direita. 
Figura 105-Variação de $y_{\text {std }}$ e de $\max \{y\}$ como função de $\hat{r}$ e $\hat{m}$.

Figura $106-y_{s t d}(\hat{m} ; \hat{r})$ e exemplos qualitativos da resposta do cilindro $y(\tau)$. $\zeta_{\theta}=0,05.218$

Figura $107-y_{s t d}(\hat{m} ; \hat{r})$ e exemplos qualitativos da resposta do cilindro $y(\tau) . \zeta_{\theta}=0,10.219$

Figura $108-y_{\text {std }}(\hat{m} ; \hat{r})$ e exemplos qualitativos da resposta do cilindro $y(\tau) . \zeta_{\theta}=0,15.219$

Figura 109-Séries temporais e análises espectrais. $\hat{m}=0,12, \hat{r}=0,35$ e $\zeta_{\theta}=0,05 . \quad$. 221

Figura 110-Séries temporais e análises espectrais. $\hat{m}=0,08, \hat{r}=0,17$ e $\zeta_{\theta}=0,05$. 223

Figura 111 -Séries temporais e análises espectrais. $\hat{m}=0,12, \hat{r}=0,35$ e $\zeta_{\theta}=0,10$. 224

Figura 112 -Séries temporais e análises espectrais. $\hat{m}=0,08, \hat{r}=0,20$ e $\zeta_{\theta}=0,15$. . 225

Figura 113 -Variação de $|\eta|$ como função de $\hat{r}$ e $\hat{m}$. . . . . . . . . . . . . . . 226

Figura 114-Séries temporais de resposta do cilindro e do supressor. $\hat{m}=0,06$, $\hat{r}=0,25$ e $\zeta_{\theta}=0,15$.

Figura 115-Apresentação da SIM para o caso onde o supressor é definido por

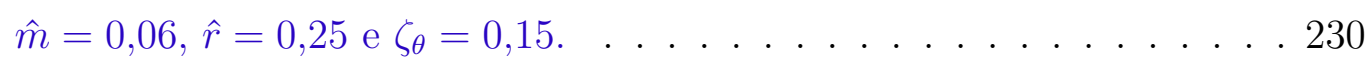

Figura 116-Série temporal da defasagem $\tilde{\alpha}-\psi \cdot \hat{m}=0,06, \hat{r}=0,25$ e $\zeta_{\theta}=0,15$. . 231

Figura 117 -Comparação entre a resposta e a SIM. $\hat{m}=0,06, \hat{r}=0,25$ e $\zeta_{\theta}=0,15$. 232

Figura 118-Representações esquemáticas do problema em estudo. . . . . . . . . . . 236

Figura 119-Influência do parâmetro $\hat{m}$ nas curvas de amplitudes características de oscilação. Simulações pertencentes ao Grupo 1 e caracterizadas por $\hat{r}=0,50$ e $\zeta_{\theta}=0,10$. G1-Sim1: $\hat{m}=0,03$, G1-Sim2: $\hat{m}=0,07$, G1-Sim3: $\hat{m}=0,10$, G1-Sim4: $\hat{m}=0,12$ e G1-Sim5: $\hat{m}=0,15 \ldots . \ldots 243$

Figura 120-Simulações pertencentes ao Grupo 2 e caracterizadas por $\hat{m}=0,05$ e $\zeta_{\theta}=0,10$. G2-Sim1: $\hat{r}=0,40$, G2-Sim2: $\hat{r}=0,30$, G2-Sim3: $\hat{r}=0,20$ e G2-Sim4: $\hat{r}=0,10 \ldots \ldots \ldots \ldots \ldots \ldots \ldots$

Figura 121-Simulações pertencentes ao Grupo 3 e caracterizadas por $\hat{m}=0,05$ e $\hat{r}=0,50$. G3-Sim1: $\zeta_{\theta}=0,20$, G3-Sim2: $\zeta_{\theta}=0,15$, G3-Sim3: $\zeta_{\theta}=0,08$, G3-Sim4: $\zeta_{\theta}=0,05$ e G3-Sim5: $\zeta_{\theta}=0,01 \ldots \ldots . \ldots 246$

Figura 122 -Exemplos de séries temporais obtidas para a condição VIV-1gl. Simula-

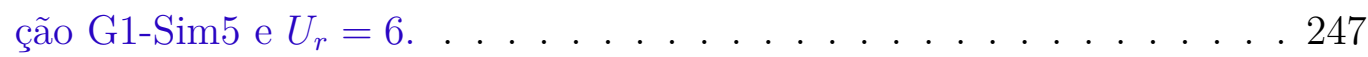

Figura 123 -Exemplos de séries temporais obtidas para a condição VIV-1gl. Simulação G1-Sim5 e $U_{r}=8,7 \ldots$. . . . . . . . . . . . . . . . . 248

Figura 124-Exemplo de séries temporais obtidas para a condição VIV-1gl. Condição G1-Sim5 e $U_{r}=10 \ldots \ldots$. . . . . . . . . . . . . . . . . 249

Figura 125 - Exemplo de séries temporais obtidas para a condição VIV-2gl. Condição

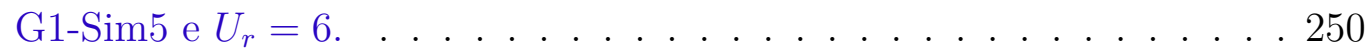

Figura 126-Exemplo de séries temporais obtidas para a condição VIV-2gl. Condição G1-Sim5 e $U_{r}=10 \ldots \ldots$. . . . . . . . . . . . . . . . 252

Figura 127 -Variação do critério $\hat{S}$ como função dos parâmetros $\hat{m}$ e $\hat{r}$. Condição VIV-1gl, $\zeta_{\theta}=0,05$ e $U_{r}=6,4$. 
Figura 128 -Variação do critério $\hat{S}$ como função dos parâmetros $\hat{m}$ e $\hat{r}$. Condição

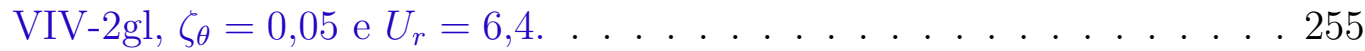

Figura 129 -Variação do critério $\hat{S}$ como função dos parâmetros $\hat{m}$ e $\hat{r}$. Condição

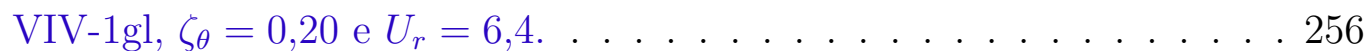

Figura 130 - Variação do critério $\hat{S}$ como função dos parâmetros $\hat{m}$ e $\hat{r}$. Condição VIV-2gl, $\zeta_{\theta}=0,20$ e $U_{r}=6,4$.

Figura 131 - Variação do critério $\hat{S}$ como função dos parâmetros $\hat{m}$ e $\hat{r}$. Condição VIV-1gl, $\zeta_{\theta}=0,05$ e $U_{r}=7,9$.

Figura 132 - Variação do critério $\hat{S}$ como função dos parâmetros $\hat{m}$ e $\hat{r}$. Condição VIV-2gl, $\zeta_{\theta}=0,05$ e $U_{r}=7,9$.

Figura 133 -Variação do critério $\hat{S}$ como função dos parâmetros $\hat{m}$ e $\hat{r}$. Condição VIV-1gl, $\zeta_{\theta}=0,20$ e $U_{r}=7,9$.

Figura 134-Variação do critério $\hat{S}$ como função dos parâmetros $\hat{m}$ e $\hat{r}$. Condição VIV-2gl, $\zeta_{\theta}=0,20$ e $U_{r}=7,9$.

Figura 135 -Variação do critério $\hat{S}$ como função dos parâmetros $\hat{m}$ e $\hat{r}$. Condição VIV-1gl, $\zeta_{\theta}=0,05$ e $U_{r}=9,2$.

Figura 136-Variação do critério $\hat{S}$ como função dos parâmetros $\hat{m}$ e $\hat{r}$. Condição VIV-2gl, $\zeta_{\theta}=0,05$ e $U_{r}=9,2$.

Figura 137 -Variação do critério $\hat{S}$ como função dos parâmetros $\hat{m}$ e $\hat{r}$. Condição VIV-1gl, $\zeta_{\theta}=0,20$ e $U_{r}=9,2$. 268

Figura 138 -Variação do critério $\hat{S}$ como função dos parâmetros $\hat{m}$ e $\hat{r}$. Condição VIV-2gl, $\zeta_{\theta}=0,20$ e $U_{r}=9,2$.

Figura 139-Representação esquemática do problema de supressão passiva utilizando um NVA rotativo.

Figura 140 - Representação esquemática da orientação do prisma estudada numericamente e experimentalmente. . . . . . . . . . . . . . . . . . . 274

Figura 141 - Variação do coeficiente de força $C_{y}(\alpha)$ com o ângulo de ataque $\alpha$. . . . 275

Figura 142 -Resultados numéricos referentes à condição onde o prisma não está dotado do supressor.

Figura 143-Influência da massa do supressor na curva de resposta do prisma como função da velocidade reduzida. $\hat{r}=0,40$ e $\zeta_{\theta}=0,05$. 277

Figura 144-Influência do raio do supressor na curva de resposta do prisma como função da velocidade reduzida. $\hat{m}=0,08$ e $\zeta_{\theta}=0,05$.

Figura 145 - Influência da taxa de amortecimento do supressor na curva de resposta do prisma como função da velocidade reduzida. $\hat{m}=0,08$ e $\hat{r}=0,40$.

Figura 146-Exemplos de séries temporais. Supressor caracterizado por $\hat{r}=0,40$ e

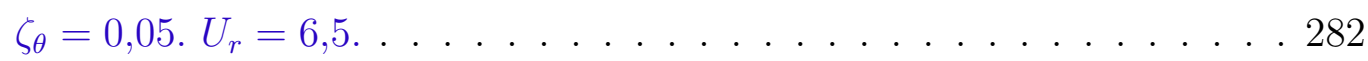

Figura 147 -Detalhe das séries temporais de resposta. $\hat{m}=0,05, \hat{r}=0,40, \zeta_{\theta}=0,05$ e $U_{r}=6,5$. 
Figura 148-Exemplos de séries temporais. Supressor caracterizado por $\hat{r}=0,40$ e

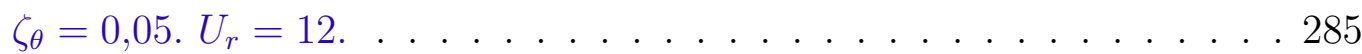

Figura 149-Detalhe das séries temporais de resposta. $\hat{m}=0,13, \hat{r}=0,40, \zeta_{\theta}=0,05$

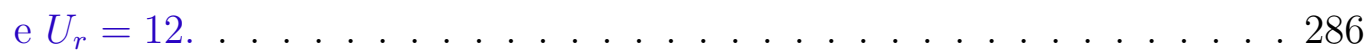

Figura 150-Exemplos de séries temporais. Supressor caracterizado por $\hat{r}=0,40$ e

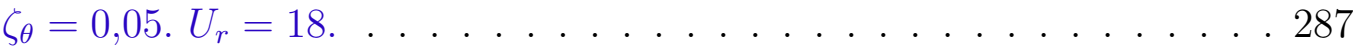

Figura 151 - Variação do critério $\hat{S}$ como função dos parâmetros $\hat{m}$ e $\hat{r}$. $\zeta_{\theta}=0,05$ e $U_{r}=6,5 . y_{s t d, 0}=0,34$.

Figura 152 -Variação do critério $\hat{S}$ como função dos parâmetros $\hat{m}$ e $\hat{r}$. $\zeta_{\theta}=0,20$ e $U_{r}=6,5 . y_{s t d, 0}=0,34$.

Figura 153 - Variação do critério $\hat{S}$ como função dos parâmetros $\hat{m}$ e $\hat{r}$. $\zeta_{\theta}=0,05$ e $U_{r}=12$.

Figura 154-Variação do critério $\hat{S}$ como função dos parâmetros $\hat{m}$ e $\hat{r}$. $\zeta_{\theta}=0,20$ e $U_{r}=12 \ldots \ldots \ldots \ldots \ldots \ldots \ldots$. . . . . . . . . . . . . . . . . . . . .

Figura 155 -Variação do critério $\hat{S}$ como função dos parâmetros $\hat{m}$ e $\hat{r}$. $\zeta_{\theta}=0,05$ e $U_{r}=18$

Figura 156 - Variação do critério $\hat{S}$ como função dos parâmetros $\hat{m}$ e $\hat{r}$. $\zeta_{\theta}=0,20$ e $U_{r}=18$.

Figura 157-Representações esquemáticas.

Figura 158-Amplitudes características de oscilação. Condições "VIV puro" (marcadores vazios) e considerando o efeito piezoelétrico com $\sigma_{1}=0,34 \mathrm{e}$ $\sigma_{2}=21,4$ (marcadores preenchidos).

Figura 159-Séries temporais de deslocamento, espectros de amplitude e trajetórias no plano horizontal. $U_{r}=6 \ldots \ldots$. . . . . . . . . . . . . 312

Figura 160 -Tensão elétrica adimensional (rms). $\sigma_{1}=0,34$ e $\sigma_{2}=21,4$. . . . . . . 313

Figura 161-Séries temporais de tensão elétrica adimensional. $\sigma_{1}=0,34, \sigma_{2}=21,4 \mathrm{e}$

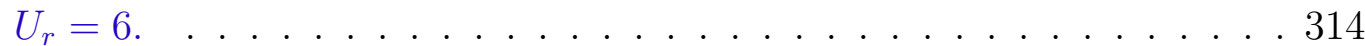

Figura 162 -Eficiência do aproveitamento de energia. $\sigma_{1}=0,34, \sigma_{2}=21,4$. . . . . 314

Figura 163-Média temporal da potência elétrica obtida no circuito associado à direção cross-wise.

Figura 164 -Estudo de sensibilidade e curvas de nível. $U_{r}=6 . . . . . . .316$

Figura 165 -Variação de $\bar{\eta}_{e l, y}$ com o parâmetro $\sigma_{1} \cdot U_{r}=6$ and $\sigma_{2}=20,5$. . . . . . . 317 


\section{Lista de tabelas}

Tabela 1 - Grandezas de interesse. . . . . . . . . . . . . . . . . . 51

Tabela 2 - Valores dos parâmetros do wake-oscillator segundo Facchinetti, de Langre e Biolley (2004) e Ogink e Metrikine (2010). . . . . . . . . . 70

Tabela 3 - Caracterização do arranjo experimental. A direção ao longo do eixo do cilindro vertical é indicada pela coordenada $z$, assumida como nula no vínculo inferior. . . . . . . . . . . . . . . . . . . . . 131

Tabela 4 - Valores característicos das séries temporais de amplitude modal. . . . . 139

Tabela 5 - Pontos experimentais no plano $\left(\delta_{k} ; \epsilon_{k}\right)$. Pontos destacados são próximos das curvas de transição ou na região de instabilidade. . . . . . . . . . 139

Tabela 6 - Relação de frequências das respostas. Predição via diagrama de Strutt comparada com as medições experimentais. . . . . . . . . . . . 145

Tabela 7 - Parâmetros do modelo de ordem reduzida. . . . . . . . . . . . . . . 189

Tabela 8 - Propriedades do arranjo experimental descrito em Franzini et al. (2012a).199

Tabela 9 - Estudo de sensibilidade do modelo desenvolvimento com relação aos parâmetros de calibração, . . . . . . . . . . . . . . . 206

Tabela 10 - Diferentes tipos de resposta do cilindro para valores selecionados de

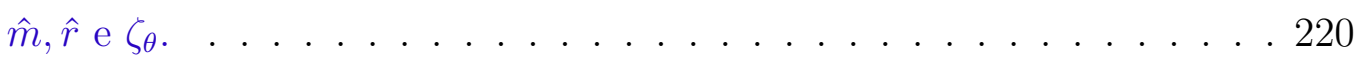

Tabela 11 - Valores dos parâmetros do modelo apresentado em Franzini e Bunzel (2018). . . . . . . . . . . . . . . . . . . 240

Tabela 12 - Valores numéricos dos parâmetros que definem o NVA rotativo. . . . . 241

Tabela 13 - Pontos no plano de parâmetros de controle para os quais as séries temporais $y(\tau)$ e $\theta(\tau)$ são exibidas juntamente aos mapas $\hat{S}(\hat{m} ; \hat{r}) \ldots 242$

Tabela 14 - Parâmetros do arranjo experimental utilizado no túnel de vento da PolyMTL. . . . . . . . . . . . . . . . . . . 273

Tabela 15 - Pontos no plano de parâmetros de controle para os quais as séries temporais $y(\tau)$ e $\theta(\tau)$ são exibidas juntamente aos mapas $\hat{S}(\hat{m} ; \hat{r}) \ldots 275$

Tabela 16 - Propriedades do arranjo experimental descrito em Franzini et al. (2012a).309

Tabela 17 - Parâmetros dos modelos de ordem reduzida. . . . . . . . . . . . . . 310 


\section{Lista de abreviaturas e siglas}

DFC Dinâmica de Fluidos Computacional

EPUSP Escola Politécnica da Universidade de São Paulo

FAPESP Fundação de Amparo à Pesquisa do Estado de São Paulo

IPT Instituto de Pesquisas Tecnológicas do Estado de São Paulo

LMO Laboratório de Mecânica Offshore

MOR Modelo de ordem reduzida

NVA Absorvedor não-linear de vibração (non-linear vibration absorber)

PEF Departamento de Engenharia de Estruturas e Geotécnica

PolyMTL École Polytechnique de Montréal

"RAC" Tipo de resposta no qual a estrutura principal oscila com amplitude constante

"RI" Tipo de resposta no qual a estrutura principal oscila com amplitude ilimitada

"RM" Tipo de resposta no qual a estrutura alterna entre trechos caracterizados por oscilações com amplitude constante e trechos nos quais há modulação da amplitude de oscilação

"RMA" Tipo de resposta no qual a estrutura principal oscila apresentando modulações em amplitude

SIM Slow invariant manifold

"SC" Tipo de resposta no qual a estrutura principal oscila com amplitude praticamente nula

TLP Tension Leg Platform

TMD $\quad$ Tuned mass damper

VIE Vibrações induzidas pelo escoamento

VIV Vibrações induzidas pela emissão de vórtices 
VIV-1gl Vibrações induzidas pela emissão de vórtices de um cilindro rígido montado em base elástica com liberdade de oscilação na direção crosswise

VIV-2gl Vibrações induzidas pela emissão de vórtices de um cilindro rígido montado em base elástica com liberdade de oscilação nas direções $i n-$ line e cross-wise 


\section{Lista de símbolos}

$A_{x}$ e $A_{y} \quad$ Parâmetros do wakes-oscillators e que devem ser calibrados experimentalmente

$\hat{A}_{x} \quad$ Amplitude característica de oscilação na direção in-line

$\hat{A}_{y} \quad$ Amplitude característica de oscilação na direção cross-wise

$a_{k} \quad$ Coeficientes do polinômio que descreve a força aerodinâmica na direção cross-wise

$\tilde{a}_{k}(\tau) \quad$ Série temporal de amplitude modal associada ao k-ésimo modo de vibrar

$C_{a} \quad$ Coeficiente de massa adicional, $C_{a}=\frac{m_{a}}{m_{d}}$

$C_{a}^{\text {pot }} \quad$ Coeficiente de massa adicional calculado como solução do problema de escoamento potencial considerando o corpo imerso em um fluido de domínio infinito, $C_{a}^{p o t}=\frac{m_{a}^{p o t}}{m_{d}}$

$C_{D} \quad$ Coeficiente de arrasto

$\bar{C}_{D} \quad$ Coeficiente de arrasto médio

$\hat{C}_{D}^{0} \quad$ Amplitude da parcela oscilatória do coeficiente de arrasto observado no problema do escoamento ao redor de um cilindro fixo

$C_{L} \quad$ Coeficiente de sustentação

$\hat{C}_{L}^{0} \quad$ Amplitude do coeficiente de sustentação observado no problema do escoamento ao redor de um cilindro fixo

$C_{P} \quad$ Capacitância

$c_{x} \quad$ Constante de amortecimento associada à direção in-line

$c_{y} \quad$ Constante de amortecimento associada à direção cross-wise

$c_{\theta} \quad$ Constante de amortecimento do NVA

D Dimensão característica da seção transversal do corpo. No caso de um cilindro, seu diâmetro

$f_{f} \quad$ Frequência de emissão de vórtices associada ao problema do escoamento ao redor de um cilindro fixo 


\begin{tabular}{|c|c|}
\hline$f_{n, y}$ & $\begin{array}{l}\text { Frequência de referência. Geralmente, é a frequência natural na direção } \\
\text { cross-wise }\end{array}$ \\
\hline$f_{n, k}$ & Frequência natural do k-ésimo modo de vibrar \\
\hline$\hat{f}$ & Frequência adimensional de oscilação, $\hat{f}=\frac{f}{f_{n, y}}$ \\
\hline$k_{x}$ & Constante de rigidez associada à direção in-line \\
\hline$k_{y}$ & Constante de rigidez associada à direção cross-wise \\
\hline$L_{0}$ & Comprimento indeformado do modelo flexível \\
\hline 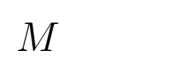 & Massa da estrutura principal \\
\hline$m$ & Massa do NVA rotativo \\
\hline$n_{a}$ & Massa adicional \\
\hline$m_{a}^{\text {pot }}$ & $\begin{array}{l}\text { Massa adicional calculada como solução do problema de escoamento } \\
\text { potencial considerando o corpo imerso em um fluido de domínio infinito }\end{array}$ \\
\hline$m_{d}$ & Massa de fluido deslocada pelo corpo \\
\hline$m^{*}$ & $\begin{array}{l}\text { Parâmetro de massa reduzida, definido como a razão entre a massa } \\
\text { oscilante e a massa de fluido deslocada pelo corpo. }\end{array}$ \\
\hline$\hat{m}$ & Parâmetro adimensional de massa, $\hat{m}=\frac{m}{M}$ \\
\hline$q_{x}$ e $q_{y}$ & Variáveis empregadas nos wake-oscillators \\
\hline$R$ & Resistência elétrica do circuito de coleta de energia \\
\hline$R e$ & Número de Reynolds \\
\hline$r$ & Comprimento da haste do NVA \\
\hline$\hat{r}$ & Parâmetro adimensional de comprimento da haste, $\hat{r}=\frac{r}{D}$ \\
\hline$\hat{S}$ & Critério adotada para quantificar a supressão passiva \\
\hline$S_{x}(\xi, \hat{f})$ & $\begin{array}{l}\text { Espectro de amplitude calculado ao longo da envergadura do cilindro e } \\
\text { referente à direção in-line }\end{array}$ \\
\hline$S_{y}(\xi, \hat{f})$ & $\begin{array}{l}\text { Espectro de amplitude calculado ao longo da envergadura do cilindro e } \\
\text { referente à direção cross-wise }\end{array}$ \\
\hline St & Número de Strouhal \\
\hline & \\
\hline
\end{tabular}




\begin{tabular}{|c|c|}
\hline$U_{\infty}$ & Velocidade do escoamento incidente \\
\hline$U_{r}$ & Velocidade reduzida \\
\hline$U_{r, k}$ & $\begin{array}{l}\text { Velocidade reduzida calculada com base na frequência natural do k-ésimo } \\
\text { modo de vibrar }\end{array}$ \\
\hline$V$ & Tensão elétrica \\
\hline$v$ & Tensão elétrica adimensional, $v=V / V_{0}$ \\
\hline$V_{0}$ & Tensão elétrica de referência \\
\hline$X$ & Deslocamento do corpo na direção in-line \\
\hline$x$ & Deslocamento adimensional do corpo na direção in-line, $x=X / D$ \\
\hline$Y$ & Deslocamento do corpo na direção cross-wise \\
\hline$y$ & Deslocamento adimensional do corpo na direção cross-wise, $y=Y / D$ \\
\hline$z$ & $\begin{array}{l}\text { Posição ao longo do eixo do cilindro flexível, medida a partir da sua } \\
\text { extremidade inferior }\end{array}$ \\
\hline$\alpha$ & $\begin{array}{l}\text { Ângulo de ataque, calculado como função da velocidade de translação } \\
\text { do corpo e da velocidade do escoamento incidente }\end{array}$ \\
\hline$\epsilon_{x}$ e $\epsilon_{x}$ & $\begin{array}{l}\text { Parâmetros dos wake-oscillators e que devem ser calibrados experimen- } \\
\text { talmente }\end{array}$ \\
\hline$\zeta_{x}$ & $\begin{array}{l}\text { Taxa de amortecimento estrutural associada ao movimento na direção } \\
\text { in-line }\end{array}$ \\
\hline$\zeta_{y}$ & $\begin{array}{l}\text { Taxa de amortecimento estrutural associada ao movimento na direção } \\
\text { cross-wise }\end{array}$ \\
\hline$\theta(\tau)$ & Série temporal de resposta do NVA rotativo \\
\hline$\theta_{x}$ e $\theta_{y}$ & $\begin{array}{l}\text { Termos de acoplamento eletromecânico nas direções in-line e cross-wise, } \\
\text { respectivamente }\end{array}$ \\
\hline$\zeta_{\theta}$ & Taxa de amortecimento do NVA \\
\hline$\eta_{e l}$ & Eficiência ou rendimento da coleta de energia \\
\hline$\xi$ & Adimensional de posição ao longo do eixo do cilindro \\
\hline$\rho$ & Massa específica do fluido \\
\hline
\end{tabular}


$\sigma_{1}$ e $\sigma_{2} \quad$ Grandezas adimensionais relacionadas ao circuito de coleta de energia e ao acoplamento eletromecânico

$\tau$

$\psi$

$\omega_{f}$

$\omega_{n, y}$

$\omega_{r}$
Tempo adimensional

Função de interpolação utilizada no método de Galerkin

Frequência angular de emissão de vórtices associada ao problema do escoamento ao redor de um cilindro fixo, $\omega_{f}=2 \pi f_{f}$

Frequência angular de referência. Geralmente, é a frequência natural na direção cross-wise, $\omega_{n, y}=2 \pi f_{n, y}$

Velocidade angular característica de resposta do NVA rotativo 


\section{Sumário}

OBJETIVOS DO TEXTO E SUA ORGANIZAÇÃO $\ldots \ldots \ldots$

INTRODUÇÃO $\ldots \ldots \ldots \ldots \ldots \ldots \ldots \ldots$

2.1 Uma breve contextualização em dinâmica das estruturas . . . . . . . 28

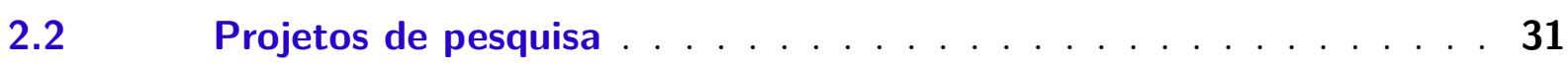

$2.3 \quad$ Tópicos de pesquisa discutidos neste texto . . . . . . . . . . 33

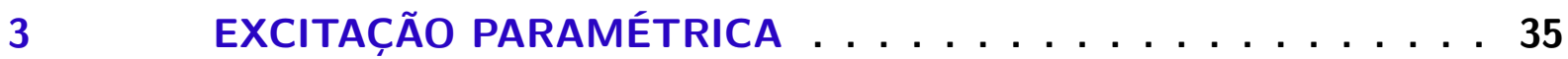

3.1 Excitação paramétrica em sistemas de um grau de liberdade . . . 35

$3.2 \quad$ Aplicações em dinâmica de risers . . . . . . . . . . . 39

3.3 Identificação de lacunas de conhecimento . . . . . . . . . . . 42

4 VIBRAÇÕES INDUZIDAS PELO ESCOAMENTO - VIE . . . . . 44

4.1 Vibrações induzidas pela emissão de vórtices - VIV . . . . . . . . 44

4.1.1 Escoamento ao redor de um cilindro fixo . . . . . . . . . . . . . . 45

4.1.2 O problema de um cilindro livre para oscilar na direção ortogonal à correnteza 49

4.1.3 O problema de um cilindro livre para oscilar nas direções da correnteza e ortogonal a ela . . . . . . . . . . . . . . . . . . 5 54

4.1.4 O problema do cilindro flexível vertical . . . . . . . . . . . 57

4.1.5 Modelos de ordem reduzida: VIV-1gI . . . . . . . . . . . . 64

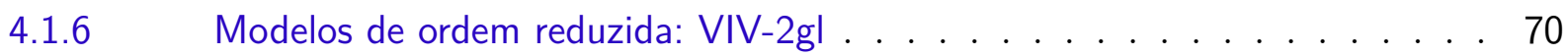

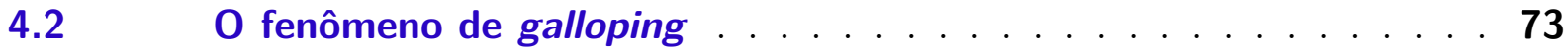

$4.3 \quad$ Identificação de lacunas de conhecimento . . . . . . . . 79

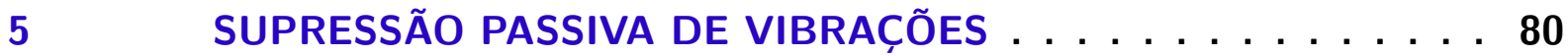

5.1 Supressão passiva de vibrações por meio de elementos lineares - uso

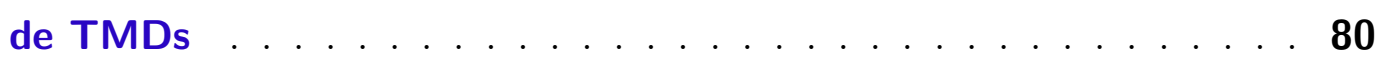

5.2 Supressão passiva de vibrações por meio de absorvedores não-lineares de vibração . . . . . . . . . . . . . . . . . 88

5.3 Identificação de lacunas de conhecimento . . . . . . . . . 109

6 APROVEITAMENTO DE ENERGIA A PARTIR DE VIBRAÇÕES INDUZIDAS PELO ESCOAMENTO . . . . . . . . . . . . 113

$6.1 \quad$ Um breve histórico de contribuições recentes $\ldots \ldots \ldots 113$

6.2 Identificação de lacunas de conhecimento . . . . . . . . . . 125 
ANÁLISE EXPERIMENTAL DOS FENÔMENOS DE EXCITAÇÃO PARAMÉTRICA E DE VIV . . . . . . . . . . . . . . . . . . . 127

7.1 Caracterização do arranjo experimental e da metodologia de análise 127

7.2 Contribuições à análise experimental do fenômeno de excitação paramétrica em um cilindro flexível submerso . . . . . . . . . . . . . . . 134

7.3 Contribuições à análise experimental do fenômeno de VIV em um cilindro flexível vertical . . . . . . . . . . . . . . . . . . . . . 145

7.3.1 Resultados para a condição "VIV puro" . . . . . . . . . . . . . . 145

7.3.2 Resultados para solicitação combinada de VIV e de excitação paramétrica . 166

7.4 Considerações finais do capítulo e perspectivas de continuidade da pesquisa . . . . . . . . . . . . . . . . . 181

8 MODELAGEM MATEMÁTICA DOS FENÔMENOS DE EXCITAÇÃO PARAMÉTRICA E DE VIV . . . . . . . . . . . . . . . . . . . 185

8.1 Contribuições à modelagem do fenômeno de excitação paramétrica em um cilindro flexível submerso . . . . . . . . . . . . . . . . . . . 185

8.2 Contribuições à modelagem do fenômeno de VIV . . . . . . . . . . 198

8.2.1 Comparação entre os modelos de ordem reduzida propostos por Facchinetti, de Langre e Biolley (2004) e por Ogink e Metrikine (2010) . . . . . . . . . 198

8.2.2 Um novo modelo fenomenológico para VIV-2gl . . . . . . . . . . . . 201

8.3 Considerações finais do capítulo e perspectivas de continuidade da pesquisa . . . . . . . . . . . . . . . . . 208

9 SUPRESSÃO PASSIVA DE EXCITAÇÃO PARAMÉTRICA . . . . . 212

9.1 Modelagem matemática do problema de supressão passiva . . . . 212

9.2 Metodologias de simulação e de análise . . . . . . . . . . . . 214

9.3 Resultados e discussões . . . . . . . . . . . . . . . . 216

$9.4 \quad$ Estudo analítico baseado em um método de perturbação . . . . . 225

9.5 Considerações finais do capítulo e perspectivas de continuidade da pesquisa . . . . . . . . . . . . . . . . . . 231

10 SUPRESSÃO PASSIVA DE VIBRAÇÕES INDUZIDAS PELO ESCOAMENTO . . . . . . . . . . . . . . . . . . . . 235

10.1 Supressão passiva do fenômeno de VIV . . . . . . . . . . . . . 235

10.1.1 Modelagem matemática do problema de supressão passiva . . . . . . . . 236

10.1.2 Metodologias de simulação e de análise . . . . . . . . . . . . . 239

10.1.3 Resultados e discussões . . . . . . . . . . . . . . . . . . . . . 242

10.2 Supressão passiva do fenômeno de galloping . . . . . . . . . . . . . 268

10.2.1 Modelagem matemática do problema de supressão passiva . . . . . . . . 270

10.2.2 Metodologias de simulação e de análise . . . . . . . . . . . . . 272 
10.2.3 Resultados e discussões . . . . . . . . . . . . . . . . . . . 276

10.3 Considerações finais do capítulo e perspectivas de continuidade da pesquisa . . . . . . . . . . . . . . . . . . . . 296

11 APROVEITAMENTO DE ENERGIA A PARTIR DO FENÔMENO DE VIV . . . . . . . . . . . . . . . . . . . . . . 301

11.1 Modelagem matemática . . . . . . . . . . . . . . 302

11.2 Metodologias de simulação numérica e de análise . . . . . . . . 308

$11.3 \quad$ Resultados e discussões . . . . . . . . . . . . . . . 309

11.4 Considerações finais do capítulo e perspectivas de continuidade da pesquisa . . . . . . . . . . . . . . . . . 318

12 CONSIDERAÇÕES FINAIS . . . . . . . . . . . . . 320 REFERÊNCIAS . . . . . . . . . . . . . . . 325

A PROduÇÃO CIENTÍficA ASSOCIAdA A ESTE TEXTO . . . . 339

B ANÁLISE ASSINTÓTICA DA EQUAÇÃO DE VAN DER POL . . . 341 


\section{Objetivos do texto e sua organização}

Este texto tem como objetivo apresentar, de maneira integrada, alguns tópicos de pesquisa em dinâmica das estruturas conduzidos pelo docente Guilherme Rosa Franzini e que focam em dois grandes grupos de problemas. O primeiro grupo está relacionados a problemas de excitação paramétrica enquanto que o segundo grupo contempla as vibrações induzidas pelo escoamento, aqui limitadas a dois fenômenos, a saber, as vibrações induzidas pela emissão de vórtices (VIV) e o galloping.

Sobre esses dois grandes grandes grupos de problemas de dinâmica das estruturas, o presente texto lança luz sobre as contribuições do docente no que tange à análise experimental e à modelagem matemática. Além dessas contribuições, o texto traz estudos numéricos visando aplicações tanto no aproveitamento de energia via efeito piezoelétrico a partir do fenômeno de VIV quanto na supressão passiva de oscilações decorrentes desses problemas supra-citados por meio de absorvedores não-lineares de vibração.

Tendo em vista que o texto aborda um conjunto de contribuições, é natural que algumas dessas já estejam publicadas na forma de artigos científicos. Mais do que um resumo desses trabalhos, faz parte do objetivo do texto buscar correlacionar de maneira mais profunda e integrada os diversos aspectos estudados e conclusões obtidas, algo que é dificultado sobremaneira em artigos científicos. Visando facilitar o entendimento, buscouse realizar uma uniformização da nomenclatura adotada. Além da análise integrada, o leitor aqui encontra a identificação de oportunidades de continuidade das pesquisas nos problemas em tela ou em novos problemas que envolvam a combinação de um ou mais aspectos aqui tratados de maneira individual.

O texto está organizado segundo outros onze capítulos. O capítulo 2 traz uma breve contextualização em dinâmica das estruturas, apresentando algumas definições importantes no tema. Além dessa contextualização, o referido capítulo apresenta os projetos de pesquisa a partir dos quais os resultados aqui descritos foram obtidos. Finalmente, o capítulo é encerrado com uma apresentação mais detalhada de quais contribuições ao estado-da-arte o leitor encontra neste texto.

Os quatro capítulos seguintes são responsáveis tanto pela apresentação das revisões bibliográficas nos problemas abordados quanto pela identificação de algumas de lacunas de conhecimento que podem ser melhor compreendidas a partir das pesquisas conduzidas pelo docente e aqui sintetizadas. O capítulo 3 é dedicado à apresentação dos principais conceitos dos problemas de excitação paramétrica, com foco no contexto de dinâmica de estruturas esbeltas. Já os aspectos físicos dos fenômenos de interação fluido-estrutura que são objetos de estudos do texto são descritos no capítulo 4 em conjunto com alguns 
modelos matemáticos deles representativos.

A revisão bibliográfica prossegue no capítulo 5, responsável pela apresentação dos principais conceitos acerca de supressão passiva de vibrações, com maior enfoque naqueles relacionados ao uso de absorvedores não-lineares de vibração. Por fim, o capítulo 6 encerra a revisão bibliográfica, trazendo o estado-da-arte no tocante ao aproveitamento de energia a partir de problemas de vibrações induzidas pelo escoamento.

As contribuições das pesquisas lideradas pelo autor deste texto são apresentadas nos cinco capítulo subsequentes, todos encerrados com as considerações finais e algumas propostas de continuidade e/ou ramificações das pesquisas. O capítulo 7 apresenta as descrições das campanhas experimentais e das metodologias de análise e de redução de resultados desenvolvidas visando o estudo dos fenômenos de excitação paramétrica e de VIV em um cilindro flexível vertical. O capítulo 7 discute, à luz das metodologias desenvolvidas, os resultados experimentais.

O capítulo 8 traz algumas contribuições à modelagem matemática dos fenômenos de excitação paramétrica e de VIV. Os capítulos 9 e 10 dedicam-se, respectivamente, a apresentar os estudos numéricos relacionados ao uso de um particular tipo de absorvedor não-linear de vibração como supressor passivo de oscilações decorrentes da excitação paramétrica e dos dois fenômenos de vibrações induzidas pelo escoamento em tela. Já no capítulo 11, o leitor encontra discussões relativas ao aproveitamento de energia a partir do fenômeno de VIV e considerando o efeito piezoelétrico como forma de conversão de energia.

Finalmente, o capítulo 12 apresenta, de maneira sintetizada, as principais contribuições de pesquisa nos assuntos que são objetos deste texto e o delineamento de novas atividades de pesquisa. Os dois apêndices trazem a lista de artigos científicos associados ao presente texto (ver apêndice A) e uma análise assintótica da equação de van der Pol (apêndice B). 


\section{Introdução}

O capítulo apresenta o panorama geral em que o presente texto é enquadrado. A seção 2.1 traz uma breve contextualização em dinâmica de estruturas, apresentando dentro desse universo os assuntos que são objetos das pesquisas aqui sintetizadas. Já a seção 2.2 apresenta três projetos de pesquisa que contaram com a participação do autor do texto e que geraram parte dos resultados descritos ao longo do texto. Finalmente, a seção 2.3 indica, dentro do contexto geral de dinâmica das estruturas, os problemas e as contribuições do autor ao estado-da-arte contempladas no texto.

\subsection{Uma breve contextualização em dinâmica das estruturas}

Estruturas de praticamente todas as ênfases da engenharia apresentam respostas que são dependentes do tempo, caracterizando assim respostas dinâmicas. Essas podem ser decorrentes de uma perturbação inicial concedida à estrutura ou de ações externas que podem ou não depender explicitamente do tempo. No contexto da engenharia civil ${ }^{1}$, as análises dinâmicas estruturais são bastante recentes. Tal fato pode ser explicado pelo crescimento da capacidade computacional experimentado nos últimos cinquenta anos.

Embora a cultura da engenharia civil esteja fortemente enraizada em análises estáticas, o uso cada vez mais frequente de estruturas leves e esbeltas tem aproximado as frequências naturais daquelas dos carregamentos externos, de sorte que a consideração de efeitos dinâmicos tem se tornado uma ferramenta cada vez mais comum e importante. Exemplos de análises dinâmicas em problemas tipicamente atinentes à engenharia civil envolvem o estudo de pontes sujeitas a vento ou tráfego, edificações sujeitas a sismos ou explosões e o estudo de cabos de pontes estaiadas.

Os problemas de dinâmica das estruturas podem ser agrupados segundo diversas categorias. Dentre esses agrupamentos, pode ser destacados os problemas de corpos rígidos ${ }^{2}$ conectados por molas e amortecedores pontuais em oposição aos que lidam com meios contínuos (por exemplo, vibrações em barras), os lineares em contraponto aos não-lineares e os autônomos (aqueles que não dependem explicitamente do tempo) contrapostos aos não-autônomos.

Na prática da engenharia civil, foco especial tem sido dado às vibrações de meios contínuos. Tal abordagem pode representar a resposta de uma ponte submetida à ação

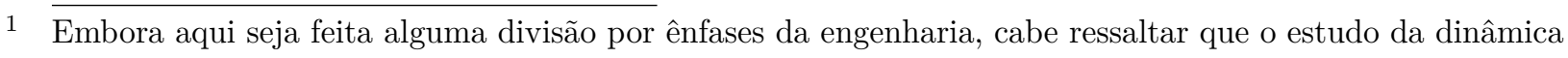
é, assim como outros tópicos, transversal às áreas de conhecimento.

2 O leitor sabe que um corpo rígido é uma idealização. No entanto, essa hipótese é válida em uma vasta gama de problemas. 
do vento e pode ser conduzida tanto no contexto de meios contínuos propriamente dito quanto no âmbito de sistemas discretizados, por exemplo, via método dos elementos finitos. No entanto, é importante ressaltar que estudos com modelos de poucos graus de liberdade envolvendo corpos rígidos e com parâmetros concentrados de rigidez e amortecimento devem ser utilizados nas etapas iniciais de análise com vista ao melhor entendimento do problema de maior hierarquia.

Já na engenharia oceânica, os modelos de corpos rígidos vinculados ao meio externo por meio de molas e amortecedores concentrados podem representar, por exemplo, a dinâmica de uma unidade flutuante amarrada. Nessa mesma ênfase de engenharia, a dinâmica de risers $^{3}$ deve ser considerada como aquela de um corpo flexível.

No tocante à confrontação entre os problemas lineares e não-lineares, algumas colocações devem ser feitas. As aplicações tecnológicas de engenharia de estruturas que envolvam grandes deslocamentos (não-linearidade geométrica), não-linearidade física (por exemplo, plastificação do material em partes da estrutura) ou uma vasta gama de fenômenos de interação fluido-estrutura ${ }^{4}$ devem levar em conta as não-linearidades. Os problemas não-lineares podem levar a aspectos por vezes complexos e não observados naqueles regidos por uma dinâmica linear. Um exemplo de aspecto observado apenas em problemas nãolineares é a possibilidade da estrutura apresentar mais do que uma resposta para um dado carregamento. Cumpre ressaltar, no entanto, que parte importante dos problemas de dinâmica podem ser resolvidos por meio de análises lineares, geralmente de menor complexidade e de solução mais rápida.

Os problemas autônomos, via de regra, envolvem problemas em vibração livre. Nesses problemas, a resposta dinâmica é causada por uma perturbação nas condições de equilíbrio trivial do sistema. Em dinâmica linear das estruturas, o amortecimento geralmente é pequeno ${ }^{5}$ e positivo, levando a um decréscimo das amplitudes de vibração com o tempo. Já em problemas não-lineares como, por exemplo, a equação de van der $\mathrm{Pol}^{6}$, uma pequena perturbação na condição de equilíbrio trivial pode levar a uma resposta oscilatória denominada ciclo-limite e caracterizada por uma amplitude estacionária.

Considerando agora os problemas lineares não-autônomos, um exemplo bastante usual é aquele onde um sistema de um grau de liberdade é solicitado por uma força externa harmônica no tempo. Ainda no contexto de uma dinâmica linear não-autônoma, porém no problema homogêneo, é de particular interesse a condição onde a rigidez varia

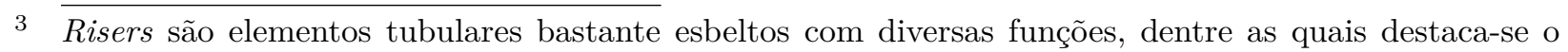
transporte de fluido do fundo do mar para a unidade flutuante.

4 Conforme o leitor percebe no capítulo 2, alguns fenômenos de interação fluido-estrutura têm importantes não-linearidades em seus modelos matemáticos.

5 Por pequeno, o leitor deve entender como aquele que acaba recaindo no caso subcrítico, onde a resposta apresenta um caráter oscilatório.

6 Ao consultar o capítulo 4, o leitor nota que a equação de van der Pol tem particular importância na modelagem de um dos fenômenos de vibrações induzidas pelo escoamento abordados no presente texto. 
de maneira harmônica e monocromática ${ }^{7}$ no tempo. O problema onde algum parâmetro do modelo matemático (no caso discutido, a rigidez) depende explicitamente do tempo é denominado como um problema de excitação paramétrica. Como é visto no capítulo 3, o caso particular no qual a rigidez é dada por um valor médio somado a uma flutuação harmônica e monocromática pode ser modelado como uma equação de Mathieu. O mesmo capítulo mostra que a equação de Mathieu pode apresentar soluções ilimitadas para alguns valores de amplitude e de frequência de modulação da rigidez. Essas respostas ilimitadas são decorrentes da chamada instabilidade paramétrica.

Retomando agora os problemas de vibrações induzidas pelo escoamento (VIE), eles constituem em um vasto campo de interesse das comunidades científica e tecnológica e usualmente envolvem vibrações auto-excitadas, isto é, nenhuma ação além daquela decorrente da interação fluido-estrutura é necessária para deflagrar uma resposta oscilatória. Dado o caráter intrinsecamente não-linear desses problemas, diversos estudos têm sido conduzidos com vistas tanto à modelagem matemática quanto ao entendimento de seus aspectos fundamentais por meio de experimentos em laboratório e simulações numéricas. Exemplos de VIE são as vibrações induzidas pelo escoamento interno, o flutter, as vibrações induzidas pela emissão de vórtices (VIV) e o galloping, sendo os dois últimos fenômenos aqueles investigados no âmbito do presente texto. O capítulo 4 apresenta os principais aspectos matemáticos e fenomenológicos dos dois fenômenos de VIE aqui focados.

Tendo em vista os potenciais aspectos danosos das respostas dinâmicas por questões relacionadas a estado limite de serviço, estado limite último ou fadiga, diversos esforços de pesquisa têm sido investidos buscando suprimir a resposta da estrutura principal. Uma possível abordagem para a supressão de vibrações é feita no projeto estrutural, onde a massa e a rigidez são definidas de sorte a evitar um eventual carregamento ressonante. $\mathrm{O}$ amortecimento também pode ser ajustado de sorte a diminuir as respostas dinâmicas.

Quando não há possibilidade de alteração nas propriedades da estrutura, técnicas de supressão ativa ou passiva podem ser empregadas, sendo apenas as últimas foco do presente texto. Na abordagem passiva e ao contrário do que deve ser feito no controle ativo, não há necessidade de conferir energia ao sistema para que haja mitigação de vibrações.

Conforme discutido no capítulo 5, um procedimento clássico de supressão passiva envolve o uso de elementos lineares acoplados à estrutura principal. Porém, na última década, diversos grupos de pesquisa têm estudado as vantagens de acoplar à estrutura a ser controlada elementos supressores caracterizados por uma dinâmica não-linear. É nessa última abordagem que o autor do presente texto tem atuado, de sorte que algumas contribuições oriundas de pesquisas por ele lideradas são encontradas nos capítulos 9 e 10 .

Embora a supressão de vibrações seja um tema importante, uma outra linha de

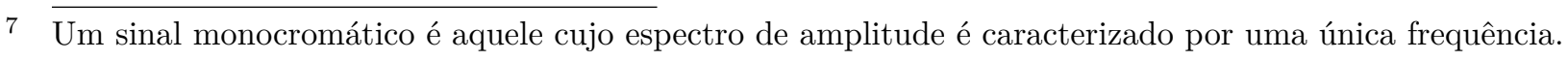


pesquisa que vem sendo foco de diversos esforços é aquela na qual vibrações estruturais são desejadas para que, a partir de fenômenos piezoelétricos ou eletromagnéticos, energia elétrica ${ }^{8}$ possa ser obtida. A revisão bibliográfica específica sobre aproveitamento (ou coleta) de energia a partir de vibrações induzidas pelo escoamento é feita no capítulo 6 . Já no capítulo 11, o leitor encontra algumas contribuições do autor deste texto no tema, considerando como fonte de vibrações o fenômeno de VIV e a conversão eletromecânica via efeito piezoelétrico.

Como visto nessa seção, os problemas de dinâmica são de grande importância para as comunidades científica e tecnológica, o que tem motivado a condução de uma série de projetos de pesquisa financiados tanto por agências de fomento quanto pela iniciativa privada. A próxima seção ilustra alguns projetos de pesquisa que contaram com a atuação do autor e a partir dos quais parte dos resultados aqui apresentados foram obtidos.

\subsection{Projetos de pesquisa}

No tocante à análise experimental dos fenômeno de VIV e de excitação paramétrica em estruturas flexíveis submersas, é importante mencionar um projeto de pesquisa em dinâmica não-linear de risers apoiado pela Petrobras e conduzido na Escola Politécnica da Universidade de São Paulo (EPUSP). Dentro de um conjunto de atividades que envolviam, também, simulações numéricas e modelagem matemática, o grupo do Laboratório de Mecânica Offshore (LMO) atuou no planejamento, execução e análise de diversos experimentos em laboratório envolvendo a resposta de cilindros flexíveis aos fenômenos supra-citados. Dentre os experimentos conduzidos, destacam-se:

- Experimentos com modelos verticais submersos e submetidos a movimento imposto ao topo simulando a excitação paramétrica decorrente da variação temporal da força normal;

- Experimentos com modelos verticais submersos e submetidos à correnteza uniforme e excitando o fenômeno de VIV;

- Experimentos com modelos verticais submersos e submetidos a movimento imposto ao topo concomitante à correnteza uniforme, induzindo simultaneamente os fenômenos de VIV e de excitação paramétrica;

- Experimentos com modelos flexíveis submersos lançados em catenária e submetidos somente a movimento imposto ao topo;

8 Convém ressaltar que o aproveitamento de energia pode ser feito por meio da conversão em uma outra forma de energia que não a elétrica como, por exemplo, energia potencial gravitacional. 
- Experimentos com modelos flexíveis submersos lançados em catenária e submetidos à correnteza no plano da linha ou a ele ortogonal, simulando o fenômeno de VIV e considerando diversos valores de rigidez do solo;

- Experimentos com modelos flexíveis submersos lançados em catenária e submetidos a movimento imposto ao topo concomitante à correnteza.

Conforme mostrado em Pesce (2013), esses experimentos geraram uma vasta base de dados. Ao contrário do usual, os deslocamentos ${ }^{9}$ de um grande número de alvos refletivos posicionados ao longo do modelo foram medidos diretamente por meio de um sistema óptico de rastreamento e identificação de imagens.

Tendo em vista a quantidade de dados, os diversos tipos de ensaios e o tipo de instrumentação empregada, essa base de dados de posse conjunta da Petrobras e do LMO possibilita um alto número de estudos capazes de lançar luz em diversos aspectos que ainda carecem de estudos na literatura. Algumas dessas lacunas de conhecimento são melhor apontadas na seção 4.3. No presente texto, foco é dado às contribuições do autor às análises dos experimentos realizados com o cilindro flexível montado na posição vertical. Como pode ser visto no capítulo 7, tais análises demandaram o desenvolvimento de procedimentos inéditos e que geraram publicações em periódicos indexados.

O primeiro projeto de pesquisa coordenado pelo autor do texto envolveu uma série de estudos numéricos com vistas ao aproveitamento de energia a partir de fenômenos de VIE. Esse projeto era vinculado ao Núcleo de Apoio à Pesquisa Oceano Sustentável $(\mathrm{NAP}-\mathrm{OS})^{10}$ e permitiu ao autor nuclear um pequeno grupo de orientados com pesquisa no tema. O leitor interessado em mais informações acerca do aproveitamento de energia a partir de diversos fenômenos de VIE é direcionado ao capítulo 6. Por sua vez, o capítulo 11 traz uma particular contribuição do autor e de um de seus orientados no tema e que foi objeto de um artigo publicado em periódico indexado.

Já no que diz respeito à supressão passiva de vibrações, um primeiro projeto que deve ser ressaltado é um Auxílio à Pesquisa Regular ${ }^{11}$ apoiado pela Fundação de Amparo à Pesquisa do Estado de São Paulo (FAPESP) e coordenado pelo autor do presente texto. O principal objetivo desse projeto é a condução de uma série de estudos numéricos acerca da eficácia de um particular absorvedor não-linear de vibração ${ }^{12}$ para o fenômeno de VIV e para o problema de excitação paramétrica. Na proposta aprovada pela FAPESP, estavam

9 Dois procedimentos clássicos na condução de experimentos envolvem a avaliação indireta dos deslocamentos via medições de deformação ou de aceleração. Note, no entanto, que a conversão de tais grandezas em deslocamentos demanda uma ou mais operações matemáticas.

10 O NAP-OS é coordenado pelo Prof. Belmiro Castro, do Instituto Oceanográfico da Universidade de São Paulo (IO/USP)

11 Ver processo FAPESP 2016/20929-2.

12 O capítulo 5 apresenta ao leitor alguns conceitos em supressão passiva de vibrações, com particular foco no uso de absorvedores não-lineares de vibração. 
previstas as participações de orientados de graduação e de pós-graduação para auxiliar na condução dos estudos. Assim, parte dos resultados apresentados nos capítulos 9 e 10 foi obtida com a contribuição de orientadas do autor e que são devidamente citadas nos capítulos correspondentes.

Um outro projeto no tema de supressão passiva de vibrações por meio de absorvedores não-lineares de vibração foi conduzido com o apoio do Fond de Recherche du Québec mediante processo seletivo internacional. Parte desse projeto foi realizada pelo autor na École Polytechnique de Montréal (PolyMTL) junto ao grupo do Prof. Frédérick Gosselin. O projeto focou no planejamento e condução de experimentos em túnel de vento visando a supressão passiva do fenômeno de galloping. Uma outra parte do projeto foi realizada em conjunto com uma orientada de graduação e foca no estudo numérico do mesmo problema experimentalmente investigado. O leitor interessado nos resultados numéricos de supressão passiva do galloping é direcionado à seção 10.2.

\subsection{Tópicos de pesquisa discutidos neste texto}

O presente texto visa apresentar alguns tópicos de pesquisa em dinâmica das estruturas conduzidos pelo autor com as correspondentes discussões de resultados e contribuições ao estado-da-arte. Além do problema de excitação paramétrica, dois fenômenos de VIE (a saber, o VIV e o galloping) compõem os objetos de estudo das pesquisas aqui sintetizadas.

Definidos os problemas de interesse, o texto apresenta as contribuições referentes à modelagem matemática e à análise experimental dos fenômenos de VIV e de excitação paramétrica em um cilindro flexível vertical. Além dos aspectos de modelagem e de análise experimental, o texto contempla estudos numéricos com vistas a duas particulares aplicações, a saber a supressão passiva por meio de absorvedores não-lineares de vibração e o aproveitamento de energia por meio do efeito piezoelétrico.

Encerrando as considerações finais apresentadas no capítulo 12, é proposta uma nova linha de pesquisa para o docente e para os grupos do LMO e do Departamento de Engenharia de Estruturas e Geotécnica da Escola Politécnica da Universidade de São Paulo e que versa sobre a concomitante supressão passiva de vibrações e aproveitamento de energia. Uma das motivações para a proposição dessa linha é a resposta dos absorvedores não-lineares de vibração a algumas solicitações. O leitor interessado nessas respostas é convidado à leitura dos capítulos 9 e 10. A Figura 1 ilustra os tópicos de pesquisa descritos no presente texto. 
Figura 1 - Representação esquemática dos tópicos de pesquisa aqui abordados.

\begin{tabular}{|c|c|c|}
\hline Contribuições & $\Longleftrightarrow$ & $\begin{array}{l}\text { - Modelagem matemática } \\
\text { - Análise experimental }\end{array}$ \\
\hline $\begin{array}{c}\text { Problemas de dinâmica das } \\
\text { estruturas }\end{array}$ & $\Longleftrightarrow$ & 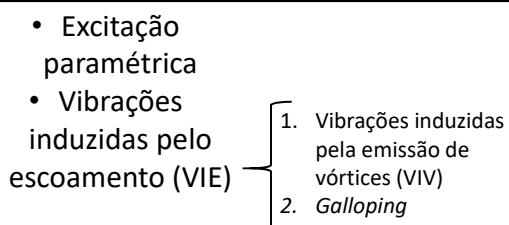 \\
\hline aplicações & $\Longleftrightarrow$ & $\begin{array}{l}\text { - Aproveitamento de energia } \\
\text { - Supressão passiva por meio de } \\
\text { absorvedores não-lineares de } \\
\text { vibração }\end{array}$ \\
\hline
\end{tabular}

Fonte: Elaborada pelo autor. 


\section{Excitação paramétrica}

Este capítulo traz os principais aspectos do problema de excitação paramétrica e está dividido em três seções. A seção 3.1 apresenta os conceitos mais importantes envolvidos no problema de um grau de liberdade. Visando prover o leitor de informações acerca da importância da excitação paramétrica em dinâmica de risers, a seção 3.2 faz uma revisão bibliográfica focada nessa aplicação tecnológica. Por fim, algumas lacunas de conhecimento são identificadas na seção 3.3 .

\subsection{Excitação paramétrica em sistemas de um grau de liberdade}

A excitação paramétrica é um problema não-autônomo clássico em dinâmica de estruturas. Esse problema é observado quando ao menos um dos parâmetros da equação de movimento do sistema depende explicitamente do tempo. O presente texto tem como foco o caso particular onde a rigidez depende do tempo de forma harmônica, monocromática e com média não nula.

Considere um corpo de massa $M$ com liberdade de deslocamento em uma direção. Esse corpo está montado em um apoio elástico de rigidez variável no tempo da forma $k(t)=\bar{k}+\Delta k \cos \Omega t$ e amortecimento linear de constante $c$. A equação de movimento desse sistema é dada por:

$$
M \frac{d^{2} u}{d t^{2}}+c \frac{d u}{d t}+(\bar{k}+\Delta k \cos \Omega t) u=0
$$

A Equação 3.1 é conhecida como equação de Mathieu amortecida, um caso particular da equação de Hill. É de grande interesse o estudo da estabilidade da solução trivial $u=0$ e $\frac{d u}{d t}=0$, aqui conduzido para o problema não amortecido ${ }^{1}$.

O estudo da estabilidade da solução trivial pode ser conduzido segundo diversas abordagens como, por exemplo, o método das múltiplas escalas e a Teoria de Floquet. O leitor interessado nessas técnicas pode consultar os clássicos livros escritos por Bender e Orszag (1978), Nayfeh e Mook (1979) e Meirovitch (2003). A dissertação de mestrado de Soares (1992) também traz estudos relativos ao problema de excitação paramétrica em sistemas de um grau de liberdade.

Em particular, é importante definir regiões no plano dos parâmetros de controle

1 O leitor interessado no estudo do problema linear amortecido é convidado a consultar o livro de Meirovitch (2003). Essa referência traz uma mudança de variáveis tal que a nova equação de movimento seja não amortecida. 
da excitação paramétrica (isso é, sua amplitude ${ }^{2} \Delta k$ e sua frequência $\Omega$ ) onde a solução trivial é estável (isto é, pequenas perturbações nas condições iniciais levam a respostas limitadas) ou instável (pequenas perturbações levam a uma resposta cuja amplitude cresce indefinidamente, dando origem à instabilidade paramétrica). Nesse sentido, o diagrama de Strutt é uma forma bastante usual de avaliar as regiões do plano de parâmetros de controle quanto à instabilidade da solução trivial.

Antes da obtenção do diagrama de Strutt, a Equação 3.1 será reescrita em sua forma adimensional. Para tanto, considere as seguintes grandezas adimensionais:

$$
2 \tau=\Omega t, x=\frac{u}{L}, \zeta=\frac{c}{2 M \omega}, 2 \epsilon=\frac{4 \Delta k}{M \Omega^{2}}, \delta=\left(\frac{2 \omega}{\Omega}\right)^{2}
$$

onde $\omega=\sqrt{\frac{\bar{k}}{M}}$ é a frequência natural não amortecida do problema sem excitação paramétrica e $L$ é um comprimento de referência. Definindo ( ) como a derivada com relação a $\tau$, a Equação 3.1 é reescrita como:

$$
\ddot{x}+4 \zeta \frac{\omega}{\Omega} \dot{x}+(\delta+2 \epsilon \cos 2 \tau) x=0
$$

O diagrama de Strutt será obtido para o caso não amortecido, ou seja, aquele $\operatorname{com} \zeta=0$. Como visto em Nayfeh e Mook (1979), a aplicação da Teoria de Floquet à equação de Mathieu não amortecida indica que as curvas de transição do diagrama de Strutt correspondem a soluções periódicas com o período da excitação paramétrica ou com o seu dobro.

Considerando a forma não amortecida da Equação 3.3, é trivial notar que o período da excitação paramétrica é $\pi$. As soluções associadas às curvas de transição podem ser escritas por meio de séries de Fourier como:

$$
x(t)=\sum_{n=0}^{\infty}\left(\tilde{a}_{n} \cos n 2 \tau+\tilde{b}_{n} \sin n 2 \tau\right)+\sum_{n=0}^{\infty}\left(\tilde{c}_{n} \cos n \tau+\tilde{d}_{n} \sin n \tau\right)
$$

O leitor prontamente nota que o primeiro somatório corresponde a soluções de período $\pi$ enquanto que o segundo somatório está associado a soluções de período $2 \pi$. Note, ainda, que os harmônicos pares (ou seja, aqueles da forma $2 n$ ) aparecem em ambos os termos, de sorte que a Equação 3.4 pode ser escrita como um único somatório da forma:

$$
x(t)=\sum_{n=0}^{\infty}\left(a_{n} \cos n \tau+b_{n} \sin n \tau\right)
$$

A dedução segue substituindo a Equação 3.5 na Equação 3.3, já assumida com $\zeta=0$. As seguintes identidades são necessárias para a continuidade da obtenção das curvas de transição:

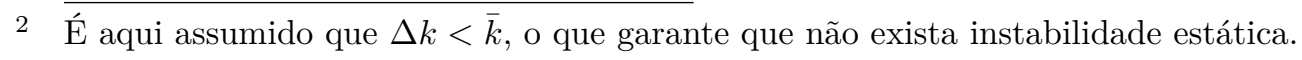




$$
\begin{aligned}
& \cos 2 t \cos n \tau=\left(\frac{e^{i 2 \tau}+e^{-i 2 \tau}}{2}\right)\left(\frac{e^{i n \tau}+e^{-i n \tau}}{2}\right)=\frac{1}{2} \cos ((2+n) \tau)+\frac{1}{2} \cos ((2-n) \tau) \\
& \cos 2 \tau \sin n \tau=\left(\frac{e^{i 2 \tau}+e^{-i 2 \tau}}{2}\right)\left(\frac{e^{i n \tau}-e^{-i n \tau}}{2 i}\right)=\frac{1}{2} \sin ((2+n) \tau)+\frac{1}{2} \sin ((n-2) \tau) \\
& x \cos 2 \tau=\sum_{n=0}^{\infty}\left[a_{n}\left(\frac{\cos ((2+n)) \tau+\cos ((2-n)) \tau}{2}\right)+b_{n}\left(\frac{\sin ((2+n)) \tau+\sin ((n-2)) \tau}{2}\right)\right] \\
& \ddot{x}=-\sum_{n=0}^{\infty} n^{2}\left(a_{n} \cos n \tau+b_{n} \sin n \tau\right)
\end{aligned}
$$

Uma primeira aproximação para as curvas de transição é agora obtida considerando o método do balanço harmônico e a solução $x(\tau)$ expandida com três termos (ou seja, com $n$ variando de 0 a 2). Com esse truncamento e o auxílio das Equações 3.6, as seguintes relações são obtidas:

$$
\begin{aligned}
& \delta x=\delta a_{0}+\delta a_{1} \cos \tau+\delta b_{1} \sin \tau+\delta a_{2} \cos 2 \tau+\delta b_{2} \sin 2 \tau \\
& x \cos 2 \tau=\frac{a_{0}}{2}(\cos 2 \tau+\cos 2 \tau)+\frac{a_{1}}{2}(\cos 3 \tau+\cos \tau)+\frac{b_{1}}{2}(\sin 3 \tau-\sin \tau)+ \\
& +\frac{a_{2}}{2}(\cos 4 \tau+1)+\frac{b_{2}}{2} \sin 4 \tau \\
& \ddot{x}=-\left(a_{1} \cos \tau+b_{1} \sin \tau+4 a_{2} \cos 2 \tau+4 b_{2} \sin 2 \tau\right)
\end{aligned}
$$

Substituindo as Equações 3.7 na forma não amortecida da Equação 3.3 e coletando os termos trigonométricos (balanço harmônico), chega-se a:

$$
\begin{aligned}
& \left(-a_{1}+\delta a_{1}+\epsilon a_{1}\right) \cos \tau+\left(-b_{1}+\delta b_{1}-\epsilon b_{1}\right) \sin \tau+\left(-4 a_{2}+\delta a_{2}+2 \epsilon a_{0}\right) \cos 2 \tau+ \\
& +\left(-4 b_{2}+\delta b_{2}\right) \sin 2 \tau+\left(\delta a_{0}+\epsilon a_{2}\right)+\ldots=0
\end{aligned}
$$

onde (...) representa harmônicos de frequências superiores à máxima considerada na expansão. A Equação 3.8 é verdadeira se o termo que multiplica cada função trigonométrica ${ }^{3}$ for nulo. Essa condição pode ser escrita como um sistema linear de cinco equações e cinco incógnitas dado, matricialmente, pela Equação 3.9.

$$
\left(\begin{array}{ccccc}
0 & -1+\delta+\epsilon & 0 & 0 & 0 \\
0 & 0 & -1+\delta-\epsilon & 0 & 0 \\
2 \epsilon & 0 & 0 & -4+\delta & 0 \\
0 & 0 & 0 & 0 & \delta-4 \\
\delta & 0 & 0 & \epsilon & 0
\end{array}\right)\left\{\begin{array}{l}
a_{0} \\
a_{1} \\
b_{1} \\
a_{2} \\
b_{2}
\end{array}\right\}=\left\{\begin{array}{l}
0 \\
0 \\
0 \\
0 \\
0
\end{array}\right\}
$$

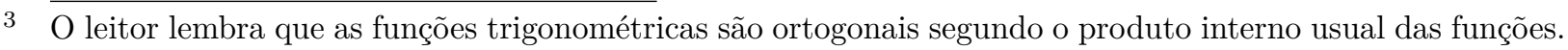


A Equação 3.9 tem solução não trivial se:

$$
\begin{aligned}
& \left|\begin{array}{ccccc}
0 & -1+\delta+\epsilon & 0 & 0 & 0 \\
0 & 0 & -1+\delta-\epsilon & 0 & 0 \\
2 \epsilon & 0 & 0 & -4+\delta & 0 \\
0 & 0 & 0 & 0 & \delta-4 \\
\delta & 0 & 0 & \epsilon & 0
\end{array}\right|= \\
& =\left(4 \delta-\delta^{2}+2 \epsilon^{2}\right)(-4+\delta)(-1+\delta-\epsilon)(-1+\delta+\epsilon)=0
\end{aligned}
$$

A Equação 3.10 apresenta uma aproximação para as curvas de transição do diagrama de Strutt que, por sua vez, estão ilustradas na Figura 2(a). É intuitivo que o aumento do número de termos empregado no método do balanço harmônico melhora a representatividade das curvas de transição, porém promove um significativo aumento no trabalho algébrico de sorte que o uso de computação simbólica torna-se praticamente indispensável. A Figura 2(b) ilustra as curvas de transição obtidas pelo método do balanço harmônico considerando sete termos.

Figura 2 - Curvas de transição do diagrama de Strutt obtidas para a equação de Mathieu não amortecida utilizando o método do balanço harmônico com três e com sete termos.

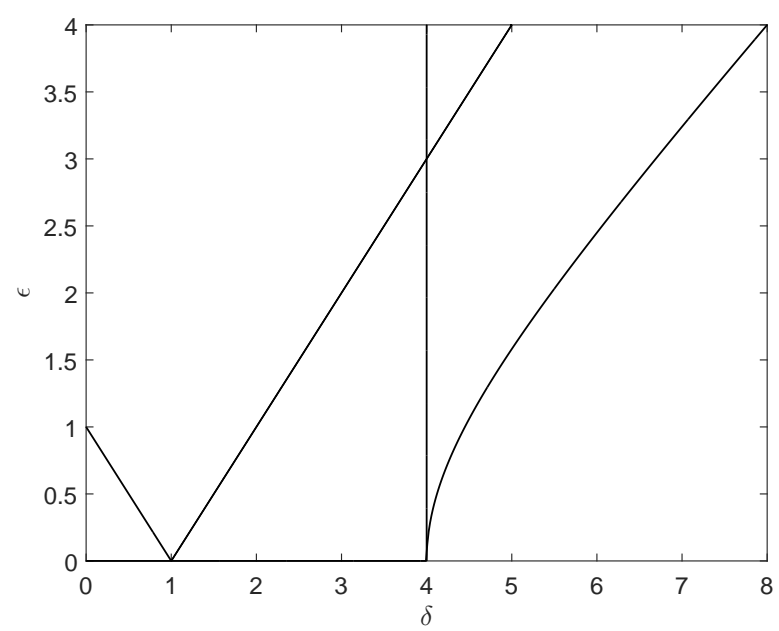

(a) Expansão com três termos.

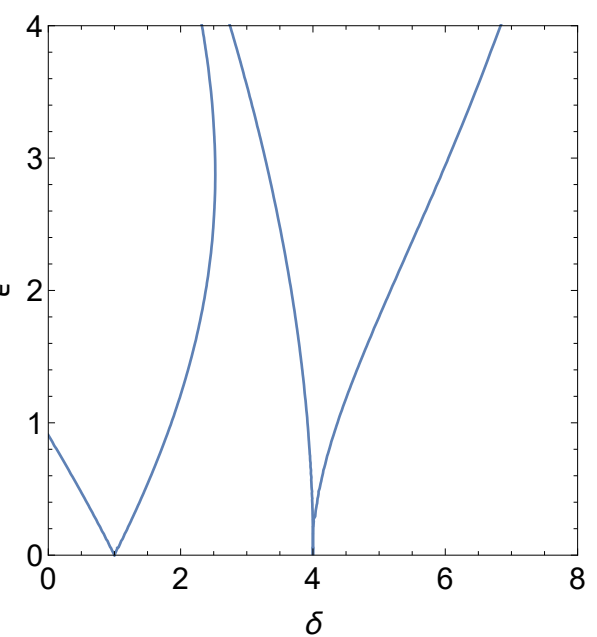

(b) Expansão com sete termos.

Fonte: Elaborada pelo autor.

Pontos pertencentes ao plano de parâmetros de controle $(\epsilon ; \delta)$ localizados acima das curvas de transição correspondem a soluções ilimitadas (instabilidade paramétrica), enquanto que pontos desse mesmo plano abaixo das curvas de transição estão associados a soluções limitadas. A partir da Figura 2, o leitor nota que a primeira região de instabilidade paramétrica é iniciada no ponto $(\delta ; \epsilon)=(1 ; 0)$. Fisicamente, esse resultado indica que um cenário favorável ao aparecimento da instabilidade paramétrica é aquele onde a frequência 
da excitação paramétrica é o dobro da frequência natural não amortecida do sistema em estudo ${ }^{4}$. Essa última condição denominada ao longo do texto como instabilidade paramétrica principal.

Antes do término da presente seção, é importante comentar o efeito da presença de amortecimento linear na equação de Mathieu. Como pode ser encontrado nos livros já mencionados, a presença do amortecimento faz com que as curvas de transição deixem de ter seus vértices sobre o eixo das abscissas e passando-os para $\epsilon>0$. Esse fato reduz as regiões do plano de parâmetros de controle onde a instabilidade paramétrica é observada.

\subsection{Aplicações em dinâmica de risers}

Além do interesse acadêmico, a excitação paramétrica possui importância tecnológica na engenharia oceânica, em particular no contexto da dinâmica de risers e de tendões de plataformas $\mathrm{TLP}^{5}$. Devido à esbeltez dessas estruturas, a rigidez geométrica (isto é, aquela associada à força normal) é dominante sobre a rigidez flexional.

Para melhor ilustrar a relação entre a força normal e a rigidez, considere o problema de um cabo horizontal ilustrado na Figura 3. O fato de os risers apresentarem arranjos distintos daquele de um cabo horizontal acarreta na variação espacial da força normal e não afeta as discussões qualitativas aqui feitas.

Figura 3 - Cabo horizontal submetido à força de tração variável no tempo.

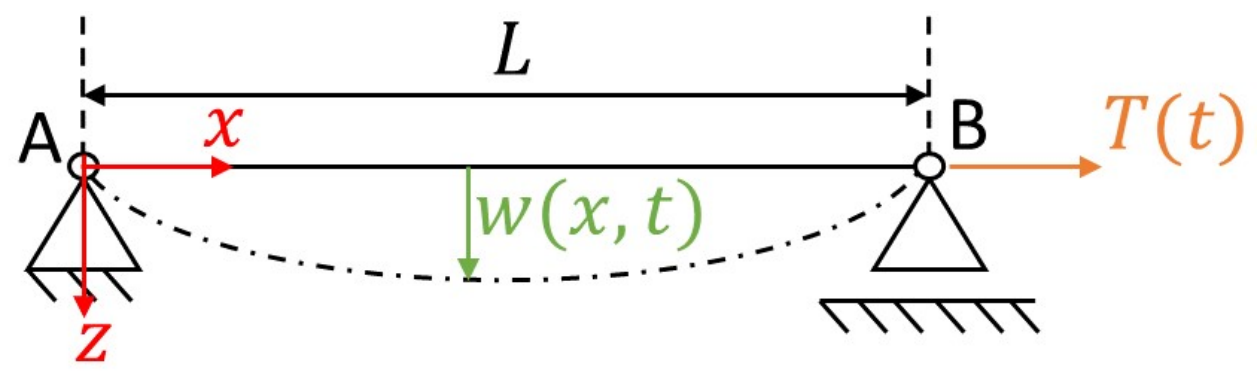

Fonte: Elaborada pelo autor.

Considere que o cabo tenha massa linear $m_{l}$ constante ao longo do seu comprimento e que a força normal seja dada por $T(t)>0$, ou seja, dependente do tempo e sempre em tração. Nestas condições, a dinâmica na direção transversal ao cabo é regida por:

$$
m_{l} \frac{\partial^{2} w}{\partial t^{2}}-T(t) \frac{\partial^{2} w}{\partial x^{2}}=0
$$

A solução dessa equação diferencial a derivadas parciais é procurada por meio da separação de variáveis na forma $w(x, t)=\psi_{n}(x) A_{n}(t)$, sendo $n$ o número do modo natural 
que é estudado. Substituindo essa definição para o campo de deslocamentos na Equação 3.11, obtém-se:

$$
m_{l} \psi_{n}(x) \frac{d^{2} A_{n}(t)}{d t^{2}}-T(t) \psi^{\prime \prime}(x) A_{n}(t)=0
$$

Aplica-se, agora, o método de Galerkin à Equação 3.12, o que leva à Equação 3.13.

$$
\left(\int_{0}^{L} m_{l} \psi_{n}^{2}(x) d x\right) \frac{d^{2} A_{n}(t)}{d t^{2}}-\left(\int_{0}^{L} T(t) \psi_{n}(x) \frac{\partial^{2} \psi_{n}(x)}{\partial x} d x\right) A_{n}(t)=0
$$

Lembrando que os modos naturais de um cabo horizontal são escritos como $\psi_{n}(x)=$ $\sin \left(n \pi \frac{x}{L}\right), n=1,2, \ldots$, definem-se a massa e a rigidez modais $\left(m_{n}\right.$ e $k_{n}$ respectivamente) como:

$$
\begin{array}{r}
\int_{0}^{L} m_{l} \psi_{n}^{2}(x) d x=\frac{m_{l} L}{2}=m_{n} ; \\
-\int_{0}^{L} T(t) \psi_{n}(x) \frac{d^{2} \psi_{n}(x)}{d x^{2}} d x=\frac{n^{2} \pi^{2}}{2 L} T(t)=k_{n}(t)
\end{array}
$$

Levando as definições de massa e rigidez modais à Equação 3.12, a Equação 3.16 é obtida. Note que, se a tração variar harmonicamente em torno de um valor médio na forma $T(t)=\bar{T}+\Delta T \cos \Omega t$, a Equação 3.16 assume a forma da equação de Mathieu não amortecida (ver Equação 3.1). Dessa forma, cabos submetidos à força de tração dependente do tempo são sujeitos à excitação paramétrica.

$$
m_{n} \frac{d^{2} A_{n}(t)}{d t^{2}}+k_{n}(t) A_{n}(t)=0
$$

Retomando o problema de engenharia oceânica, tanto os risers quanto os tendões de plataformas TLP são vinculados ao fundo do mar e à unidade flutuante que, por sua vez, movimenta-se no plano vertical em decorrência das forças de primeira ordem oriundas da ação das ondas. Esse movimento leva à variação da força normal, o que, por consequência, leva a uma variação temporal da rigidez. Assim, risers e tendões de plataformas TLP são passíveis de sofrerem instabilidade paramétrica.

Embora as ondas de superfície (e, por consequência, a variação da força normal nas estruturas em discussão) sejam irregulares, a maior parte dos estudos de excitação paramétrica em estruturas de engenharia oceânica tem como foco a variação harmônica e monocromática da rigidez. O leitor interessado em um maior aprofundamento sobre a resposta de um riser a uma excitação paramétrica irregular pode consultar o trabalho de Yang, Xiao e Xu (2013). 
No contexto de corpos submersos, parte importante da energia dissipada advém do amortecimento hidrodinâmico que, por sua vez, pode ser modelado por meio da fórmula de Morison. Segundo essa expressão, um corpo submerso em um fluido inicialmente em repouso está sujeito a uma força por unidade de comprimento dada por:

$$
f=-m_{a} \frac{d^{2} u}{d t^{2}}-\frac{1}{2} \rho \frac{d u}{d t}\left|\frac{d u}{d t}\right| \bar{C}_{D} D
$$

onde $m_{a}$ é a massa adicional seccional e $\bar{C}_{D}$ é o coeficiente de arrasto médio da seção transversal, $D$ uma dimensão característica da seção transversal do corpo e $\rho$ a massa específica do fluido. Note que o segundo termo da Equação 3.17 corresponde ao amortecimento hidrodinâmico, quadrático na velocidade do corpo.

O trabalho de Patel e Park (1991) é de grande importância no tema, uma vez que ele foi um dos primeiros a considerar o amortecimento hidrodinâmico (portanto, quadrático na velocidade do corpo). Dentre outras conclusões, os autores apontam que o amortecimento não-linear é responsável por limitar a amplitude da resposta à instabilidade paramétrica, mesmo em situações onde o diagrama de Strutt prevê a existência de respostas ilimitadas. Cumpre ressaltar que, para corpos cilíndricos, a prática da engenharia oceânica usualmente adota os seguintes valores do coeficientes de massa adicional $C_{a}$ e de arrasto médio:

$$
\begin{aligned}
& C_{a}=\frac{m_{a}}{\rho \pi D^{2} / 4}=1 \\
& \bar{C}_{D}=1,2
\end{aligned}
$$

O valor unitário para o coeficiente de massa adicional advém da solução analítica obtida assumindo a hipótese de escoamento potencial e considerando que o cilindro está imerso em um fluido de domínio infinito. Salvo quando explicitado o contrário, este texto assume que a massa adicional é igual à massa adicional potencial $m_{a}=m_{a}^{p o t}$ e que $C_{a}=C_{a}^{p o t}=1$. Já o coeficiente de arrasto médio corresponde ao valor obtido a partir de um experimento com um corpo fixo e submetido a uma correnteza uniforme e invariante no tempo.

No entanto, é conhecido que os coeficientes de massa adicional e de arrasto médio dependem da condição de movimento do corpo por meio do número de Keulegen-Carpenter $K C=2 \pi A_{i} / D$. Para estudos nos quais movimentos harmônicos são impostos a um cilindro rígido, $A_{i}$ é a amplitude do movimento prescrito. A Figura 4 ilustra a variação dos coeficientes hidrodinâmicos como função do número de Keulegen-Carpenter para diversos valores do parâmetro $\beta=R e / K C$.

O grupo de pesquisa do LMO também possui contribuições no problema de excitação paramétrica em risers. Em Simos e Pesce (1997), os autores discutem, de maneira analíticonumérica, a influência da variação linear de força normal ao longo de um riser na construção 
Figura 4 - Variação dos coeficientes $C_{m}=\left(1+C_{a}\right)$ e $C_{d}=\bar{C}_{D}$ com o número de KeulegenCarpenter.

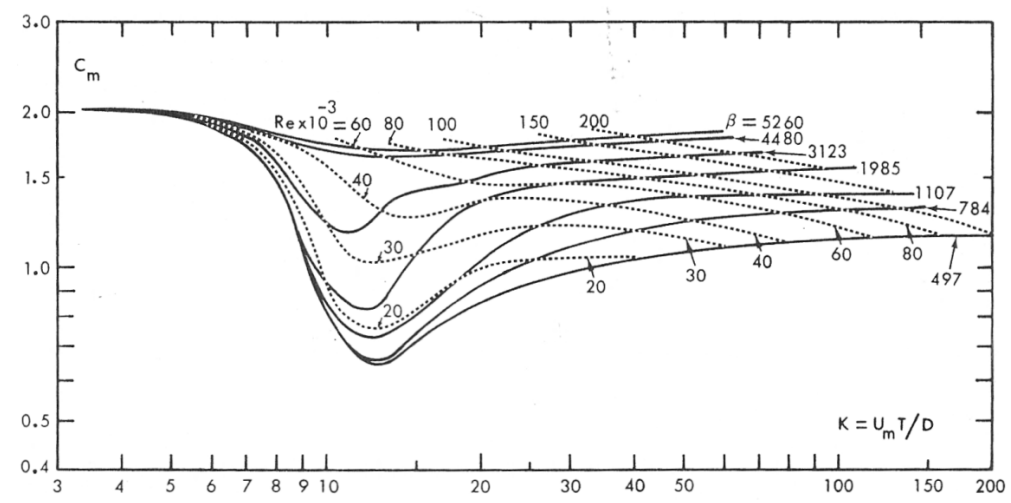

(a) $C_{m}(K C)$.

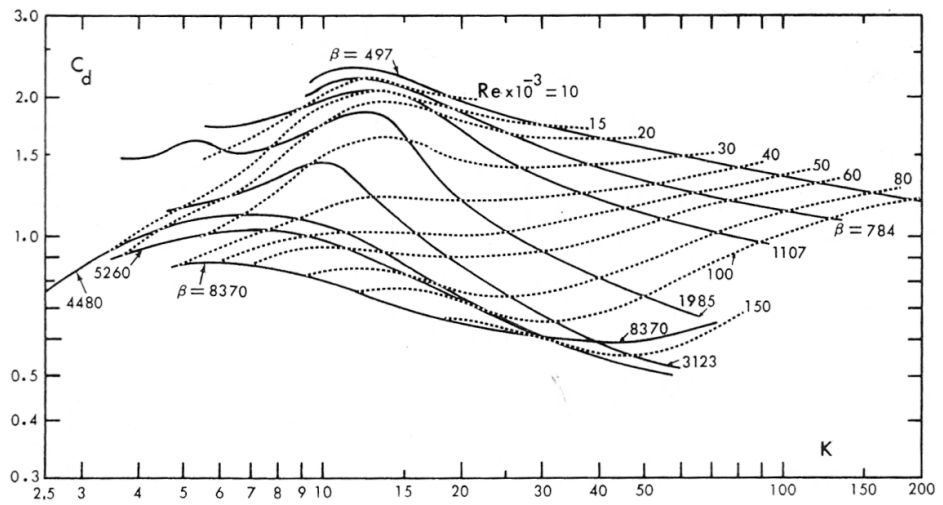

(b) $\bar{C}_{D}(K C)$.

Fonte: Extraída de Sarpkaya (1977).

do diagrama de Strutt, apontando para a importância dessa variação para tendões utilizados em águas profundas. A consideração da variação da força normal ao longo de um tendão de plataforma TLP também foi feita em Chandrasekaran, Chandak e Anupam (2006).

Cumpre também mencionar na presente revisão bibliográfica o trabalho de Rainey (1977), que aborda o problema do movimento lateral de uma plataforma TLP como aquele governado por uma equação de Mathieu. Dentre as conclusões obtidas, o autor aponta tanto para a existência da ressonância paramétrica principal quanto para a existência de oscilações sub-harmônicas dependendo da onda incidente.

\subsection{Identificação de lacunas de conhecimento}

A revisão bibliográfica apresentada neste capítulo possibilitou a identificação de algumas lacunas de conhecimento, abaixo enumeradas:

1. Baixo número de análises experimentais em modelos flexíveis sujeitos à excitação vertical imposta ao topo, simulando o movimento prescrito pela unidade flutuante 
ao ponto de conexão com um riser;

2. Baixo número de estudos numéricos com foco na determinação da resposta pós-crítica (isto é, após a instabilidade paramétrica);

3. Estudos experimentais com foco na resposta de um modelo flexível a uma solicitação policromática.

Embora o terceiro item seja um aspecto bastante importante na dinâmica de risers, ele não é abordado no âmbito deste texto. O leitor interessado na análise experimental apontada no item 1 deve consultar a seção 7.2, que apresenta as metodologias empregadas e os resultados obtidos. Por sua vez, o leitor que deseja ler sobre o item 2 é direcionado à seção 8.1 . 


\section{Vibrações induzidas pelo escoamento - VIE}

As vibrações induzidas pelo escoamento (daqui por diante identificadas por VIE) são problemas que usualmente envolvem oscilações auto-excitadas e estão presentes em diversas aplicações tecnológicas da engenharia. Tais aplicações, aliadas ao seu interessante aspecto científico (em particular pelo caráter não-linear das VIE), têm motivado uma série de estudos com vistas à compreensão de seus aspectos fenomenológicos e à modelagem matemática.

Como mencionado no capítulo 2, este texto foca em dois fenômenos particulares, a saber, as vibrações induzidas pela emissão de vórtices (VIV) e o galloping translacional. O objetivo deste capítulo é trazer tanto os conceitos físicos básicos para a compreensão desses fenômenos quanto alguns modelos matemáticos que os descrevem. Busca-se, ao final do capítulo, identificar lacunas de conhecimento existentes (algumas das quais atacadas na pesquisa aqui sintetizada). Cumpre ressaltar que o leitor interessado em um aprofundamento dos conceitos aqui vistos e também em outros fenômenos de VIE deve consultar diversos livros clássicos no tema como, por exemplo, Païdoussis (1998), Blevins (2001), Naudascher e Rockwell (2005) e Païdoussis, Price e de Langre (2011), além dos artigos referenciados.

O presente capítulo está organizado em três seções. A seção 4.1 traz os conceitos básicos do fenômeno de VIV, enquanto que o galloping é apresentado na seção 4.2. As lacunas de conhecimento identificadas são apresentadas na seção 4.3.

\subsection{Vibrações induzidas pela emissão de vórtices - VIV}

Tendo em vista a complexidade do VIV, esta seção é subdivida em seis subseções. A subseção 4.1.1 descreve alguns conceitos básicos do escoamento ao redor de um cilindro fixo e que são importantes para o entendimento do problema onde o cilindro tem liberdade para oscilar. Crescendo em complexidade, as subseções 4.1.2 e 4.1.3 discutem, respectivamente, o fenômeno de VIV em cilindros rígidos montados em apoios elásticos de um e dois graus de liberdade. Os principais aspectos da resposta de cilindros flexíveis ao VIV são apresentados na subseção 4.1.4. Já as subseções 4.1.5 e 4.1.6 são dedicadas à apresentação de modelos de ordem reduzida para o fenômeno. Tais modelos, aqui denominados como wake-oscillators, são de fundamental importância nos estudos conduzidos no âmbito do presente texto. 


\subsubsection{Escoamento ao redor de um cilindro fixo}

O escoamento ao redor de um cilindro é um dos problemas mais estudados em Mecânica dos Fluidos, sendo objeto de vários textos, dentre eles os livros de Zdravkovich (2003a, 2003b). Esta breve revisão bibliográfica tem início considerando o cilindro como sendo um corpo fixo, submetido a um campo de escoamento de um fluido real, isto é, com viscosidade não nula.

Ao atingir o ponto de estagnação frontal do cilindro, a alta pressão faz com que o fluido tente contornar a superfície do corpo. No entanto, a presença da viscosidade e do gradiente adverso de pressão ${ }^{1}$ fazem com que a velocidade das partículas de fluido dentro da camada limite ${ }^{2}$ seja reduzida, até um ponto onde há uma inversão no sentido do escoamento. Essa inversão está associada à separação do escoamento que, por sua vez, leva à formação de duas camadas cisalhantes livres e de circulação oposta. Da interação entre as camadas cisalhantes livres resulta a formação e o desprendimento alternado de vórtices.

A Figura 5 traz representações esquemáticas da separação do escoamento ao redor de um fólio e da relação entre os perfis de velocidade na camada limite e o gradiente adverso de pressão.

Segundo o modelo bidimensional apresentado em Gerrard (1966), o fluido segue por três caminho após a separação da camada limite. Esses caminhos estão ilustrados na Figura 6 e abaixo descritos:

- Caminho a: Essa parcela diminui a intensidade do vórtice em formação do vórtice;

- Caminho b: Essa parcela é atraída pelo vórtice de alta circulação, até o instante em que ela interrompe a sua formação, fazendo com que o vórtice seja emitido e configurando uma esteira vorticosa. A emissão de vórtices pode ser bem definida por meio de sua frequência $f_{f}$;

- Caminho c: Essa parcela contribui para a formação de um novo vórtice, agora alimentado pela camada cisalhante de circulação oposta.

O caráter oscilatório da esteira induz uma variação temporal dos campos de pressão e de tensão de cisalhamento, de sorte que a força de sustentação (ou seja, a componente da força fluída na direção perpendicular àquela da correnteza incidente) pulsa com a frequência de emissão de vórtices $f_{f}$. É trivial notar que a força de arrasto é composta de duas parcelas, sendo um valor médio e uma parcela oscilatória com frequência igual ao dobro da frequência de emissão de vórtices. A duplicidade da frequência de oscilação da

1 O leitor deve entender como gradiente adverso de pressão a condição onde a pressão aumenta no sentido do escoamento.

2 A camada limite é uma fina camada de fluido formada próximo ao corpo e dentro da qual os efeitos viscosos são importantes. 
Figura 5 - Representações esquemáticas da separação do escoamento ao redor de um fólio e perfis de velocidade na camada limite.

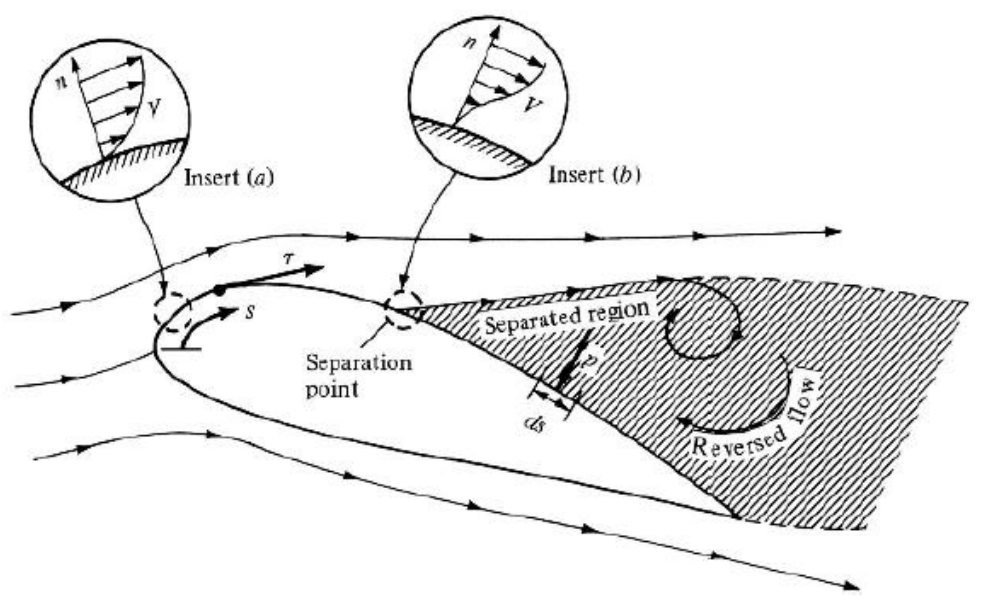

(a) Separação do escoamento e perfis de velocidade.
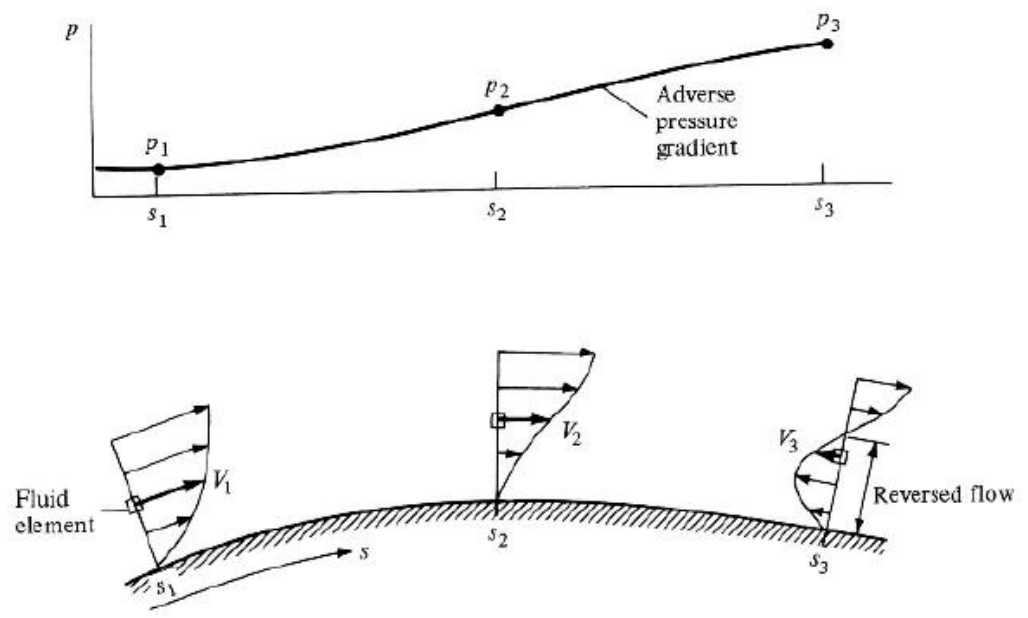

(b) Detalhamento acerca do gradiente adverso de pressão.

Fonte: Extraída de Anderson Jr. (2011).

força de arrasto vem da observação de que, a cada ciclo de emissão de vórtices (um ciclo da força de sustentação), o campo de escoamento muda de tal forma que a integral dos campos de pressão e de tensões de cisalhamento (devidamente projetada na direção da correnteza incidente) varia duas vezes.

Como um cilindro é um corpo de seção transversal sem cantos vivos, os padrões da esteira vorticosa são altamente dependentes do número de Reynolds, dado por:

$$
R e=\frac{U_{\infty} D}{\nu}
$$

sendo $U_{\infty}$ é a velocidade da correnteza incidente, $D$ o diâmetro do cilindro e $\nu$ a viscosidade cinemática do fluido. A descrição dos efeitos do número de Reynolds na esteira vorticosa é aqui conduzida segundo a classificação apresentada em Zdravkovich (2003a), embora 
Figura 6 - Modelo bidimensional para a geração e desprendimento de vórtices.

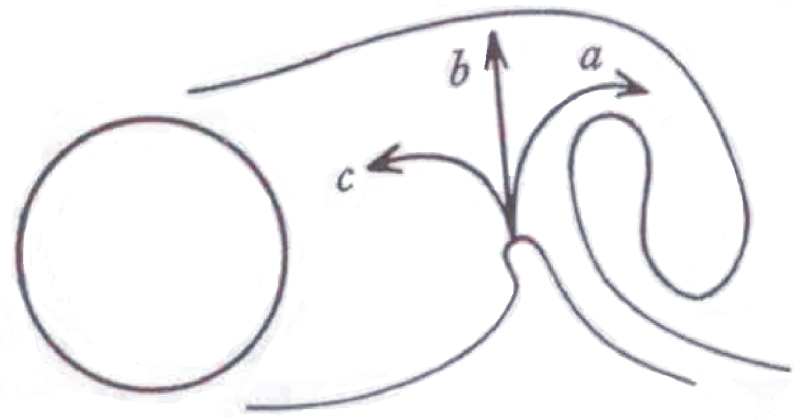

Fonte: Extraída de Gerrard (1966).

outras descrições possam ser encontradas em Blevins (2001) e em Norberg (2001, 2003). É claro ao leitor que mudanças na esteira promovem mudanças nos coeficientes de arrasto $\left(C_{D}\right)$ e sustentação $\left(C_{L}\right)$ e no número de Strouhal $(S t)$ definidos como:

$$
\begin{aligned}
& C_{D}=\frac{F_{D}}{\frac{1}{2} \rho U_{\infty}^{2} D L} \\
& C_{L}=\frac{F_{L}}{\frac{1}{2} \rho U_{\infty}^{2} D L} \\
& S t=\frac{f_{f} D}{U_{\infty}}
\end{aligned}
$$

onde $\rho$ é a massa específica do fluido, $L$ é o comprimento do cilindro e $F_{D}$ e $F_{L}$ são, respectivamente, as forças de arrasto e de sustentação.

Para $R e<1$, Zdravkovich (2003a) define o escoamento como creeping flow, caracterizado por forças viscosas bastante elevadas, de sorte que as linhas de corrente do fluido praticamente coincidem com a superfície do cilindro. No intervalo $2-5<R e<30-40$, existe a formação de duas bolhas de recirculação quem se mantém próximas ao cilindro e essa configuração é estável. Um ligeiro aumento do número de Reynolds levando-o para $30-40<R e<150-300$ faz com que a configuração onde as duas bolhas coexistem deixe de ser estável, o que dá origem à geração de vórtices e formação de uma esteira laminar.

Considerando o intervalo $150-200<R e<200-250$, existe uma transição laminar-turbulento observada na esteira de vórtices, em um regime denominado TrW1. Já para números de Reynolds entre 200 - 250 e 350 - 500, existe o regime denominado TrW2, no qual a transição laminar-turbulento ocorre na formação dos vórtices.

Um novo aumento do número de Reynolds, agora para o intervalo $250-500<$ $R e<1 \times 10^{3}-2 \times 10^{3}$, leva a transição laminar-turbulento a ocorrer nas camadas cisalhantes livres, configurando um regime denominado TrSL1. Novos aumentos desse adimensional de controle para os intervalos $1 \times 10^{3}-2 \times 10^{3}<R e<2 \times 10^{4}-4 \times 10^{4}$ e $2 \times 10^{4}-4 \times 10^{4}<R e<1 \times 10^{5}-2 \times 10^{5}$ levam a regimes caracterizados por pequenos 
vórtices de transição nas próprias camadas cisalhantes livres (TrSL2) e por camadas limites totalmente turbulentas (TrSL3) respectivamente.

Os regimes caracterizados por números de Reynolds acima de $2 \times 10^{5}$ estão associados à turbulência na camada limite (genericamente, um regime denominado $\operatorname{TrBL}$ ) e são de menor interesse neste texto e por isso não serão tão detalhadas. A justificativa para a menor atenção reside no fato de que este texto tem como problema motivador o fenômeno de VIV em estruturas esbeltas como risers. Considere um riser de 8 in de diâmetro submetido a uma correnteza típica de $0,5 \mathrm{~m} / \mathrm{s}$. Assumindo a viscosidade cinemática da água como $\nu=10^{-6} \mathrm{~m}^{2} / \mathrm{s}$, o número de Reynolds obtido é $R e=1,01 \times 10^{5}$.

Cumpre aqui ressaltar que o escoamento ao redor de cilindros caracterizado por $R e>2 \times 10^{5}$ ainda é de interesse da engenharia oceânica, mas não mais no contexto da dinâmica de risers $^{3}$. Existe um outro fenômeno denominado movimento induzido pela emissão de vórtices (em inglês, vortex-induced motion - VIM) caracterizado por vibrações induzidas pelo escoamento em um cilindro de pequena razão de aspecto $(L / D<5)$ e que causa movimentos na unidade flutuante que recebe os risers e as linhas de amarração. Embora o fenômeno de VIM não seja o foco da presente revisão bibliográfica, o leitor interessado no tema é direcionado à leitura das teses de Fujarra (2013) e de Gonçalves (2013).

A Figura 7 traz a variação dos coeficientes de sustentação, de arrasto médio $\bar{C}_{D}$ e de suas componentes associadas à pressão e ao cisalhamento como funções do número de Reynolds. O leitor nota que além dos regimes aqui mencionados, existem esquemas ilustrativos da esteira vorticosa. Já a Figura 8 ilustra, a partir da compilação de dados da literatura feita em Norberg (2001), as variações do número de Strouhal e do valor root-mean square (rms) do coeficiente de sustentação. Enquanto o número de Strouhal é aproximadamente constante e igual a 0,20 para uma extensa faixa de número de Reynolds, o valor rms do coeficiente de sustentação apresenta uma grande sensibilidade com relação a esse adimensional, com notável dispersão para valores próximos a $R e=10^{4}$.

Cabe uma última discussão na presente subseção. As discussões aqui tecidas acerca da influência do número de Reynolds fazem menção ao caso no qual a superfície do cilindro é lisa. A inserção de rugosidade à superfície do cilindro (por exemplo, por meio da fixação de lixas) é uma forma artificial de estimular a turbulência, alterando os valores de números de Reynolds nos quais as diversas transições são verificadas.

$3 \overline{\text { Cumpre ressaltar que algumas estruturas }}$ de captação de água que vêm sido investigadas como possíveis soluções tecnológicas têm diâmetro superior a $1 \mathrm{~m}$. 
Figura 7 - Variação dos coeficientes de arrasto médio $\bar{C}_{D}$ e de sustentação com o número de Reynolds. Os subscritos ()$_{f}$ e ()$_{p}$ indicam as parcelas de atrito e de pressão respectivamente. A área tracejada indica dispersão dos dados da literatura.

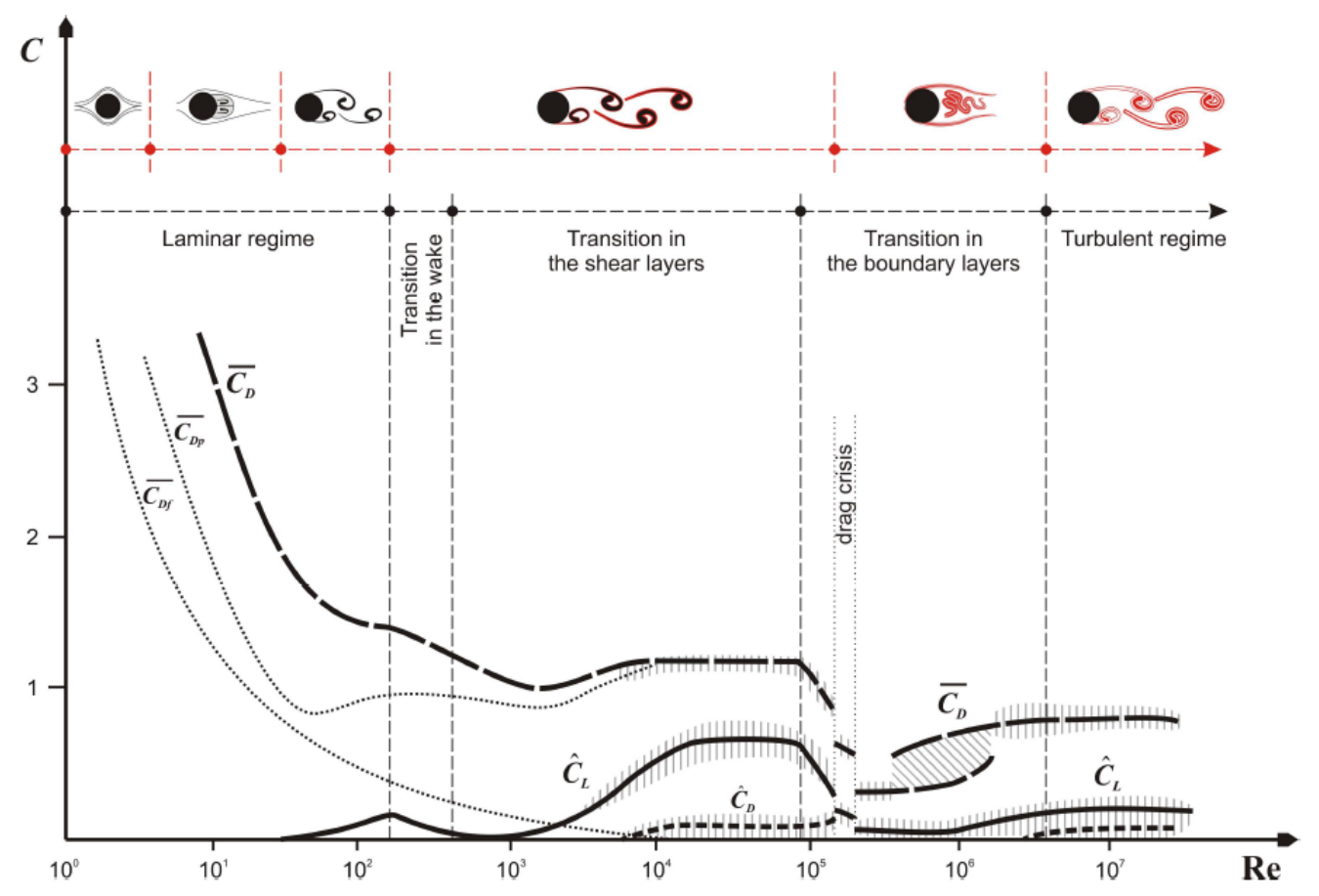

Fonte: Extraída de Assi (2009).

\subsubsection{O problema de um cilindro livre para oscilar na direção ortogonal à correnteza}

Discute-se, agora, o caso onde o cilindro possui comprimento imerso $L$ e está montado em um apoio elástico com liberdade de movimento apenas na direção ortogonal àquela da correnteza ${ }^{4}$ incidente. Essa condição será identificada ao longo deste texto por VIV-1gl. Considere que o deslocamento do cilindro seja identificado por $Y$, que a massa oscilante total seja $M$ e que o apoio elástico seja caracterizado por sua rigidez $k_{y}$ e por um amortecedor linear de constante $c_{y}$. A frequência natural desse sistema, medida em água parada, é dada por:

$$
f_{n, y}=\frac{1}{2 \pi} \sqrt{\frac{k_{y}}{M+m_{a}^{p o t}}}
$$

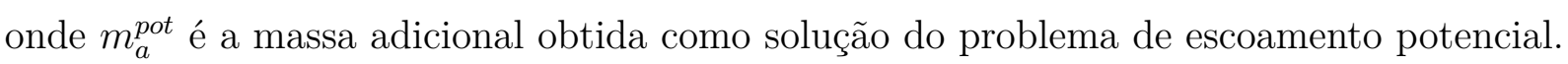
Como visto na seção 3.2 , o coeficiente de massa adicional potencial ${ }^{5} C_{a}^{\text {pot }}$ associado a uma seção transversal circular assume valor unitário se o fluido possui domínio infinito (Korotkin (2009)).

4 Essa direção também é denominada de cross-wise, nomenclatura adotada ao longo deste texto.

5 O coeficiente de massa adicional é aqui definido como a razão entre a massa adicional e a massa de fluido deslocada pelo corpo. 
Figura 8 - Variações do número de Strouhal e do valor rms do coeficiente de sustentação com o número de Reynolds.

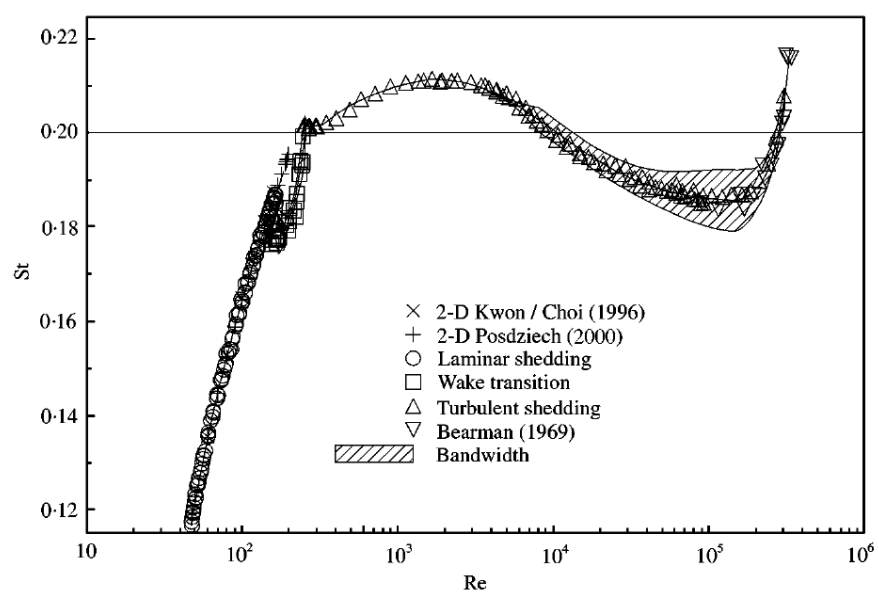

(a) $\operatorname{St}(\operatorname{Re})$.

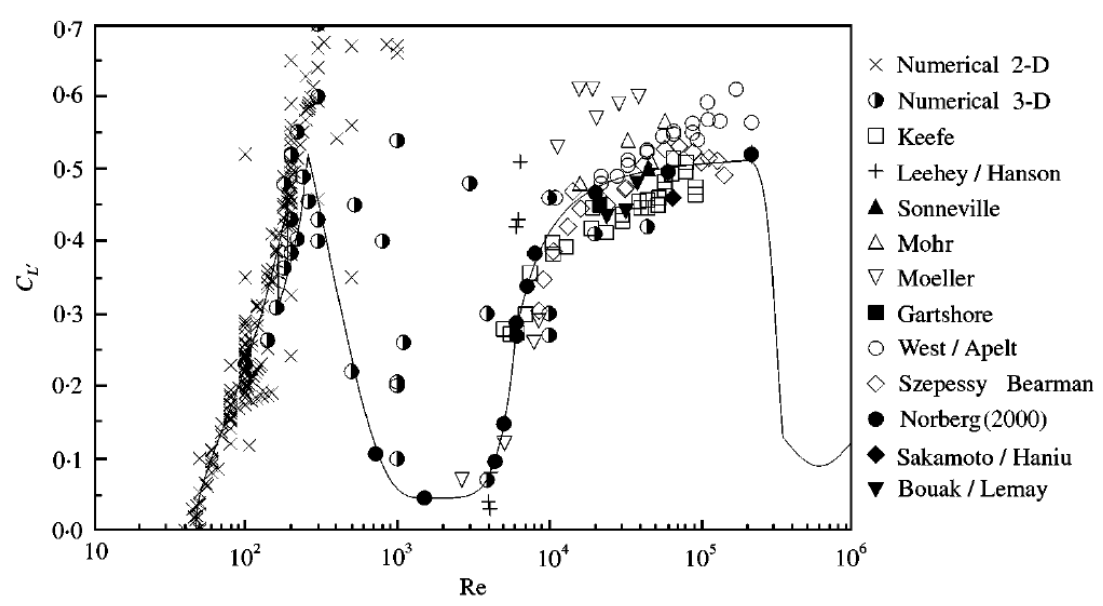

(b) $C_{L, r m s}(R e)$.

Fonte: Extraída de Norberg (2001).

Quando a frequência de emissão de vórtices é próxima da frequência natural do corpo avaliada em água parada, observa-se um comportamento ressonante denominado lock-in. O lock-in ocorre em um intervalo típico de velocidades reduzidas $3<U_{r}=\frac{U_{\infty}}{f_{n, y} D}<12$.

Ao contrário de um problema ressonante clássico, a movimentação do cilindro acaba por alterar a esteira vorticosa que é, em essência, a causadora dos esforços atuantes na estrutura. Um efeito dessa movimentação é que os deslocamentos da estrutura acabam ficando limitados a valores da ordem de um diâmetro estrutural. Outras modificações causadas pela movimentação do cilindro incluem:

- Aumento da intensidade de vórtices;

- Aumento do comprimento de correlação;

- Aumento do coeficiente de arrasto médio; 
- Mudança no padrão de emissão de vórtices.

Alguns parâmetros importantes na análise do VIV, bem como na sua modelagem matemática, são apresentados na Tabela 1.

Tabela 1 - Grandezas de interesse.

\begin{tabular}{ccc}
\hline \hline Grandeza & Símbolo & Expressão \\
\hline \hline Parâmetro de massa reduzida & $m^{*}$ & $\frac{M}{\rho \pi D^{2} L / 4}$ \\
Trequência natural em água parada & $f_{n, y}$ & $\frac{1}{2 \pi} \sqrt{\frac{k_{y}}{M+m_{a}^{p o t}}}$ \\
Velocidade reduzida & $\zeta_{y}$ & $\frac{c_{\infty}}{2 \sqrt{k_{y}\left(M+m_{a}^{p o t}\right)}}$ \\
Deslocamento adimensional & $U_{r}$ & $\frac{Y}{D}$ \\
Frequência adimensional & $\hat{f}$ & $\frac{f}{f_{n, y} D}$ \\
Coeficiente de arrasto & $C_{D}$ & $\frac{F_{D}}{\frac{1}{2} \rho U_{\infty}^{2} D L}$ \\
Coeficiente de sustentação & $C_{L}$ & $\frac{F_{L}}{\frac{1}{2} \rho U_{\infty}^{2} D L}$ \\
Número de Reynolds & $R e$ & $\frac{U_{\infty} D}{\nu}$ \\
\hline \hline
\end{tabular}

Fonte: Adaptada de Khalak e Williamson (1999).

Cabe ressaltar um aspecto relacionado ao cálculo da amplitude característica de oscilação $\hat{A}_{y}$. Não existe um consenso sobre como proceder com tal cálculo, de sorte que literatura contempla procedimentos como a média calculada a partir dos $10 \%$ maiores valores extremos (Hover, Miller e Triantafyllou (1997), Franzini et al. (2009, 2013)), o máximo valor da série temporal ou mesmo seu desvio padrão multiplicado por $\sqrt{2}$. O leitor nota, no entanto, que se o sinal de resposta é harmônico e monocromático e com média nula, todos esses procedimentos levam ao mesmo valor.

Em particular, o parâmetro de massa reduzida é bastante importante nos aspectos quantitativos e qualitativos da curva de resposta, sendo objeto de estudo de diversas referências como, por exemplo, Khalak e Williamson (1999). A Figura 9 ilustra a curva de resposta ao VIV para sistemas com dois valores de $m^{*}$ bastante distintos ${ }^{6}$. Para o sistema

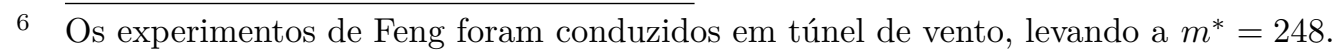


com menor parâmetro de massa (referente a ensaios conduzidos em água), três ramos de resposta são observados, a saber o initial branch, o upper branch e o lower branch. Note que, para o estudo em túnel de vento, existe um decréscimo pronunciado da máxima amplitude de vibração, além da inexistência do lower branch.

Figura 9 - Amplitude de resposta como função da velocidade reduzida. VIV-1gl.

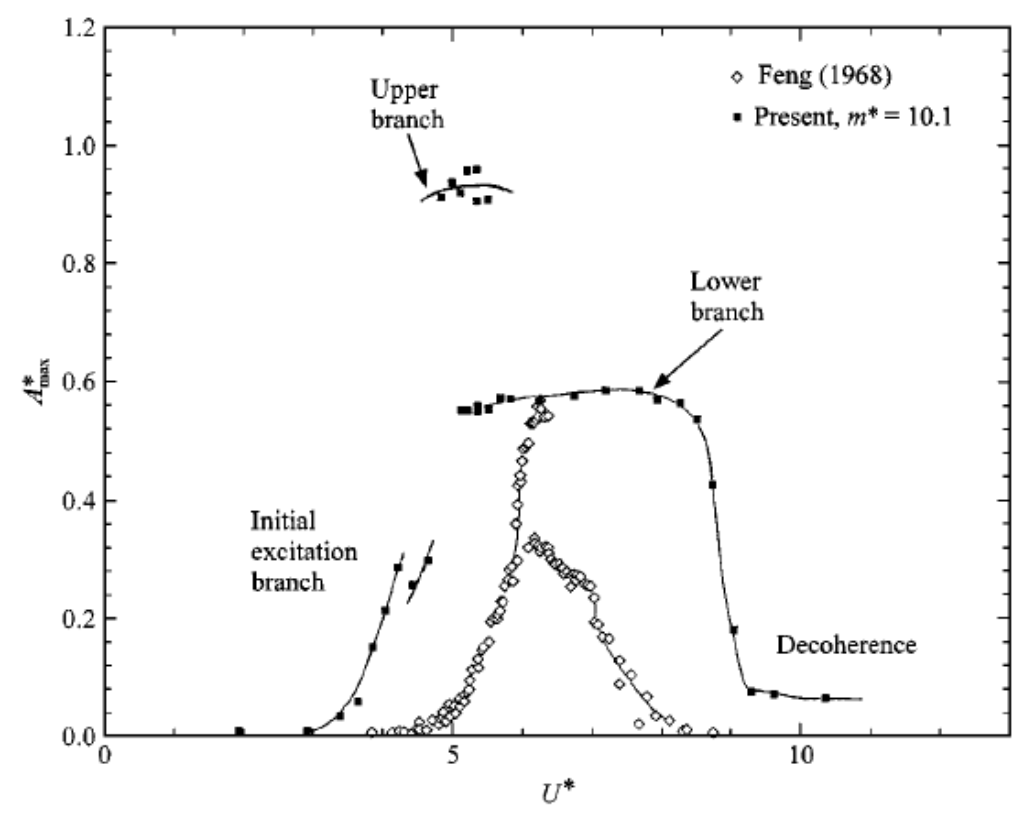

Fonte: Extraída de Khalak e Williamson (1999).

A Figura 10 ilustra a variação da frequência dominante de oscilação do cilindro normalizada pela frequência natural obtida em água parada como função da velocidade reduzida. Para sistema com valores baixos do parâmetro de massa reduzida (tipicamente, $\left.m^{*}<10\right)$ a frequência adimensional de oscilação pode assumir valores diferentes da unidade, o que decorre da intensa oscilação do cilindro que, por sua vez, acaba por alterar a esteira vorticosa. Por outro lado, para valores de $m^{*}$ superiores a 10 , a frequência de oscilação coincide com a frequência natural obtida em água parada, configurando o resultado clássico do lock-in $f^{*}=\hat{f} \approx 1$.

Tendo em vista que a resposta da estrutura é caracterizada por diferentes ramos, é natural que os padrões de emissão de vórtices também variem segundo esses ramos. A Figura 11 ilustra os padrões de emissão de vórtices obtidos a partir da condição VIV1gl. No initial branch, dois vórtices simples são emitidos a cada ciclo de oscilação do cilindro, originando o padrão de emissão "2S". Já no upper branch e no lower branch, cada ciclo de oscilação do cilindro gera a emissão de dois pares de vórtices, justificando a nomenclatura " $2 \mathrm{P}$ " para esse padrão. Já no intervalo de velocidades reduzidas onde existe a dessincronização, a esteira vorticosa tem período diferente daquele que caracteriza a oscilação do cilindro.

Um último aspecto a ser discutido na presente subseção é o efeito do número de 
Figura 10 - Frequência adimensional de oscilação como função da velocidade reduzida. VIV-1gl.
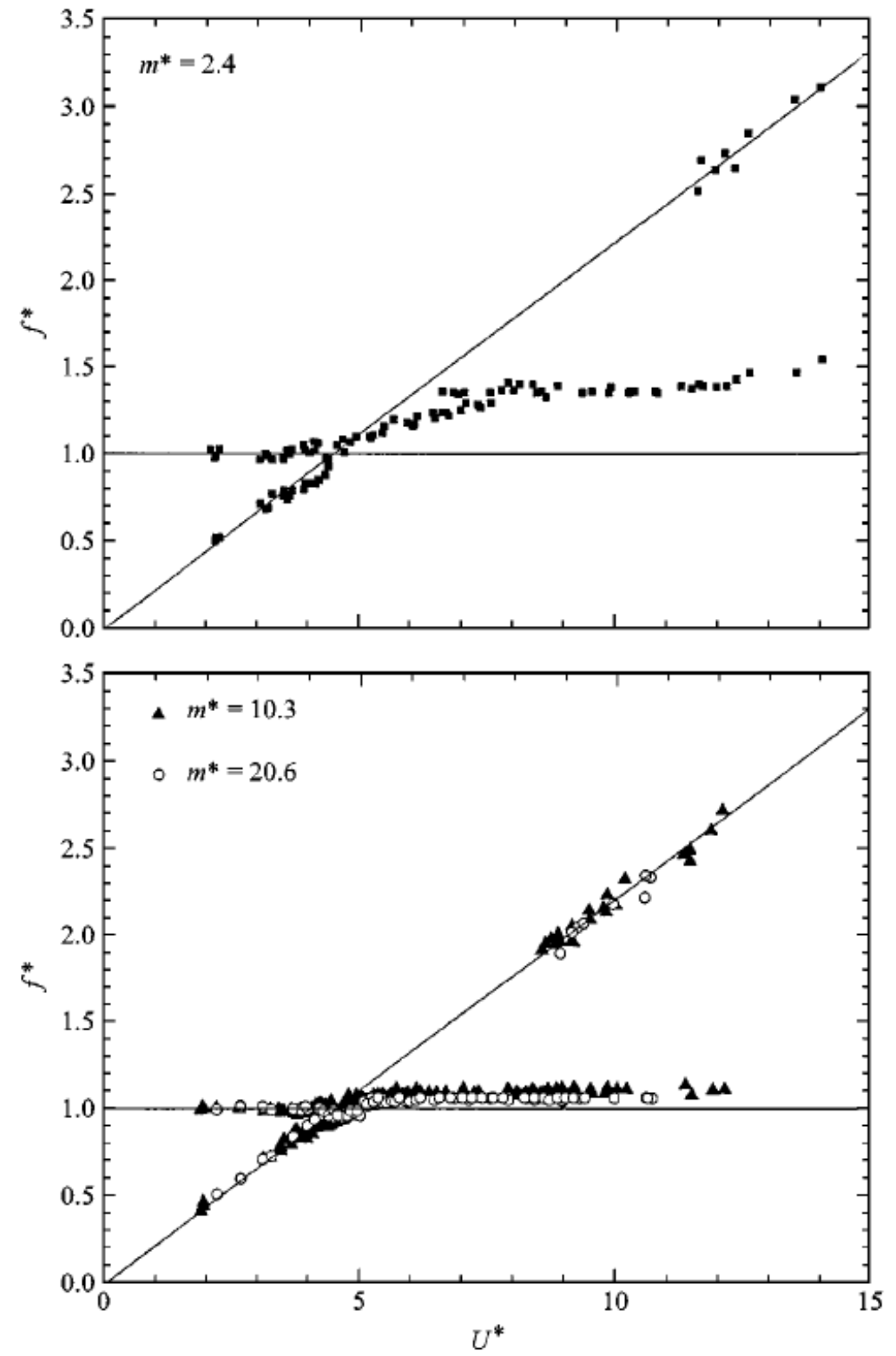

Fonte: Extraída de Khalak e Williamson (1999).

Reynolds na amplitude característica de oscilação. Raghavan e Bernitsas (2011) trazem uma extensa compilação de resultados experimentais obtidos em laboratório, indicando que a grande maioria das investigações estão no regime TrSL2. Além da mencionada compilação, os autores trazem dados experimentais obtidos em um intervalo de número de Reynolds característico dos regimes TrSL3 e TrBL.

A Figura 12 traz resultados experimentais publicados em Raghavan e Bernitsas (2011) mostrando a variação da amplitude característica de oscilação como funções da velocidade reduzida e do número de Reynolds. Conforme a discussão tecida nesse artigo, os autores mostram que mesmo considerando o parâmetro de massa-amortecimento $m^{*} \zeta_{y}$ 
Figura 11 - Padrões de emissão de vórtices.

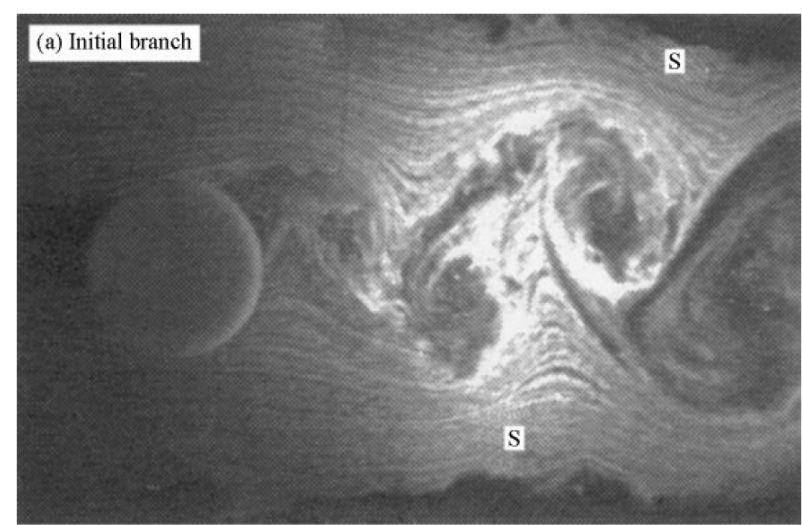

(a) Padrão de emissão "2S".

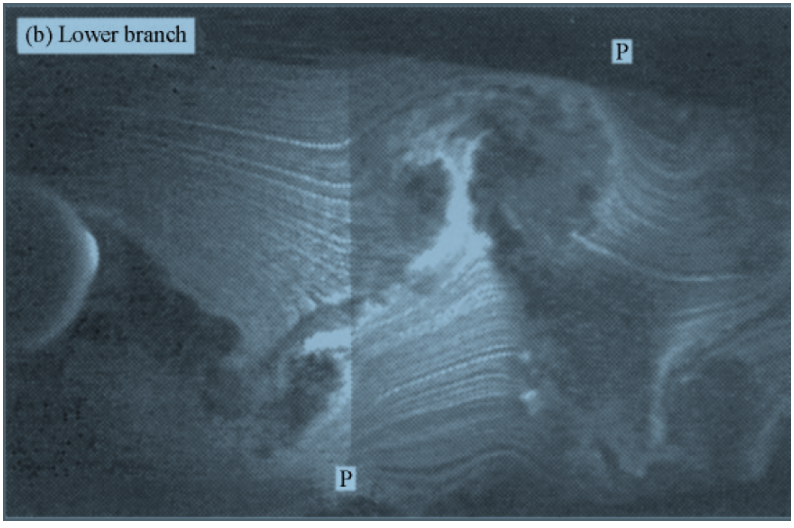

(b) Padrão de emissão "2P".

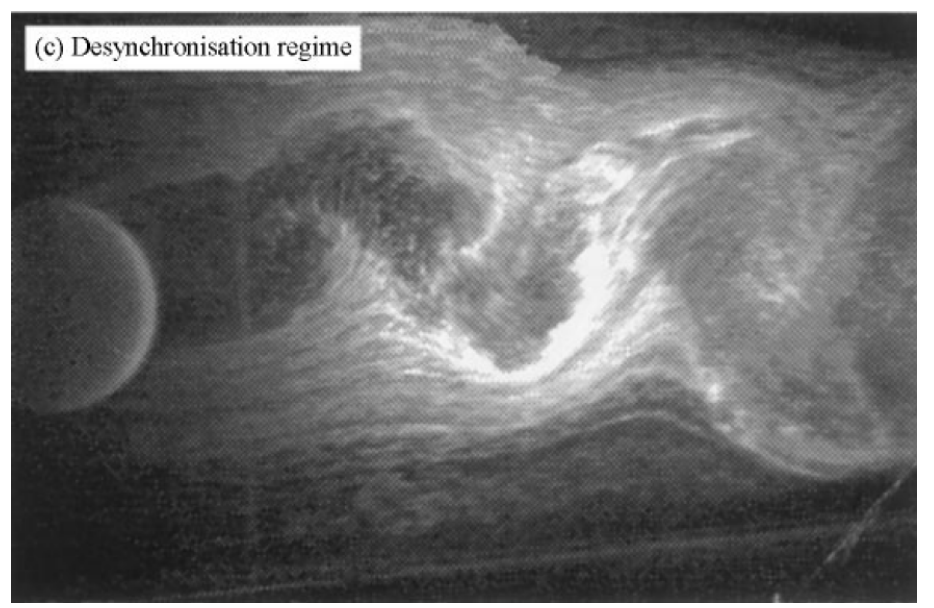

(c) Ausência de padrão de emissão.

Fonte: Extraída de Khalak e Williamson (1999).

cerca de vinte vezes superior àquele estudado experimentalmente por Khalak e Williamson (1999) no regime TrSL2, o fato de os experimentos de Raghavan e Bernitsas (2011) terem sido conduzidos também no regime TrSL3 levou a amplitudes de oscilação superiores a $1,5 D$. Note, ainda, que o experimento conduzido no regime $\operatorname{TrBL}\left(R e \approx 10^{5}\right)$ apresenta máxima amplitude característica de oscilação próxima a $1,8 D$.

\subsubsection{O problema de um cilindro livre para oscilar nas direções da correnteza e ortogonal a ela}

Até o fim da década de 1990, a comunidade científica da área deu foco no problema de um cilindro rígido montado em apoio elástico de um grau de liberdade. Com forte motivação da indústria, o problema de um cilindro rígido montado em apoio elástico com liberdade de oscilação nas direções da correnteza (daqui em diante referida pelo termo em língua inglesa, direção in-line) e cross-wise simultaneamente passou a ser mais investigado. Este texto identifica essa última configuração como VIV-2gl. 
Figura 12 - Variações da amplitude característica de oscilação como funções da velocidade reduzida e do número de Reynolds.

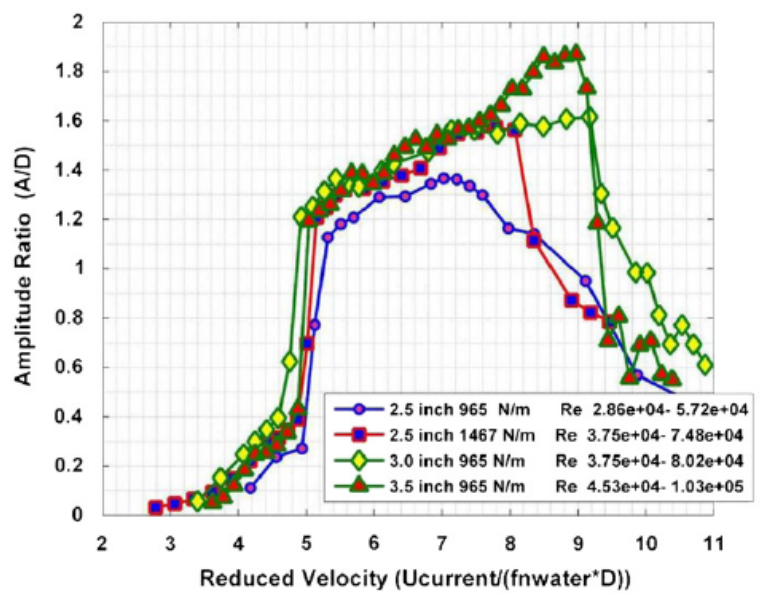

(a) Amplitude característica de oscilação como (b) função da velocidade reduzida.

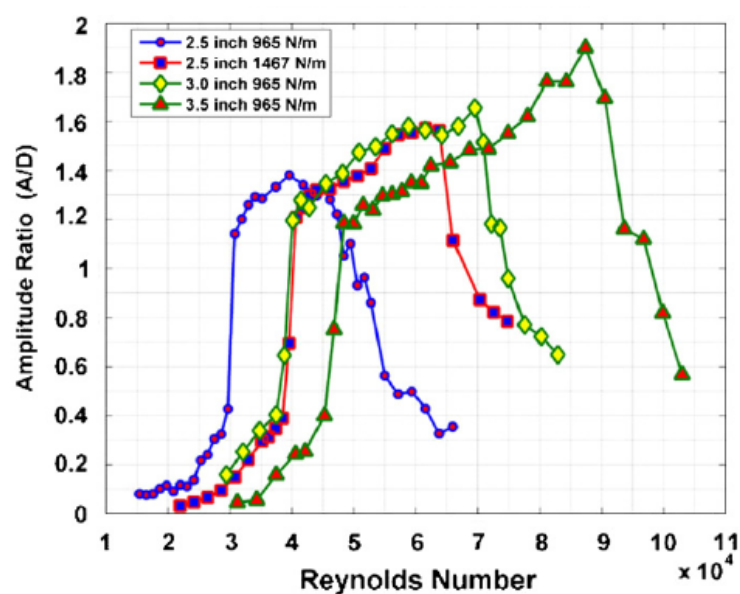

(b) Amplitude característica de oscilação como função do número de Reynolds.

Fonte: Extraída de Raghavan e Bernitsas (2011).

Um dos primeiros e mais importantes trabalhos nesse contexto é o de Jauvtis e Williamson (2004). Por meio de experimentos fundamentais em um canal de água recirculante, os autores apontaram importantes modificações no fenômeno decorrentes da presença de um grau de liberdade adicional.

Um primeiro e bastante relevante resultado é o fato de que, para sistema com valores baixos do parâmetro de massa reduzida $m^{*}$ (tipicamente, $m^{*}<6$ ), o cilindro apresenta oscilações na direção in-line que, mesmo sendo de pequena amplitude (no máximo 0,30D), acabam por promover um aumento de cerca de 50\% nos valores da amplitude de oscilação na direção cross-wise. Além disso, a velocidade reduzida na qual a máxima resposta na direção cross-wise é observada é deslocada de $U_{r} \approx 5,5$ para $U_{r} \approx 8$. Por meio de medidas de visualização de escoamento, os autores associaram esse aumento na resposta a um novo ramo denominado super upper branch que, por sua vez, está associado a um padrão de esteira vorticosa no qual duas trincas de vórtices são emitidas a cada ciclo de oscilação do cilindro (padrão "2T").

A Figura 13 ilustra as curvas de amplitudes características de oscilação como funções da velocidade reduzida obtidas a partir de um experimento na condição VIV-2gl e com parâmetro de massa reduzida $m^{*}=2,6$. Já a Figura 14 ilustra as trajetórias no plano horizontal em conjunto com as curvas de amplitude de oscilação na direção cross-wise. É importante ressaltar que o arranjo estudado por Jauvtis e Williamson (2004) apresenta valores de rigidez nas direções cross-wise e in-line idênticos. O leitor interessado em estudos acerca do fenômeno VIV-2gl nos quais existe diferença de rigidez é convidado a consultar o trabalho de Dahl et al. (2010). 
Figura 13 - Amplitude de resposta e frequência adimensional de oscilação como funções da velocidade reduzida. VIV-2gl.

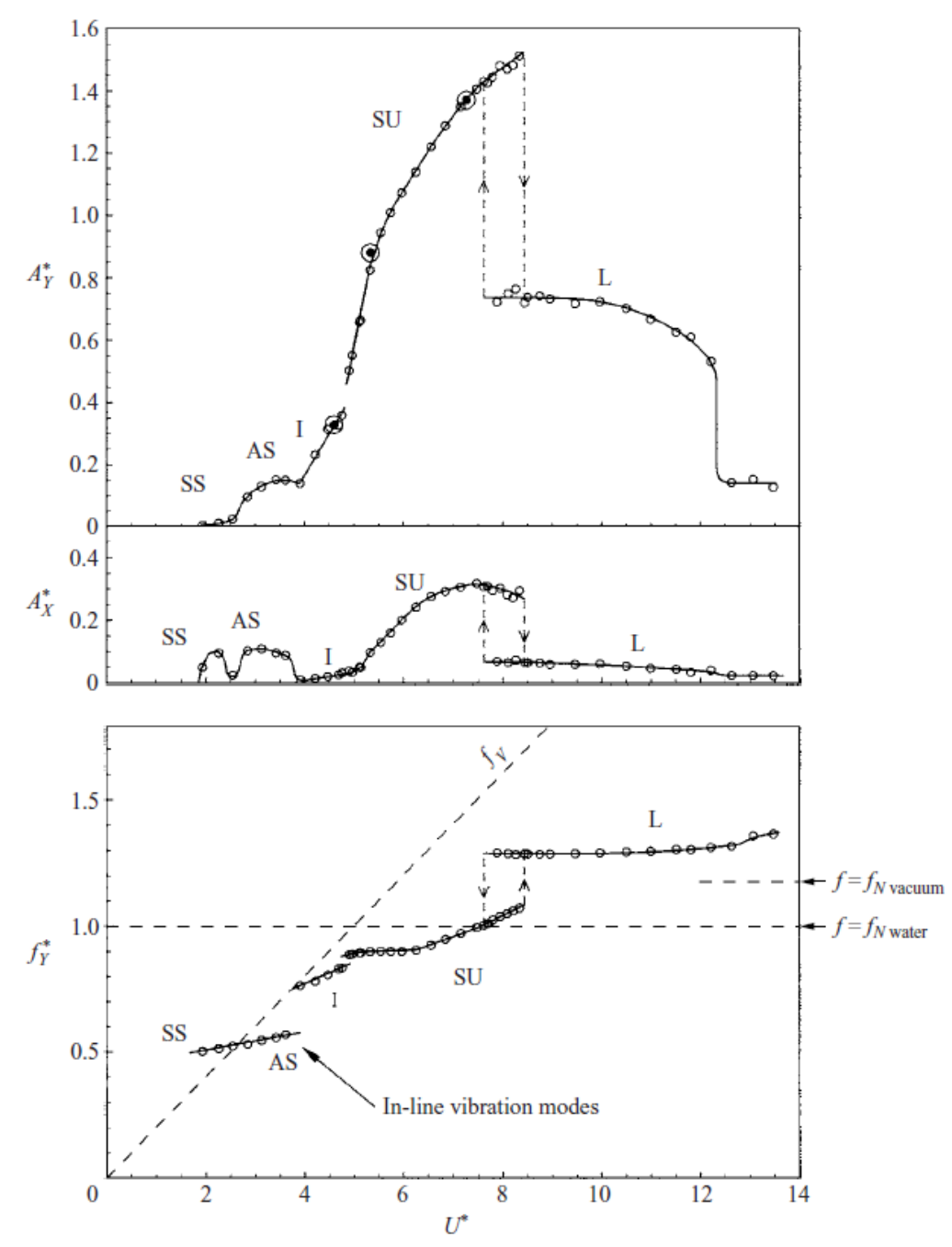

Fonte: Extraída de Jauvtis e Williamson (2004).

Já para sistemas com parâmetro de massa $m^{*}>6$, Jauvtis e Williamson (2004) verificaram que as amplitudes de oscilação na direção da correnteza são desprezíveis. Como consequência desse fato, a curva de amplitude de resposta na direção cross-wise para o caso VIV-2gl praticamente não exibe distinção quando comparada àquela obtida para a condição VIV-1gl sob parâmetros comparáveis de massa e de amortecimento. Alguns anos mais tarde, Franzini et al. (2012a) experimentalmente verificaram que essas conclusões tecidas acerca das amplitudes de oscilação, podem ser aplicadas aos coeficientes de arrasto médio e de sustentação.

Nos anos seguintes, novos estudos paramétricos buscaram o aprofundamento dos efeitos dos parâmetros $m^{*}$ e $\zeta_{y}$ na resposta ao fenômeno de VIV em dois graus de liberdade. Dentre estes trabalhos, podem ser destacados os estudos experimentais apresentados em Stappenbelt e Lalji (2008), Blevins e Coughran (2009) e em Freire e Meneghini (2010). 
Figura 14 - Amplitude de resposta na direção cross-wise e ângulo de fase entre as oscilações nas direções cross-wise e in-line.

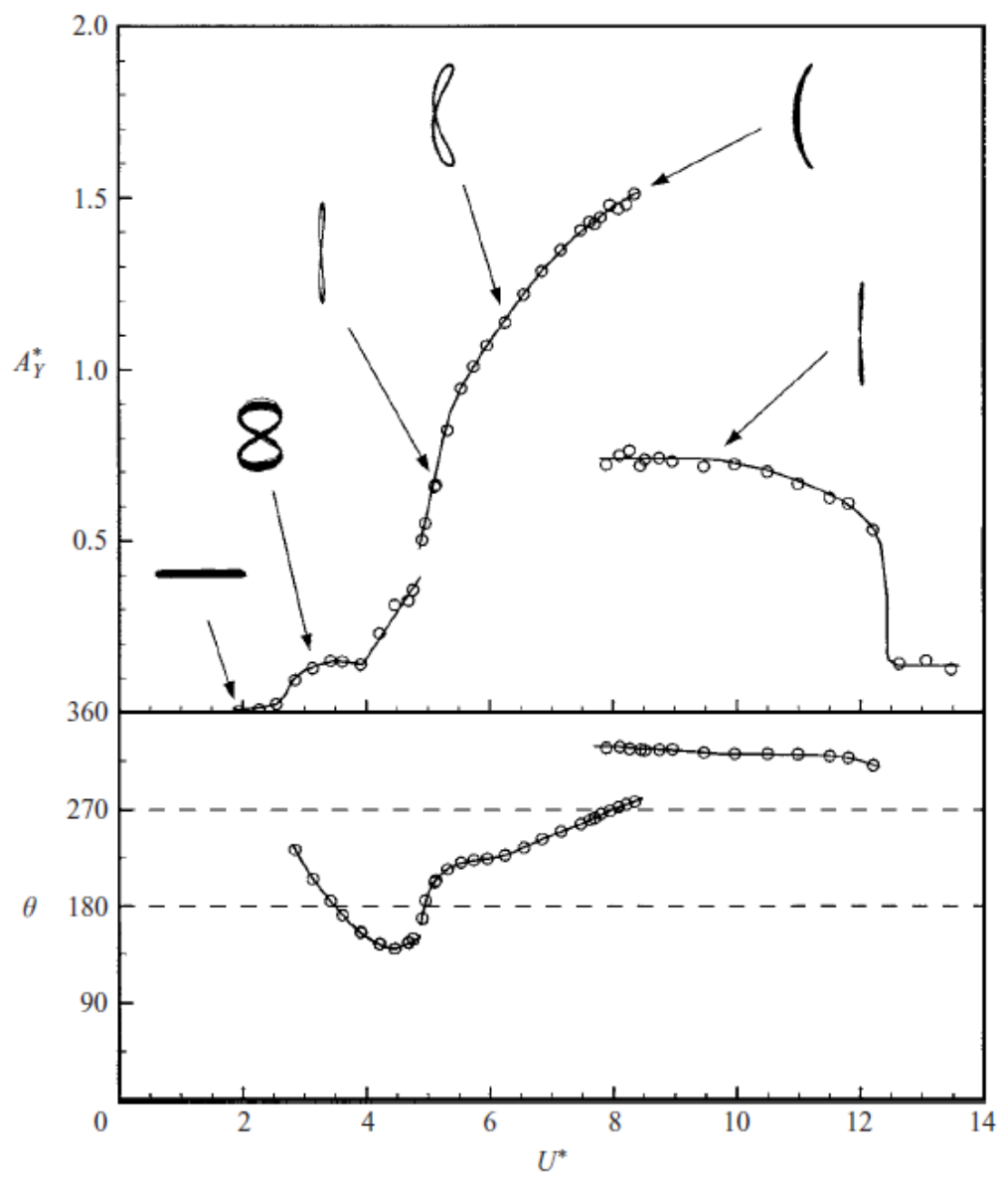

Fonte: Extraída de Jauvtis e Williamson (2004).

\subsubsection{O problema do cilindro flexível vertical}

Conforme mencionado anteriormente, o fenômeno de VIV é bastante relevante na dinâmica de estruturas oceânicas. Em particular, risers e tendões de plataformas TLP são elementos flexíveis sobre os quais o VIV pode ser importante. Embora as amplitudes de oscilação continuem a ser limitadas a valores próximos a um diâmetro (o que, dada a elevada esbeltez destas estruturas, não é tão impactante em termos de tensões mecânicas), o VIV é motivo de interesse da indústria ${ }^{7}$ devido a questões relacionadas à fadiga estrutural.

Além do interesse tecnológico, os cilindros flexíveis apresentam aspectos naturalmente mais complexos e não encontradas nos cilindros rígidos montados em apoio elástico. Dentre esses aspectos, podem ser destacados:

- A presença de ondas progressivas ao longo da estrutura;

7 Conforme mencionado na seção 2.2, uma base de dados bastante completa foi gerada pelo grupo de pesquisa do autor deste texto a partir de um projeto financiado pela indústria. 
- Excitação multi-modal, envolvendo tanto modos em direções ortogonais quanto modos na mesma direção;

- Coexistência entre excitação pelo VIV e a imposição de movimento ao topo da estrutura pela unidade flutuante. O movimento imposto ao topo acaba por modular a força normal, o que pode levar à instabilidade paramétrica. O leitor interessado nesse último fenômeno é direcionado a retornar ao capítulo 3 deste texto.

Dada a sua importância tecnológica em engenharia oceânica, diversos estudos têm sido conduzidos no sentido da melhor compreensão do fenômeno de VIV em cilindros flexíveis, incluindo um grande número de trabalhos experimentais. Este texto foca na discussão de alguns resultados obtidos para cilindros verticais, embora aspectos como efeito da inclinação em um cilindro flexível reto (Vieira (2017)) e de estruturas em catenária (Morooka e Tsukada (2013), Pereira (2014), Malta (2015) e Rateiro et al. (2016)) também sejam comumente investigados. O leitor interessado em uma revisão de literatura acerca do fenômeno de VIV em cilindros flexíveis pode consultar o trabalho de Wu, Ge e Hong (2012).

Um dos primeiros trabalhos no tema é de autoria do grupo de pesquisa da EPUSP. O artigo de Pesce e Fujarra (2000) discute resultados experimentais do fenômeno de VIV em um cilindro flexível em balanço. Nesse trabalho, as amplitudes de oscilação do modelo flexível foram avaliadas indiretamente por meio de extensômetros ${ }^{8}$. Dentre outros aspectos, os autores identificaram a presença de saltos entre ramos de resposta para velocidades reduzidas em torno de 8,3.

Além da identificação dos saltos entre os ramos de resposta, os experimentos de Pesce e Fujarra (2000) foram empregados em uma análise bastante interessante, conduzida pelos mesmos autores alguns anos depois. Comparando os resultados experimentais obtidos com um cilindro flexível com aqueles obtidos por Jauvtis e Williamson (2004) para um cilindro rígido sujeito à condição VIV-2gl e caracterizado por valores similares do parâmetro $m^{*} \zeta_{y}$, Pesce e Fujarra (2005) apontam para uma notável similaridade entre as respostas obtidas a partir de ensaios com cilindros flexíveis ou cilindros rígidos montados em base elástica; ver Figura 15. Conforme o leitor pode ver na seção 7.3, essa similaridade também é verificada para cilindros flexíveis verticais e para mais do que um modo de vibração, desde que a velocidade reduzida seja calculada de maneira apropriada.

Em Fujarra et al. (2001), os autores estudaram experimentalmente um cilindro flexível em balanço sujeito ao fenômeno de VIV. Embora, do ponto de vista hidrodinâmico,

8 Conforme mencionado na seção 2.2, os experimentos da base de dados de propriedade do grupo de pesquisa e que são objeto de análise da seção 7.3 foram conduzidos utilizando de um sistema óptico de medição. Esse sistema avalia diretamente os deslocamentos de alvos refletivos posicionados ao longo do modelo. A obtenção de sinais de deslocamento a partir de medidas de deformação envolvem o conhecimento dos modos de vibrar da estrutura, nem sempre disponíveis para o modelo as-built. 
Figura 15 - Comparação entre resultados experimentais obtidos com cilindros rígidos montados em apoio elástico de dois graus de liberdade (círculos) e com cilindros flexíveis em balanço (demais marcadores).

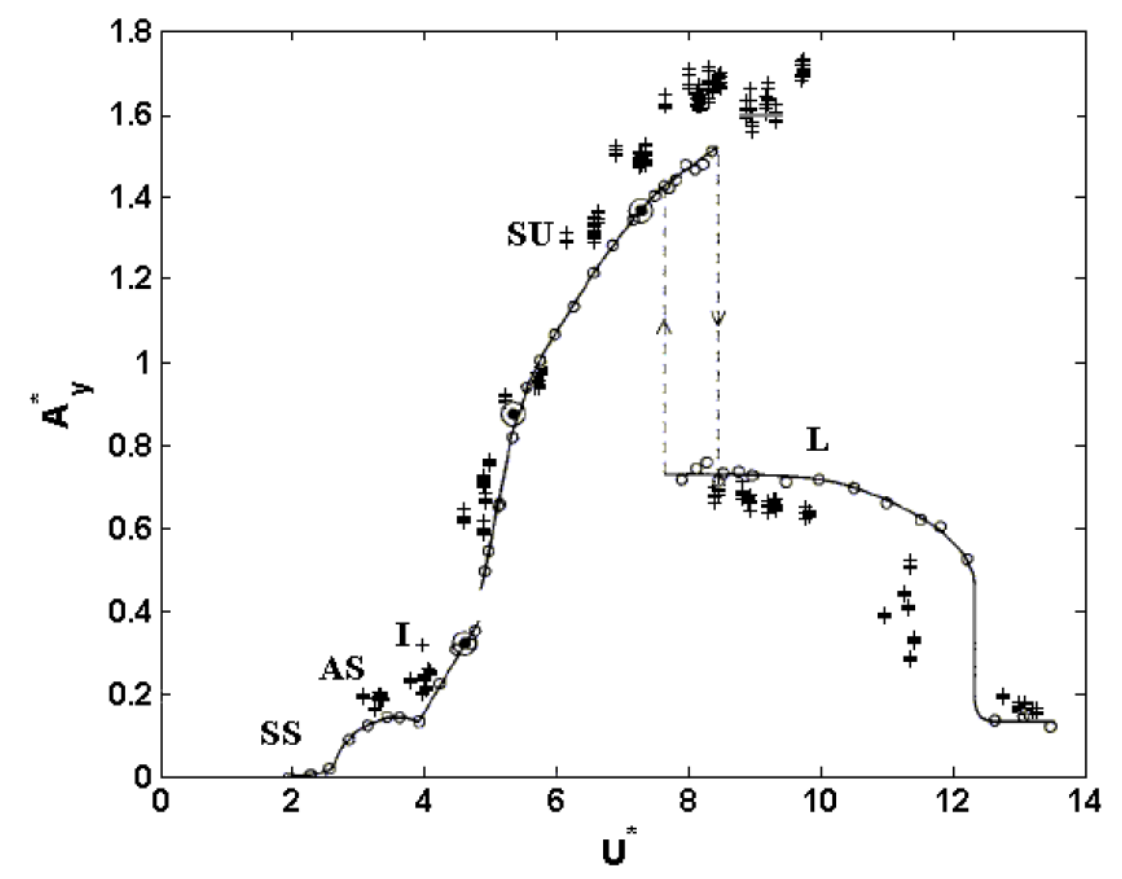

Fonte: Extraída de Pesce e Fujarra (2005).

a seção transversal do cilindro fosse circular, o modelo era composto de uma alma metálica de seção transversal retangular recoberta por uma camada de silicone responsável tanto pela garantia de circularidade da seção transversal do modelo quanto pela estanqueidade dos extensômetros. O leitor percebe que a concepção da seção transversal da alma conferia valores de rigidez diferente nas direções cross-wise e in-line. Dentre os principais resultados, os autores apontaram para a existência de um ramo de resposta denominado high-speed mode e observado para $U_{r}>12$, fato bastante curioso e que permaneceu sem novas investigações durante quase duas décadas. A Figura 16 traz as curvas de amplitude característica de oscilação e da correspondente frequência dominante como funções da velocidade reduzida, de onde é possível notar que o high-speed mode é caracterizado por altas amplitudes e frequências de oscilação.

As referências Chaplin et al. (2005a,2005b) são bastante importantes no contexto do estudo experimental da resposta de cilindros flexíveis ao VIV. Nesses trabalhos, os dados foram obtidos a partir da condução de uma campanha experimental em tanque de reboque com um longo modelo totalmente submerso porém excitado pelo fenômeno apenas em sua porção inferior. Tal condição foi garantida por meio de uma câmara de vácuo instalada no carro de reboque. Tendo em vista a elevada esbeltez do modelo $(L / D \approx 460$, sendo $L$ o comprimento total do modelo), foi possível a obtenção de respostas até o nono modo natural. Cumpre ressaltar que, nesses artigos e ao contrário do que foi conduzido 
Figura 16 - Amplitude e frequências características de oscilação como função da velocidade reduzida. Experimentos com um modelo flexível com rigidez ortotrópica.
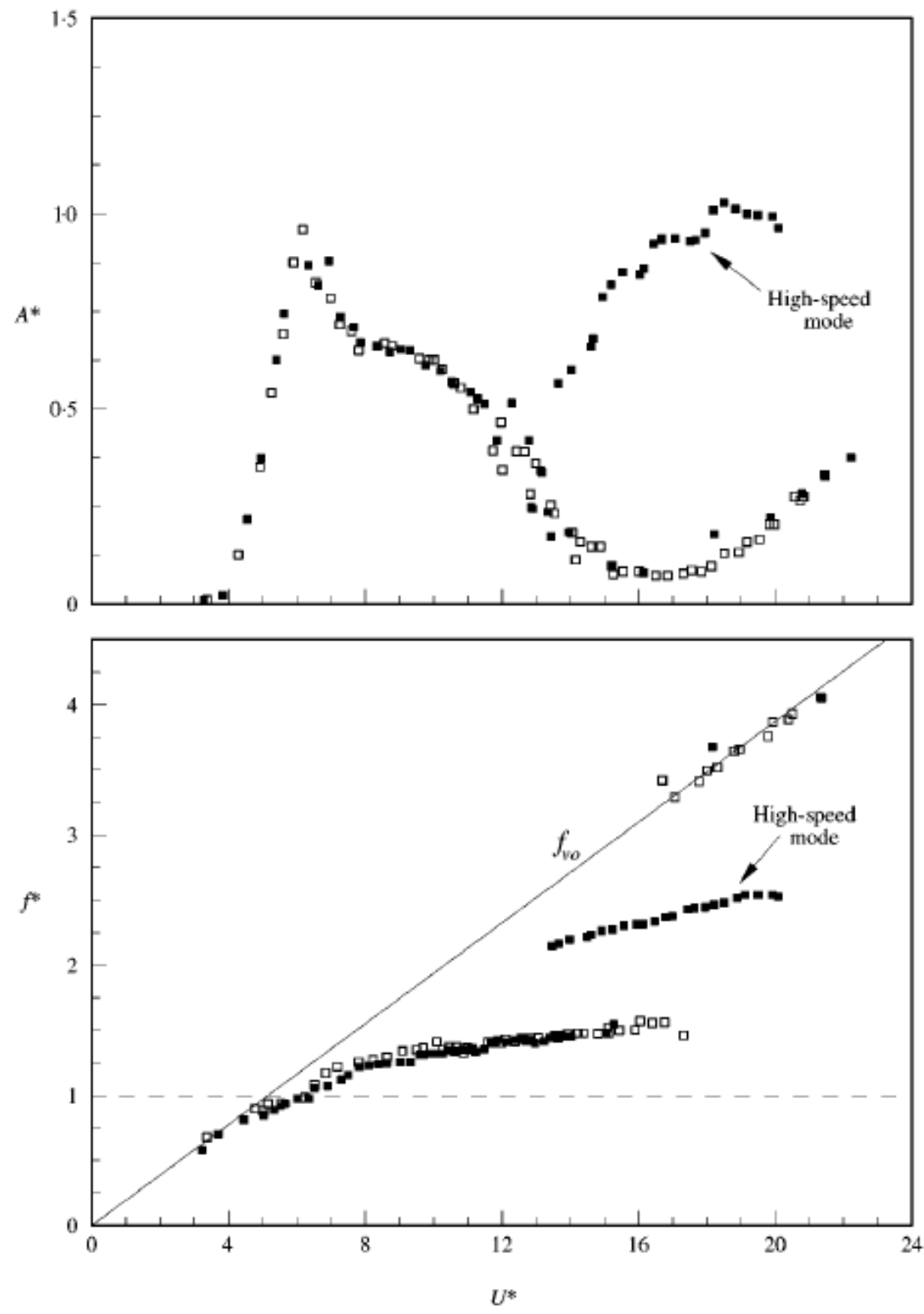

Fonte: Extraída de Fujarra et al. (2001).

nos experimentos que compõem a base de dados descrita na seção 2.2, a medição dos deslocamentos foi feita de maneira indireta via acelerômetros e extensômetros.

Além da apresentação dos dados experimentais, Chaplin et al. (2005a) trazem correlações numérico-experimentais com onze códigos numéricos desenvolvidos por grupos de pesquisa de todo o mundo, incluindo o grupo da EPUSP. Essas correlações envolveram a comparação de grandezas como curvaturas nas direções in-line e cross-wise, máximas respostas e frequências dominantes de oscilação e número de modos participantes na resposta. 
Embora as conclusões obtidas variem segundo a figura de mérito adotada, os autores agrupam as tendências segundo as naturezas dos códigos (isto é, segundo as diferentes classes de modelos nas quais as ferramentas são baseadas), pontuando a dificuldade de obtenção de uma ferramenta capaz de recuperar na totalidade os aspectos experimentalmente observados. Nesse sentido, a base de dados já apresentada na seção 2.2 e que será parcialmente analisada na seção 7.3 do presente texto pode fornecer novos paradigmas experimentais para confrontações, considerando efeitos importantes encontrados na prática da engenharia oceânica e que não foram contemplados na campanha experimental apresentada em Chaplin et al. (2005b). Como um exemplo de efeito não considerado, destaca-se a concomitância entre as excitações pelo VIV e pela excitação de topo. Como o leitor pode ver na seção 7.3, a presença de excitação de topo é responsável por importantes mudanças na resposta de um cilindro flexível ao VIV.

Os trabalhos de Huera-Huarte e Bearman (2009a, 2009b) também abordam estudos experimentais com um cilindro flexível sujeito à correnteza apenas em sua porção inferior. No entanto, esses trabalhos consideram que parte do modelo é mantida emersa. Mesmo caracterizado por um parâmetro de massa reduzida bastante baixo $\left(m^{*}=1,8\right)$, as máximas amplitudes de oscilação obtidas foram próximas a $0,70 D$ para a direção cross-wise e 0,30D na direção in-line. Os autores indicam que, para parâmetros de massa reduzida semelhantes, os cilindros rígidos montados em apoio elástico com liberdade de oscilação nas duas direções do plano horizontal apresentam amplitudes de oscilação na direção cross-wise significativamente maiores (próximas 1,40D; ver Jauvtis e Williamson (2004) e Franzini et al. (2012a)).

As medições do campo de escoamento via técnica de PIV ${ }^{9}$ descritas em HueraHuarte e Bearman (2009b) mostram que o padrão de emissão de vórtices possui relação com a posição ao longo do cilindro na qual o plano de laser é empregado. Essa dependência pode ser explicada pela presença de diferentes amplitudes de oscilação ao longo do cilindro, fato intrínseco às estruturas flexíveis. Também merece destaque o fato de que, mesmo com a presença de oscilações na direção in-line, o padrão de emissão " $2 \mathrm{~T}$ " não foi observado nesse experimento.

Medições do campo de escoamento via PIV também são objeto do estudo experimental apresentado em Xu, He e Bose (2009), porém considerando o cilindro totalmente imerso e caracterizado por seu parâmetro de massa $m^{*}=1,35$. A exemplo do que fora obtido em Huera-Huarte e Bearman (2009b), o padrão de emissão "2T" não foi observado. Em Xu, He e Bose (2009), os autores buscam correlacionar os padrões de emissão de vórtices obtidos para o cilindro flexível sujeito ao VIV com aqueles de um cilindro rígido sob oscilação prescrita, objeto da pesquisa apresentada em Williamson e Roshko (1988). Embora existam algumas aderências entre os padrões de esteira obtidos, as distintas con- 
cepções experimentais devem ser levadas em conta quando da correlação entre resultados de um cilindro flexível sob ação do VIV e um cilindro rígido sob movimentação imposta.

Tendo em vista a importância tecnológica da amplificação do coeficiente de arrasto médio seccional em um cilindro flexível sob ação do VIV, Huang, Khorasanchi e Herfjord (2011) apresentam resultados experimentais com foco na medição dessa grandeza com posterior correlação com expressões empíricas utilizadas em ferramentas de projeto e de análise de risers. Nesse trabalho, as séries temporais de deslocamento foram indiretamente obtidas a partir de sinais de aceleração.

Uma das expressões empíricas adotadas foi:

$$
\frac{\bar{C}_{D}}{\bar{C}_{D}^{0}}=1+1,043\left(3,33 y_{s t d}\right)^{0,65}
$$

sendo $\bar{C}_{D}$ o coeficiente de arrasto médio seccional, $\bar{C}_{D}^{0}$ o coeficiente de arrasto médio obtido para um cilindro fixo e $y_{s t d}$ o desvio padrão da resposta na direção cross-wise para a seção transversal em consideração. Essa expressão pode ser entendida como uma adaptação daquela que considera o mesmo tipo de formulação, porém avalia o coeficiente de arrasto médio total (ou seja, aquele ao longo de toda a estrutura) como função do máximo desvio padrão obtido ao longo da envergadura.

Nesses experimentos descritos em Huang, Khorasanchi e Herfjord (2011), o valor máximo do desvio padrão da resposta na direção cross-wise foi próximo a 0,50D e a Equação 4.6 apresentou um erro médio inferior a $8 \%$ em comparação com os dados experimentais. Dentre as conclusões, os autores apontam a necessidade de novas confrontações entre resultados experimentais e a Equação 4.6 no caso em que o desvio padrão da resposta na direção cross-wise exceda $0,50 D$.

Em Song et al. (2011), um cilindro longo cilindro flexível horizontal com razão de aspecto $L / D=1750$ e parâmetro de massa reduzida $m^{*}=1$ foi experimentalmente estudado em um tanque de provas, sendo que as séries temporais de deslocamento foram avaliadas por meio de extensômetros. Nesse trabalho, a elevada razão de aspecto favoreceu a resposta multi-modal, além de uma distribuição assimétrica dos envelopes de resposta ao longo do modelo.

Os autores conjecturaram que a assimetria na distribuição dos envelopes de resposta estaria associada ao caráter multi-modal da resposta. A avaliação de tal conjectura foi feita por meio de um estudo paramétrico, considerando respostas sintetizadas por meio da composição de dois modos (a saber, o terceiro e o quarto) e variando a relação entre as amplitude, frequências e defasagens entre as séries de amplitude modal. Por meio de simulações simples com esses sinais sintetizados, Song et al. (2011) concluíram que, de fato, a assimetria experimentalmente observada era devido à presença de respostas multi-modais com diferentes amplitudes, frequências e defasagens. 
Recentemente, a dissertação de mestrado de Defensor Filho (2018) e os artigos dela oriundos (ver Defensor Filho, Pesce e Franzini $(2017,2018)$ ) lançaram novo foco sobre o high-speed mode. Por meio de novos experimentos ${ }^{10}$ que buscaram o estudo sistemático dos efeitos da relação de rigidez nas direções cross-wise e in-line, os autores associaram o high-speed mode a oscilações na direção in-line.

Uma contribuição adicional desse trabalho de mestrado conduzido no grupo do LMO refere-se à metodologia de análise empregada. Como a variação da velocidade de escoamento foi feita de maneira praticamente monotônica no tempo, não foi possível a identificação de trechos de resposta em regime permanente. Dessa forma, foi feito uso recursivo da Empirical Mode Decomposition (EMD), um técnica de extração de componentes do sinal original segundo as diversas escalas de tempo que o caracterizam. Cada uma destas componentes é chamada de Intrinsic Mode Functions (IMFs) e é obtida sem a necessidade da definição, a priori, de uma base. Maiores detalhes acerca da EMD podem ser encontrados em Huang et al. (1998).

Conforme mencionado no capítulo 3 e também no início desta subseção, além da solicitação pelo fenômeno de VIV, os risers estão sujeitos a movimentos impostos ao topo e que podem levar à instabilidade paramétrica. Embora a concomitância entre estes dois fenômenos tenha relevância tecnológica, seu estudo ainda é bastante raro.

De maneira análoga àquela conduzida em Huera-Huarte e Bearman (2009a), Franzini et al. (2015) apresentam resultados experimentais da resposta de um cilindro flexível, imerso somente em sua porção inferior e submetido ao fenômeno de VIV. No entanto, o último trabalho também incorpora os efeitos da imposição de movimento harmônico e vertical ao topo do modelo. A amplitude do movimento prescrito foi $A_{t} / L_{0}=1 \%$, sendo $L_{0}$ o comprimento indeformado do modelo. Já no tocante à frequência do movimento imposto $\left(f_{t}\right)$, três valores foram adotados, a saber: $f_{t}: f_{n, 1}=1: 3, f_{t}: f_{n, 1}=1: 2 \mathrm{e}$ $f_{t}: f_{n, 1}=1: 1$, onde $f_{n, 1}$ é a primeira frequência natural do modelo, obtida a partir de um ensaio de decaimento em água parada.

Mesmo que a instabilidade paramétrica principal (ou seja, aquela onde $f_{t}: f_{n, 1}=$ $2: 1)$ não tenha sido estudada, Franzini et al. (2015) mostram que a resposta de um cilindro vertical sujeita somente à excitação pelo VIV pode ser substancialmente distinta daquela na qual o fenômeno de interação fluido-estrutura coexiste com o movimento prescrito ao topo do modelo. Um efeito particularmente relevante é o enriquecimento do conteúdo espectral da resposta estrutural observado tanto por meio de análises clássicas baseadas na Transformada de Fourier Discreta quanto por meio de análises no domínio tempo-frequência conduzidas por meio da Transformada de Hilbert-Huang ${ }^{11}$.

10 A metodologia de análise experimental apresentada na seção 7.1 foi empregada com êxito na análise dos experimentos investigativos do high-speed mode.

11 Essa técnica aplica a Transformada de Hilbert às IMFs já mencionadas, possibilitando a obtenção da distribuição de amplitude em cada frequência de oscilação e ao longo do tempo. Maiores detalhes sobre essa 
Em Yuan, Xue e Tang (2018), os autores estudam numericamente a influência da excitação paramétrica na resposta de um cilindro flexível sujeito ao fenômeno de VIV. Nesse trabalho, os carregamentos hidrodinâmicos são modelados por meio de uma excitação harmônica de amplitude dependente da resposta estrutural e de um amortecimento linear na velocidade e também proporcional à resposta estrutural. Uma das conclusões apontadas pelos autores é que a imposição de movimento imposto com o dobro da frequência natural do modo excitado pelo VIV (correspondendo, portanto, à instabilidade paramétrica principal com o primeiro modo de vibrar) aumenta em até $80 \%$ o máximo deslocamento estrutural quando comparado ao caso de excitação somente pelo VIV. Cumpre ressaltar que, nas conclusões, Yuan, Xue e Tang (2018) indicam a necessidade de um maior número de dados experimentais para novas correlações. O presente texto apresenta algumas análises experimentais desse problema de solicitação combinada na seção 7.3.

Finalizada a revisão bibliográfica acerca dos principais aspectos do VIV, a próxima seção é dedicada à apresentação de uma classe de modelos matemáticos descritivos do fenômeno e que é amplamente empregada neste texto.

\subsubsection{Modelos de ordem reduzida: VIV-1gI}

Tendo em vista sua complexidade, o VIV pode ser estudado segundo três abordagens complementares. Na abordagem experimental, modelos em escala laboratorial (ou mesmo em escala real) são instrumentados e submetidos a condições de escoamento precisamente controladas (no caso de ensaios em laboratório) ou com menor controle (caso de ensaios em escala real). Os dados coletados são analisados segundo diversas metodologias e, então, a redução de resultados é feita.

Na abordagem numérica, utilizam-se ferramentas de Dinâmica de Fluidos Computacional $^{12}$ (DFC) para a resolução numérica das equações de Navier-Stokes e da equação de movimento do sólido considerado. Essa técnica permite a avaliação de grandezas de difícil ou impossível medição experimental. Por outro lado, essas simulações podem ser bastante custosas computacionalmente, além de ainda não serem capazes de recuperar totalmente alguns aspectos verificados em experimentos.

Por fim, existe a abordagem analítica e baseada no conceito de wake-oscillator. Nessa abordagem, o caráter auto-excitado e auto-limitado do VIV é emulado por meio de equações não-lineares ${ }^{13}$ representativas da esteira vorticosa. Essas equações são acopladas a osciladores estruturais por meio de coeficientes empiricamente calibrados. Tendo em vista que essa abordagem leva a resultados muito mais rápidos do que aqueles obtidos via DFC,

técnica, própria para sinais oriundos de sistemas não-lineares e não-estacionários, podem ser encontrados em Huang et al. (1998).

12 Em inglês, Computational Fluids Dynamics - CFD.

13 Um número significativo de wake-oscillators adota variações da equação de van der Pol como representativas da esteira vorticosa. 
esses modelos têm sido empregado em ferramentas numéricas de projeto e análise de risers como, por exemplo, o programa desenvolvido no grupo do LMO denominado PoliVIV e oriundo da tese de Silveira (2009). Além disso, tais modelos permitem a condução de estudos analíticos acerca do fenômeno.

Cumpre ressaltar, no entanto, que essa abordagem depende de uma série de parâmetros obtidos a partir de correlações com experimentos e é justamente na forma de calibração destes parâmetros que reside uma das críticas com relação ao seu uso. O leitor interessado em uma revisão de literatura acerca da modelagem matemática do VIV pode consultar o trabalho de Gabbai e Benaroya (2005).

No entanto, tendo em vista que os modelos fenomenológicos apresentam notável aderência não só quantitativa como qualitativa com dados experimentais, eles ainda têm recebidos inúmeros esforços por meio da comunidade científica. Parte desses esforços tem sido investido na tentativa de formalizar esses modelos, tomando como ponto de partida equações ou princípios da mecânica bem estabelecidos.

Aranha (2004) discute o problema do escoamento ao redor de um cilindro fixo para número de Reynolds $R e \approx 45$. Por meio da discretização das equações de NavierStokes com posterior análise assintótica, o autor obtém as equações de Landau (problema bidimensional) e de Ginszburg-Landau (problema com fraca tridimensionalidade).

Para um problema bidimensional, Gabbai e Benaroya (2008) apresentam a derivação de um wake-oscillator para a condição VIV-1gl a partir do princípio estendido de Hamilton para sistemas abertos. Embora tenham como ponto de partida um princípio variacional clássico, Gabbai e Benaroya (2008) ainda fazem algumas hipóteses acerca das forças decorrentes da interação fluido-estrutura, em particular assumindo-a como análoga à fórmula de Morison para a dedução do modelo de ordem reduzida final. Note que, embora algumas hipóteses tenham sido feitas ao longo da dedução, a base para a obtenção do modelo matemático é um princípio clássico em mecânica.

O início do uso dos wake-oscillators data de meados da segunda metade século XX, com os trabalhos de Hartlen e Currie (1970) e Iwan e Blevins (1974). O grupo de pesquisa da EPUSP também tem contribuições no tema, em particular no trabalho de Parra e Aranha (1996), onde o modelo clássico de Iwan e Blevins (1974) é revisitado e estudado por meio de métodos de perturbação e na dissertação de mestrado de Cunha (2005), que traz uma revisão crítica e comparativa de resultados numéricos obtidos a partir de simulações numéricas considerando diversos modelos existentes na literatura.

Aqui, é conveniente destacar alguns aspectos. Em modelos clássicos como, por exemplo, aquele apresentado em Iwan e Blevins (1974), a equação não-linear representativa da esteira vorticosa possui um sentido físico abstrato. No referido trabalho, a variável que descreve a esteira representa uma média ponderada da componente vertical da velocidade 
em um volume de controle que abrange o cilindro. Já no modelo de Facchinetti, de Langre e Biolley (2004) e posteriormente revisitado por Ogink e Metrikine (2010), essa equação nãolinear é descrita por meio de uma variável com claro sentido físico e que está relacionada à força hidrodinâmica na direção ortogonal àquela da correnteza incidente.

Essa subseção apresenta as deduções de dois wake-oscillators para descrição do fenômeno de VIV um grau de liberdade e que têm sido bastante empregados pela comunidade científica desde o início dos anos 2000. Estas deduções são releituras daquelas apresentadas em Facchinetti, de Langre e Biolley (2004) e Ogink e Metrikine (2010), porém considerando outras grandezas adimensionais, de sorte a permitir uma correlação direta entre seus resultados.

Aqui, o cilindro rígido de diâmetro $D$ e comprimento $L$ apresenta massa $M$ e o apoio elástico $^{14}$ é caracterizado por sua rigidez linear $k_{y}$ e sua constante de amortecimento (também linear) $c_{y}$. O deslocamento do cilindro é definido, na forma dimensional, pela coordenada generalizada $Y$. A correnteza incidente é uniforme e de intensidade $U_{\infty}$. A Figura 17 ilustra o problema aqui estudado.

Figura 17 - Representação esquemática - fenômeno de VIV com um grau de liberdade para a estrutura.

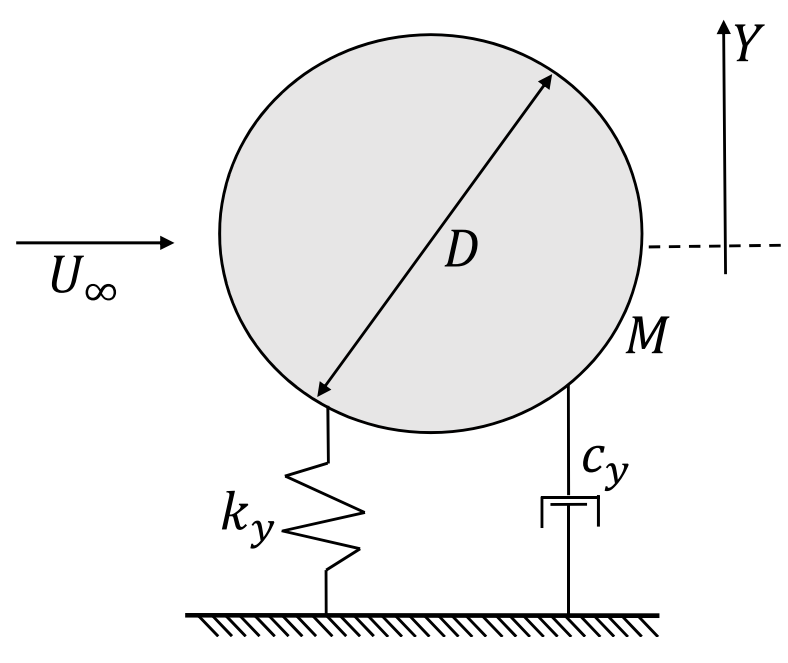

Fonte: Elaborada pelo autor.

A representação da força hidrodinâmica é feita por meio de uma equação não-linear. Analisemos a seguinte equação de van der Pol:

$$
\frac{d^{2} q_{y}}{d t^{2}}+\epsilon_{y} \omega_{f}\left(q_{y}^{2}-1\right) \frac{d q_{y}}{d t}+\omega_{f}^{2} q_{y}=0
$$

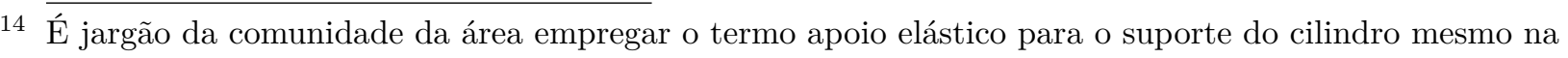
existência de um termo dissipativo. 
Para a Equação 4.7, pode-se mostrar (ver apêndice B) que a amplitude da resposta em regime permanente é $\hat{q}_{y}=2$. Mais ainda, essa solução tem frequência $\omega_{f}$.

Caso seja tomado $\omega_{f}$ como a frequência de emissão de vórtices (ou seja, $\omega_{f}=$ $\left.2 \pi S t U_{\infty} / D\right)$, a equação acima pode representar o coeficiente de sustentação atuando em um cilindro fixo. Para tanto, multiplica-se a solução $q_{y}(t)$ por $\hat{C}_{L}^{0} / \hat{q}_{y}$, sendo $\hat{C}_{L}^{0}$ a amplitude do coeficiente de sustentação obtido para um cilindro fixo imerso em um campo de escoamento.

Conforme visto na subseção 4.1.2, um dos efeitos da movimentação do cilindro é modificar a esteira (e, portanto, as forças hidrodinâmicas na estrutura). Em uma abordagem fenomenológica, os efeitos da modificação do cilindro são considerando acrescentando um termo forçante do lado direito da Equação 4.7. Após sistemáticos estudos, Facchinetti, de Langre e Biolley (2004) sugerem que a melhor forma é considerar esse termo forçante como proporcional à aceleração do cilindro.

Com base nessas considerações, as equações de movimento do sistema apresentado na Figura 17 são escritas na forma dimensional como:

$$
\begin{aligned}
& M \frac{d^{2} Y}{d t^{2}}+c_{y} \frac{d Y}{d t}+k_{y} Y=F_{v, y}+F_{p}=\frac{1}{2} \rho U_{\infty}^{2} D L C_{y, v}-m_{a}^{p o t} \frac{d^{2} Y}{d t^{2}} \\
& \frac{d^{2} q_{y}}{d t^{2}}+\epsilon_{y} \omega_{f}\left(q_{y}^{2}-1\right) \frac{d q_{y}}{d t}+\omega_{f}^{2} q_{y}=\frac{A_{y}}{D} \frac{d^{2} Y}{d t^{2}}
\end{aligned}
$$

onde a força hidrodinâmica total foi decomposta em uma parcela decorrente do escoamento potencial $F_{p}$ e uma parcela dependente da emissão de vórtices $F_{v, y}$. Já os parâmetros $\epsilon_{y}$ e $A_{y}$ devem ser calibrados com base em experimentos e/ou simulações numéricas.

Considere as seguintes grandezas:

$$
\begin{aligned}
& \omega_{n, y}=2 \pi f_{n, y}=\sqrt{\frac{k_{y}}{M+m_{a}^{p o t}}}, \quad \zeta_{y}=\frac{c_{y}}{2\left(M+m_{a}^{p o t}\right) \omega_{n, y}}, U_{r}=\frac{U_{\infty}}{f_{n, y} D} \\
& y=\frac{Y}{D}, \quad \tau=\omega_{n, y} t, \quad \frac{d()}{d t}=\omega_{n, y}(\dot{)}), m^{*}=4 \frac{M}{\rho \pi D^{2} L}, \quad C_{a}^{p o t}=4 \frac{m_{a}^{p o t}}{\rho \pi D^{2} L}
\end{aligned}
$$

Substituindo as definições 4.10 nas Equações 4.8 e 4.9, obtém-se o seguinte sistema de equações de movimento:

$$
\begin{aligned}
& D \omega_{n, y}^{2} \ddot{y}+2 \zeta_{y} \omega_{n, y}^{2} D \dot{y}+\omega_{n, y}^{2} D y=\frac{1}{2} \frac{4}{\rho \pi D^{2} L\left(m^{*}+C_{a}^{p o t}\right)} \rho U_{\infty}^{2} D L C_{y, v} \\
& \omega_{n, y}^{2} \ddot{q}_{y}+\epsilon_{y} \omega_{f}\left(q_{y}^{2}-1\right) \omega_{n, y} \dot{q}_{y}+\omega_{f}^{2} q_{y}=\frac{A_{y}}{D} \omega_{n, y}^{2} D \ddot{y}
\end{aligned}
$$


Ou, de forma mais simplificada,

$$
\begin{aligned}
& \ddot{y}+2 \zeta_{y} \dot{y}+y=\frac{1}{2 \pi^{3}} \frac{U_{r}^{2}}{\left(m^{*}+C_{a}^{p o t}\right)} C_{y, v} \\
& \ddot{q}_{y}+\epsilon_{y} S t U_{r}\left(q_{y}^{2}-1\right) \dot{q}_{y}+\left(S t U_{r}\right)^{2} q_{y}=A_{y} \ddot{y}
\end{aligned}
$$

O cálculo do coeficiente hidrodinâmico $C_{y, v}$ merece discussão pois é nele que reside uma das principais diferenças entre os modelos propostos por Facchinetti, de Langre e Biolley (2004) e por Ogink e Metrikine (2010), sendo o último agora detalhado. Para tanto considere a Figura 18, que ilustra os esforços hidrodinâmicos decorrentes do VIV atuantes no cilindro.

Figura 18 - Representação esquemática das forças hidrodinâmicas atuando em um cilindro sujeito ao VIV. O cilindro tem liberdade de oscilação somente na direção $Y$.

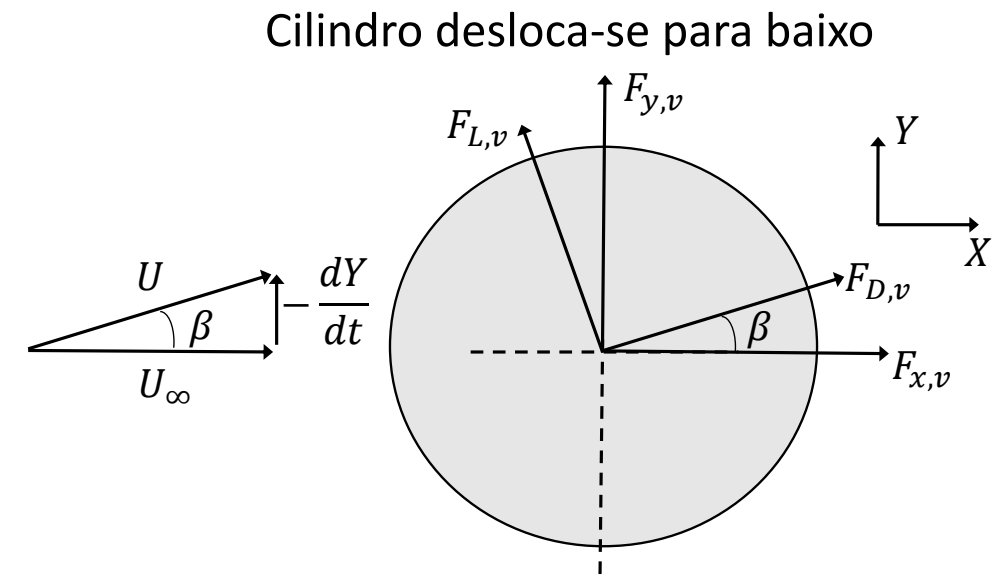

Fonte: Elaborada pelo autor.

A análise da Figura 18 permite afirmar que:

$$
F_{v, y}=\frac{1}{2} \rho U_{\infty}^{2} D L C_{y, v}=F_{L, v} \cos \beta+F_{D, v} \sin \beta
$$

onde

$$
\begin{aligned}
& F_{D, v}=\frac{1}{2} \rho U^{2} D L C_{D, v} \\
& F_{L, v}=\frac{1}{2} \rho U^{2} D L C_{L, v} \\
& U=\sqrt{U_{\infty}^{2}+\left(\frac{d Y}{d t}\right)^{2}}=U_{\infty} \sqrt{1+\left(\frac{2 \pi \dot{y}}{U_{r}}\right)^{2}} \\
& \sin \beta=\frac{-\frac{d Y}{d t}}{U}=-\frac{D \omega_{n} \dot{y}}{U_{\infty} \sqrt{1+\left(\frac{D \omega_{n}}{U_{\infty}} \dot{y}\right)^{2}}}=-\frac{2 \pi \dot{y}}{U_{r} \sqrt{1+\left(\frac{2 \pi \dot{y}}{U_{r}}\right)^{2}}} \\
& \cos \beta=\frac{U_{\infty}}{U}=\frac{1}{\sqrt{1+\left(\frac{2 \pi \dot{y}}{U_{r}}\right)^{2}}}
\end{aligned}
$$


Assim, vale a seguinte relação:

$$
\begin{aligned}
& C_{y, v}=\left(\frac{U}{U_{\infty}}\right)^{2}\left(C_{L, v} \cos \beta+C_{D, v} \sin \beta\right)= \\
& \left(C_{L, v} \frac{1}{\sqrt{1+\left(\frac{2 \pi \dot{y}}{U_{r}}\right)^{2}}}-\frac{C_{D, v}}{U_{r}} \frac{2 \pi \dot{y}}{\sqrt{1+\left(\frac{2 \pi \dot{y}}{U_{r}}\right)^{2}}}\right)\left(1+\left(\frac{2 \pi \dot{y}}{U_{r}}\right)^{2}\right)
\end{aligned}
$$

$\mathrm{Ou}$, de maneira mais compacta:

$$
C_{y, v}=\left(C_{L, v}-\frac{C_{D, v}}{U_{r}} 2 \pi \dot{y}\right) \sqrt{1+\left(\frac{2 \pi \dot{y}}{U_{r}}\right)^{2}}
$$

Os termos $C_{L, v}$ e $C_{D, v}$ (respectivamente, coeficientes de arrasto e de sustentação) referem-se à solução do escoamento ao redor de um cilindro estacionário. Conforme mencionado, o termo $C_{L, v}$ pode ser calculado a partir da solução da equação de van der Pol por meio da seguinte relação.

$$
C_{L, v}=\frac{q_{y}}{\hat{q}_{y}} \hat{C}_{L}^{0}
$$

e $C_{D, v}=\bar{C}_{D}^{0}$. Logo, o modelo matemático descritivo do fenômeno de VIV de um cilindro rígido montado em base elástica de um grau de liberdade é escrito em sua forma adimensional como:

$$
\begin{array}{r}
\ddot{y}+2 \zeta_{y} \dot{y}+y=\frac{1}{2 \pi^{3}} \frac{U_{r}^{2}}{\left(m^{*}+C_{a}^{p o t}\right)}\left[\left(\frac{q_{y}}{\hat{q}_{y}} \hat{C}_{L}^{0}-\frac{C_{D, v} 2 \pi \dot{y}}{U_{r}}\right) \sqrt{1+\left(\frac{2 \pi \dot{y}}{U_{r}}\right)^{2}}\right] \\
\ddot{q}_{y}+\epsilon_{y} S t U_{r}\left(q_{y}^{2}-1\right) \dot{q}_{y}+\left(S t U_{r}\right)^{2} q_{y}=A_{y} \ddot{y}
\end{array}
$$

As Equações 4.25 e 4.26 correspondem ao modelo apresentado em Ogink e Metrikine (2010), porém reescritas considerando como tempo adimensional $\tau=t \omega_{n, y}$ ao invés de $\tau=t U_{\infty} / D$

O trabalho de Facchinetti, de Langre e Biolley (2004) (e que seria posteriormente revisitado em Ogink e Metrikine (2010)) adota uma hipótese simplificadora relacionada à velocidade de translação do corpo. Enquanto Facchinetti, de Langre e Biolley (2004) assumem que a velocidade de translação do corpo é muito inferior à velocidade da correnteza incidente, Ogink e Metrikine (2010) prescindem dessa hipótese. Em termos das grandezas adimensionais, essa hipótese é descrita matematicamente por:

$$
\frac{2 \pi}{U_{r}} \dot{y}<<1
$$


O modelo de Facchinetti, de Langre e Biolley (2004) é obtido substituindo a Equação 4.27 na Equação 4.25, resultando no seguinte sistema de equações diferenciais:

$$
\begin{array}{r}
\ddot{y}+\left(2 \zeta_{y}+\frac{C_{D, v} U_{r}}{\pi^{2}\left(m^{*}+C_{a}^{p o t}\right)}\right) \dot{y}+y=\frac{1}{2 \pi^{3}} \frac{U_{r}^{2}}{\left(m^{*}+C_{a}^{p o t}\right)} \frac{\hat{C}_{L}^{0}}{\hat{q}_{y}} q_{y} \\
\ddot{q}_{y}+\epsilon_{y} S t U_{r}\left(q_{y}^{2}-1\right) \dot{q}_{y}+\left(S t U_{r}\right)^{2} q_{y}=A_{y} \ddot{y}
\end{array}
$$

Além da hipótese relacionada à magnitude da velocidade de translação do cilindro (e, por consequência, do ângulo de ataque $\beta$ ), os modelos de Facchinetti, de Langre e Biolley (2004) e de Ogink e Metrikine (2010) ainda apresentam outra importante diferença. Enquanto no primeiro modelo a calibração dos parâmetros $A_{y}$ e $\epsilon_{y}$ é independente da velocidade reduzida, o segundo trabalho sugere a adoção de um par de parâmetros para o upper branch e um outro par para o lower branch. A Tabela 2 ilustra os valores dos parâmetros $A_{y}$ e $\epsilon_{y}$ adotados.

Tabela 2 - Valores dos parâmetros do wake-oscillator segundo Facchinetti, de Langre e Biolley (2004) e Ogink e Metrikine (2010).

\begin{tabular}{ccc}
\hline \hline \multicolumn{3}{c}{ Facchinetti, de Langre e Biolley (2004) } \\
\hline \hline \multicolumn{4}{c}{$A_{y}$} & 12 \\
$\epsilon_{y}$ & 0,30 \\
$\hat{C}_{L}^{0}$ & 0,30 \\
$C_{D, v}=\bar{C}_{D}^{0}$ & 2 \\
$S t$ & 0,20 \\
\hline \hline \multicolumn{4}{c}{ Ogink e Metrikine (2010) } \\
\hline \hline \multicolumn{4}{c}{ upper branch lower branch } \\
\hline$A_{y}$ & 4 & 12 \\
$\epsilon_{y}$ & 0,05 & 0,7 \\
$\hat{C}_{L}^{0}$ & \multicolumn{2}{c}{0,3842} \\
$C_{D, v}=\bar{C}_{D}^{0}$ & \multicolumn{2}{c}{1,1856} \\
$S t$ & \multicolumn{2}{c}{0,1932} \\
\hline \hline
\end{tabular}

Antes do término desta seção, é importante ressaltar que Facchinetti, de Langre e Biolley (2004) adotam $C_{D, v}=\bar{C}_{D}^{0}=2$ como uma forma de contemplar o aumento do coeficiente de arrasto médio observado quando o cilindro oscila em decorrência do fenômeno de VIV.

\subsubsection{Modelos de ordem reduzida: VIV-2gI}

Tendo em vista o interesse mais recente da comunidade científica para a condição VIV-2gl, é natural que os modelos de ordem reduzida para esse caso sejam mais recentes 
do que aqueles para a condição VIV-1gl. Buscando facilitar o entendimento dos conceitos abordados nesta subseção, as formulações apresentadas nas referências bibliográficas são reescritas seguindo a nomenclatura adotada no presente texto.

O primeiro trabalho no tema, a menos do conhecimento do autor do presente texto, é apresentado em Furnes e Sørensen (2007) e tem como objetivo o estudo do fenômeno de VIV em estruturas cilíndricas flexíveis. Uma hipótese bastante interessante adotada em Furnes e Sørensen (2007) e que posteriormente seria empregada nos demais modelos descritos nesta subseção diz respeito ao uso de duas equações de van der Pol para representar os esforços hidrodinâmicos. Esstas equações têm a forma geral dada por:

$$
\begin{aligned}
\frac{d^{2} q_{y}}{d t^{2}}+\epsilon_{y} \omega_{f}\left(q_{y}^{2}-1\right) \frac{d q_{y}}{d t}+\omega_{f}^{2} q_{y} & =\frac{A_{y}}{D} \frac{d^{2} Y}{d t^{2}} \\
\frac{d^{2} q_{x}}{d t^{2}}+\epsilon_{x} \omega_{f}\left(q_{x}^{2}-1\right) \frac{d q_{x}}{d t}+\left(2 \omega_{f}\right)^{2} q_{x} & =\frac{A_{x}}{D} \frac{d^{2} X}{d t^{2}}
\end{aligned}
$$

A Equação 4.30 possui interpretação análoga àquela da condição VIV-1gl e não é objeto de nova discussão na presente subseção, de sorte que o leitor pode retornar à subseção 4.1.5 caso necessário. Já a Equação 4.31, se tomada com seu lado direito nulo, tem como solução $q_{x}$ que, por sua vez, é linearmente proporcional à parcela oscilatória do coeficiente de arrasto observado no escoamento ao redor de um cilindro fixo. Como já discutido na subseção 4.1.1, a força de arrasto oscila com o dobro da frequência de emissão de vórtices, justificando o termo $\left(2 \omega_{f}\right)^{2}$ da Equação 4.31. Para representar o caso onde o cilindro oscila, toma-se um acoplamento na aceleração na direção in-line $\frac{d^{2} X}{d t^{2}}$. Note que, para a condição VIV-2gl, é necessário calibrar quatro coeficientes, a saber $A_{y}, A_{x}, \epsilon_{y}$ e $\epsilon_{x}$.

Em Furnes e Sørensen (2007), as componentes da força hidrodinâmica seccional atuante nas direções in-line $\left(F_{x}\right)$ e cross-wise $\left(F_{y}\right)$ da estrutura flexível são calculada como:

$$
\begin{aligned}
& F_{x}=\frac{1}{2} \rho U_{\infty}^{2} D\left(C_{D} \frac{U_{x}}{U_{\infty}}+C_{L} \frac{U_{y}}{U_{\infty}}\right) \\
& F_{y}=\frac{1}{2} \rho U_{\infty}^{2} D\left(C_{D} \frac{U_{y}}{U_{\infty}}-C_{L} \frac{U_{x}}{U_{\infty}}\right)
\end{aligned}
$$

sendo $\mathbf{U}_{\infty}=U_{x} \mathbf{i}+U_{y} \mathbf{j}$ a velocidade da correnteza incidente em cada seção e $U_{\infty}=\left\|\mathbf{U}_{\infty}\right\|$. O leitor nota que a formulação de Furnes e Sørensen (2007), até este ponto, não possui acoplamento entre as oscilações nas duas direções do plano horizontal. Tal acoplamento é feito inserindo, por meio de um coeficiente a calibrar, a dependência da variável da esteira $q_{y}$ no valor do coeficiente de arrasto médio.

Agora, o foco passa a ser a discussão dos principais aspectos do modelo apresentado em Srinil e Zanganeh (2012) para a condição na qual um cilindro rígido de comprimento unitário é montado em apoio elástico com liberdade de oscilação no plano horizontal. 
Os autores empregam uma hipótese para o ângulo de ataque $\beta$ análoga àquela feita por Facchinetti, de Langre e Biolley (2004) e obtém o seguinte modelo de ordem reduzida para a condição VIV-2gl:

$$
\begin{aligned}
& \left(M+m_{a}^{p o t}\right) \frac{d^{2} Y}{d t^{2}}+\left(c_{y}+c_{f}\right) \frac{d Y}{d t}+k_{y}\left(Y+\alpha_{y}^{*} Y^{3}+\beta_{y}^{*} Y X^{2}\right)= \\
& =\frac{1}{2} \rho D U_{\infty}^{2} C_{L}+\frac{1}{2} \rho D U_{\infty}^{2} C_{D} \frac{1}{U_{\infty}} \frac{d Y}{d t} \\
& \left(M+m_{a}^{p o t}\right) \frac{d^{2} X}{d t^{2}}+\left(c_{x}+c_{f}\right) \frac{d X}{d t}+k_{x}\left(X+\alpha_{x}^{*} X^{3}+\beta_{x}^{*} X Y^{2}\right)= \\
& =-\frac{1}{2} \rho D U_{\infty}^{2} C_{L} \frac{1}{U_{\infty}} \frac{d Y}{d t}+\frac{1}{2} \rho D U_{\infty}^{2} C_{D} \\
& \frac{d^{2} q_{y}}{d t^{2}}+\epsilon_{y} \omega_{f}\left(q_{y}^{2}-1\right) \frac{d q_{y}}{d t}+\omega_{f}^{2} q_{y}=\frac{A_{y}}{D} \frac{d^{2} Y}{d t^{2}} \\
& \frac{d^{2} q_{x}}{d t^{2}}+\epsilon_{x} \omega_{f}\left(q_{x}^{2}-1\right) \frac{d q_{x}}{d t}+\left(2 \omega_{f}\right)^{2} q_{x}=\frac{A_{x}}{D} \frac{d^{2} X}{d t^{2}} \\
& C_{D}=\frac{q_{x}}{\hat{q}_{x}} \hat{C}_{D}^{0} \\
& C_{L}=\frac{q_{y}}{\hat{q}_{y}} \hat{C}_{L}^{0}
\end{aligned}
$$

onde $\hat{q}_{x}=2$ e $\hat{C}_{D}^{0}$ representam, respectivamente, a amplitude do ciclo-limite da Equação 4.39 tomada como homogênea e a amplitude da parcela oscilatória do coeficiente de arrasto no problema do escoamento ao redor de um cilindro fixo.

Os últimos termos do lado esquerdo das Equações 4.34 e 4.35 indicam um acoplamento entre as oscilações nas direções cross-wise e in-line e que estão relacionados puramente à dinâmica estrutural. Em caso de pequenos deslocamentos, é esperado que a a força elástica em uma determinada mola seja apenas na direção na qual ela está montada. A outra fonte de acoplamento entre as oscilações nas direções do plano horizontal é a não-linearidade quadrática existente no lado direito da Equação 4.34.

Srinil e Zanganeh (2012) propõem a calibração, via correlação com resultados experimentais, tanto dos coeficientes relacionados à interação fluido-estrutura $\left(A_{x}, A_{y}\right.$, $\epsilon_{x}$ e $\epsilon_{y}$ ) quanto dos parâmetros relacionados aos termos não-lineares estruturais (formas adimensionais dos parâmetros $\alpha_{x}^{*}, \alpha_{y}^{*}, \beta_{x}^{*}$ e $\beta_{y}^{*}$ ). Note, no entanto, que os parâmetros $\alpha_{x}^{*}, \alpha_{y}^{*}$, $\beta_{x}^{*}$ e $\beta_{y}^{*}$ são, do ponto de vista formal, completamente definidos pelo suporte elástico e pela expansão polinomial das forças restauradoras conduzidas, não necessitando de qualquer forma de calibração.

O trabalho de Dhanwani, Sarkar e Patnaik (2013) também apresenta um modelo fenomenológico para a condição VIV-2gl. De maneira análoga àquela conduzida por Srinil e Zanganeh (2012) (e em Facchinetti, de Langre e Biolley (2004) por ocasião da obtenção de um modelo para a condição VIV-1gl), o ângulo de ataque $\beta$ é suposto pequeno, o que 
permite uma série de simplificações nos termos trigonométricos que surgiriam quando da decomposição dos esforços nas direções in-line e cross-wise.

Porém, e ao contrário do trabalho descrito em Srinil e Zanganeh (2012), Dhanwani, Sarkar e Patnaik (2013) consideram a velocidade de translação do cilindro na direção in-line no cálculo da velocidade relativa entre o sólido e o fluido para posterior uso na avaliação dos esforços de sustentação e arrasto (isto é, as parcelas da força na direção ortogonal e alinhada à velocidade relativa). Um outro diferencial do trabalho de Dhanwani, Sarkar e Patnaik (2013) é a consideração de um coeficiente de arrasto médio que deve ser somado à parcela oscilatória desse coeficiente que, por sua vez, é proporcional à variável descritiva da esteira $q_{x}$.

Por fim, cabe mais um comentário antes do encerramento desta subseção. Todos os trabalhos aqui citados empregam coeficientes empiricamente calibrados que independem do valor da velocidade reduzida. Como mostrado em Ogink e Metrikine (2010) para a condição VIV1-gl, uma melhor aderência com os dados experimentais pode ser conseguida propondo calibrações que variem de acordo com o ramo de resposta excitado. Tal calibração respeita a física do fenômeno, uma vez que aspectos importantes da esteira vorticosa como, por exemplo, o padrão de emissão de vórtices dependem do ramo de resposta e, por consequência da velocidade reduzida.

\subsection{O fenômeno de galloping}

Assim como o VIV, o galloping também é um problema pertencente ao escopo das vibrações induzidas pelo escoamento. No entanto, enquanto o VIV é caracterizado por ser um fenômeno ressonante, o galloping não apresenta essa característica. A modelagem matemática que segue tem como objetivo explicar a origem desse fenômeno.

Considere um corpo prismático, bidimensional e caracterizado por sua massa $M$, constante de amortecimento linear $c_{y}$ e rigidez $k_{y}$, todas por unidade de comprimento. A Figura 19 traz uma representação esquemática do problema. Esse corpo está sujeito a um escoamento uniforme de intensidade $U_{\infty}$ e tem liberdade de oscilação na direção $Y$, ortogonal à direção da correnteza incidente.

É trivial verificar que a equação de movimento do sistema representado na Figura 19 é dada por:

$$
M \frac{d^{2} Y}{d t^{2}}+c_{y} \frac{d Y}{d t}+k_{y} Y=F_{y}=\frac{1}{2} \rho U_{\infty}^{2} D C_{y}
$$

onde $\rho$ é a massa específica do fluido, $F_{y}$ é a componente da força aerodinâmica na direção transversal ao escoamento e $C_{y}$ o coeficiente de força na direção associado a essa direção e mais adiante detalhado. Por ora, convém ressaltar que $C_{y}$ é usualmente calculado com 
Figura 19 - Corpo prismático sujeito ao fenômeno de galloping. Representação esquemática do problema.

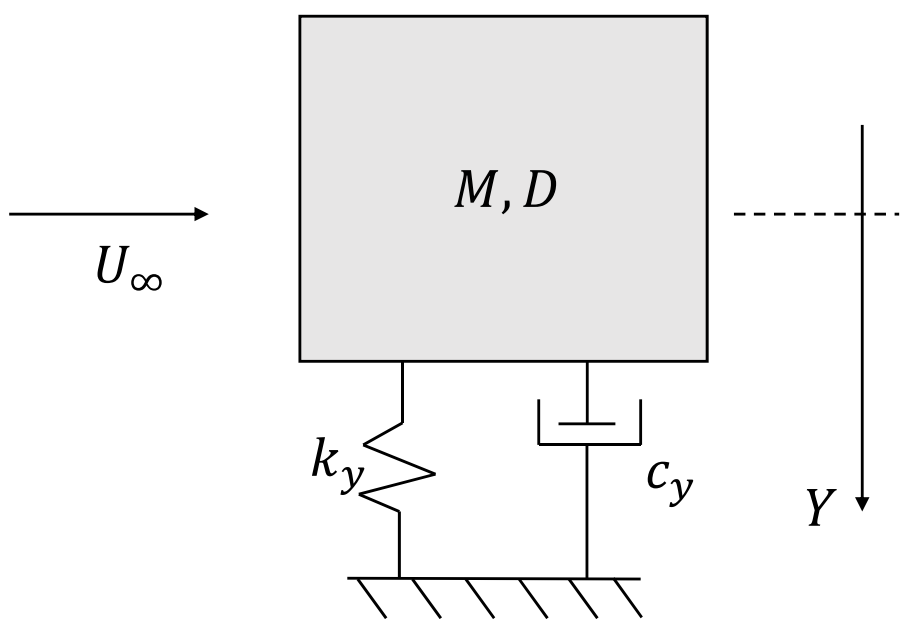

Fonte: Elaborada pelo autor.

base na hipótese quase-estática para força aerodinâmica. Essa hipótese faz uso de curvas de força de arrasto $F_{D}$ e de sustentação $F_{L}$ obtidas por meio de regressões a partir de dados experimentais obtidos com o corpo estático submetido a diversos ângulos de ataque $\alpha$, conforme esquematizado na Figura 20. A relação entre o coeficiente $C_{y}$ e as forças de arrasto e sustentação são vistas mais adiantes nesta seção.

Figura 20 - Representação esquemática de experimentos com cilindros estacionários para obtenção das forças de arrasto e de sustentação.

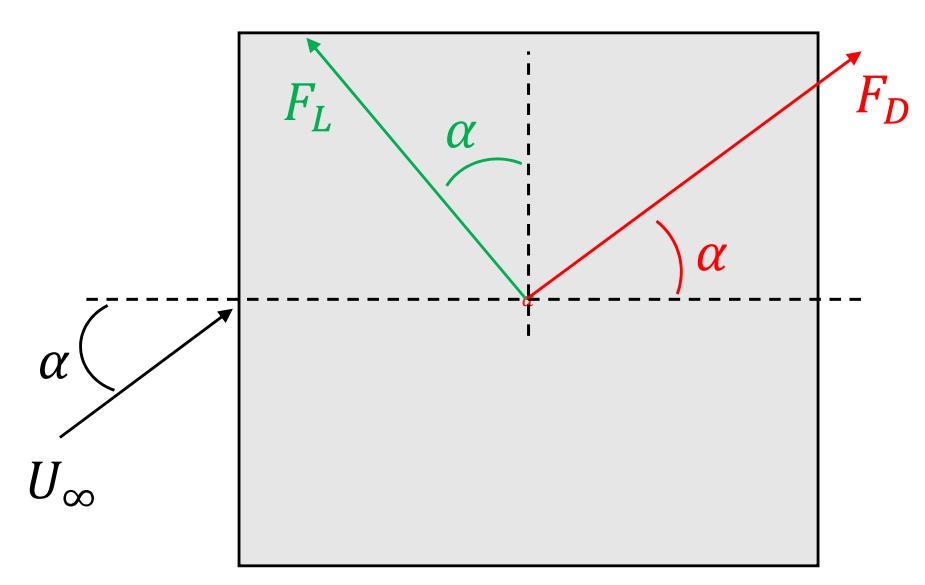

Fonte: Elaborada pelo autor. 
Um aspecto bastante importante relacionado à hipótese quase-estática é que sua validade está intimamente relacionada à relação entre a escala de tempo típica do fluido $T_{f}=D / U_{\infty}$ e a escala de tempo do corpo $T_{n, y}$, correspondente ao seu período natural não amortecido.

Segundo Blevins (2001), a validade da hipótese quase-estática é verificada se a escala de tempo de movimento do corpo é muito maior do que a escala de tempo associada ao fluido. Matematicamente, esta relação escreve-se como:

$$
\frac{T_{n, y}}{T_{f}}>>1 \leftrightarrow \frac{\frac{1}{f_{n, y}}}{\frac{D}{U_{\infty}}}>>1 \leftrightarrow \frac{U_{\infty}}{f_{n, y} D}>>1
$$

Em Blevins (2001), o autor sugere que a hipótese quase-estática mantém-se válida para a seguinte condição:

$$
\frac{U_{\infty}}{f_{n, y} D}>20
$$

Do ponto de vista físico, a hipótese quase-estática significa que a velocidade do escoamento é tal que a frequência de emissão de vórtices é muito superior à frequência natural da estrutura, de sorte que o fenômeno de VIV não se faz importante. Cabe salientar, contudo, que pode ocorrer uma excitação mista envolvendo os fenômenos de VIV e de galloping. Esse efeito combinado, no entanto, não está contemplado no uso da hipótese quase-estática. O leitor interessado em saber mais sobre a validade da hipótese quase-estática e alternativas de modelagem do problema de interação fluido-estrutura pode consultar o livro de Païdoussis, Price e de Langre (2011).

Discute-se, agora, como obter a componente da força hidrodinâmica $F_{y}$. Para tanto, considere a Figura 21, que ilustra o corpo se movimentando com velocidade positiva (ou seja, para baixo) e sujeito ao escoamento incidente.

Note que o ângulo de ataque $\alpha$, resultante da composição do escoamento incidente $U_{\infty}$ com o movimento do corpo e a magnitude da velocidade do escoamento relativo ao corpo $U$ são dadas, respectivamente, por:

$$
\begin{aligned}
& \tan \alpha=\frac{\frac{d Y}{d y}}{U_{\infty}} \\
& U=\sqrt{\left(\frac{d Y}{d t}\right)^{2}+U_{\infty}^{2}}
\end{aligned}
$$

Já as forças de arrasto e sustentação desenvolvidas no corpo são escritas como: 
Figura 21 - Forças aerodinâmicas decorrentes da incidência de escoamento e da movimentação do corpo.

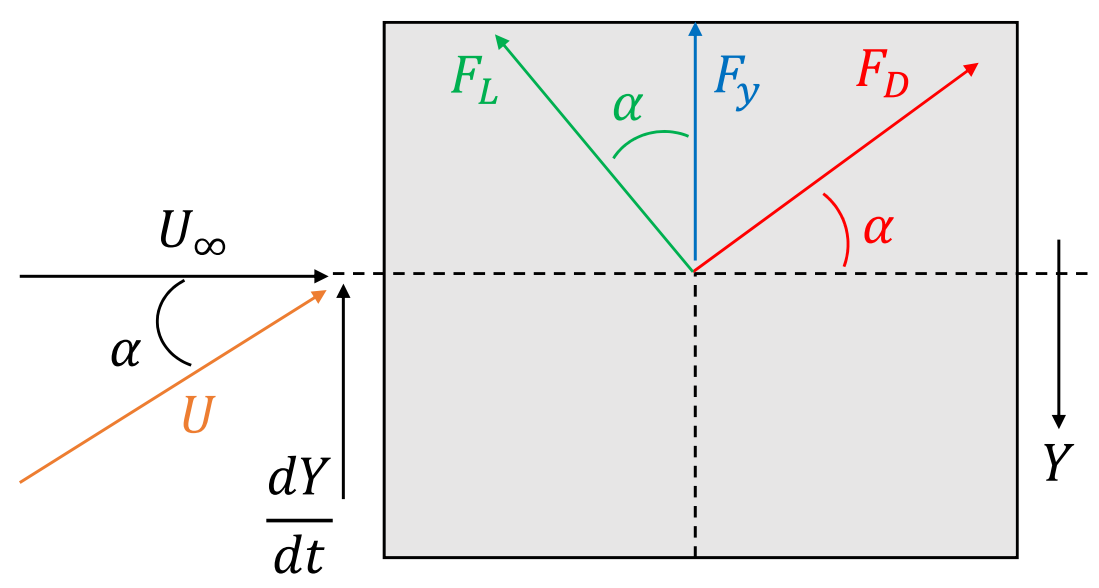

Fonte: Elaborada pelo autor.

$$
\begin{aligned}
& F_{L}=\frac{1}{2} \rho U^{2} D C_{L} \\
& F_{D}=\frac{1}{2} \rho U^{2} D C_{D}
\end{aligned}
$$

Um cálculo geométrico elementar permite mostrar que a relação entre $F_{L}, F_{D}$ e $F_{y}$ é expressa como:

$$
F_{y}=\frac{1}{2} \rho U_{\infty}^{2} D C_{y}=-F_{D} \sin \alpha-F_{L} \cos \alpha
$$

Substituindo-se as Equações 4.45 e 4.46 na Equação 4.47, chega-se que o coeficiente $C_{y}$ é dado pela Equação 4.48 .

$$
C_{y}=\left(\frac{U}{U_{\infty}}\right)^{2}\left(-C_{D} \sin \alpha-C_{L} \cos \alpha\right)
$$

onde os coeficientes de arrasto $C_{D}$ e de sustentação $C_{L}$ adotados correspondem àqueles medidos a partir de experimentos com corpos estacionários e sob diversos valores do ângulo de ataque $\alpha$.

Admitindo que a velocidade do corpo $\frac{d Y}{d t}$ seja pequena em comparação à velocidade do escoamento incidente, as Equações 4.43, 4.44 e 4.48 são aproximadas por: 


$$
\begin{array}{r}
\tan \alpha \approx \alpha=\frac{\frac{d Y}{d t}}{U_{\infty}} \\
U \approx U_{\infty} \\
C_{y} \approx-C_{L}-C_{D} \alpha
\end{array}
$$

Note que $C_{y}=C_{y}(\alpha)$ é função do ângulo de ataque $\alpha$ e pode ser facilmente obtido a partir dos mesmos experimentos com corpos estacionários que geram as curvas $C_{D}(\alpha)$ e $C_{L}(\alpha)$. Uma forma bastante comum de reproduzir a dependência de $C_{y}$ com o ângulo de ataque é por meio de uma regressão polinomial, exemplificada na Equação 4.52.

$$
C_{y}=\sum_{k=1}^{N} a_{k} \alpha^{k}=\sum_{k=1}^{N} a_{k}\left(\frac{\frac{d Y}{d t}}{U_{\infty}}\right)^{k}
$$

Por fim, levando a Equação 4.52 na equação de movimento do corpo (Equação 4.40), chega-se a:

$$
M \frac{d^{2} Y}{d t^{2}}+c_{y} \frac{d Y}{d t}+k_{y} Y=\frac{1}{2} \rho U_{\infty}^{2} D \sum_{k=1}^{N} a_{k}\left(\frac{\frac{d Y}{d t}}{U_{\infty}}\right)^{k}
$$

Para um corpo de seção transversal quadrada e com o escoamento incidindo perpendicularmente a uma de suas arestas, Parkinson e Smith (1964) propõem, a partir de experimentos com o corpo fixo, uma expressão polinomial de sétimo grau para o coeficiente $C_{y}$ definida por ${ }^{15} a_{1}=2,69, a_{3}=-168, a_{5}=6,27 \times 10^{3}, a_{7}=-5,99 \times 10^{4}$, $a_{0}=a_{2}=a_{4}=a_{6}=0$. A Figura 22 apresenta tanto os pontos experimentais quanto o ajuste proposto.

É bastante simples a explicação para que o coeficientes associados às potências pares sejam nulos na expansão proposta por Parkinson e Smith (1964). Pela simetria do escoamento ao redor de um corpo de seção quadrada com a orientação estudada pelos autores, a rotação da seção transversal de $\pm \alpha$ induz esforços iguais mas de sentido contrário. Logo, $C_{y}(\alpha)$ deve ser uma função ímpar. Por fim, cumpre ressaltar que o termo $a_{0}$ está relacionado a um termo constante da força aerodinâmica.

Discute-se, agora, a Equação 4.53 quando os termos não-lineares da força aerodinâmica são desprezados. Realizando esse procedimento e com o auxílio de simples manipulação algébrica, chega-se à Equação 4.54 .

$$
M \frac{d^{2} Y}{d t^{2}}+\left(c_{y}-\frac{1}{2} \rho D U_{\infty} a_{1}\right) \frac{d Y}{d t}+k_{y} Y=0
$$

15 Cumpre ressaltar que Blevins (2001) e Païdoussis, Price e de Langre (2011) indicam, provavelmente por conta de um equívoco de digitação, $a_{7}=-5,99 \times 10^{3}$. 
Figura 22 - Variação do coeficiente de força $C_{y}$ como função do ângulo de ataque.

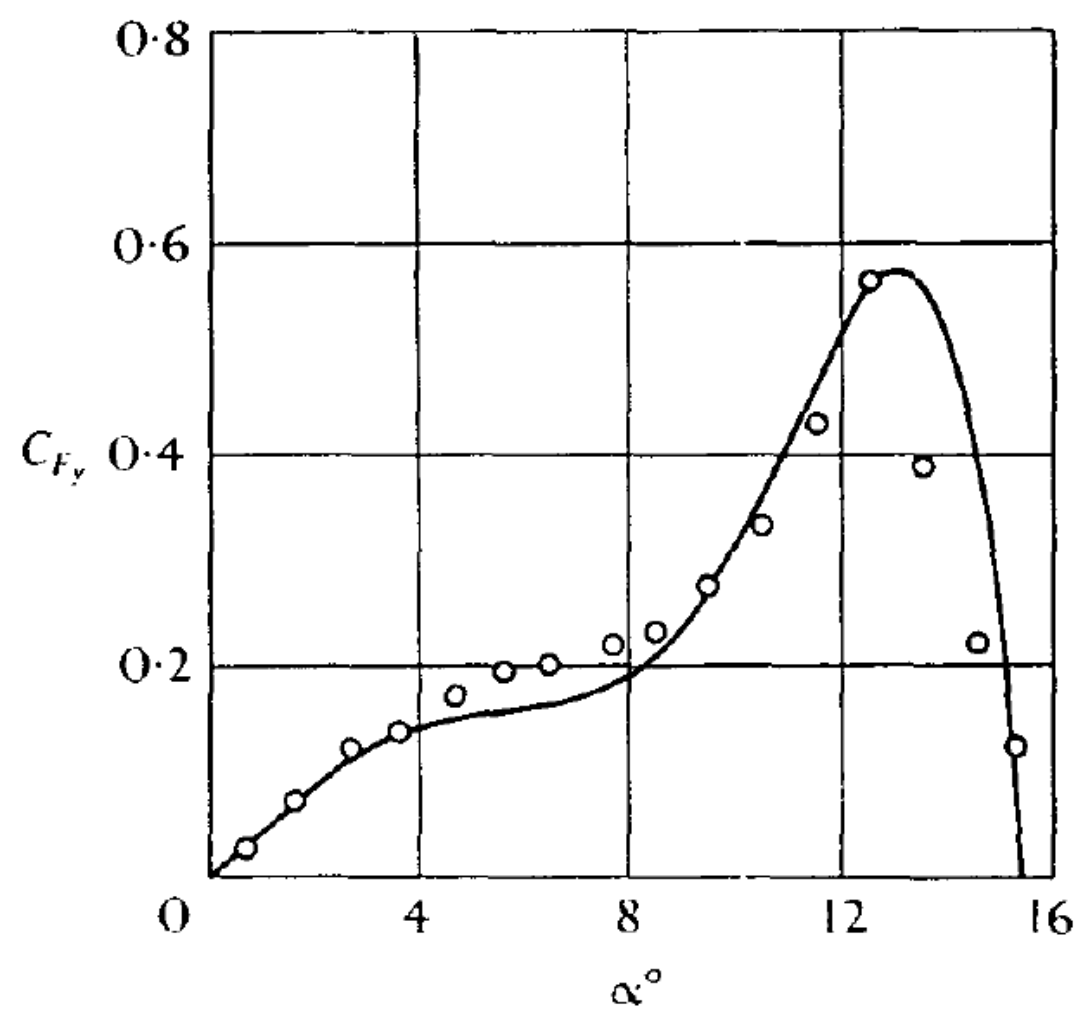

Fonte: Extraída de Parkinson e Smith (1964).

Note que o termo $\left(c_{y}-\frac{1}{2} \rho D U_{\infty} a_{1}\right)$ representa um amortecimento equivalente, composto de uma parcela puramente estrutural $c_{y}$ e de uma parcela aerodinâmica dada por $-\frac{1}{2} \rho D U_{\infty} a_{1}$. Se $a_{1}<0$, então o amortecimento total é positivo e pequenas perturbações são amortecidas. Já se $a_{1}>0$, o amortecimento total pode assumir valores negativos, indicando que o corpo absorve energia do fluido enquanto realiza o movimento oscilatório decorrente de uma pequena perturbação em sua posição de equilíbrio.

Considere que a velocidade do escoamento incidente $U_{\infty}$ seja o parâmetro de controle que regula o sinal do amortecimento equivalente. O amortecimento equivalente é nulo quando a seguinte velocidade crítica é atingida:

$$
U_{\infty}^{c}=\frac{2 c_{y}}{\rho a_{1} D}
$$

Na linguagem de dinâmica não-linear e seguindo a discussão apresentada em Thompson e Stewart (1986), o escoamento incidente com velocidade $U_{\infty}^{c}$ leva ao surgimento de uma bifurcação de Hopf supercrítica, de sorte que a solução trivial passa de um foco estável para $U_{\infty}<U_{\infty}^{c}$ para um foco instável quando $U_{\infty}>U_{\infty}^{c}$, dando origem a uma solução periódica denominada ciclo-limite.

Ainda no contexto da teoria linearizada, o amortecimento equivalente negativo faz 
com que o sólido absorva continuamente energia do meio fluido. Essa absorção de energia promove um aumento indefinido de sua amplitude de oscilação. Note entanto, oscilações ilimitadas não são fisicamente realizáveis.

No problema aqui estudado, o aumento da amplitude de oscilação e o consequente aumento em sua velocidade faz com que os termos não-lineares inicialmente desprezados passem a ser relevantes. De fato, os termos não-lineares existentes no carregamento aerodinâmico são os responsáveis pela obtenção de amplitudes estacionárias (respostas pós-críticas) para uma dada velocidade de escoamento.

Dessa forma, a teoria linearizada é útil para prever a velocidade crítica de escoamento incidente a partir da qual pequenas perturbações na posição de equilíbrio do corpo não são amortecidas. Já a obtenção do comportamento pós-crítico deve, obrigatoriamente, envolver os termos não-lineares.

\subsection{Identificação de lacunas de conhecimento}

A revisão bibliográfica apresentada neste capítulo possibilitou a identificação de algumas lacunas de conhecimento, abaixo enumeradas:

1. Um modelo de ordem reduzida para a condição VIV-2gl que prescinda da hipótese de pequenos ângulos de ataque e que tenha seus coeficientes empíricos com dependência do ramo de resposta, configurando uma expansão natural do trabalho de Ogink e Metrikine (2010);

2. Técnicas de análise experimental que possam ser aplicadas à resposta de um cilindro flexível ao VIV e que permitam uma melhor interpretação da resposta multi-modal;

3. Resultados experimentais que demonstrem alguns efeitos da concomitância entre os fenômenos de VIV e de excitação paramétrica em um cilindro flexível;

4. Existência de modelos de ordem reduzida para os fenômenos de VIV-1gl e VIV-2gl nos quais os parâmetros empiricamente calibrados dependem não apenas da velocidade reduzida, mas também de outras quantidades importantes para os referidos fenômenos como, por exemplo, o parâmetro de massa reduzida e o número de Reynolds.

Este texto apresenta contribuições nos três primeiros itens. A subseção 8.2.2 traz um modelo que contempla a primeira lacuna de conhecimento. Já o leitor interessado em contribuições nos itens 2 e 3 acima numerados é convidado à leitura da seção 7.3. 


\section{Supressão passiva de vibrações}

Este capítulo foca na apresentação de conceitos gerais relacionados à supressão passiva $^{1}$ de vibrações e está dividido em três seções. A seção 5.1 foca no uso de absorvedores passivos lineares denominados TMDs (tuned mass dampers). Por sua vez, a seção 5.2 apresenta os principais conceitos relacionados à supressão passiva por meio de absorvedores não-lineares de vibração (non-linear vibration absorbers - NVA), além de exemplos de aplicação em engenharia com particular foco nos problemas que são objetos da estudo da presente tese. Finalmente, a seção 5.3 identifica algumas lacunas de conhecimento que estão sendo preenchidas por meio da pesquisa conduzida pelo autor do presente texto.

\subsection{Supressão passiva de vibrações por meio de elementos lineares - uso de TMDs}

Os TMDs já são empregados como supressores passivos de vibração há décadas. Em linhas gerais, um TMD é uma massa acoplada por meio de um arranjo de molas e amortecedores a uma estrutura principal (ou estrutura a ser controlada) submetida à excitação externa. A Figura 23 apresenta uma estrutura principal (representada por uma massa $\left.m_{1}\right)$ sujeita a um carregamento externo $p_{1}(t)=\hat{p} \sin (\bar{\omega} t)$. Um TMD de massa $m_{2}<<m_{1}$ está acoplado à estrutura principal por meio de uma mola de rigidez $k_{2}$ e de um amortecedor linear de constante $c_{2}$

Considere, em um primeiro momento, o caso da estrutura principal sem o TMD e que o carregamento externo seja ressonante, ou seja $\bar{\omega}=\omega=\sqrt{k_{1} / m_{1}}$, sendo $\omega$ a frequência natural não amortecida do sistema de um grau de liberdade. Um resultado clássico em dinâmica de estruturas é que a amplitude de resposta desse sistema, quando em regime permanente, é dada por:

$$
\bar{\rho}=\frac{\hat{p}}{k_{1}} \frac{1}{2 \zeta}
$$

sendo $\zeta=c_{1} / 2 m_{1} \omega$ a taxa de amortecimento do problema de um grau de liberdade. Usualmente, as estruturas comumente encontradas na engenharia civil são pouco amortecidas, apresentando valores típicos de $\zeta=5 \%$ ou inferiores. Note que, em ressonância e com valores de taxa de amortecimento como aquele mencionado, o sistema é levado a oscilar com grandes amplitudes, o que geralmente deve ser evitado.

1 Como já mencionado, os supressores passivos são aqueles onde não há necessidade do fornecimento de energia para o controle das vibrações. O sistema de controle onde o fornecimento de energia é imprescindível para seu funcionamento é denominado de ativo. 
Figura 23 - Representação esquemática de um TMD.

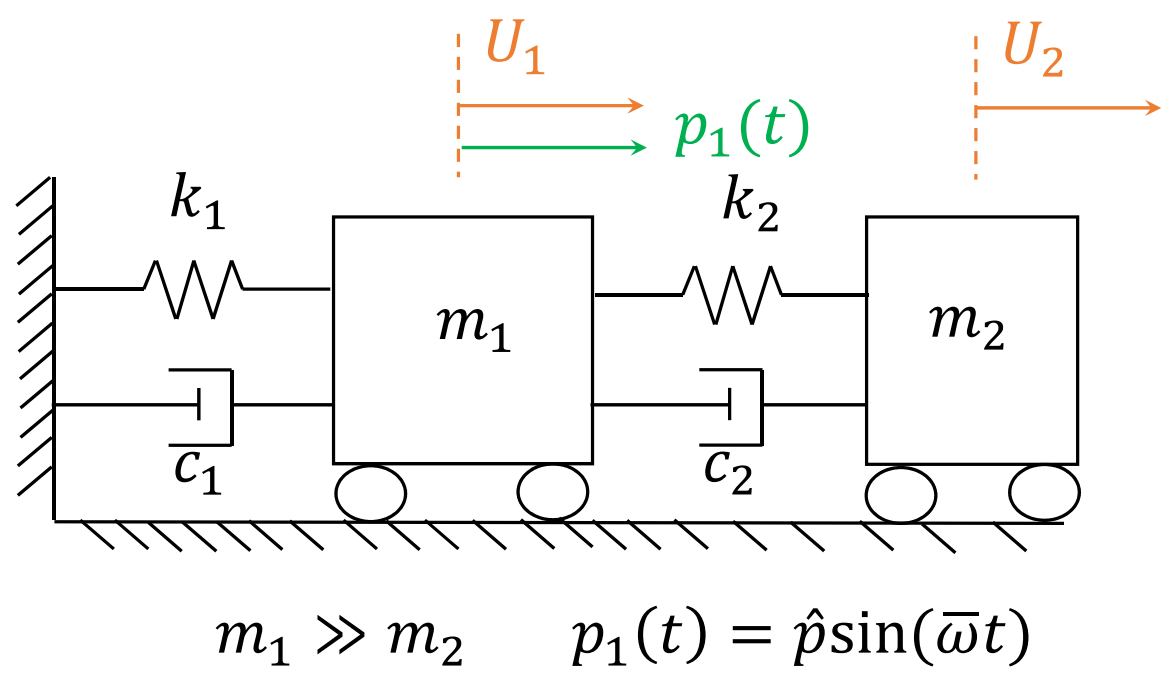

Fonte: Elaborada pelo autor.

Retomando o problema ilustrado na Figura 23, trata-se de um sistema com dois graus de liberdade e, portanto, com duas frequências naturais não amortecidas $\omega_{1}$ e $\omega_{2}$.

É trivial mostrar que as equações de movimento para o sistema ilustrado na Figura 23 são dadas por:

$$
\begin{aligned}
& m_{1} \frac{d^{2} U_{1}}{d t^{2}}+\left(c_{1}+c_{2}\right) \frac{d U_{1}}{d t}-c_{2} \frac{d U_{2}}{d t}+\left(k_{1}+k_{2}\right) U_{1}-k_{2} U_{2}=p_{1}(t)=\hat{p} \sin (\bar{\omega} t) \\
& m_{2} \frac{d^{2} U_{2}}{d t^{2}}-c_{2} \frac{d U_{1}}{d t}+c_{2} \frac{d U_{2}}{d t}-k_{2} U_{1}+k_{2} U_{2}=0
\end{aligned}
$$

Visando uma maior generalidade das análises, as Equações 5.2 e 5.3 são reescritas em sua forma adimensional. Para tanto, considere as seguintes grandezas adimensionais ${ }^{2}$

$$
\begin{aligned}
& \tau=\omega t, \quad u_{1}=\frac{U_{1}}{L}, \quad u_{2}=\frac{U_{2}}{L}, \quad \zeta_{1}=\frac{c_{1}}{2 m_{1} \omega}, \quad \zeta_{2}=\frac{c_{2}}{2 m_{2} \omega}, \quad \kappa=\frac{k_{2}}{k_{1}}, \quad \epsilon=\frac{m_{2}}{m_{1}} \\
& \beta=\frac{\bar{\omega}}{\omega}, \quad p^{*}=\frac{\hat{p}}{m_{1} \omega^{2} L}
\end{aligned}
$$

sendo $L$ um comprimento característico da estrutura. Inserindo os adimensionais propostos na Equação 5.4 nas Equações 5.2 e 5.3, definindo o vetor $\mathbf{U}=\left\{\begin{array}{ll}u_{1} & u_{2}\end{array}\right\}^{t}$ e

2 É claro ao leitor que a condição de que a massa do supressor seja pequena face à massa da estrutura principal leva a $\epsilon<<1$. 
adotando ( ) como sendo a derivada com relação ao tempo adimensional $\tau$, o seguinte sistema modelo matemático adimensional é obtido em sua forma matricial:

$$
\underbrace{\left[\begin{array}{ll}
1 & 0 \\
0 & \epsilon
\end{array}\right]}_{\mathbf{M}}\left\{\begin{array}{l}
\ddot{u}_{1} \\
\ddot{u}_{2}
\end{array}\right\}+\underbrace{\left[\begin{array}{cc}
2 \zeta_{1}+2 \epsilon \zeta_{2} & -2 \epsilon \zeta_{2} \\
-2 \epsilon \zeta_{2} & 2 \epsilon \zeta_{2}
\end{array}\right]}_{\mathbf{C}}\left\{\begin{array}{l}
\dot{u}_{1} \\
\dot{u}_{2}
\end{array}\right\}+\underbrace{\left[\begin{array}{cc}
1+\kappa & -\kappa \\
-\kappa & \kappa
\end{array}\right]}_{\mathbf{K}}\left\{\begin{array}{l}
u_{1} \\
u_{2}
\end{array}\right\}=\underbrace{\left\{\begin{array}{c}
p^{*} \sin \beta \tau \\
0
\end{array}\right\}}_{\mathbf{R}}
$$

Na Equação 5.5, M, C e K indicam, respectivamente, as matrizes de massa, de amortecimento e de rigidez. Os quadrados das frequências naturais não amortecidas (dadas por $\omega_{1}$ e $\left.\omega_{2}\right)$ são $\lambda_{1}$ e $\lambda_{2}$, auto-valores da matriz $\mathbf{A}=\mathbf{M}^{-1} \mathbf{K}$.

Esta seção dá foco na análise do problema onde o carregamento é ressonante com a estrutura original, ou seja, quando $\bar{\omega} / \omega=\beta=1$. Como é verificado mais adiante na presente seção, um caso interessante para supressão de vibrações da estrutura principal é aquele onde $k_{2} / m_{2}=\bar{\omega}^{2}=k_{1} / m_{1}$, ou seja, quando a frequência do carregamento (ressonante com a estrutura original) é igual à frequência natural do TMD se ele fosse um sistema isolado de um grau de liberdade. Em termos adimensionais, esse caso indica que $\kappa / \epsilon=1$. Tendo em vista um estudo nas vizinhanças dessa última condição, é interessante adotar a seguinte definição:

$$
\frac{\kappa}{\epsilon}=1+\epsilon \sigma
$$

onde $\sigma$ desempenha um papel análogo ao parâmetro de dessintonia usualmente empregado no estudo analítico com métodos de perturbação. Utilizando a Equação 5.6, a matriz $\mathbf{A}$ e a equação característica que permite obter seus auto-valores são:

$$
\begin{aligned}
& \mathbf{A}=\left[\begin{array}{cc}
1+\epsilon(1+\epsilon \sigma) & -\epsilon(1+\epsilon \sigma) \\
-(1+\epsilon \sigma) & (1+\epsilon \sigma)
\end{array}\right] \\
& \lambda^{2}-\lambda[(1+\epsilon \sigma)(1+\epsilon)+1]+(1+\epsilon \sigma)=0
\end{aligned}
$$

Já os modos naturais não amortecidos são os auto-vetores da matriz $\mathbf{A}$ associados aos correspondentes auto-valores. Definindo $\phi_{1}^{k}=1, k=1,2$, como sendo a primeira componente do $k$-ésimo modo de vibrar, a segundo componente do mesmo modo de vibrar é:

$$
\phi_{2}^{k}=\frac{1+\epsilon(1+\epsilon \sigma)-\lambda_{k}}{1+\epsilon(1+\epsilon \sigma)}, k=1,2
$$

Em decorrência da adimensionalização conduzida, nota-se que as frequências naturais não amortecidas e os correspondentes modos de vibrar (também não amortecidos) 
são funções dos parâmetros de controle $\epsilon$ (relação entre a massa do TMD e da estrutura principal) e de $\sigma$ (parâmetro de dessintonia). A Figura 24 mostra as frequências e modos naturais não amortecidos como funções dos parâmetros de controle.

Como pode ser notado nas Figuras 24(a) e 24(b), as frequências naturais não amortecidas do sistema com dois graus de liberdade são $\omega_{1}<1$ e $\omega_{2}>1$. Relembrando que a frequência natural adimensional do sistema de um grau de liberdade representativo da estrutura principal é $\omega=1$, nota-se que a inclusão de um grau de liberdade leva um carregamento ressonante no sistema sem o supressor a deixar de ser ressonante no sistema com mais graus de liberdade. Já os valores positivos de $\phi_{2}^{1}$ ilustrados na Figura 24(c) mostram que o modo associado à frequência $\omega_{1}$ é caracterizado por movimentos das massas em fase. Por sua vez, o modo associado à frequência $\omega_{2}$ indica que, enquanto uma das massas atinge seu máximo deslocamento, a outra atinge o seu mínimo (antífase); ver Figura 24(d).

Tendo em vista o foco na condição onde a frequência do carregamento é ressonante com a estrutura original sem o TMD (o que leva a $\beta=1$ ), a análise da resposta forçada também é conduzida em função dos parâmetros $\epsilon$ e $\sigma$ e da matriz modal $\phi$. O uso dos modos de vibrar não amortecidos como base de expansão da resposta é denominado de superposição modal e pode ser encontrado em diversos livros-texto em dinâmica das estrutura como, por exemplo, Den Hartog (1956), Clough e Penzien (2003) e Mazzilli et al. (2016).

Para o estudo da resposta forçada, considere o problema não amortecido e, sem perda de generalidade, $\hat{p}=1$. Tendo em vista a linearidade do problema, a amplificação do carregamento por um ganho implica na amplificação da resposta pelo mesmo ganho. Considere a matriz modal $\phi$ e a transformação de variáveis dadas, respectivamente pelas Equações 5.10 e 5.11. Essa última equação tem um claro sentido físico, a saber, a troca das coordenadas generalizadas físicas (deslocamentos das duas massas) para coordenadas generalizadas associadas à amplitude de vibração de cada modo.

$$
\begin{aligned}
& \phi=\left[\begin{array}{ll}
\phi_{1}^{1} & \phi_{1}^{2} \\
\phi_{2}^{1} & \phi_{2}^{2}
\end{array}\right]=\left[\begin{array}{cc}
1 & 1 \\
\phi_{2}^{1}(\epsilon, \sigma) & \phi_{2}^{2}(\epsilon, \sigma)
\end{array}\right] \\
& \mathbf{U}=\phi \mathbf{Y}
\end{aligned}
$$

Pré-multiplicando à esquerda a Equação 5.5 (já sem os termos dissipativos) por $\phi^{t}$ e substituindo a transformação de variáveis dada pela Equação 5.11, a seguinte expressão 
Figura 24 - Frequências e modos naturais não amortecidos como funções dos parâmetros de controle $\epsilon$ e $\sigma$.

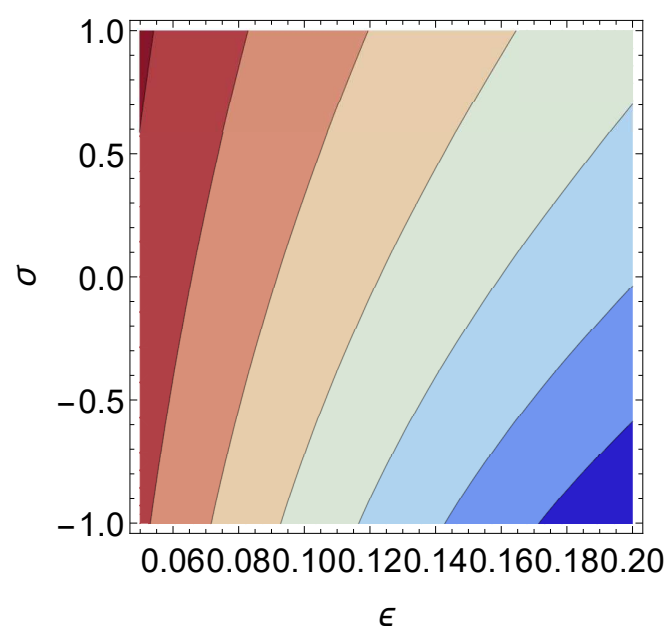

(a) $\omega_{1}(\epsilon, \sigma)$.

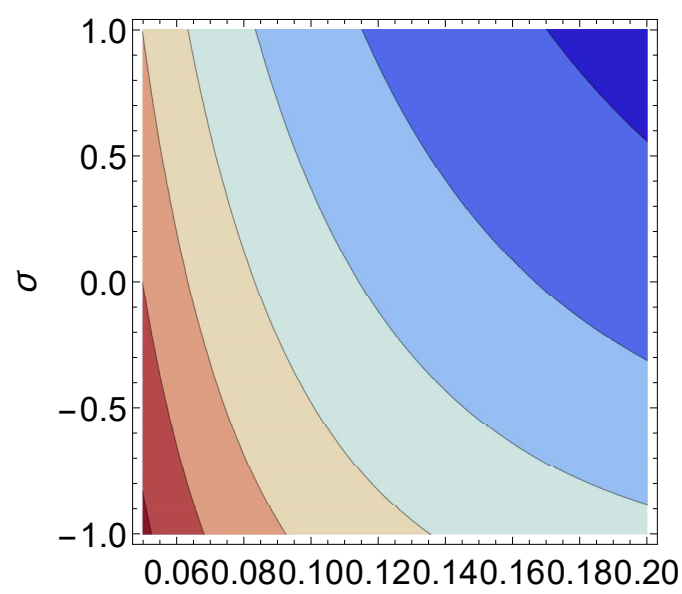

$\epsilon$

(c) $\phi_{2}^{1}(\epsilon, \sigma)$.
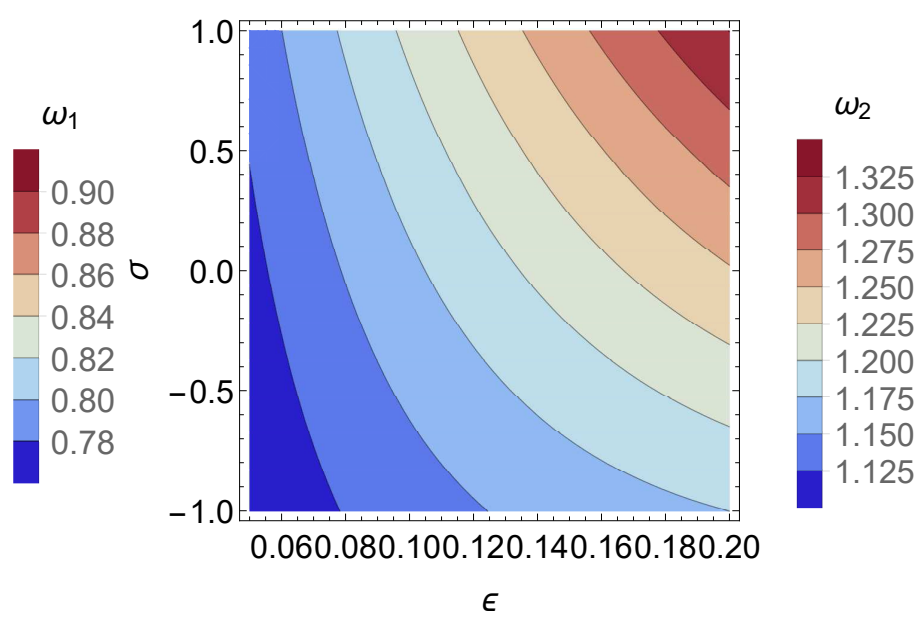

(b) $\omega_{2}(\epsilon, \sigma)$.

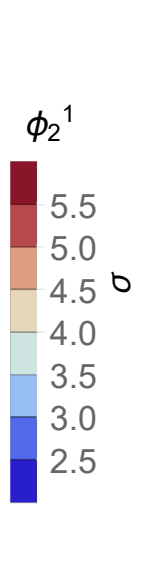

$-1.0+060.080 .100 .120 .140 .160 .180 .20$
0.01

$\epsilon$

(d) $\phi_{2}^{2}(\epsilon, \sigma)$.

Fonte: Elaborada pelo autor.

é obtida:

$$
\underbrace{\left(\phi^{t}\left[\begin{array}{ll}
1 & 0 \\
0 & \epsilon
\end{array}\right] \phi\right)}_{\mathbf{M}^{*}} \ddot{\mathbf{Y}}+\underbrace{\left(\phi^{t}\left[\begin{array}{cc}
1+\kappa & -\kappa \\
-\kappa & \kappa
\end{array}\right] \phi\right)}_{\mathbf{K}^{*}} \mathbf{Y}=\underbrace{\phi^{t}\left\{\begin{array}{c}
p^{*} \sin \tau \\
0
\end{array}\right\}}_{\mathbf{R}^{*}}
$$

Verifica-se que as matrizes de massa modal $\mathbf{M}^{*}$ e de rigidez modal $\mathbf{K}^{*}$ são diagonais e que $\mathbf{R}^{*}=\left\{p_{1}^{*}(\tau) \quad p_{2}^{*}(\tau)\right\}^{t}=p^{*} \sin \tau\left\{\begin{array}{ll}1 & 1\end{array}\right\}^{t}$. Esse fato permite escrever a equação de movimento 5.5 (sistema de equações diferenciais acopladas e descritas nas coordenadas generalizadas físicas) como um sistema de duas equações diferenciais ordinárias desacopladas (ou seja, como se fossem dois sistemas de um grau de liberdade) e cujas incógnitas são as amplitudes modais. Diz-se, assim, que os modos de vibrar formam uma base para a expansão da resposta de um sistema linear. Os termos não nulos das matrizes de massa e 
de rigidez modal obtidos como funções dos parâmetros $\epsilon$ e $\sigma$ são apresentados na Figura 25 .

Figura 25 - Termos não nulos das matrizes de massa e de rigidez modal.

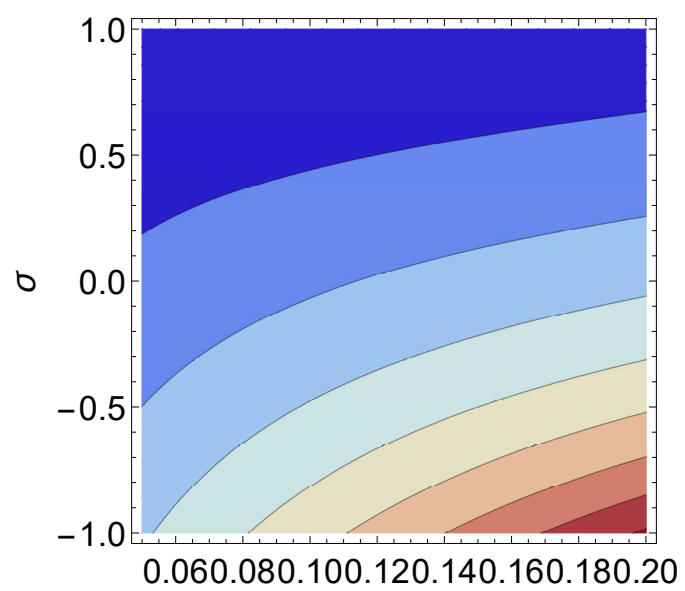

$\epsilon$

(a) $m_{1,1}^{*}(\epsilon, \sigma)$.

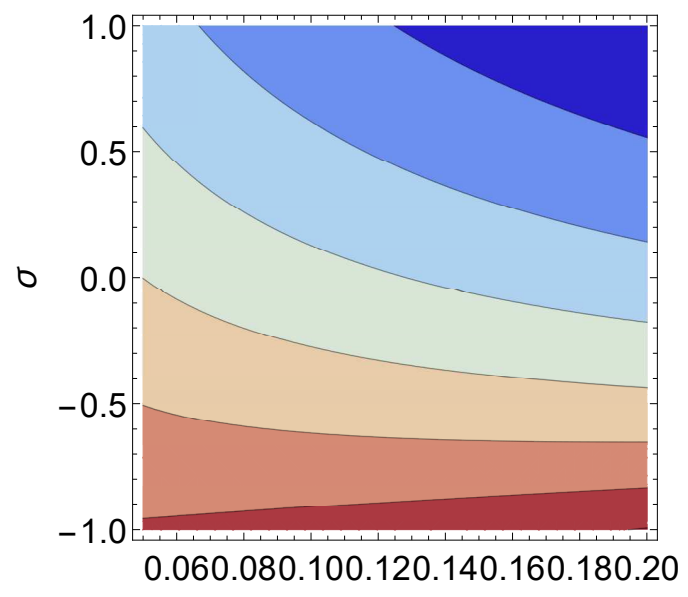

$\epsilon$

(c) $k_{1,1}^{*}(\epsilon, \sigma)$.

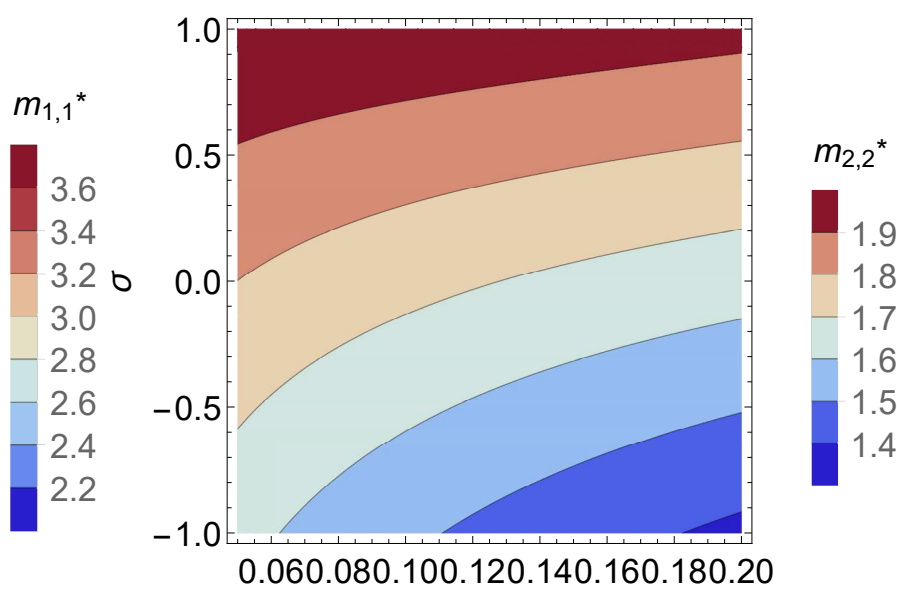

$\epsilon$

(b) $m_{2,2}^{*}(\epsilon, \sigma)$.

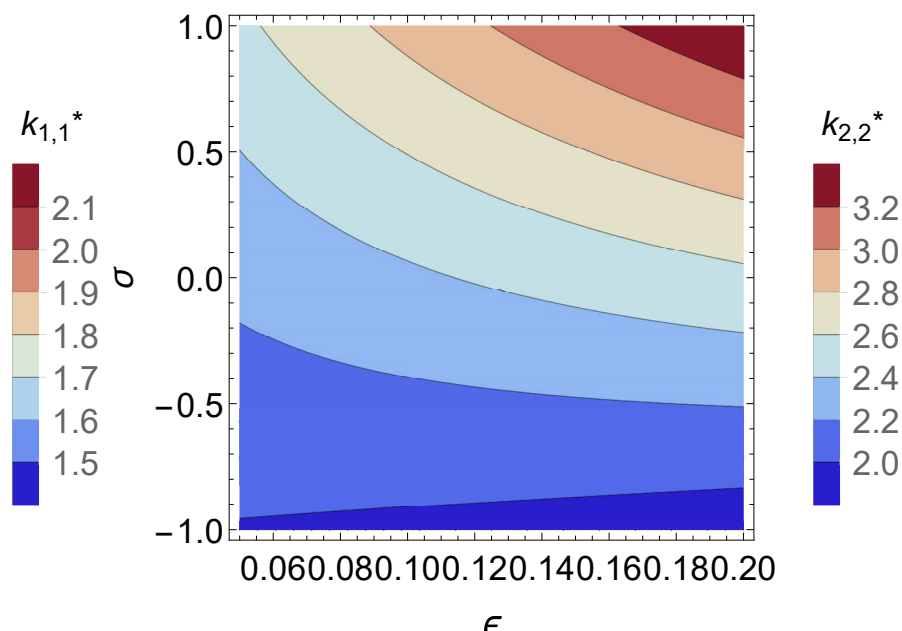

(d) $k_{2,2}^{*}(\epsilon, \sigma)$.

Fonte: Elaborada pelo autor.

De posse das equações de um grau de liberdade nas amplitudes modais, pode-se resolvê-las analiticamente e fazer a regeneração das coordenadas originais invertendo a transformação de variáveis definida pela Equação 5.11. Considere, a equação do oscilador modal dada por:

$$
m_{k, k}^{*} \ddot{y}_{k}+k_{k, k}^{*} y_{k}=p_{k}^{*}(\tau)=p^{*} \sin \tau, k=1,2
$$

onde $\mathbf{Y}=\left\{\begin{array}{ll}y_{1} & y_{2}\end{array}\right\}^{t}$. Cumpre ressaltar que $\omega_{k}^{2}=k_{k, k}^{*} / m_{k, k}^{*}, k=1,2$. A solução particular da Equação 5.13 é dada pela Equação 5.14. 


$$
\begin{aligned}
& y_{P, 1}(\tau)=-\frac{p^{*}}{k_{1,1}^{*}} D_{1}(\beta=1, \epsilon, \sigma) \sin \tau=-\frac{p^{*}}{k_{1,1}^{*}} \frac{1}{\sqrt{\left(1-\left(\frac{1}{\omega_{1}}\right)^{2}\right)^{2}}} \sin \tau \\
& y_{P, 2}(\tau)=-\frac{p^{*}}{k_{2,2}^{*}} D_{2}(\beta=1, \epsilon, \sigma) \sin \tau=-\frac{p^{*}}{k_{2,2}^{*}} \frac{1}{\sqrt{\left(1-\left(\frac{1}{\omega_{2}}\right)^{2}\right)^{2}}} \sin \tau
\end{aligned}
$$

sendo $D_{k}$ o fator de amplificação dinâmica para um carregamento de frequência unitária e associado ao k-ésimo modo, $k=1,2$. É claro ao leitor que, como as frequências naturais não amortecidas dependem dos parâmetros de controle $\epsilon$ e $\sigma$, os fatores de amplificação dinâmica também dependem desses parâmetros.

Cabe, aqui, uma maior explicação acerca da Equação 5.14. Na dinâmica linear de estruturas de um grau de liberdade e na ausência de amortecimento, o ângulo de fase entre o carregamento externo harmônico e deslocamento salta de 0 para $\pi$ quando da passagem pela ressonância. Como $\omega_{1}<1$ e a frequência do carregamento aqui analisada é unitária, a resposta do oscilador modal referente ao primeiro modo está em antífase com o carregamento modal correspondente. Por outro lado, o segundo modo natural é caracterizado por sua frequência natural não amortecida $\omega_{2}>1$ (portanto, maior do que a frequência do carregamento), de sorte que o carregamento e o deslocamento modais estão em fase.

De posse das soluções particulares dos osciladores modais, a regeneração das soluções nas coordenadas físicas $u_{1}$ e $u_{2}$ é feita por meio da transformação de variáveis dada na Equação 5.11. Atentando para a estrutura da matriz modal $\phi$ e, utilizando a Equação 5.11, nota-se que a resposta associada à estrutura principal $u_{1}(\tau)$ é:

$$
\begin{aligned}
& u_{1}(\tau)=y_{P, 1}(\tau)+y_{P, 2}(\tau)= \\
& p^{*}\left(-\frac{1}{k_{1,1}^{*}} \frac{1}{\sqrt{\left(1-\left(\frac{1}{\omega_{1}}\right)^{2}\right)^{2}}}+\frac{1}{k_{2,2}^{*}} \frac{1}{\sqrt{\left(1-\left(\frac{1}{\omega_{2}}\right)^{2}\right)^{2}}}\right) \sin \tau=\hat{u}_{1} \sin \tau
\end{aligned}
$$

onde $\hat{u}_{1}$ representa a amplitude da solução particular associada ao deslocamento da estrutura principal.

A Figura 26 ilustra a variação da grandeza $\hat{u}_{1} / p^{*}$ como função dos parâmetros de controle $\epsilon$ e $\sigma$ e revela que a amplitude de resposta da estrutura principal é nula quando $\sigma=0 \mathrm{ou}$, de maneira equivalente, a $\kappa / \epsilon=1$ (ver Equação 5.6). Fisicamente, $\kappa / \epsilon=1$ indica que, definindo os parâmetros de massa e de rigidez do TMD de sorte que sua frequência natural (se considerada como um sistema isolado de um grau de liberdade) coincida 
com aquela do carregamento ressonante com a estrutura principal antes da inserção do supressor, anula a a solução particular do sistema a ser controlado.

Figura 26 - Variação da grandeza $\hat{u}_{1} / p^{*}$ com os parâmetros de controle $\epsilon$ e $\sigma$.

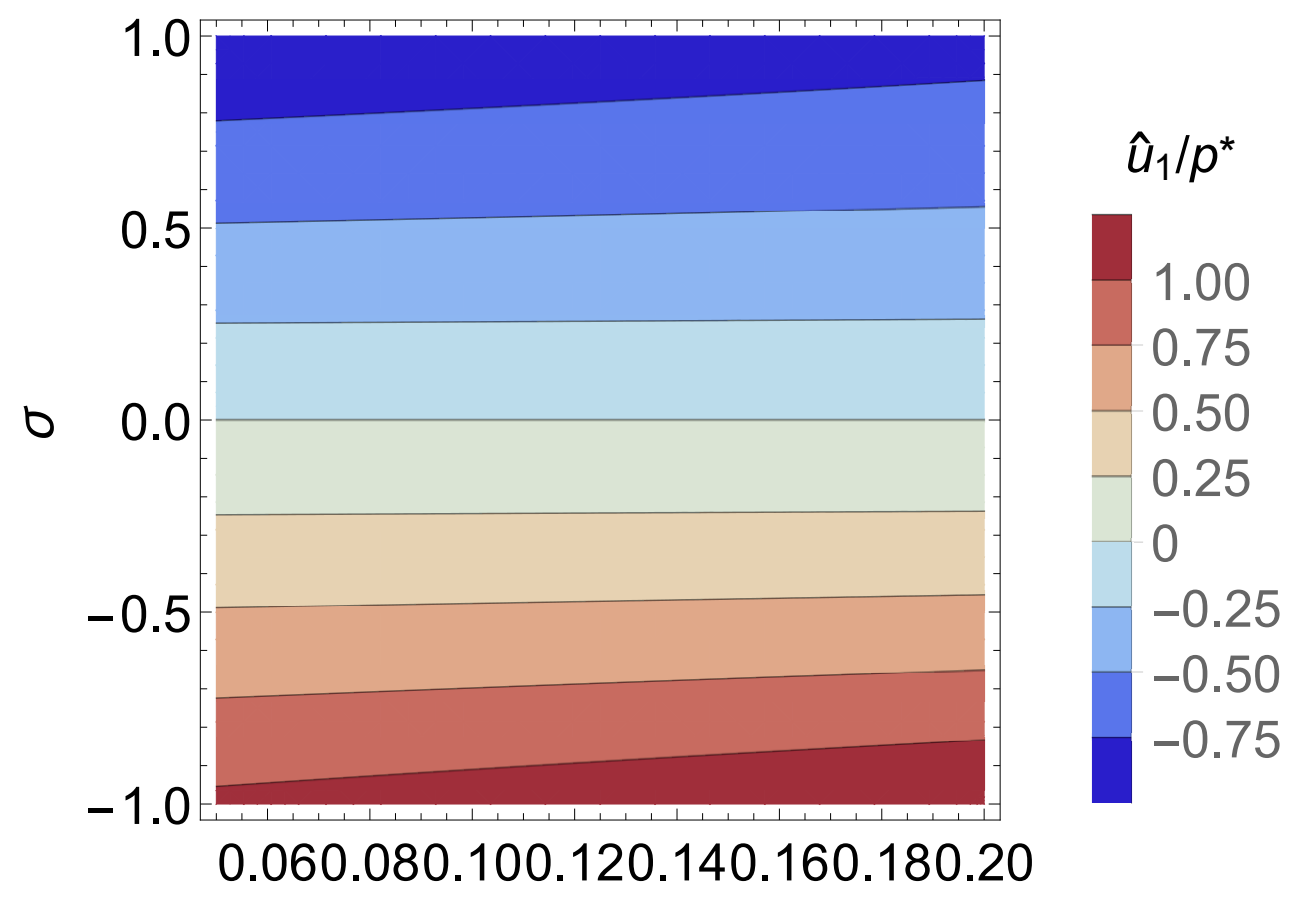

$\epsilon$

Fonte: Elaborada pelo autor.

Segue, agora, uma discussão acerca da influência da frequência do carregamento na resposta do sistema de dois graus de liberdade definido pela estrutura principal e pelo TMD. A Figura 27 mostra os fatores de amplificação dinâmica modais $D_{1}$ e $D_{2}$, bem como as defasagens entre o carregamento e o deslocamento modal $\bar{\theta}_{1}$ e $\bar{\theta}_{2}$ para um particular valor de massa do supressor $\epsilon=0,10$ e dois valores do parâmetro $\sigma$. Considerando um carregamento de frequência $\beta=\bar{\omega} / \omega=0,70$, as Figuras 27(a) e 27(b) revelam que $\bar{\theta}_{1}=\bar{\theta}_{2}=0$, indicando que os deslocamentos modais estão em fase com os correspondentes carregamentos. Já os fatores de amplificação dinâmica apresentados nas Figuras 27(c) e 27(d) indicam um aumento significativo das respostas modais o que, por consequência, pode levar ao surgimento de vigorosas oscilações da estrutura principal (ver Equação 5.15). Assim, pode-se afirmar que o uso de TMDs como supressores passivos de vibrações é eficaz no caso onde o carregamento é de banda estreita, ou seja, seu espectro de amplitude apresenta uma frequência dominante e com energia desprezível nas demais frequências.

Visando contornar a limitação dos TMDs para carregamentos de banda larga, surgiram os supressores passivos de vibração que têm um comportamento dinâmico nãolinear. A próxima seção é dedicada à apresentação dos aspectos principais desses elementos e de suas aplicações em diversos problemas, em particular naqueles que são objeto deste 
Figura 27 - Defasagens entre força e deslocamento modais e fatores de amplificação dinâmica modais. Sistema sem amortecimento.

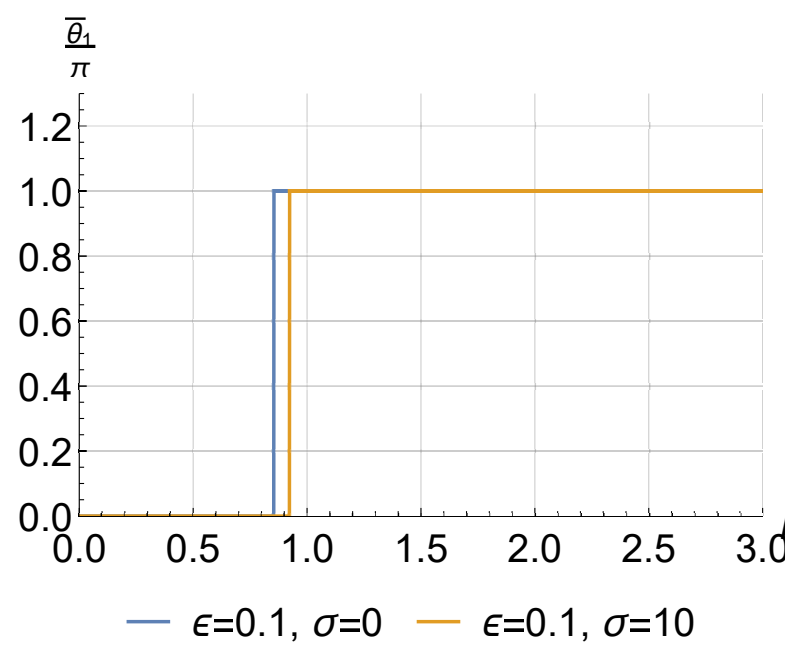

(a) $\bar{\theta}_{1}$.

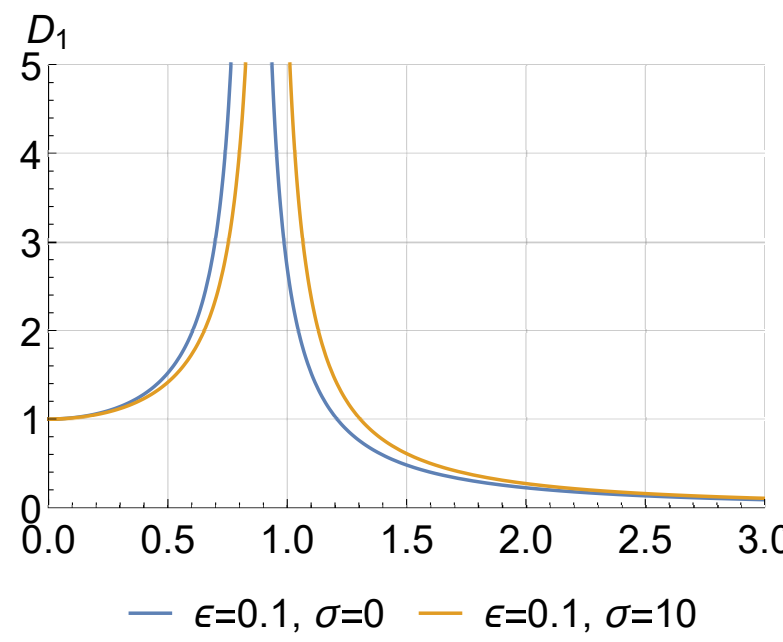

(c) $D_{1}$.

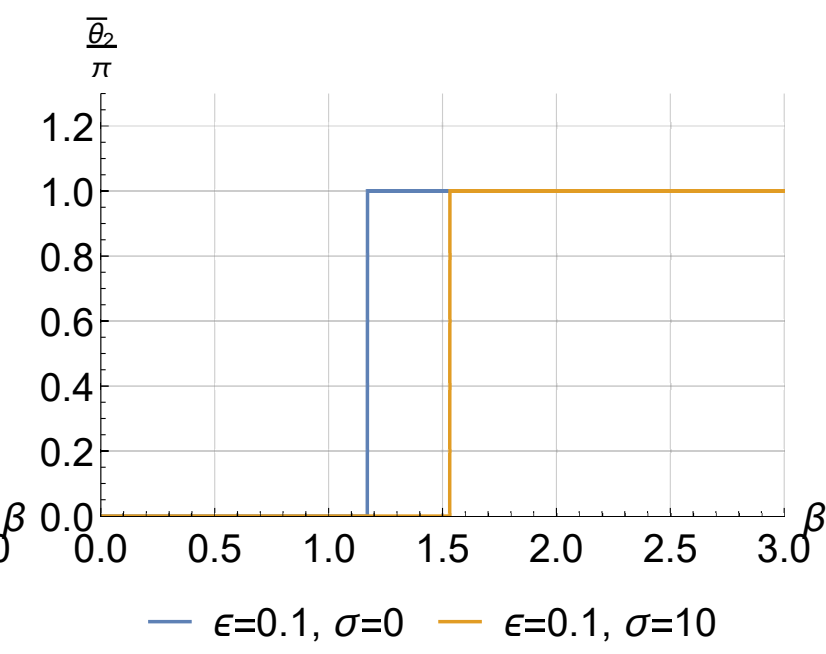

(b) $\bar{\theta}_{2}$.

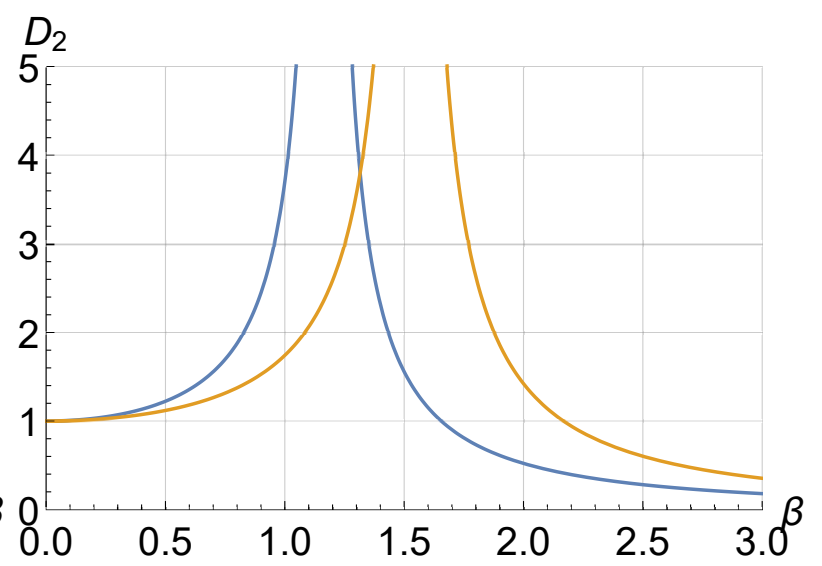

$-\epsilon=0.1, \sigma=0-\epsilon=0.1, \sigma=10$

(d) $D_{2}$.

Fonte: Elaborada pelo autor.

texto.

\subsection{Supressão passiva de vibrações por meio de absorvedores não- lineares de vibração}

Como visto na seção anterior, o uso de supressores de vibração caracterizados por uma dinâmica linear como, por exemplo, os TMDs é eficiente quando a excitação é de banda estreita. Desde o início dos anos 2000 e tendo como objetivo tecnológico a superação da limitação do uso de TMDs em sistemas com excitação de banda larga, o uso de absorvedores não-lineares de vibração tem sido foco de recentes trabalhos desenvolvidos por diversos grupos de pesquisa. Em particular, os trabalhos de Vakakis (2001), Gendelman 
et al. (2001) e de Vakakis e Gendelman (2001) podem ser considerados como seminais no tema. Já Vakakis $(2017,2018)$ são trabalhos bastante recentes e que apresentam algumas exemplos de aplicações deses absorvedores em problemas de dinâmica das estruturas.

Em um primeiro momento desta seção, apresentam-se os principais conceitos relativos à supressão passiva por meio de elementos caracterizados por uma dinâmica essencialmente não-linear, aqui definida como aquela onde o dispositivo supressor não possui uma frequência natural linearizada. Em um segundo momento, são apresentadas uma série de aplicações dessa classe de supressores em diversos problemas de engenharia de estruturas, em particular naqueles que são objeto de estudo das pesquisas aqui sintetizadas.

Antes do início da apresentação dos diversos conceitos, cabe discutir um aspecto relacionado à nomenclatura. Boa parte dos trabalhos no tema denominam a classe de supressores de vibração que é objeto desta seção como absorvedores não-lineares de energia, tradução do termo em inglês non-linear energy sinks - NES. Em Pennisi et al. (2018), os autores indicam que um absorvedor não-linear de energia também é conhecido como absorvedor não-linear de vibração (em inglês, non-linear vibration absorber). O presente texto usa esta a última nomenclatura, incluindo a sua sigla em língua inglesa NVA.

Segundo a extensa revisão bibliográfica apresentada em Lee et al. (2008), um NVA geralmente requer duas características, a saber: (i) a ausência de um elemento da força restauradora linear no deslocamento do supressor, conferindo ao NVA uma dinâmica essencialmente não-linear e (ii) um amortecedor, via de regra linear. A característica (i) leva à ausência de uma frequência natural linearizada para o supressor, permitindo com que ele responda com eficiência para uma vasta gama de condições de carregamento. Já a característica (ii) está relacionada à capacidade de dissipação de energia do dispositivo.

Um conceito de capital importância no tema é o de Targeted Energy Transfer (TET) ou bombeamento de energia ${ }^{3}$. Tendo em vista sua importância, a TET é discutida com maior profundidade neste ponto. Seu mecanismo de funcionamento é ilustrado na Figura 28, que revela uma estrutura caracterizada por suas matrizes de massa $\mathbf{M}$, de rigidez $\mathbf{K}$ e de amortecimento $\mathbf{C}$ e solicitada por uma ou mais fontes como, por exemplo, sismos, impacto ou interação fluido-estrutura.

Considerando essa estrutura como de comportamento linear e com $N$ graus de liberdade, a mesma é caracterizada por suas frequências naturais não amortecidas ${ }^{4}$ da forma $\omega_{k}, k=1,2, \ldots, N$. Como o NVA (NES, segundo a identificação da Figura 28) é caracterizado pela ausência de uma frequência natural linearizada, ele é capaz de induzir infinitas condições de ressonâncias internas da forma $\alpha_{1} \omega_{k}=\alpha_{2} \omega_{N V A}$ com $\alpha_{1}$ e $\alpha_{2}$ números inteiros e $\omega_{N V A}$ a frequência instantânea de operação do supressor (respectivamente, $m, n$ e $\omega_{N E S}$ na Figura 28).

3 Do inglês, energy pumping.

4 Na Figura 28, essas frequências naturais correspondem à identificação $\omega_{\text {Primary }}^{(k)}$. 
Figura 28 - Representação esquemática do fenômeno TET.

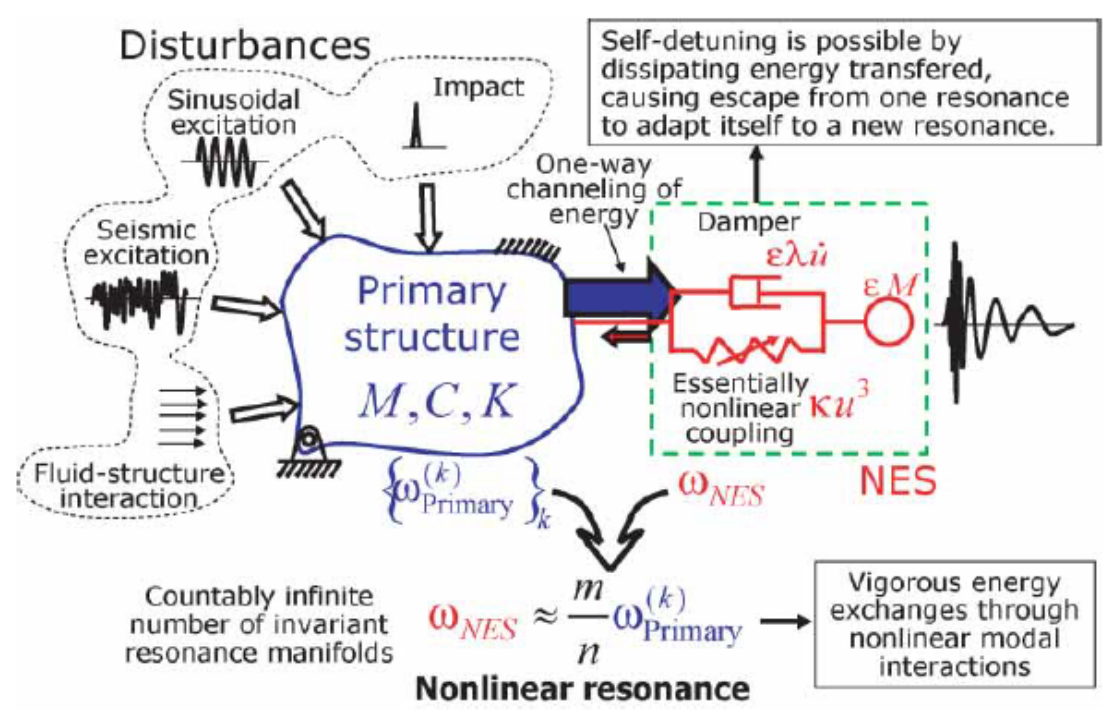

Fonte: Extraída de Lee et al. (2008).

Em decorrência das ressonâncias internas, o supressor não-linear é induzido a apresentar importantes respostas que acabam levando à transferência de energia da estrutura principal para o NVA. Como o NVA é dotado de um elemento dissipativo, a energia é localmente dissipada. Ao processo de transferência de energia da estrutura principal para o NVA com a posterior dissipação dá-se o nome de TET. Com a diminuição da energia do sistema provocada pela dissipação localizada no NVA, pode ocorrer o escape da ressonância interna, o que cessa o fenômeno de TET. Isso pode levar a um aumento da resposta da estrutura principal e possibilitando novas ressonâncias internas.

Existem diversas formas de NVAs, sendo uma delas esquematizada na Figura 29(a) e com funcionamento baseado no impacto de uma massa contra paredes rígidas montadas na estrutura a ser controlada. Nesse tipo de supressor, denominado VI-NES ${ }^{5}$, a dissipação da energia está associada à sequência de choques da massa contra as paredes rígidas. $\mathrm{O}$ uso de VI-NES foi objeto de estudo da tese de Pennisi (2016), que mostrou por meio de experimentos com modelos físicos e de simulações numéricas a eficiência desse dispositivo na mitigação das vibrações de um pórtico com um grau de liberdade sujeito à excitação de suporte.

Uma segunda classe de NVAs é aqui denominada como NVA translativo e está representada na Figura 29(b). Um NVA translativo é caracterizado por uma massa acoplada à estrutura principal por meio de uma mola não-linear e um amortecedor, que pode ou não ter comportamento linear. Uma possível realização prática para um NVA é translativo é aquela onde a mola é posicionada na direção ortogonal ao movimento da massa do supressor. Caso a mola não seja ortogonal à direção de movimento do supressor, a força

5 Do inglês, vibro-impact NES. 
restauradora permanece não-linear, porém com a presença de uma frequência natural linearizada para o supressor e que decorre de um termo de rigidez constante.

Por fim, este texto destaca o NVA rotativo esquematizado na Figura 29(c), caracterizado por uma massa acoplada à extremidade de uma barra rígida que, por sua vez, conecta-se à estrutura principal por meio de uma articulação e de um amortecedor rotacional. Os tópicos de pesquisa em supressão passiva abordados no presente texto consideram apenas o NVA rotativo. O leitor interessado em uma contribuição do autor no tocante ao de um NVA rotativo como supressor do fenômeno de excitação paramétrica deve consultar o capítulo 9. Por sua vez, a aplicação dessa classe de supressores com vistas à mitigação dos fenômenos de VIV e de galloping é feita no capítulo 10.

Cumpre salientar que, no caso de um NVA rotativo, os movimentos devem ocorrer no plano horizontal, de sorte que a aceleração gravitacional não promova torque restaurador à haste rotativa. Esse torque, caso existente, induziria uma frequência natural linearizada para a dinâmica do supressor de maneira semelhante ao que é encontrado no problema do pêndulo.

Antes do aprofundamento em alguns aspectos particulares ao uso de um NVA rotativo, cabe ressaltar que um arranjo semelhante denominado $\mathrm{CPVA}^{6}$ é o objeto de estudos de Chao, Lee e Shaw (1997), Alsuwaiyan e Shaw (2014) e Issa e Shaw (2015) como mitigador de vibrações torcionais em rotores. Nesses trabalhos, uma série de caminhos prédeterminados na seção transversal do rotor (não necessariamente circulares) são percorridos por uma ou mais massas. O movimento das massas é decorrente das vibrações torcionais e acabam por induzir torques restauradores. A Figura 30 traz uma representação esquemática de um CPVA.

O trabalho de Gendelman et al. (2012) é um dos pioneiros no estudo de um NVA rotativo como supressor passivo de vibrações. Essa referência aponta que, além de sua simplicidade de montagem quando comparado ao caso com um NVA translativo, o NVA rotativo é capaz operar com qualquer velocidade angular e, com isso, operar para uma série de frequências de excitação.

Após estudos de caráter analítico, numérico e experimental, Gendelman et al. (2012) identificam a existência de três regimes de resposta do supressor. Um deles, denominado de resposta oscilatória, está associado a excitações de pequena energia e é caracterizado por uma resposta do supressor com caráter praticamente harmônico e por uma lenta dissipação de energia. O segundo regime é caracterizado por uma resposta intermitente do supressor com maior concentração de energia no NVA do que aquela observada na resposta oscilatória. Por fim, a resposta rotativa do NVA é definida por uma velocidade praticamente constante e é onde existe a maior transferência de energia da estrutura

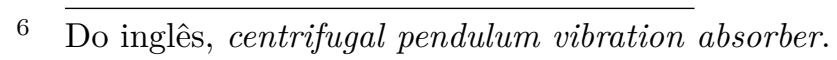


Figura 29 - Exemplos de absorvedores não-lineares de vibração.

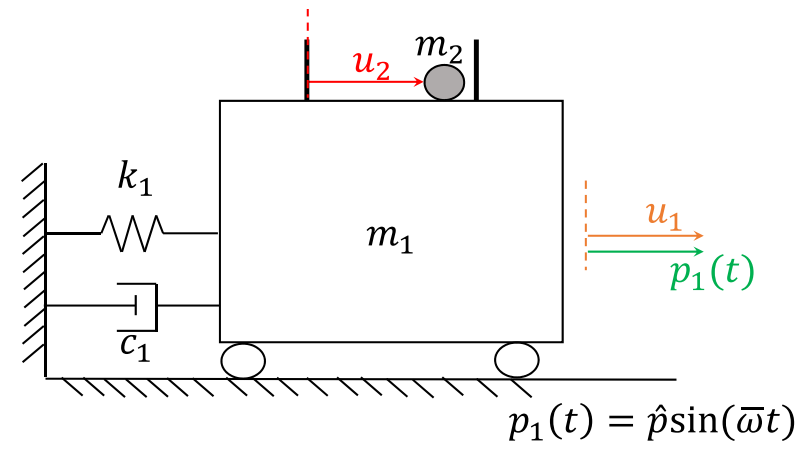

(a) VI-NES.

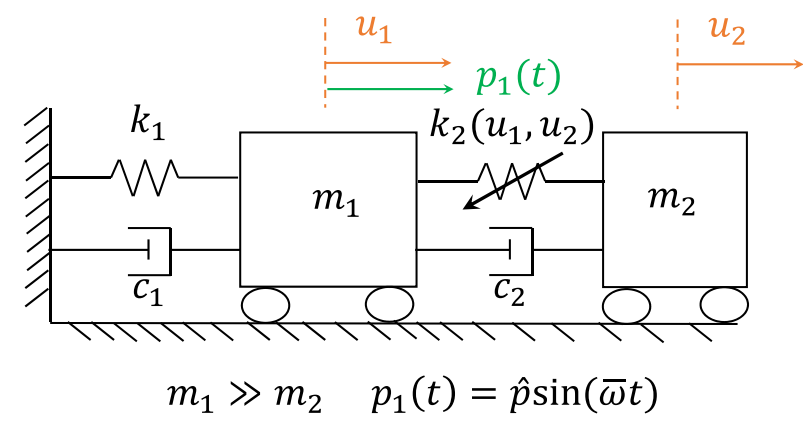

(b) NES translativo.

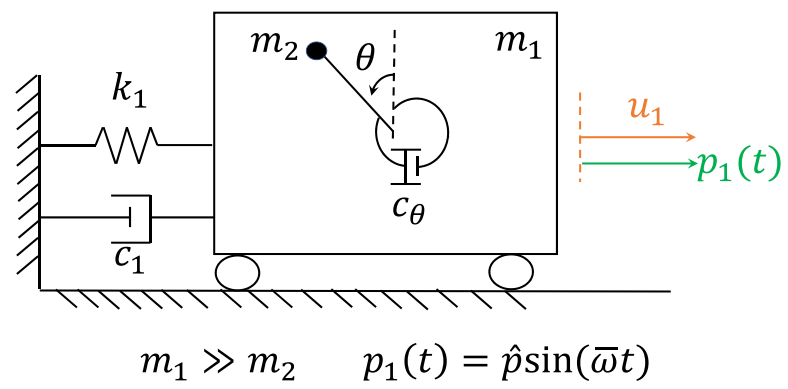

(c) NVA rotativo.

Fonte: Elaborada pelo autor.

principal para o supressor.

Embora com foco em um absorvedor não-linear do tipo VI-NES, o trabalho de Gendelman e Alloni (2015) acaba tecendo algumas comparações entre as respostas obtidas para esse tipo de supressor e um NVA rotativo. Dentre as semelhanças, os autores apontam para as semelhanças das slow invariant manifolds ${ }^{7}$ (SIMs) associadas aos problemas com essas classes de NVAs. Mais especificamente, as SIMs relacionadas aos problemas de supressão passiva com um NVA rotativo ou com o VI-NES são compostas de dois ramos, sendo um instável. A Figura 31 ilustra as SIMs obtidas para o sistema originalmente de um grau de liberdade dotado com os supressores do tipo VI-NES ou NVA rotativo.

Benarous e Gendelman (2016) estudam o problema de supressão passiva de uma estrutura principal modelada como possuindo um único grau de liberdade por meio de um

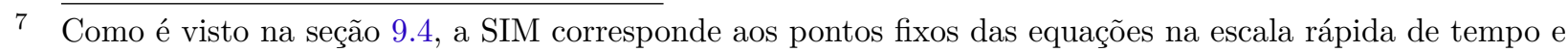
está relacionada à captura na ressonância $1: 1$ onde ocorre a TET. A menos do conhecimento do autor do texto, não existe uma tradução para esse termo em língua portuguesa, de sorte que o presente texto adota a denominação em inglês. 
Figura 30 - Representação esquemática de um CPVA.

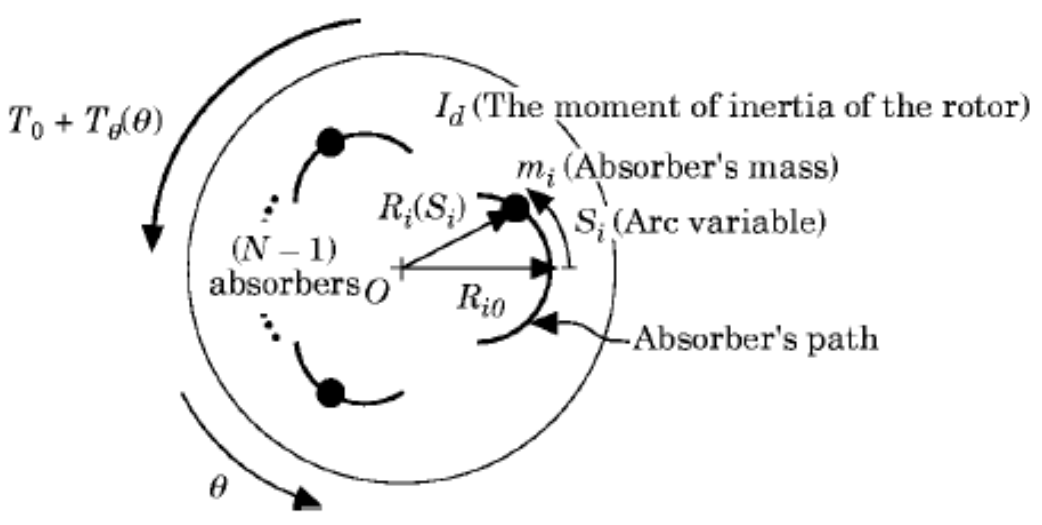

Fonte: Extraída de Chao, Lee e Shaw (1997).

Figura 31 - Exemplos de SIM para os problemas de supressão com VI-NES e NVA rotativo.

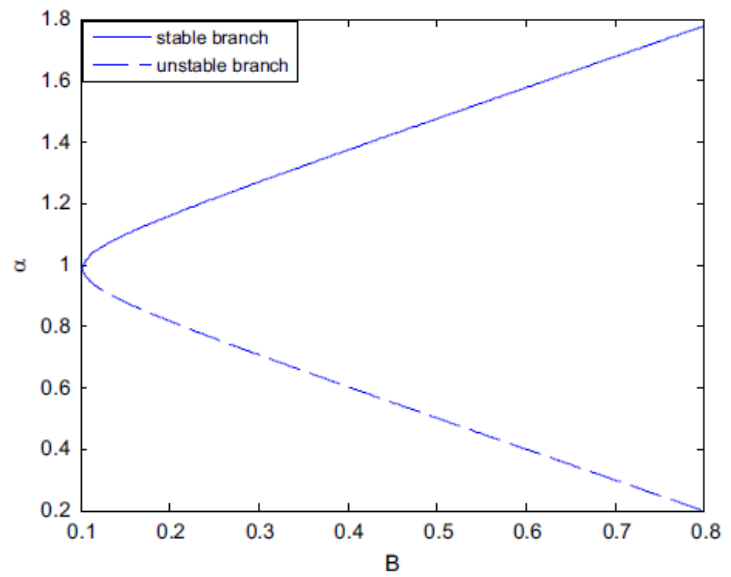

(a) VI-NES.

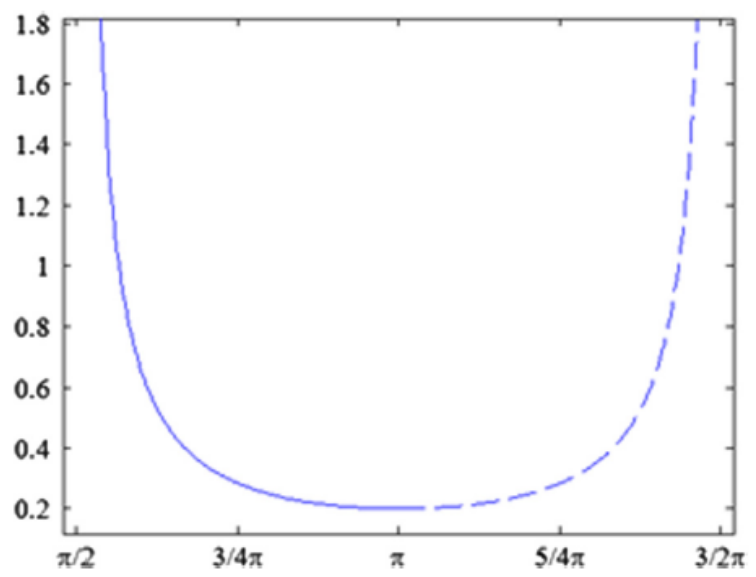

(b) NVA rotativo.

Fonte: Extraída de Gendelman e Alloni (2015).

NVA. No entanto e de maneira distinta das demais formas apresentadas na presente seção, o elemento supressor ${ }^{8}$ consiste de um NVA rotativo posicionado em um NVA translativo que está conectado à estrutura principal; ver Figura 32.

Benarous e Gendelman (2016) conduzem uma análise comparativa entre a capacidade de supressão do sistema ilustrado na Figura 32 e um NVA translativo clássico. Na análise conduzida pelos autores, a estrutura principal é animada de uma certa velocidade inicial e na ausência de esforços externos. Em particular para altos valores de velocidade inicial, o dispositivo supressor com dois graus de liberdade apresenta um desempenho superior ao clássico NVA translativo. Uma justificativa para a melhoria do desempenho da nova modalidade de NVA consiste do fenômeno de amplitude locking ${ }^{9}$, definido como a 
Figura 32 - Representação esquemática do dispositivo estudado em Benarous e Gendelman (2016).

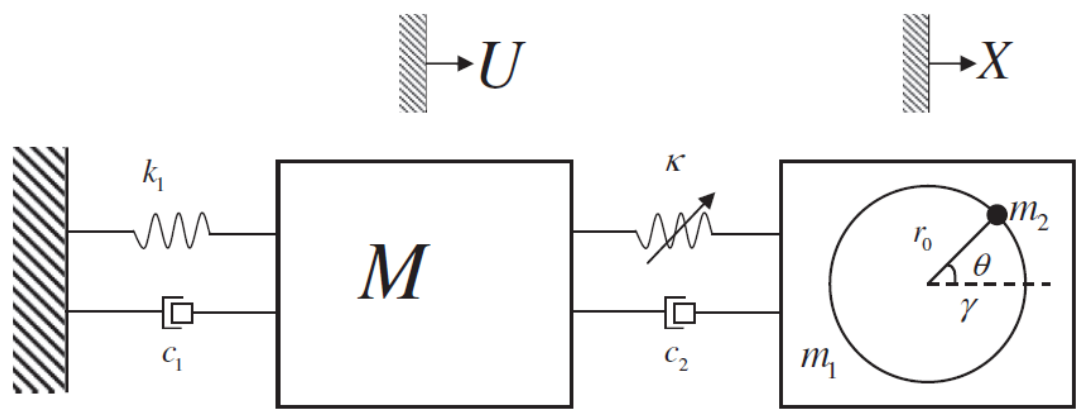

Fonte: Extraída de Benarous e Gendelman (2016).

invariância da amplitude de oscilação da massa sobre a qual o NVA rotativo é posicionado com a sua frequência de oscilação.

Por ser um tema muito mais recente do que o uso de TMDs, as aplicações de supressores de vibração do tipo NVA em diversos sistemas de engenharia são novas e datam do início dos anos 2010. No contexto da dinâmica de edifícios, os trabalhos de Nucera et al. $(2008,2010)$ trazem resultados experimentais e analíticos mostrando a eficácia de um arranjo envolvendo NVAs translativos e VI-NES na supressão de vibrações decorrentes da excitação de suporte policromática aplicada às fundações e com o objetivo de simular um sismo. Dentre as conclusões tecidas nesses trabalhos destacam-se a capacidade de mitigação do conjunto de NVAs nas fases iniciais (e mais energéticas) do sismo. Além disso, os autores apontam que os supressores do tipo VI-NES acabam por redistribuir a solicitação por várias frequências, abrangendo tanto os modos mais baixos quanto os mais elevados.

Já em Wierschen et al. (2017), o foco é na investigação experimental da supressão de vibrações decorrentes de um carregamento impulsivo gerado por uma explosão na proximidade da estrutura utilizando conjuntos de NVAs que combinam tanto os translativos quanto os VI-NES. Nesse trabalho, os autores demonstram, entre outros resultados, que a distribuição de energia por uma larga banda espectral (o que excita vários modos naturais da estrutura) decorrente do funcionamento dos VI-NES desempenha um papel fundamental na rápida mitigação de vibrações.

Em Motato et al. (2017), o foco é a aplicação do uso de um NVA com vistas à supressão das vibrações torcionais em automóveis decorrentes de desenvolvimento de novos motores. Segundo essa referência, a diminuição das vibrações da estrutura principal decorre de um mecanismo análogo àquele observado na mitigação de vibrações em edifícios, com o NVA funcionando como um elemento que induz vibrações em modos mais altos que, naturalmente mais amortecidos, dissipam a energia de forma mais rápida do que aquela 
que seria observada se a dinâmica da estrutura principal fosse dominada por modos mais baixos.

Após a apresentação de alguns trabalhos que focam no uso de NVAs como mitigadores de vibrações em estruturas mais relacionadas ${ }^{10}$ às engenharias civil e mecânica, a revisão bibliográfica conduzida passa a focar na supressão de alguns fenômenos de VIE, assunto que apresenta transversalidade a diversas aplicações de engenharia. Luongo e Zulli (2014) estudam o uso de um NVA translativo como supressor passivo para as vibrações de uma estrutura com vários graus de liberdade e sujeita à instabilidade aeroelástica. Empregando uma abordagem que mescla o método das múltiplas escalas com o método do balanço harmônico além de simulações numéricas, os autores demonstram que a presença do NVA aumenta a velocidade crítica de escoamento a partir do qual oscilações auto-excitadas são observadas. Os autores ainda ressaltam a importância da localização do NVA na estrutura principal, indicando que a diminuição das amplitudes pós-críticas é observada apenas se o NVA está à jusante do centro de massa do fólio.

Um outro problema de VIE que também tem sido estudado do ponto de vista de supressão passiva por meio de NVAs é aquele que envolve estruturas tubulares conduzindo fluido. Esse é um clássico problema onde existe uma velocidade crítica para o escoamento interno que leva a instabilidades estática ou dinâmica. Como esse fenômeno não faz parte do escopo desse texto, maiores detalhes acerca da sua modelagem matemática não são aqui discutidos, porém o leitor interessado em um aprofundamento no tema deve consultar o livro de Païdoussis (1998).

Yang et al. (2018) estudam numericamente o problema de supressão passiva das vibrações induzidas pelo escoamento interno em uma viga bi-apoiada. Nesse trabalho, o supressor é composto de duas molas pré-comprimidas e conectadas a uma massa, como mostra a Figura 33. O arranjo estudado em Yang et al. (2018) possui uma característica distinta daquela vista nos supressores apresentados nesta seção. A pré-compressão das molas confere ao supressor um termo negativo na sua rigidez linearizada, enquanto que o movimento da massa na direção ortogonal àquela que define as molas confere não-linearidade à dinâmica do supressor. Por meio de simulações numéricas, os autores mostram que a capacidade de supressão do dispositivo caracterizado por um termo de rigidez linearizada negativo (por eles denominado enhanced NES) é ainda maior do que aquela de um NVA translativo usual.

O trabalho de Zhou et al. (2018) também aborda a supressão de vibrações induzidas por escoamento interno por meio de um NVA, porém com algumas diferenças em relação ao artigo de Yang et al. (2018). Zhou et al. (2018) estudam o problema de uma viga

10 Aqui, deve ser ressaltado que, embora essas estruturas estejam mais relacionadas às engenharias civil e mecânica, a análise de tais problemas do ponto de vista da dinâmica pode ser feita por engenheiros de diversas modalidades, desde que com formação sólida em dinâmica e com algum conhecimento das áreas. 
Figura 33 - Representação esquemática do dispositivo estudado em Yang et al. (2018).

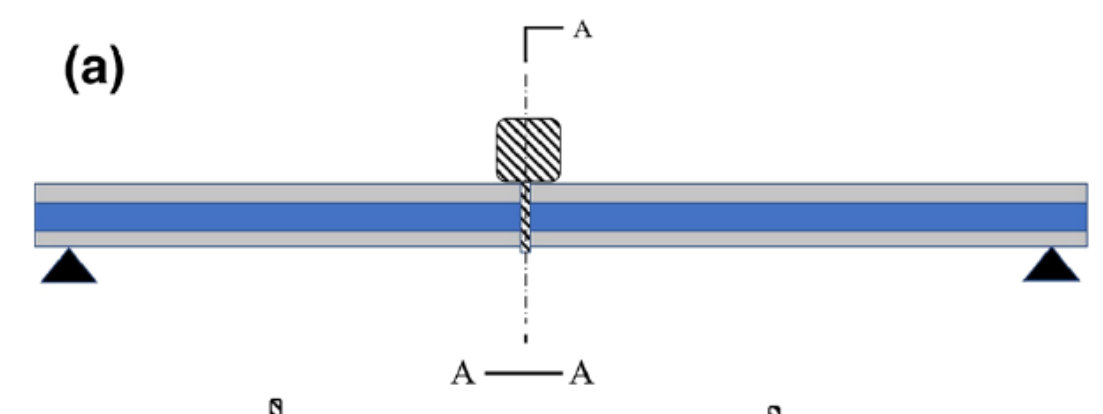

(b)

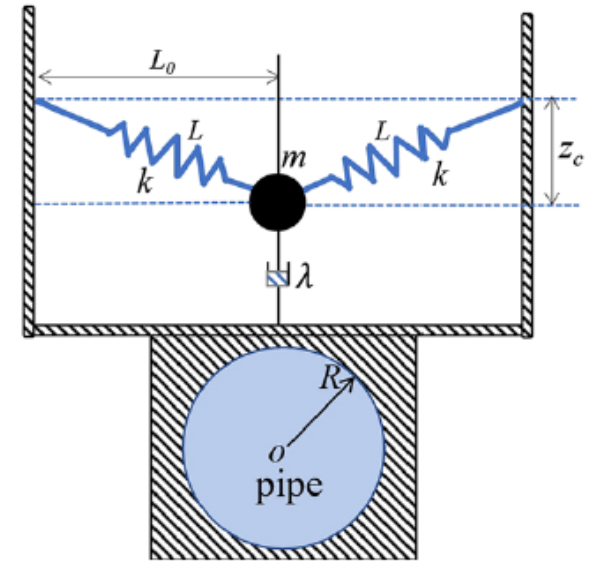

Fonte: Extraída de Yang et al. (2018).

em balanço condutora de fluido dotada de um NVA translativo usual e cuja dissipação estrutural é caracterizada por uma reologia viscoelástica.

Considerando ainda a referência Zhou et al. (2018), os autores investigam a influência dos diversos parâmetros que caracterizam o NVA (sua posição de instalação, massa, rigidez e constante de amortecimento) no comportamento do conjunto. Os resultados numericamente obtidos apontam que a instalação do NVA promove um aumento da velocidade crítica do escoamento interno a partir da qual a solução trivial perde estabilidade. Além do aumento da velocidade crítica, o supressor também se mostra capaz de diminuir as amplitudes de resposta pós-críticas. Alguns exemplos de resultados são apresentados na Figura 34.

Após a apresentação de algumas aplicações de NVAs em problemas de VIE, esta seção passa a focar na mitigação dos fenômenos de VIV e de galloping, focos do presente texto. A supressão passiva do VIV já é um aspecto estudado há bastante tempo. Dentre os diversos tipos de supressores passivos, podemos destacar os strakes, elementos unifilares posicionados ao longo do cilindro em forma de hélice e que acabam por fixar o ponto de separação do escoamento. Como consequência da posição da separação do escoamento fixa no strake e variando ao longo da envergadura, tem-se uma redução no comprimento de correlação e uma queda nas amplitudes de oscilação decorrentes do VIV. Maiores detalhes acerca do uso de strakes no contexto de VIV podem ser encontrados em Korkischko e Meneghini (2010, 2011). 
Figura 34 - Diagramas de bifurcação. As subfiguras a), b) c) e d) estão relacionadas a distintos valores da rigidez do NVA.

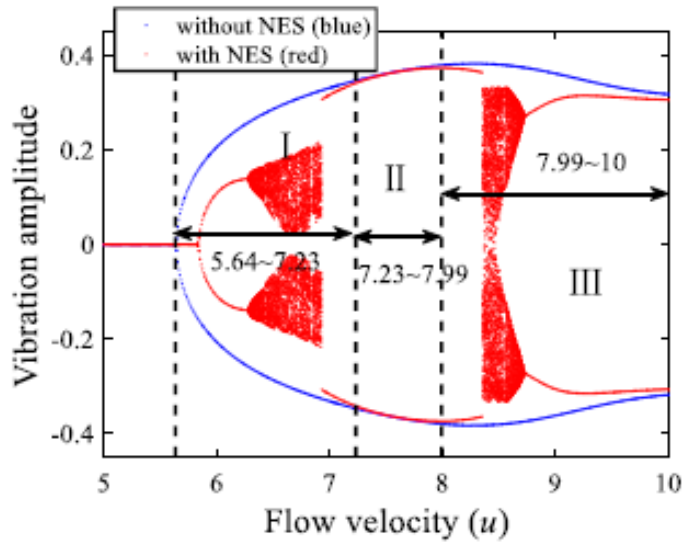

(a)

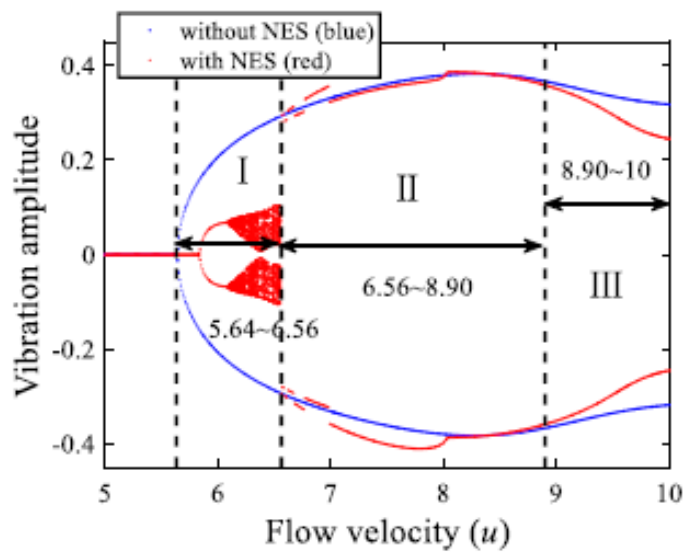

(c)

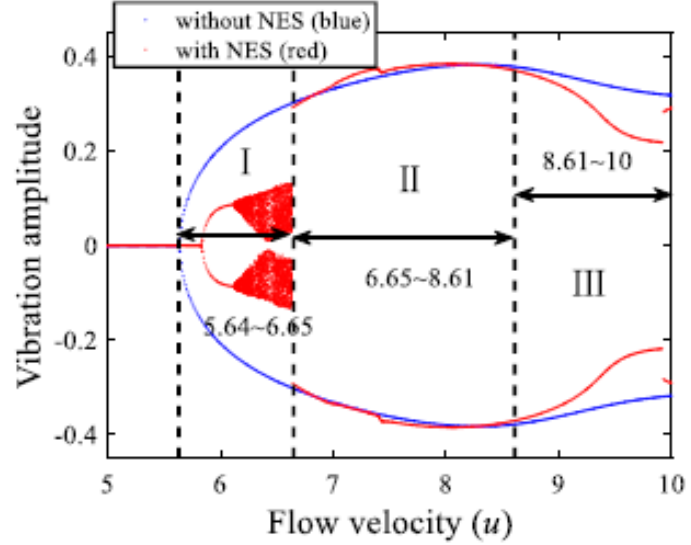

(b)

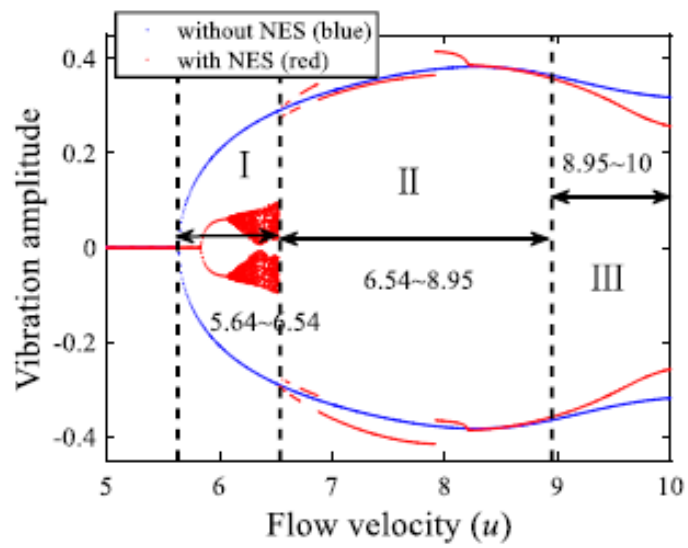

(d)

Fonte: Extraída de Zhou et al. (2018).

Um outro tipo de supressor passivo para o fenômeno de VIV que tem sido objeto de pesquisa por parte do grupo da EPUSP é denominado Ventilated-Trousers (VT). O VT consiste de uma rede dotada de pequenos cilindros e que envolve a estrutura a ser controlada. Por meio da modificação do campo de escoamento, a resposta ao fenômeno de VIV é diminuída. Uma campanha experimental com foco no uso de um supressor do tipo VT pode ser encontrada em Cicolin e Assi (2017). Ao contrário dos strakes e do VT, os NVAs rotativo e translativo são posicionados internamente ao cilindro (estrutura principal), de sorte que o supressor não fica em contato com o fluido.

O trabalho de Tumkur et al. (2013) é um dos primeiros no tema e emprega técnicas de DFC para a modelagem do carregamento do fenômeno VIV-1gl e faz uso de um de um NVA translativo como dispositivo supressor. Considerando $m^{*}=10$ (valor mais elevado do que aquele encontrado em estruturas de engenharia oceânica), os autores apresentam séries temporais de resposta do cilindro e do supressor para o caso onde a massa do NVA é $11 \%$ da massa da estrutura principal. 
A Figura 35, extraída de Tumkur et al. (2013), ilustra as séries temporais de deslocamento do cilindro para os casos sem e com o NVA translativo. Essa figura mostra que a presença do NVA translativo leva uma resposta da estrutura principal com um estado estacionário completamente definido e com amplitude próxima a 0,5 (Figura 35(a)) para um regime onde a amplitude apresenta fortes modulações, porém com valor de amplitude característica próxima a 78\% daquele obtido na ausência do supressor (ver Figura 35(b)).

Figura 35 - Séries temporais de deslocamento do cilindro. A massa do NVA é $11 \%$ da massa do cilindro. $R e=100$.

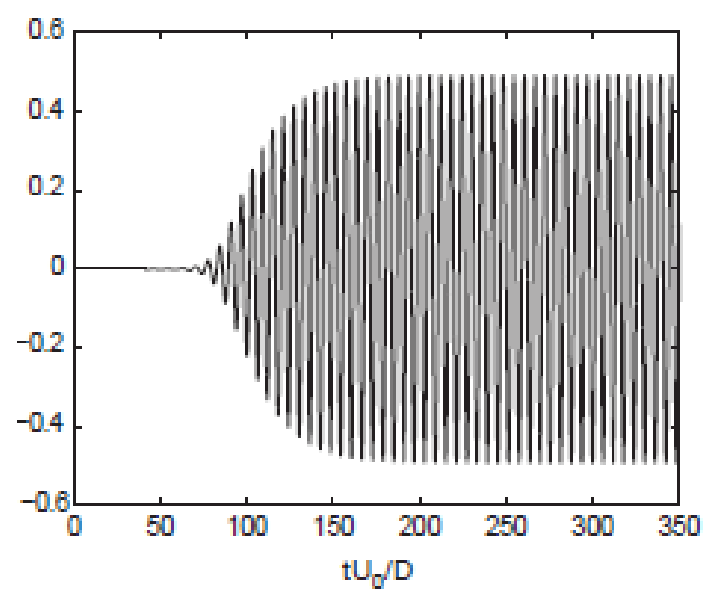

(a) Sem o NVA.

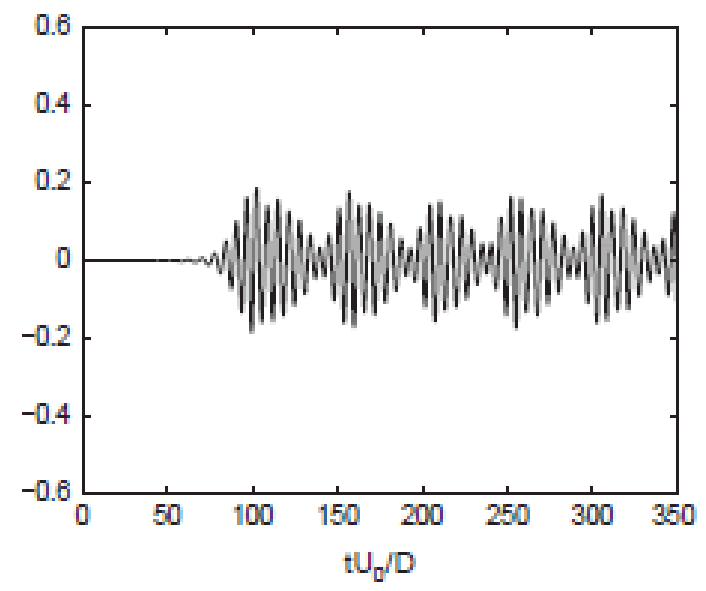

(b) Com o NVA.

Fonte: Extraída de Tumkur et al. (2013).

Tumkur et al. (2013) apresentam, ainda, a resposta de um cilindro dotado de um NVA translativo cuja massa é 6,6\% da massa da estrutura a ser controlada. Embora os autores tenham alterado não somente a massa, mas também a rigidez e a constante de amortecimento do NVA quando comparado ao caso acima discutido, a Figura 36 revela que a série temporal de deslocamento do cilindro é qualitativamente distinta daquela observada na Figura 35(b), apresentando uma resposta com pouca modulação de amplitude após um transitório inicial.

O último aspecto a ser discutido acerca do artigo de Tumkur et al. (2013) é a variação do máximo deslocamento do cilindro como função do número de Reynolds para as condições do cilindro sem qualquer dispositivo supressor (linha tracejada) e dotado de um NVA translativo (símbolo " $\times$ ") e de um TMD (círculo preenchido em preto) projetado para maior eficiência para $R e=100$. Como mostrado na Figura 37, tanto o NVA quanto o TMD são capazes de reduzir as amplitudes de vibração do cilindro, porém o desempenho do TMD é superior apenas no intervalo $87<R e<103$, não por acaso nas vizinhanças do seu ponto de projeto.

A maior eficiência de supressão do NVA nas outras condições simuladas é justificada pela dependência da frequência de emissão de vórtices (e, portanto, da excitação) com a 
Figura 36 - Série temporal de deslocamento do cilindro. A massa do NVA é 6,6\% da massa do cilindro. $R e=100$.

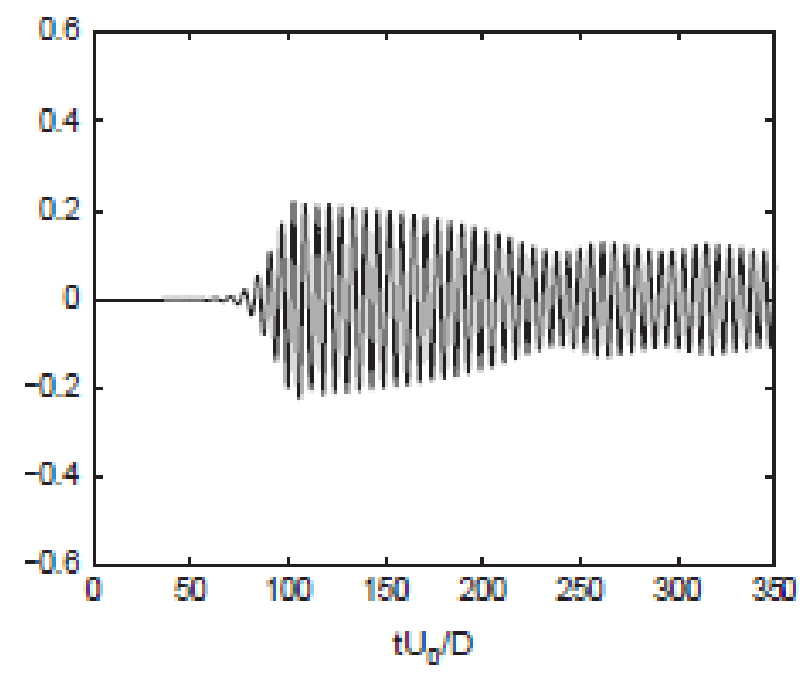

Fonte: Extraída de Tumkur et al. (2013).

velocidade do escoamento ${ }^{11}$, representada pelo número de Reynolds. Como já explicado nesta seção, a ausência de um termo constante de rigidez (termo linear na força de restauração) dos NVAs possibilita a supressão em uma gama de frequências maior do que a que seria possível com o uso de um TMD. Em particular para o fenômeno de VIV em sistemas com parâmetro de massa reduzida $m^{*}$ próximo a 1 , a revisão bibliográfica conduzida na subseção 4.1.2 mostra que a frequência de oscilação do cilindro não permanecesse constante mesmo na faixa de velocidades reduzidas característica do lock-in.

Figura 37 - Valores máximos de deslocamento do cilindro como função do número de Reynolds.

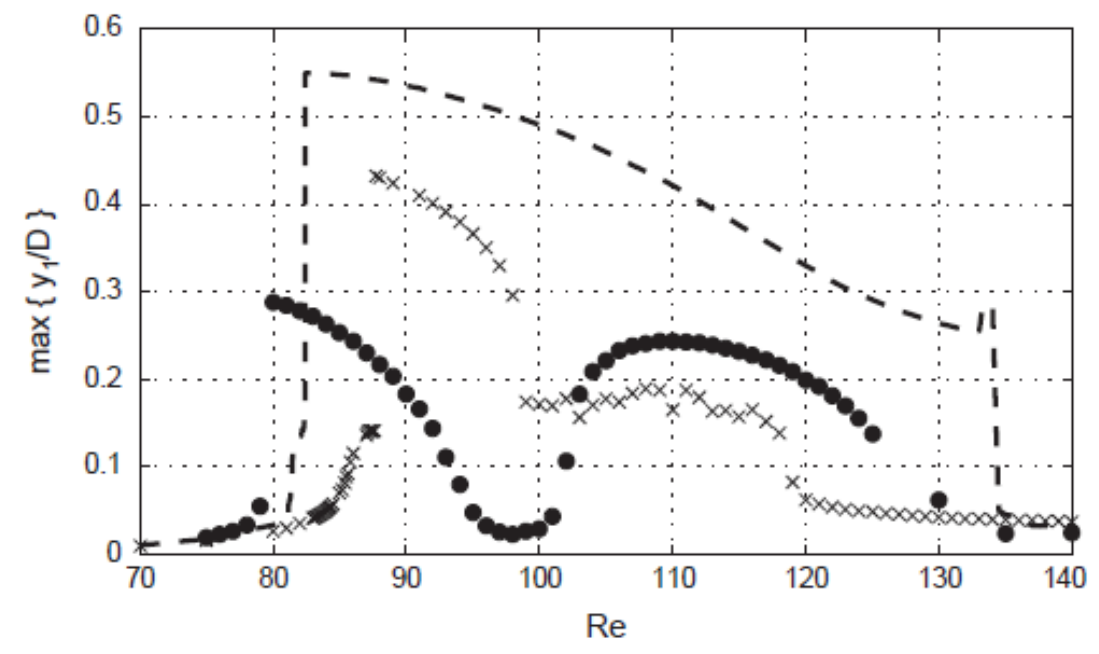

Fonte: Extraída de Tumkur et al. (2013).

11 Cumpre ressaltar que o usual no estudo do fenômeno de VIV é a normalização da velocidade de escoamento incidente na forma da velocidade reduzida. 
Mehmood, Nayfeh e Hajj (2014) também focam no problema de supressão passiva do fenômeno VIV-1gl via um NVA translativo e por meio de técnicas de DFC. No referido trabalho, os autores utilizam um valor de parâmetro de massa reduzida da ordem de 100, ainda maior do que aquele adotado em Tumkur et al. (2013) e focam no caso no qual a velocidade do escoamento incidente leva a um número de Reynolds igual a 106 com vistas ao estudo da influência das condições iniciais e da massa e do amortecimento do NVA na resposta do sistema hidro-elástico.

Em um primeiro momento e considerando apenas condições iniciais triviais, os autores estudam o efeito da massa do NVA variando-a entre $1 \%$ e $10 \%$ da massa da estrutura principal, ou seja, $0,1<\mu<0,10$ onde $\mu$ foi definido pelos autores como sendo a razão entre as massas do supressor e da estrutura principal. Como mostrado na Figura 38, as séries temporais de deslocamento do cilindro (devidamente adimensionalizadas pelo diâmetro) obtidas para $\mu=0,01$ e $\mu=0,02$ não apresentam modulação em amplitude. Tomando como valores de referência a amplitude de oscilação do cilindro para o caso sem o dispositivo supressor como 0,42 (resultado não exibido no presente texto), é possível notar de o NVA com massa $\mu=0,02$ acaba por reduzir a amplitude de oscilação da estrutura principal em cerca de $10 \%$.

Figura 38 - Séries temporais de deslocamento do cilindro e do NVA. Condições iniciais triviais. $R e=106$.

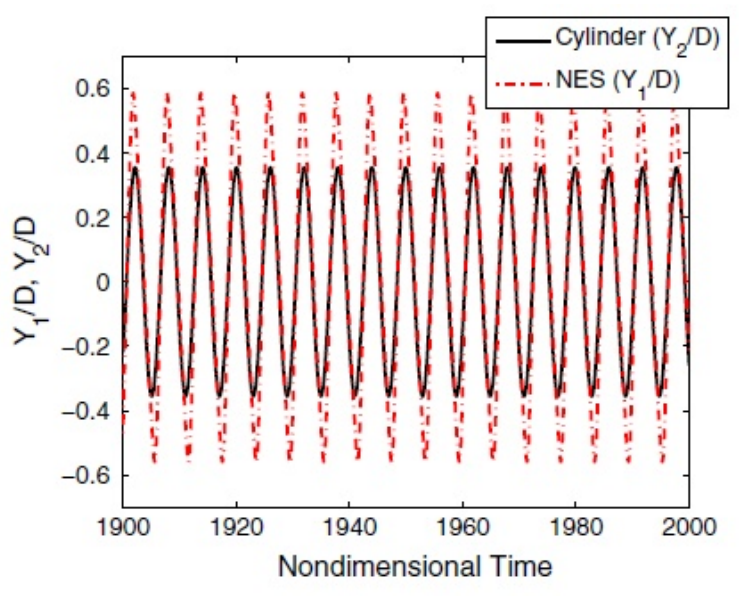

(a) $\mu=0,01$.

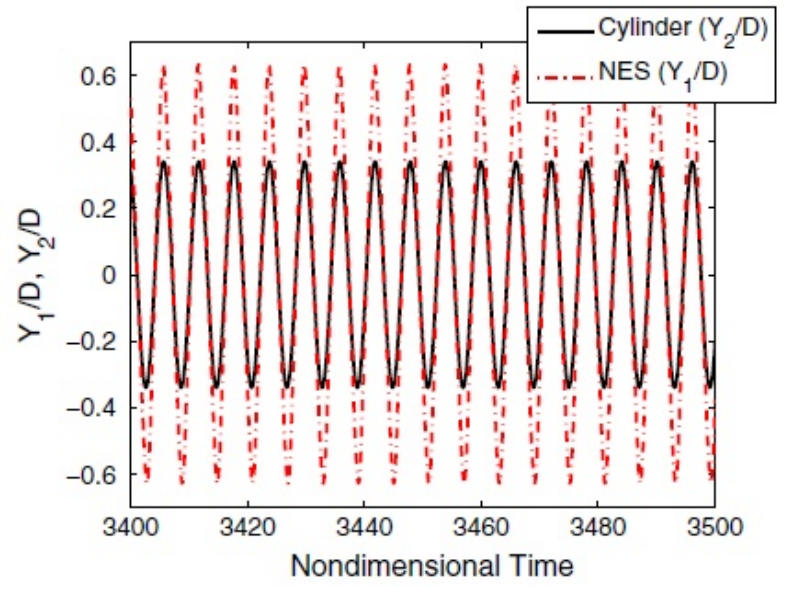

(b) $\mu=0,02$.

Fonte: Extraída de Mehmood, Nayfeh e Hajj (2014).

A Figura 39 também foi extraída de Mehmood, Nayfeh e Hajj (2014) e ilustra as séries temporais de deslocamento do cilindro e do NVA para $\mu=0,03$ e os demais parâmetros iguais àqueles empregados nas simulações mostradas na Figura 38. Como pode ser notado, o ligeiro aumento na massa do NVA promoveu mudanças quantitativas e qualitativas na resposta do cilindro, que deixou de ser caracterizada por uma amplitude constante para uma resposta com fortes modulações em amplitude. Note que, associado à 
mudança de caráter da resposta da estrutura principal, é possível identificar um importante ganho de capacidade de supressão do NVA, uma vez que o máximo deslocamento do cilindro não excede 0,12 .

Figura 39 - Séries temporais de deslocamento do cilindro e do NVA. Condições iniciais triviais e $\mu=0,03$. $R e=106$.

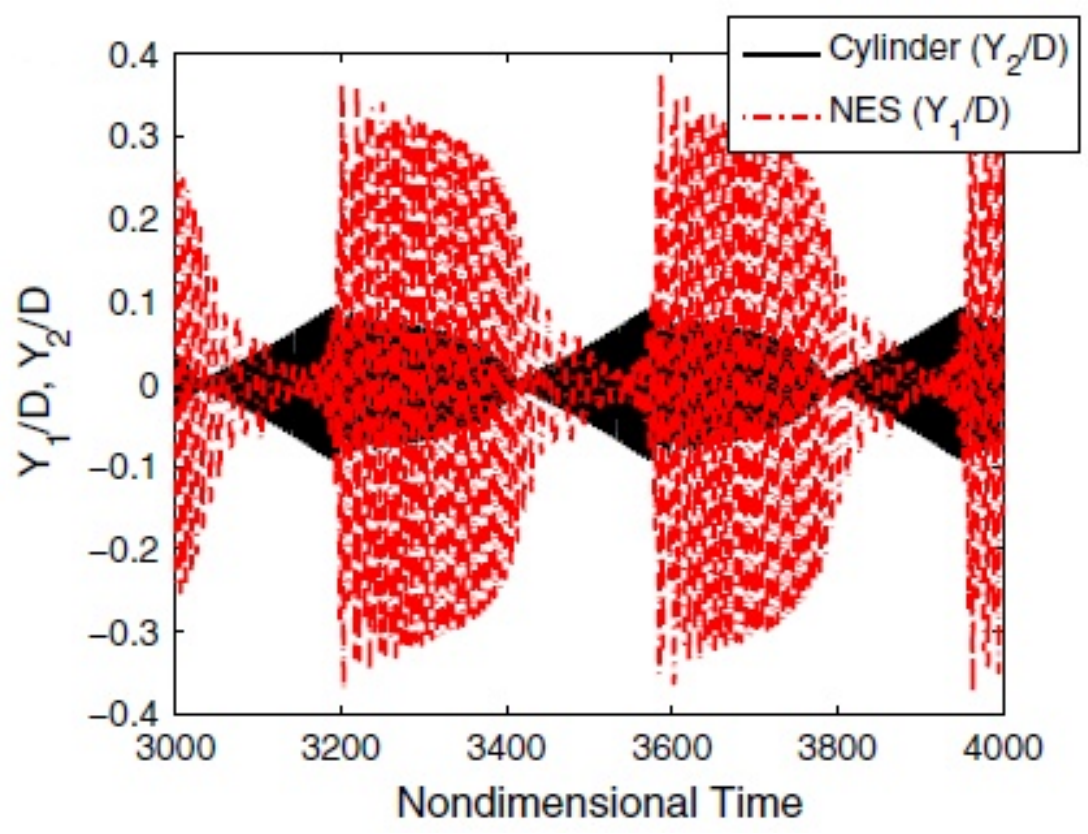

Fonte: Extraída de Mehmood, Nayfeh e Hajj (2014).

O último aspecto a ser relatado acerca do trabalho de Mehmood, Nayfeh e Hajj (2014) é a influência da condição inicial. Mantendo todas demais as condições iniciais triviais e variando apenas o deslocamento inicial do cilindro, os autores mostram que a resposta da estrutura principal pode ser caracterizada tanto por uma amplitude estacionária quanto por importantes modulações em amplitude semelhante àquela ilustrada na Figura 39. De fato, as condições inciais desempenham um papel importante na dinâmica de sistemas não-lineares, de sorte que o conceito de estabilidade global do sistema deve ser levado em conta.

Neste ponto, cabe tecer alguns comentários acerca de tópicos de pesquisa em dinâmica não-linear e que tem sido focos de estudos nas últimas décadas. Como mostram, por exemplo, Rega e Lenci (2015) e Thompson (2019), tem sido cada vez mais importantes o estudo $^{12}$ da resposta de sistemas não-lineares mediante variações não apenas nas condições iniciais mas também dos parâmetros do modelo matemático. Como pode ser visto nos capítulos 9 e 10, a supressão passiva dos fenômenos de excitação paramétrica e de VIE apresentam importantes erosões no plano de parâmetros de controle.

$12 \widehat{O}$ leitor lembra que o conceito clássico de estabilidade de Lyapunov é relacionado a perturbações infinitesimais nas condições iniciais de um sistema e que a estabilidade estrutural, por sua vez, é ligada a mudanças na topologia do espaço de fase decorrentes da variação de um parâmetro do modelo matemático. 
Retornando à revisão bibliográfica, Dai, Abdelkefi e Wang (2017) também empregam um NVA translativo como um supressor passivo para o fenômeno de VIV-1gl, porém com uma abordagem distinta dos trabalhos vistos até este ponto da revisão bibliográfica. Ao invés de utilizarem modelos matemáticos de maior hierarquia, Dai, Abdelkefi e Wang (2017) empregam um modelo de ordem reduzida baseado em um wake-oscillator como ferramenta de modelagem das forças hidrodinâmicas. Dentre os aspectos investigados pelos autores, destacam-se os efeitos da massa, rigidez e amortecimento do NVA na sua capacidade de supressão.

A Figura ${ }^{13} 40$ mostra a variação do máximo deslocamento do cilindro com a velocidade da correnteza incidente para um particular valor de rigidez do NVA e para alguns valores do parâmetro $\beta$, definido em Dai, Abdelkefi e Wang (2017) como sendo a relação entre a massa do NVA e a massa do cilindro. Como mostrado nessa figura, o aumento na massa do supressor é favorável à supressão de vibrações.

Figura 40 - Máximo deslocamento adimensional do cilindro como função da velocidade da correnteza incidente, parametrizado na massa do supressor.

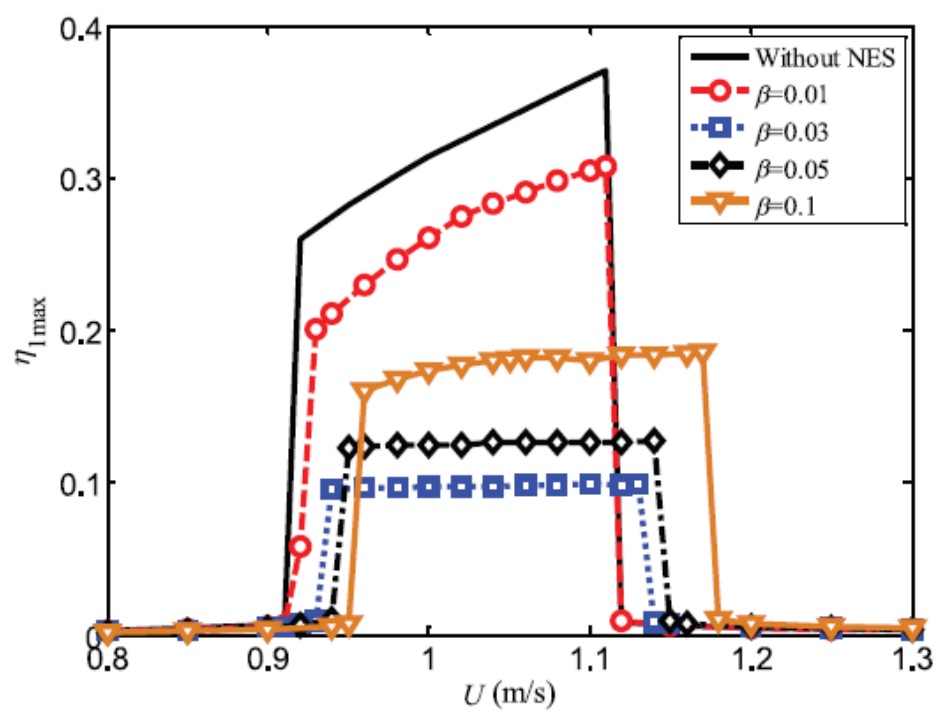

Fonte: Extraída de Dai, Abdelkefi e Wang (2017).

Dai, Abdelkefi e Wang (2017) ainda investigam o efeito da rigidez do NVA na curva de máximo deslocamento do cilindro. Em termos adimensionais, os autores consideram como $\gamma^{*}$ uma normalização da rigidez do supressor com relação ao diâmetro e à rigidez associada ao cilindro. Como ilustrado na Figura 41, o aumento na rigidez do supressor promove um decréscimo na máxima resposta do cilindro.

O recente trabalho de Dongyang et al. (2018) discute a eficiência de um NVA translativo como supressor do fenômeno de VIV nas condições onde o cilindro é só possui

13 O leitor nota que, ao contrário do que é usual na análise do fenômeno de VIV, a velocidade da correnteza é apresentada em sua forma dimensional em detrimento do uso da velocidade reduzida $U_{r}$. 
Figura 41 - Máximo deslocamento adimensional do cilindro como função da velocidade da correnteza incidente, parametrizado na rigidez do supressor.

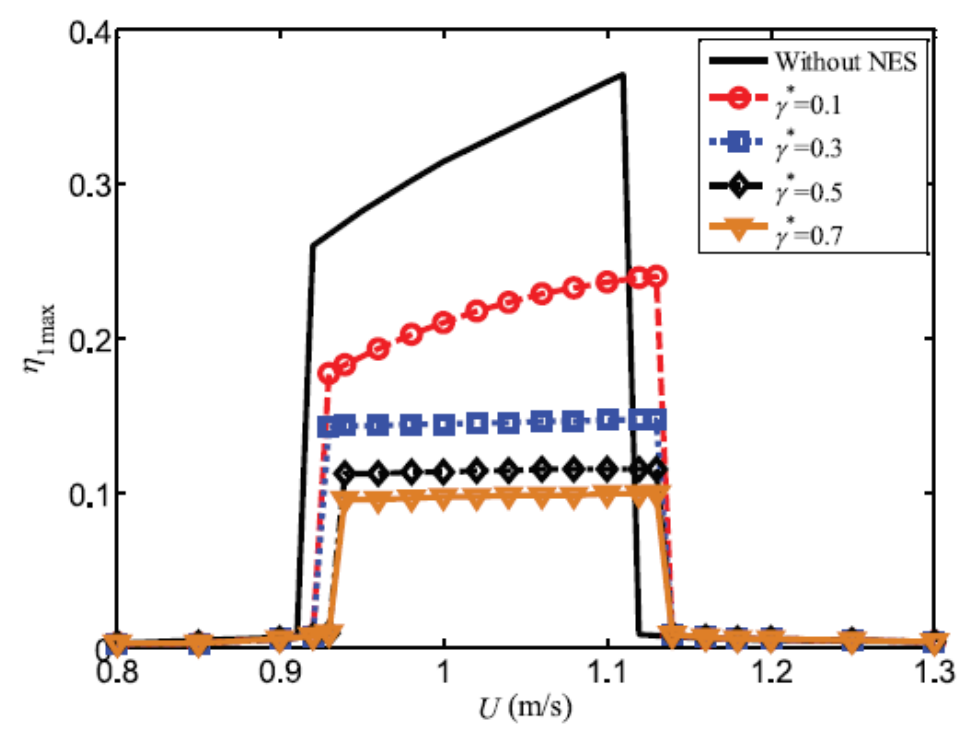

Fonte: Extraída de Dai, Abdelkefi e Wang (2017).

liberdade de oscilação na direção cross-wise e na condição onde ele oscila nas duas direções do plano horizontal. Além das condições VIV-1gl e VIV-2gl, os autores ainda estudam a mitigação de vibrações quando existem dois cilindros alinhados e montados em apoios elásticos bi-direcionais. Para a condição VIV-1gl, os autores lançam mão tanto de uma abordagem via wake-oscillator quanto via DFC para o cálculo do carregamento decorrente da interação fluido-estrutura. Já para as demais configurações estudadas, apenas técnicas de DFC são adotadas.

A exemplo do que já fora observado por Dai, Abdelkefi e Wang (2017) para a condição VIV-1gl, Dongyang et al. (2018) mostram que o aumento da massa do supressor acaba por aumentar sua capacidade de mitigação das oscilações da estrutura principal, além de deslocar a faixa de lock-in para valores de velocidade reduzida superiores, como mostrado na Figura 42(a). Embora o autor não explicite, infere-se que o parâmetro de massa $m^{*}$ seja substancialmente maior do que aquele típico da engenharia oceânica, uma vez que o máximo deslocamento adimensional do cilindro é encontrado como inferior a 0,5. Note, ainda, que o valor do parâmetro adimensional da massa do NVA é $\beta=0,50$, indicando um supressor com massa igual à metade da massa da estrutura a ser controlada.

No tocante à configuração VIV-2gl investigada em Dongyang et al. (2018), a Figura 42(b) revela que a máxima amplitude de oscilação do cilindro é próxima a $0,55 D$, próxima àquela observada para a condição VIV1-gl quando o carregamento hidrodinâmico é calculado via DFC. Esse resultado reforça a conjectura de que o parâmetro de massa reduzida $m^{*}$ empregado pelos autores é maior do que aquele típico da engenharia oceânica ${ }^{14}$.

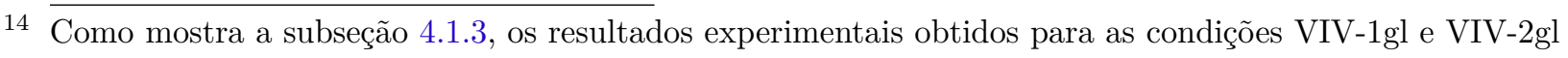


Figura 42 - Amplitudes característica de oscilação do cilindro como função da velocidade reduzida.

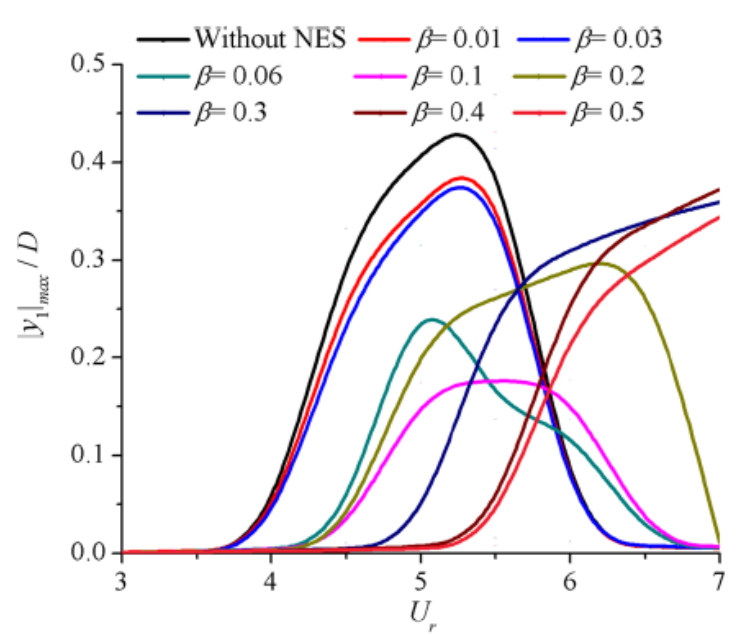

(a) VIV-1gl - wake-oscillator.

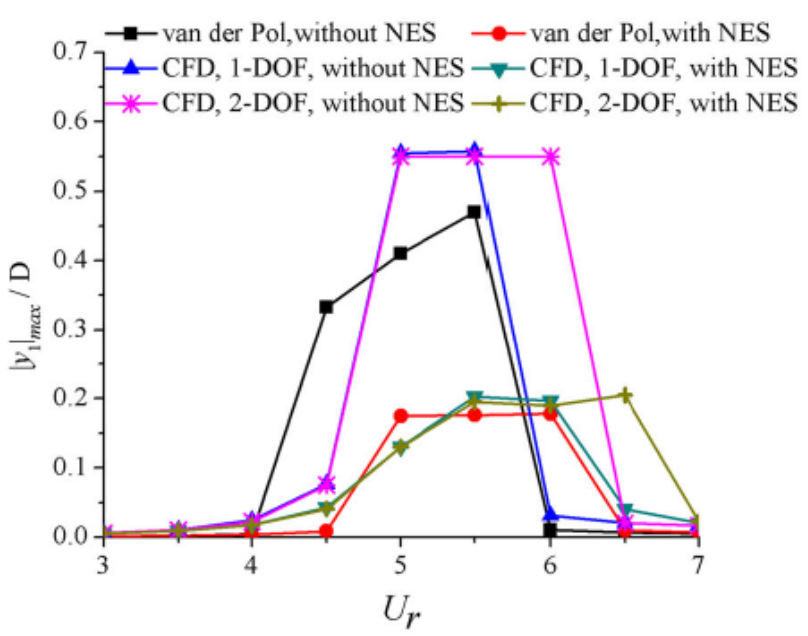

(b) VIV-1gl e VIV-2gl.

Fonte: Extraída de Dongyang et al. (2018).

Até este ponto da revisão bibliográfica, os estudos envolvendo o uso de NVAs como supressores do fenômeno de VIV envolveram apenas o NVA translativo. Agora, discutem-se alguns trabalhos que focam no uso de um NVA rotativo. O trabalho de Blanchard et al. (2016) foca na condição VIV-1gl e emprega ferramentas de DFC para o cálculo das forças hidrodinâmicas para um único valor de número de Reynolds, a saber, $R e=100$.

A Figura 43 mostra exemplos de séries temporais obtidas por Blanchard et al. (2016). A análise dessa figura revela que a resposta do cilindro $Y / D$ é caracterizada por intensas modulações em amplitude. Mais ainda, durante os regimes de diminuição da resposta do cilindro, o supressor rotaciona com velocidade angular praticamente constante e igual a 1, configurando uma ressonância $1: 1$ na qual o cilindro oscila com frequência igual à velocidade angular do supressor.

Complementando os resultados numéricos, Blanchard et al. (2016) trazem, ainda, um modelo de ordem reduzida para a análise do problema de supressão. Esse modelo considerada que a força de sustentação é dada por uma amplitude constante no tempo multiplicada por uma função harmônica monocromática e que a posição angular do supressor é dada na forma $\theta(\tau)=\omega_{r} \tau+\psi(\tau)$, sendo $\omega_{r}$ uma velocidade de rotação característica e idêntica à frequência de oscilação do cilindro e $\psi(\tau)$ uma fase lentamente variável no tempo. A partir da aplicação conjunta dos métodos de complexificação-média ${ }^{15}$ (C-X) e das múltiplas escalas, os autores avaliam a SIM do modelo de ordem reduzida, comparando-a com resultados obtidos a partir da integração numérica do modelo de maior hierarquia baseado em DFC. 
Figura 43 - Séries temporais de deslocamento do cilindro e do supressor, de velocidade angular do supressor e dos coeficientes de arrasto e sustentação.
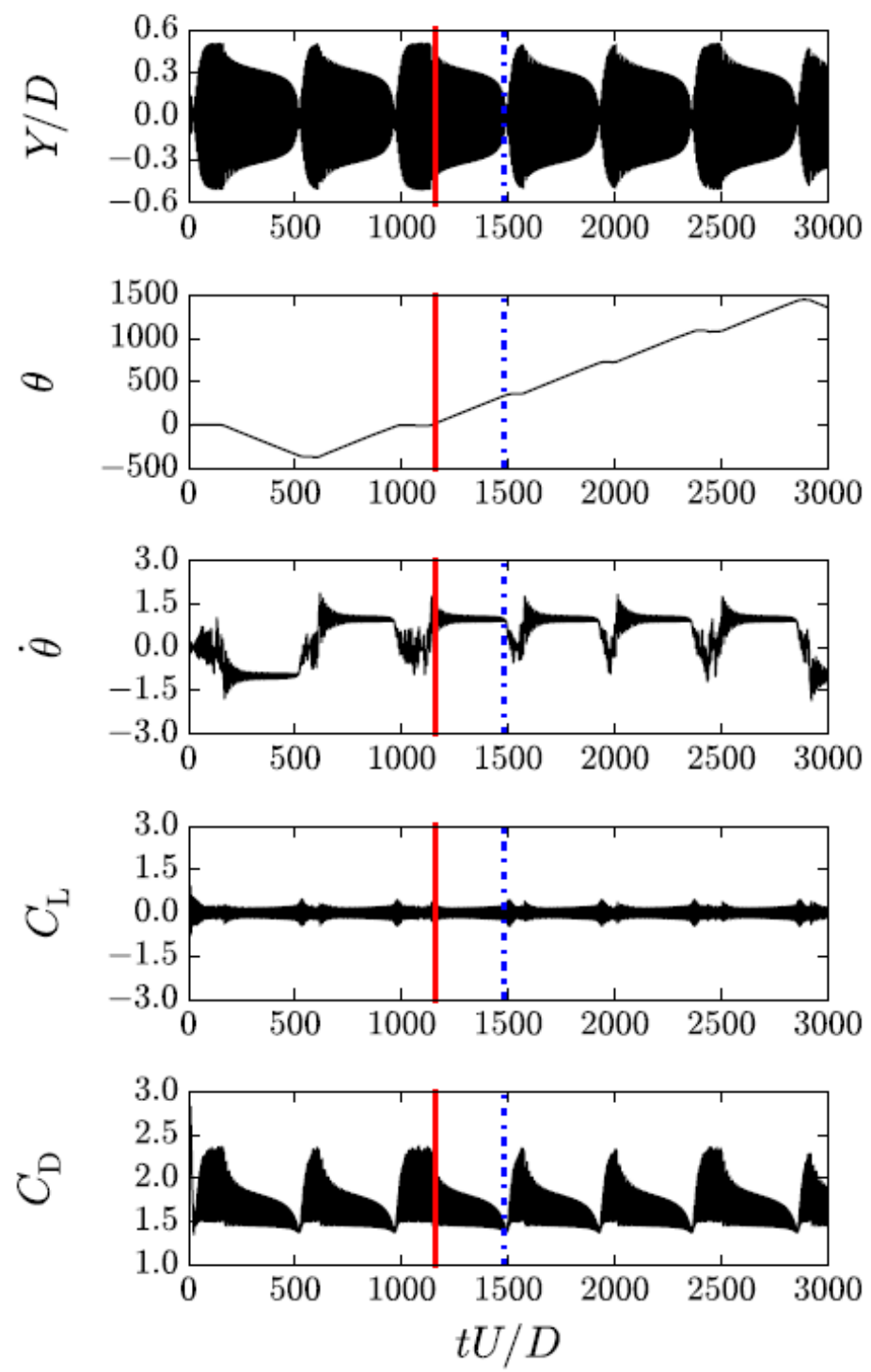

Fonte: Extraída de Blanchard et al. (2016).

Como ilustrado na Figura 44, o mecanismo de supressão se dá na captura em uma ressonância 1 : 1 representada pela SIM. Como o sistema não encontra um ponto fixo na SIM, a sua amplitude (representada por $|N|$ ) vai diminuindo até que ocorra um escape da SIM. Os autores associam regimes de respostas caóticas ${ }^{16}$ ao escape dessa variedade. Além dessa discussão, os autores indicam que o escape da SIM está associado à baixa energia cinética do cilindro ao final do passo de supressão, de sorte que o NVA não consegue mais dissipar energia. Após o regime caótico supra-citado, o fenômeno de VIV confere mais energia ao cilindro, o que faz com que sua amplitude de vibração vá gradativamente sendo aumentada até uma condição onde a captura na ressonância $1: 1$ (e, por consequência, na

16 Convém ressaltar que Blanchard et al. (2016) utilizam a nomenclatura "caótica", porém sem qualquer menção à sensibilidade às condições iniciais. 
SIM) seja possível, dando origem a um novo ciclo.

Figura 44 - Slow invariant manifold e a trajetória do cilindro obtida a partir do modelo de maior hierarquia. $\delta-\gamma$ representa a diferença entre a fase de resposta do cilindro e do supressor.

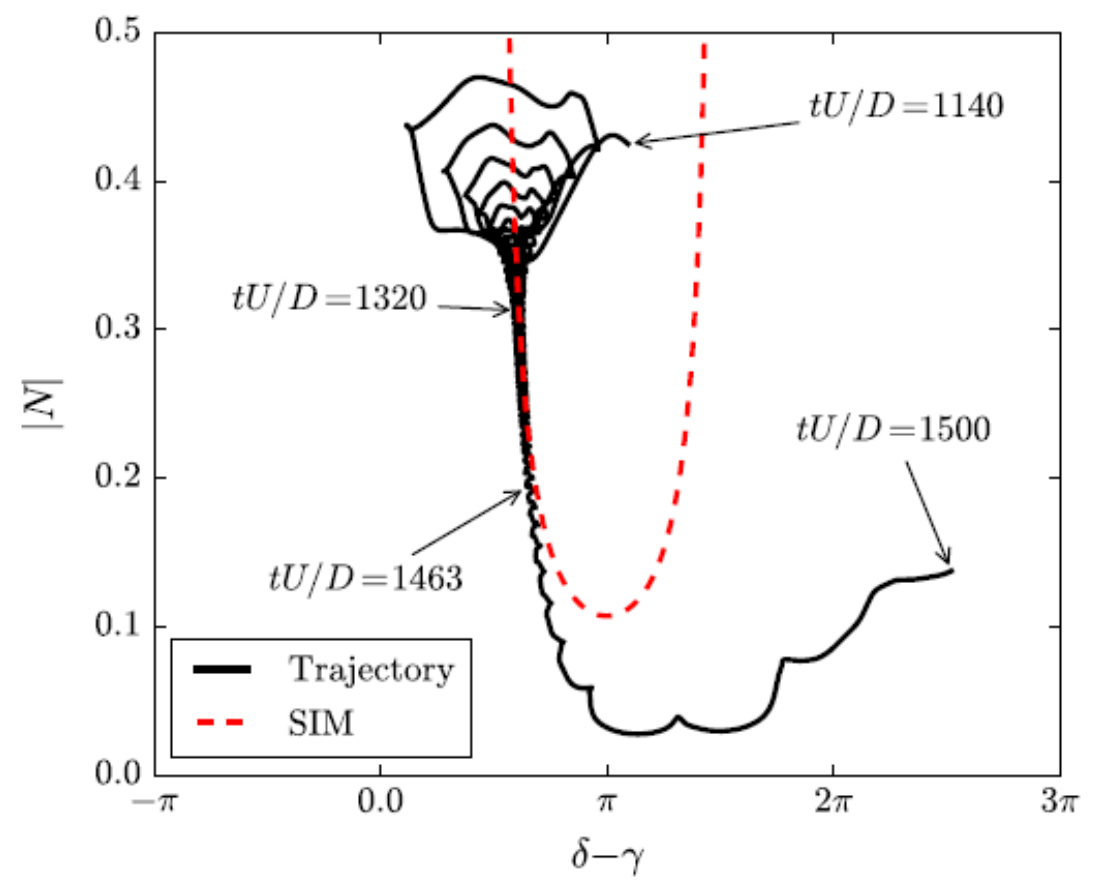

Fonte: Extraída de Blanchard et al. (2016).

O trabalho de Tumkur et al. (2017) também aborda o uso de um NVA rotativo como supressor do fenômeno VIV-1gl via abordagem baseada em técnicas de DFC. Embora Blanchard et al. (2016) apresentem alguns resultados relativos à esteira vorticosa, Tumkur et al. (2017) dão maior foco a esse aspecto. Por meio da avaliação dos campos de vorticidade, os autores demonstram que os regimes de resposta caótica decorrentes do escape da SIM estão associados a um alongamento da esteira de vórtices à jusante do cilindro.

A Figura 45 ilustra a série temporal de deslocamento do cilindro em conjunto com alguns campos instantâneos de vorticidade. De fato, a Figura 45(b) mostra que, no instante onde a resposta do cilindro é de pequena amplitude (associada ao regime caótico logo após o escape da SIM), a esteira de vórtices e é significativamente mais alongada do que aquela observada em um instante de tempo onde a amplitude de resposta do cilindro é elevada (ver Figura 45(c)) ou, ainda, nos casos de um cilindro fixo ou sujeito ao fenômeno de VIV e sem o NVA; Figuras 45(d) e 45(e) respectivamente.

O último aspecto a ser mencionado acerca do trabalho de Tumkur et al. (2017) é a apresentação de um segundo regime de resposta para o sistema. Ao contrário do que já fora observado por Blanchard et al. (2016) e exibido na Figura 44, o NVA rotativo pode, dependendo de seus parâmetros de massa, rigidez e amortecimento, gerar respostas do 
Figura 45 - Exemplos de resposta do cilindro e da esteira para uma particular configuração de NVA rotativo. $R e=100$.

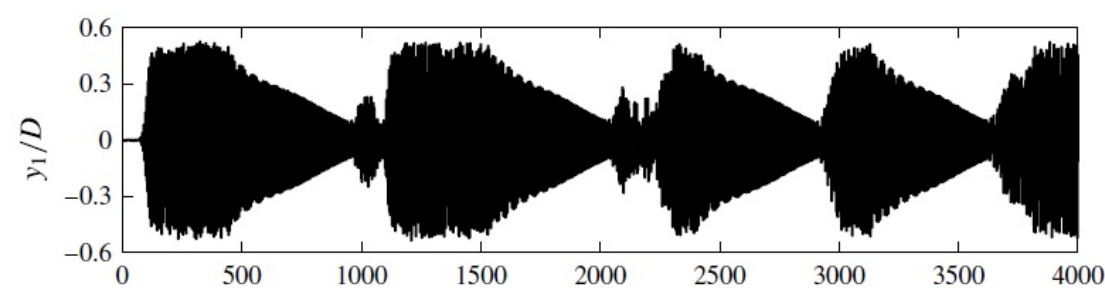

(a) Série temporal de deslocamento do cilindro.

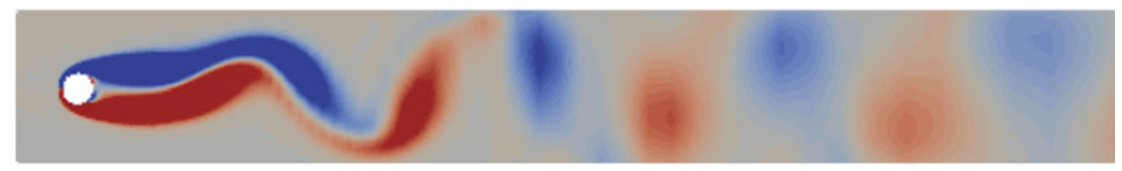

(b) Campo de vorticidade - tempo adimensional 910,25.

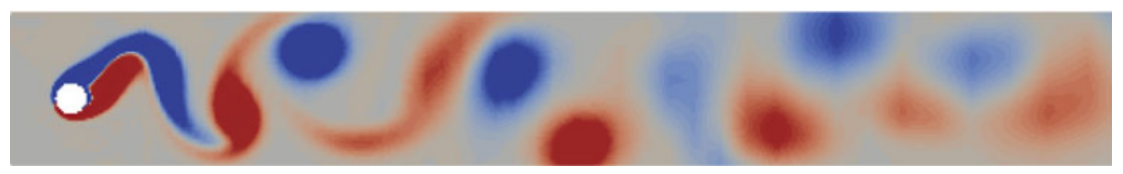

(c) Campo de vorticidade - tempo adimensional 1181,375.

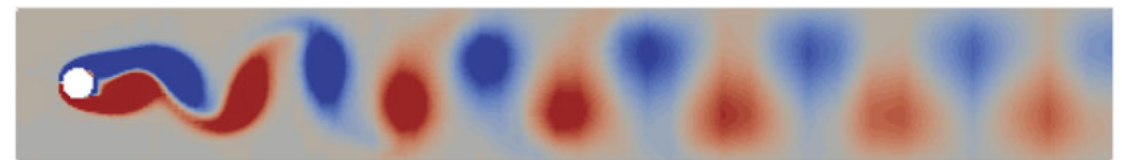

(d) Cilindro fixo.

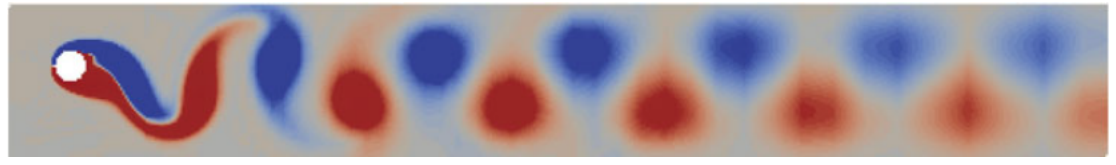

(e) Cilindro sujeito ao fenômeno VIV-1gl e sem NVA.

Fonte: Extraída de Tumkur et al. (2017).

cilindro e do supressor caracterizadas por oscilações com amplitude constante. A Figura 46 ilustra esse último tipo de resposta.

Finalizada a discussão dos trabalhos que focam no uso de NVAs como supressores do fenômeno de VIV, a presente revisão bibliográfica passa a focar na mitigação do galloping. Embora tanto o VIV quanto o galloping pertençam a uma mesma classe mais abrangente de problemas (a saber, VIE), a supressão passiva do galloping via NVA é significativamente menos explorada na literatura do que a do VIV.

Dai, Abdelkefi e Wang (2016) focam na análise numérica do problema de supressão passiva de um prisma de seção transversal quadrada e dotado de um NVA translativo. Nesse trabalho, os autores empregam a hipótese quase-estática já discutida na seção 4.2 como metodologia para modelagem dos esforços decorrentes da interação fluido-estrutura.

Segundo o estudo de caso conduzido em Dai, Abdelkefi e Wang (2016) a partir de 
Figura 46 - Resposta limitada em amplitude obtida para um determinado conjunto de parâmetros do NVA rotativo.
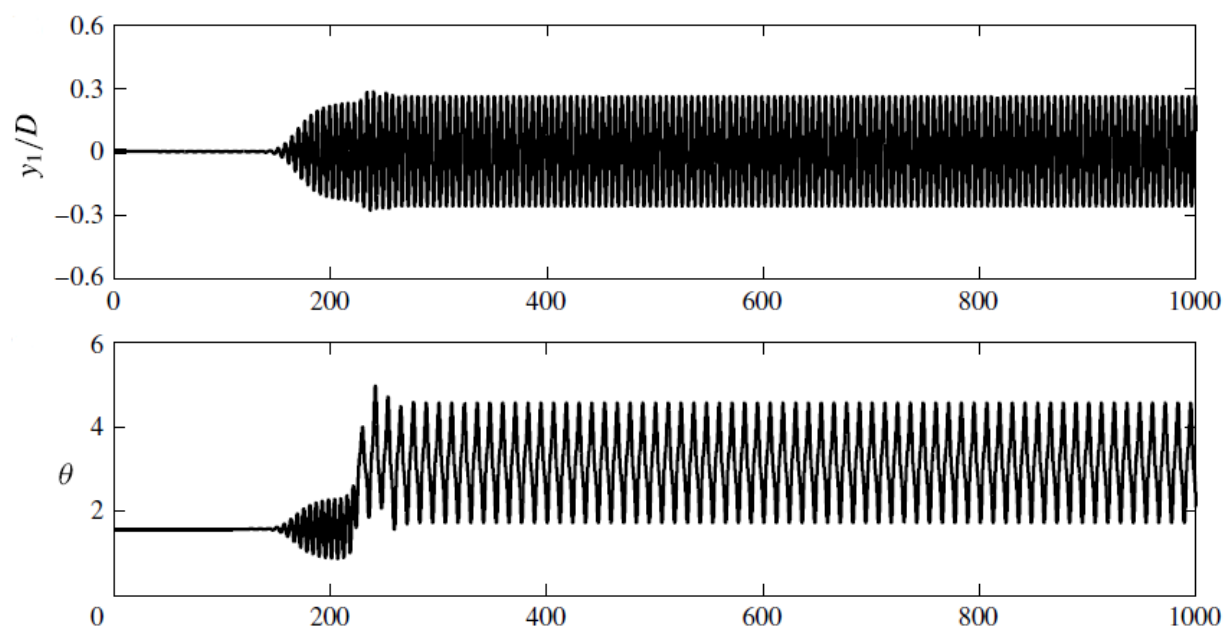

Fonte: Extraída de Tumkur et al. (2017).

uma análise do problema linearizado, os autores mostram que a presença do NVA é capaz de aumentar a velocidade crítica do escoamento incidente a partir do qual o galloping existe. Tal resultado é mostrado na Figura 47, onde $\beta$ é a razão entre a massa do NVA e a massa do prisma e $\xi_{n e s}^{*}$ é o quociente entre as constantes de amortecimento do NVA e do prisma. Nota-se que, na ausência do supressor, a velocidade crítica para a existência do galloping é próxima a $1,7 \mathrm{~m} / \mathrm{s}$, e atinge $1,91 \mathrm{~m} / \mathrm{s}$ para o caso onde o prisma é dotado de um supressor caracterizado por $\xi_{\text {nes }}^{*}=0,1$ e $\beta=0,01$.

Dai, Abdelkefi e Wang (2016) apresentam, ainda, curvas de amplitude de resposta pós-crítica como função da velocidade do escoamento incidente para alguns valores selecionados ${ }^{17}$ de parâmetros do NVA. Segundo os resultados ilustrados na Figura 48, o NVA acaba por aumentar a velocidade crítica para o fenômeno de galloping (fato já obtido a partir da análise do problema linearizado), além de promover uma importante redução das amplitudes pós-críticas de oscilação do prisma. Note que, para $U=1,9 \mathrm{~m} / \mathrm{s}$, a presença do NVA é capaz de reduzir em cerca de $50 \%$ as respostas da estrutura a ser controlada.

Assim como para o fenômeno de galloping, o número de trabalhos que focam no uso de NVAs como supressores passivos para oscilações decorrentes da excitação paramétrica é significativamente menor do que aqueles relacionados a outros fenômenos. A menos do conhecimento do autor do presente texto, o único trabalho a focar na supressão passiva de oscilações oriundas da excitação paramétrica é apresentado em Shiroky e Gendelman (2008).

Nessa referência, a excitação paramétrica possui frequência próxima daquela que

$17 \overline{\text { Dai, Abdelkefi e Wang (2016) adotam } k_{n e s}^{*}}$ como sendo a normalização da rigidez do NVA com relação ao diâmetro e a rigidez do prisma. 
Figura 47 - Velocidade crítica para o fenômeno de galloping como função do amortecimento e da massa do NVA.

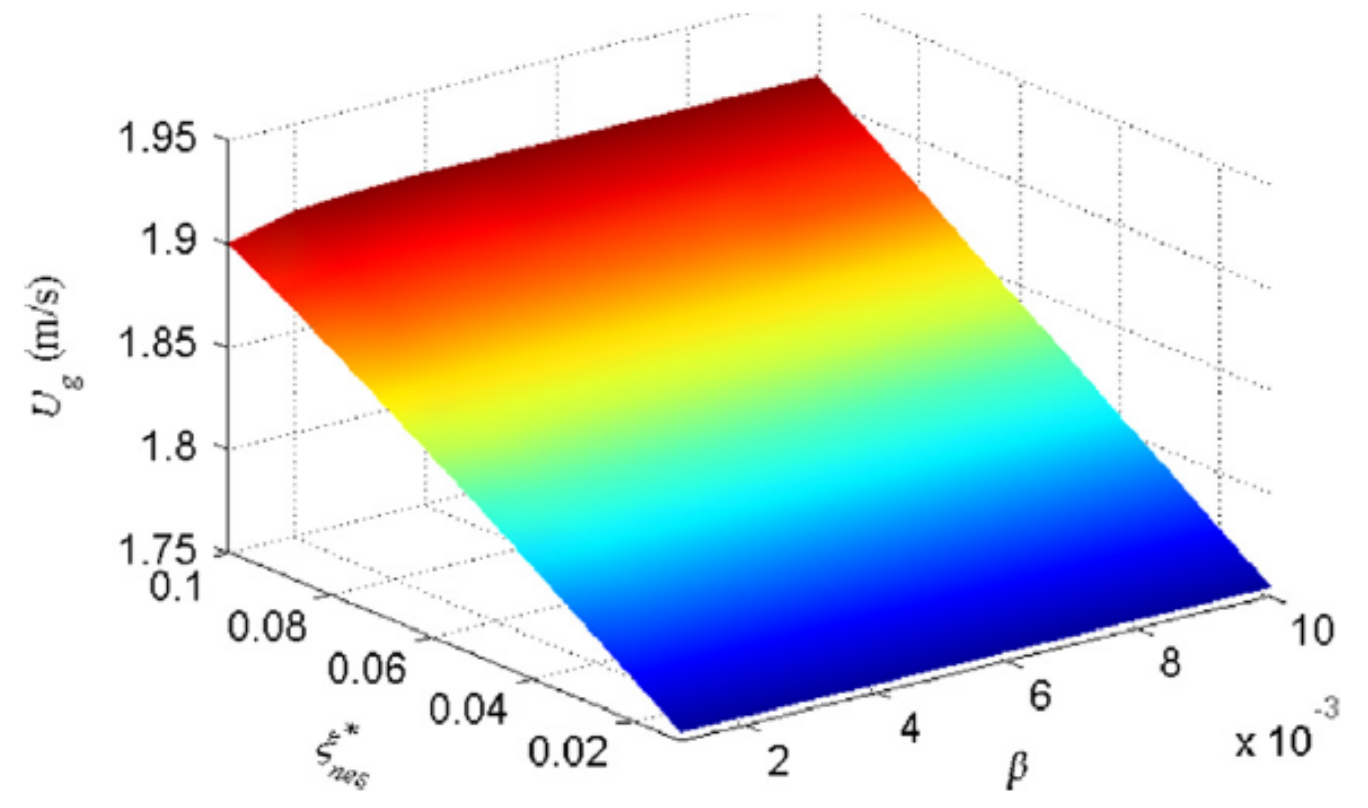

Fonte: Extraída de Dai, Abdelkefi e Wang (2016).

caracteriza a instabilidade paramétrica principal (ou seja, aquela onde a frequência de variação da rigidez é próxima do dobro da frequência natural não amortecida; ver seção 3.1) os autores adotam como supressor um NVA translativo e focam em uma abordagem analítica considerando o método $\mathrm{C}-\mathrm{X}$ em conjunto com o método das múltiplas escalas.

Por meio dos métodos analíticos já citados e também da integração numérica das equações de movimento, Shiroky e Gendelman (2008) relatam a existência de diversas tipos de resposta do NVA como funções dos parâmetros que o definem. Algumas dessas respostas são ilustradas na Figura 49 e incluem oscilações ${ }^{18}$ com amplitude constante (Figura 49(a)), supressão completa (Figura 49(b)), resposta ilimitada (Figura 49(c)) e resposta com amplitude modulada (Figura 49(d)).

O último aspecto do trabalho de Shiroky e Gendelman (2008) a ser aqui descrito é a sensibilidade com relação às condições iniciais. Como mostrado na Figura 50, existem diferenças tanto quantitativas quanto qualitativas na resposta do supressor, indicando a existência de mais do que um atrator.

\subsection{Identificação de lacunas de conhecimento}

Segundo a revisão bibliográfica conduzida neste capítulo, algumas lacunas de conhecimento no tema foram identificadas e estão abaixo enumeradas:

18 Ao ler o capítulo 9, o leitor percebe que essas mesmas respostas foram obtidas quando do uso de um NVA rotativo para supressão do problema de excitação paramétrica. 
Figura 48 - Máximo deslocamento adimensional do prisma como função da velocidade do escoamento incidente. $\beta=0,005, \xi_{\text {nes }}=0,05$ e $k_{\text {nes }}^{*}=0,02$.

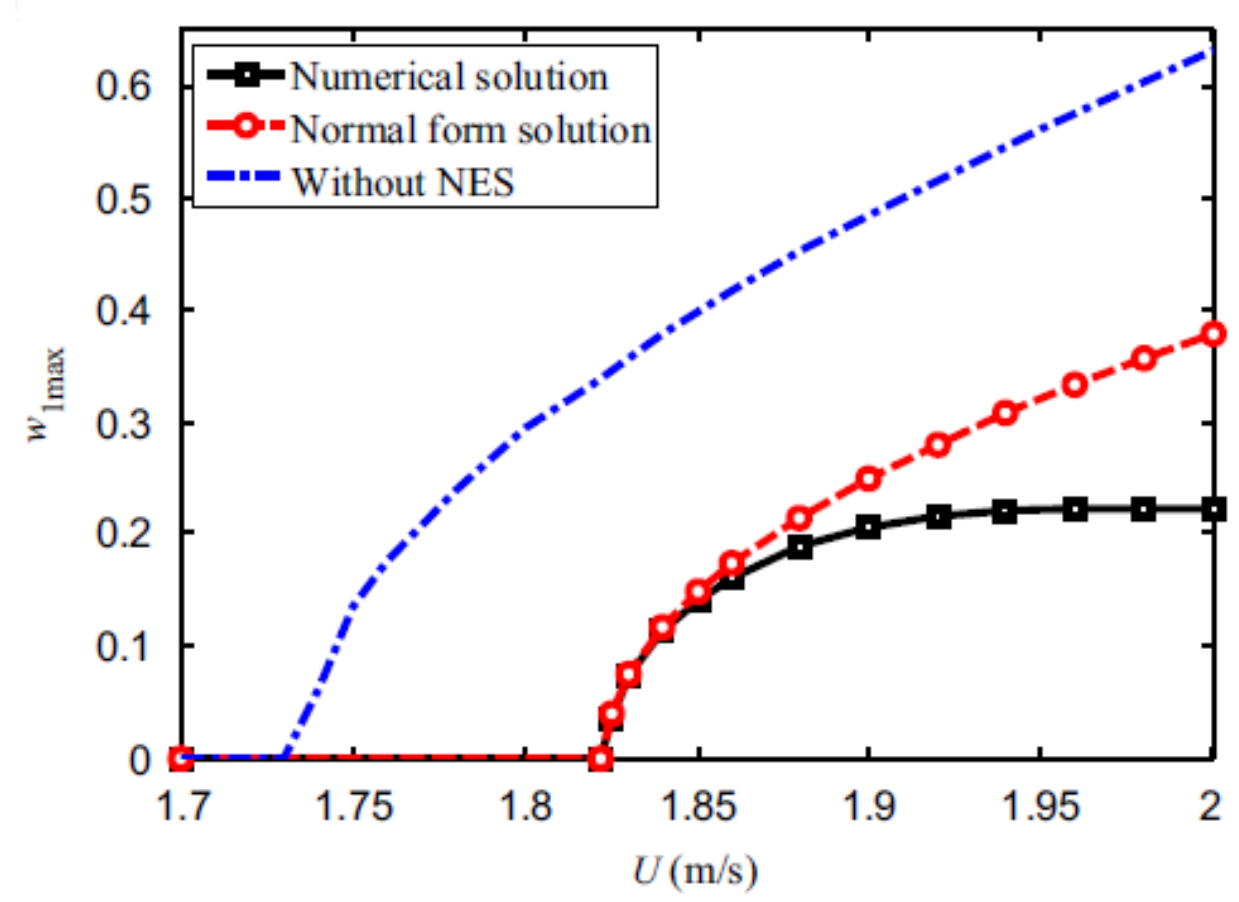

Fonte: Extraída de Dai, Abdelkefi e Wang (2016).

1. Ausência de dados experimentais de supressão passiva por meio de NVAs para os fenômenos de VIV, galloping e excitação paramétrica;

2. Ausência de resultados de supressão passiva do fenômeno VIV-2gl utilizando um NVA rotativo;

3. Reduzido número de trabalhos que foquem no estudo sistemático da influência dos parâmetros que definem o NVA rotativo nas supressão dos fenômenos de VIV, galloping e excitação paramétrica;

O presente texto foca na apresentação de contribuições nos itens 2 e 3 acima numerados. O leitor que buscar informações sobre a capacidade de supressão de oscilações decorrentes do problema de excitação paramétrica deve consultar o capítulo 9 . O referido capítulo mostra, por meio de estudos numéricos, que o NVA rotativo é bastante eficaz na mitigação de oscilações decorrentes desse problema.

No tocante à análise da supressão passiva do fenômeno de VIV, foco é dado à modelagem dos carregamentos por meio dos modelos de ordem reduzida baseados no conceito de wake-oscillator. Essa abordagem, além de ser menos explorada na literatura do que aquela baseada em técnicas de DFC, permite a análise de um número maior de 
Figura 49 - Séries temporais de deslocamento do NVA com relação à estrutura principal, obtidas a partir de mudanças nos parâmetros que o definem.

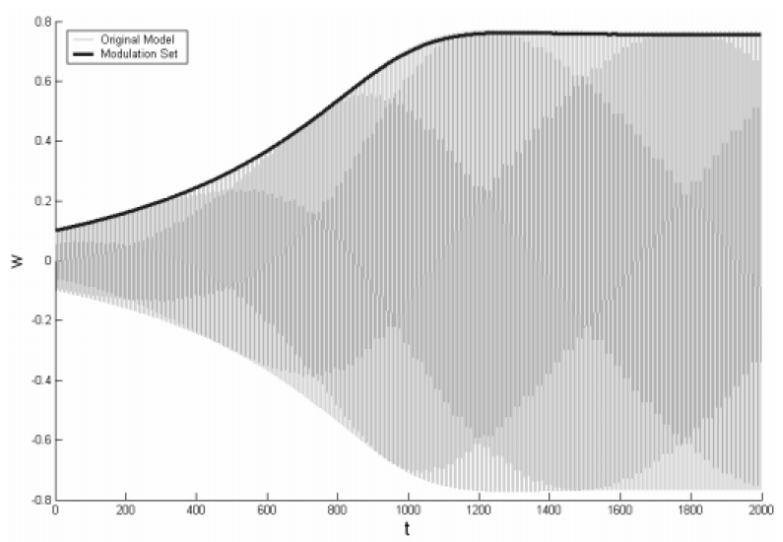

(a) Resposta com amplitude constante.

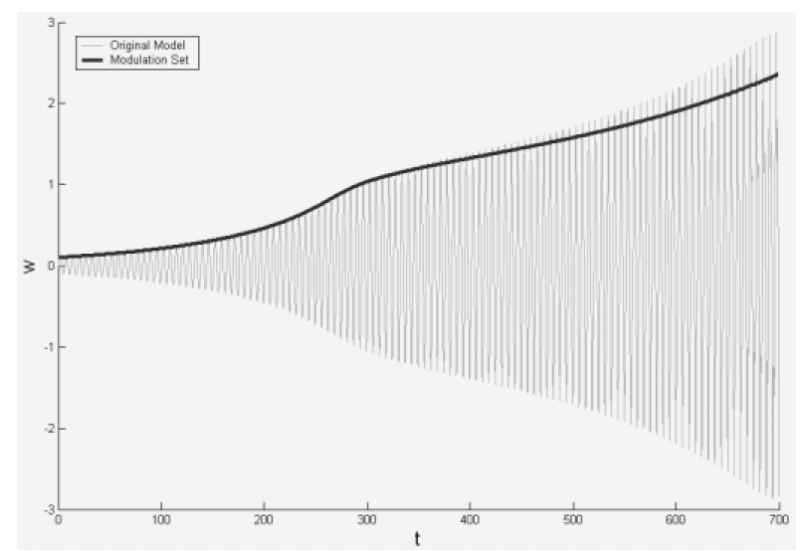

(c) Resposta ilimitada.

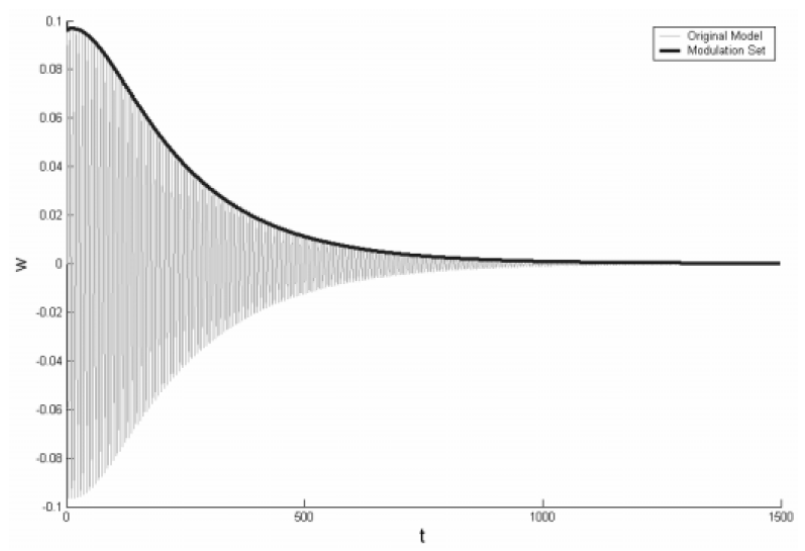

(b) Decaimento.

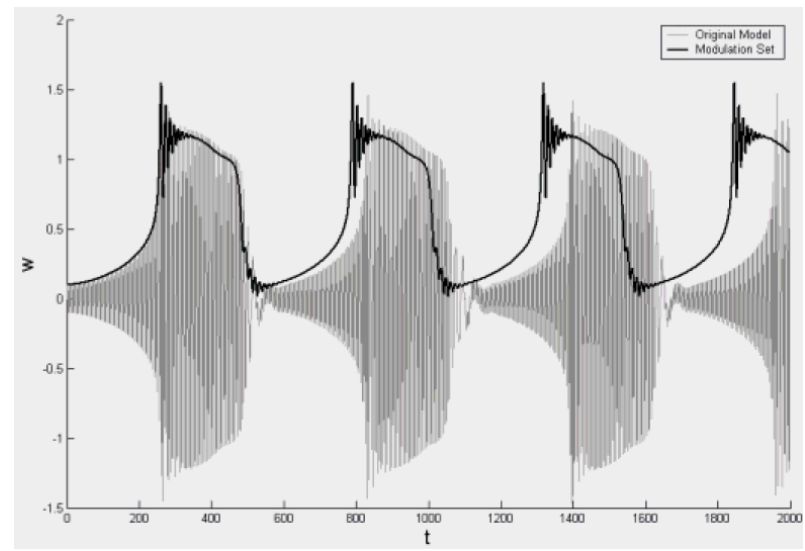

(d) Resposta modulada em amplitude.

Fonte: Extraída de Shiroky e Gendelman (2008).

condições em menos tempo, sendo interessante para a condução de estudos de sensibilidade com relação aos parâmetros que definem o NVA rotativo. O leitor interessado no uso de um NVA rotativo como supressor para o fenômeno de VIV é convidado à leitura da seção 10.1 .

Considerando a aplicação relativa à supressão passiva do fenômeno de galloping por meio de um NVA rotativo, a seção 10.2 traz uma série de estudos numéricos que também focam nos efeitos da variação dos parâmetros que definem o supressor na sua capacidade de supressão do referido fenômeno em um prisma de seção quadrada montado em base elástica. Cabe aqui adiantar que os resultados numéricos indicam que o NVA rotativo possui alta capacidade de supressão do galloping, diminuindo as respostas oscilatórias em até $50 \%$ quando comparadas ao caso onde o prisma não é dotado de qualquer dispositivo de supressão. 
Figura 50 - Séries temporais de deslocamento do NVA com relação à estrutura principal, obtidas a partir de mudanças nas suas condições iniciais.

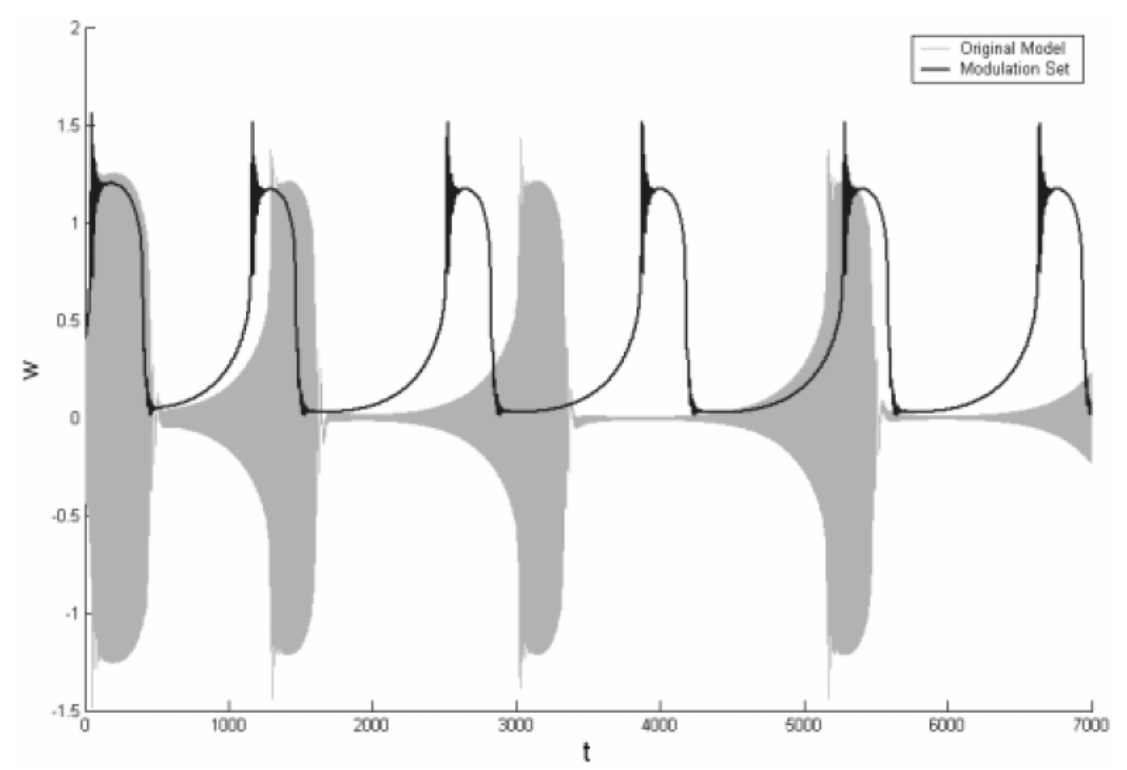

(a) Respostas obtidas a partir de um primeiro conjunto de condições iniciais.

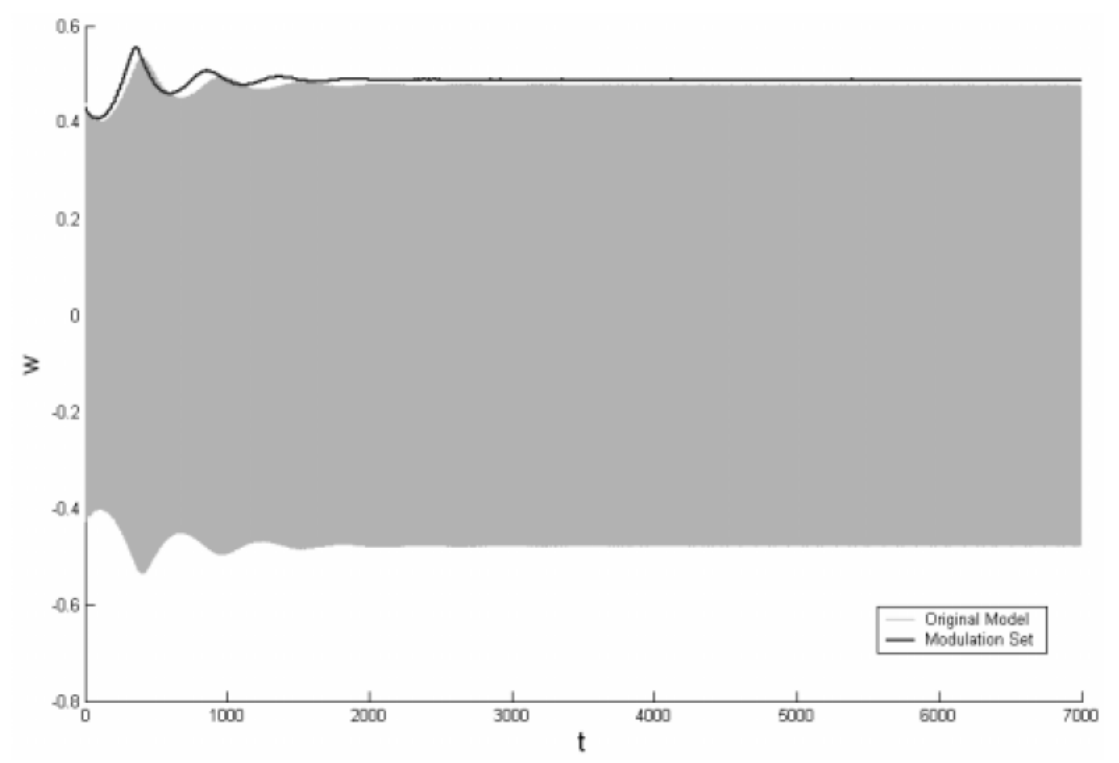

(b) Respostas obtidas a partir de um segundo conjunto de condições iniciais.

Fonte: Extraída de Shiroky e Gendelman (2008). 


\section{Aproveitamento de energia a partir de vi- brações induzidas pelo escoamento}

A busca por fontes renováveis de energia é um importante desafio científico e tecnológico a ser suplantado no século XXI. Nesse sentido, diversas fontes de energia como, por exemplo, a eólica tem ganho destaque com a construção de fazendas de turbinas eólicas em terra (onshore), no oceano (turbinas offshore) ou mesmo montadas sobre plataformas flutuantes posicionadas em águas profundas. A energia eólica tem como foco a obtenção de grandes potências elétricas (da ordem de kW até MW).

Existe, porém, uma série de estudos que visam a obtenção de sistemas de menor porte capazes de gerar energia elétrica para aplicações de baixas potências como, por exemplo, atender a pequenos sensores. Uma forma de obter energia elétrica visando essa aplicação é induzir respostas estruturais oscilatórias para, então, transformar parte da energia mecânica em energia elétrica. Além de energia elétrica, outras formas de energia como, por exemplo, a energia gravitacional também podem ser perseguidas.

Essa linha de pesquisa é denominada na literatura como aproveitamento ou coleta de energia ${ }^{1}$ e contempla uma grande gama de fenômenos dinâmicos. As formas de conversão eletromecânica de energia podem envolver efeitos gravitacionais, eletromagnéticos ou piezoelétricos. Em particular, essa última modalidade de conversão eletromecânica tem sido objeto de sistemáticos estudos e em problemas diversos como, por exemplo, vibração de barras dotadas de lâminas piezoelétricas (ver, por exemplo, Erturk e Inman (2008, 2009) e de Paula, Inman e Savi (2015)). O leitor interessado em uma ampla discussão acerca da coleta de energia considerando o efeito piezoelétrico é direcionado ao livro de Erturk e Inman (2011).

Embora bastante abrangente, esse tema é tratado no âmbito do presente texto apenas no contexto de aproveitamento de energia a partir de fenômenos de VIE. A seção 6.1 apresenta um breve histórico recente de contribuições no assunto. Já a seção 6.2 traz algumas lacunas de conhecimento identificadas ao término da revisão bibliográfica.

\subsection{Um breve histórico de contribuições recentes}

Como visto no capítulo 4, as VIEs geralmente promovem respostas auto-excitadas e auto-limitadas. Em uma grande gama de aplicações tecnológicas, é de interesse a mitigação dessas oscilações com vistas à prevenção da diminuição da vida útil da estrutura por questão

\footnotetext{
1 Em inglês, energy harvesting.
} 
de fadiga. Algumas soluções de supressão passiva de VIEs são objeto de apresentação no capítulo 5. No entanto, embora por vezes danosos, as características das VIE constituem um cenário promissor no que diz respeito à coleta de energia.

Dentre os fenômenos de VIE que são foco de discussões na presente seção, destacamse o as vibrações induzidas pelo escoamento axial, o galloping, o flutter e o VIV. O tema em tela é bastante amplo, de sorte que o leitor interessado no aprofundamento do aproveitamento de energia a partir da vibração de fólios pode consultar o trabalho de Xiao e Zhu (2014).

Como mencionado, o objetivo aqui é a apresentação de uma revisão de literatura acerca do aproveitamento de energia a partir de VIE. No tocante à organização, esta seção poderia estar dividida segundo os particulares fenômenos de VIE ou de acordo com a forma de conversão eletromecânica. Embora essas formas de organização tenham suas vantagens, a revisão bibliográfica é apresentada em ordem cronológica, contextualizando as contribuições do grupo da EPUSP.

Um dos trabalhos com maior relevo no tema e que já conta com um produto tecnológico é o dispositivo VIVACE (Vortex-Induced Vibrations Aquatic Clean Energy), desenvolvido pelo grupo da Universidade de Michigan sob coordenação do Prof. Michael Bernitsas. Introduzido em Bernitsas et al. (2006b), o VIVACE aproveita as oscilações de um arranjo de cilindros em tandem ${ }^{2}$ para movimentar um gerador eletromagnético e pode ser empregado tanto para correntes fluviais ou oceânicas. No início de seu desenvolvimento, este dispositivo apresentava eficiência na conversão eletromecânica próxima a $22 \%$; ver Bernitsas et al. (2006a).

É interessante pontuar que, mesmo uma década após sua introdução, o VIVACE ainda tem motivado uma série de esforços de pesquisa de cunho mais fundamental com vistas à melhoria de sua performance. Em particular, o grupo liderado pelo Prof. Bernitsas tem buscado formas de aumentar as amplitudes de oscilação dos cilindros. Dentre essas formas, destacam-se alternativas para modificar a superfície lateral do cilindro por meio de fitas com diferentes rugosidades e em diversas posição de sorte a estimular a turbulência no escoamento e, por consequência, alterar o regime de escoamento existente ${ }^{3}$. Em Bernitsas, Raghavan e Duchene (2008), os autores mostram que as amplitudes de oscilação decorrentes do VIV podem superar dois diâmetros caso a superfície lateral cilindro seja dotada de elementos rugosos.

O aproveitamento de energia a partir das vibrações induzidas pelo escoamento em uma placa flexível engastada em uma das extremidades é o objeto de estudo descrito em Tang, Païdoussis e Jiang (2009). Nesse trabalho, a conversão de energia é feita por

2 Configuração na qual os cilindros estão alinhados com relação à direção da correnteza incidente.

3 O leitor pode retornar à seção 4.1.2 para rememorar alguns efeitos do número de Reynolds na curva de resposta do fenômeno VIV-1gl. 
meio de fios condutores internos à placa que, por sua vez, está imersa em um campo magnético. A esse conceito, os autores denominam de moinho baseado no flutter $^{4}$. Por meio de simulações numéricas considerando uma placa compacta $(58 \mathrm{~cm} \times 20 \mathrm{~cm} \times 0,5$ $\mathrm{mm})$, os autores calculam a potência elétrica extraída em $10 \mathrm{~W}$.

O galloping translacional é um fenômeno de interesse no tocante à coleta de energia. Um aspecto que confere ao referido fenômeno alguma vantagem com relação ao VIV diz respeito ao fato de que as amplitudes de oscilação não são restritas a um particular intervalo de velocidades de correnteza. Motivado por essa vantagem, Barrero-Gil, Alonso e Sanz-Andres (2010) estudam a coleta de energia a partir do galloping translacional de prismas com diversas seções transversais. Nesse trabalho, o rendimento da coleta de energia é avaliado pela razão entre a potência conferida pela força exercida pelo fluido sobre o prisma e o fluxo de densidade de energia cinética ao longo da seção frontal do corpo, de sorte que não há qualquer menção em relação à conversão eletromecânica de energia.

Lançando mão da hipótese quase-estática para a modelagem do carregamento fluído (ver seção 4.2), os autores discutem a influência dos termos $a_{k}$ do polinômio ${ }^{5}$ que define o coeficiente de força na direção cross-wise como função do ângulo de ataque e da massa do corpo. Em particular, os autores apontam ser interessante o aumento do termo $a_{1}$ e a diminuição do valor absoluto de $a_{3}$. Esse artigo é bastante relevante no sentido de prover guias para o projeto de um dispositivo de coleta de energia a partir do galloping translacional de um corpo prismático.

O aproveitamento de energia a partir das vibrações induzidas pelo escoamento axial em uma placa flexível também é o objeto de estudo descrito em Doaré e Michelin (2011), porém considerando o efeito piezoelétrico como forma de conversão eletromecânica de energia. Nesse trabalho, os autores conduzem uma análise de estabilidade linear do sistema sólido-fluido-elétrico. Embora a análise conduzida seja linear, de sorte que as amplitudes pós-críticas não possam ser previstas, os autores apontam que o estudo do problema linearizado pode ser relevante no sentido de indicar a influência de alguns dos parâmetros que caracterizam o modelo matemático. Dentre as conclusões obtidas a partir do estudo de sensibilidade da potência com relação aos parâmetros de controle, os autores indicam o aumento da eficiência da conversão eletromecânica de energia com o aumento de um adimensional de massa definido pela relação entre a massa de fluido deslocada por unidade de área e a massa superficial da placa.

Uma investigação experimental acerca da coleta de energia a partir do VIV é apresentada em Akaydin, Elvin e Andreopoulos (2012). Como ilustrado na Figura 51(a),

4 Tradução livre do termo flutter-mill empregado no artigo.

5 O leitor pode retornar à equação 4.52 e apresentada seção 4.2 para relembrar a modelagem matemática do galloping translacional de um prisma. 
um cilindro é montado na extremidade livre de uma viga em balanço parcialmente coberta por lâminas piezoelétricas e ensaiado em um túnel de vento. Note que, nesse experimento, a rigidez é conferida pela viga que, por sua vez, induz a obtenção de energia a partir do efeito piezoelétrico. Utilizando um dispositivo bastante compacto, envolvendo um cilindro de diâmetro de diâmetro $D=39,6 \mathrm{~mm}$, uma viga de comprimento igual a $267 \mathrm{~mm}$ recoberta pelas lâminas piezoelétricas ao longo de 31,8 mm, a Figura 51(b) mostra a obtenção de até $0,1 \mathrm{~mW}$ de potência elétrica em uma resistência elétrica de valor $R=2,46 \mathrm{M} \Omega$. Essa figura mostra, ainda, que a máxima potência elétrica é obtida para $U_{\infty}=1,19 \mathrm{~m} / \mathrm{s}$.

Figura 51 - Arranjo experimental e potência elétrica obtida como função da velocidade do vento.

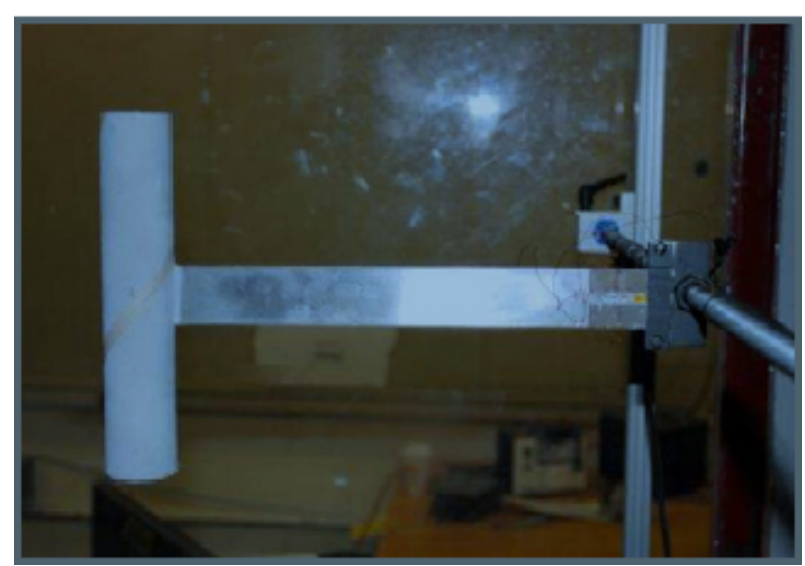

(a) Foto do arranjo experimental.

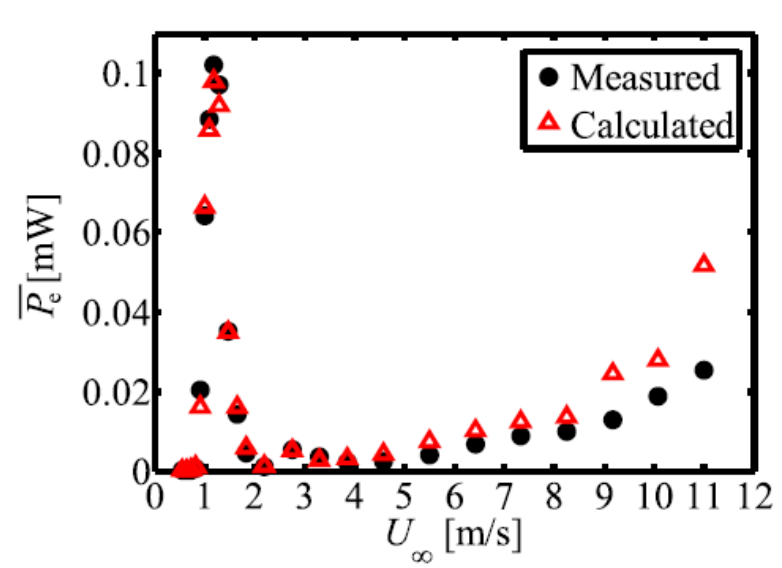

(b) Potência elétrica extraída a partir dos ensaios em túnel de vento.

Fonte: Extraída de Akaydin, Elvin e Andreopoulos (2012).

Tomando como base o diâmetro do cilindro já mencionado e a frequência natural descrita no trabalho $f_{n, y}=3,14 \mathrm{~Hz}$, a velocidade reduzida associada ao pico de potência elétrica é $U_{r}=U_{\infty} / f_{n, y} D=9,58$, valor distinto daquele esperado para a máxima amplitude de oscilação. Cabe, ainda, um comentário adicional acerca de um possível desdobramento para o trabalho Akaydin, Elvin e Andreopoulos (2012). Como discutido na revisão bibliográfica apresentada na subseção 4.1.2, os ensaios em túnel de vento são caracterizados por valores do parâmetro de massa reduzida $m^{*}$ bastante altos (da ordem de $10^{2}$ ), levando a amplitudes de oscilação inferiores àquelas que seriam obtidas com experimentos que utilizam água como meio fluído. Espera-se que o aumento das amplitudes de oscilação promova um aumento da potência elétrica obtida, embora essa conjectura deva ser experimentalmente validada.

Mehmood et al. (2013) estudam a coleta de energia a partir do fenômeno VIV-1gl por meio de uma abordagem baseada em técnicas de DFC para o cálculo das forças hidrodinâmicas $(R e \approx 100)$ e do efeito piezoelétrico como forma de conversão eletromecânica. Nesse trabalho, a equação de movimento da estrutura contém tanto o termo de força hidrodinâmica quanto um termo de acoplamento piezoelétrico. Uma segunda equação 
diferencial, acoplada à equação representativa da dinâmica estrutural, governa a evolução da tensão elétrica no circuito de coleta de energia que, por sua vez, é representado pela capacitância do elemento piezoelétrico e por uma resistência elétrica. Nessa referência, os autores realizam um estudo de sensibilidade da tensão elétrica obtida como função da resistência elétrica.

Em Fernandes e Armandei (2014), os autores investigam experimentalmente o aproveitamento de energia a partir do galloping torcional de uma placa rígida capaz de oscilar em torno de um eixo. Nesse trabalho, as oscilações da placa foram utilizada para levantar pesos por meio de um sistema de polias. Dentre as conclusões tecidas pelos autores, pode ser destacado fato de que a diminuição da corda da placa promove o aumento do coeficiente de potência.

A coleta de energia a partir do VIV é numericamente investigada em Grouthier et al. (2012b, 2014). Nesses trabalhos, as forças hidrodinâmicas decorrentes do fenômeno de interação fluido-estrutura são calculadas por meio do modelo de ordem reduzida apresentado em Facchinetti, de Langre e Biolley (2004), de sorte que apenas oscilações estruturais na direção cross-wise são permitidas. Duas configurações estruturais são estudadas, a saber, o fenômeno VIV-1gl e o problema de cabo tracionado dotado de alguns amortecedores concentrados em diversas posições ao longo de sua envergadura. Nessas referências, o aproveitamento de energia é discutido à luz da energia dissipada nos amortecedores, de sorte que nenhuma consideração acerca da conversão da energia dissipada em alguma forma útil de energia (por exemplo, energia elétrica) é feita.

Ainda considerando esses artigos e, para a configuração VIV-1gl, o rendimento ${ }^{6}$ da coleta de energia foi estudado como função da frequência natural da estrutura $\delta$ e da sua taxa de amortecimento estrutural $\xi$, sendo o máximo valor obtido de $23 \%$ (ver Figura 52), valor bastante próximo àquele obtido para o VIVACE. A existência de um ponto ótimo de amortecimento pode ser justificada por meio de um simples argumento físico. A coleta naturalmente retira energia da estrutura, de sorte que pode ser considerada como um amortecedor em um modelo de baixa hierarquia. Um aumento excessivo da taxa de amortecimento leva a uma diminuição das respostas estruturais, o que reduz tanto a força no amortecedor (proporcional à velocidade) quanto a potência dessa força (associada, portanto, com a velocidade ao quadrado).

Já para o problema envolvendo corpos flexíveis, Grouthier et al. (2012b, 2014) pontuam como uma das vantagens face ao aproveitamento de energia a partir da condição VIV-1gl o fato de que a possibilidade de lock-in com os diversos modos de vibrar permite a coleta de energia para diversas faixas de velocidade de escoamento. O leitor logo nota

6 Nesse trabalho e em outros artigos da literatura, o rendimento da coleta de energia é definido como a razão entre potência média dissipada pelo amortecedor em um ciclo de oscilação e o fluxo de energia cinética ao longo da seção frontal do cilindro. 
Figura 52 - Rendimento da coleta de energia como função da frequência natural da estrutura $\delta$ e da taxa de amortecimento estrutural $\xi$.

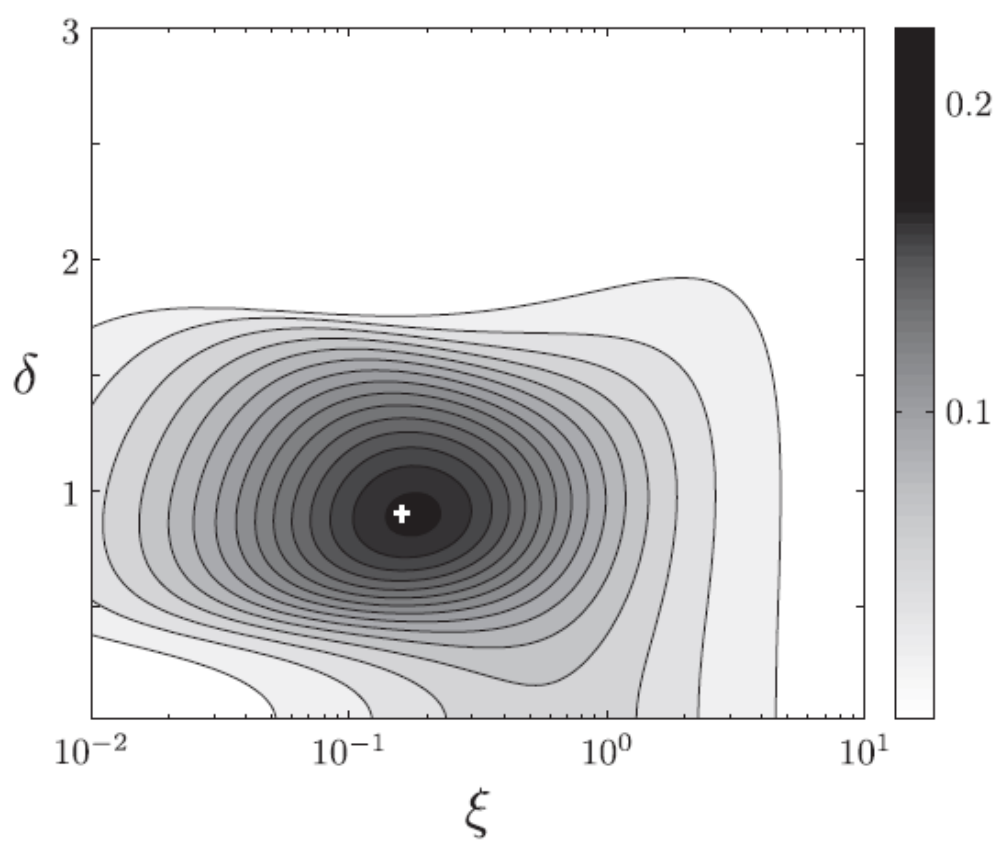

Fonte: Extraída de Grouthier et al. (2014).

que essa possibilidade de coleta de energia para diversas faixas de velocidade reduzida é de interesse tecnológico e constitui uma vantagem do arranjo com cilindros flexíveis perante aquele envolvendo cilindros rígidos elasticamente suportados, uma vez que estes últimos apresentam oscilações estruturais em apenas um único intervalo de velocidades reduzidas, a saber, entre $3<U_{r}<12$.

Dai, Abdelkefi e Wang (2014) buscam formular o mesmo problema experimentalmente investigado em Akaydin, Elvin e Andreopoulos (2012), a saber, um cilindro rígido montado em uma viga parcialmente recoberta por lâminas piezoelétricas e submetido ao fenômeno VIV-1gl, avaliado por meio do modelo fenomenológico proposto por Facchinetti, de Langre e Biolley (2004). A Figura 53 ilustra o problema investigado.

Ao contrário de outros trabalhos, as equações de movimento deduzidas em Dai, Abdelkefi e Wang (2014) inicialmente consideram a viga e as lâminas como corpos flexíveis (constituindo, portanto, um modelo a parâmetros distribuídos) com posterior aplicação do método de Galerkin para a obtenção de um sistema de equações ordinárias. A Figura 54 ilustra a correlação entre os resultados obtidos a partir do modelo numérico apresentado em Dai, Abdelkefi e Wang (2014) com aqueles oriundos dos experimentos de Akaydin, Elvin e Andreopoulos (2012). Embora a análise dessa figura mostre uma notável aderência entre os resultados numéricos e experimentais, uma ressalva deve ser feita no tocante ao modelo numérico. Como exposto em Dai, Abdelkefi e Wang (2014), os autores adotaram como número de Strouhal $S t=0,116$, pouco mais da metade do resultado clássico obtido 
Figura 53 - Representação esquemática do problema estudado em Dai, Abdelkefi e Wang (2014).

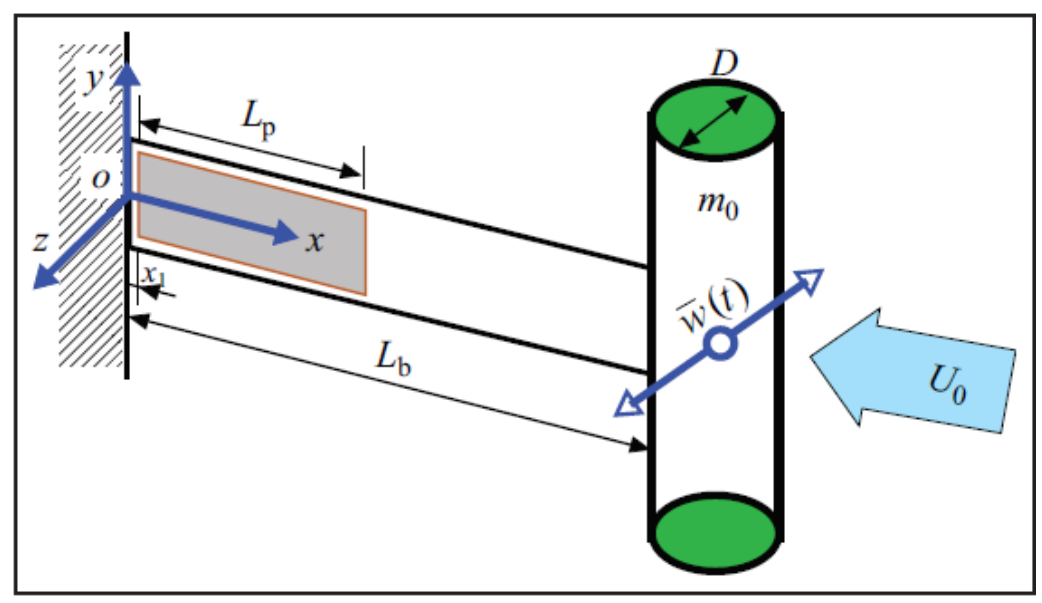

Fonte: Extraída de Dai, Abdelkefi e Wang (2014).

para cilindros e também dos valores adotados nos modelos fenomenológicos de Facchinetti, de Langre e Biolley (2004) e Ogink e Metrikine (2010) (ver Tabela 2 da subseção 4.1.5). Um conjectura para esse resultado é fato de que a montagem da lâmina afeta a esteira de vórtices de sorte a dificultar a interação a interação entre as camadas cisalhantes livres, diminuindo a frequência de emissão de vórtices e também o número de Strouhal.

Figura 54 - Correlação numérico-experimental.

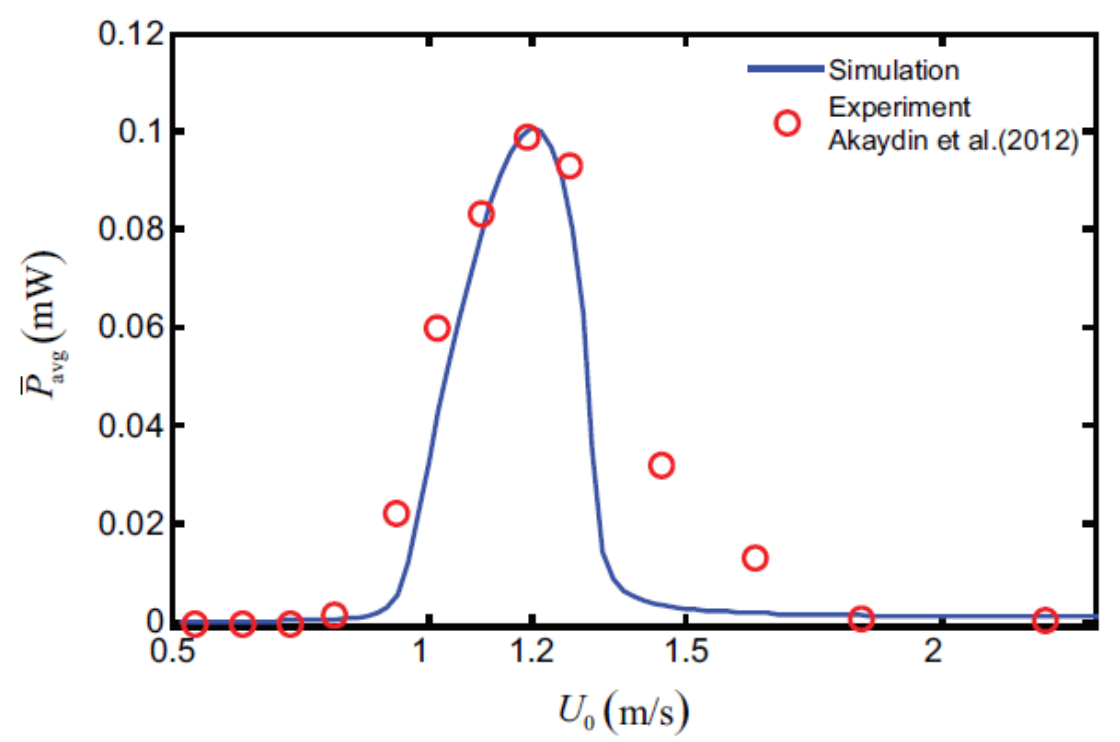

Fonte: Extraída de Dai, Abdelkefi e Wang (2014).

O trabalho de Antoine, de Langre e Michelin (2016) tem como objetivo a obtenção de uma distribuição de elementos dissipativos (amortecedores) ao longo de um cilindro flexível em configuração de catenária e sujeito ao fenômeno de VIV de sorte a maximizar o rendimento da coleta de energia. Nesse trabalho e a exemplo do que já fora conduzido 
em Grouthier et al. (2014), os esforços hidrodinâmicos são calculados por meio do modelo fenomenológico apresentado em Facchinetti, de Langre e Biolley (2004) e a coleta de energia é avaliada por meio da potência dissipada nos amortecedores. Lançando mão de estudos numéricos que variaram tanto a velocidade reduzida quanto a taxa de amortecimento, os autores apontam que a solução que garante o maior rendimento é aquela na qual o amortecedor é localizado próximo a uma das extremidades do cabo.

Experimentos em túnel de vento, agora com foco na coleta de energia a partir do galloping translacional de corpos prismáticos, são descritos em Hémon, Amandolese e Andrianne (2017). A Figura 55 ilustra o arranjo experimental empregado pelos autores. Nesse trabalho, a coleta de energia é realizada por meio de imãs afixados nas vigas que atuam como elementos restauradores do conjunto. O movimento desses imãs induz corrente elétrica em um circuito composto de uma bobina e uma resistência elétrica.

Figura 55 - Representação esquemática de arranjo experimental.

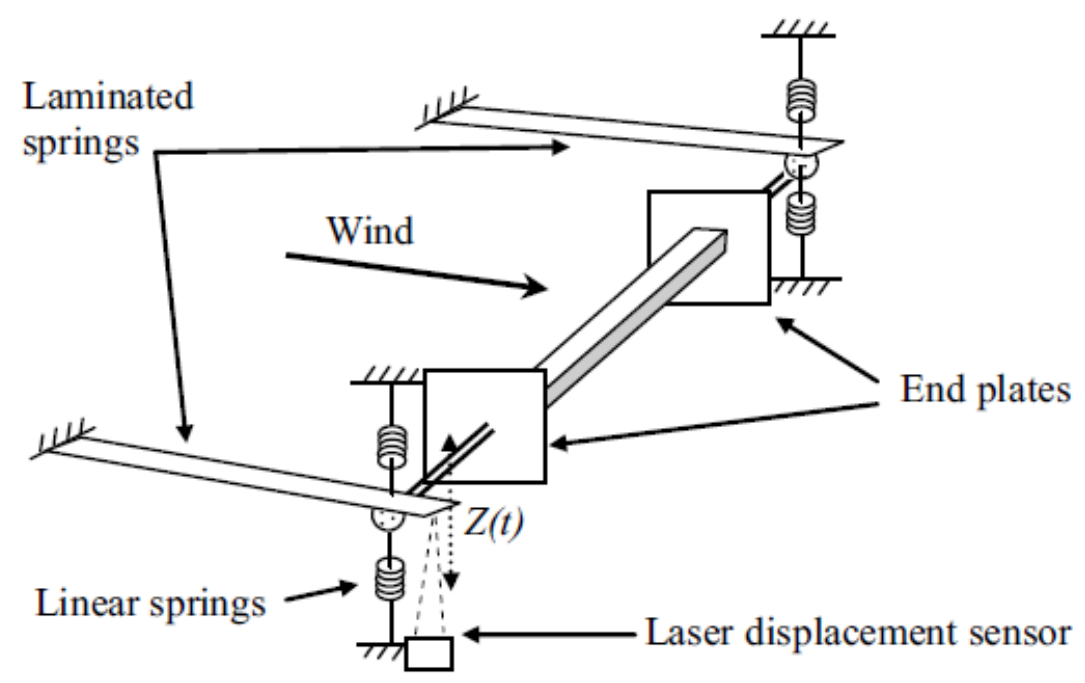

Fonte: Extraída de Hémon, Amandolese e Andrianne (2017).

O foco do trabalho de Hémon, Amandolese e Andrianne (2017) é na investigação sistemática dos efeitos da resistência elétrica, da seção transversal (quadrada ou retangular) e do ângulo de ataque na eficiência da coleta de energia. Os resultados obtidos pelos autores revelam que configuração que leva ao maior rendimento envolve uma seção quadrada com ângulo de ataque inicial de $10^{\circ}$, embora a conclusão do artigo revele que novos experimentos devem ser realizados com vistas à proposição para um dispositivo de coleta de energia semelhante àquele investigado.

Um dispositivo bastante distinto dos demais apresentados neste capítulo é proposto em Arionfard e Nishi (2017). O dispositivo consiste de um cilindro sujeito ao fenômeno de VIV-1gl conectado a um braço livre para rotacionar em torno de um eixo. Um conjunto de molas de translação é adotado como forma de compor um elemento que confere rigidez 
ao movimento de rotação do braço causado pelo fenômeno em tela. Uma representação esquemática desse arranjo é feita na Figura 56.

Figura 56 - Representação esquemática de arranjo experimental.

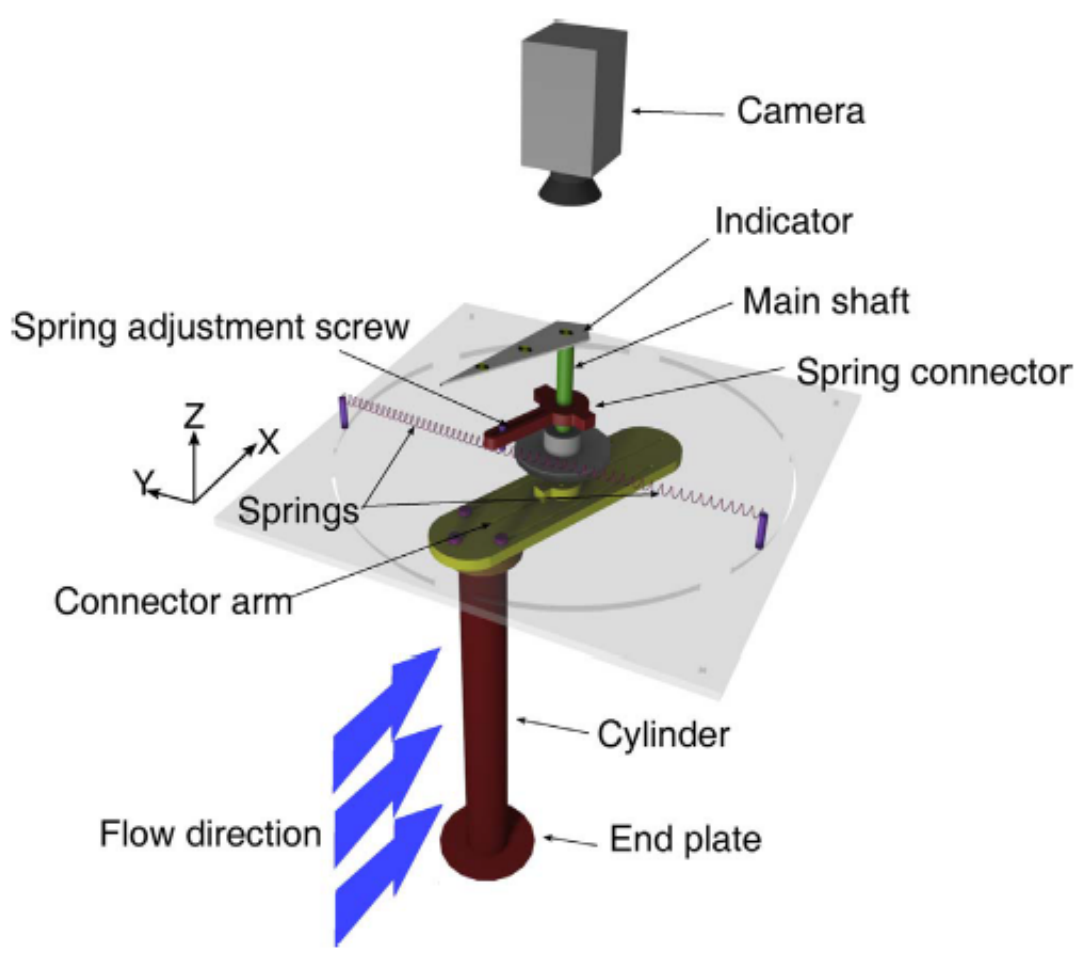

Fonte: Extraída de Arionfard e Nishi (2017).

A exemplo de outros trabalhos já mencionados nesta seção, Arionfard e Nishi (2017) adotam como medida de potência aquela dissipada nos amortecedores. Uma particularidade desse arranjo e que foi objeto de discussão por parte dos autores diz respeito à diferença de comportamento dinâmico decorrente do ponto de localização do eixo de rotação do braço com relação ao cilindro. No caso onde o cilindro está à montante do eixo de rotação, a força de arrasto média tem um efeito de diminuição da rigidez, enquanto que essa força é restauradora quando o cilindro está à jusante desse eixo ${ }^{7}$. Por meio de estudos paramétricos onde a velocidade reduzida, o comprimento do braço e a constante de rigidez das molas são variados, os autores identificam a configuração que maximiza a potência extraída. Em particular, é apontado que o comprimento do braço que torna a coleta de energia mais eficiente é menor quando o cilindro está à montante do eixo de rotação.

Soti et al. (2017) apresentam uma série de estudos numéricos com foco na coleta de energia a partir da condição VIV-1gl. O problema estudado nessa referência consiste de um cilindro rígido montado em base elástica e solidário a um imã. As forças hidrodinâmicas são calculadas por meio de técnicas de $\operatorname{DFC}(R e<200)$ e induzem movimentos de translação no conjunto formado pelo cilindro e pelo imã. Uma bobina composta de um fio condutor e

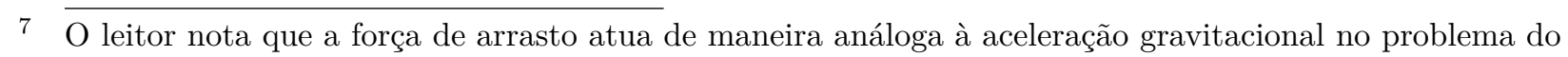
pêndulo. 
conectada a uma resistência elétrica está posicionada externamente à base elástica que suporta o cilindro. A variação de fluxo de campo magnético associada à movimentação do cilindro por conta da interação fluido-estrutura leva ao aparecimento de corrente elétrica no circuito, com consequente obtenção de potência elétrica.

Do ponto de vista de modelagem matemática, Soti et al. (2017) fazem duas considerações acerca da força no cilindro decorrente da variação de fluxo de campo magnético na bobina. Na primeira delas, essa força é incorporada na forma de uma constante de amortecimento equivalente. Já na segunda forma, a força é dependente de maneira não-linear tanto da posição do cilindro quanto de sua velocidade. É claro ao leitor que a primeira abordagem leva a um modelo matemático mais simples, porém menos realista.

Os autores estudam os efeitos da variação de diversos parâmetros como, por exemplo, o raio e o comprimento da bobina, e o parâmetro de massa reduzida. Considerando os modelos lineares e não-lineares, o máximo rendimento da coleta de energia (definido como a razão entre a potência dissipada pela força magnética no cilindro e o fluxo de densidade de energia cinética através da área da seção frontal do cilindro) é próximo a 13\%.

Os trabalhos de Franzini, Santos e Pesce $(2016,2017)^{8}$ estudam numericamente a coleta de energia, via efeito piezoelétrico, a partir da resposta de um prisma de seção quadrada de lado $D$, comprimento imerso $L$ e massa $m_{s}$ a uma solicitação combinada de galloping e de excitação paramétrica. A motivação para esse trabalho reside no fato de que a excitação paramétrica pode ser conseguida no ambiente marinho sem a necessidade de imposição de energia ao sistema, bastando afixar a extremidade superior de um corpo esbelto, prismático e de seção transversal não-circular a uma boia projetada para apresentar movimentos verticais com frequência correspondente ao dobro de uma das frequências naturais da estrutura ${ }^{9}$.

Nesses trabalhos, uma hipótese $a d$-hoc é formulada com relação à concomitância entre os fenômenos de excitação paramétrica e de galloping. Em sua versão dimensional, as equações de movimento do sistema sólido-fluido-elétrico são dadas por:

$$
\begin{aligned}
& \left(m_{s}+m_{a}^{p o t}\right) \frac{d^{2} Y}{d t^{2}}+c_{y} \frac{d Y}{d t}+(k(t)+\Delta k \sin \Omega t) Y+\frac{1}{2} \rho C_{D} D\left|\frac{d Y}{d t}\right| \frac{d Y}{d t}-\theta V= \\
& =\frac{1}{2} \rho D L U_{\infty}^{2} \sum_{k=1}^{3} a_{k}\left(\frac{1}{U_{\infty}} \frac{d Y}{d t}\right)^{k} \\
& C_{P} \frac{d V}{d t}+\frac{V}{R}+\theta \frac{d Y}{d t}=0
\end{aligned}
$$

8 Esses trabalhos foram escritos a partir da iniciação científica da aluna Rebeca Caramêz Saraiva Santos, orientada pelo autor deste texto.

9 O leitor pode retornar ao capítulo 3 para maiores detalhes acerca do fenômeno de excitação paramétrica em estruturas típicas da engenharia oceânica. 
sendo $\theta$ o termo de acoplamento eletromecânico, $C_{P}$ a capacitância do elemento piezoelétrico e $V$ a tensão elétrica no circuito de coleta de energia, aqui assumido como composto de uma resistência $R$. Enquanto o lado direito da Equação 6.1 apresenta a força na direção do movimento (definido pela coordenada generalizada $Y$ ), o penúltimo termo do lado esquerdo da mesma equação representa o amortecimento hidrodinâmico (ver seção 3.2, Equação 3.17).

Do ponto de vista de modelagem matemática, a hipótese ad-hoc é feita quando da afirmação de que o modelo matemático representativo da solicitação combinada é a superposição daquele descritivo de um corpo submerso sob galloping (Equação 6.1, porém tomando $\Delta k$ e $C_{D}$ como nulos) com aquele que representa a dinâmica de um corpo submerso vinculado ao meio externo por uma mola de rigidez variável no tempo (Equação 6.1, porém tomando seu lado direito como nulo).

Como exemplificado na Figura 57, as simulações numéricas conduzidas em Franzini, Santos e Pesce (2017) mostram que a excitação paramétrica aumentam a tensão elétrica obtida no circuito de coleta de energia. Curiosamente, esse aumento não se dá quando a frequência de variação da rigidez, representada por $n=\omega_{n, y} / \Omega$, é o dobro da frequência natural do prisma sem consideração do efeito piezoelétrico.

Figura 57 - Desvio padrão da tensão elétrica adimensional como função da velocidade reduzida.

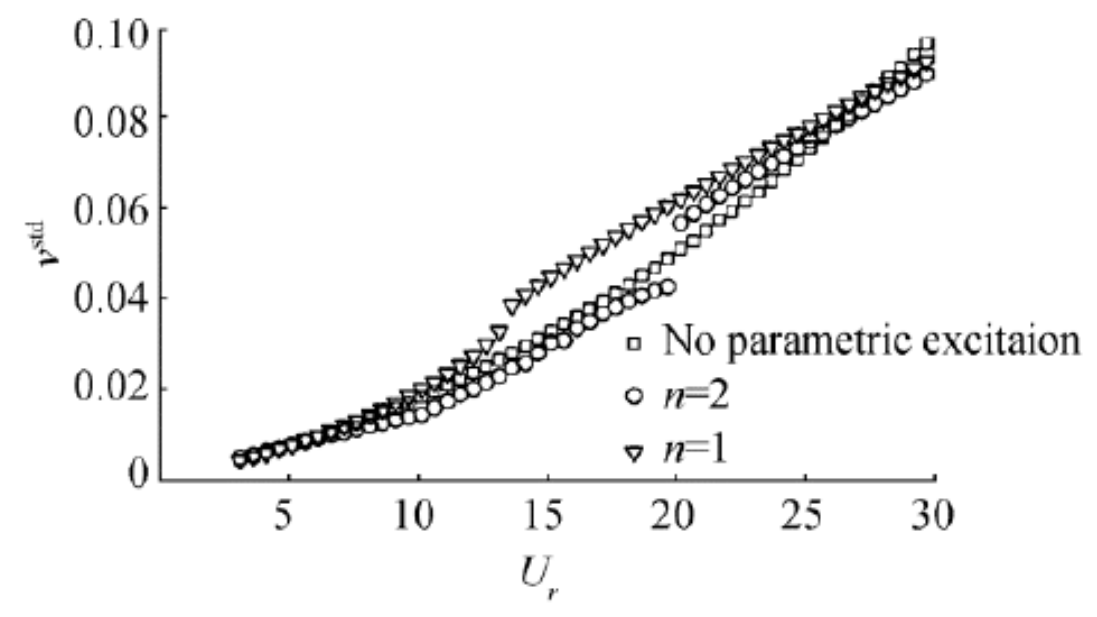

Fonte: Extraída de Franzini, Santos e Pesce (2017).

Tang e Dowel (2018) também estudam a dinâmica de uma placa engastada em um dos lados, recoberta por lâminas piezoelétricas e sujeita a uma velocidade de correnteza incidente contida no plano da estrutura. Nessa referência, o carregamento aerodinâmico é calculado por meio de um método de painéis de vórtices. Entre outros aspectos, os autores avaliam a influência da resistência elétrica do circuito e do ângulo de inclinação de um lados com relação à direção da correnteza incidente em características do sistema eletromecânico como, por exemplo, a velocidade crítica de flutter, a amplitude da resposta 
estrutural e a tensão elétrica obtida. Os autores relatam que a direção de correnteza que maximiza a potência elétrica extraída é ortogonal ao lado engastado, e o seu sentido é do lado engastado para o lado livre. Além disso, o artigo aponta que o aumento da resistência elétrica é benéfico no que tange à coleta de energia.

Andrianne et al. (2018) apresentam resultados experimentais e numéricos acerca da coleta de energia a partir dos fenômenos VIV-1gl e galloping. Os experimentos foram conduzidos com um corpo prismático de seção quadrada em um túnel de vento e envolveram dois arranjos distintos. Para o estudo da coleta de energia a partir do VIV, uma das seções transversais do corpo prismático foi engastada ao túnel de vento, permanecendo a outra livre. Por sua vez, os experimentos relativos ao galloping envolveram um corpo rígido montado em apoio elástico com liberdade de oscilação na direção cross-wise. Em ambos os arranjos, a coleta de energia é feita por meio de bobinas presas aos corpos em oscilação e de um imã fixo ao túnel de vento nas proximidades da bobina, em um arranjo bastante parecido com aquele adotado em Soti et al. (2017).

A análise experimental conduzida em Andrianne et al. (2018) revela que, devido à velocidade crítica para o fenômeno de galloping ser próxima do intervalo de velocidades de vento que excitam o lock-in, existe concomitância entre os dois fenômenos. A Figura 58(a) mostra claramente que a amplitude de resposta do corpo ao fenômeno de VIV é pouco afetada pelo valor da resistência elétrica. O mesmo comentário é válido para os experimentos onde coexistem os fenômenos de galloping e VIV-1gl. Por outro lado, a dependência da potência elétrica extraída com o valor da resistência elétrica é notável, sendo que existe um valor ótimo (no sentido de maximizar a potência elétrica obtida) de resistência elétrica $R=440 \Omega$ para a estrutura é solicitada somente pelo VIV. Cumpre ressaltar que Andrianne et al. (2018) não publicam qualquer resultado relativo às oscilações na direção in-line do prisma em balanço sujeito ao VIV.

A Figura 58 permite ressaltar alguns aspectos já mencionados neste capítulo e que foram objeto de discussão dos trabalhos aqui analisados. As Figuras 58(a) e 58(b) mostram que a potência elétrica obtida a partir do galloping (aqui, combinado com o VIV) é significativamente superior àquela obtida quando da excitação somente pelo VIV. Essa constatação pode ser explicada pelo fato de que as respostas do VIV atingem valores máximos de um diâmetro e, no caso de cilindros rígidos montados em apoio elástico, estão restritas a um particular intervalo de velocidades que caracterizam o lock-in. Por outro lado, o galloping tem como característica o crescimento das respostas estruturais com o aumento da velocidade, o que contorna uma possível limitação prática para o uso do VIV como excitação para a coleta de energia.

Agora, foco é dedicado a discutir um trabalho conduzido no âmbito da EPUSP, cabendo ressaltar a motivação tecnológica para a dissertação de mestrado de Defensor Filho (2018). Essa dissertação, defendida pelo hoje doutorando do LMO Wagner Antônio 
Figura 58 - Resultados experimentais.
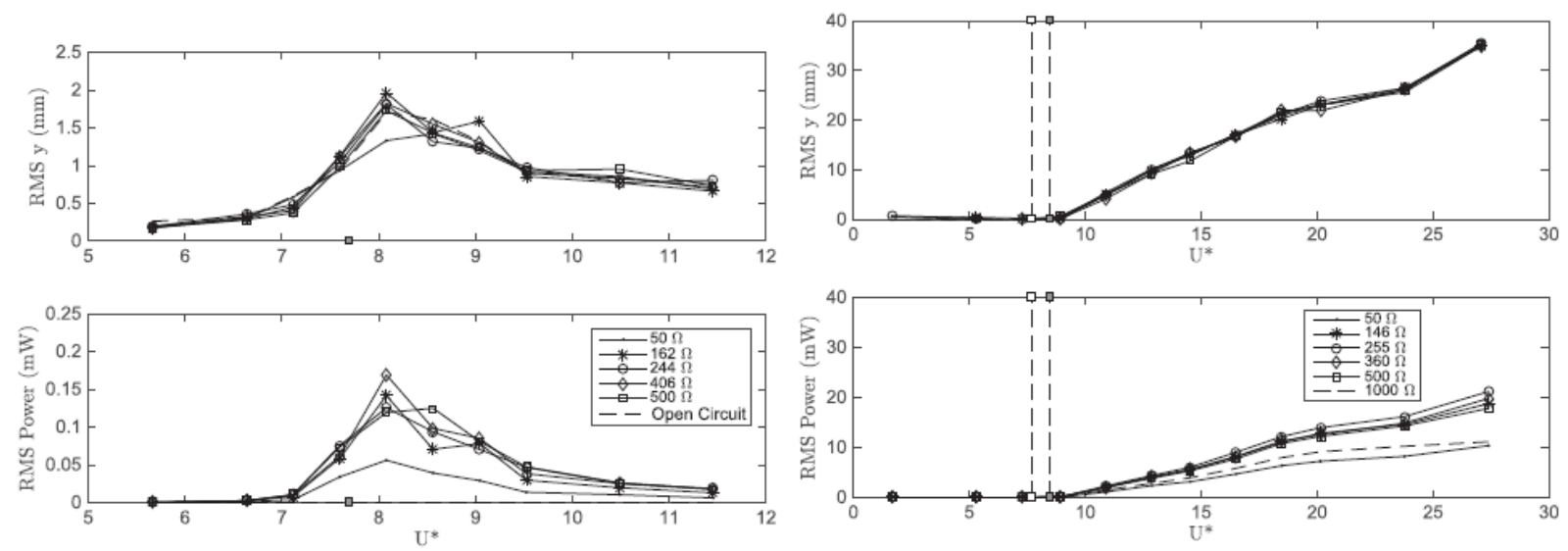

(a) Curvas de resposta obtidas a partir dos experimentos de VIV.

-(b) Curvas de resposta obtidas a partir dos experimentos de concomitância entre VIV e galloping.

Fonte: Extraída de Andrianne et al. (2018).

Defensor Filho sob orientação do Prof. Dr. Celso Pupo Pesce, teve como panorama o aproveitamento de energia a partir do fenômeno de VIV em um cilindro flexível, com particular foco no high-speed branch ${ }^{10}$ identificado em Fujarra et al. (2001) e já discutido na subseção 4.1.4. Como discutido em Defensor Filho (2018) após uma extensa campanha experimental, o high-speed branch está intimamente ligado às oscilações na direção in-line. $\mathrm{Na}$ mesma dissertação, o autor tece algumas considerações acerca da potência elétrica que seria possível extrair caso a alma que compunha o cilindro ensaiado fosse composta de lâminas piezoelétricas.

\subsection{Identificação de lacunas de conhecimento}

A revisão bibliográfica apresentada neste capítulo possibilitou a identificação de algumas lacunas de conhecimento como, por exemplo, aquelas agora enumeradas:

1. Não consideração das oscilações na direção in-line no que diz respeito ao aproveitamento de energia a partir do VIV;

2. Ausência de um modelo de ordem reduzida para o estudo numérico do problema de um cilindro flexível composto de uma alma metálica dotada de lâminas piezoelétricas e sujeito ao fenômeno de VIV;

3. Reduzido número de estudos experimentais acerca da coleta de energia a partir das VIE considerando corpos imersos em água, de sorte a reduzir o valor do parâmetro de massa reduzida;

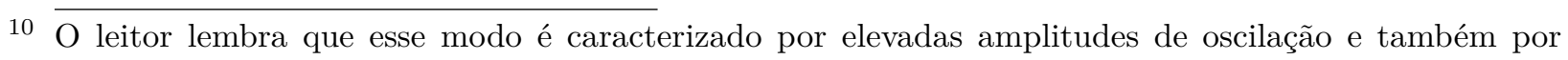
frequências maiores do que aquelas esperadas quando da análise experimental do VIV. 
4. Estudos analítico-numéricos a partir de modelos de ordem reduzida para os sistemas sólido-fluido-elétrico característicos do problema de coleta de energia utilizando técnicas empregadas no âmbito da dinâmica não-linear como, por exemplo, os modos normais não-lineares.

Este texto aborda diretamente o primeiro item aqui numerado, convidando o leitor interessado nesse tema à leitura do capítulo 11. 


\section{Análise experimental dos fenômenos de ex- citação paramétrica e de VIV}

O presente capítulo apresenta algumas contribuições oriundas de pesquisas lideradas pelo autor deste texto no tocante às análises experimentais dos fenômenos de VIV e de excitação paramétrica em um cilindro flexível submerso e montado na vertical. Este capítulo tem como base alguns artigos publicados em periódicos indexados e/ou em anais de conferências científicas e que são oportunamente citados.

Tendo em vista uma melhor organização, o capítulo está estruturado da seguinte forma. A seção 7.1 apresenta o arranjo experimental e a metodologia empregada nas análises experimentais supra-citadas. A seção 7.2 discute as principais contribuições à análise experimental de um cilindro submerso sujeito à excitação paramétrica. Seguindo, as contribuições à análise experimental do fenômeno de VIV em um cilindro flexível, excitado tanto pelo fenômeno de VIV quanto por efeitos combinados de VIV e de excitação paramétrica são apresentadas na seção 7.3. Finalmente, a seção 7.4 traz as considerações finais deste capítulo, em conjunto com os impactos das metodologias aqui descritas junto aos grupos de pesquisa da EPUSP e as propostas de continuidade das pesquisas.

\subsection{Caracterização do arranjo experimental e da metodologia de análise}

Os experimentos analisados neste capítulo compõem a base de dados mencionada na seção 2.2 e que teve sua origem em um projeto financiado pela indústria e conduzido na EPUSP. Em particular, os experimentos foram planejados, conduzidos e analisados ${ }^{1}$ pelo grupo do LMO. Os relatórios técnicos de caráter confidencial Pesce et al. (2013a, 2013b) trazem as análises preliminares dos experimentos conduzidos em tanque de reboque.

Todos os experimentos aqui analisados foram conduzidos no tanque de reboques do Instituto de Pesquisas Tecnológicas do Estado de São Paulo (IPT). Esse tanque tem 240 $\mathrm{m}$ de comprimento, $6 \mathrm{~m}$ de largura, $4 \mathrm{~m}$ de profundidade e pode operar em velocidades de até $4,5 \mathrm{~m} / \mathrm{s}$. Como a correnteza é induzida pelo reboque da estrutura em um fluido em repouso, o nível de turbulência é significativamente inferior àquele obtido em experimentos em um canal de água recirculante.

O modelo flexível adotado é composto de um tubo de silicone preenchido com microesferas de aço inoxidável e foi concebido com vistas a atingir um certo grau de 
similaridade com um riser em catenária ${ }^{2}$ de 8 in de diâmetro. Maiores detalhes sobre a metodologia de definição do modelo podem ser encontrados em Rateiro et al. (2012).

Cumpre ressaltar que é impossível compatibilizar todos os adimensionais que regem a resposta dinâmica do modelo. Foi adotado como parâmetro de escala a equivalência entre os números de Froude das configurações real e do laboratório. Um dos adimensionais que foge à regra de escala é a razão de aspecto. A justificativa para esse fato é que, caso a escala fosse mantida, o diâmetro do modelo seria bastante pequeno, o que impossibilitaria qualquer instrumentação.

O modelo foi afixado em sua porção superior no carro de reboque, enquanto que sua porção inferior ficou presa a um fundo falso solidário ao carro. As duas extremidades do modelo têm como condições de contorno o engastamento. Ao contrário dos artigos mencionados na seção 4.1.4, aqui a medição dos deslocamentos ao longo do cilindro foi feita de maneira direta por meio de um sistema óptico de reconhecimento de imagens da marca Qualisys ${ }^{\circledR}$. Esse sistema consiste no uso de, no mínimo, duas câmeras que registram o movimento de um certo número de alvos refletivos (no caso do experimento aqui descrito, quarenta e três alvos) e de um software específico que identifica as coordenadas cartesianas em relação a uma dada referência de cada alvo a cada frame gravado. A incerteza na medição dos deslocamentos é inferior a 0,1 mm (ver Salles e Pesce (2017)).

No total, seis câmeras foram empregadas, sendo quatro responsáveis pela monitoração dos alvos submersos e duas para o pequeno trecho emerso. As câmeras foram presas a um suporte rígido vinculado ao carro de reboque, estando à jusante do modelo flexível. A tração no topo foi medida por meio de uma célula de carga da marca HBM, modelo S2. Os movimentos verticais foram prescritos ao topo do modelo por meio de um servo-atuador. Embora alguns experimentos tenham sido feitos impondo movimentos que simulam a excitação por um mar irregular ${ }^{3}$, o foco das análises aqui conduzidas reside nos casos onde a excitação de topo é harmônica e monocromática, caracterizada por uma amplitude $A_{t}$ e uma frequência $f_{t}$.

Os sinais dos sensores foram todos devidamente sincronizados, de forma a ser obter uma única base de tempo caracterizada pela frequência de amostragem $f_{s p}=60 \mathrm{~Hz}$. Para os ensaios onde o carro de reboque foi acionado, a resposta do modelo foi medida por 300 s após a velocidade do carro ter cessado sua aceleração. O intervalo de velocidades de reboque, em regime, foi $0,03<U_{\infty}<0,28 \mathrm{~m} / \mathrm{s}$, o que leva o número de Reynolds a assumir valores entre 700 e 6100 . Já para os experimentos onde a única fonte de excitação é o movimento prescrito ao topo, o tempo de duração dos experimentos foi de $120 \mathrm{~s}$.

2 Como foram conduzidos experimentos na configuração de catenária, essa foi a condição real sobre a qual buscou-se similaridade. Uma vez definido o modelo para o estudo da catenária, ele foi aproveitado para o estudo da configuração vertical.

3 A análise desse experimento foi tema da iniciação científica da aluna Giovanna Ribeiro Campedelli, orientada pelo autor deste texto. 
As Figuras 59 e 60 apresentam, respectivamente, representações esquemáticas do arranjo experimental e algumas fotografias do mesmo. Já a Tabela 3 traz as propriedades geométricas e inerciais do cilindro e outras grandezas características do arranjo vertical.

Figura 59 - Representações esquemáticas do arranjo experimental. O carro de reboque movimenta-se da esquerda para a direita. O eixo $z$ tem a direção do modelo e sua origem no vínculo inferior.

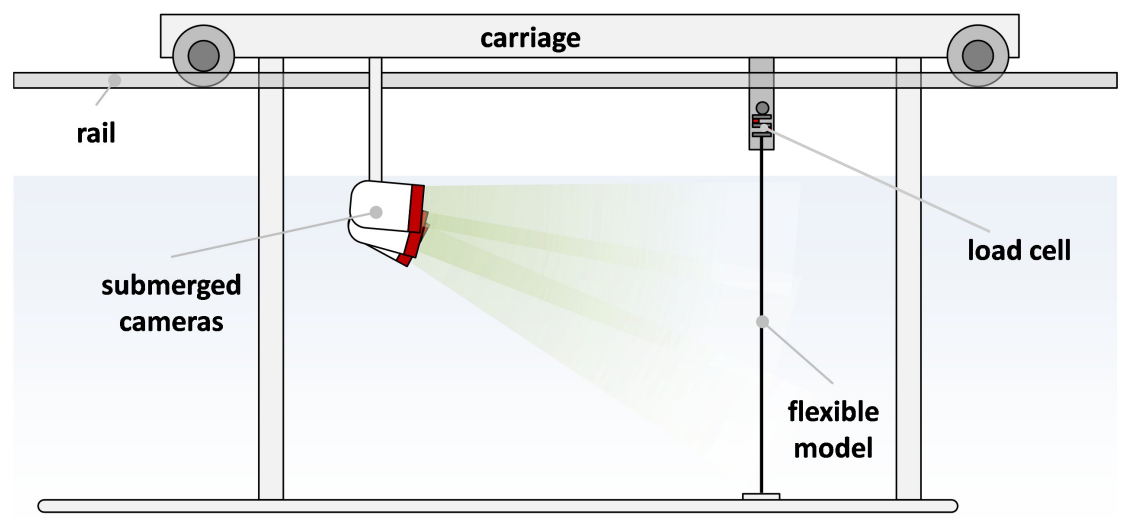

(a) Vista lateral.

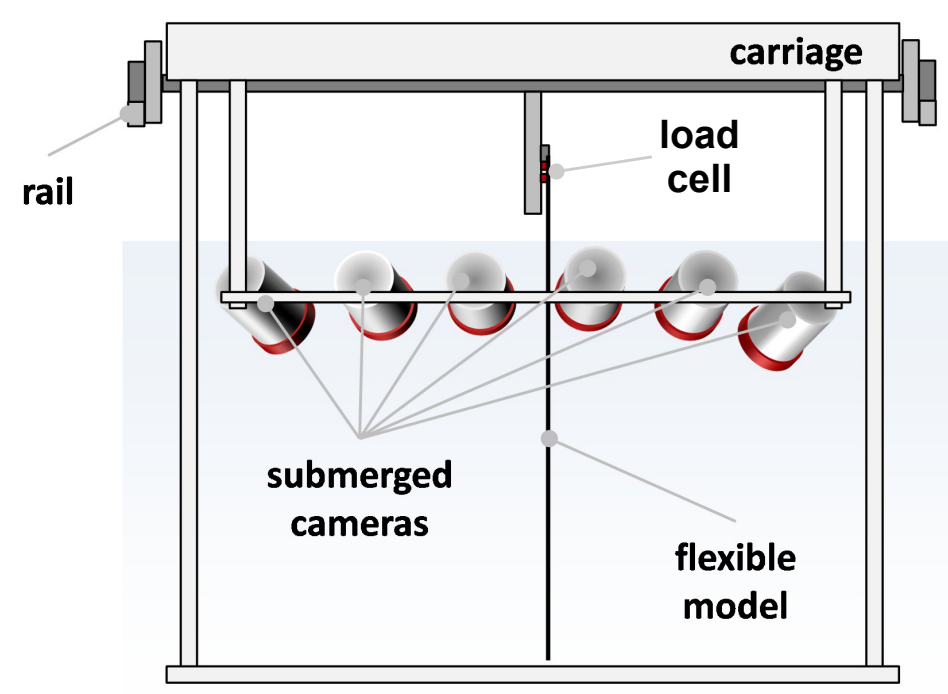

(b) Vista traseira.

Fonte: Extraída de Franzini et al. (2016a).

A caracterização do modelo flexível imerso foi feita por meio de ensaios de decaimento. Tais ensaios foram conduzidos conferindo impactos localizados no meio do vão do modelo e medindo as respostas dos alvos refletivos. Calculando o espectro de amplitude para cada série temporal medida, foi possível a avaliação tanto das três primeiras frequências naturais quanto das correspondentes formas modais. Esses resultados estão ilustrados na Figura 61. 
Figura 60 - Fotografias do arranjo experimental.

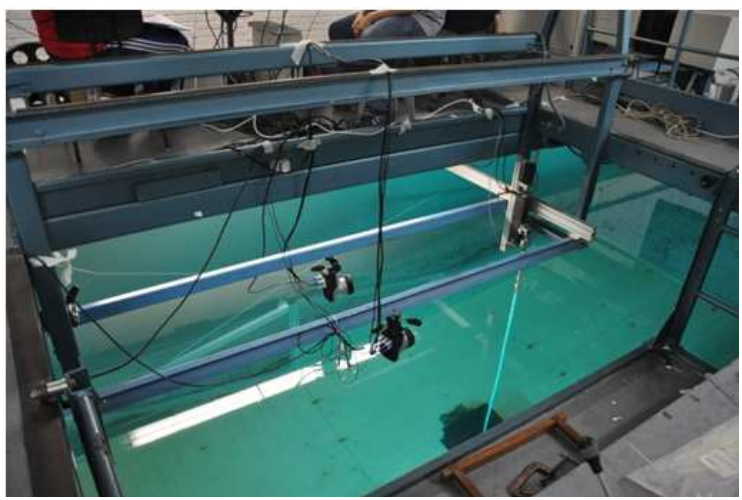

(a) Arranjo experimental geral.

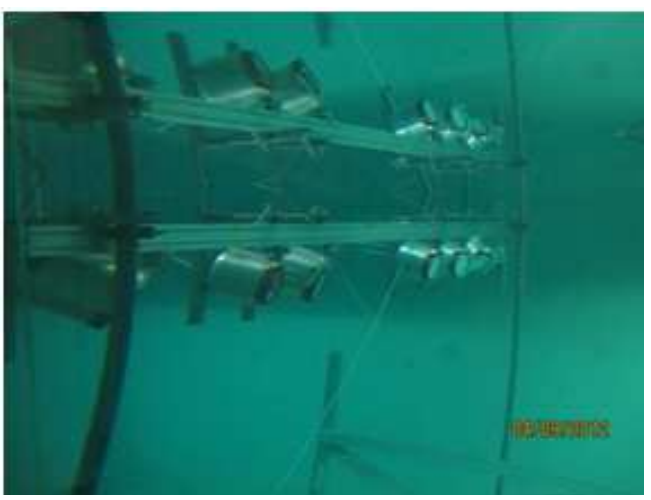

(b) Câmeras submersas.

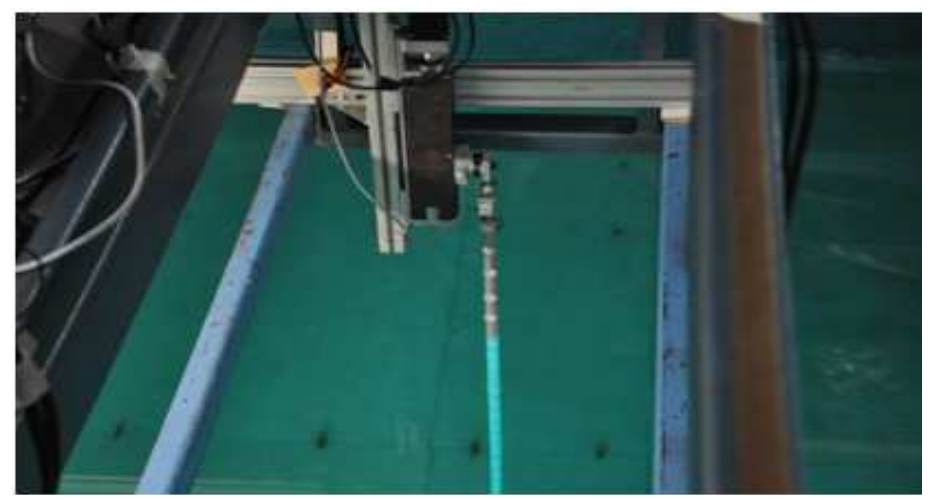

(c) Dispositivo de imposição de movimento ao topo do modelo.

Fonte: Extraída de Franzini et al. (2015)

Como revela a Figura 61, as três primeiras frequências naturais seguem uma relação praticamente linear com o número do modo dada por $f_{n, k}=k 0,84 \mathrm{~Hz}$. A mesma figura mostra, ainda, que a segunda frequência natural está associada a um modo com um nó interno localizado praticamente na metade do vão. Já a terceira frequência natural está associada a uma forma de vibrar (modo) com dois nós internos, localizados aproximadamente em $\xi=z / L_{0}=1 / 3$ e $\xi=2 / 3$. Como o leitor nota mais adiante na presente seção, esses resultados são úteis quando da definição das funções de projeção utilizadas no método de Galerkin.

A metodologia de análise envolveu tanto procedimentos clássicos como outros cujas aplicações e sistematizações consistem em algumas contribuições apresentadas neste texto. As análises clássicas consistem naquelas baseadas nos valores estatísticos e nos espectros de amplitude obtidos a partir das séries temporais medidas em cada um dos alvos posicionados ao longo do modelo.

Já as outras análises têm como ponto de partida o cálculo das séries temporais de amplitude modal. A obtenção dessas séries temporais é agora explicada. Inicialmente, 
Tabela 3 - Caracterização do arranjo experimental. A direção ao longo do eixo do cilindro vertical é indicada pela coordenada $z$, assumida como nula no vínculo inferior.

\begin{tabular}{cc}
\hline \hline \multicolumn{3}{c}{ Propriedades do cilindro } \\
\hline Diâmetro externo $D$ & $22,2 \mathrm{~mm}$ \\
Rigidez axial $E A$ & $1,2 \mathrm{kN}$ \\
Rigidez flexional $E I$ & $0,056 \mathrm{Nm}{ }^{2}$ \\
Linear massa linear $m_{l}$ & $1,19 \mathrm{~kg} / \mathrm{m}$ \\
Peso imerso $\gamma$ & $7,88 \mathrm{~N} / \mathrm{m}$ \\
\hline Comprimento indeformado $L_{0}$ & $2552 \mathrm{~mm}$ \\
Comprimento deformado $L$ & $2602 \mathrm{~mm}$ \\
Comprimento imerso $L_{i}$ & $2257 \mathrm{~mm}$ \\
Parâmetro de massa $m^{*}$ & 3,48 \\
Razão de aspecto $L_{i} / D$ & 102 \\
\multicolumn{3}{c}{$L / D$} & 117 \\
Tração estática no topo $T_{t}$ & $40 \mathrm{~N}$ \\
\multicolumn{3}{c}{$\zeta_{1}$} \\
$\zeta_{1}^{a r}$ & $4,17 \%$ \\
\hline \multicolumn{3}{c}{ Frequências naturais } \\
\hline modo k $f_{n, k}^{a r}$ \\
$1,49 \%$ \\
$2,05 \mathrm{~Hz}$ \\
3
\end{tabular}

Fonte: Adaptada de Franzini et al. (2018).

definem-se, respectivamente, $X^{*}\left(z, t_{j}\right)$ e $Y^{*}\left(z, t_{j}\right)$ como os deslocamentos normalizados pelo diâmetro do cilindro nas direções in-line e cross-wise e medidos em uma dada posição $z$ ao longo do modelo e para um particular instante $t_{j}$. Admita que tanto $X^{*}\left(z, t_{j}\right)$ quanto $Y^{*}\left(z, t_{j}\right)$ possam ser escritos como uma composição, para vários modos de vibrar (representados pelo índice $k$ ), de uma função temporal $\left(a_{k}^{x}\left(t_{j}\right)\right.$ ou $\left.a_{k}^{y}\left(t_{j}\right)\right)$ multiplicadas por uma função que depende somente da posição ao longo do modelo $\psi_{k}(z)$. Matematicamente, essa expansão é representada pelas Equações 7.1 e 7.2 .

$$
\begin{aligned}
& X^{*}\left(z, t_{j}\right)=\sum_{k=1}^{\infty} \tilde{a}_{k}^{x}\left(t_{j}\right) \psi_{k}(z) \\
& Y^{*}\left(z, t_{j}\right)=\sum_{k=1}^{\infty} \tilde{a}_{k}^{y}\left(t_{j}\right) \psi_{k}(z)
\end{aligned}
$$

Considerando o conjunto de funções espaciais $\psi_{k}(z)$ como ortogonal segundo o produto interno usual do espaço das funções, as séries temporais de amplitude modal $\tilde{a}_{k}^{x}\left(t_{j}\right)$ ou $\tilde{a}_{k}^{y}\left(t_{j}\right)$ são escritas como: 
Figura 61 - Resultado experimental do ensaio de decaimento com o modelo imerso.

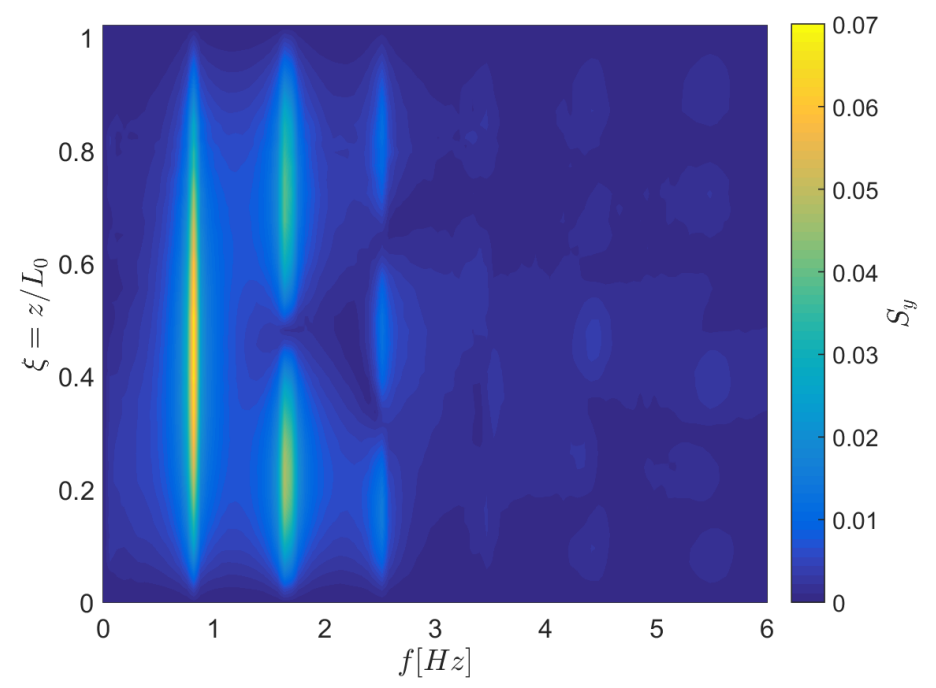

Fonte: Adaptada de Franzini et al. (2015).

$$
\begin{aligned}
& \tilde{a}_{k}^{x}\left(t_{j}\right)=\frac{\int_{0}^{1} X^{*}\left(\xi, t_{j}\right) \psi_{k}(\xi) d \xi}{\int_{0}^{1}\left(\psi_{k}(\xi)\right)^{2} d \xi} \\
& \tilde{a}_{k}^{y}\left(t_{j}\right)=\frac{\int_{0}^{1} Y^{*}\left(\xi, t_{j}\right) \psi_{k}(\xi) d \xi}{\int_{0}^{1}\left(\psi_{k}(\xi)\right)^{2} d \xi}
\end{aligned}
$$

sendo $\xi=z / L_{0}$. Embora o procedimento usual empregue as funções de projeção $\psi_{k}(\xi)$ como sendo os modos naturais de vibração, aqui faz-se uso de uma função senoidal na forma da Equação 7.5.

$$
\psi_{k}(\xi)=\sin (k \pi \xi)
$$

No caso de cabos horizontais onde a força normal não varia ao longo da estrutura, os modos naturais são dados pela Equação 7.5. No entanto, o modelo flexível vertical tem a força normal variando linearmente com a posição $z$ (ou, em termos de uma grandeza adimensional, com a variável $\xi$ ), de sorte que os seus modos naturais são escritos como funções de Bessel (ver, por exemplo, Pesce (1997)).

A escolha do conjunto de funções trigonométricas como base para a expansão da resposta é agora justificada. A primeira é que ela respeita as condições de deslocamento nulo nas extremidades do modelo. Embora engastadas em ambas as extremidades, a baixa rigidez flexional do modelo confere à estrutura investigada um comportamento semelhante ao de um cabo. A segunda justificativa é que as funções de Bessel, além de mais complicadas de serem tratadas do ponto de vista analítico, não constituem uma base ortogonal. Por fim e como já visto na Figura 61, a análise de um ensaio de decaimento 
mostrou que a aproximação do modo de vibrar por uma função trigonométrica adere bem ao comportamento experimentalmente obtido.

O procedimento acima descrito é denominado ao longo deste texto como decomposição modal, embora não faça uso dos modos de vibrar e sim de aproximações para os mesmos. As séries temporais de amplitude modal permitem interpretações complementares àquelas conferidas pela análise clássica. Um primeiro aspecto é que elas contemplam informações acerca de diversos alvos em um número baixo de séries temporais, o que permite a construção e análise de modelos de ordem reduzida. Cumpre ressaltar que, embora alguns trabalhos já tenham empregado as séries temporais de amplitude modal (ver, por exemplo, Huera-Huarte e Bearman (2009a) e Shang, Stone e Smits (2014)4), algumas contribuições inovadoras são aqui pontuadas.

Uma contribuição é o estudo do sincronismo entre as séries temporais de amplitude modal por meio da avaliação da série temporal de defasagem entre as referidas respostas. Essa defasagem (e, por consequência, análise de sincronismo) pode contemplar tanto modos no mesmo plano quanto modos em planos ortogonais. Segundo Pikovsky, Rosenblum e Kurths (2001), dois sinais estão sincronizados quando a diferença de fase entre eles é invariantes com o tempo. A avaliação da série temporal de defasagem foi feita com base na Transformada de Hilbert existente no ambiente MATLAB ${ }^{\circledR}$ segundo o procedimento descrito em sequência.

Seja $w(t)$ um sinal qualquer e $\mathscr{H}(w)$ sua Transformada de Hilbert que, por sua vez, permite a avaliação de sua fase $\phi^{w}(t)$ e de sua amplitude $a^{w}(t)$ instantâneas, por meio da Equação 7.6.

$$
\mathscr{H}(w)=a^{w}(t) \mathrm{e}^{\mathrm{j} \phi^{w}(t)}
$$

Uma vez definido o procedimento para o cálculo da fase de um sinal, a série temporal de defasagem é definida, no âmbito das análises deste capítulo, como:

$$
{ }_{n}^{m} \phi_{p}^{q}(t)=-\beta \phi_{n}^{p}(t)+\phi_{m}^{q}(t)
$$

onde $p$ e $q$ representam a direção ( $x$ para in-line e $y$ para cross-wise) e $\beta$ a relação entre as frequências dominantes. Esse procedimento já foi aplicado no contexto de VIV em Huera-Huarte e Bearman (2009a) para o estudo do sincronismo entre as oscilações nas direções in-line e cross-wise de certos pontos do modelo flexível e em Franzini et al. (2013) na análise da defasagem entre força e deslocamento em experimentos nas condições VIV-1gl e VIV-2gl.

4 Esses trabalhos também usam funções trigonométricas como funções de projeção e denominam as séries temporais de amplitude modal como, simplesmente, pesos modais. 
Uma segunda contribuição corresponde ao cálculo do valor característico da série temporal de amplitude modal $\left(\hat{A}_{k}^{x}\right.$ ou $\left.\hat{A}_{k}^{x}\right)$, dado pela média dos $10 \%$ maiores $^{5}$ valores extremos das séries temporais de amplitude modal $\tilde{a}_{k}^{x}(t)$ ou $\tilde{a}_{k}^{y}(t)$. Cumpre destacar que o cálculo da amplitude característica de vibração é um ponto que deve sempre ser explicitado no âmbito de análises do fenômeno de VIV, uma vez que as diversas formas existentes (por exemplo, o valor máximo da série temporal ou o produto do desvio padrão por $\sqrt{2}$ ) podem levar a distintos resultados, dependendo do nível de modulação em amplitude do sinal.

Por fim, e consistindo de uma contribuição inédita da pesquisa aqui descrita, os valores característicos de amplitudes modais são exibidos não como função da velocidade reduzida clássica, mas sim daquela que considera as diversas frequências naturais. s adimensional é definido como velocidade reduzida modal e é dado pela Equação 7.8.

$$
U_{r, k}=\frac{U_{\infty}}{f_{n, k} D}
$$

Note que $U_{r, k}$ emprega a frequência natural do k-ésimo modo de vibrar $f_{n, k}$ obtida a partir dos ensaios de decaimento conduzidos em água parada. Conforme o leitor pode ver na seção 7.3, essa grandeza permite a avaliação do lock-in nos diversos modos naturais.

As análises espectrais foram conduzidas por meio do cálculo de espectros de amplitude via Transformada de Fourier Discreta (TFD). Nas análises espectrais, os resultados são exibidos como função da frequência de oscilação adimensionalizada pela frequência natural do primeiro modo, ou seja, $\hat{f}=f / f_{n, 1}$. No caso dos espectros calculados ao longo da envergadura do cilindro, adota-se como nomenclatura $S_{x}(\xi, \hat{f})$ ou $S_{y}(\xi, \hat{f})$, sendo $\xi=0$ o vínculo inferior do modelo.

\subsection{Contribuições à análise experimental do fenômeno de excitação paramétrica em um cilindro flexível submerso}

Os resultados apresentados nesta seção contemplam aqueles apresentados inicialmente em Franzini et al. (2014), artigo publicado na 33rd International Conference on Ocean, Offshore and Arctic Engineering - OMAE2014, importante conferência na área de engenharia oceânica. Tendo em vista a boa receptividade do trabalho por parte do comitê científico da conferência, uma versão mais aprofundada desse trabalho foi posteriormente publicada no Journal of Vibration and Acoustics; ver Franzini et al. (2015). Em uma primeira fase de análise, esta seção discute os resultados dos escalogramas $x^{*}(\xi, \tau)$ e dos espectros de amplitude $S_{x}(\xi, \hat{f})$ avaliados a partir do processamento das séries temporais

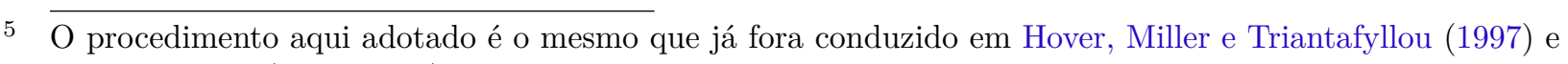
Franzini et al. $(2009,2013)$. 
de deslocamento de todos os alvos monitorados. Visando relembrar o leitor de que os experimentos analisados na presente seção foram conduzidos com o carro de reboque parado, os escalogramas e os espectros de amplitude vêm gravados com a indicação $U_{r, 1}=0$.

A Figura 62 apresenta os escalogramas e os espectros de amplitude obtidos a partir de experimentos com movimento imposto de frequências $f_{t}: f_{n, 1}=1: 3$ e $f_{t}: f_{n, 1}=1: 1$. Como ilustra a Figura 62(a), a resposta à excitação de topo com $f_{t}: f_{n, 1}=1: 3$ é bastante baixa. Para essa mesma condição de movimento prescrito, a Figura 62(b) revela a presença de respostas em $\hat{f}=1 / 3$ (ou seja, na frequência da excitação de suporte) e nas componentes $\hat{f}=2 / 3$ e $\hat{f}=1$.

Os resultados relativos à condição de movimento imposto com $f_{t}: f_{n, 1}=1: 1$ são ilustrados nas Figuras 62(c) e 62(d). As franjas em cores exibidas no escalograma da Figura 62(c) não são verticais, o que indica uma resposta caracterizada por ondas progressivas no modelo. Já o espectro de amplitude $S_{x}(\xi, \hat{f})$ apresentado na Figura $62(\mathrm{~d})$ revela a existência de três componentes de frequência distintas, a saber, $\hat{f}=1, \hat{f}=2$ e $\hat{f}=3$. A Figura 62(d) revela, ainda, que a resposta nessas são dominadas pelas correspondentes formas de vibrar, embora com alguma distorção se comparada à forma de vibrar dada por uma função senoidal. Essa inferência ${ }^{6}$ pode ser feita olhando a posição dos nós (pontos com baixa densidade espectral de potência).

Os escalogramas e os espectros de amplitudes obtidos para as condições com movimento de topo definidas por $f_{t}: f_{n, 1}=2: 1$ e $f_{t}: f_{n, 1}=3: 1$ são apresentados na Figura 63. Iniciando a análise pela condição $f_{t}: f_{n, 1}=2: 1$, a Figura 63(a) ilustra um escalograma distinto daqueles observados na outras condições, onde o formato predominante é assemelhado ao de um garfo, com uma transição da primeira para a segunda forma modal em aproximadamente metade do comprimento do modelo.

Ainda considerando essa condição de movimento imposto, o espectro de amplitude $S_{x}(\xi, \hat{f})$ apresentado na Figura 63(b) corrobora a existência dos dois primeiros modos na resposta, sendo o primeiro o modo dominante. A dominância do primeiro modo não surpreende, uma vez que o movimento prescrito ao topo (e, por consequência, a variação temporal da força normal) se dá com o dobro da primeira frequência natural, constituindo a instabilidade paramétrica principal com o primeiro modo de vibrar.

As Figuras 63(c) e 63(d) trazem, respectivamente, o escalograma e o espectro de amplitude $S_{x}(\xi, \hat{f})$ avaliados a partir do ensaio com movimento prescrito com frequência $f_{t}: f_{n, 1}=3: 1$. Esses gráficos revelam claramente que a resposta a essa solicitação é composta apenas do terceiro modo natural de vibrar.

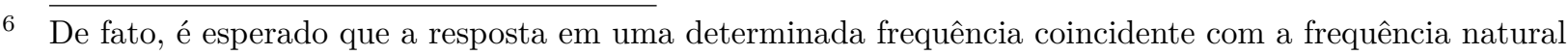
de um modo leva a uma resposta com a correspondente forma modal. No entanto, como o leitor pode ver ainda neste capítulo, são observadas situação onde o cilindro vibra na forma de um modo natural mas com a frequência de um modo distinto. 
Figura 62 - Escalogramas $x^{*}(\xi, \tau)$ e espectros de amplitude $S_{x}(\xi, \hat{f})$. Os escalogramas ilustram apenas 10 instantes de tempo adimensional de medição. $f_{t}: f_{n, 1}=$ $1: 3$ e $f_{t}: f_{n, 1}=1: 1$.

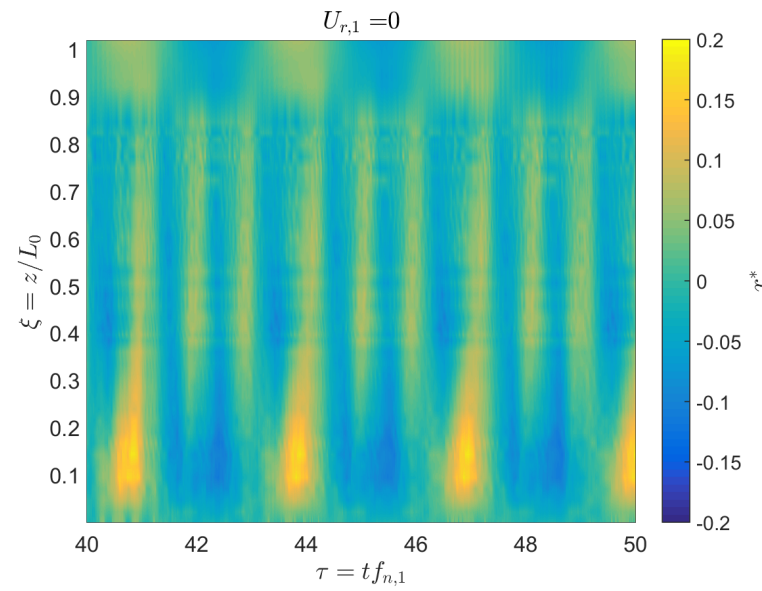

(a) $f_{t}: f_{n, 1}=1: 3$.

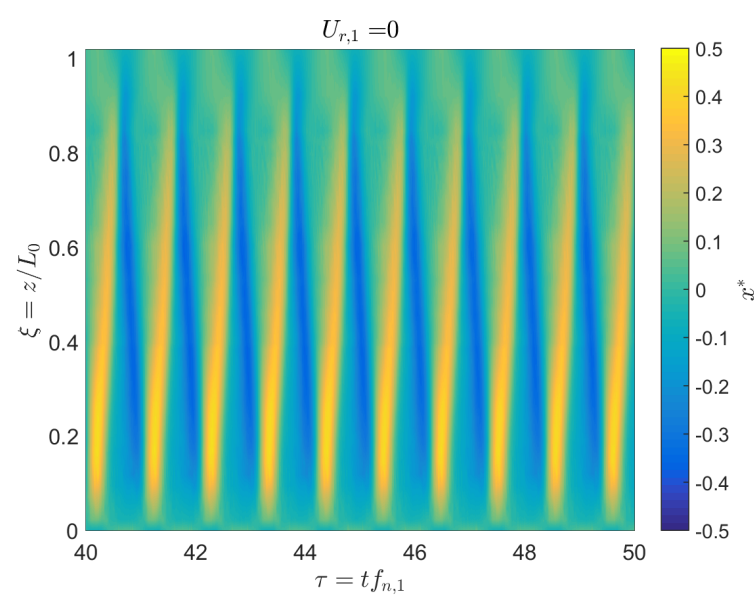

(c) $f_{t}: f_{n, 1}=1: 1$.

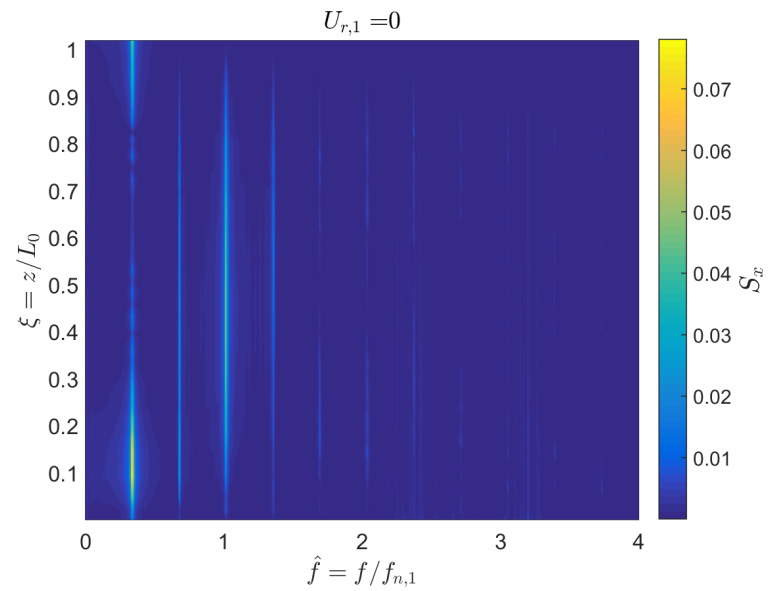

(b) $f_{t}: f_{n, 1}=1: 3$.

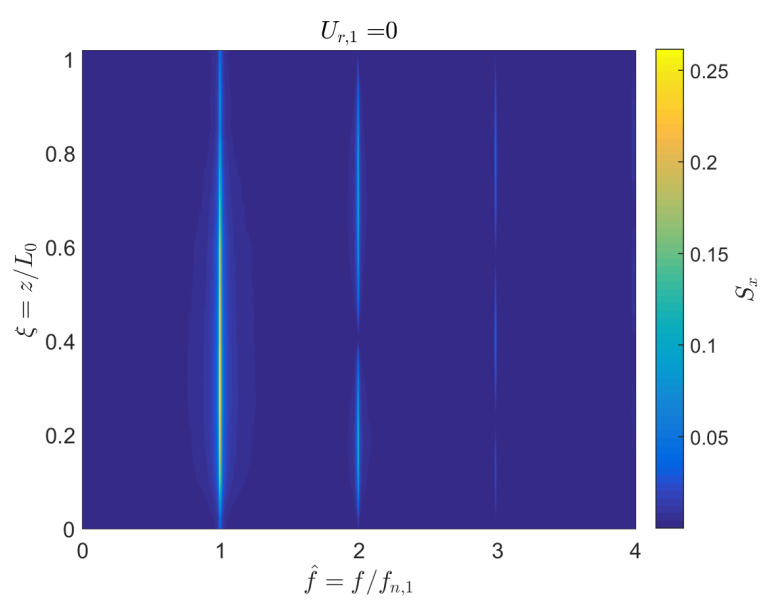

(d) $f_{t}: f_{n, 1}=1: 1$.

Fonte: Adaptada de Franzini et al. (2015).

As análises conduzidas até este momento focaram no estudo das respostas medidas em todos os pontos monitorados do modelo, de sorte que nenhuma informação sobre as séries temporais de amplitude modal foi dada. Assim, esta seção passa a focar nessa última análise mencionada.

Antes do início da análise das séries temporais de amplitude modal, cabe a apresentação de um modelo analítico simplificado para a dinâmica planar de um cabo vertical submerso $^{7}$ A equação de movimento para o problema mencionado é dada na forma da

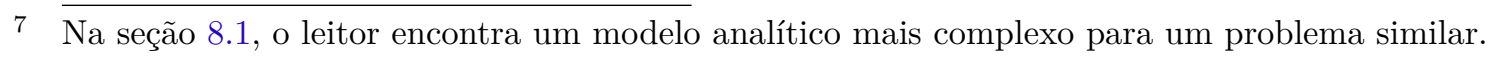


Figura 63 - Escalogramas $x^{*}(\xi, \tau)$ e e espectros de amplitude $S_{x}(\xi, \hat{f})$. Os escalogramas ilustram apenas 10 instantes de tempo adimensional de medição. $f_{t}: f_{n, 1}=$ $2: 1$ e $f_{t}: f_{n, 1}=3: 1$.

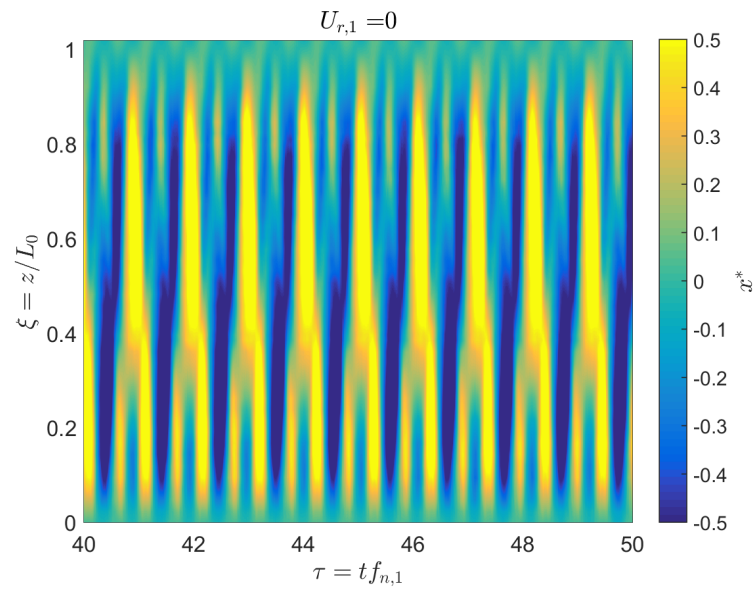

(a) $f_{t}: f_{n, 1}=2: 1$.

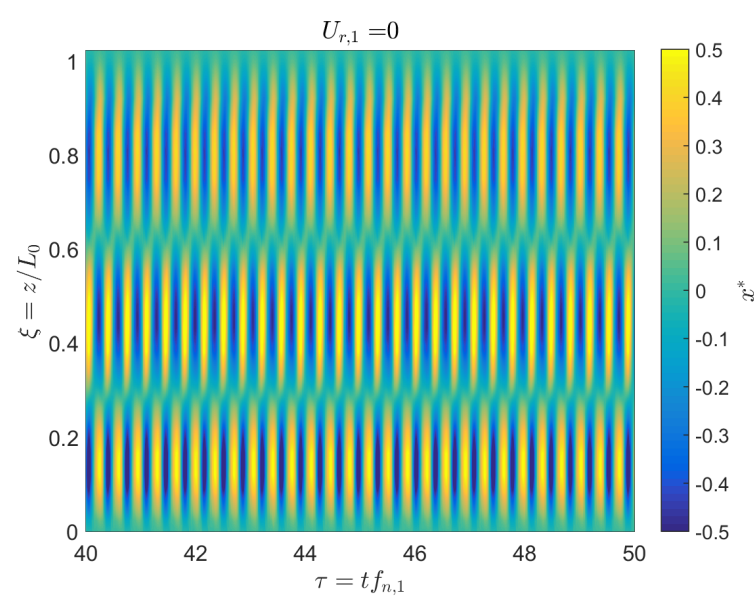

(c) $f_{t}: f_{n, 1}=3: 1$.

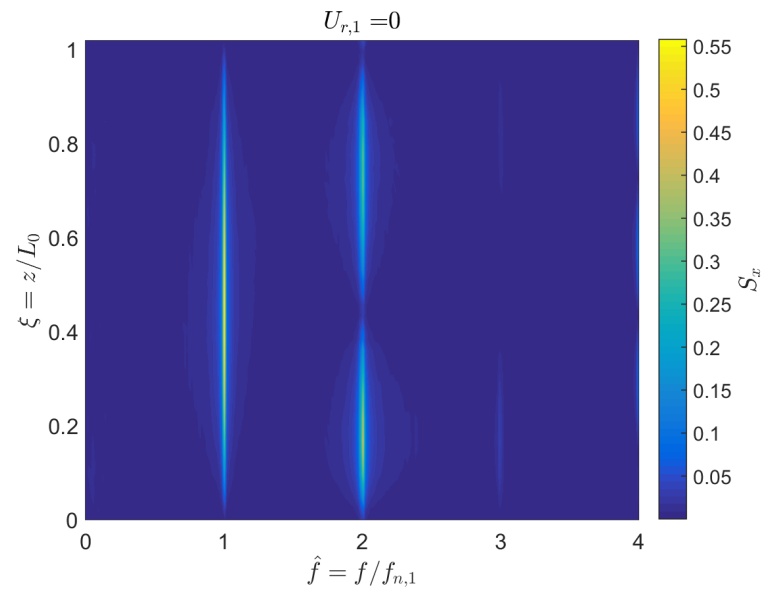

(b) $f_{t}: f_{n, 1}=2: 1$.

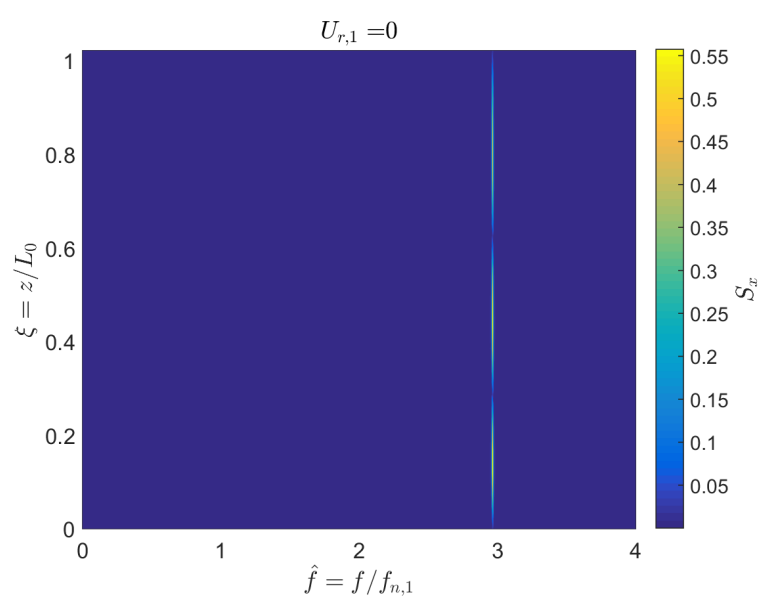

(d) $f_{t}: f_{n, 1}=3: 1$.

Fonte: Adaptada de Franzini et al. (2015).

Equação 7.9 .

$$
m_{t} \frac{\partial^{2} x(z, t)}{\partial t^{2}}+\frac{1}{2} \rho D \bar{C}_{D} \frac{\partial x(z, t)}{\partial t}\left|\frac{\partial x(z, t)}{\partial t}\right|-\frac{\partial}{\partial z}\left(T(z, t) \frac{\partial x(z, t)}{\partial z}\right)=0
$$

onde $x=x(z, t)$ é o deslocamento lateral do cabo, $m_{t}=m_{l}+m_{a}^{p o t}$ é a massa linear total (soma de um termo estrutural $m_{l}$ com a massa adicional $m_{a}$ potencial), $\bar{C}_{D}$ é o coeficiente de arrasto médio e $T(z, t)$ é a tração ao longo do modelo e que pode ser escrita como:

$$
T(z, t)=\underbrace{T_{t}-\gamma\left(z-L_{0}\right)}_{\text {Parcela estática }}+\underbrace{T_{\text {din }}}_{\text {Parcela dinâmica }}
$$

Ao contrário do que é explorado na seção 8.1, esta seção propõe uma solução 
unimodal da forma $x(z, t)=\psi_{k}(z) a_{k}(t)$, sendo $k$ o número do modo. Tendo em vista a adoção do modo senoidal como função de aproximação (ver Equação 7.5), a equação modal de movimento é dada por:

$$
M_{k} \frac{d^{2} a_{k}}{d t^{2}}+\beta_{k}\left|\frac{d a_{k}}{d t}\right| \frac{d a_{k}}{d t}+\left(\eta_{k}+\xi_{k} \cos \left(\omega_{t} t\right)\right) a_{k}=0
$$

com

$$
\begin{aligned}
M_{k} & =\int_{0}^{L_{0}} m_{t} \psi_{k}^{2}(z) d z=\left(m_{l}+m_{a}^{p o t}\right) \frac{L}{2} \\
\beta_{k} & =\int_{0}^{L_{0}} \frac{1}{2} \rho C_{D} D\left|\psi_{k}(z)\right| \psi_{k}^{2}(z) d z \\
\eta_{k} & =-\int_{0}^{L_{0}} \frac{\partial}{\partial z}\left[\left(T_{t}-\gamma(L-z)\right) \frac{d \psi_{k}(z)}{d z}\right] \psi_{k}(z) d z=\left(\frac{k \pi}{2}\right)^{2}\left(2 \frac{T_{t}}{L}-\gamma\right) \\
\xi_{k} & =\left(\frac{k \pi}{2}\right)^{2}\left(\frac{E A}{L_{o}}\right) \frac{2 A_{t}}{L}
\end{aligned}
$$

Por questão de maior generalidade, a Equação 7.11 é, agora, reescrita em sua forma adimensional. Para tanto, considere as seguintes quantidades:

$$
2 \tau=\omega_{t} t=2 \pi f_{t} t, \mu_{k}=\frac{\beta_{k}}{2 M_{k}}, \delta_{k}=\frac{4 \eta_{k}}{M_{k} \omega_{t}^{2}}, \epsilon_{k}=\frac{2 \xi_{k}}{M_{k} \omega_{t}^{2}}
$$

Definindo ( $)$ como a derivada com relação a $\tau$ e $\tilde{a}_{k}=a_{k} / D$, a Equação 7.11 é adimensionalizada na forma da Equação 7.17.

$$
\ddot{\tilde{a}}_{k}+2 \mu_{k} D \dot{\tilde{a}}_{k}\left|\dot{\tilde{a}}_{k}\right|+\left(\delta_{k}+2 \epsilon_{k} \cos (2 \tau)\right) \tilde{a}_{k}=0
$$

O leitor nota, neste ponto, as similaridades existentes entre as Equações 3.3 (ver seção 3.1) e 7.17, sendo a forma do termo dissipativo a única diferença entre elas.

O modelo analítico apresentado nesta seção permite a obtenção de equações de Mathieu com amortecimento quadrático para cada modo de vibrar. Essas equações modais, em conjunto com as definições de $\delta_{k}$ e $\epsilon_{k}$, permitem a construção de diagramas de Strutt modais. Tais diagramas não são encontrados na literatura e constituem uma colaboração da pesquisa liderada pelo autor deste texto. Por questão de simplicidade, as curvas de transição destes diagramas de Strutt correspondem ao problema não amortecido, embora o cilindro submerso sujeito à excitação paramétrica tenha importante dissipação decorrente do amortecimento hidrodinâmico.

Cabe ressaltar uma nomenclatura aqui adotada. Na condição onde um ponto experimental estiver localizado em uma região na qual o diagrama prevê soluções ilimitadas, 
este texto adotará indicará este ponto como suscetível à instabilidade paramétrica, mesmo sabendo que as respostas são limitadas por conta do amortecimento hidrodinâmico quadrático. A Tabela 4 apresenta os valores característicos das séries temporais de amplitude modal aqui estudadas $\left(\hat{A}_{k}\right)$. Como mencionado na seção 7.1 , o valor característico $\hat{A}_{k}$ é aqui calculado considerando a média dos $10 \%$ maiores picos das séries temporais $\tilde{a}(\tau)$. A Tabela 4 ainda traz a relação entre a frequência dominante de oscilação das séries temporais de amplitude modal $f_{d}$ e a frequência natural do primeiro modo.

Tabela 4 - Valores característicos das séries temporais de amplitude modal.

\begin{tabular}{c|c|c|c|c|c|c}
\hline \hline \multirow{2}{*}{$f_{t}: f_{n, 1}$} & \multicolumn{3}{|c|}{$\hat{A}_{k}$} & \multicolumn{3}{c|}{$f_{d} / f_{n, 1}$} \\
\cline { 2 - 7 } & $k=1$ & $k=2$ & $k=3$ & $k=1$ & $k=2$ & $k=3$ \\
\hline \hline $1: 3$ & 0,10 & 0,05 & 0,04 & 1,00 & 0,33 & 0.33 \\
\hline $1: 1$ & 0,38 & 0,18 & 0,10 & 1,00 & 1,00 & 2.00 \\
\hline $2: 1$ & 0,63 & 0,45 & 0,16 & 1,00 & 2,00 & 2.00 \\
\hline $3: 1$ & 0,05 & 0,12 & 0,45 & 3,00 & 3,00 & 3.00 \\
\hline \hline
\end{tabular}

Fonte: Adaptada de Franzini et al. (2015).

A Tabela 5 exibe os pontos do plano $\left(\delta_{k} ; \epsilon_{k}\right)$ experimentalmente estudados enquanto que a Figura 64 ilustra os diagramas de $\operatorname{Strutt}^{8}$ construídos para $k=1,2$ e 3 .

Tabela 5 - Pontos experimentais no plano $\left(\delta_{k} ; \epsilon_{k}\right)$. Pontos destacados são próximos das curvas de transição ou na região de instabilidade.

\begin{tabular}{c|c|c|c|c|c|c}
\hline \hline \multirow{2}{*}{$k$} & \multicolumn{3}{|c|}{$\delta_{k}$} & \multicolumn{3}{c|}{$\epsilon_{k}$} \\
\cline { 2 - 7 } & 1 & 2 & 3 & 1 & 2 & 3 \\
\hline \hline$f_{t}: f_{n, 1}=1: 3$ & 35,54 & 142,17 & 319,88 & 7,02 & 28,09 & 63,19 \\
\hline$f_{t}: f_{n, 1}=1: 1$ & $\mathbf{3 , 9 5}$ & 15,80 & 35,54 & $\mathbf{0 , 7 8}$ & 3,12 & 7,02 \\
\hline$f_{t}: f_{n, 1}=2: 1$ & $\mathbf{0 , 9 9}$ & $\mathbf{3 , 9 5}$ & 8,89 & $\mathbf{0 , 2 0}$ & $\mathbf{0 , 7 8}$ & 1,76 \\
\hline$f_{t}: f_{n, 1}=3: 1$ & 0,44 & 1,76 & $\mathbf{3 , 9 5}$ & 0.09 & 0,35 & $\mathbf{0 , 7 8}$ \\
\hline \hline
\end{tabular}

Fonte: Adaptada de Franzini et al. (2015).

No diagrama de Strutt modal correspondente a $k=1$ (ver Figura 64(a)), a condição $f_{t}: f_{n, 1}=2: 1$ aparece na região de instabilidade da solução trivial, enquanto que o caso com $f_{t}: f_{n, 1}=1: 1$ está nas vizinhanças de uma curva de transição. Já a condição de movimento $f_{t}: f_{n, 1}=3: 1$ está claramente na região de estabilidade da solução trivial.

Aprofundando a discussão, a condição $f_{t}: f_{n, 1}=2: 1$ é um exemplo clássico de instabilidade paramétrica principal e indica oscilações estruturais com predomínio do

8 Embora esses gráficos também sejam chamados de diagramas de Strutt modais, tal nomenclatura, do ponto de vista formal, não é precisa. O leitor relembra que os parâmetros $\delta_{k}$ e $\epsilon_{k}$ foram avaliados tomando como função de projeção no método de Galerkin uma função trigonométrica. 
Figura 64 - Diagramas de Strutt modais. Vermelho (triângulo): $f_{t}: f_{n, 1}=1: 1$; Verde (círculo): $f_{t}: f_{n, 1}=2: 1$; Azul (quadrado): $f_{t}: f_{n, 1}=3: 1$. Os resultados para $f_{t}: f_{n, 1}=1: 3$ estão dentro da região estável e não são visíveis.

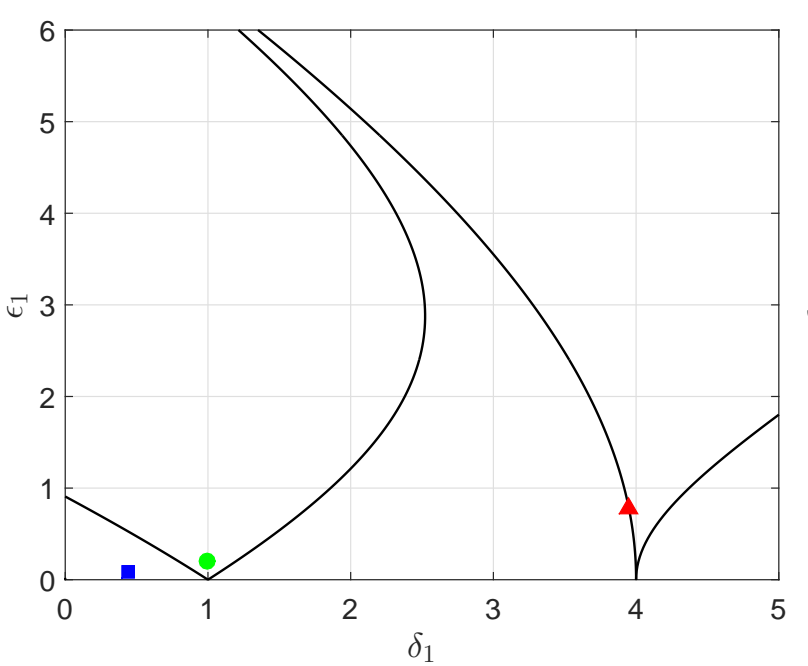

(a) $k=1$.

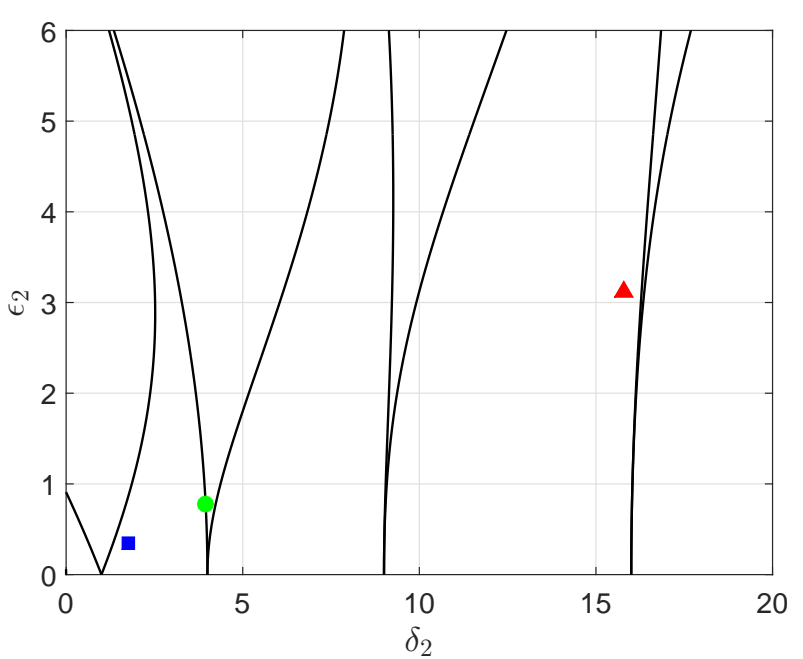

(b) $k=2$.

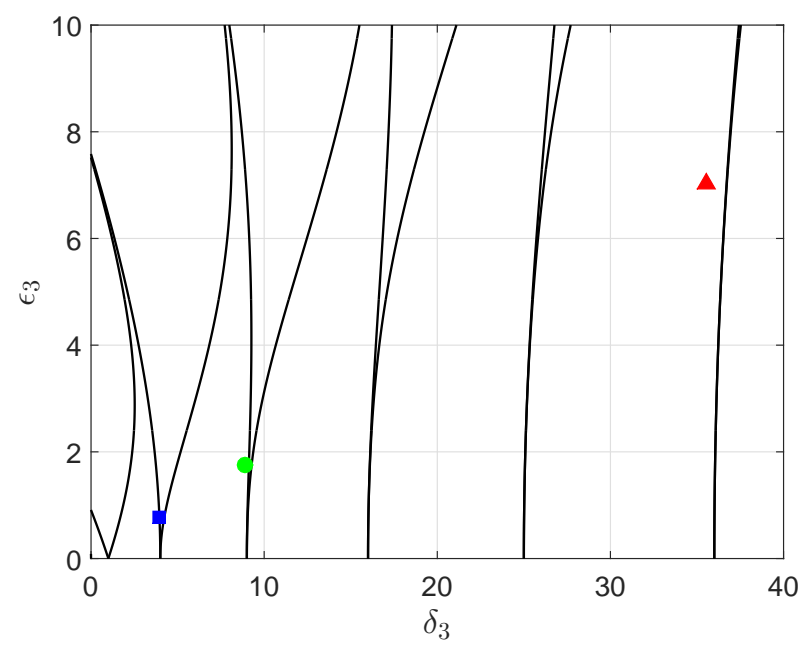

(c) $k=3$.

Fonte: Adaptada de Franzini et al. (2015).

primeiro modo. Convém ressaltar que, mesmo na região onde o diagrama de Strutt para o problema não amortecido prevê soluções ilimitadas, o amortecimento hidrodinâmico limita a resposta modal, em concordância com o trabalho de Patel e Park (1991).

Já o diagrama de Strutt modal para $k=2$ ilustrado na Figura 64(b) mostra que a condição $f_{t}: f_{n, 1}=2: 1$ (ou, de maneira equivalente, $f_{t}: f_{n, 2}=1: 1$ ) está sobre uma curva de transição. Além disso, os demais pontos estão nas proximidades de tais curvas, de sorte que uma pequena variação nos parâmetros que governam a dinâmica do sistema (por exemplo, a massa adicional) pode levar esses pontos para a região onde a instabilidade paramétrica no segundo modo é prevista para o caso não amortecido. Note, no entanto, que a condição identificada pelo triângulo vermelho $\left(f_{t}: f_{n, 1}=1: 1 \mathrm{ou}\right.$, de maneira 
equivalente, $\left.f_{f}: f_{n, 2}=1: 2\right)$ mesmo perto das curvas de transição, está próxima de uma estrita região de instabilidade.

Finalizada a discussão acerca dos diagramas de Strutt modais, o texto seugue para a análise das séries temporais de amplitude modal. A Figura 65 apresenta as séries temporais correspondentes ao primeiro modo de vibrar. Em concordância com o que já fora apresentado por ocasião da análise da Figura 62(a), o ensaio com movimento imposto definido por $f_{t}: f_{n, 1}=1: 3$ leva a uma resposta no primeiro modo de vibrar bastante baixa (amplitudes inferiores a 0,10; ver Figura 65(a)).

Figura 65 - Séries temporais de amplitude modal $\tilde{a}_{1}(\tau)$.
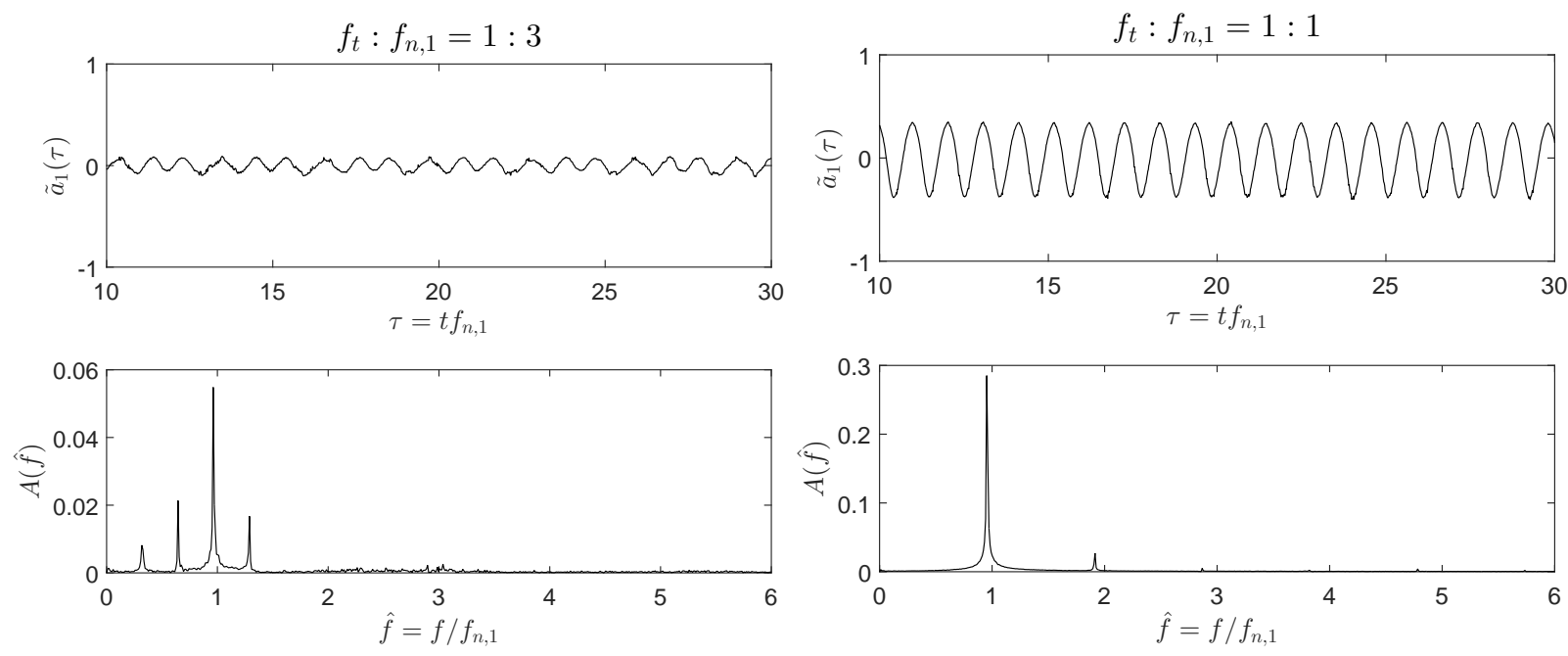

(a) $f_{t}: f_{n, 1}=1: 3$.

(b) $f_{t}: f_{n, 1}=1: 1$.
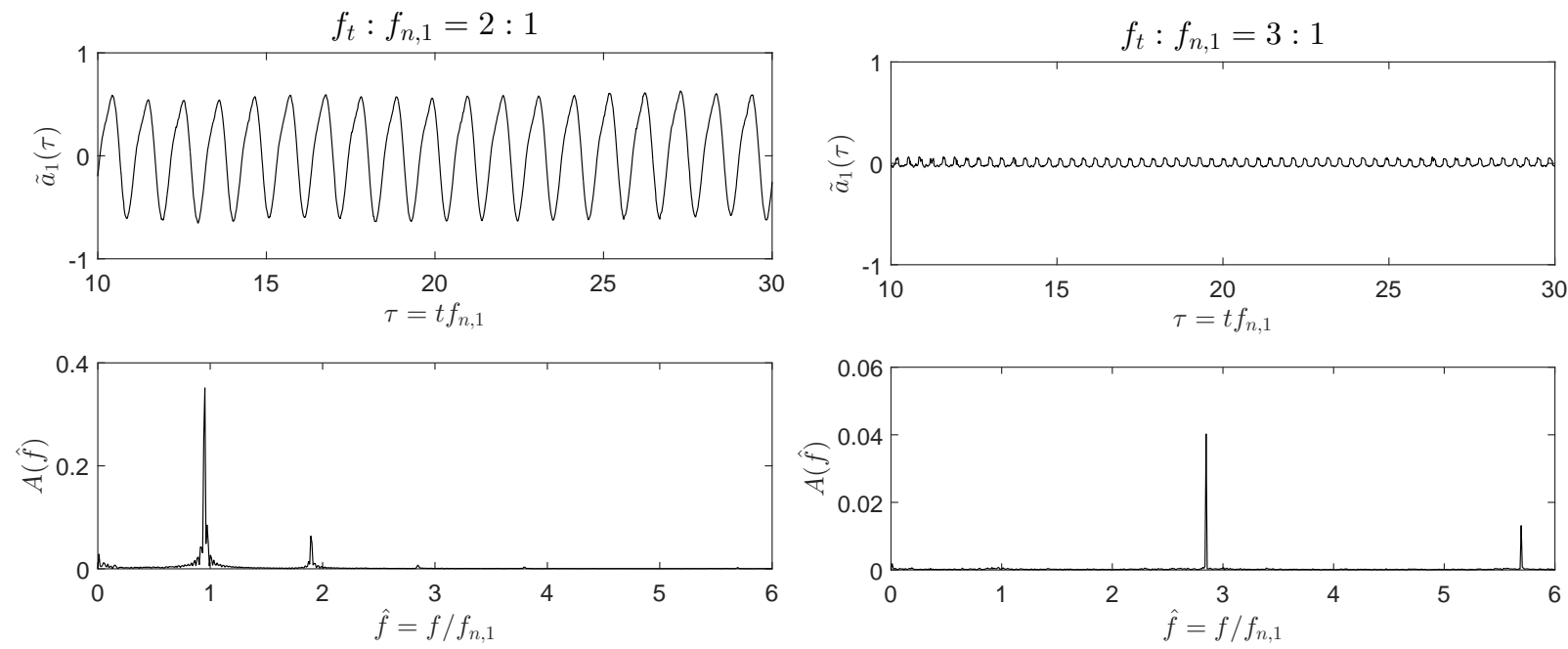

(c) $f_{t}: f_{n, 1}=2: 1$.

(d) $f_{t}: f_{n, 1}=3: 1$.

Fonte: Adaptada de Franzini et al. (2015).

Já as condições de excitação de suporte com $f_{t}: f_{n, 1}=1: 1$ e $f_{t}: f_{n, 1}=2$ : 1, ilustradas nas Figuras 65(b) e 65(c), apresentam respostas no primeiro modo com amplitudes próximas a 0,25 e 0,50 respectivamente, sendo a condição de instabilidade 
paramétrica principal aquela com a maior amplitude. Para essas condições, os espectros de amplitude revelam respostas praticamente monocromáticas com frequência $\hat{f}=1$. Finalmente, a Figura 65(d) revela que, embora com amplitude bastante baixa, a série temporal $\tilde{a}_{1}$ (ou seja, relacionada ao primeiro modo de vibrar) tem a frequência dominante do terceiro modo natural ( $\hat{f}=f / f_{n, 1}=3$ ou, de maneira equivalente, $f / f_{n, 3}=1$ ).

As séries temporais $\tilde{a}_{2}(\tau)$ e os correspondentes espectros de amplitude são ilustrados na Figura 66. A Figura 66(a) indica que praticamente não há contribuição de oscilações no segundo modo de vibrar para uma excitação de topo com $f_{t}: f_{n, 1}=1: 3$, corroborando a discussão já tecida na presente seção. Por sua vez, a série temporal $\tilde{a}_{2}(\tau)$ obtida a partir do experimento com $f_{t}: f_{n, 1}=1: 1$ apresenta duas frequências principais $\hat{f}=1$ e $\hat{f}=2$ e com amplitudes próximas; ver Figura 66(b).

Figura 66 - Séries temporais de amplitude modal $\tilde{a}_{2}(\tau)$.
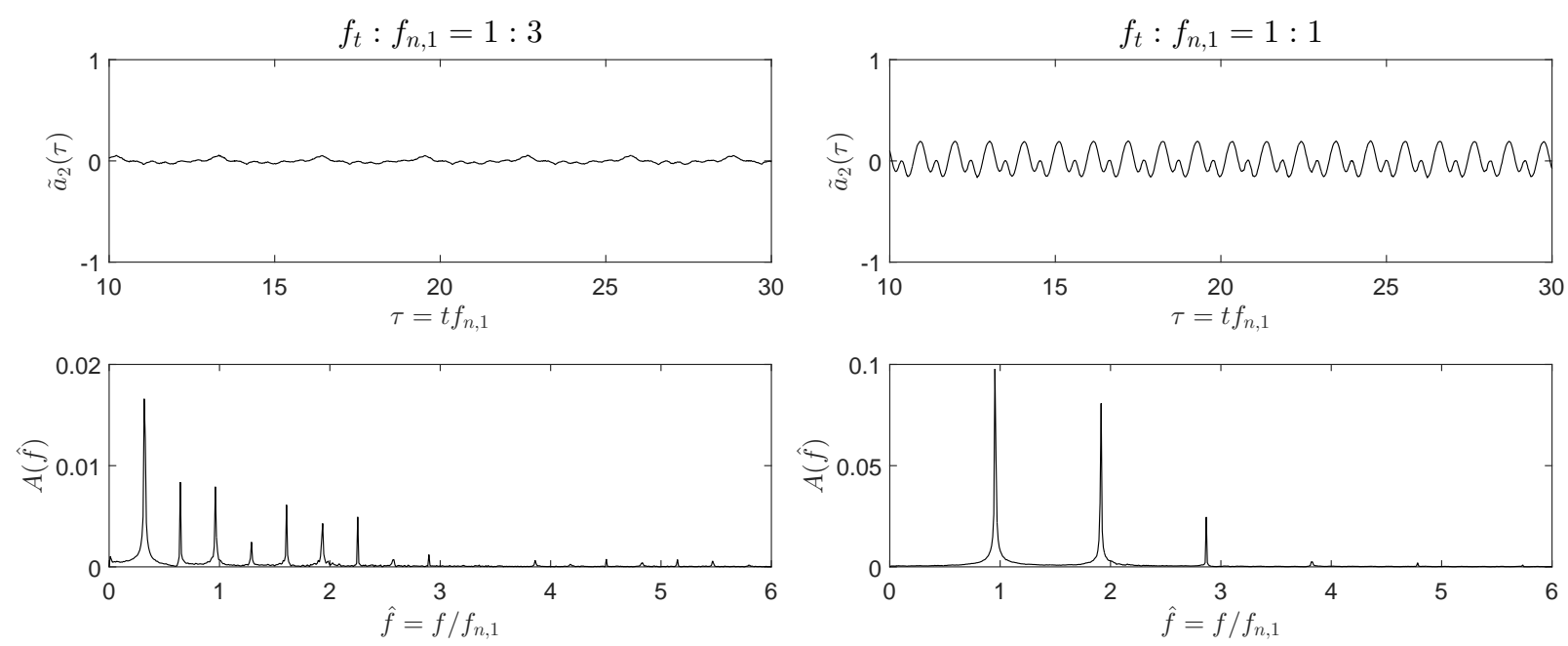

(a) $f_{t}: f_{n, 1}=1: 3$.

(b) $f_{t}: f_{n, 1}=1: 1$.
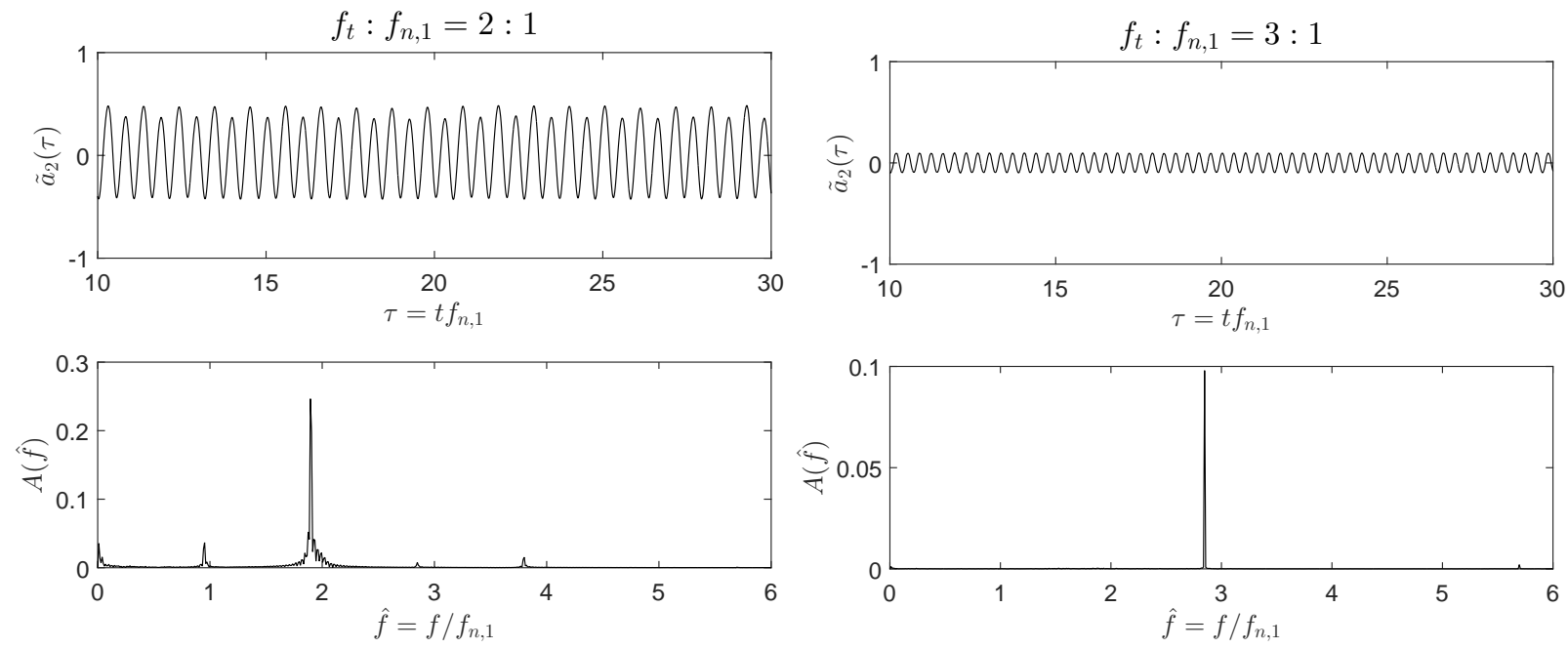

(c) $f_{t}: f_{n, 1}=2: 1$.

(d) $f_{t}: f_{n, 1}=3: 1$.

Fonte: Adaptada de Franzini et al. (2015). 
A série temporal apresentada na Figura 66(c) mostra que a série $\tilde{a}_{2}(\tau)$ apresenta modulações de amplitude quando o movimento prescrito tem frequência $f_{t}: f_{n, 1}=2: 1$. Nessa condição, a frequência dominante da série temporal $\tilde{a}_{2}(\tau)$ é $\hat{f}=2$, correspondendo à segunda frequência natural do modelo. Ao revisitar as Figuras 63(a) e 63(b), o leitor nota que, de fato, a imposição de movimento ao topo com $f_{t}: f_{n, 1}=2: 1$ leva a respostas nos dois primeiros modos naturais.

Por fim, a Figura 66(d) revela que $\tilde{a}_{2}(\tau)$ tem amplitude próxima a 0,10 quando a estrutura é solicitada por movimento de topo com $f_{t}: f_{n, 1}=3: 1$. Mais ainda e, constituindo um resultado análogo àquele observado para a análise da série $\tilde{a}_{1}(\tau)$, a frequência dominante identificada não é aquela do modo natural estudado, e sim coincidente com a frequência do movimento prescrito.

As últimas séries temporais de amplitude modal aqui estudada correspondem ao terceiro modo $(k=3)$ e os resultados a elas pertinentes são apresentados na Figura 67 . As condições de movimento prescrito $f_{t}: f_{n, 1}=1: 3, f_{t}: f_{n, 1}=1: 1$ e $f_{t}: f_{n, 1}=2: 1$ apresentadas nas Figuras 67(a), 67(b) e 67(c) respectivamente, pouco excitam respostas no terceiro modo de vibrar, de sorte que essa resposta modal compõe de maneira importante somente a resposta a uma excitação com frequência $f_{t}: f_{n, 1}=3: 1$ (ver Figura $67(\mathrm{~d})$ ). Note que, em decorrência da relação $f_{n, 3}=3 f_{n, 1}$, o movimento imposto com frequência $f_{t}: f_{n, 1}=3: 1$ induz uma ressonância clássica.

Esta seção é finalizada com a apresentação da Tabela 6, que resume os conteúdos espectrais das séries temporais de amplitude modal. Essa tabela apresenta, para cada cada modo de vibrar $k(k=1,2$ e 3$)$, quais as relações entre a frequência do movimento imposto e a frequência do correspondente modo de vibrar $f_{t}: f_{n, k}$, entre as frequências da resposta ${ }^{9}$ e a primeira frequência natural e entre as frequências da resposta e a frequência do k-ésimo modo de vibrar. Na Tabela 6, o símbolo "-" indica estabilidade da solução trivial, de sorte que $\tilde{a}_{k}=0 . f_{R}$ indica as componentes de frequência presentes na resposta enquanto que a marcação "*" está relacionada a respostas de baixa amplitude como, por exemplo, aquela apresentada na Figura 66(d).

Discutem-se, agora, formas de uso conjunto das informações apresentadas na Tabela 6 com aquelas existentes nos diagramas de Strutt modais da Figura 64. Considere o modo $k=1$ e a condição de movimento imposto $f_{t}: f_{n, 1}=2: 1$. Analisando a segunda linha da Tabela 6 , nota-se ${ }^{10}$ que a resposta modal tem o dobro do período da excitação paramétrica. Consultando o diagrama de Strutt construído para $k=1$ apresentado na Figura 65(a),

9 Nesse contexto, as frequências da resposta dizem respeito tanto aos valores previstos pelo diagrama de Strutt quanto aquelas experimentalmente observadas. No tocante às frequências previstas pelo diagrama de Strutt, o leitor relembra que na seção 3.1 foi mencionado que as curvas de transição correspondem a soluções com o período da excitação paramétrica ou com o seu dobro.

10 Como apoio, o leitor é direcionado à Figura 66(c), que mostra que a frequência dominante da série temporal de amplitude modal é $\hat{f}=f / f_{n, 1}=1$, ou seja, $\left.f / f_{t}=0,5\right)$ que a frequência de resposta corresponde à metade da frequência (ou, de maneira equivalente, o dobro do período) da excitação paramétrica. 
Figura 67 - Séries temporais de amplitude modal $\tilde{a}_{3}(\tau)$.
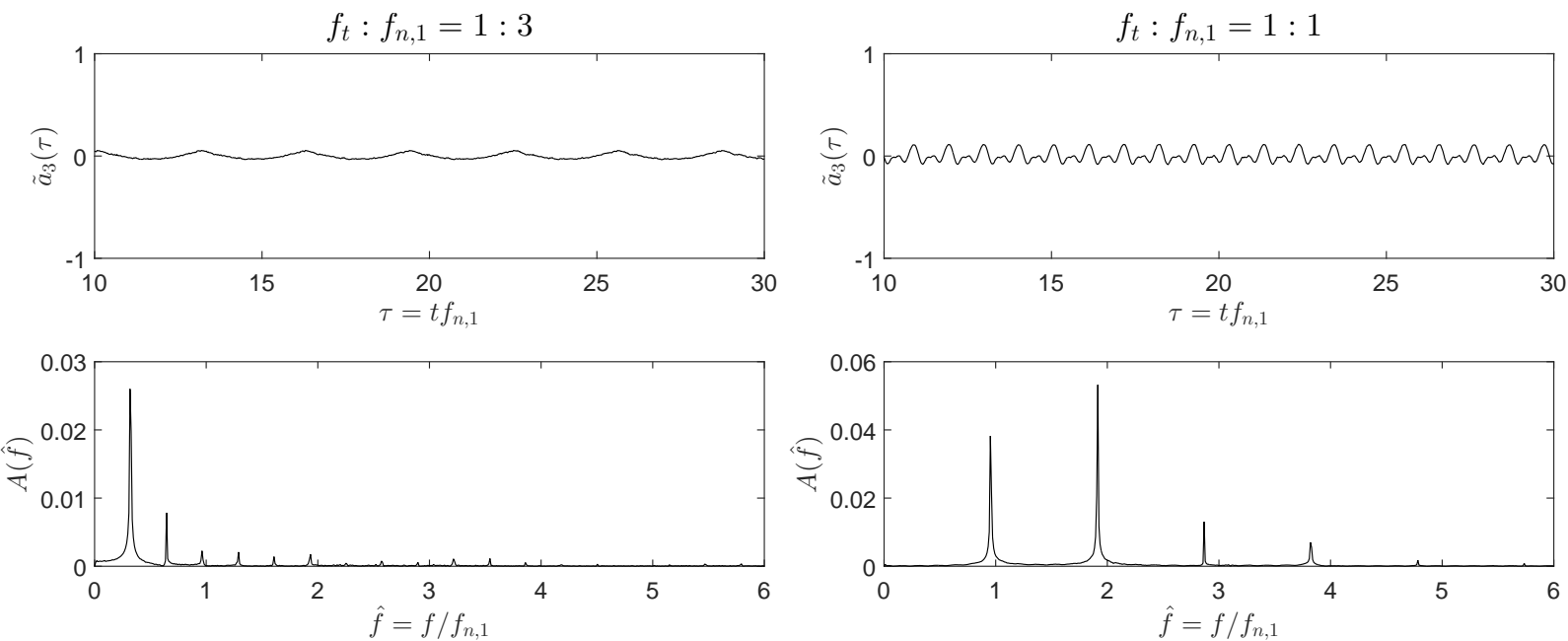

(a) $f_{t}: f_{n, 1}=1: 3$.

(b) $f_{t}: f_{n, 1}=1: 1$.
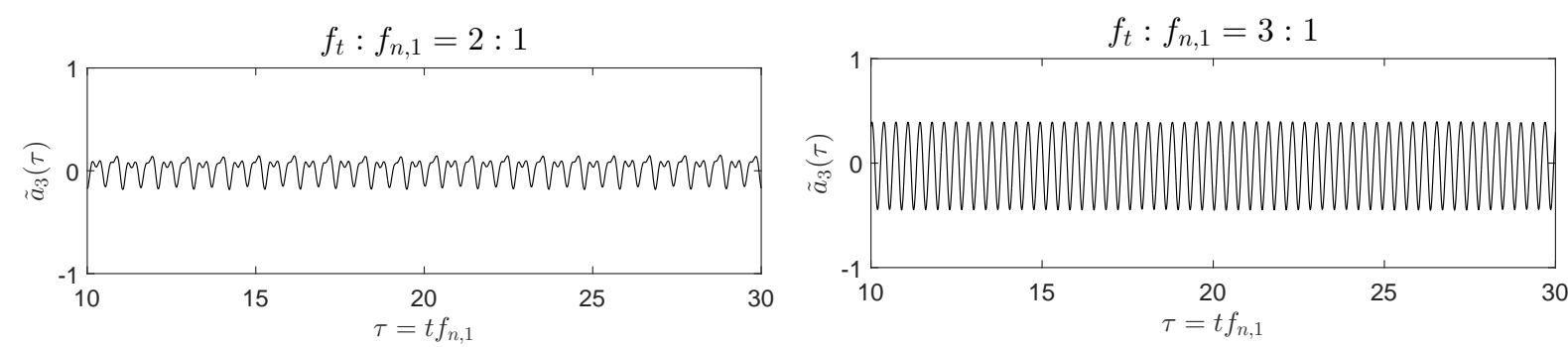

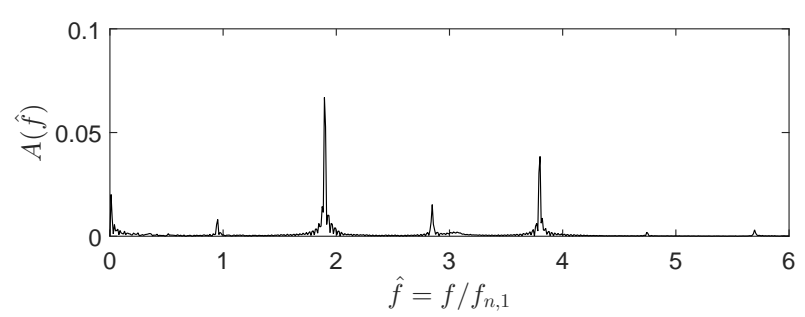

(c) $f_{t}: f_{n, 1}=2: 1$.

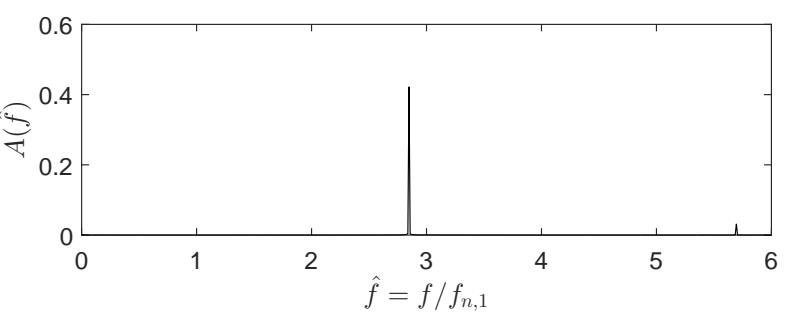

(d) $f_{t}: f_{n, 1}=3: 1$.

Fonte: Adaptada de Franzini et al. (2015).

o leitor nota que o marcador correspondente (a saber, o círculo verde) está próximo ao vértice das curvas de transição.

Ainda considerando a condição de movimento imposto $f_{t}: f_{n, 1}=2: 1$, porém para o modo $k=2$, a Tabela 6 e a Figura $67(\mathrm{c})$ mostram que a série temporal $\tilde{a}_{2}(\tau)$ tem frequência dominante $\hat{f}=f / f_{n, 1}=2 \leftrightarrow f / f_{t}=1$, ou seja, com o mesmo período da excitação paramétrica. Considerando o diagrama de Strutt modal apresentado na Figura 65(b), nota-se que o círculo verde está localizado sobre uma curva de transição. 
Tabela 6 - Relação de frequências das respostas. Predição via diagrama de Strutt comparada com as medições experimentais.

\begin{tabular}{ccccccccc}
\hline \hline \multirow{2}{*}{$\mathrm{k}$} & \multirow{2}{*}{$f_{t}: f_{n, 1}$} & \multirow{2}{*}{$f_{t}: f_{n, k}$} & \multicolumn{2}{c}{$f_{R}: f_{n, 1}$} & \multicolumn{2}{c}{$f_{R}: f_{t}$} & \multicolumn{2}{c}{$f_{R}: f_{n, k}$} \\
\cline { 3 - 9 } & & Strutt & Exp. & Strutt & Exp. & Strutt & Exp. \\
\hline \multirow{2}{*}{1} & $1: 1$ & $1: 1$ & $\mathbf{1} 1$ & $1: 1$ & $\mathbf{1} 1$ & $1: 1$ & $1: 1$ & $1: 1$ \\
\cline { 2 - 9 } & $2: 1$ & $2: 1$ & $1: 1$ & $1: 1$ & $1: 2$ & $1: 2$ & $1: 1$ & $1: 1$ \\
\cline { 2 - 9 } & $3: 1$ & $3: 1$ & - & $3: 1^{*}$ & - & $1: 1^{*}$ & - & $3: 1^{*}$ \\
\hline \multirow{2}{*}{2} & $1: 1$ & $1: 2$ & - & $1: 1,2: 1$ & - & $1: 1,2: 1$ & - & $1: 2,1: 1$ \\
\cline { 2 - 9 } & $2: 1$ & $2: 2$ & $2: 1$ & $2: 1$ & $1: 1$ & $1: 1$ & $1: 1$ & $1: 1$ \\
\cline { 2 - 9 } 3 & $3: 1$ & $3: 2$ & - & $3: 1^{*}$ & - & $3: 3^{*}$ & - & $3: 2^{*}$ \\
\hline \multirow{2}{*}{3} & $1: 1$ & $1: 3$ & - & $1: 1,2: 1$ & - & $1: 1,2: 1$ & - & $1: 3,2: 3$ \\
\cline { 2 - 9 } & $2: 1$ & $2: 3$ & - & $2: 1,4: 1$ & - & $1: 1,2: 1$ & - & $2: 3,4: 3$ \\
\hline \hline
\end{tabular}

Fonte: Adaptada de Franzini et al. (2015).

\subsection{Contribuições à análise experimental do fenômeno de VIV em um cilindro flexível vertical}

Parte dos resultados que compõem esta seção foi publicada na 11th International Conference on Flow-Induced Vibration na forma dos artigos Franzini et al. (2016a, 2016b). Esses trabalhos foram aglutinados e, após análises adicionais, geraram o artigo Franzini et al. (2018) publicado na Ocean Engineering, importante periódico indexado na área de engenharia oceânica. Outros resultados aqui descritos foram obtidos a partir de novas análises e são publicados pela primeira vez neste texto.

Duas condições foram analisadas, a saber, aquela onde a resposta do cilindro é decorrente somente do fenômeno de VIV ("VIV puro") e aquela onde a resposta estrutural é devida à concomitância entre os fenômenos de VIV e de excitação paramétrica decorrente do movimento prescrito ao topo. Em um primeiro momento, a análise é feita a partir das séries temporais de deslocamento adimensionalizadas pelo diâmetro do cilindro e os correspondentes espectros de amplitude. Essas séries temporais correspondem aos deslocamentos de alguns pontos localizados ao longo do modelo nas direções cross-wise e in-line $\left(y^{*}(\tau)\right.$ e $x^{*}(\tau)$ respectivamente).

\subsubsection{Resultados para a condição "VIV puro"}

Em um primeiro momento desta subseção, as discussões são baseadas nas análises clássicas. A Figura 68 apresenta os espectros de amplitude ao longo da posição no cilindro associados às direções in-line e cross-wise $\left(S_{x}(\xi, \hat{f})\right.$ e $S_{y}(\xi, \hat{f})$ respectivamente) para três valores de velocidades reduzidas baseadas na frequência do primeiro modo natural e compreendidos no intervalo $4<U_{r, 1}<8$. Em uma analogia direta com os resultados 
obtidos a partir do estudo de cilindros rígidos em montados em base elástica, é esperado o lock-in com o primeiro modo de vibrar na direção cross-wise.

Considerando a velocidade reduzida $U_{r, 1}=4,26$, o espectro de amplitude na direção cross-wise apresenta baixas amplitudes de oscilação (próximas a 0,1D) e com frequência ligeiramente abaixo da primeira frequência natural obtida em água parada (ver Figura 68(a)). O leitor nota que a forma predominante de vibração é a do primeiro modo, sem qualquer nó interno à estrutura. Esse fato não surpreende, uma vez que a velocidade reduzida em estudo corresponde ao início do lock-in com o primeiro modo de vibrar.

Para essa mesma velocidade reduzida, o espectro de amplitude correspondente à direção in-line é ilustrado na Figura 68(b), que demonstra a presença de vibrações com a forma do segundo e do terceiro modo com frequência ligeiramente superiores a $\hat{f}=2$ e $\hat{f}=3$ respectivamente. Note que, em virtude das frequências naturais do arranjo, $\hat{f}=f / f_{n, 1} \approx 2 \leftrightarrow f / f_{n, 2} \approx 1$ e $\hat{f}=f / f_{n, 1} \approx 3 \leftrightarrow f / f_{n, 3} \approx 1$.

A explicação para a excitação do segundo modo de vibrar na direção in-line pode ser dada à luz dos resultados obtidos para cilindros fixos ou rígidos e montados em apoio elástico. Nessas condições, a revisão bibliográfica apresentada nas subseções 4.1.1, 4.1.2 e 4.1.3 mostra que a força de arrasto contém, em sua assinatura em frequência, um termo com frequência $2 \omega_{f}$, ou seja, com o dobro da frequência de emissão de vórtices. Dessa forma, no lock-in com o primeiro modo natural na direção cross-wise, espera-se $\omega_{f} \approx 2 \pi f_{n, 1}$, que leva à presença de uma força de arrasto com frequência $2 \omega_{f}=4 \pi f_{n, 1}=2 \pi f_{n, 2}$, configurando o lock-in com o segundo modo de vibrar na direção in-line.

Um aumento da velocidade de reboque de sorte que $U_{r, 1}=5,63$ ou $U_{r, 1}=6,99$ torna mais intensa as oscilações acima discutidas, como mostram as Figuras 68(c), 68(d), 68(e) e 68(f). Um outro aspecto que merece ser acrescido à discussão é o fato do surgimento de oscilações no terceiro e quarto modos na direção in-line (ver Figuras 68(d) e 68(f)).

Considerando a velocidade reduzida $U_{r, 1}=6,99$, nota-se uma leve tendência de surgimento de uma resposta no segundo modo na direção cross-wise. Esse fato não é surpreendente, uma vez que a renormalização da velocidade de reboque pela segunda frequência natural leva a $U_{r, 2}=3,50$, condição de início do lock-in com o modo $k=2$.

Uma vez discutidos os espectros de amplitude para cenários favoráveis ao lock-in com o primeiro modo de vibrar, o foco passa a ser no caso onde o segundo modo natural na direção cross-wise é majoritariamente excitado. A Figura 69 apresenta os espectros de amplitude $S_{y}(\xi, \hat{f})$ e $S_{x}(\xi, \hat{f})$ obtidos para valores de velocidade reduzida $8<U_{r, 1}<14$, o que corresponde ao intervalo $4<U_{r, 2}<7$. A Figura 69(a), que ilustra a condição $U_{r, 1}=8,35$, revela claramente a coexistência entre os dois primeiros modos de vibrar na direção cross-wise, porém com a dominância do modo $k=1$. De fato, essa velocidade reduzida baseada na primeira frequência natural a importantes oscilações na direção 
Figura 68 - Espectros de amplitude $S_{x}(\xi, \hat{f})$ e $S_{y}(\xi, \hat{f}) .4<U_{r, 1}<8$.

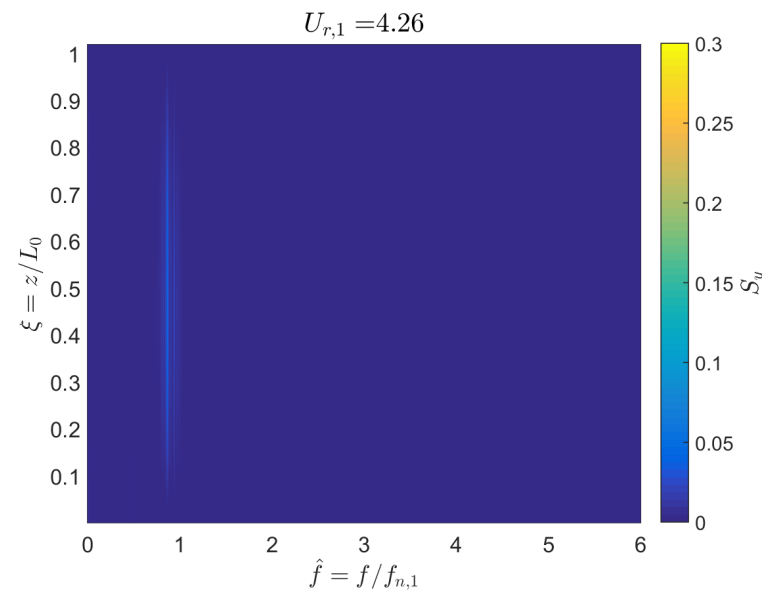

(a) $S_{y}(\xi, \hat{f}) . U_{r, 1}=4,26$.

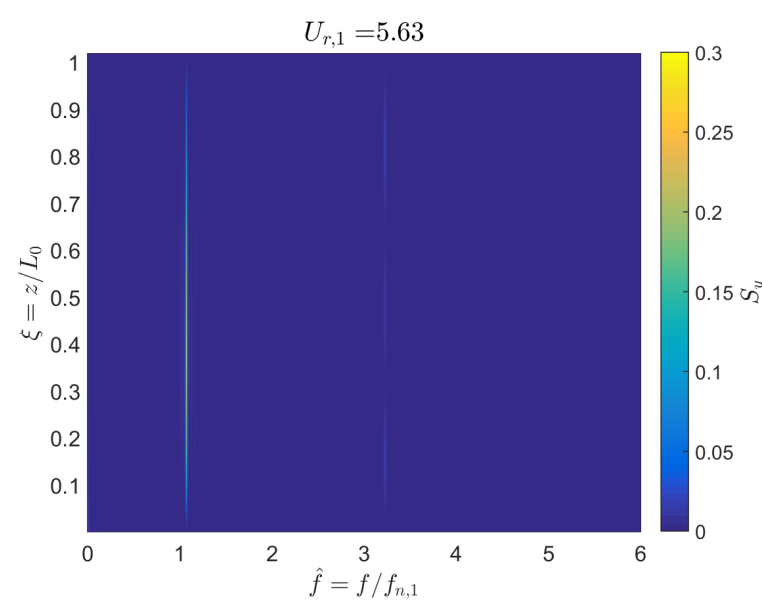

(c) $S_{y}(\xi, \hat{f}) . U_{r, 1}=5,63$.

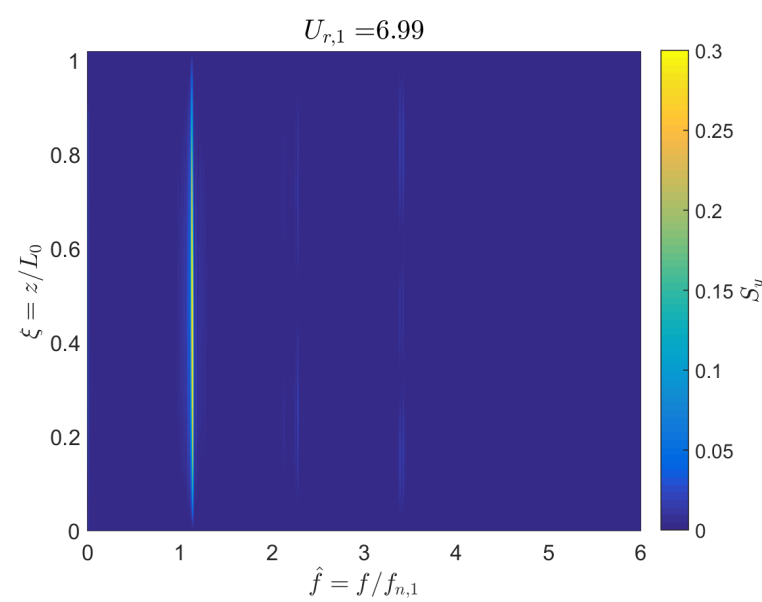

(e) $S_{y}(\xi, \hat{f}) . U_{r, 1}=6,99$.

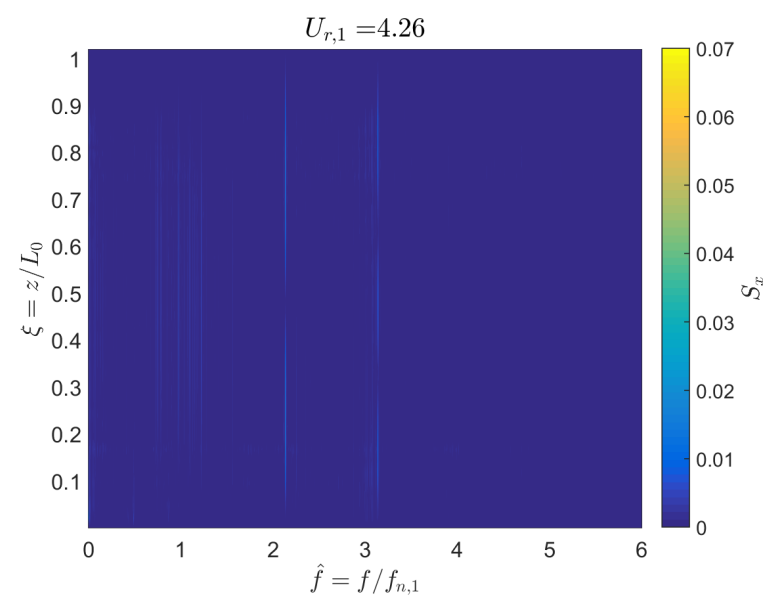

(b) $S_{x}(\xi, \hat{f}) \cdot U_{r, 1}=4,26$.

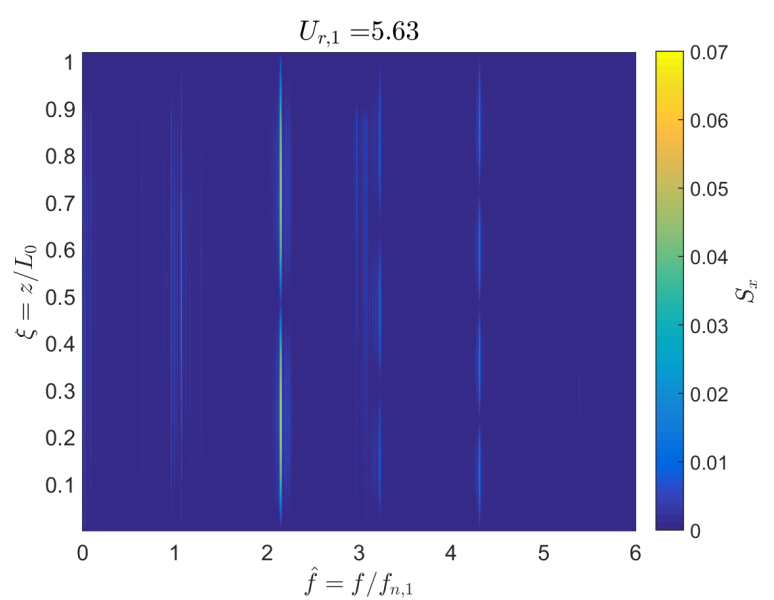

(d) $S_{x}(\xi, \hat{f}) \cdot U_{r, 1}=5,63$.

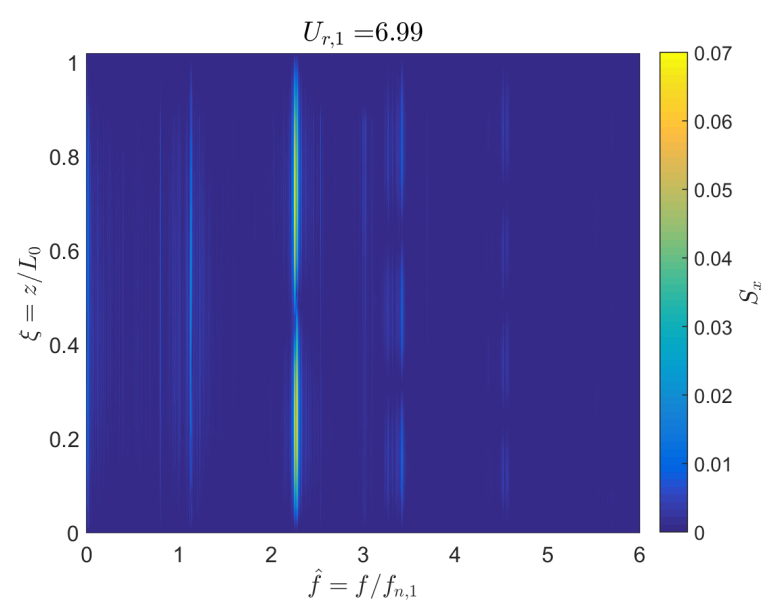

(f) $S_{x}(\xi, \hat{f}) . U_{r, 1}=6,99$.

Fonte: Elaborada pelo autor. 
cross-wise para a condição VIV-2gl; ver Figura 13 na subseção 4.1.3.

No entanto, tomando como fator de normalização da velocidade de reboque a frequência natural do segundo modo de vibrar, a velocidade reduzida modal correspondente é $U_{r, 2} \approx 4,2$, o início do lock-in com o modo $k=2$. Esse fato explica a presença do espalhamento de energia entre $1<\hat{f}<2$ no espectro $S_{y}(\xi, \hat{f})$, com predomínio da forma de vibrar do primeiro modo. Essa coexistência entre modos de vibrar é refletida no caráter policromático do espectro de amplitude $S_{x}(\xi, \hat{f})$ apresentado na Figura 69(b).

As Figuras 69(c) e 69(d) referem-se à condição de velocidade reduzida $U_{r, 1}=11,57$ ou, de maneira equivalente, $U_{r, 2}=5,80$. O valor de velocidade reduzida baseado na segunda frequência natural indica o lock-in predominantemente com o segundo modo de vibrar na direção cross-wise, fato confirmado pela Figura 69(c).

Já a Figura 69(d) mostra um intrincado espectro de amplitude associado à direção in-line. Além de uma rica assinatura em frequência, as oscilações na direção in-line estão predominantemente associadas à forma do terceiro modo de vibrar. Mais ainda, essa forma está associada a uma frequência próxima àquela do quarto modo natural $\hat{f} \approx 4$. Outras contribuições presentes nesse espectro de amplitude incluem a do primeiro modo de vibrar com a frequência do segundo $(\hat{f}=2)$, a do segundo modo com frequência $\hat{f} \approx 3$ e do quarto e quinto modos com múltiplos não inteiros de 1.

Um novo aumento na velocidade de reboque tal que $U_{r, 1}=13,67\left(U_{r, 2}=6,84\right)$ promove novas mudanças nos conteúdos espectrais. Nessa condição de velocidade de reboque, a velocidade reduzida $U_{r, 1}$ já é bastante elevada, de sorte que o lock-in com o primeiro modo já não se faz presente. Por sua vez, é esperado que lock-in com o segundo modo já esteja completamente estabelecido. Essa conjectura é verificada por meio do espectro $S_{y}(\xi, \hat{f})$ ilustrado na Figura $69(\mathrm{e})$, que ilustra a dominância do segundo modo de vibrar com uma frequência ligeiramente superior a $\hat{f}=2$, ou seja, a frequência natural $f_{n, 2}$.

Considerando ainda a corrida com velocidade reduzida $U_{r, 1}=13,67$, o espectro de amplitude $S_{x}(\xi, \hat{f})$ mostra um conteúdo espectral menos rico do que aquele obtido para $U_{r, 1}=11,57$ (ver Figuras $69(\mathrm{~d})$ e $69(\mathrm{f})$ ). Note, ainda, que o espectro $S_{x}(\xi, \hat{f})$ obtido para $U_{r, 1}=13,67$ é dominado por oscilações com a forma do quarto modo com frequência próxima daquela do quinto modo natural.

Os espectros de amplitude exibidos nas Figuras 68 e 69 mostraram, em muitos casos, que a frequência dominante da oscilação na direção in-line como sendo o dobro daquela observada para a direção cross-wise, com algumas condições nas quais a forma modal na direção in-line não corresponde à frequência esperada. Esses aspectos são agora discutidos. 
Figura 69 - Espectros de amplitude $S_{x}(\xi, \hat{f})$ e $S_{y}(\xi, \hat{f}) .8<U_{r, 1}<14$.

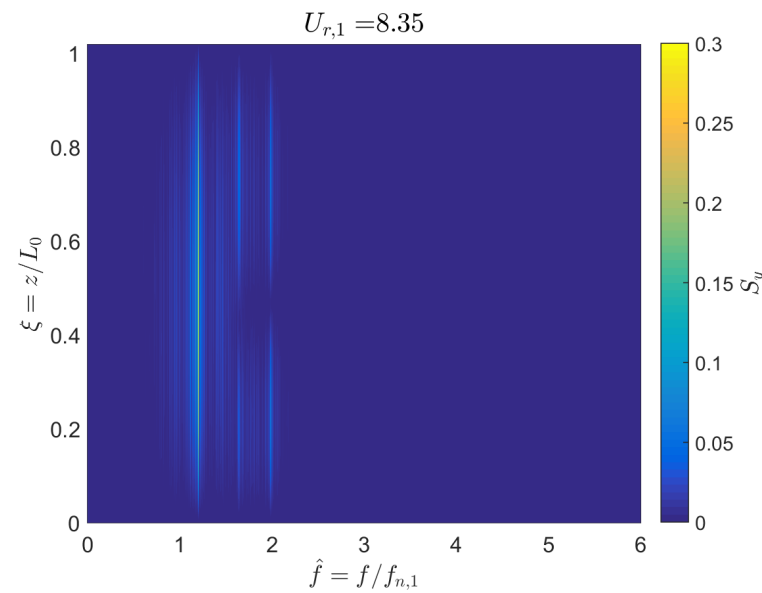

(a) $S_{y}(\xi, \hat{f}) . U_{r, 1}=8,35$.

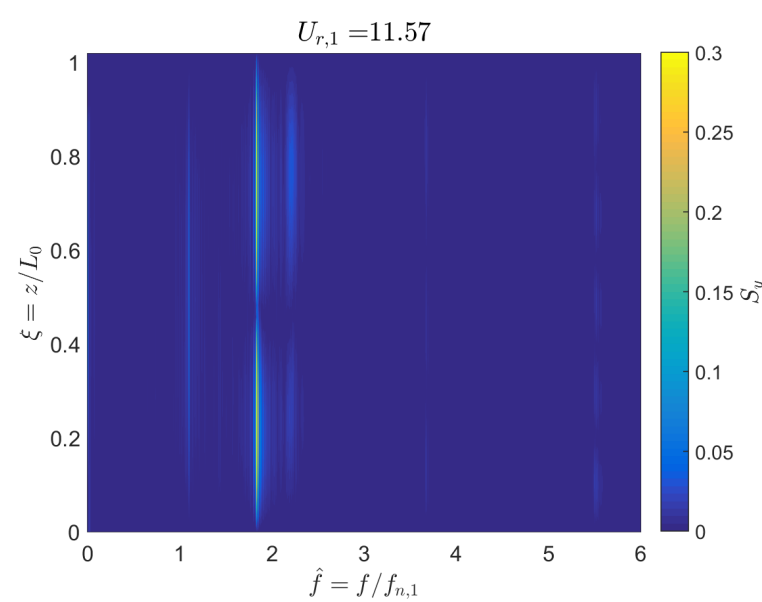

(c) $S_{y}(\xi, \hat{f}) . U_{r, 1}=11,57$.

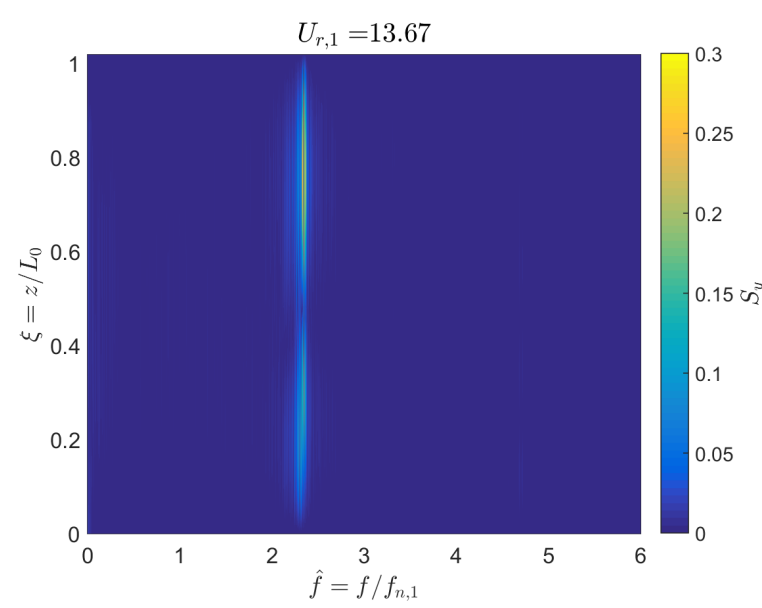

(e) $S_{y}(\xi, \hat{f}) \cdot U_{r, 1}=13,67$.

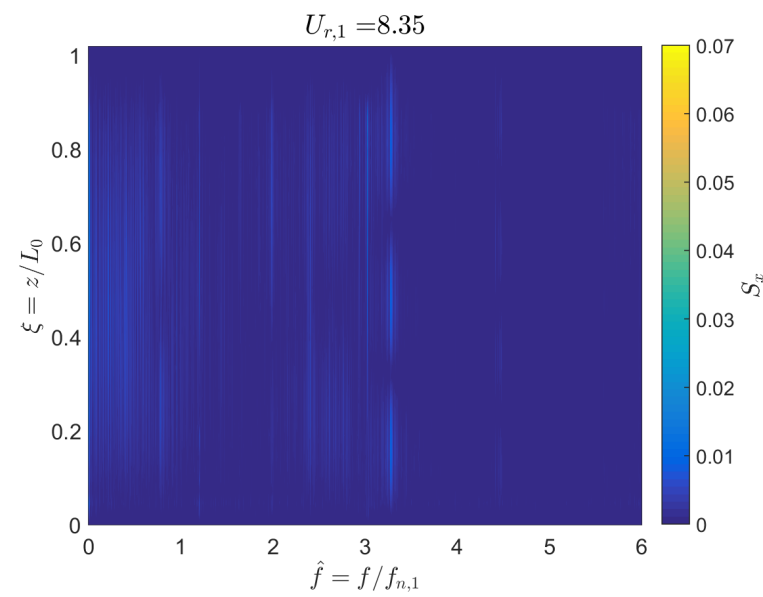

(b) $S_{x}(\xi, \hat{f}) \cdot U_{r, 1}=8,35$.

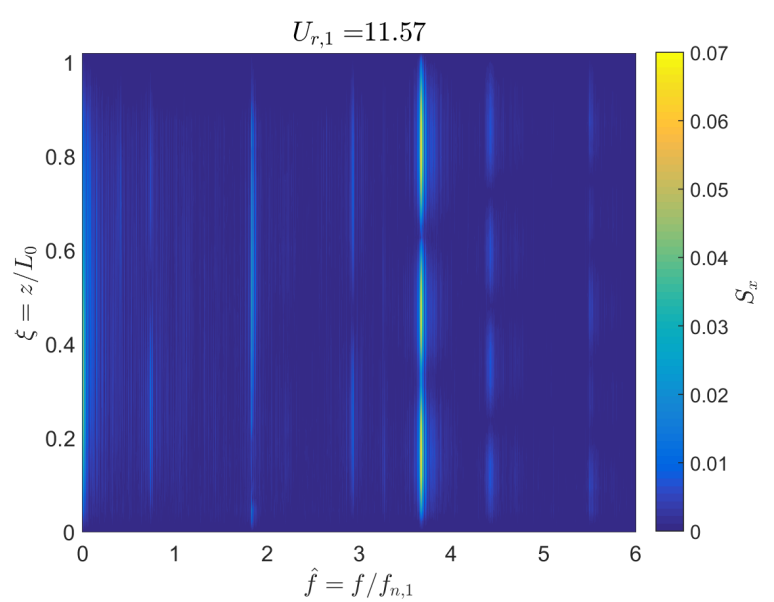

(d) $S_{x}(\xi, \hat{f}) . U_{r, 1}=11,57$.

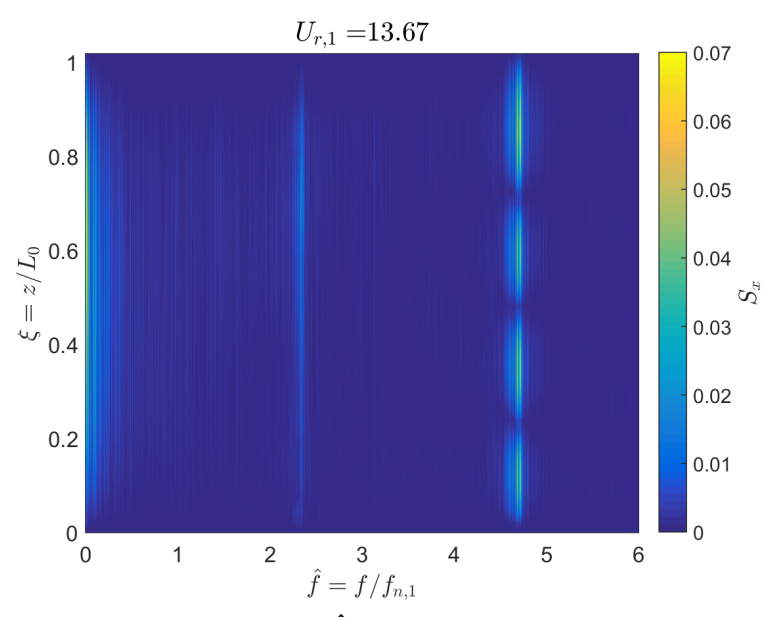

(f) $S_{x}(\xi, \hat{f}) . U_{r, 1}=13,67$.

Fonte: Elaborada pelo autor. 
Dahl et al. (2010) definem, para o problema VIV-2gl, a ressonância dual ${ }^{11}$ como a condição na qual as oscilações na direção cross-wise têm frequência de oscilação $f_{d}$ próxima à frequência de emissão de vórtices enquanto que a resposta na direção in-line é caracterizada por uma frequência dominante $2 f_{d}$. Os autores ainda apontam que a ressonância dual está intimamente relacionada a uma relação de frequência natural efetiva (isso é, aquela que considera a parcela da força hidrodinâmica em fase com a aceleração do corpo, ou seja, a massa adicional efetiva ${ }^{12}$ ) nas direções in-line e cross-wise próxima a 2.

Dessa forma, os espectros de amplitude $S_{y}(\xi, \hat{f})$ e $S_{x}(\xi, \hat{f})$ aqui apresentados evidenciam a ressonância dual para o fenômeno de VIV em cilindros flexíveis. Tal evidência é reforçada pela relação de frequências naturais nominais $f_{n, 2}=2 f_{n, 1}$ e $f_{n, 4}=2 f_{n, 2}$. Já a identificação de formas modais com frequências muito próximas daquelas associadas a formas distintas (ver, por exemplo, Figura 69(f)) pode ter relação com mudanças na massa adicional efetiva. Essa conjectura, porém, deve ser estudada por meio do avaliação da força hidrodinâmica com sua posterior decomposição em uma parcela em fase com a velocidade (amortecimento) e em fase com a aceleração (massa adicional efetiva).

Após a discussão acerca dos espectros de amplitude, o foco desta subseção passa a ser os envelopes de amplitude característica de oscilação para cada alvo monitorado, $\hat{A}^{y}(\xi)$ e $\hat{A}^{x}(\xi)$. Esses resultados, além de também fornecerem ideia dos modos que compõem a resposta, são de grande interesse para correlações com códigos numéricos.

A Figura 70 apresenta os envelopes de amplitude característica de oscilação para os mesmos valores de velocidade reduzida exemplificados na Figura 68 e que excitam principalmente o primeiro modo de vibrar na direção cross-wise. Para os três valores de velocidade ilustrados, as Figuras 70(a), 70(c) e 70(e) indicam que a máxima amplitude característica de oscilação na direção cross-wise ocorre em uma cota $\xi \approx 0,40$, ou seja, um pouco abaixo do meio do vão e onde a resposta seria máxima se o modo de vibrar fosse, de fato, uma função senoidal. Note que a máxima amplitude de resposta é $\max \left\{\hat{A}^{y}(\xi)\right\} \approx 0,70$ para $U_{r, 1}=5,63$ e $\max \left\{\hat{A}^{y}(\xi)\right\} \approx 0,85$ para $U_{r, 1}=6,99$. No tocante aos envelopes de amplitude característica de oscilação relacionados à direção in-line, nota-se um decréscimo nos valores quando comparados àqueles referentes à direção cross-wise. Essa constatação não surpreende, já tendo sido objeto de discussão para a condição VIV-2gl (ver subseção 4.1.3).

Considerando as condições de velocidade reduzida $U_{r, 1}=5,63$ e $U_{r, 1}=6,99$ (lock-in com o primeiro modo na direção cross-wise plenamente definido), as Figuras $70(\mathrm{~d})$ e $70(\mathrm{f})$ indicam máximas amplitudes características de oscilação $\max \left\{\hat{A}^{x}(\xi)\right\} \approx$ 0,20 e $\max \left\{\hat{A}^{x}(\xi)\right\} \approx 0,30$ respectivamente. Essas mesmas figuras mostram, ainda, uma

11 Em língua inglesa, "dual resonance".

12 No contexto de VIV, a massa adicional $m_{a}$ depende da amplitude e da frequência de oscilação do corpo, dependendo, portanto, da velocidade reduzida. A variação da massa adicional com a velocidade reduzida já foi objeto dos artigos Vikestad, Vandiver e Larsen (2000), Fujarra e Pesce (2002) e Franzini et al. (2012b). 
Figura 70 - Envelopes de amplitude característica de oscilação. $4<U_{r, 1}<8$.

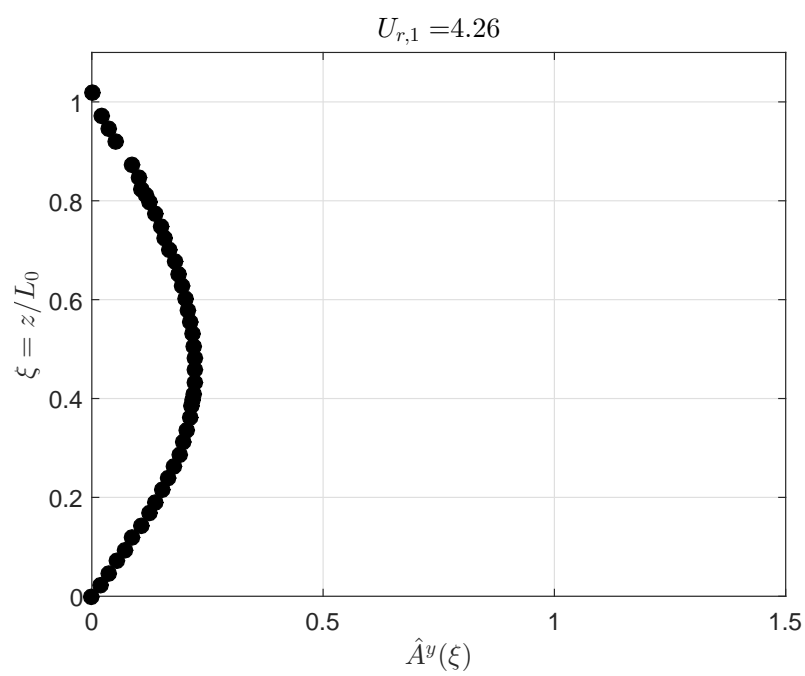

(a) $\hat{A}^{y}(\xi) \cdot U_{r, 1}=4,26$.

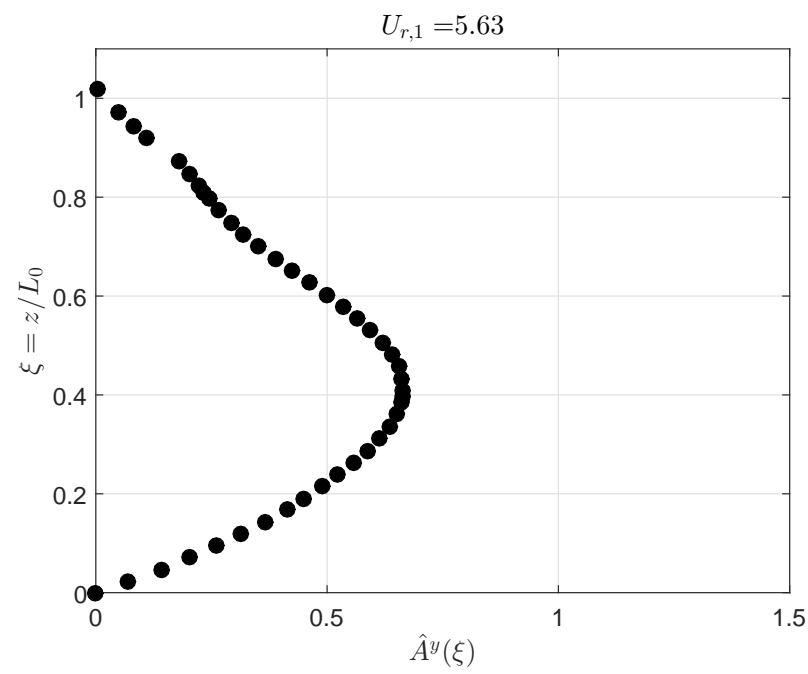

(c) $\hat{A}^{y}(\xi) \cdot U_{r, 1}=5,63$.

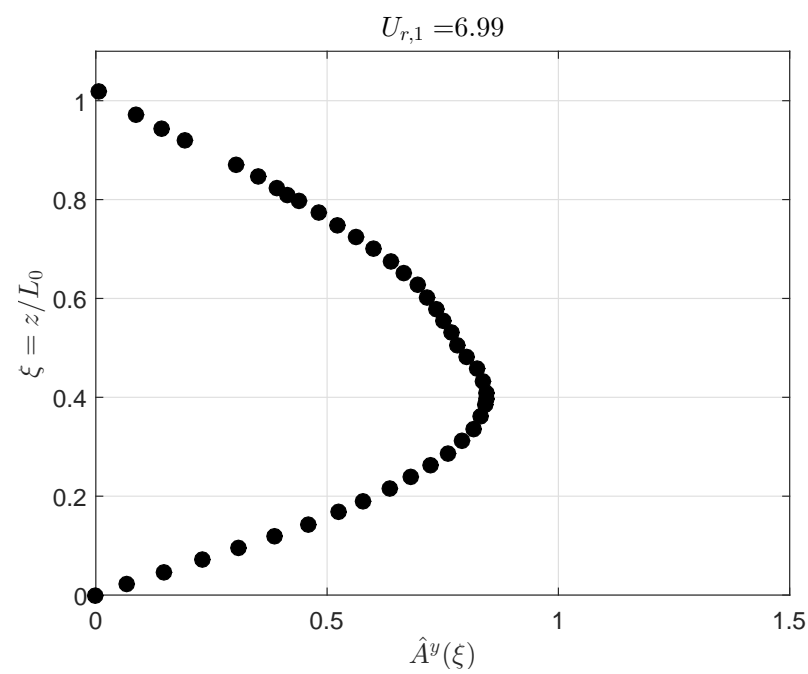

(e) $\hat{A}^{y}(\xi) . U_{r, 1}=6,99$.

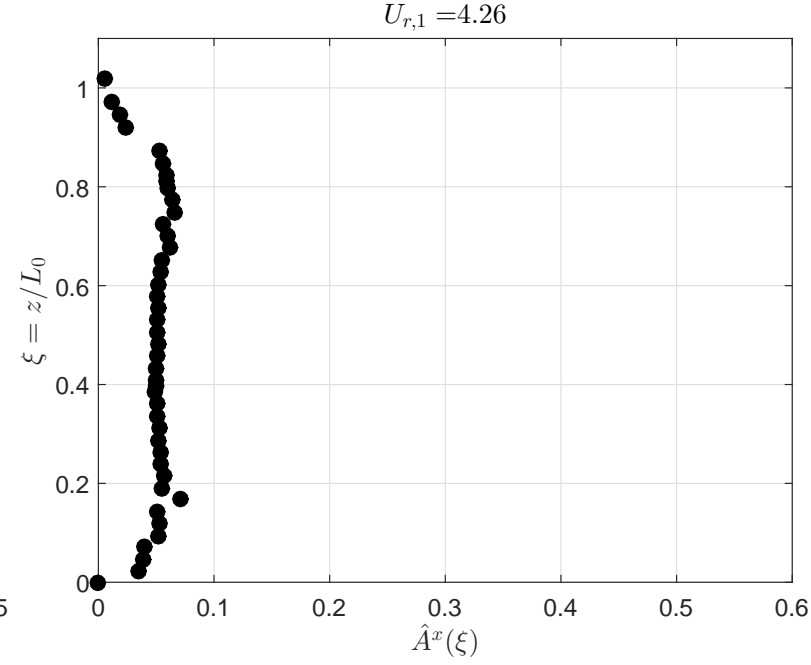

(b) $\hat{A}^{x}(\xi) \cdot U_{r, 1}=4,26$.

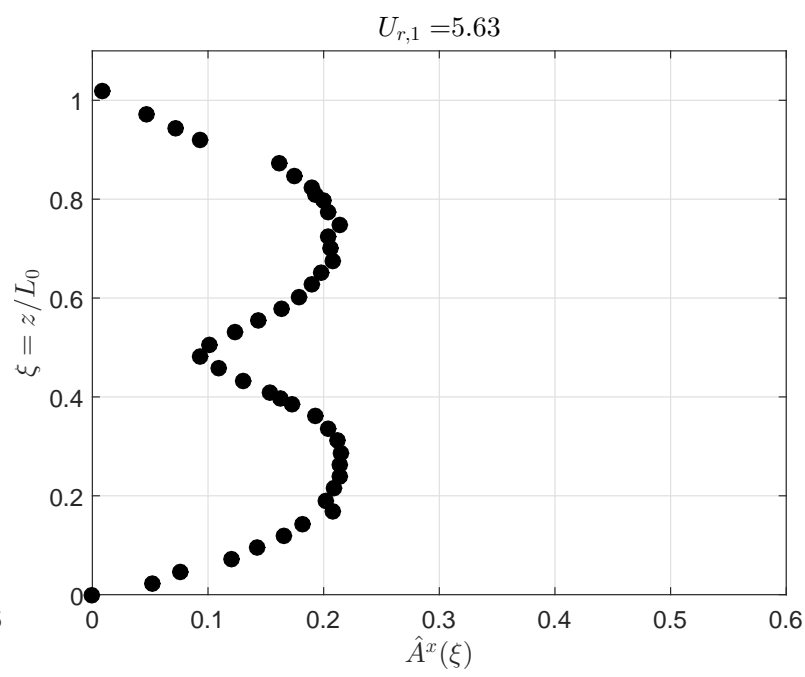

(d) $\hat{A}^{x}(\xi) \cdot U_{r, 1}=5,63$.

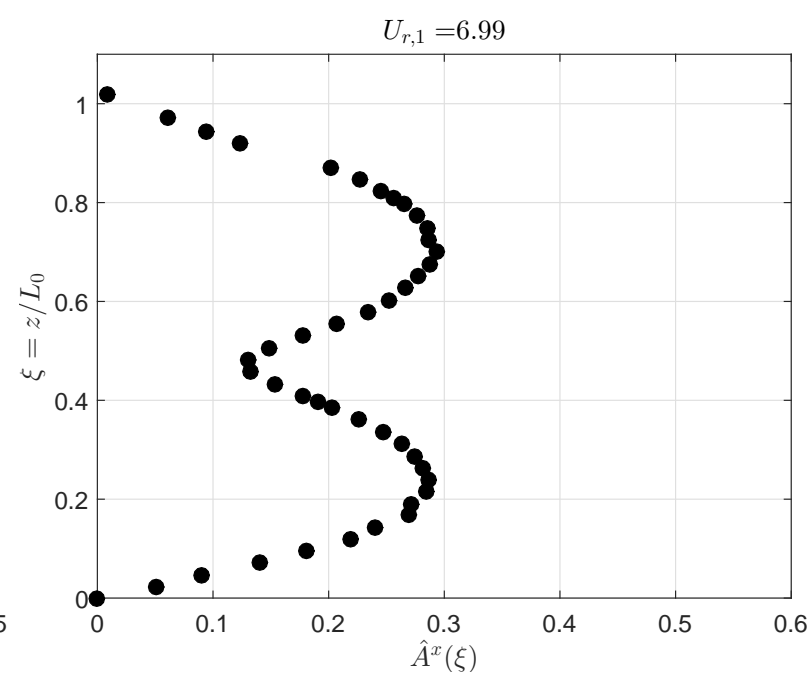

(f) $\hat{A}^{x}(\xi) . U_{r, 1}=6,99$.

Fonte: Elaborada pelo autor. 
resposta multi modal, caracterizada pela dominância do segundo modo de vibrar e alguma contribuição do primeiro modo que notada pela ausência de um nó nos envelopes $\hat{A}^{x}(\xi)$. Cumpre ressaltar que essa inferência acerca dos modos participantes na resposta na direção in-line corrobora as discussões conduzidas quando da análise dos espectros de amplitude $S_{x}(\xi, \hat{f})$ apresentados na Figura 68.

A Figura 71 apresenta os envelopes de amplitudes características de oscilação obtidos a partir de experimentos com velocidades de reboque que privilegiam o lock-in com o segundo modo de vibrar na direção cross-wise. As velocidades reduzidas aqui exemplificadas são as mesmas utilizadas na Figura 69. A Figura 71(a) apresenta o envelope de amplitudes características de oscilação na direção cross-wise para $U_{r, 1}=8,35$ e indica que $\max \left\{\hat{A}^{y}(\xi)\right\} \approx 0,80$. Essa figura revela, ainda, o predomínio do primeiro modo na resposta, em concordância com o espectro de amplitude $S_{y}(\xi, \hat{f})$ apresentado na Figura 69(b). A ligeira inflexão no envelope $\hat{A}^{y}(\xi)$ observada próxima a $\xi=0,50$ revela alguma contribuição do segundo modo de vibrar, conforme também apontado no espectro de amplitude relativo a essa velocidade reduzida.

Já o envelope $\hat{A}^{x}(\xi)$ ilustrado na Figura 71(b) revela uma diminuição nas amplitudes características em comparação com a condição de velocidade reduzida $U_{r, 1}=6,99$ (ver Figura $70(f)$ ). Outro aspecto identificado a partir análise do envelope $\hat{A}^{x}(\xi)$ é a coexistência das formas do primeiro e do terceiro modo de vibrar. Essa coexistência já fora identificada a partir do espectro de amplitudes $S_{x}(\xi, \hat{f})$ apresentado na Figura 69(b) e que revela, ainda, que as contribuições do primeiro modo de vibrar à resposta do sistema são de baixa amplitude e estão distribuídas no intervalo de frequências $0<\hat{f}<1$. Note que a análise somente do espectro de amplitude levaria a uma conclusão de que o primeiro modo de vibrar não contribui significativamente para a resposta estrutural, de sorte que a análise conjunta de envelopes de amplitude característica e dos espectros de amplitude é de capital importância para a interpretação dos resultados experimentais.

Como já mencionado, são esperadas contribuições dos dois primeiros modos de vibrar do cilindro quando a velocidade de reboque leva a $U_{r, 1}=8,35$. A análise passa, agora, para a condição $U_{r, 1}=11,57$ (ou, de maneira equivalente, $U_{r, 2}=5,79$ ), onde espera-se uma predominância do lock-in com o segundo modo de vibrar na direção cross-wise. $\mathrm{O}$ envelope $\hat{A}^{y}(\xi)$ apresentado na Figura 71(c) claramente revela o predomínio da forma do segundo modo de vibrar, embora a ausência de um nó próximo a $\xi=0,50$ indique contribuição de algum modo ímpar. A máxima amplitude característica nessa direção é $\max \left\{\hat{A}^{y}(\xi)\right\} \approx 1,10$ e verificada em $\xi \approx 0,25$.

Cabe, neste momento, comparar os envelopes $\hat{A}^{y}(\xi)$ apresentados nas Figuras 70(c) e 71(c). Embora as duas velocidades de reboque sejam diferentes, de sorte que cada uma delas prioriza um modo de vibrar, as velocidades reduzidas modais são semelhantes. De fato, a Figura $70(\mathrm{c})$ ilustra um resultado obtido para $U_{r, 1}=5,63$ enquanto que a Figura 
Figura 71 - Envelopes de amplitude característica de oscilação. $8<U_{r, 1}<14$.

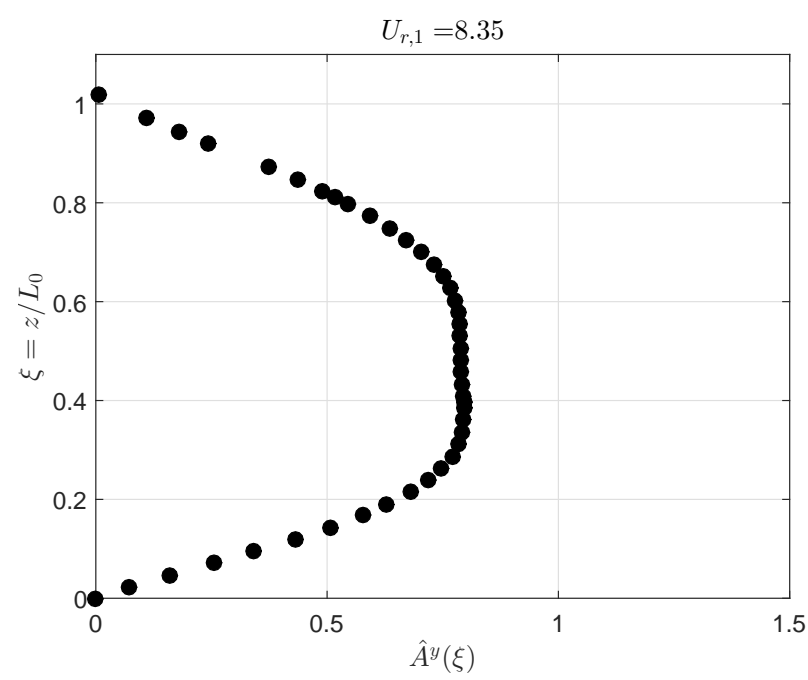

(a) $\hat{A}^{y}(\xi) \cdot U_{r, 1}=8,35$.

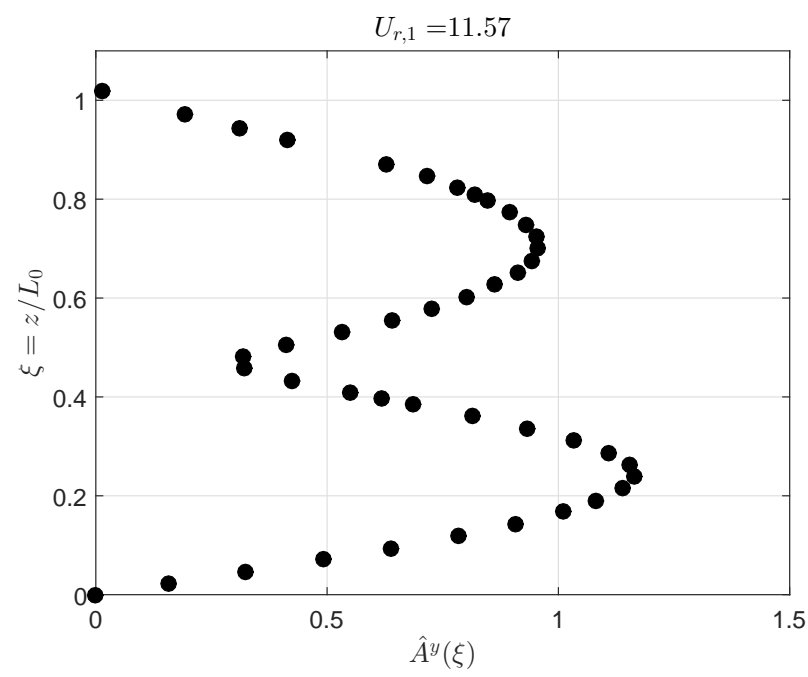

(c) $\hat{A}^{y}(\xi) \cdot U_{r, 1}=11,57$.

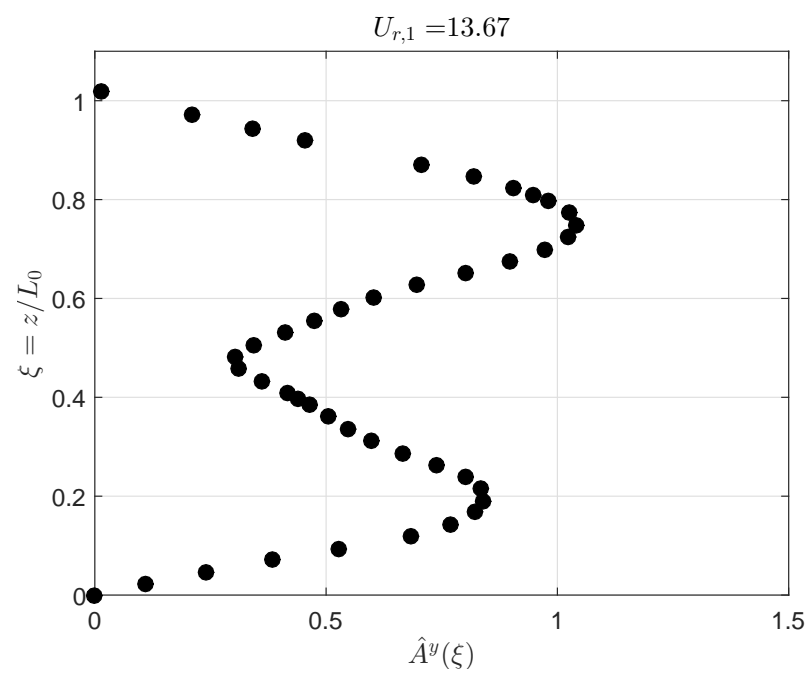

(e) $\hat{A}^{y}(\xi) \cdot U_{r, 1}=13,67$.

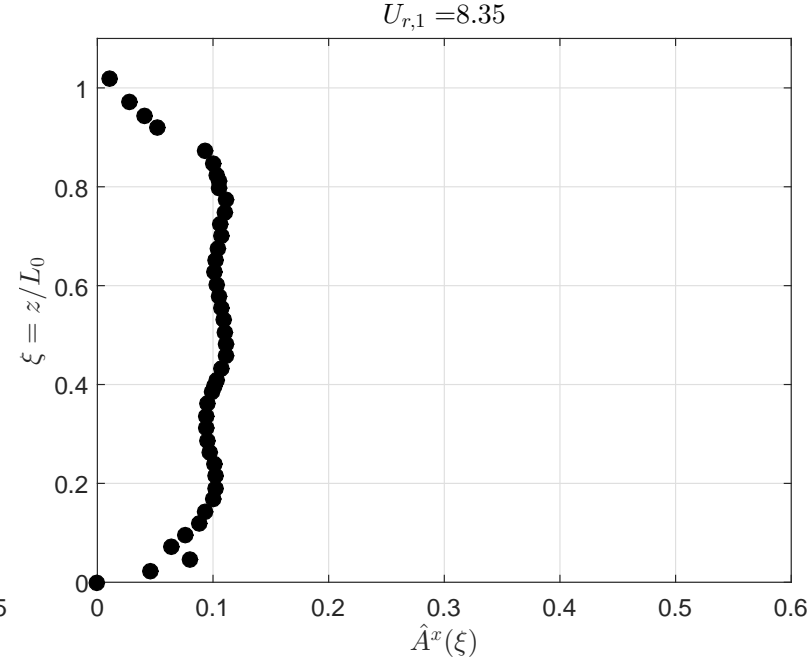

(b) $\hat{A}^{x}(\xi) \cdot U_{r, 1}=8,35$.

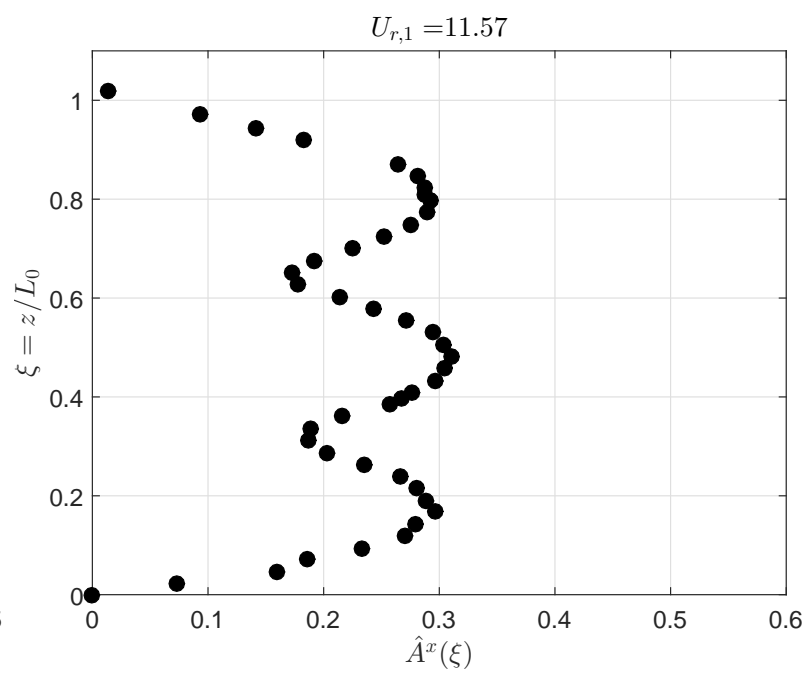

(d) $\hat{A}^{x}(\xi) \cdot U_{r, 1}=11,57$.

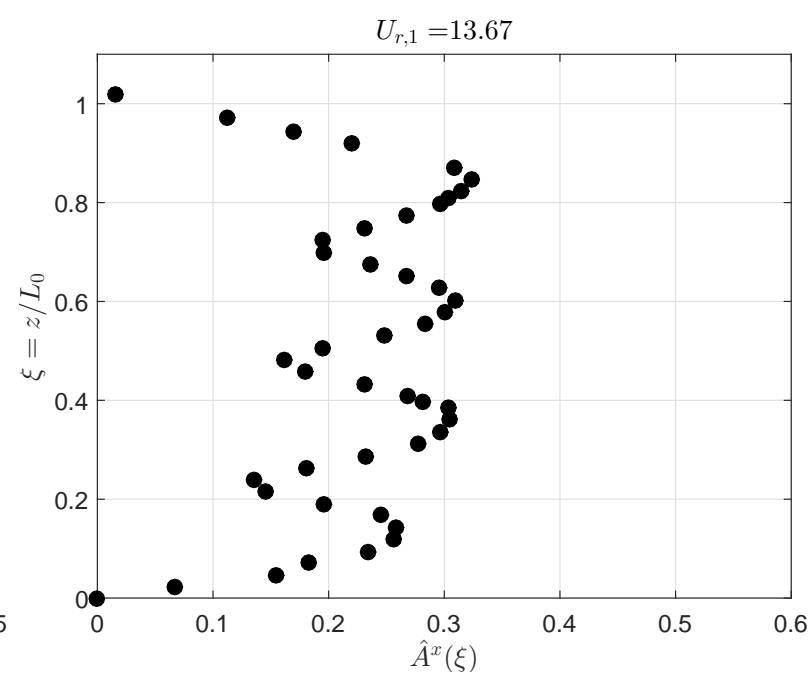

(f) $\hat{A}^{x}(\xi) . U_{r, 1}=13,67$.

Fonte: Elaborada pelo autor. 
71(c) foi obtida para $U_{r, 1}=11,57 \leftrightarrow U_{r, 2}=5,79$. Mesmo com velocidades reduzidas modais semelhantes, é nítido que as máximas amplitudes características na direção cross-wise obtidas para uma condição de lock-in com o segundo são maiores do que aquelas no primeiro. Note, no entanto, que o envelope $\hat{A}^{y}(\xi)$ apresentado na Figura 71(c) apresenta alguma contribuição do primeiro modo, de sorte que esse tipo de resultado não permite qualquer discussão acerca da participação de cada modo na resposta. Essa discussão é feita ainda nesta subseção com base na análise via decomposição modal.

Ainda considerando a condição definida por $U_{r, 1}=11,57$, o envelope $\hat{A}^{x}(\xi)$ ilustrado na Figura $71(\mathrm{~d})$ revela máximas amplitudes características de oscilação $\max \left\{\hat{A}^{x}(\xi)\right\} \approx 0,30$ em $\xi=0,20, \xi=0,50$ e $\xi=0,80$. Em concordância com o espectro de amplitude $S_{x}(\xi, \hat{f})$ ilustrado na Figura $69(\mathrm{~d})$, nota-se a presença importante do terceiro modo de vibrar, embora sobreposta a outros modos.

Finalmente, a discussão segue para a condição onde a velocidade de reboque é aumentada de sorte que $U_{r, 1}=13,67$. O envelope $\hat{A}^{y}(\xi)$ apresentado na Figura $71(\mathrm{e})$ novamente sugere uma coexistência entre os dois primeiros modos de vibrar, embora o espectro de amplitude $S_{y}(\xi, \hat{f})$ indique apenas respostas no segundo modo de vibrar; ver Figura 69(e). A máxima amplitude característica de vibração é $\max \left\{\hat{A}^{y}(\xi)\right\} \approx 1$ e ocorre em um ponto localizado ligeiramente abaixo de $\xi=0,80$.

No que tange à resposta na direção in-line, o aumento da velocidade de reboque leva o envelope $\hat{A}^{x}(\xi)$ exibido Figura $71(\mathrm{f})$ a ter forte presença do quarto modo de vibrar, ainda que composta com outros modos. A substituição do predomínio do terceiro para o quarto modo de vibrar já fora discutida quando da análise da Figura 69(f), cujo espectro de amplitude $S_{x}(\xi, \hat{f})$ revelou, ainda, a presença do primeiro modo na resposta.

Até este ponto da presente subseção, os resultados mostraram que a resposta pode ser composta de mais de um modo de vibrar. No entanto, tanto os espectros de amplitude quanto os envelopes de amplitudes características de oscilação envolveram análises em toda a série temporal medida após a velocidade de reboque atingir um estado estacionário. $\mathrm{O}$ foco desta subseção passa a ser a análise de séries temporais por trechos, o que possibilitará identificar algumas transições na resposta para uma dada condição nominal de velocidade de reboque.

Essas transições são exemplificadas em um primeiro momento para a condição onde $U_{r, 1}=6,99$. A Figura 72 traz elementos que permitem a discussão acerca de existência de uma transição entre dois regimes de resposta. As Figuras 72(a) e 72(b) mostram, respectivamente, os escalogramas $y^{*}(\xi, \tau)$ e $x^{*}(\xi, \tau)$ considerando todo o tempo de medição. A Figura 72(a) claramente mostra uma transição de um regime onde as oscilações na direção cross-wise são mais intensas na porção superior do modelo para um outro onde as oscilações são mais vigorosas em sua porção inferior. Essa transição ocorre em $\tau \approx 100 \mathrm{e}$ não é tão perceptível na análise do escalograma $x^{*}(\xi, \tau)$. 
Figura 72 - Exemplo de existência de dois regimes distintos de resposta. $U_{r, 1}=6,99$.

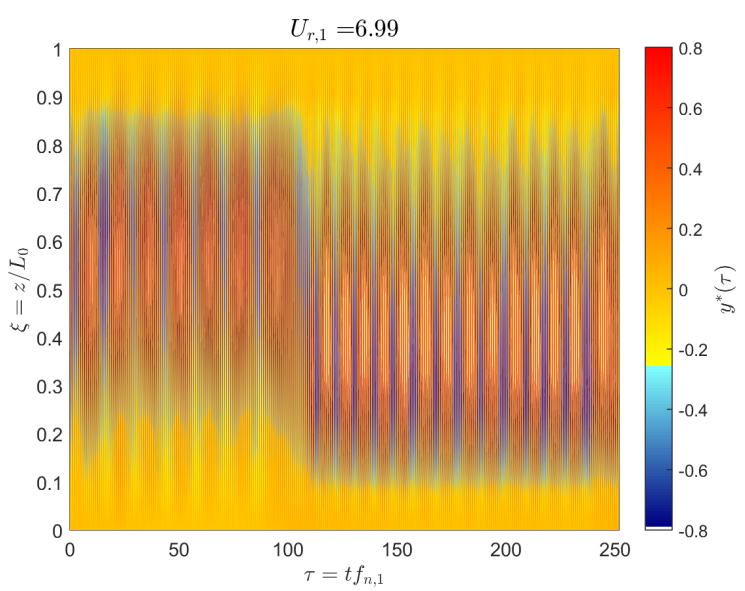

(a) Escalograma $y^{*}(\xi, \tau)$.

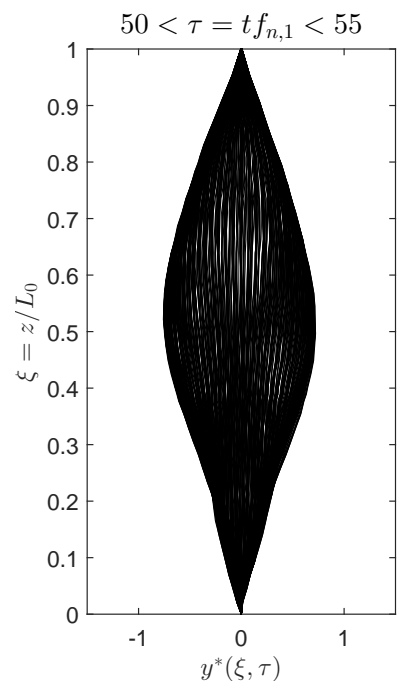

(c) Configurações deformadas instantâneas. Dire- $($ d) ção cross-wise.

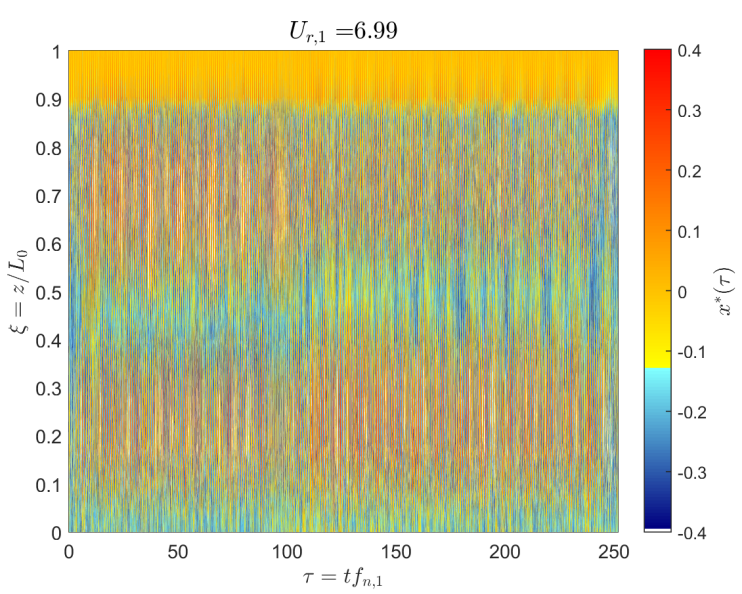

(b) Escalograma $x^{*}(\xi, \tau)$.
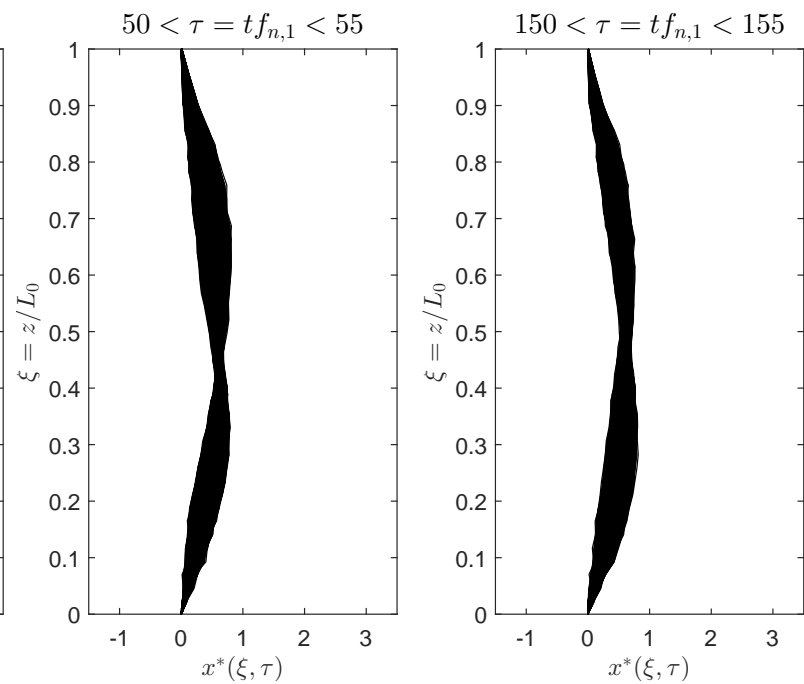

-(d) Configurações deformadas instantâneas. Direção in-line.

Fonte: Elaborada pelo autor.

A Figura 72(c) apresenta as configurações deformadas instantâneas na direção cross-wise para diversos instantes de tempo considerando tanto $50<\tau<55$ (antes da transição) e $150<\tau<155$ (após a transição). Essa figura claramente ilustra diferentes respostas estruturais, onde a máxima amplitude de oscilação deixa de ser observada próximo ao meio do vão e passa para o ponto de cota $\xi \approx 0,40$. O mesmo tipo de resultado, porém referente à direção in-line, é ilustrado na Figura 72(d), que mostra uma ligeira elevação do ponto semelhante a um nó estrutural.

Dando continuidade ao estudo da existência de dois regimes dentro de um experimento conduzido com a mesma velocidade de reboque nominal, a Figura 73 apresenta as trajetórias no plano horizontal de alguns pontos do modelo monitorados pelo sistema óptico. A análise comparativa das Figuras 73(a) e 73(b) revela que, associadas à transição 
Figura 73 - Trajetórias no plano horizontal. Os pontos vermelhos indicam a posição média de cada ponto para o qual a trajetória é exibida. $U_{r, 1}=6,99$.

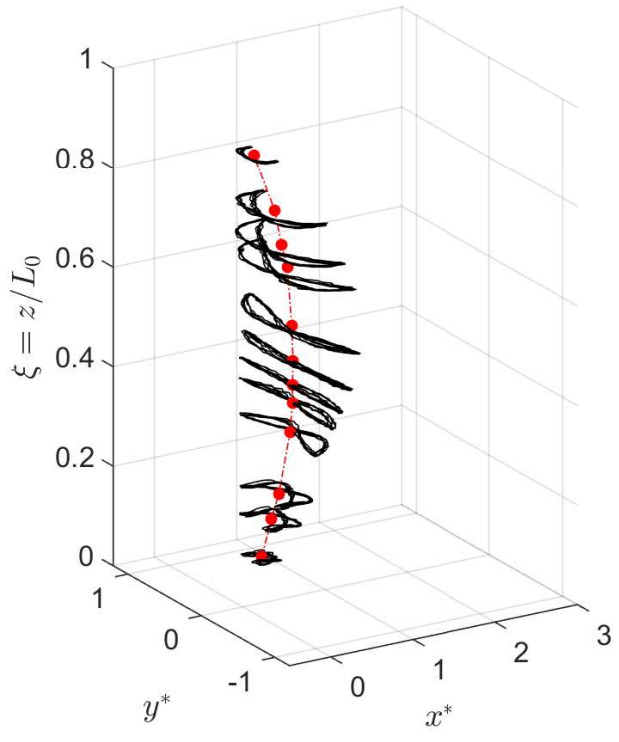

(a) $50<\tau<55$.

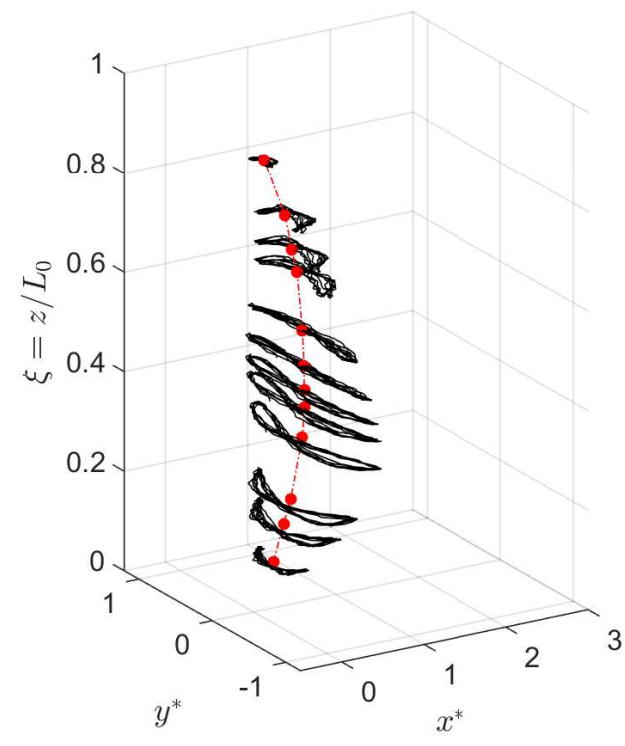

(b) $150<\tau<155$.

Fonte: Elaborada pelo autor.

entre regimes ocorrida em $\tau \approx 100$, existem mudanças nas trajetórias no plano horizontal. Embora o clássico formato de oito seja observado, a transição de regimes promove mudanças na defasagem entre os sinais, o que leva a alterações topológicas nas trajetórias no plano horizontal. Na Figura 73(a), a topologia das trajetórias no plano horizontal observadas para seções abaixo do meio do vão são semelhantes àquelas observadas na porção superior do modelo para $150<\tau<155$ (ver Figura $73(\mathrm{~b})$ ), valendo a observação recíproca.

Uma segunda condição de velocidade de reboque a ser investigada é aquela caracterizada por $U_{r, 1}=11,57 \leftrightarrow U_{r, 2}=5,79$. Como visto nos espectros de amplitude $S_{y}(\xi, \hat{f})$ e $S_{x}(\xi, \hat{f})$ (Figuras $71(\mathrm{c})$ e $71(\mathrm{~d})$ respectivamente), as assinaturas em frequências são bastante ricas, com formas modais semelhantes em frequência próximas. Note que os valores de velocidades reduzidas modais $U_{r, 1}$ e $U_{r, 2}$ associados a essa velocidade de reboque indicam uma resposta bimodal.

Os escalogramas exibidos nas Figuras 74(a) e 74(b) mostram que uma transição entre dois regimes de resposta também ocorre para $U_{r, 1}=11,57$, porém agora sendo verificada em um instante de tempo significativamente inferior, em $\tau \approx 15$. A Figura $74(\mathrm{c})$ revela que, embora a resposta na direção cross-wise seja caracterizada por um nó próximo a $\xi \approx 0,45$, as oscilações na porção inferior do modelo são significativamente inferiores quando o intervalo de tempo analisado é $5<\tau<10$.

Nesse último intervalo de tempo destacado e considerando a resposta na direção in- 
Figura 74 - Exemplo de existência de dois regimes distintos de resposta. $U_{r, 1}=11,57$.

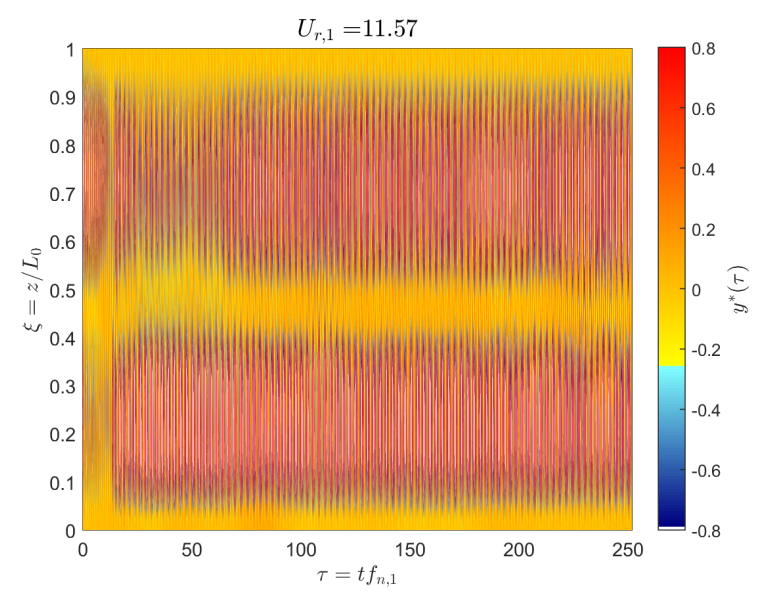

(a) Escalograma $y^{*}(\xi, \tau)$.
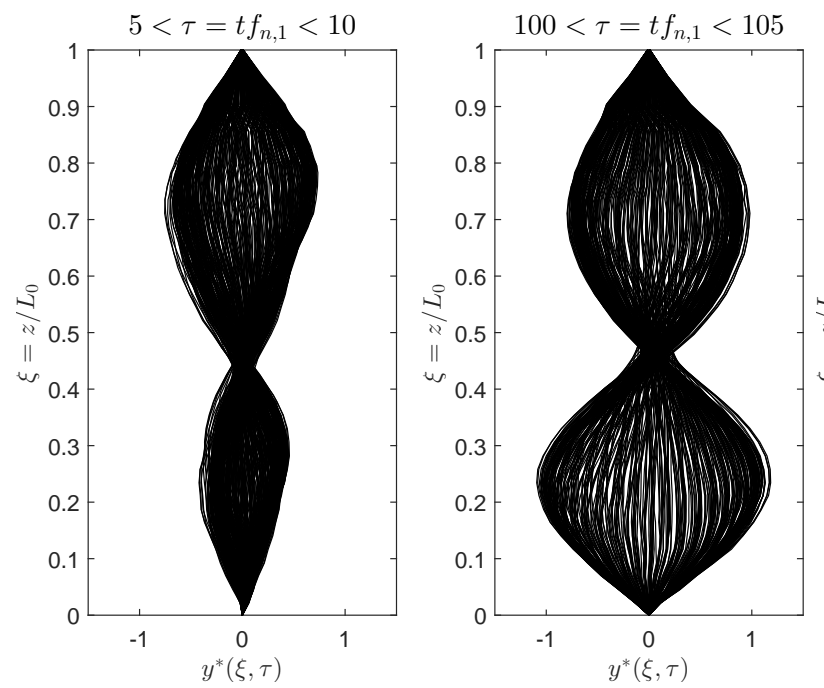

(c) Configurações deformadas instantâneas. Dire- $($ ( ) ção cross-wise.

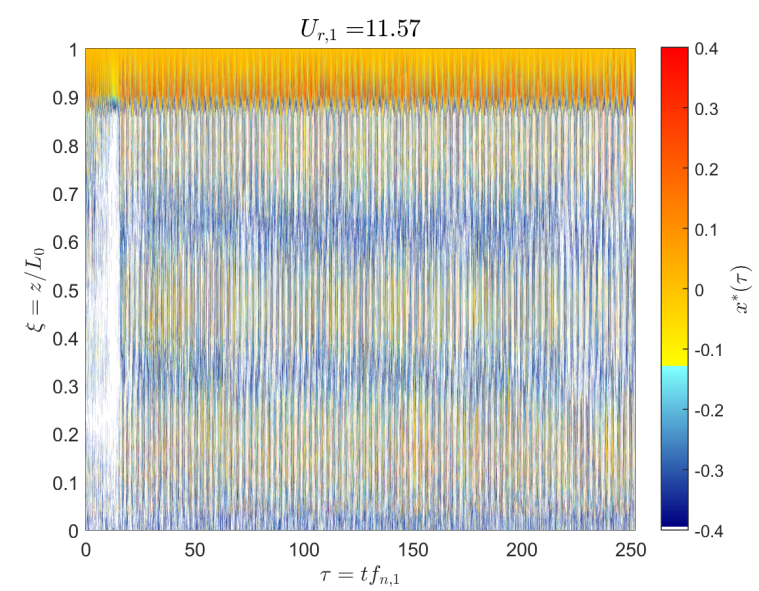

(b) Escalograma $x^{*}(\xi, \tau)$.
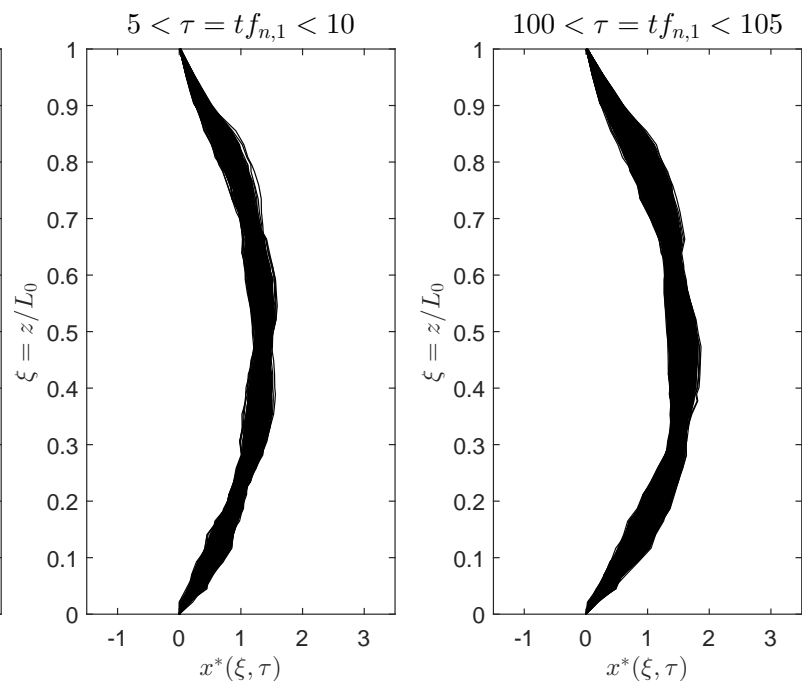

(d) Configurações deformadas instantâneas. Direção in-line.

Fonte: Elaborada pelo autor.

line ilustrada na Figura 74(d), é possível notar quatro pontos que assemelham-se a nós em $\xi \approx 0,22, \xi \approx 0,48$ e $\xi \approx 0,68$, indicando uma resposta com característica de quarto modo. Por outro lado, as configurações deformadas referentes ao intervalo $100<\tau<105$ indicam a presença de dois nós e, portanto, do terceiro modo. De fato, o espectro de amplitude $S_{x}(\xi, \hat{f})$ já identificava contribuições desses dois modos, porém não fornecia indicativos se estas respostas coexistiam ou se faziam parte de dois regimes distintos observados para um mesmo experimento. Assim, a análise dos escalogramas e das configurações deformadas instantâneas mostra-se relevante como ferramenta complementar à análise espectral.

Ainda considerando a velocidade reduzida $U_{r, 1}=11,57$, a Figura 75 apresenta as trajetórias no plano horizontal de um conjunto de pontos monitorados. De maneira similar àquela observada quando da análise da Figura 73, a mudança de regimes promove 
Figura 75 - Trajetórias no plano horizontal. Os pontos vermelhos indicam a posição média de cada ponto para o qual a trajetória é exibida. $U_{r, 1}=11,57$.

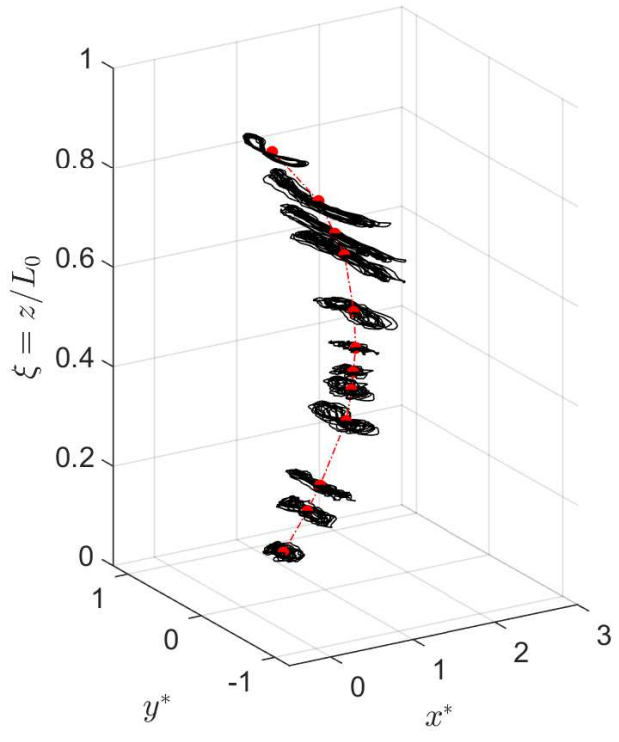

(a) $5<\tau<10$.

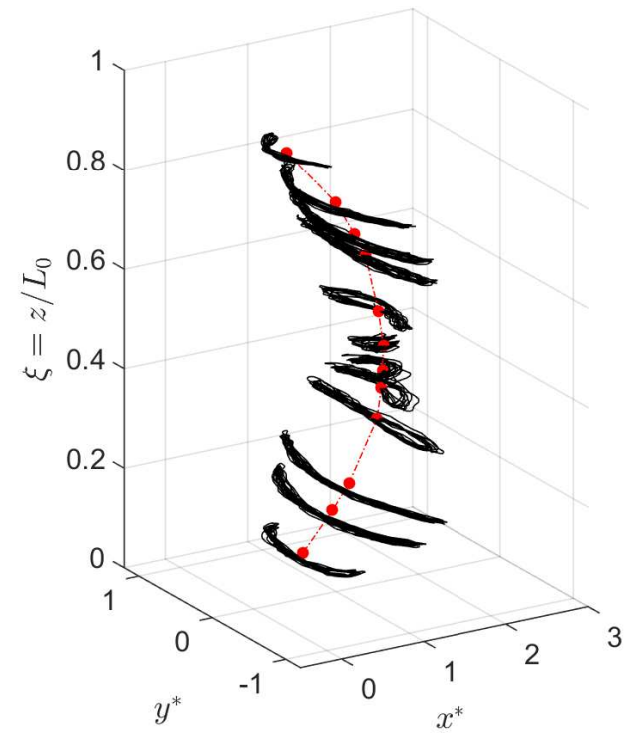

(b) $100<\tau<105$.

Fonte: Elaborada pelo autor.

alterações topológicas nas trajetórias no plano horizontal. Note que, além do aumento das amplitudes, o regime identificado para $100<\tau<105$ apresenta trajetórias melhor definidas, induzindo um processo de sincronização entre as oscilações na direção in-line e cross-wise melhor definido.

O leitor percebe que, até este ponto da presente subseção, as análises foram conduzidas em uma abordagem clássica, isto é, por meio das séries temporais de alguns pontos do modelo. Essa abordagem já permitiu a identificação de respostas multi-modais e também da transição entre dois regimes de resposta para uma mesma velocidade de reboque nominal. É interesse, agora, analisar as séries temporais de amplitude modal e mencionar quais os ganhos de interpretação por elas possibilitados.

A discussão das séries temporais de amplitude modal é iniciada buscando avaliar similaridades nas respostas modais dos dois primeiros modos quando comparam-se experimentos com velocidades de reboque distintas mas com valores próximos de velocidade reduzida modal, ou seja $U_{r, 1} \approx U_{r, 2}$.

Em um primeiro momento, a análise é feita considerando apenas a direção crosswise. A Figura 76 apresenta as séries temporais $\tilde{a}_{1}^{y}(\tau)$ e $\tilde{a}_{2}^{y}(\tau)$ e os correspondentes espectros de amplitude ${ }^{13}$ para duas corridas distintas, porém caracterizadas por $U_{r, 1} \approx U_{r, 2} \approx 4,20$. Note que essas velocidades reduzidas modais correspondem ao início do lock-in com o primeiro e com o segundo modo de vibrar.

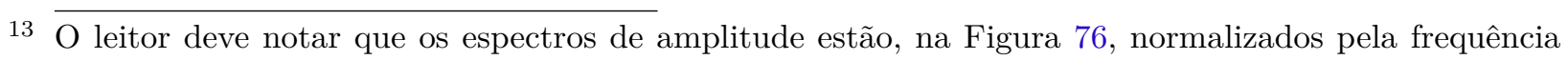
natural do modo a que se refere cada série temporal de amplitude modal. 
A Figura 76 já ilustra algumas semelhanças entre as respostas modais quando consideradas em velocidades reduzidas modais semelhantes. Ambas as séries temporais modais apresentam significativa modulação em amplitude, sendo a amplitude característica $\hat{A}_{2}^{y}$ ligeiramente superior. Em termos de assinatura em frequência, os dois espectros de amplitude possuem pico em uma frequência ligeiramente inferior àquela do correspondente modo natural avaliado em água parada $f_{n, k}$ com alguma dispersão de energia no entorno da frequência dominante.

Figura 76 - Séries temporais de amplitude modal - direção cross-wise. Velocidades reduzidas modais $U_{r, 1} \approx U_{r, 2} \approx 4,20$.
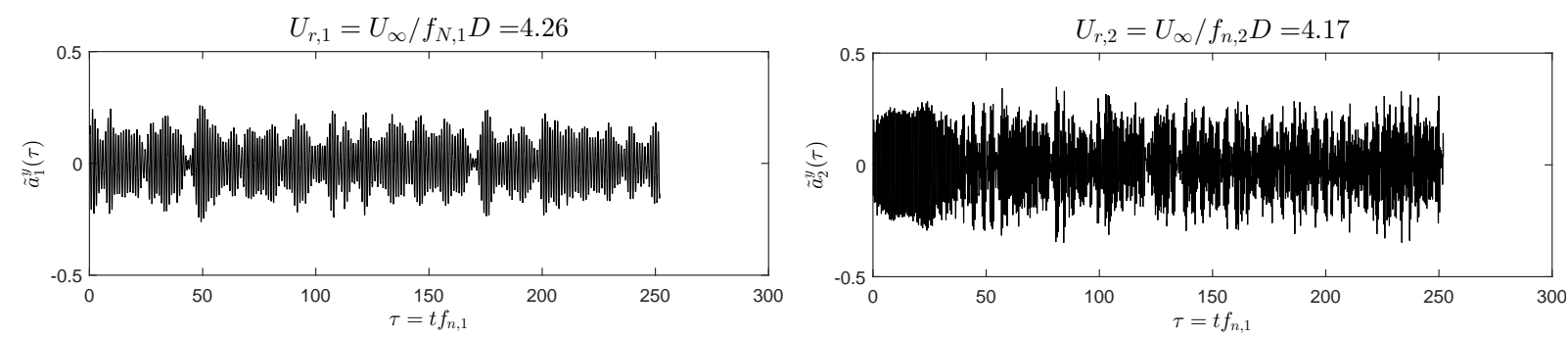

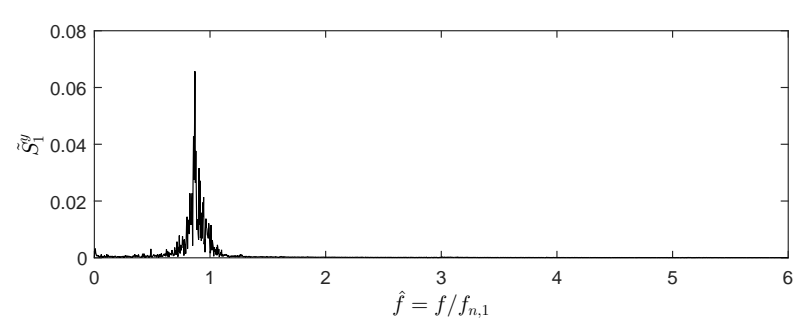

(a) $\tilde{a}_{1}^{y}(\tau)$ e espectro de amplitude.

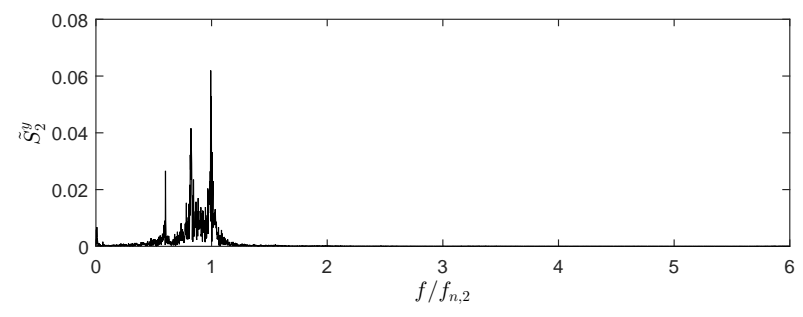

(b) $\tilde{a}_{1}^{y}(\tau)$ e espectro de amplitude.

Fonte: Elaborada pelo autor.

Analisa-se agora e com o apoio da Figura 77, a condição onde a velocidade reduzida modal é $U_{r, k} \approx 5,70(k=1,2)$, um valor ligeiramente superior àquela estudada na Figura 76. Além disso, as séries temporais de oscilação na direção in-line também serão discutidas. Para $U_{r, k} \approx 5,70$, é esperado o lock-in com o k-ésimo modo de vibrar, de sorte que a frequência de oscilação na direção cross-wise deve ser próxima da k-ésima frequência natural em água parada $f_{n, k}$ e que, portanto, a frequência de excitação na direção in-line deve ser aproximadamente igual a $2 f_{n, k}$. Dessa forma e considerando a velocidade reduzida modal em questão, é natural o estudo conjunto das séries temporais $\tilde{a}_{1}^{y}(\tau)$ e $\tilde{a}_{2}^{x}(\tau)$ para $U_{r, 1}=5,63$ e $\tilde{a}_{2}^{y}(\tau)$ e $\tilde{a}_{4}^{x}(\tau)$ para $U_{r, 2}=5,78$.

A Figura 77(a) revela que, quando existe o lock-in com o primeiro modo de vibrar, a série temporal $\tilde{a}_{1}^{y}(\tau)$ praticamente não apresenta modulações em amplitude e tem seu espectro de amplitude com banda estreita com frequência dominante ligeiramente superior à primeira frequência natural. Já série temporal $\tilde{a}_{2}^{x}(\tau)$ também apresenta pouca modulação de amplitude e possui espectro de amplitude monocromático com frequência igual ao dobro daquela obtida a partir de $\tilde{a}_{1}^{y}(\tau)$; ver Figura $77(\mathrm{~b})$. 
Figura 77 - Séries temporais de amplitude modal obtidas a partir de dois experimentos distintos e caracterizados por velocidades reduzidas modais $U_{r, 1} \approx U_{r, 2} \approx 5,70$.
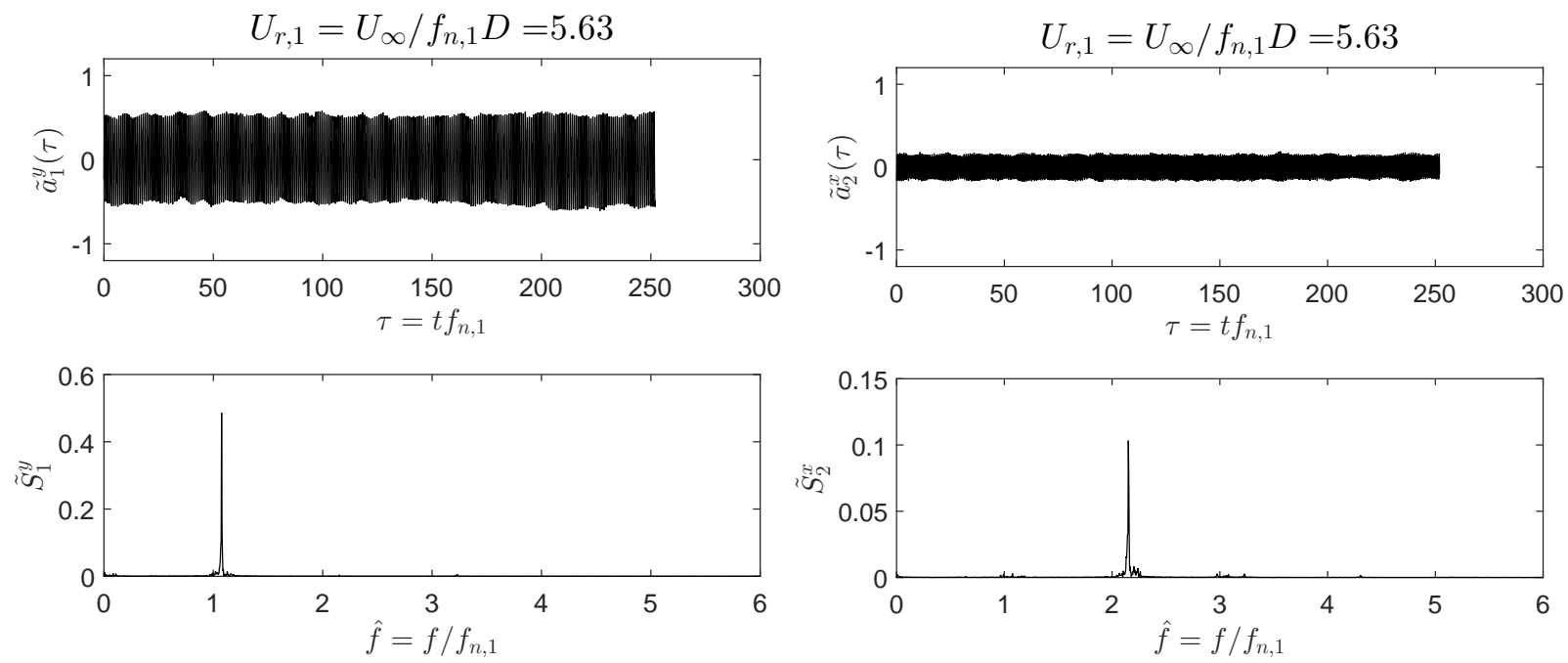

(a) $\tilde{a}_{1}^{y}(\tau)$ e espectro de amplitude.

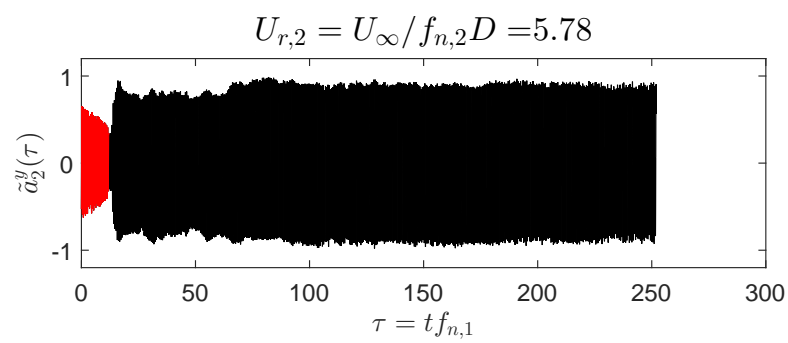

(b) $\tilde{a}_{2}^{x}(\tau)$ e espectro de amplitude.
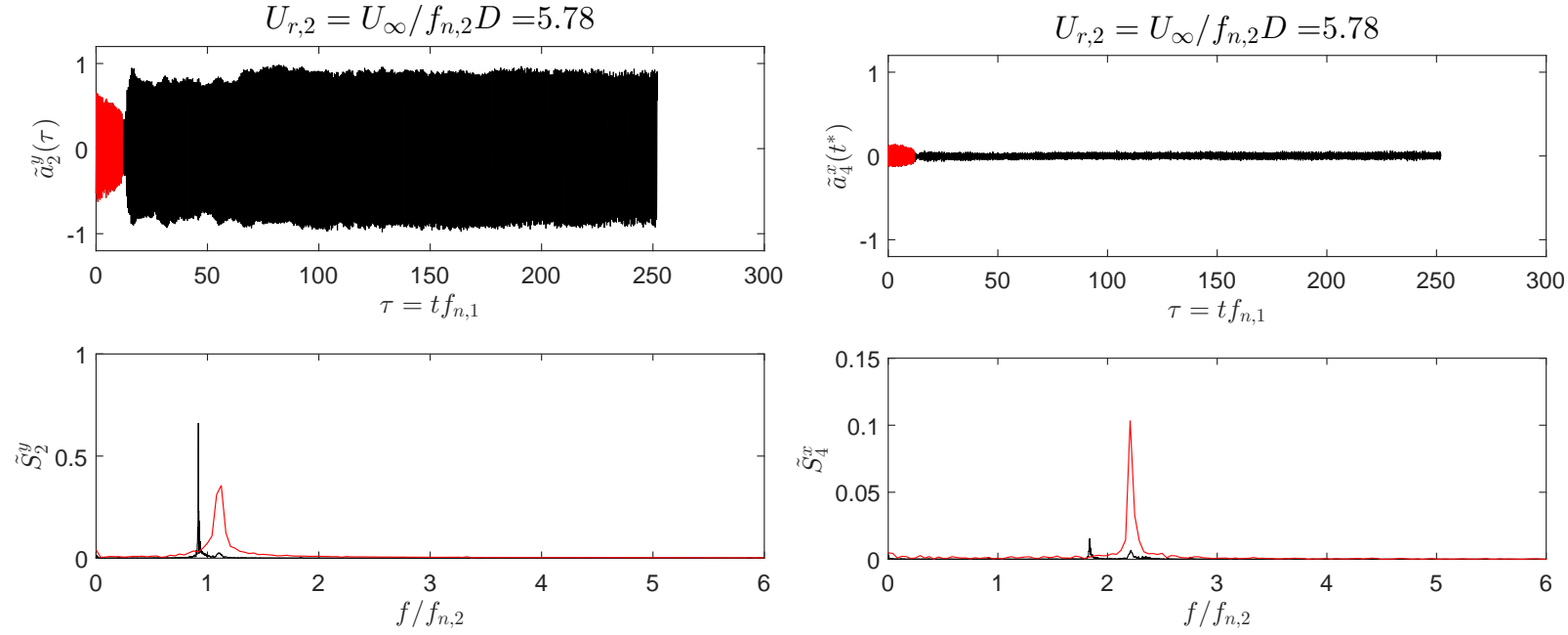

(c) $\tilde{a}_{2}^{y}(\tau)$ e espectro de amplitude.

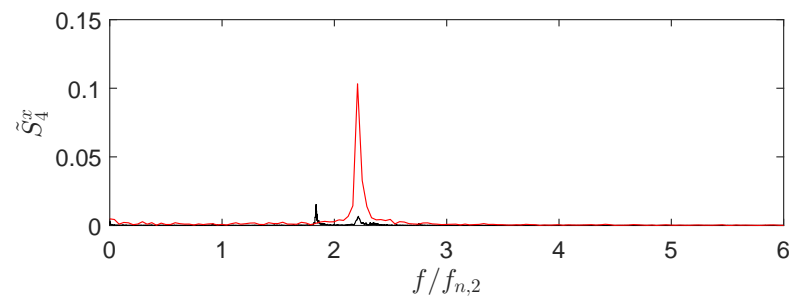

(d) $\tilde{a}_{4}^{x}(\tau)$ e espectro de amplitude.

Fonte: Elaborada pelo autor.

Considerando a velocidade reduzida $U_{r, 1}=5,63$, as séries temporais $\tilde{a}_{1}^{y}(\tau)$ e $\tilde{a}_{2}^{x}(\tau)$, em conjunto com a relação de frequências naturais $f_{n, 2}=2 f_{n, 1}$, permitem afirmar a existência da ressonância dual entre o primeiro modo de vibrar na direção cross-wise e o segundo modo de vibrar na direção in-line. Note que essa ressonância dual já havia sido especulada quando da análise dos espectros de amplitude $S_{y}(\xi, \hat{f})$ e $S_{y}(\xi, \hat{f})$, porém a análise via séries temporais de amplitude modal permite verificar a conjectura anteriormente proposta.

As Figuras $77(\mathrm{c})$ e $77(\mathrm{~d})$ trazem, respectivamente, as séries temporais $\tilde{a}_{2}^{y}(\tau)$ e $\tilde{a}_{4}^{x}(\tau)$ e os correspondentes espectros de amplitude. Note que a velocidade reduzida modal associada ao segundo modo de vibrar $U_{r, 2}$ é semelhante àquela estudada nas Figuras 
77(a) e 77(b) embora as velocidades de reboque sejam distintas. Tendo em vista que $U_{r, 2}=5,78 \leftrightarrow U_{r, 1}=11,57^{14}$, é natural o interesse por vibrações no segundo modo na direção cross-wise e no quarto modo na direção in-line.

Tanto a Figura 77(c) quanto a Figura 77(d) são caracterizadas por uma mudança de regime observada em $\tau \approx 10$ e identificadas por cores distintas nas séries temporais e nos espectros de amplitude. A partir dessas figuras, é possível notar um aumento no valor característico na série temporal $\tilde{a}_{2}^{y}(\tau)$ enquanto há uma diminuição na mesma grandeza para a série temporal $\tilde{a}_{4}^{x}(\tau)$. Note, ainda, que após a transição observada, existe um decréscimo nas frequências dominantes de oscilação e também uma diminuição da banda espectral. Do ponto de vista físico, as mudanças nas frequências de oscilação associadas à transição entre regimes de resposta mostram que, considerando a mesma forma de vibrar (ou seja, seu modo), existem mudanças na frequência de oscilação. Cumpre ressaltar que, mesmo com a mudança nas frequências dominantes de oscilação, a ressonância dual entre o segundo modo de vibrar na direção cross-wise e o quarto modo de vibrar na direção in-line é mantida.

Um outro resultado interessante obtido por meio das séries temporais de amplitude modal diz respeito às trajetórias nos planos modais, que representam seções transversais do espaço de configuração gerado pelas coordenadas modais $\tilde{a}_{i}^{y}$ e $\tilde{a}_{j}^{x}$ sendo $i$ e $j$ índices que representam o número do modo. A Figura 78 apresenta as trajetórias nos planos modais $\tilde{a}_{x}^{2 k} \times \tilde{a}_{y}^{k}$, sendo $k$ o número do modo.

Foram escolhidas seções transversais onde o número do modo associado à série temporal de amplitude modal na direção in-line seja o dobro daquele associado à direção cross-wise, o que constitui o cenário da ressonância dual. A Figura 78(a) foi obtida a partir do experimento com $U_{r, 1}=5,63$ e, portanto, excitando o lock-in no modo $k=1$ na direção cross-wise. A trajetória ilustrada nessa figura indica o clássico formato de oito observado quando da análise da condição VIV-2gl. Além de revelar a relação de frequências dominantes $f_{d, x} / f_{d, y}=2$, a diferença de fase entre estas séries temporais modais guarda notáveis similaridades com aquela encontrada entre as séries temporais $x^{*}(\tau)$ e $y^{*}(\tau)$ existentes na condição VIV-2gl.

Por sua vez, a Figura 78(b) foi construída a partir do experimento com velocidade de reboque tal que $U_{r, 2}=5,78$ e que o lock-in com o segundo modo de vibrar na direção cross-wise seja observado. Como nota o leitor, essa figura segue o mesmo código de cores apresentado nas Figuras 77(c) e $77(\mathrm{~d})$. Durante o intervalo $0<\tau<13$, a trajetória no plano $\tilde{a}_{4}^{x} \times \tilde{a}_{2}^{y}$ tem notável similaridade com aquela apresentada na Figura 78(a) e que representa o lock-in com o primeiro modo de vibrar na direção cross-wise. Já para o intervalo $\tau>13$, a trajetória guarda similaridades com aquela obtida na condição VIV-2gl

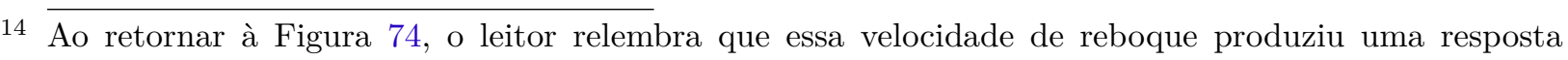
caracterizada pela existência dos regimes mencionados. 
próxima da transição do super upper branch para o lower branch e ilustrada na Figura 14.

Figura 78 - Trajetórias nos planos modais $\tilde{a}_{x}^{2 k} \times \tilde{a}_{y}^{k}$. Velocidades reduzidas modais $U_{r, 1} \approx$ $U_{r, 2} \approx 5,70$.

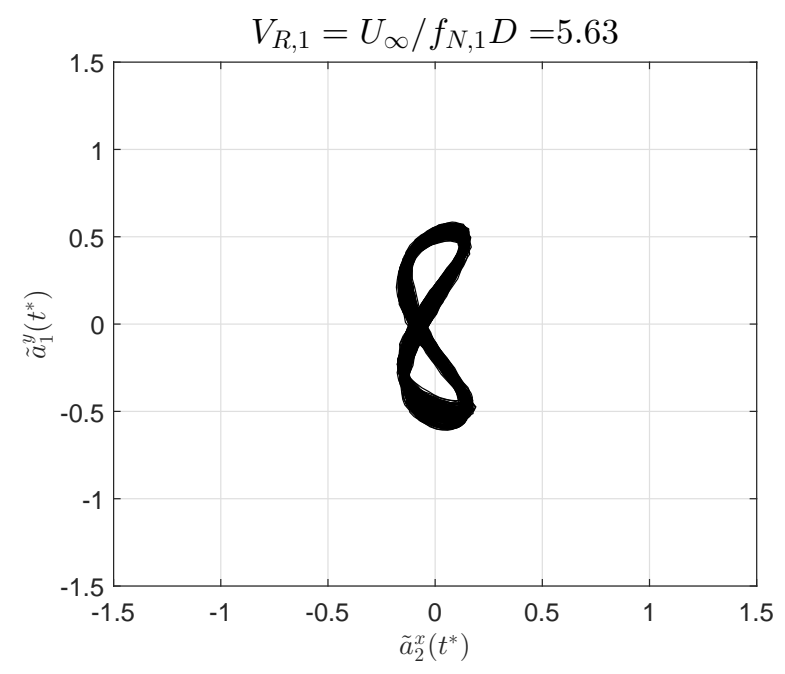

(a) Trajetória no plano $\tilde{a}_{2}^{x} \times \tilde{a}_{1}^{y} \cdot U_{r, 1}=5,63$.

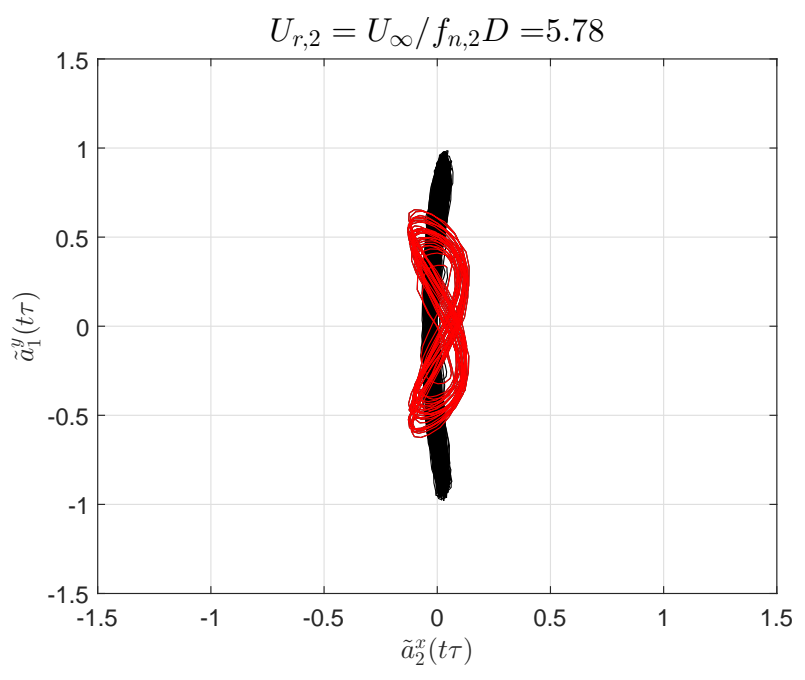

(b) Trajetória no plano $\tilde{a}_{4}^{x} \times \tilde{a}_{2}^{y} \cdot U_{r, 2}=5,78$.

Fonte: Adaptada de Franzini et al. (2016a).

Como visto, existe uma mudança na diferença de fase entre as séries temporais de amplitude modal. Essa defasagem, aliada ao conceito de sincronização, será agora discutida considerando as mesmas velocidades reduzidas modais estudadas na Figura 78.

A Figura 79(a) ilustra a série temporal ${ }_{1}^{2} \phi_{y}^{x}(\tau)$ (ou seja, a diferença de fase entre as séries temporais $\tilde{a}_{1}^{y}(\tau)$ e $\left.\tilde{a}_{2}^{x}(\tau)\right)$ obtida a partir do experimento com $U_{r, 1}=5,63$. Note que ${ }_{1}^{2} \phi_{y}^{x}(\tau)$ é praticamente constante no tempo, indicando um processo de sincronização entre as oscilações no primeiro modo na direção cross-wise e aquelas associadas ao segundo modo na direção in-line muito bem definido. Embora a regularidade da trajetória no plano $\tilde{a}_{2}^{x} \times \tilde{a}_{1}^{y}$ (ver Figura 78(a)) já permita inferir acerca da pouca modulação da diferença de fase, a série temporal ${ }_{1}^{2} \phi_{y}^{x}(\tau)$ e o histograma ${ }^{15}$ apresentados na Figura 79(a) permitem discussões com aspecto quantitativo mais fortes.

Já a Figura 79(b) foi obtida a partir do experimento caracterizado por $U_{r, 2}=5,78$ e apresenta a série temporal de defasagem entre as oscilações na direção in-line e com a forma do quarto modo $\tilde{a}_{4}^{x}(\tau)$ e aquelas na direção cross-wise com a forma do segundo modo $\tilde{a}_{2}^{y}(\tau)$. Note que a transição observada em $\tau \approx 13$ e já discutida é caracterizada por um salto de ${ }_{2}^{4} \phi_{y}^{x}(\tau) \approx 220^{\circ}$ para ${ }_{2}^{4} \phi_{y}^{x}(\tau) \approx 45^{\circ}$.

Embora o valor médio da defasagem seja similar àquele observado para a condição ilustrada na Figura 79(b) quando o lock-in era observado com o primeiro modo de vibrar na direção cross-wise, a maior variação temporal de ${ }_{2}^{4} \phi_{y}^{x}(\tau)$ indica que a sincronização

15 Nos histogramas, $N^{*}$ é o número de ocorrências normalizado pelo número total de observações. 
Figura 79 - Séries temporais de diferença de fase ${ }_{k}^{2 k} \phi_{y}^{x}(\tau)$. Velocidades reduzidas modais $U_{r, 1} \approx U_{r, 2} \approx 5,70$.
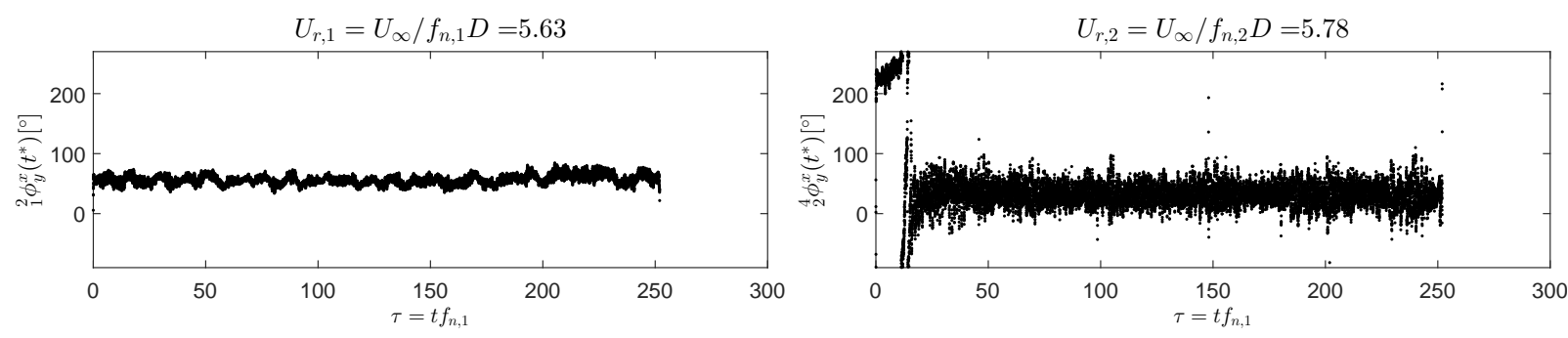

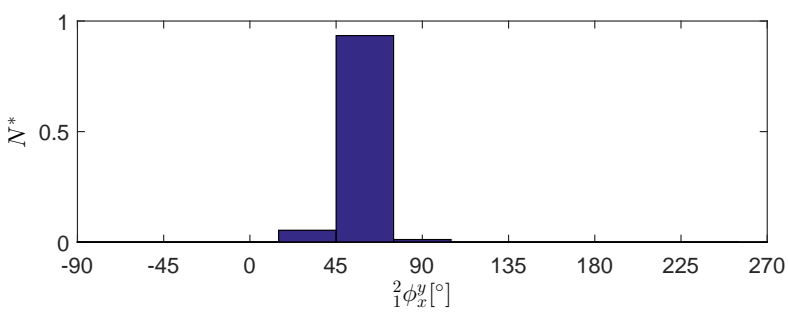

(a) ${ }_{1}^{2} \phi_{y}^{x}(\tau) . U_{r, 1}=5,63$.

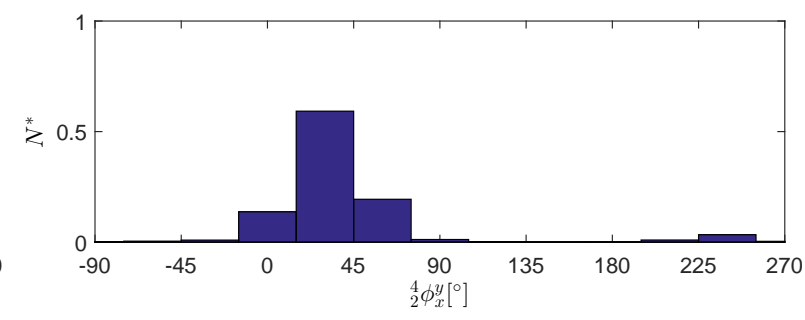

(b) ${ }_{2}^{4} \phi_{y}^{x}(\tau) . U_{r, 2}=5,78$.

Fonte: Adaptada de Franzini et al. (2016a).

entre as oscilações no quarto modo de vibrar na direção in-line e o segundo modo de vibrar na direção cross-wise é menos pronunciada do que na condição onde a velocidade de reboque excita o lock-in no primeiro modo.

As análises de sincronismo até aqui conduzidas envolveram modos em direções ortogonais. No entanto, tais análises podem ser conduzidas considerando modos na mesma direção, sendo de especial interesse para condições de velocidade de reboque do carro dinamométrico nas quais pode existir um cenário favorável ao lock-in com mais de um modo natural.

Nesse cenário, considere a condição tal que $U_{r, 1}=6,99 \leftrightarrow U_{r, 2}=3,49$. Claramente, o lock-in com o primeiro modo na direção cross-wise está bem definido e ocorre de maneira concomitante ao início do lock-in com o segundo modo nessa mesma direção. As séries temporais de amplitude modal associadas aos modos $k=1$ e $k=2$ e referentes à direção cross-wise estão apresentadas na Figura ${ }^{16} 80$.

Mesmo que a série temporal de amplitude modal $\tilde{a}_{1}^{y}(\tau)$ ilustrada na Figura 80(a) não indique uma mudança de regime, a Figura 80(b) mostra um salto na série temporal $\tilde{a}_{2}^{y}(\tau)$ ocorrido para um instante de tempo ligeiramente superior a $\tau=100$. Embora esse salto esteja associado a um acréscimo na amplitude característica de $\tilde{a}_{2}^{y}(\tau)$, não há mudança significativa nos espectros de amplitude $\tilde{S}_{1}^{y}\left(f / f_{n, 1}\right)$ e $\tilde{S}_{2}^{y}\left(f / f_{n, 2}\right)$.

Buscando investigar essa transição entre regimes, a Figura 81 apresenta a série temporal ${ }_{1}^{2} \phi_{y}^{y}(\tau)$ correspondente à variação temporal da diferença de fase entre as séries

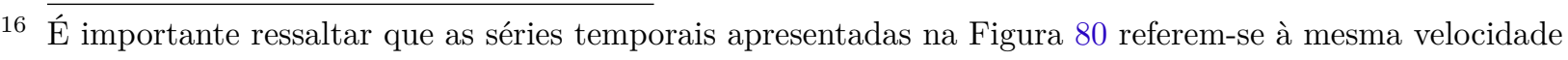
de reboque. 
Figura 80 - Séries temporais de amplitude modal $\tilde{a}_{1}^{y}(\tau)$ e $\tilde{a}_{2}^{y}(\tau)$.
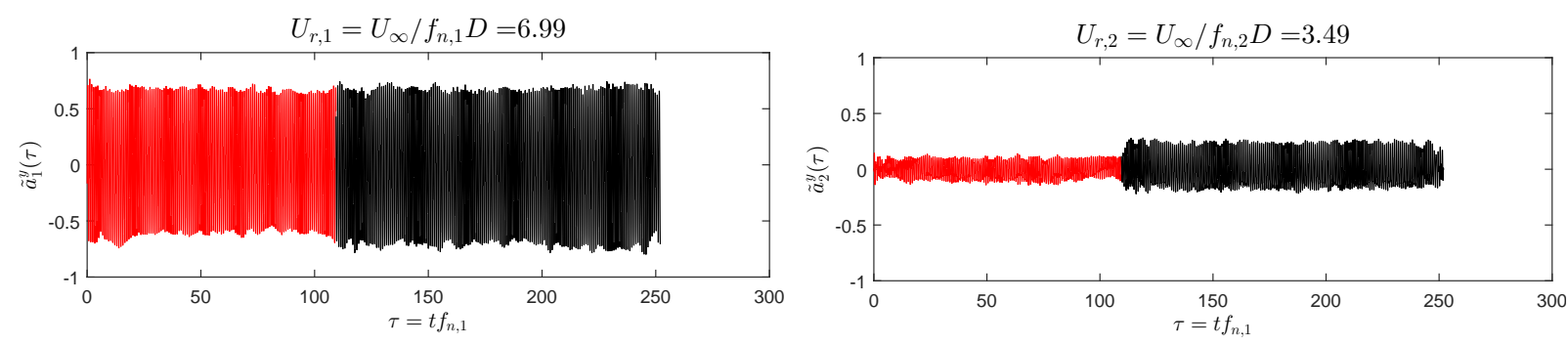

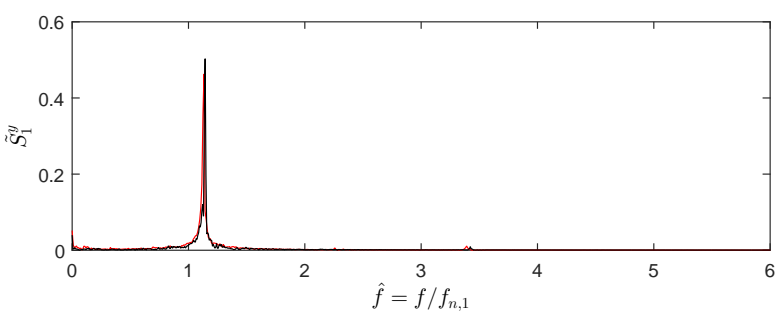

(a) $\tilde{a}_{1}^{y}(\tau)$.

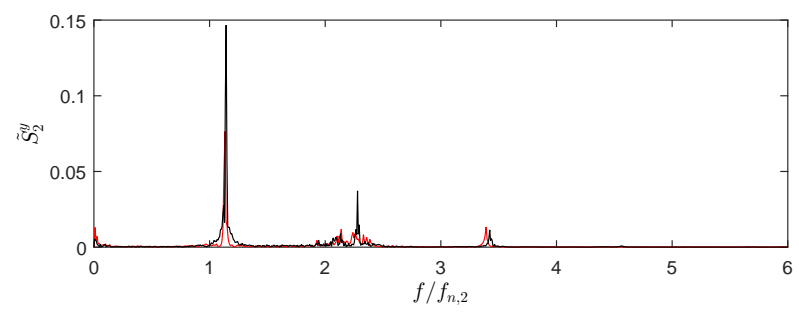

(b) $\tilde{a}_{2}^{y}(\tau)$.

Fonte: Elaborada pelo autor.

temporal de vibração no primeiro e no segundo modo, ambas na direção cross-wise. A Figura 81 claramente revela que o aumento na amplitude característica da série temporal $\tilde{a}_{2}^{y}(\tau)$ está associado à mudança em ${ }_{1}^{2} \phi_{y}^{y}(\tau)$, que passa de $180^{\circ}$ para $0^{\circ}$ em $\tau \approx 100$. Qualitativamente, as variações temporais da diferença de fase é menor para $\tau>100$, indicando um processo de sincronização entre as séries temporais de amplitude modal estudadas melhor definido do que aquele observado para $\tau<100$. Como consequência dessa melhor definição, justifica-se o aumento na amplitude característica da série temporal $\tilde{a}_{2}^{y}(\tau)$ ilustrada na Figura 80(b).

Conforme visto nesta subseção, em particular por ocasião da análise das Figuras 77 e 79, as séries temporais de amplitude modal podem apresentar notáveis semelhanças se tomadas em valores de velocidades reduzidas modais $U_{r, k}$ comparáveis. Dessa forma, é interessante avaliar a variação dos valores característicos das séries temporais de amplitude modal $\hat{A}_{k}^{y}$ e $\hat{A}_{k}^{x}$ como funções de $U_{r, k}$.

A Figura 82 apresenta as curvas $\hat{A}_{k}^{y}\left(U_{r, k}\right)$ e $\hat{A}_{k}^{x}\left(U_{r, k}\right)$. No tocante aos resultados associados à direção cross-wise, a Figura 82(a) revela uma notável aderência entre as curvas para os quatro primeiros modos de vibrar, em particular no intervalo $3<U_{r, k}<5$, o que corresponde ao initial branch e, portanto, ao início da sincronização entre a frequência de emissão de vórtices e a frequência natural do k-ésimo modo de vibrar. O mesmo comentário vale para a resposta referente à direção in-line apresentada na Figura in-line 82(b), porém considerando o intervalo $2<U_{r, k}<4$ e associado à ressonância na direção in-line.

Considerando agora o intervalo $5<U_{r, k}<8$, a Figura 82(a) mostra boa aderência entre as amplitudes características $\hat{A}_{1}^{y}$ e $\hat{A}_{2}^{y}$. Esse resultado revela não que não só o início do lock-in é semelhante para os modos $k=1$ e $k=2$ como que os valores característicos 
Figura 81 - Séries temporais de diferença de fase ${ }_{1}^{2} \phi_{y}^{y}(\tau) . U_{r, 1}=6,99 \leftrightarrow U_{r, 2}=3,49$.
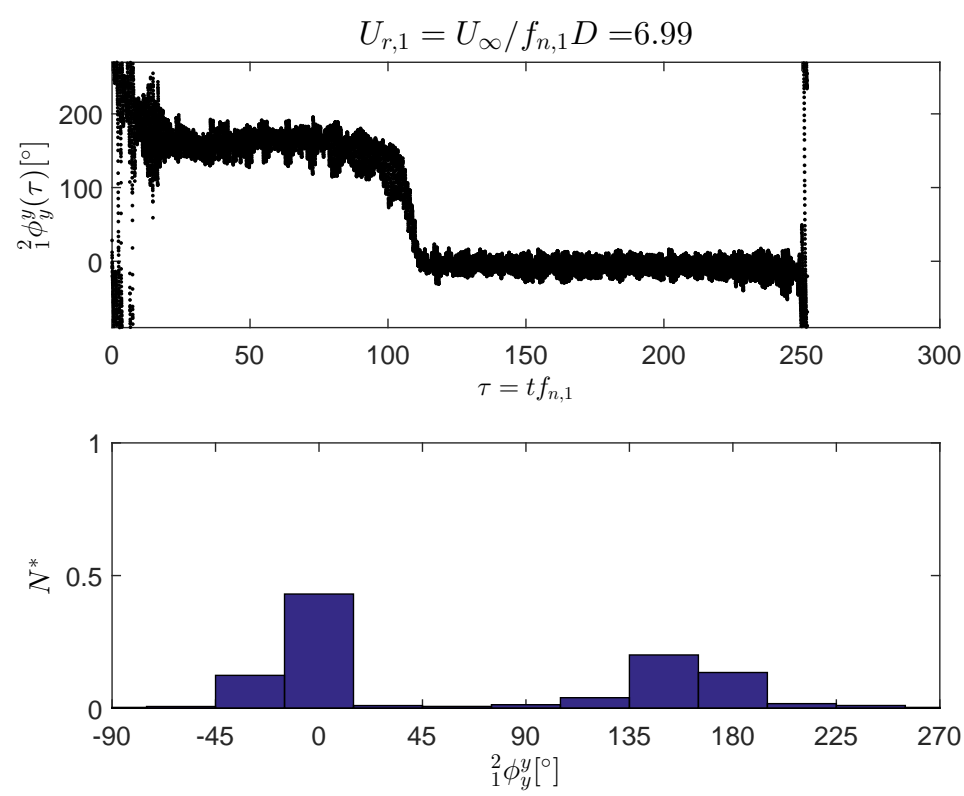

Fonte: Elaborada pelo autor.

Figura 82 - Valores característicos das séries temporais de amplitude modal como funções da velocidade reduzida modal.

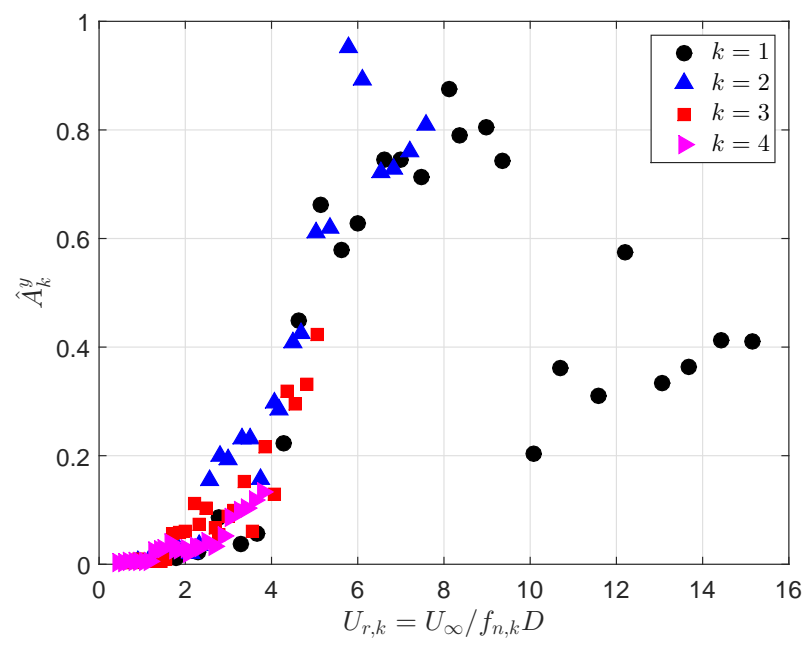

(a) Direção cross-wise.

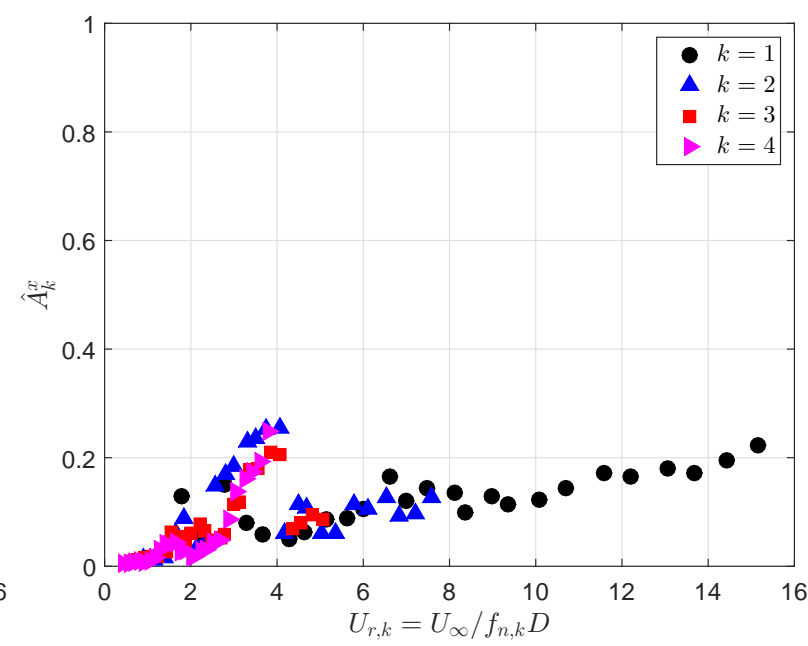

(b) Direção in-line.

Fonte: Adaptada de Franzini et al. (2016a).

das séries temporais de amplitude modal também o são, desde que a velocidade reduzida seja tomada com base na frequência natural do correspondente modo.

Esse resultado, apresentado inicialmente em Franzini et al. (2016a), constitui a primeira evidência experimental (ao menos do conhecido do autor deste texto e do grupo de pesquisa do LMO) de que a curva de valores característicos de oscilação calculados a partir das séries temporais de amplitude modal é pouco afetada pelo modo de vibrar. Essa é uma hipótese intrinsecamente adotada quando são feitas análises do fenômeno de VIV 
em cilindros flexíveis por meio de wake-oscillators.

\subsubsection{Resultados para solicitação combinada de VIV e de excitação paramétrica}

A Figura 83 ilustra as séries temporais de deslocamento e os correspondentes espectros de amplitude para o ponto de coordenada $\xi=0,43$ e para $U_{r, 1} \approx 5,70$ considerando tanto os experimentos com excitação somente pelo VIV quanto aqueles nos quais o cilindro flexível é solicitado simultaneamente pela correnteza e pela excitação de topo. Para esse valor de velocidade reduzida, é esperado o lock-in com o primeiro modo de vibrar na direção cross-wise, o que indica oscilações importantes na região próxima à metade do modelo.

Como mostra a Figura 83(a), a resposta na direção cross-wise à excitação somente pelo VIV é praticamente livre de modulações em amplitude e é caracterizada por uma frequência adimensional ligeiramente superior a $\hat{f}=1$, embora uma pequena energia possa ser notada em uma frequência correspondente ao triplo desse valor. De fato, esse resultado não surpreende, uma vez que o escoamento incidente é caracterizado por um valor de velocidade reduzida modal no qual é esperado o lock-in com o primeiro modo de vibrar.

Ainda para a condição "VIV puro", a Figura 83(b) mostra a resposta na direção in-line para o mesmo ponto do modelo. Como consequência de uma força de arrasto média atuante no modelo, a média da resposta $x^{*}(\tau)$ é não nula. O espectro de amplitude correspondente possui um conteúdo espectral com frequência dominante próxima ao dobro daquela observada para a direção cross-wise, além da presença de energia significativa em uma componente $\hat{f}$ ligeiramente superior a 1 e em múltiplos inteiros dessa última frequência.

As Figuras 83(c) e 83(d) ilustram as séries temporais obtidas a partir do ensaio no qual a excitação pela correnteza coexiste com o movimento imposto com frequência $f_{t}: f_{n, 1}=2: 1$, ou seja, na instabilidade paramétrica principal com o primeiro modo de vibrar. Como pode ser visto na Figura 83(c), a concomitante excitação pelo VIV e pela instabilidade paramétrica principal promove mudanças qualitativas e quantitativas importantes na série temporal $y^{*}(\tau)$, que passa a caracterizada por intensas modulações em amplitude e por um aumento de quase $100 \%$ em seu valor máximo quando comparado ao caso onde as vibrações decorrem somente da interação fluido-estrutura (ver Figura 83(a)). Embora caracterizada por importantes modulações em amplitude, a série temporal

$y^{*}(\tau)$ tem um espectro de banda estreita, com frequência dominante $\hat{f}=1$ e uma pequena fração de energia em $\hat{f}=2$.

Ainda para a condição $f_{t}: f_{n, 1}=2: 1$, a Figura 83(d) ilustra a resposta na direção in-line. Embora essa excitação de topo promova um aumento na amplitude de oscilação quando comparada ao caso "VIV Puro" ilustrado na Figura 83(b), as componentes 
Figura 83 - Séries temporais de deslocamento e espectros de amplitude para um ponto localizado em $\xi=z / L_{0}=0,43$. (a), (b): "VIV puro"; (c)-(f) VIV com movimento imposto ao topo. $U_{r, 1} \approx 5,70$.
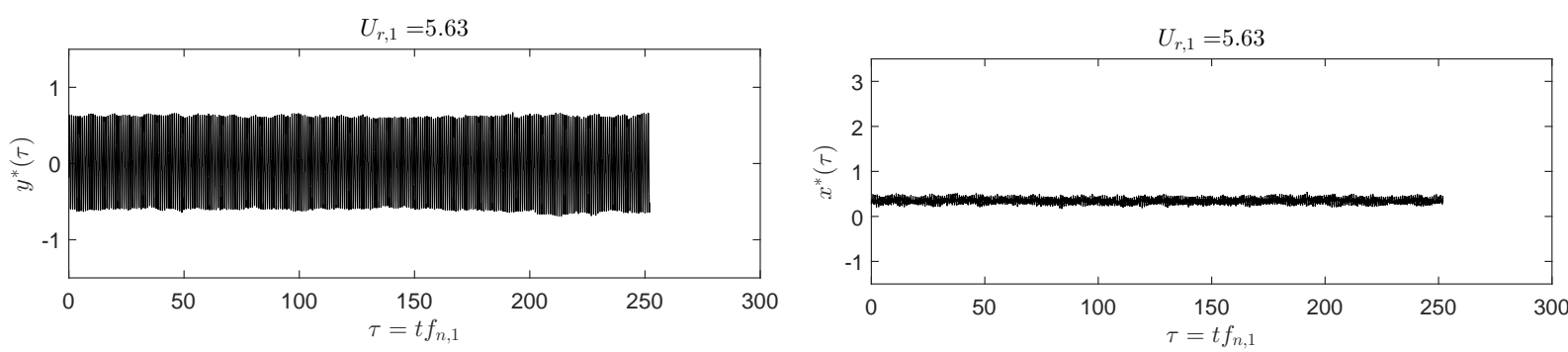

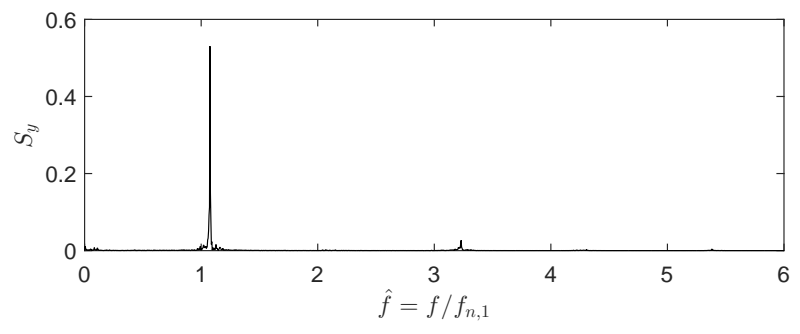

(a) "VIV puro" - direção cross-wise.
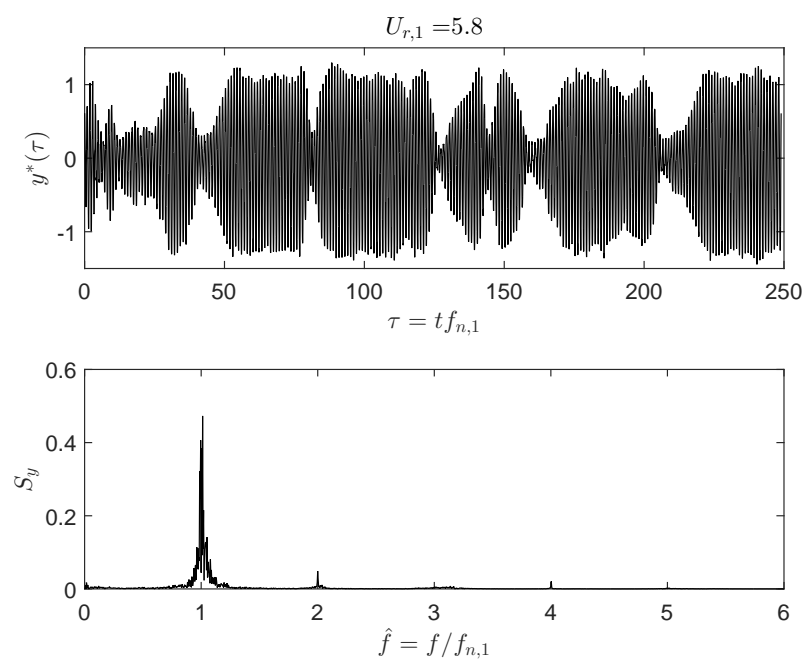

(c) $f_{t}: f_{n, 1}=2: 1$ - direção cross-wise.
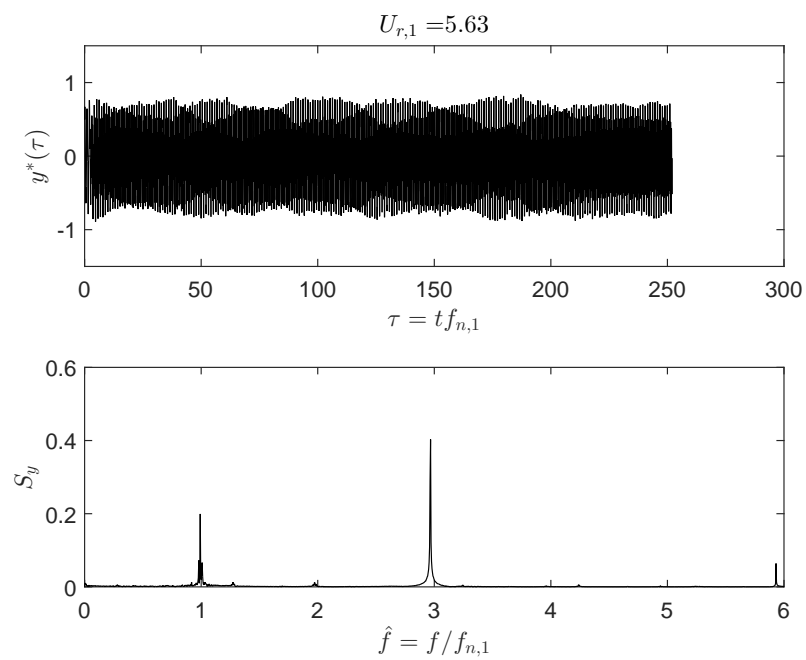

(e) $f_{t}: f_{n, 1}=3: 1$ - direção cross-wise.

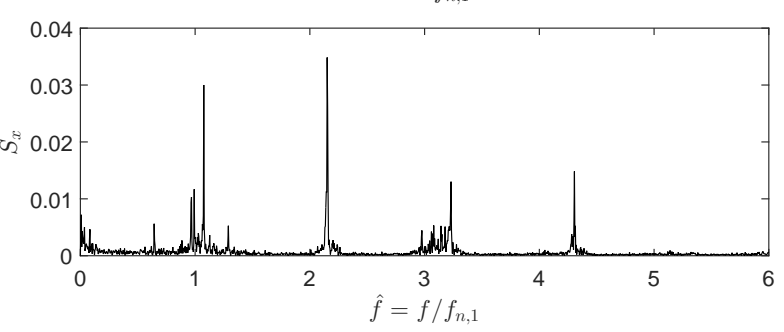

(b) "VIV puro" - direção in-line.
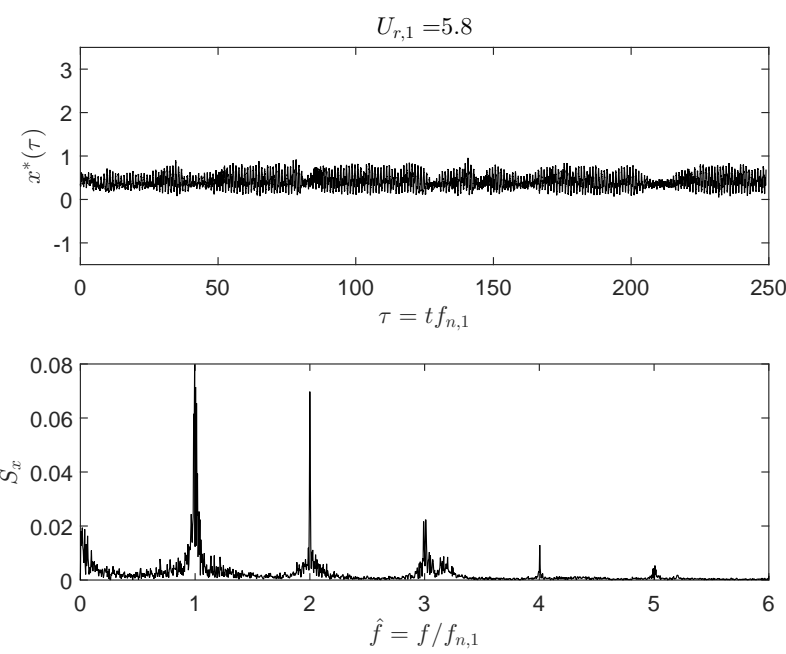

(d) $f_{t}: f_{n, 1}=2: 1$ - direção in-line.
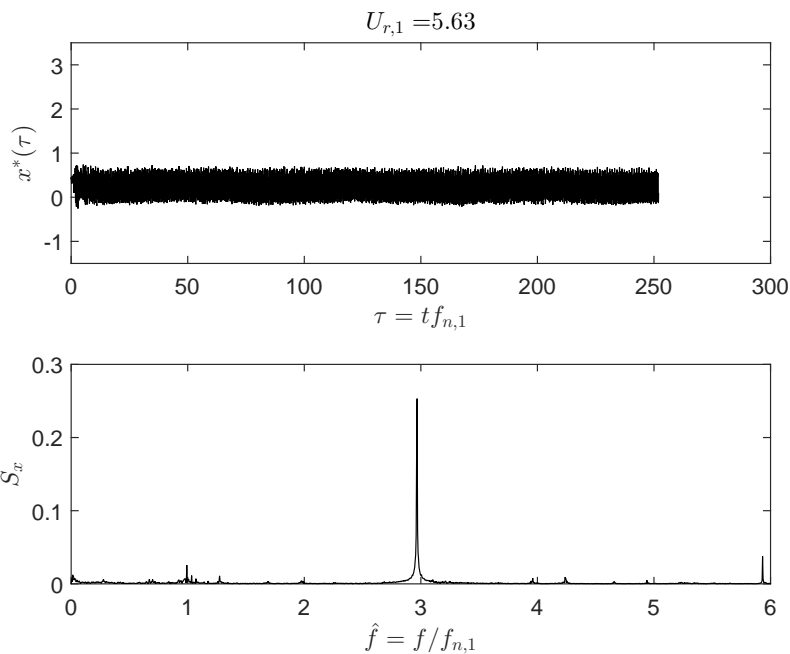

(f) $f_{t}: f_{n, 1}=3: 1$ - direção in-line.

Fonte: Adaptado de Franzini et al. (2018). 
de frequência que contribuem no espectro de amplitude são praticamente as mesmas observadas quando o cilindro é solicitado somente pelo VIV. De fato, a imposição de movimento ao topo com frequência $f_{t}: f_{n, 1}=2: 1$ induz a instabilidade paramétrica principal com o primeiro modo de vibrar e com frequência igual à $\hat{f}=1$, ou seja, metade da frequência da excitação de suporte.

A instabilidade paramétrica principal com o primeiro modo induz uma resposta com forte componente nesse modo natural. Tendo em vista que a velocidade reduzida estudada $\left(U_{r, 1} \approx 5,7\right)$ naturalmente induz vibrações na direção cross-wise com predomínio do primeiro modo, a concomitância entre esses dois fenômenos foi responsável pelo substancial incremento da resposta nessa direção.

Como visto, a excitação paramétrica com frequência $f_{t}: f_{n, 1}=2: 1$ promoveu um significativo aumento nas amplitudes de oscilação, além de conferir à resposta na direção cross-wise um caráter modulado em amplitude. No entanto, as frequências que compõem os espectros de amplitude não foram significativamente alteradas, ao contrário do que é observado para a excitação paramétrica definida por $f_{t}: f_{n, 1}=3: 1$.

A Figura 83(e) apresenta a série temporal $y^{*}(\tau)$ obtida a partir de um ensaio com movimento imposto com frequência $f_{t}: f_{n, 1}=3: 1$ concomitante a uma velocidade de reboque que excita o lock-in no primeiro modo de vibrar na direção cross-wise. A análise dessa série temporal revela dois aspectos em comum com a resposta obtida para a condição "VIV puro" e ilustrada na Figura 83(a), a saber, seu máximo valor próximo a 0,60 e a pouca modulação de amplitude. Note, no entanto, que a excitação de topo com frequência igual ao triplo da frequência natural do primeiro modo leva a uma mudança significativa no espectro de amplitude, agora caracterizado por uma frequência dominante $\hat{f}=3$ (a mesma frequência da excitação) e alguma energia na componente $\hat{f}=1$, a frequência de excitação pelo VIV.

No tocante à série temporal de deslocamento na direção in-line a partir da solicitação combinada dos fenômenos de VIV e de excitação paramétrica com frequência $f_{t}: f_{n, 1}=3$ : 1, a Figura 83(f) revela uma resposta com modulação em amplitude menos pronunciada do que aquela obtida para a condição $f_{t}: f_{n, 1}=2: 1$ e com predomínio da frequência $\hat{f}=3$, ou seja, a resposta tem como frequência dominante aquela da excitação de topo. A partir da análise das séries temporais $x^{*}(\tau)$ e $y^{*}(\tau)$, é possível concluir que a resposta do cilindro à solicitação combinada é dominada pelo movimento prescrito ao suporte quando $f_{t}: f_{n, 1}=3: 1$.

A Figura 84 apresenta as distribuições das amplitudes características de oscilação na direção cross-wise ao longo do modelo e dos correspondentes espectros de amplitude para os mesmos valores de velocidade reduzida ilustrados na Figura 83. Como a velocidade reduzida exemplificada corresponde a um típico lock-in com o primeiro modo, é de se esperar o predomínio dessa forma de vibrar para a condição "VIV puro", fato corroborado 
pela Figura 84(a) e a partir da qual é possível notar que a máxima amplitude característica é $\max \left\{\hat{A}^{y}\right\} \approx 0,70$ e ocorre em $\xi=0,40$.

A predominância do primeiro modo de vibrar na direção cross-wise é reforçada pelo espectro de amplitude $S_{y}(\xi, \hat{f})$, ilustrado na Figura $84(\mathrm{~b})$ e que revela o predomínio de oscilações com frequência $\hat{f}=1$ (isso é, na primeira frequência natural) com uma pequena contribuição de vibrações no terceiro modo e com frequência próxima a $\hat{f}=3$ (ou, de maneira equivalente, $\left.f / f_{n, 3}=f / 3 f_{n, 1}=1\right)$.

Cabe, neste ponto, pontuar alguns aspectos inerentes ao fenômeno de VIV em cilindros rígidos montados em apoio elástico. Como experimentalmente verificado em Khalak e Williamson (1999) e Franzini et al. (2012a), a força de sustentação tem como frequência dominante aquela associada à emissão de vórtices $\omega_{f}$ porém a componente de frequência $3 \omega_{f}$ também se faz presente na sua assinatura em frequência, embora com energia significativamente inferior àquela associada à $\omega_{f}$.

No contexto de cilindros rígidos montados em base elástica com mesma rigidez nas direções cross-wise e in-line, a componente de frequência $3 \omega_{f}$ não possui grande relevância em termos de amplitude de resposta. No entanto e em consonância com um aspecto já apontado na subseção 4.1.4 e que torna a análise do fenômeno de VIV em cilindros flexíveis mais complexa, as diversas componentes obtidas no espectro de amplitude da força de sustentação podem ser ressonantes com outras frequências naturais da estrutura. No caso da estrutura em análise, o leitor deve relembrar que $f_{n, 3}=3 f_{n, 1}$, de sorte que o cenário ilustrado na Figura 84(b) é decorrente do lock-in principal com o primeiro modo de vibrar e um lock-in secundário com o terceiro modo de vibrar.

Os resultados referentes à condição com movimento imposto de frequência $f_{t}$ : $f_{n, 1}=2: 1$ estão apresentados nas Figuras 84(c) e 84(d). A distribuição $\hat{A}^{y}(\xi)$ revela o predomínio do primeiro modo de vibrar com um aumento de até $100 \%$ das amplitudes características de oscilação. Embora esse resultado já tenha sido obtido por ocasião da análise da Figura 83, o objeto de estudo, naquele ponto do texto, era um particular ponto do modelo.

Ainda para a condição de movimento prescrito caracterizado por $f_{t}: f_{n, 1}=2: 1$, a distribuição do espectro de amplitude ao longo do modelo (ver Figura 84(d)) revela, além de uma amplificação da resposta no primeiro modo de vibrar, participação de vibrações no segundo modo de vibrar e com a frequência desse, coincidente com a frequência da excitação de suporte.

Por fim, discutem-se os resultados referentes à excitação de suporte com frequência $f_{t}: f_{n, 1}=3: 1$. A distribuição $\hat{A}^{y}(\xi)$ apresentada na Figura 84(e) ilustra a coexistência de vibrações no primeiro e no terceiro modo. Essa afirmação pode ser feita pela ausência dos dois nós estruturais típicos de uma vibração puramente no terceiro modo. Tal inferência é 
Figura 84 - (a), (c) e (e): Amplitudes características de oscilação na direção cross-wise $\hat{A}_{y}(\xi) ;(\mathrm{b}),(\mathrm{d})$ e (f): Espectro de amplitude na direção cross-wise $S_{y}(\xi, \hat{f})$. $U_{r, 1} \approx 5,70$. e $A_{t} / L_{0}=1 \%$.

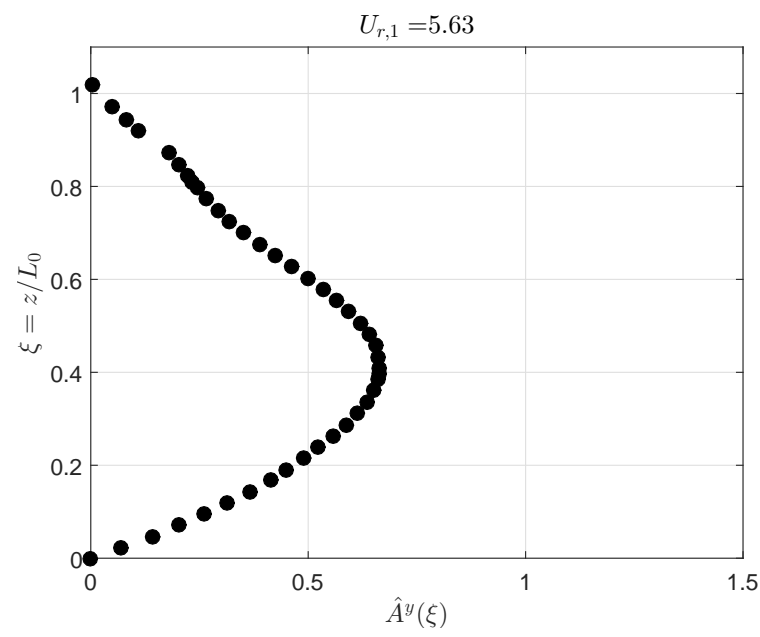

(a) $\hat{A}^{y}(\xi)$. "VIV puro".

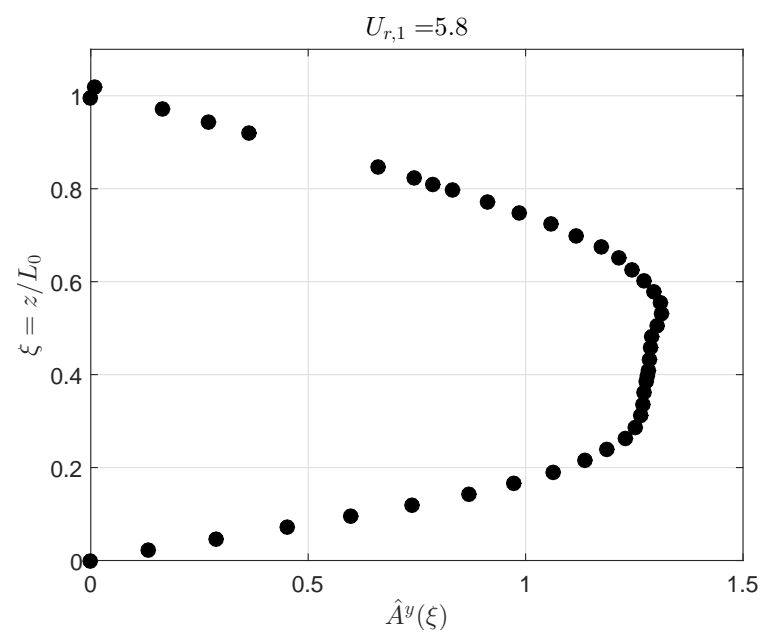

(c) $\hat{A}^{y}(\xi) \cdot f_{t}: f_{n, 1}=2: 1$.

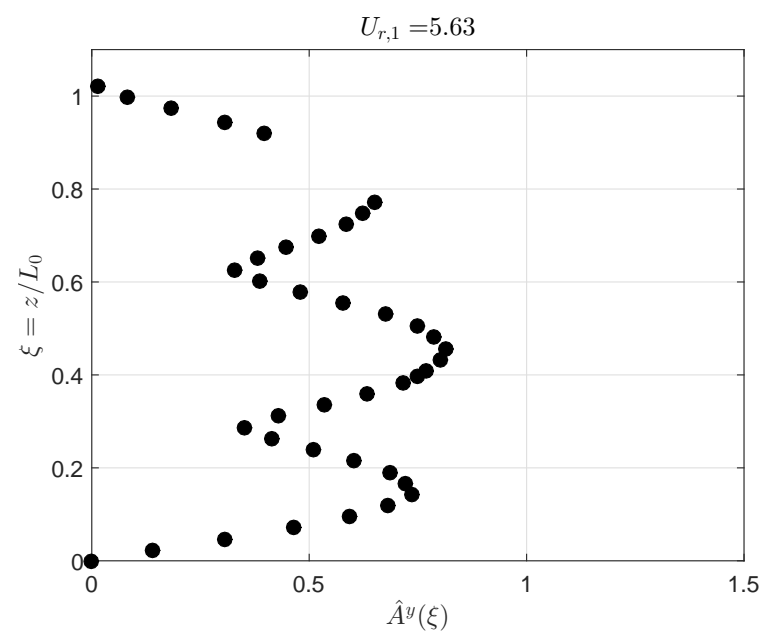

(e) $\hat{A}^{y}(\xi) \cdot f_{t}: f_{n, 1}=3: 1$.

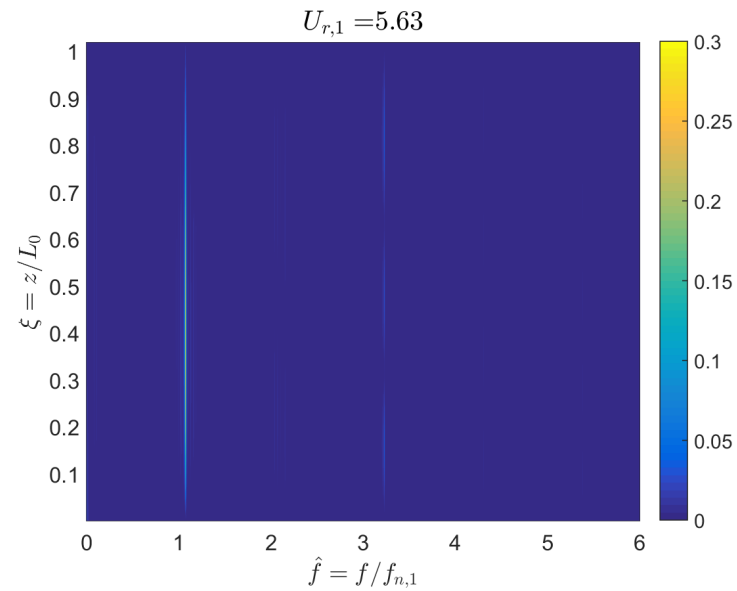

(b) $S_{y}(\xi, \hat{f})$. "VIV puro".

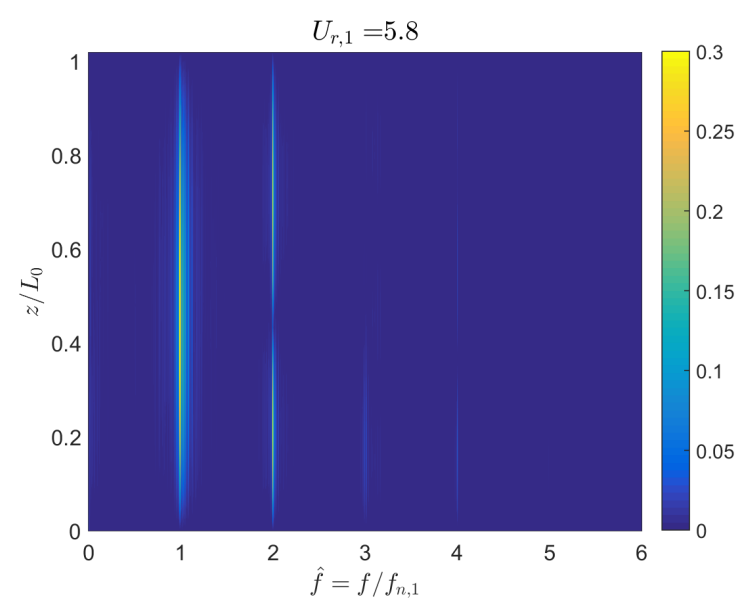

(d) $S_{y}(\xi, \hat{f}) \cdot f_{t}: f_{n, 1}=2: 1$.

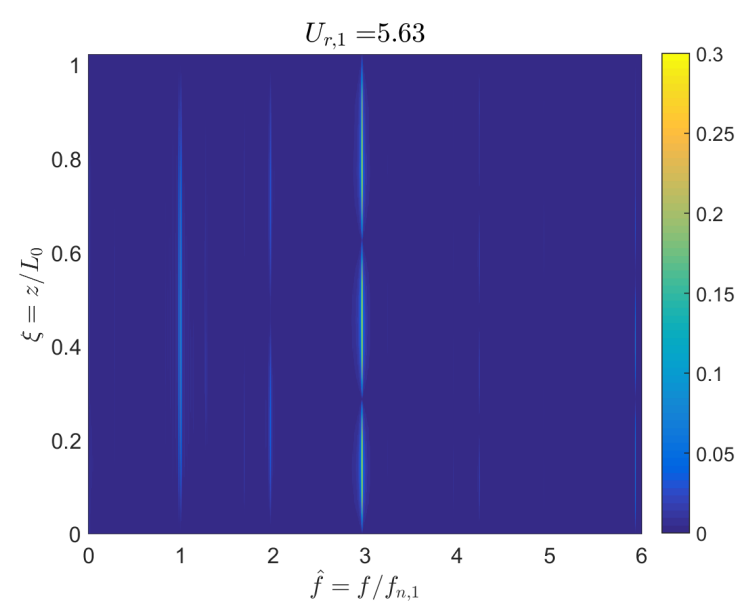

(f) $S_{y}(\xi, \hat{f}) . f_{t}: f_{n, 1}=3: 1$.

Fonte: Adaptada de Franzini et al. (2018). 
corroborada pelo espectro de amplitude $S_{y}(\xi, \hat{f})$ ilustrado na Figura 84(f), que revela o predomínio de vibrações no terceiro modo com frequência $\hat{f}=3$, porém com participação do primeiro modo com $\hat{f}=1$.

A Figura 85 ilustra as distribuições das amplitudes características de oscilação e dos espectros de amplitude ${ }^{17}$ associados à direção in-line e para a velocidade reduzida $U_{r, 1}=5,70$. A distribuição de amplitudes características de oscilação para a condição "VIV puro" exibida na Figura 85(a) revela, além de valores máximos de $\hat{A}^{x}$ próximos a 0,20 , a presença de respostas predominantemente no segundo modo de vibrar, embora com contribuições de outros modos. O correspondente espectro de amplitude corrobora essas afirmações e exibe, além da dominância do segundo modo de vibrar com a sua frequência natural ( $\hat{f} \approx 2 \mathrm{ou}$, de maneira equivalente, $f / f_{n, 2}=1$ ), presença de respostas até no quarto modo.

A predominância da resposta no segundo modo pode ser explicada à luz de resultados obtidos para cilindros rígidos montados em apoio elástico com dois graus de liberdade. Como visto na seção 4.1.3, a parcela oscilatória da força de arrasto pulsa com o dobro da frequência de emissão de vórtices $\omega_{f}$. Como a velocidade reduzida $U_{r, 1}=5,70$ consiste em um cenário favorável ao lock-in no primeiro modo na direção cross-wise, tem-se que $\omega_{f} \approx 2 \pi f_{n, 1}$ e, por consequência a frequência da parcela oscilatória da força de arrasto é $2 \omega_{f}=4 \pi f_{n, 1}=2 \pi f_{n, 2}$, o que excita o segundo modo natural na direção in-line.

Do ponto de vista da análise de tensões em um riser, a consideração de oscilações na direção in-line tem dupla importância. A primeira delas é que, como visto na subseção 4.1.3, a presença de oscilações na direção in-line promove um importante aumento na resposta medida na direção cross-wise. A segunda é que as oscilações na direção in-line, embora de amplitudes inferiores, têm maior frequência e estão associadas a um menor comprimento de onda. Dessa forma, é importante que as ferramentas de projeto e análise de risers e que realizam simulações de VIV contemplem as oscilações nas duas direções do plano horizontal.

Retomando a análise da Figura 85, o foco passa a ser os resultados obtidos a partir do experimento com movimento imposto de frequência $f_{t}: f_{n, 1}=2: 1$. A Figura 85(c) não revela claramente quais os modos compõem a resposta, apenas apontam para um aumento das amplitudes características de oscilação na direção in-line. Já o espectro $S_{x}(\xi, \hat{f})$, apresentado na Figura $85(\mathrm{~d})$, revela o caráter policromático da resposta, porém com algumas distinções quando comparadas ao espectro $S_{y}(\xi, \hat{f})$ ilustrado na Figura 84(d).

Embora a resposta na direção cross-wise também seja policromática, as duas

17 Tendo em vista a presença de uma força de arrasto média atuando no modelo, é de se esperar a presença de componentes na frequência nula. No entanto, tendo em vista o interesse somente na parcela oscilatória da resposta, os espectros de amplitude foram calculados a partir dos sinais subtraídos de seus valores médios. 
Figura 85 - (a), (c) e (e): Amplitudes características de oscilação na direção in-line $\hat{A}_{x}(\xi)$; (b), (d) e (f): Espectro de amplitude na direção in-line $S_{x}(\xi, \hat{f}) . U_{r, 1} \approx 5,70$. e $A_{t} / L_{0}=1 \%$.

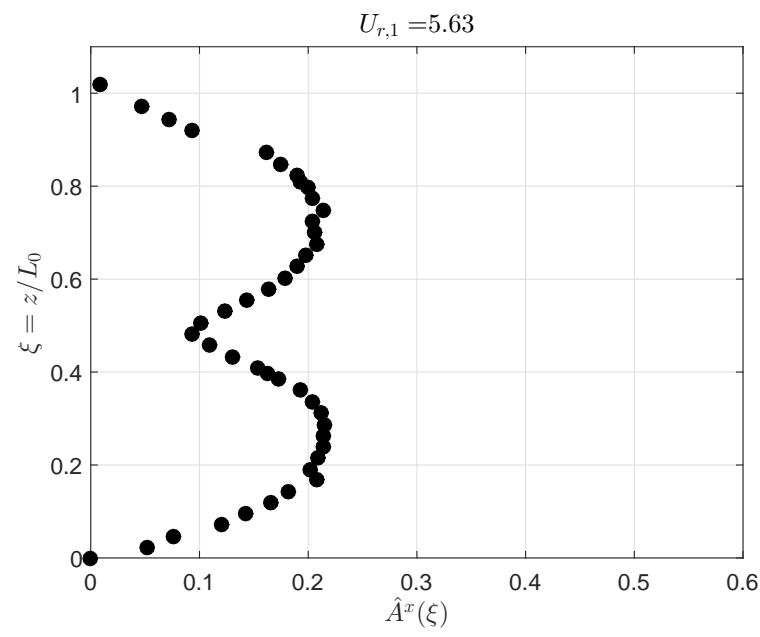

(a) $\hat{A}^{x}(\xi)$. "VIV puro".

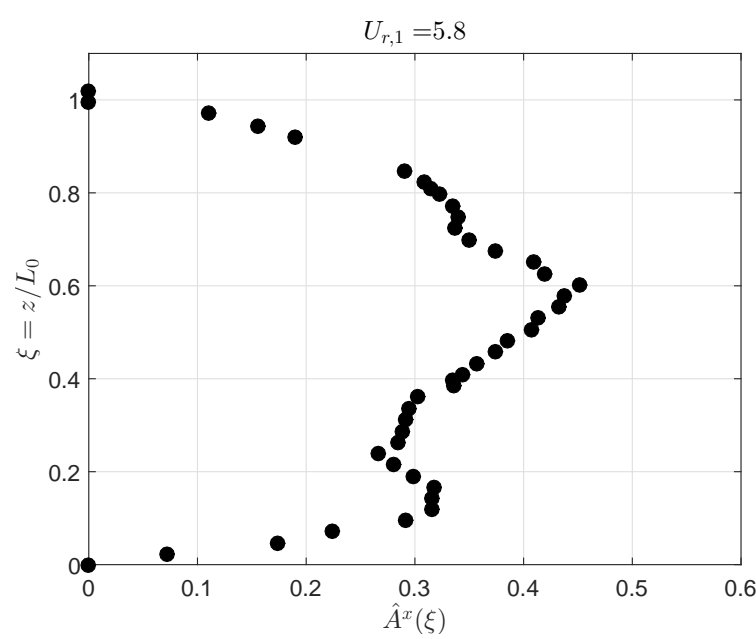

(c) $\hat{A}^{x}(\xi) \cdot f_{t}: f_{n, 1}=2: 1$.

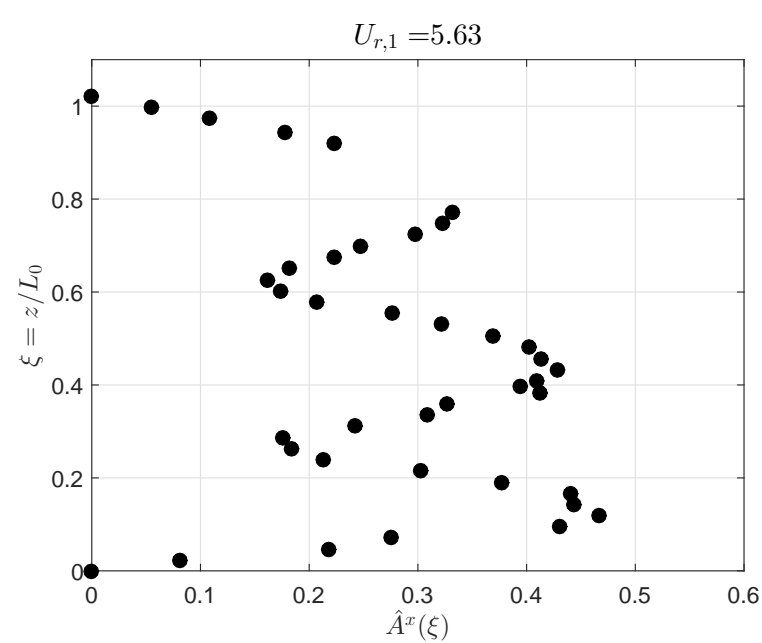

(e) $\hat{A}^{x}(\xi) \cdot f_{t}: f_{n, 1}=3: 1$.

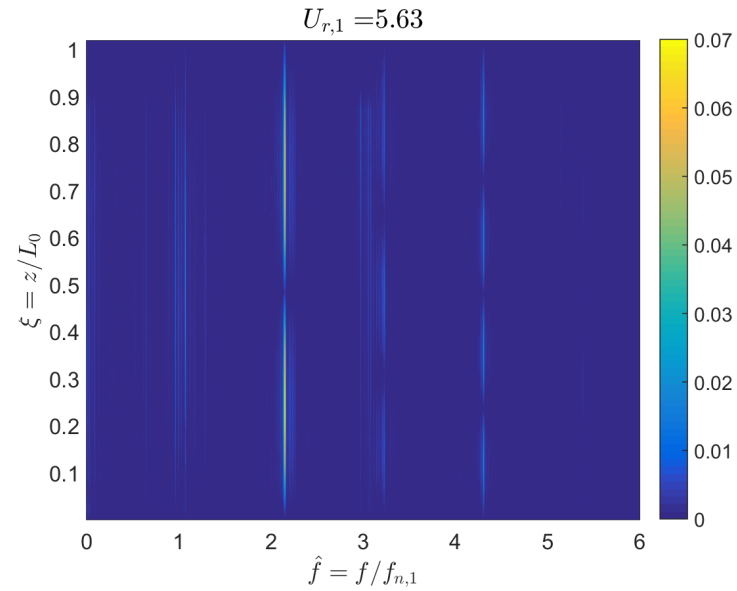

(b) $S_{x}(\xi, \hat{f})$. "VIV puro".

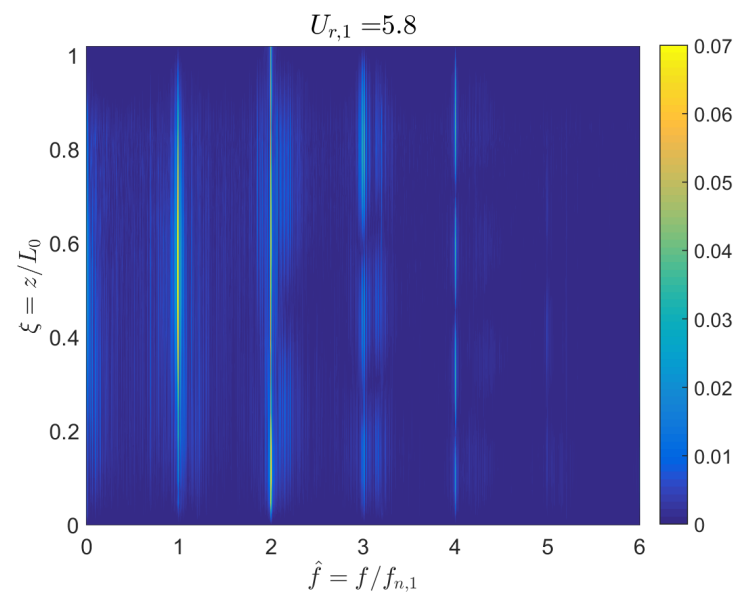

(d) $S_{x}(\xi, \hat{f}) . f_{t}: f_{n, 1}=2: 1$.

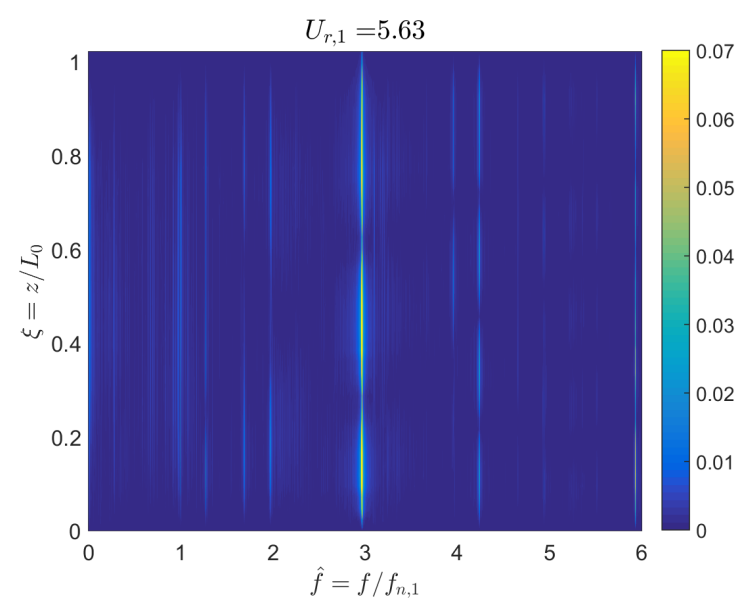

(f) $S_{x}(\xi, \hat{f}) . f_{t}: f_{n, 1}=3: 1$.

Fonte: Adaptada de Franzini et al. (2018). 
frequências dominantes são aquelas dos dois primeiros modos. Já para a direção in-line, além do enriquecimento do conteúdo espectral, nota-se que tanto a componente em $\hat{f}=1$ quanto em $\hat{f}=2$ revelam uma forma de vibração estrutural que remonta ao primeiro modo de vibrar. Em outras palavras, a condição $f_{t}: f_{n, 1}=2: 1$ levou a uma resposta no segundo modo com a frequência do primeiro.

Por fim, discutem-se os resultados obtidos a partir dos experimentos com movimento imposto com frequência $f_{t}: f_{n, 1}=3: 1$. A Figura ${ }^{18} 85($ e) revela uma importantes semelhanças com entre as distribuições $\hat{A}^{x}(\xi)$ e $\hat{A}^{y}(\xi)$, essa última ilustrada na Figura 84(e). Dentre as semelhanças, destacam-se o máximo valor de amplitude característica $\max \left\{\hat{A}^{x}\right\} \approx 0,50$ (comparável, portanto, ao máximo valor obtido na distribuição $\hat{A}^{y}(\xi)$ apresentada na Figura 84(e)) e a composição multimodal dessas distribuições.

Ainda considerando os experimentos com excitação de suporte definida por $f_{t}$ : $f_{n, 1}=3: 1$, o espectro de amplitude $S_{x}(\xi, \hat{f})$ também guarda notável semelhança com aquele observado para a direção cross-wise (ver Figura 84(f)). Existe uma clara dominância do terceiro modo de vibrar com sua própria frequência natural (ou seja, com $\hat{f}=3$ ), embora as oscilações na direção in-line tenham um conteúdo espectral mais rico do que aquelas correspondentes à direção cross-wise.

Como a velocidade reduzida estudada nas Figuras 84 e 85 privilegia oscilações no primeiro modo na direção cross-wise e no segundo modo na direção in-line, os resultados até aqui apresentados já permitem tecer algumas conclusões acerca dos efeitos da excitação paramétrica na resposta de um cilindro flexível ao VIV. A primeira delas é que a instabilidade paramétrica principal com o primeiro modo de vibrar, decorrente da imposição de movimento vertical ao vínculo superior com frequência $f_{t}: f_{n, 1}=2: 1$, amplifica as amplitudes de oscilação nas duas direções do plano horizontal. De fato, para essa condição de movimento imposto e na ausência de correnteza, a resposta tem predomínio do primeiro modo de vibrar, embora com alguma contribuição do segundo modo (ver Figura 63(b) na seção 7.2).

Uma segunda conclusão possível de ser tecida diz respeito ao comportamento da estrutura quando a excitação de suporte tem frequência $f_{t}: f_{n, 1}=3: 1$. Tanto a resposta decorrente somente pela excitação paramétrica apresentada na Figura 63(d) quanto aquelas obtidas para as direções in-line e cross-wise quando da solicitação combinada (ver Figuras 84(f) e 85(f)) são dominadas pelo terceiro modo de vibrar. Assim, conclui-se que a resposta do cilindro à concomitância entre os fenômenos de VIV e de excitação paramétrica com $f_{t}: f_{n, 1}=3: 1$ é dominada pelo último.

Complementando as análises acerca das séries temporais medidas nos diversos

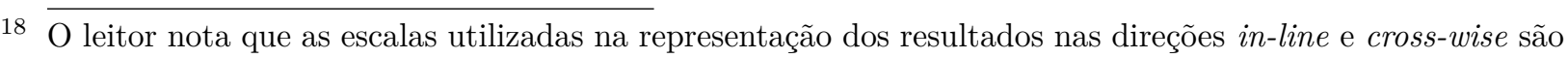
distintas. Essa escolha foi feita devido à diferença observada entre os valores de amplitude característica de oscilação nessas duas direções. 
pontos do cilindro monitorados, a Figura 86 apresenta as trajetórias no plano horizontal para algumas seções transversais e para três valores de velocidades reduzidas, a saber, $U_{r, 1} \approx 5,70, U_{r, 1} \approx 8,10$ e $U_{r, 1} \approx 13$ para as três condições que são objetos de estudo da presente seção. Tendo em vista uma melhor visualização dessas trajetórias, apenas os instantes de tempo no intervalo $150<\tau=t f_{n, 1}<155$ estão ilustrados. A linha tracejada em vermelho corresponde à deflexão média do cilindro flexível decorrente da existência da força de arrasto com média não nula.

Considerando as três velocidades reduzidas ilustradas, nota-se que as trajetórias no plano horizontal perdem a sua organização quando a condição "VIV puro" é substituída por aquelas nas quais coexistem os fenômenos de VIV e de excitação paramétrica. Associado a essa desorganização, é claro o pronunciado aumento das oscilações quando a frequência do movimento imposto é $f_{t}: f_{n, 1}=2: 1$.

Agora, esta seção passa a se dedicar à análise das séries temporais de amplitude modal e que permitem interpretações complementares àquelas apresentadas até este ponto. A Figura 87 apresenta as séries de amplitude modais associadas aos dois primeiros modos e nas duas direções do plano horizontal para a velocidade reduzida $U_{r, 1} \approx 5,70$, a mesma que já foi objeto de análise das Figuras 83, 84 e 85.

As Figuras 87(a) e 87(b) mostram que as séries temporais $\tilde{a}_{1}^{y}(\tau)$ e $\tilde{a}_{2}^{x}(\tau)$ obtidas a partir da condição "VIV Puro" são caracterizas por oscilações com pouca modulação em amplitude e com conteúdo espectral praticamente monocromático e de frequências dominantes $\hat{f} \approx 1$ e $\hat{f} \approx 2$ respectivamente. Fisicamente, essas séries temporais indicam que os termos que multiplicam $\psi_{1}(\xi)=\sin (\pi \xi)$ (direção cross-wise) e $\psi_{2}(\xi)=\sin (2 \pi \xi)$ (direção in-line) variam no tempo de maneira harmônica e monocromática, caracterizando o clássico lock-in com o primeiro modo de vibrar na direção cross-wise e a ressonância dual com o segundo modo de vibrar na direção in-line.

Cumpre ressaltar que o caráter com pouca modulação de amplitude já fora averiguado por ocasião da análise da Figura 83. No entanto, essa última figura discute somente a um único ponto do modelo, enquanto que as séries temporais modais guardam informações acerca da resposta de todos os pontos monitorados. Sem dúvida, a consideração da informação de vários pontos em poucas séries temporais é um dos aspectos de maior interesse no estudo das séries temporais de amplitude modal, consolidadas dentro do grupo de pesquisa da EPUSP a partir das análises lideradas, em um primeiro momento, pelo autor deste texto.

As séries temporais $\tilde{a}_{1}^{y}(\tau)$ e $\tilde{a}_{2}^{x}(\tau)$ obtidas a partir do ensaio com movimento prescrito com $f_{t}: f_{n, 1}=2: 1$ são apresentadas nas Figuras 87(c) e 87(d) respectivamente. A exemplo da série temporal para o alvo localizado em $\xi=0,43$ e ilustrada na Figura 83(c), a série temporal $\tilde{a}_{1}^{y}(\tau)$ possui importantes modulações em amplitude. Como a resposta de um particular alvo resulta da composição de vários modos de vibrar, a Figura 87(c) atesta 
Figura 86 - Trajetórias no plano horizontal. (a), (d) e (g): "VIV puro"; (b), (e) e (h): $f_{t}: f_{n, 1}=2: 1, A_{t} / L_{0}=1 \%$; (c), (f) e (i): $f_{t}: f_{n, 1}=3: 1, A_{t} / L_{0}=1 \%$. $150<\tau=t f_{n, 1}<155$.

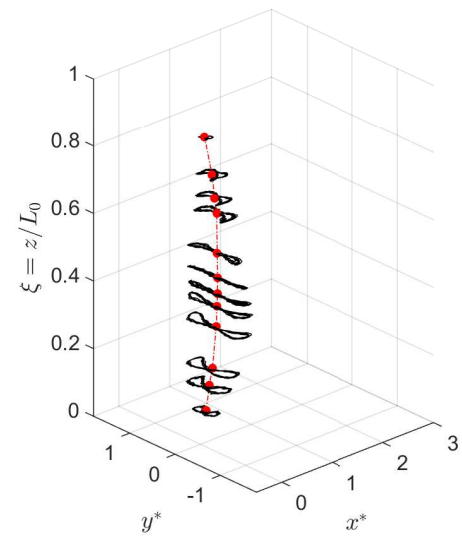

(a) $U_{r, 1}=5,63$.

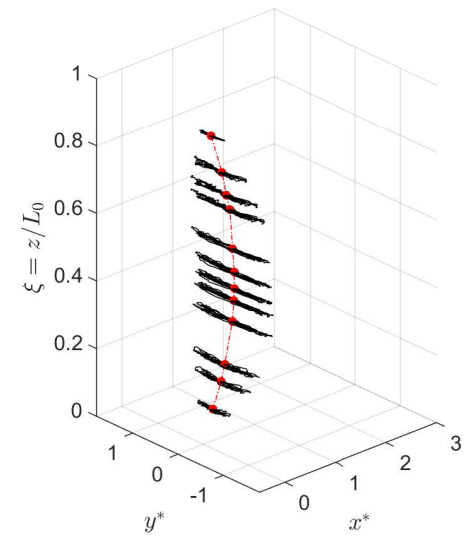

(d) $U_{r, 1}=8,11$.

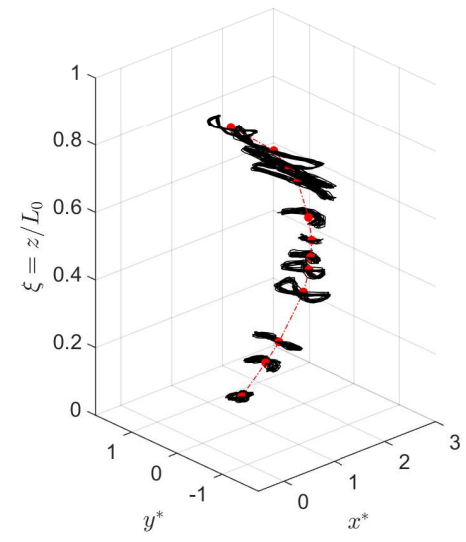

(g) $U_{r, 1}=13,7$.

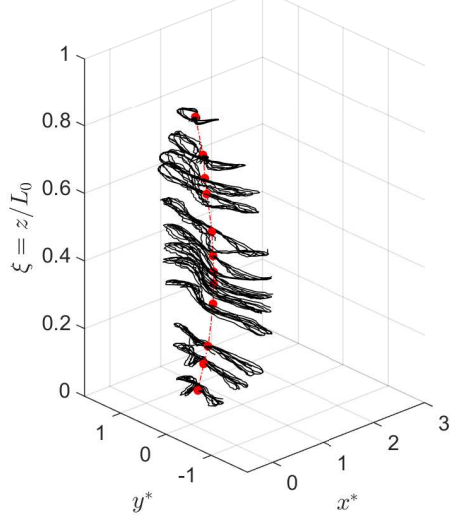

(b) $U_{r, 1}=5,73$.

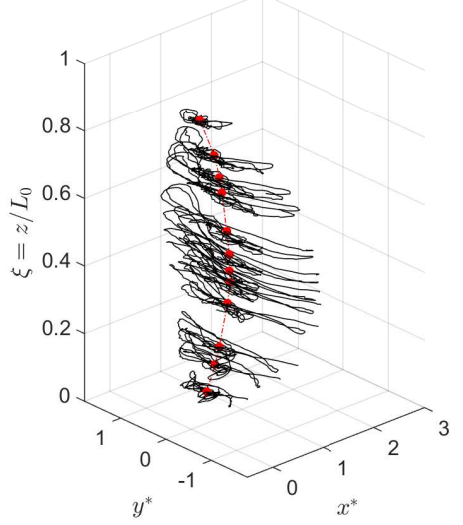

(e) $U_{r, 1}=8,21$.

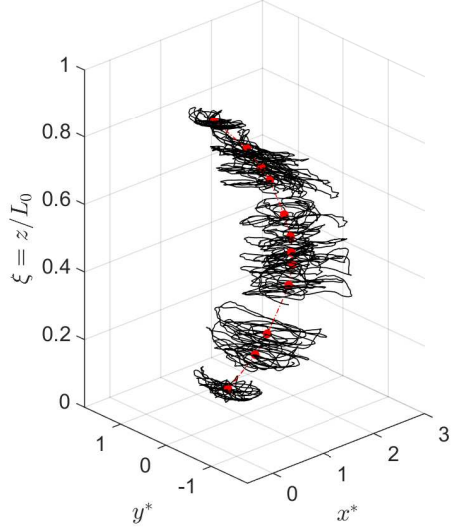

(h) $U_{r, 1}=12,8$.

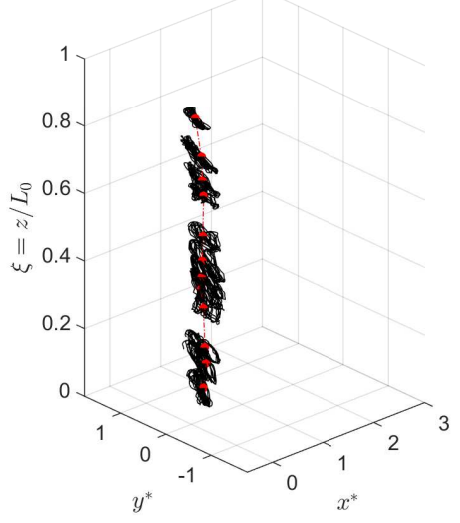

(c) $U_{r, 1}=5,63$.

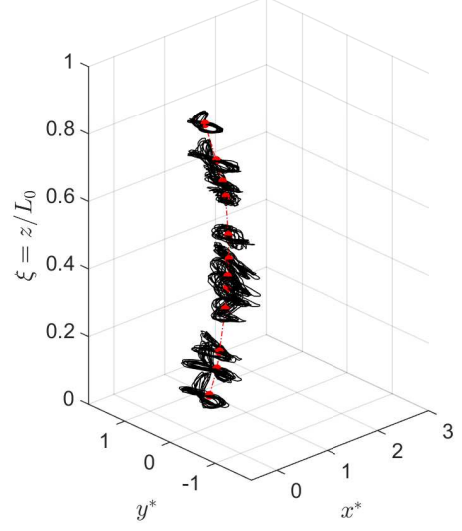

(f) $U_{r, 1}=8,11$.

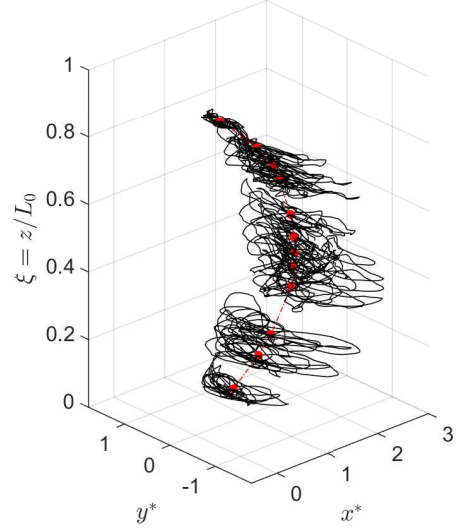

(i) $U_{r, 1}=13,7$.

Fonte: Adaptada de Franzini et al. (2018). 
que as modulações em amplitude observadas nessa condição experimental resultam de modulações na série temporal modal correspondente ao primeiro modo de vibrar. Aqui fica mais uma evidência da importância das análises das séries temporais de amplitude modais como complemento às análises clássicas (ou seja, aquelas baseadas nas respostas medidas em alguns pontos ao longo do cilindro), uma vez que essas últimas análises não fornecem maiores subsídios para a análise da fonte das modulações em amplitude observadas.

Finalmente, as séries temporais modais correspondentes ao experimento com movimento imposto de frequência $f_{t}: f_{n, 1}=3: 1$ são apresentadas nas Figuras 87(e) e 87(f). É claramente visível na Figura $87(\mathrm{e})$ que a série temporal de amplitude modal $\tilde{a}_{1}^{y}(\tau)$ tem frequência dominante $\hat{f}=1$, ou seja, a resposta esperada no fenômeno de VIV. Fisicamente, esse resultado indica que a resposta no primeiro modo de vibrar e na direção cross-wise é governada pela excitação decorrente do fenômeno de interação fluido-estrutura. Por outro lado, a série temporal $\tilde{a}_{2}^{x}(\tau)$ ilustrada na Figura $87(f)$, tem frequência dominante próxima à frequência do movimento imposto, implicando em vibrações com a forma do segundo modo natural porém com a frequência do terceiro.

Ainda considerando os experimentos com movimento imposto de frequência $f_{t}$ : $f_{n, 3}=3: 1$, é interessante estudar a resposta na direção cross-wise associada ao terceiro modo de vibrar, uma vez que essa foi a condição predominante observada quando da análise clássica apresentada na Figura 84(f). A série temporal de amplitude modal $\tilde{a}_{3}^{y}(\tau)$, exibida na Figura 88, claramente apresenta uma resposta com praticamente nenhuma modulação em amplitude e frequência dominante $\hat{f} \approx 3 \mathrm{ou}$, de maneira equivalente, $f / f_{n, 3} \approx 1$.

Aqui cabe uma comparação com relação ao resultado experimental obtido para a condição de excitação somente pelo movimento prescrito ao topo. A série temporal $\tilde{a}_{3}^{y}(\tau)$ ilustrada na Figura 88 apresenta amplitude característica próxima a $\hat{A}^{y}=0,30$, valor bastante próximo àquele obtido na condição de excitação paramétrica sem correnteza e ilustrado na Figura 67(d). Esse resultado reitera a assertiva feita acerca da dominância da resposta associada ao movimento prescrito ao topo em detrimento daquela decorrente do fenômeno de VIV quando a excitação de topo tem frequência $f_{t}: f_{n, 1}=3: 1$.

Buscando tecer algumas analogias com a condição VIV-2gl, é interessante exibir as trajetórias no plano das amplitudes modais. Buscando emular a clássica trajetória em formato de oito obtida para o caso em que a base elástica que suporta o cilindro tenha os mesmos valores de rigidez nas duas direções do plano horizontal, a Figura 89 exibe as trajetórias modais para o k-ésimo modo na direção cross-wise e no 2k-ésimo modo de vibrar na direção in-line. Como essa figura ilustra respostas correspondentes a $U_{r, 1} \approx 5,70$, é natural que foco seja dado à condição $k=1$.

A condição "VIV puro", apresentada na Figura 89(a), apresenta o clássico formato de oito encontrado na condição VIV-2gl e já discutido na subseção 4.1.3. A boa definição da forma dessa trajetória indica um alto grau de sincronização entre as respostas no primeiro 
Figura 87 - Séries temporais de amplitude modal. $U_{r, 1} \approx 5,70$. (a), (b): "VIV puro"; (c)-(f) VIV concomitante com movimento imposto ao topo de amplitude $A_{t} / L_{0}=1 \%$.
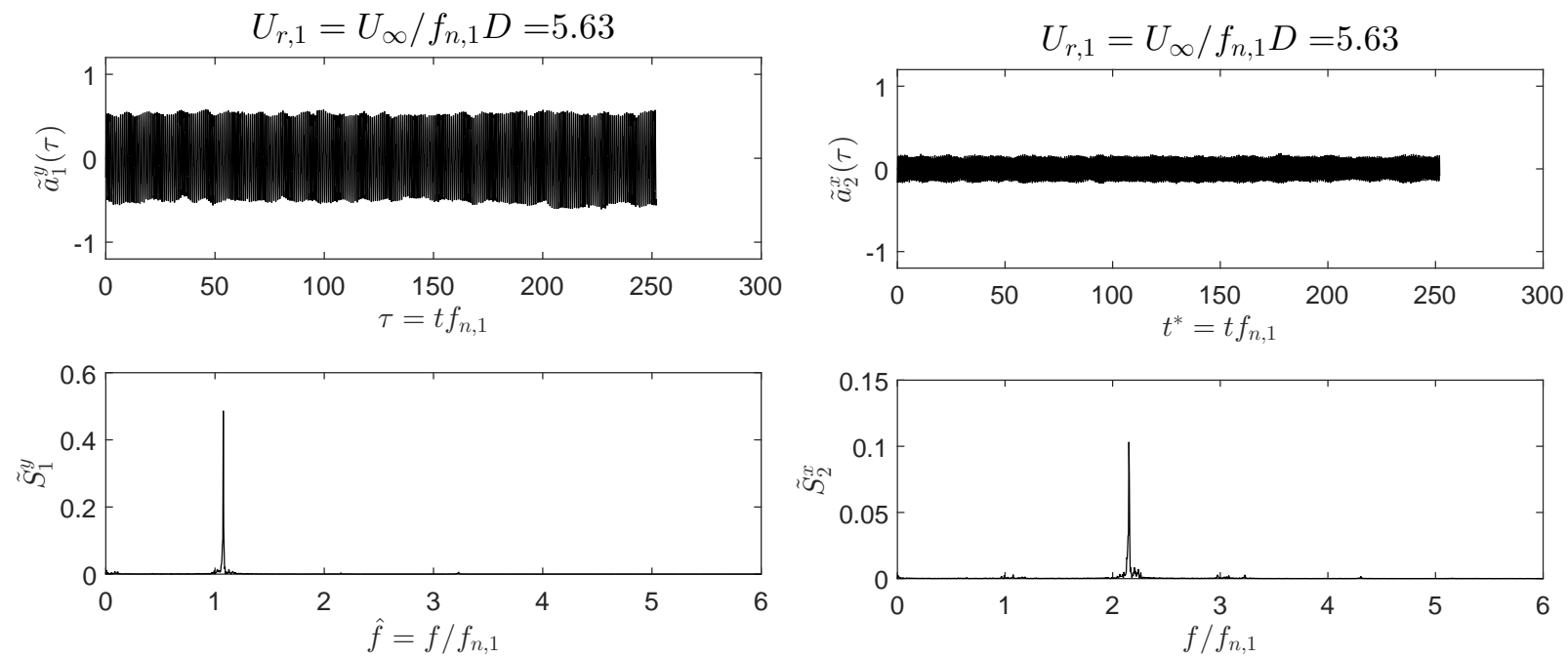

(a) $\tilde{a}_{1}^{y}(\tau)$. "VIV Puro".

(b) $\tilde{a}_{2}^{x}(\tau)$. "VIV Puro".
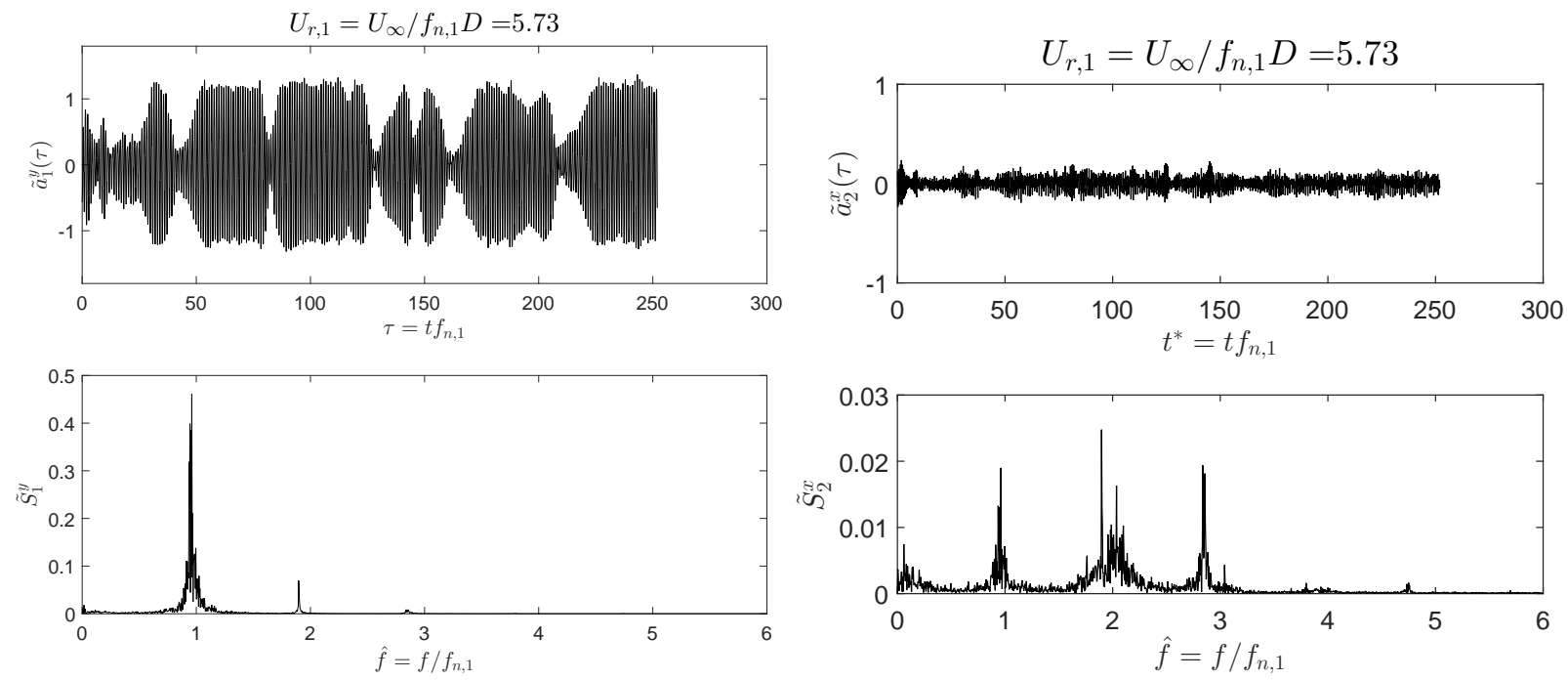

(c) $\tilde{a}_{1}^{y}(\tau) . f_{t}: f_{n, 1}=2: 1$.

(d) $\tilde{a}_{2}^{x}(\tau) . f_{t}: f_{n, 1}=2: 1$.
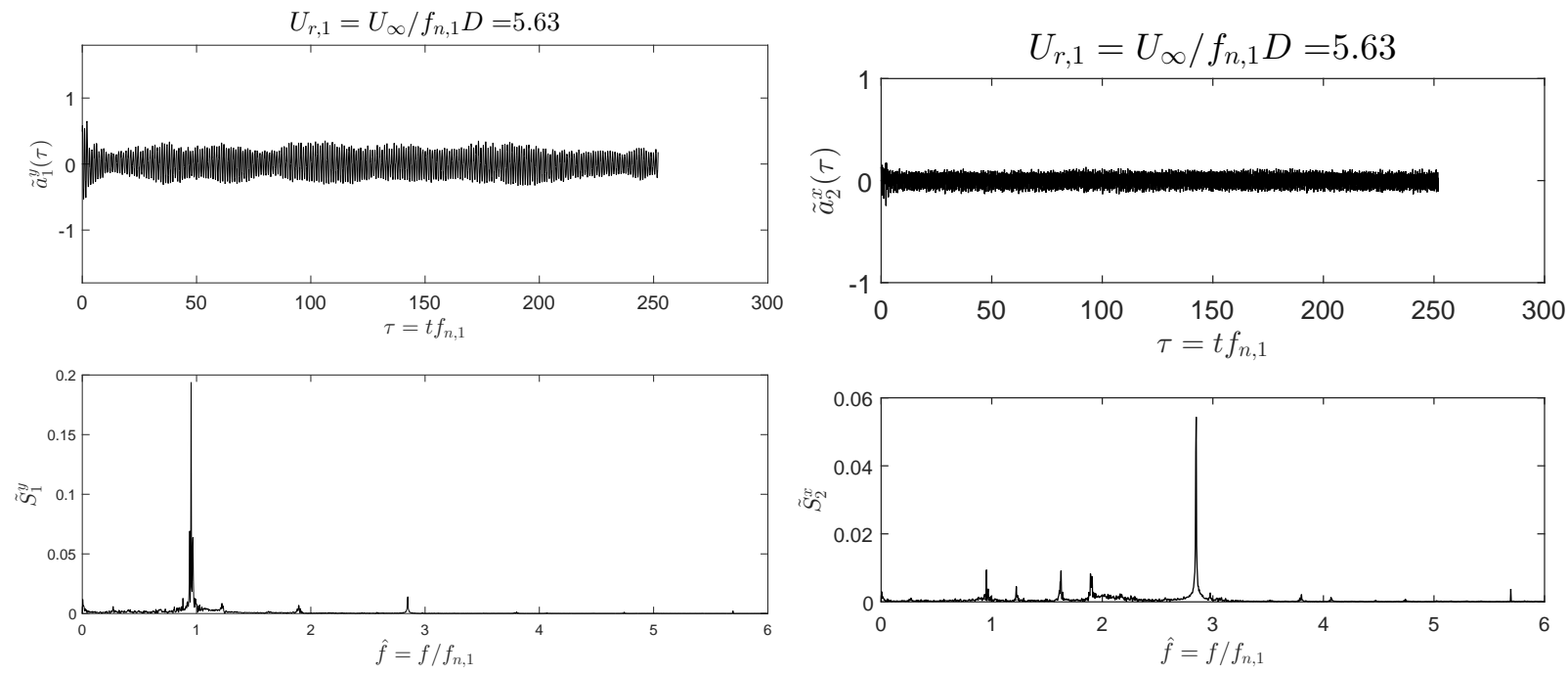

(e) $\tilde{a}_{1}^{y}(\tau) \cdot f_{t}: f_{n, 1}=3: 1$.

(f) $\tilde{a}_{2}^{x}(\tau) . f_{t}: f_{n, 1}=3: 1$.

Fonte: Adaptada de Franzini et al. (2018). 
Figura 88 - Série temporal de amplitude modal $\tilde{a}_{3}^{y}(\tau)$ e correspondente espectro de amplitude. $f_{t}: f_{n, 1}=3: 1$.
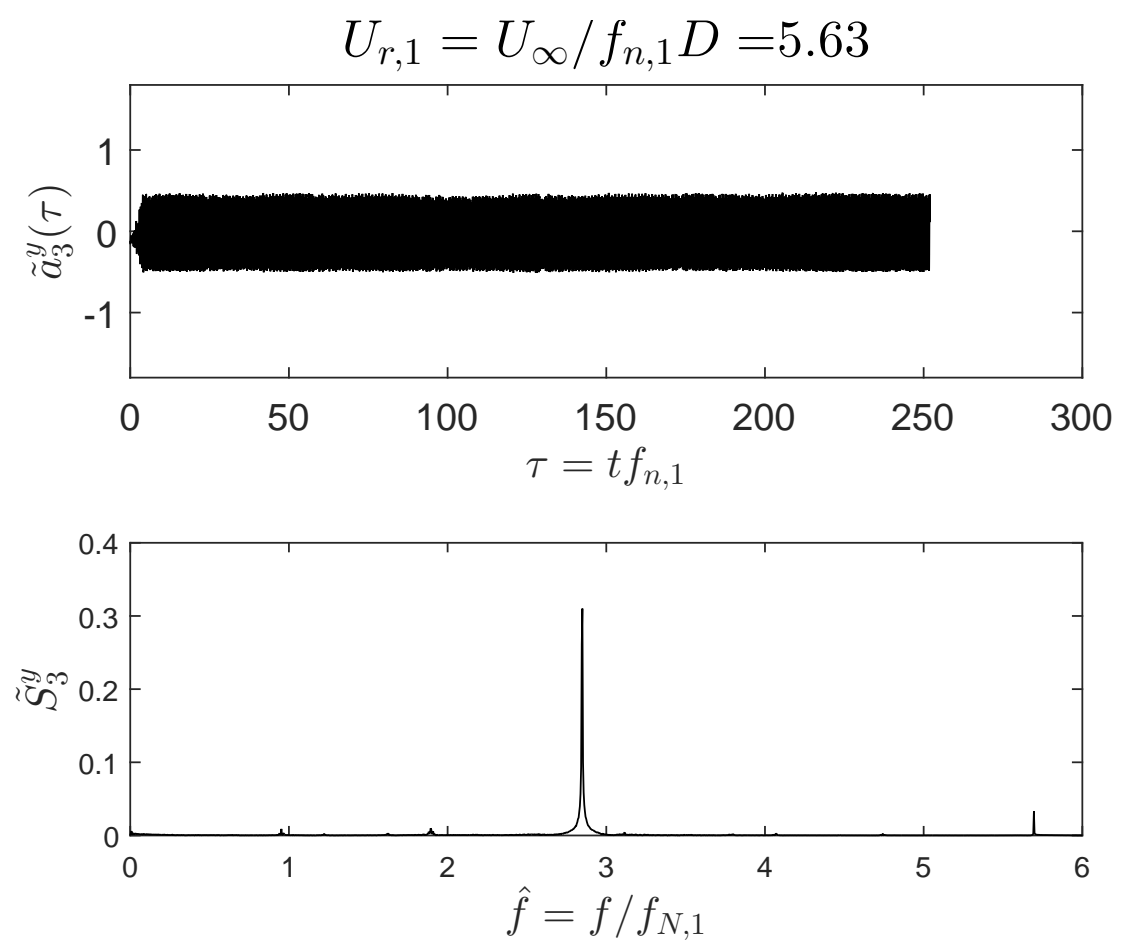

Fonte: Adaptada de Franzini et al. (2018).

modo na direção cross-wise e no segundo modo na direção in-line.

Já as trajetórias obtidas a partir dos experimentos com concomitância entre os fenômenos de VIV e de excitação paramétrica (ver Figuras 89(b) e 89(c)) não apresentam qualquer organização, indicando um processo de sincronização menos definido do que na condição "VIV puro", mesmo quando a frequência de movimento prescrito ao topo assume $f_{t}: f_{n, 1}=2: 1$ e amplifica as respostas estruturais.

Uma vez discutidos alguns aspectos quantitativos e qualitativos acerca das séries temporais de amplitude modal, o foco passa a ser nos seus valores característicos $\hat{A}_{k}^{x}$ e $\hat{A}_{k}^{y}$ como funções da velocidade reduzida modal $U_{r, k}$ dada pela Equação 7.8. Esse resultado permite avaliar as diferenças nas amplitudes características de oscilação do k-ésimo modo considerando as condições de lock-in desse mesmo modo. Esse estudo é mais uma contribuição inédita da análise liderada pelo autor deste texto e apresentada em Franzini et al. (2018).

A Figura 90 mostra as curvas $\hat{A}_{k}^{x}\left(U_{r, k}\right)$ e $\hat{A}_{k}^{y}\left(U_{r, k}\right)$. Ao contrário do que foi feito na subseção anterior, aqui as curvas para cada modo são apresentadas separadamente visando a melhor identificação dos resultados. Considerando o primeiro modo de vibrar, a Figura 90(a) claramente revela o significativo aumento nas respostas modais causado pela coexistência de lock-in e instabilidade paramétrica principal nesse modo. Embora o formato das curvas $\hat{A}_{1}^{y}\left(U_{r, 1}\right)$ seja semelhante para as condições "VIV puro" e aquela onde 
Figura 89 - Trajetórias no plano modal $\tilde{a}_{2}^{x} \times \tilde{a}_{1}^{y}$. a): "VIV puro"; (b), (c) VIV concomitante com movimento imposto ao topo de amplitude $A_{t} / L_{0}=1 \%$.

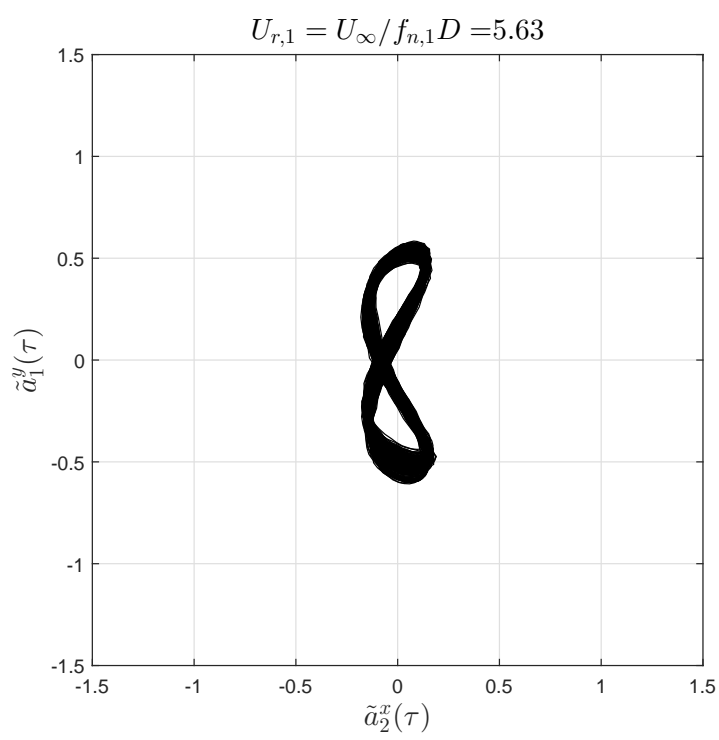

(a) "VIV puro".

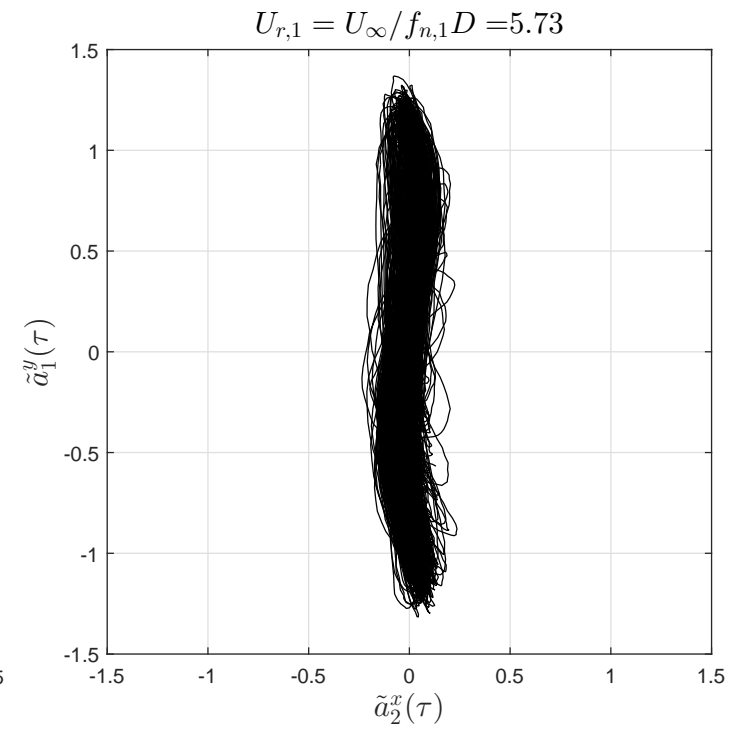

(b) $f_{t}: f_{n, 1}=2: 1$.

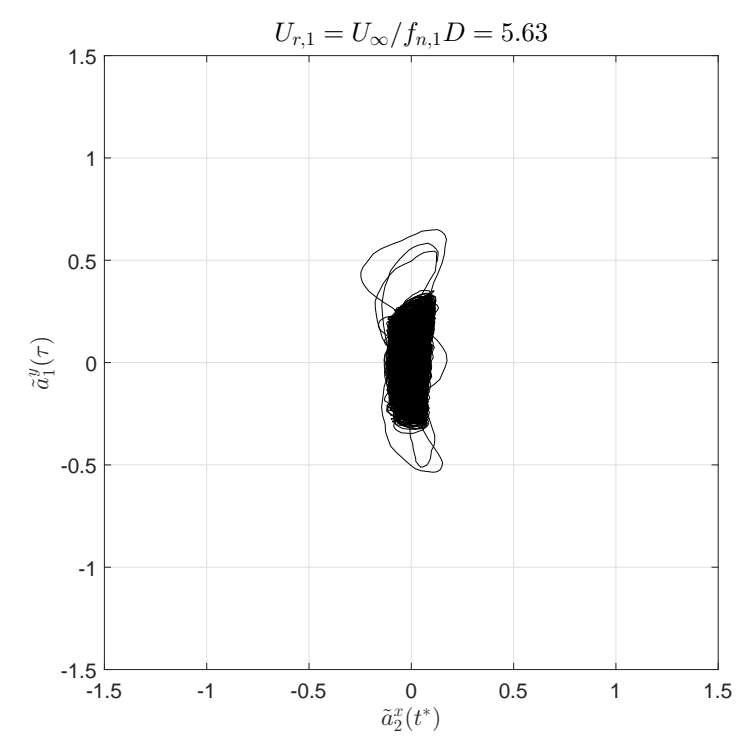

(c) $f_{t}: f_{n, 1}=3: 1$.

Fonte: Adaptada de Franzini et al. (2018).

existe movimento imposto de frequência $f_{t}: f_{n, 1}=2: 1$, essa última tem seus valores fortemente amplificados para toda a faixa de velocidades reduzidas $U_{r, 1}$ ensaiada.

Comparando os resultados obtidos para a condição sem movimento prescrito com aquela com movimento imposto dado por $f_{t}: f_{n, 1}=3: 1$, observa-se que concomitância de excitações promove uma diminuição dos valores da curva $\hat{A}_{1}^{y}\left(U_{r, 1}\right)$ para $U_{r, 1}<10$. Para valores de velocidade reduzida superiores a 10, o movimento prescrito promove um significativo aumento das amplitudes características de oscilação do primeiro modo. Note também que a condição de movimento prescrito $f_{t}: f_{n, 1}=3: 1$ também promove a 
Figura 90 - Valores característicos de amplitude modal como funções da velocidade reduzida modal $U_{r, k}$.

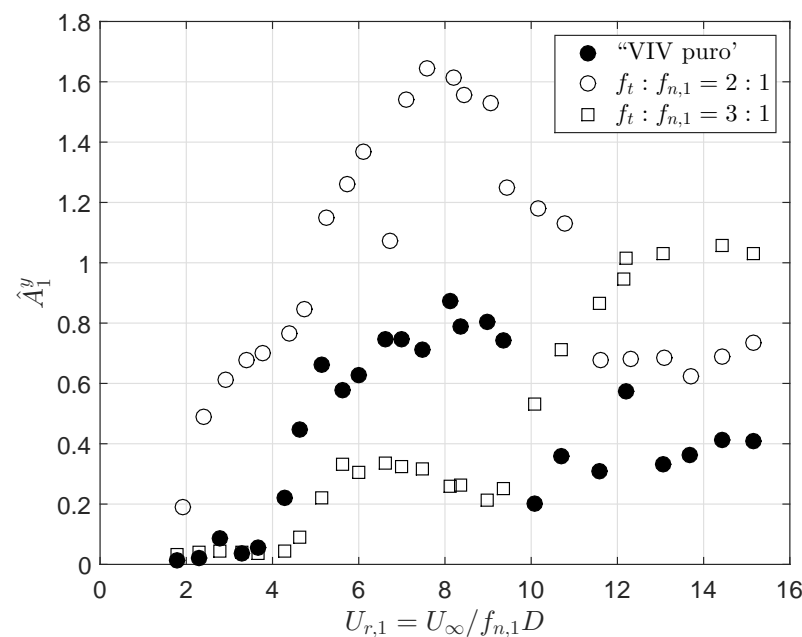

(a) $\hat{A}_{1}^{y}\left(U_{r, 1}\right)$.

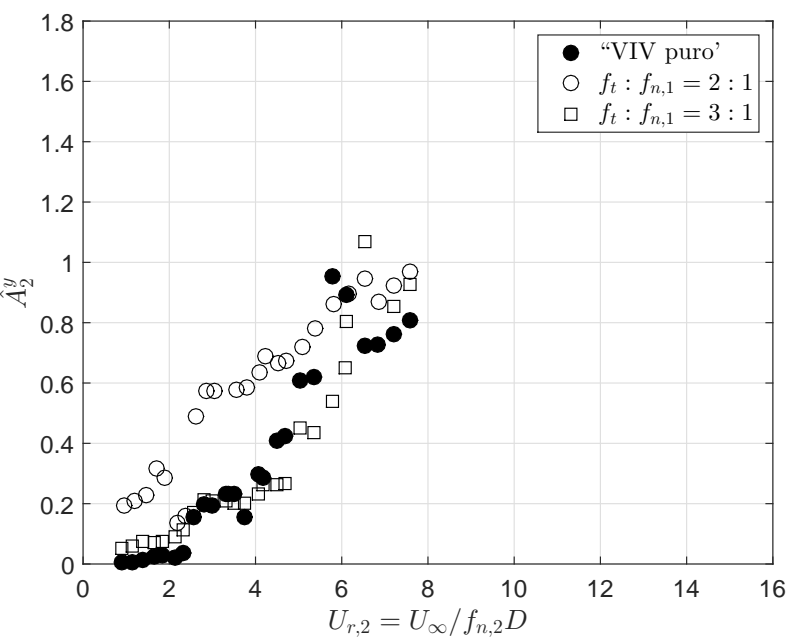

(c) $\hat{A}_{2}^{y}\left(U_{r, 2}\right)$.

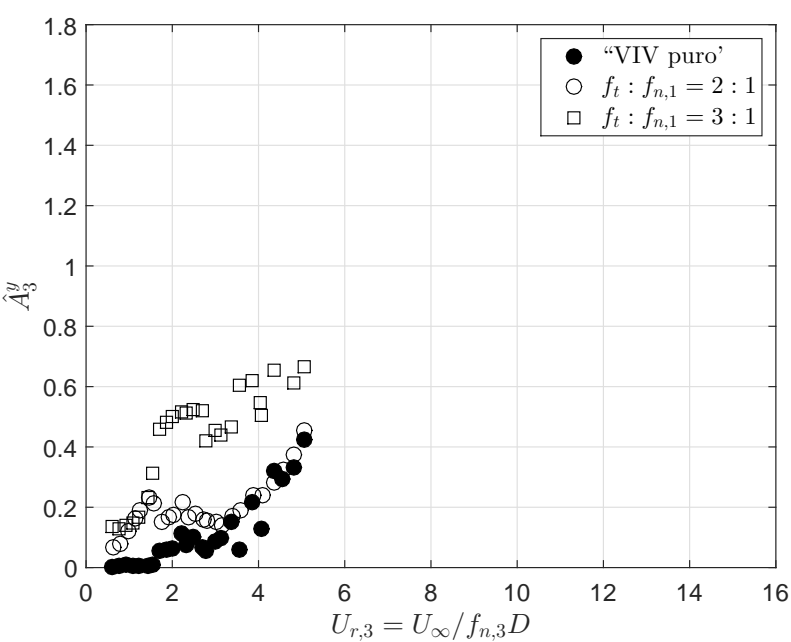

(e) $\hat{A}_{3}^{y}\left(U_{r, 3}\right)$.

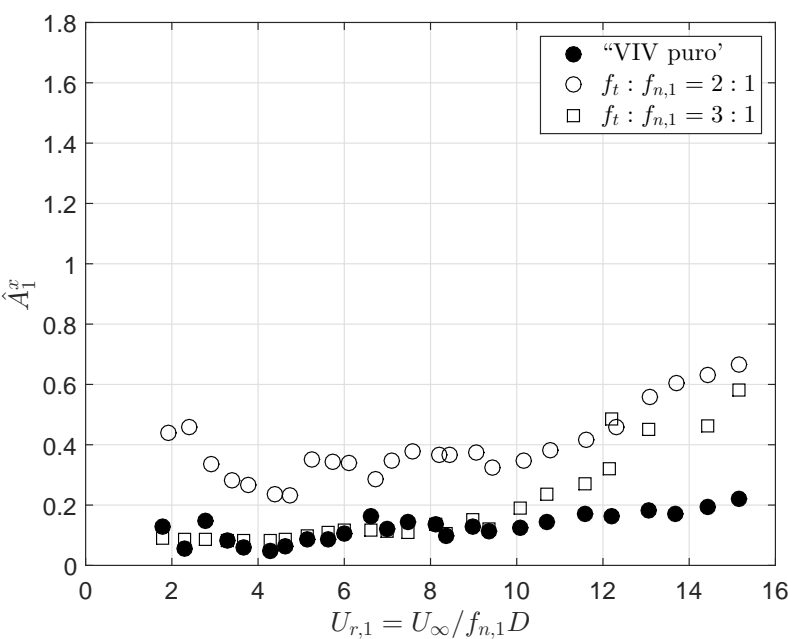

(b) $\hat{A}_{1}^{x}\left(U_{r, 1}\right)$.

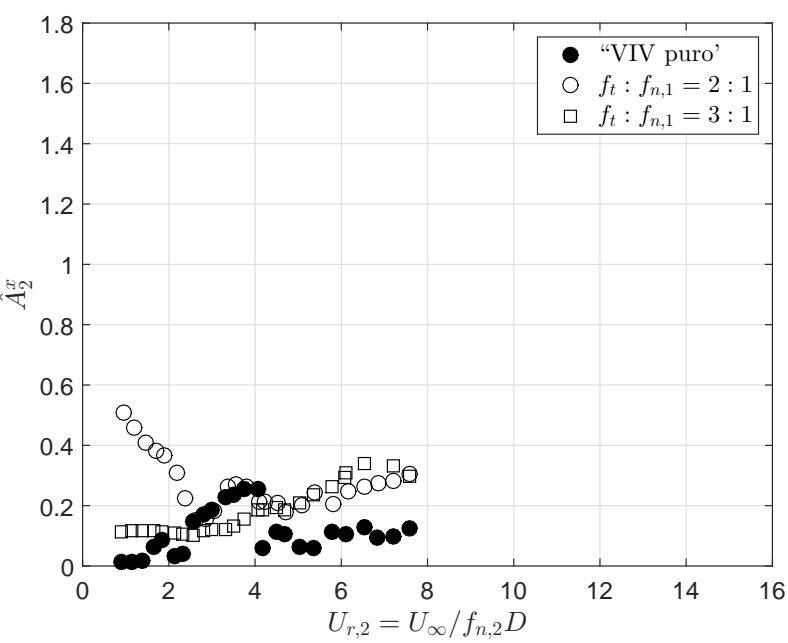

(d) $\hat{A}_{2}^{x}\left(U_{r, 2}\right)$.

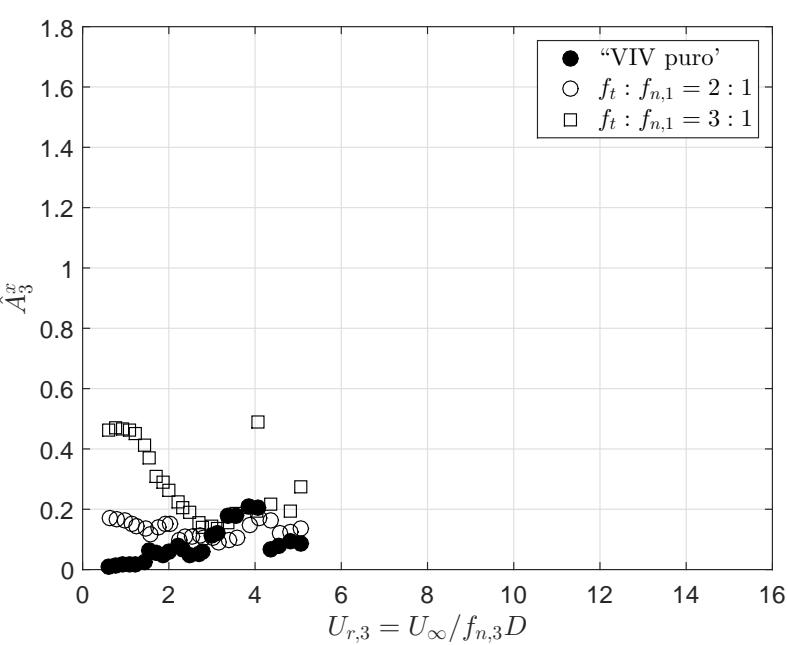

(f) $\hat{A}_{3}^{x}\left(U_{r, 3}\right)$.

Fonte: Adaptada de Franzini et al. (2018). 
amplificação das respostas observadas na curva $\hat{A}_{1}^{x}\left(U_{r, 1}\right)$ (ver Figura 90(b)). Embora exista essa amplificação, os valores atingidos não ultrapassam $0,60 D$.

Discutem-se, agora, as curvas mostrando a variação dos valores característicos das séries temporais de amplitude modal referentes ao segundo modo natural. No caso dos resultados referentes à direção cross-wise, a Figura 90(c) revela que, enquanto as condições "VIV puro" e aquela com movimento imposto de frequência $f_{t}: f_{n, 1}=3: 1$ têm boa aderência, existe uma amplificação das respostas no segundo modo para o caso definido por $f_{t}: f_{n, 1}=2: 1$. Uma explicação para tal amplificação reside no fato de que a excitação de topo com frequência igual ao dobro da primeira frequência natural leva, por conta da relação de frequências naturais, à uma ressonância clássica com o modo $k=2$.

A curva $\hat{A}_{2}^{x}\left(U_{r, 2}\right)$ apresentada na Figura $90($ d) mostra a amplificação da resposta pela ressonância clássica no segundo modo para velocidades reduzidas modais $U_{r, 2}<2$ e $U_{r, 2}>4$. Já para $2 \leq U_{r, 2} \leq 4$, a resposta estrutural em decorrência somente do fenômeno de VIV domina aquela decorrente da excitação de topo, reduzindo assim os valores característicos obtidos a partir da solicitação combinada. Em uma analogia com os resultados já disponíveis na literatura para a condição VIV-2gl, o leitor nota que o intervalo de velocidades reduzidas onde o VIV domina a resposta do cilindro flexível é o mesmo onde existe a ressonância in-line, ou seja, entre velocidades reduzidas modais 2 e 4 .

Esta seção é finalizada com a discussão das curvas dos valores característicos das séries temporais de amplitude modal referentes ao modo $k=3$ como funções da velocidade reduzida modal associada ao mesmo modo $U_{r, 3}$. Como mostram as Figuras $90($ e) $90(\mathrm{f})$, a condição de movimento imposto com frequência $f_{t}: f_{n, 1}=3: 1$ (ou, de maneira equivalente, $f_{t}: f_{n, 3}=1: 1$ ) induz respostas apreciáveis na direção cross-wise para toda a faixa de velocidades reduzidas modais $U_{r, 3}$, indicando dominância da resposta estrutural à ressonância clássica decorrente da excitação de topo.

\subsection{Considerações finais do capítulo e perspectivas de continuidade da pesquisa}

Este capítulo apresentou as principais contribuições do autor do presente texto no tocante às análises experimentais dos fenômenos de excitação paramétrica e de VIV. Em ambos os fenômenos, o objeto de estudo foi a resposta de um longo cilindro flexível, vertical e submerso em praticamente sua totalidade aos fenômenos atuantes de maneira isolada ou concomitante.

O problema de excitação paramétrica foi obtido por meio da imposição de movimentos harmônicos e monocromáticos ao topo do modelo. Tais movimentos induzem a variação temporal da força normal o que, por sua vez, modula a rigidez geométrica da estrutura. 
Para esse problema, verificou-se que as respostas mais significativas são aquelas obtidas quando o movimento foi imposto com frequência igual ao dobro da primeira frequência natural, correspondendo à instabilidade paramétrica principal do primeiro modo. Como pontuado por Patel e Park (1991), a presença do amortecimento hidrodinâmico quadrático na velocidade levou a respostas estruturais limitadas.

Em concordância com o que foi mencionado na seção 3.3, existe na literatura um baixo número de estudos experimentais acerca do fenômeno de excitação paramétrica em cilindros flexíveis submersos. Assim, já foi identificada uma contribuição do autor do texto ao estado-da-arte.

No entanto, a análise dos resultados experimentais não contemplou somente por meio de técnicas clássicas como, por exemplo, a análise das séries temporais de particulares pontos do modelo nos quais a resposta foi medida. A técnica de decomposição modal foi aplicada aos dados experimentais, o que possibilitou avaliar a resposta de cada modo à solicitação. Dessa forma e considerando a avaliação de diagramas de Strutt para alguns modos de vibrar, foi possível discutir quais modos naturais são suscetíveis à instabilidade paramétrica.

No tocante à análise experimental da base de dados referente ao caso onde o cilindro era solicitado somente pelo fenômeno de VIV, a técnica de decomposição modal proposta pelo autor possibilitou a identificação de uma série de aspectos que não seriam possíveis a partir do estudo das séries temporais de alguns pontos do modelo. Enquanto que as últimas séries temporais apresentam contribuições de diversos modos, as séries temporais de amplitude modal representam vibrações em uma determinada forma (modo natural ou uma aproximação) e com poucas frequências em seu espectro de amplitude.

A obtenção das séries temporais de amplitude modal possibilitaram, ainda, a obtenção de curvas dos seus valores característicos como função da velocidade de reboque do carro. Normalizando a velocidade de reboque com base nas frequências naturais dos modos (o que dá origem às velocidades reduzidas modais), é possível notar uma boa aderência entre as curvas de amplitude característica de oscilação de cada modo como funções da correspondente velocidade reduzida modal. Esse resultado experimental, antes inédito (a menos do conhecimento do autor e do grupo do LMO) é usualmente empregado na modelagem do fenômeno por meio de wake-oscillators.

Outra análise possibilitada pela decomposição modal inclui a discussão de saltos entre diversos regimes de resposta para uma mesma condição de velocidade de reboque. Por meio da diferença de fase entre as séries temporais de amplitude modal, observou-se que esses regimes correspondem a diferentes graus de sincronização entre vibrações modais nas direções in-line e cross-wise ou mesmo entre modos na mesma direção. A menos do conhecimento do autor desse texto, tal análise não foi apresentada em artigos científicos. 
Uma lacuna de conhecimento apontada na seção 4.3 e que está sendo preenchida com o apoio da pesquisa descrita no presente capítulo diz respeito aos estudos experimentais de um corpo flexível sujeito à excitação concomitante dos fenômenos de VIV e de excitação paramétrica. Esse tema tem sido objeto de recentes estudos numéricos (ver Yuan, Xue e Tang (2018)), porém nenhum estudo experimental era encontrado na literatura. Os resultados experimentais descritos no presente capítulo mostraram que a excitação paramétrica com frequência igual ao dobro da frequência natural do modo excitado em lock-in promove um pronunciado aumento da resposta ao fenômeno de VIV no modo considerado. É importante ressaltar que esse resultado pode ter impacto tecnológico no contexto da dinâmica de risers e que tanto os resultados aqui apresentados quanto outros que podem ser extraídos a partir da base de dados experimental aqui analisada têm a possibilidade de serem utilizados como paradigmas de comparação com códigos numéricos baseados em diversas abordagens, o que pode garantir ao grupo do LMO um reconhecimento ainda maior por parte das comunidades científica e tecnológica.

As técnicas de análise propostas pelo autor do presente texto já tiveram impactos dentro dos grupos de pesquisa do LMO e do Tanque de Provas Numérico ${ }^{19}$ (TPN). Em particular, a técnica de decomposição modal foi de grande valia para a análise experimental do fenômeno de VIV em cilindros flexíveis em catenária, foco das teses de doutorado de Pereira (2014) e de Malta (2015) e na análise de cilindros flexíveis inclinado, objeto de estudo da tese de Vieira (2017).

A pesquisa descrita neste capítulo pode ter diversos desdobramentos e continuidades. Uma primeira proposta de continuidade diz respeito à aplicação da técnica de decomposição modal seguida da análise de sincronia como forma de complementar os estudos do problema de excitação combinada pelos fenômenos de VIV e de excitação paramétrica. Uma segunda proposta consiste no uso funções mais ricas como funções de projeção no método de decomposição modal, discutindo os eventuais ganhos de análise e qual a sensibilidade do método com relação à escolha das funções de projeção. Em particular, pretende-se investir esforços de pesquisa visando o uso de um modo não-linear "quase-Bessel" como função de projeção, comparando os resultados com aqueles descritos neste capítulo. Maiores detalhes acerca dos modos "quase-Bessel" podem ser encontrados em Mazzilli, Lenci e Demeio (2014).

O leitor nota que as propostas acima descritas podem ser iniciadas o mais breve possível, uma vez que não demandam a condução novos experimentos. No caso de uma possível nova rodada de experimentos, fica a sugestão da investigação de um número maior de pares de amplitude e frequência dos movimentos verticais impostos ao topo, o que possibilitará um melhor entendimento do problema de excitação paramétrica em risers e

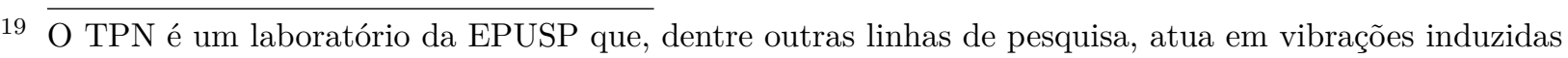
pelo escoamento. O TPN é coordenado pelo Prof. Dr. Kazuo Nishimoto, Professor Titular do Departamento de Engenharia Naval e Oceânica da EPUSP. 
também da resposta de um cilindro flexível à solicitação combinada por VIV e excitação paramétrica.

Uma outra sugestão de continuidade da pesquisa diz respeito a um estudo aprofundado dos efeitos de um movimento policromático imposto ao topo, de sorte a emular a resposta aleatória de uma unidade flutuante ao carregamento devido às ondas de superfície. Embora a campanha experimental conduzida contemple um ensaio desta natureza, esse não tem como frequência dominante aquela correspondente ao dobro da frequência natural de algum modo, o que possibilitaria o estudo experimental da instabilidade paramétrica com caráter aleatório e também dos efeitos concomitantes dessa última excitação paramétrica com o fenômeno de VIV. 


\section{Modelagem matemática dos fenômenos de excitação paramétrica e de VIV}

Este capítulo visa a apresentação de algumas contribuições lideradas pelo autor no tocante à modelagem matemática dos problemas de excitação paramétrica e de VIV. A seção 8.1 apresenta uma contribuição à modelagem matemática do problema de um cilindro flexível, vertical e submerso, sujeito à excitação paramétrica decorrente de uma excitação de suporte vertical e harmônica aplicada ao vínculo superior. Já a seção 8.2 traz algumas considerações acerca do uso de wake-oscillators na modelagem do fenômeno de VIV em cilindros rígidos montados em apoio elástico. Por fim, as considerações finais do capítulo e perspectivas de continuidade das pesquisas nele descritas podem ser encontradas na seção 8.3 .

\subsection{Contribuições à modelagem do fenômeno de excitação para- métrica em um cilindro flexível submerso}

Inicialmente, esta seção apresenta a dedução de um modelo de ordem reduzida (MOR) de três graus de liberdade para o problema de excitação paramétrica de um cilindro flexível vertical sujeito a movimento harmônico prescrito em seu apoio superior. Em um segundo momento, os resultados numéricos obtidos a partir desse modelo matemático são analisados e discutidos. Cabe ressaltar que esta seção é baseada em Franzini e Mazzilli (2016), publicado no International Journal of Non-Linear Mechanics.

Considere o problema esquematizado na Figura 91, que ilustra um cilindro flexível e totalmente submerso, com diâmetro $D$, comprimento indeformado $L_{0}$ já protendido de sorte a seu comprimento total ser $L$ e totalmente submerso. Esse cilindro possui rigidez axial $E A$, rigidez flexional $E I$ e massa por unidade de comprimento $m_{l}$. As duas extremidades do cilindro estão apoiadas, sendo que é aplicado à extremidade superior um movimento vertical da forma $A_{t} \cos (\Omega t)$. Considere que $\gamma$ seja o carregamento axial distribuído ao longo do comprimento da estrutura e que decorre do peso próprio e do empuxo. Apenas movimentos no plano $x z$ são permitidos, sendo $u(z, t)$ o deslocamento lateral do cilindro. O movimento da seção transversal satisfaz à hipótese de Navier, levando a um modelo de viga de Bernoulli-Euler. Essa hipótese está ilustrada na Figura 91(b).

Para essas condições e ainda sem considerar qualquer efeito do fluido no qual o cilindro está submerso, a Equação 8.1 descreve o movimento lateral do cilindro e adapta aquela apresentada em Mazzilli et al. (2008) e em Mazzilli, Lenci e Demeio (2014) para 
Figura 91 - Representações esquemáticas.

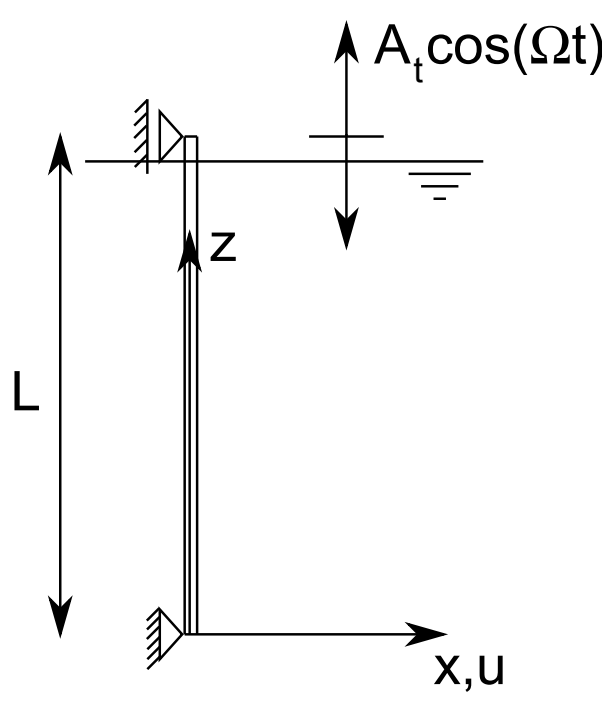

(a) Problema em estudo.

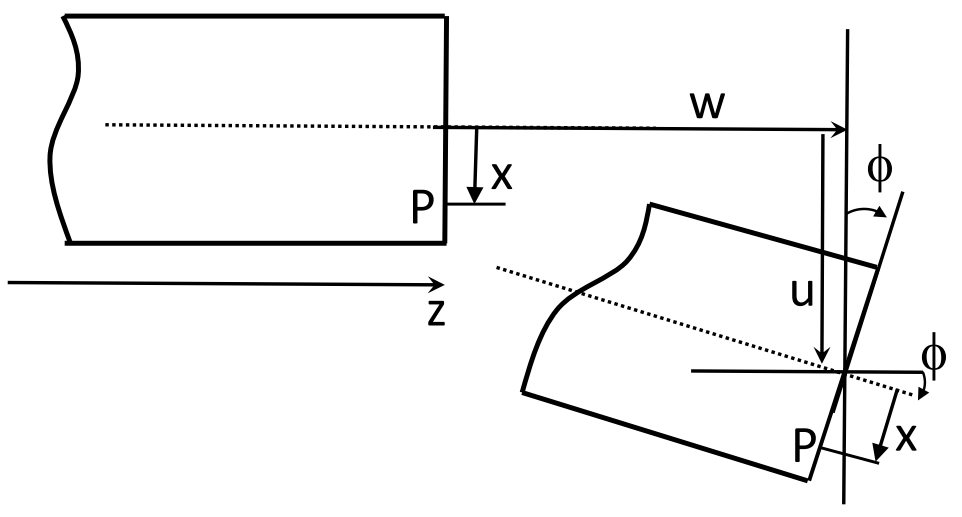

(b) Hipótese cinemática para a seção transversal.

Fonte: Extraída de Franzini e Mazzilli (2016).

uma estrutura na qual a força normal é função apenas da posição ao longo do eixo do cilindro.

$$
m_{l} \frac{\partial^{2} u}{\partial t^{2}}+E I \frac{\partial^{4} u}{\partial z^{4}}-\gamma \frac{\partial u}{\partial z}-T(z, t) \frac{\partial^{2} u}{\partial z^{2}}-\frac{E A}{2 L_{0}} \frac{\partial^{2} u}{\partial z^{2}} \int_{0}^{L_{0}}\left(\frac{\partial u}{\partial z}\right)^{2} d z=0
$$

O leitor rapidamente nota a seguinte identidade:

$$
\gamma \frac{\partial u}{\partial z}+T(z, t) \frac{\partial^{2} u}{\partial z^{2}}=\frac{\partial}{\partial z}\left(T(z, t) \frac{\partial u}{\partial z}\right)
$$

Agora, discute-se como os carregamentos devido ao fluido são incorporados ao modelo matemático. Aqui, os esforços hidrodinâmicos são decorrentes apenas da aplicação da clássica fórmula de Morison, que decompõe a força em uma parcela proporcional à aceleração da estrutura (efeito de massa adicional potencial) e uma outra quadrática na velocidade da estrutura respondendo pelos efeitos viscosos. Essa força hidrodinâmica é incorporada no lado direito da Equação 8.1, dando origem à Equação 8.3.

$$
\begin{aligned}
& m_{l} \frac{\partial^{2} u}{\partial t^{2}}+c \frac{\partial u}{\partial t}+E I \frac{\partial^{4} u}{\partial z^{4}}-\frac{\partial}{\partial z}\left(T(z, t) \frac{\partial u}{\partial z}\right)-\frac{E A}{2 L_{0}} \frac{\partial^{2} u}{\partial z^{2}} \int_{0}^{L_{0}}\left(\frac{\partial u}{\partial z}\right)^{2} d z=- \\
& -m_{a}^{p o t} \frac{\partial^{2} u}{\partial t^{2}}-\frac{1}{2} \rho D \bar{C}_{D}\left|\frac{\partial u}{\partial t}\right| \frac{\partial u}{\partial t}
\end{aligned}
$$

A força normal ao longo do modelo é dada pela soma da tração no topo $T_{t}(t)$ (dada pela soma de um valor médio $\bar{T}_{t}$ com uma parcela de variação harmônica no tempo) 
subtraída de uma parcela decorrente do carregamento axial distribuído, como mostra a Equação 8.4 .

$$
T(z, t)=\underbrace{\bar{T}_{t}+\frac{E A}{L_{0}} A_{t} \cos (\Omega t)}_{T_{t}(t)}-\gamma\left(L_{0}-z\right)
$$

O deslocamento lateral $u(z, t)$ é escrito por meio da clássica técnica de separação de variáveis. Tendo em a obtenção de um MOR que descreva a resposta estrutural nas vizinhas da ressonância paramétrica principal com o primeiro modo de vibrar, $u(z, t)$ é expandido com três termos na forma da Equação 8.5. Já a velocidade e a aceleração são dadas pelas Equações 8.6 e 8.7 respectivamente enquanto que as Equações 8.8, 8.9 e 8.10 trazem as derivadas do deslocamento transversal com relação à coordenada $z$.

$$
\begin{aligned}
& u(z, t)=\sum_{k=1}^{3} \psi_{k}(z) a_{k}(t) \\
& \frac{d u(z, t)}{d t}=\sum_{k=1}^{3} \psi_{k}(z) \frac{d a_{k}(t)}{d t} \\
& \frac{d^{2} u(z, t)}{d t^{2}}=\sum_{k=1}^{3} \psi_{k}(z) \frac{d^{2} a_{k}(t)}{d t^{2}} \\
& \frac{d u(z, t)}{d z}=\sum_{k=1}^{3} \frac{d \psi_{k}(z)}{d z} a_{k}(t) \\
& \frac{d^{2} u(z, t)}{d z^{2}}=\sum_{k=1}^{3} \frac{d^{2} \psi_{k}(z)}{d z^{2}} a_{k}(t) \\
& \frac{d^{4} u(z, t)}{d z^{4}}=\sum_{k=1}^{3} \frac{d^{4} \psi_{k}(z)}{d z^{4}} a_{k}(t)
\end{aligned}
$$

Levando as Equações 8.5, 8.6, 8.7, 8.8, 8.9 e 8.10 na Equação 8.3, obtém-se:

$$
\begin{aligned}
& m_{l}\left(\sum_{k=1}^{3} \psi_{k}(z) \frac{d^{2} a_{k}(t)}{d t^{2}}\right)+c\left(\sum_{k=1}^{3} \psi_{k}(z) \frac{d a_{k}(t)}{d t}\right)-\frac{\partial}{\partial z}\left[T(t, z)\left(\sum_{k=1}^{3} \frac{d \psi_{k}(z)}{d z} a_{k}(t)\right)\right]+ \\
& +E I\left(\sum_{k=1}^{3} \frac{d^{4} \psi_{k}(z)}{d z^{4}} a_{k}(t)\right)-\frac{E A}{2 L_{0}}\left(\sum_{k=1}^{3} \frac{d^{2} \psi_{k}(z)}{d z^{2}} a_{k}(t)\right) \int_{0}^{L_{0}}\left(\sum_{k=1}^{3} \frac{d \psi_{k}(z)}{d z} a_{k}(t)\right)^{2} d z= \\
& -m_{a}\left(\sum_{k=1}^{3} \psi_{k}(z) \frac{d^{2} a_{k}(t)}{d t^{2}}\right)-\frac{1}{2} \rho D \bar{C}_{D}\left|\left(\sum_{k=1}^{3} \psi_{k}(z) \frac{d a_{k}(t)}{d t}\right)\right|\left(\sum_{k=1}^{3} \psi_{k}(z) \frac{d a_{k}(t)}{d t}\right)
\end{aligned}
$$

Tendo em vista uma maior generalidade do modelo matemático, as equações de movimento que governam a resposta estrutural são escritas na forma adimensional. Para 
tanto, considere as seguintes quantidades:

$$
\tau=t \omega_{n, 1} ; \xi=\frac{z}{L_{0}} ; n=\frac{\Omega}{\omega_{n, 1}} ; \tilde{a}_{k}=\frac{a_{k}}{D} ; C_{a}^{p o t}=\frac{m_{a}^{p o t}}{m_{d}} ; \tilde{m}=\frac{m_{l}}{m_{d}} ; \Lambda_{M}=\frac{D^{2}}{m_{d}\left(\tilde{m}+C_{a}^{p o t}\right)} \rho \bar{C}_{D}
$$

Substituindo as quantidades definidas na Equação 8.12 na Equação 8.12 e aplicando o método de Galerkin para cada uma das três funções de interpolação $\psi_{k}(\xi)$, o seguinte sistema de equações diferenciais ordinárias é obtido:

$$
\begin{aligned}
& \ddot{\tilde{a}}_{1}+\alpha_{1} \dot{\tilde{a}}_{1}+\left(\delta_{1}+\epsilon_{1} \cos (n \tau)\right) \tilde{a}_{1}+\alpha_{2} \tilde{a}_{2}+\alpha_{3} \tilde{a}_{1}^{3}+\alpha_{4} \tilde{a}_{2}^{2} \tilde{a}_{1}+\alpha_{5} \tilde{a}_{1} \tilde{a}_{3}^{2}+ \\
& +\Lambda_{M} \int_{0}^{1}\left|\dot{\tilde{a}}_{1} \psi_{1}+\dot{\tilde{a}}_{2} \psi_{2}+\dot{\tilde{a}}_{3} \psi_{3}\right|\left(\dot{\tilde{a}}_{1} \psi_{1}+\dot{\tilde{a}}_{2} \psi_{2}+\dot{\tilde{a}}_{3} \psi_{3}\right) \psi_{1} d \xi=0 \\
& \ddot{\tilde{a}}_{2}+\beta_{1} \dot{\tilde{a}}_{2}+\left(\delta_{2}+\epsilon_{2} \cos (n \tau)\right) \tilde{a}_{2}+\beta_{2} \tilde{a}_{3}+\beta_{3} \tilde{a}_{1}+\beta_{4} \tilde{a}_{2} \tilde{a}_{1}^{2}+\beta_{5} \tilde{a}_{2}^{3}+\beta_{6} \tilde{a}_{2} \tilde{a}_{3}^{2}+ \\
& +\Lambda_{M} \int_{0}^{1}\left|\dot{\tilde{a}}_{1} \psi_{1}+\dot{\tilde{a}}_{2} \psi_{2}+\dot{\tilde{a}}_{3} \psi_{3}\right|\left(\dot{\tilde{a}}_{1} \psi_{1}+\dot{\tilde{a}}_{2} \psi_{2}+\dot{\tilde{a}}_{3} \psi_{3}\right) \psi_{2} d \xi=0 \\
& \ddot{\tilde{a}}_{3}+\gamma_{1} \dot{\tilde{a}}_{3}+\left(\delta_{3}+\epsilon_{3} \cos (n \tau)\right) \tilde{a}_{3}+\gamma_{2} \tilde{a}_{2}+\gamma_{3} \tilde{a}_{3} \tilde{a}_{2}^{2}+\gamma_{4} \tilde{a}_{3} \tilde{a}_{1}^{2}+\gamma_{5} \tilde{a}_{3}^{3}+ \\
& +\Lambda_{M} \int_{0}^{1}\left|\dot{\tilde{a}}_{1} \psi_{1}+\dot{\tilde{a}}_{2} \psi_{2}+\dot{\tilde{a}}_{3} \psi_{3}\right|\left(\dot{\tilde{a}}_{1} \psi_{1}+\dot{\tilde{a}}_{2} \psi_{2}+\dot{\tilde{a}}_{3} \psi_{3}\right) \psi_{3} d \xi=0
\end{aligned}
$$

onde

$$
\begin{aligned}
\dot{(}) & =\frac{d}{d \tau}() ; \psi_{k}(\xi)=\sin (k \pi \xi) ; \epsilon_{k}=\frac{E A}{L_{0}}\left(\frac{k \pi}{L_{0}}\right)^{2} \frac{A_{t}}{m_{d}\left(\tilde{m}+C_{a}^{p o t}\right) \omega_{1}^{2}} \\
\delta_{k} & =\frac{E I}{m_{d}\left(\tilde{m}+C_{a}^{p o t}\right) \omega_{1}^{2}}\left(\frac{k \pi}{L_{0}}\right)^{4}-\frac{1}{2} \frac{\gamma L_{0}}{m_{d}\left(\tilde{m}+C_{a}^{p o t}\right) \omega_{1}^{2}}\left(\frac{k \pi}{L_{0}}\right)^{2}+\left(\frac{k \pi}{L_{0}}\right)^{2} \frac{\bar{T}_{t}}{m_{d}\left(\tilde{m}+C_{a}^{p o t}\right) \omega_{1}^{2}}
\end{aligned}
$$

Cabe ressaltar que o MOR dado pelas Equações 8.13, 8.14 e 8.15 é não-linear e acoplado nas amplitudes modais $\tilde{a}_{k}(k=1,2$ e 3$)$. Essas características decorrem do caráter não-linear da equação de movimento sobre a qual o método de Galerkin foi aplicado (ver Equação 8.3). Em particular, as não-linearidades adotadas advém da extensibilidade da estrutura e do amortecimento hidrodinâmico.

Por sua vez, os parâmetros $\alpha_{m}, \beta_{m}$ e $\gamma_{m}(m=1, \ldots, 6)$ são apresentados na Tabela 7. A Equação 8.13 revela que o valor adimensional da frequência natural não amortecida do primeiro modo é $\tilde{\omega}_{n, 1}=\sqrt{\delta_{1}}$. Utilizando esse último resultado em conjunto com a definição do tempo adimensional, a frequência natural não amortecida do primeiro modo, é dada, em rad/s, pela Equação 8.17.

$$
\omega_{n, 1}=\sqrt{\frac{1}{m_{d}\left(\tilde{m}+C_{a}^{p o t}\right)}\left(\frac{\pi}{L_{0}}\right)^{2}\left[E I\left(\frac{\pi}{L_{0}}\right)^{2}-\frac{1}{2} \gamma L_{0}+\bar{T}_{t}\right]}
$$


Tabela 7 - Parâmetros do modelo de ordem reduzida.

\begin{tabular}{c|ccc}
\hline \hline$m$ & & $\alpha_{m}$ & $\gamma_{m}$ \\
\hline \hline 1 & $\alpha_{1}=\frac{c}{m_{d}\left(\tilde{m}+C_{a}^{p o t}\right) \omega_{1}}$ & $\beta_{1}=\alpha_{1}$ & $\gamma_{1}=\alpha_{1}$ \\
2 & $\alpha_{2}=\frac{40}{9} \frac{\gamma}{m_{d}\left(\tilde{m}+C_{a}^{p o t}\right) \omega_{n, 1}^{2} L_{0}}$ & $\beta_{2}=\frac{312}{25} \frac{\gamma}{\omega_{n, 1}^{2} m_{d}\left(\tilde{m}+C_{a}^{p o t}\right) L_{0}}$ & $\gamma_{2}=\beta_{2}$ \\
3 & $\alpha_{3}=\frac{1}{4} \frac{D^{2} E A}{m_{d}\left(\tilde{m}+C_{a}^{p o t}\right) \omega_{n, 1}^{2}}\left(\frac{\pi}{L_{0}}\right)^{4}$ & $\beta_{3}=\alpha_{2}$ & $\gamma_{3}=9 \frac{D^{2} E A}{m_{d}\left(\tilde{m}+C_{a}^{\text {pot }}\right) \omega_{n, 1}^{2}}\left(\frac{\pi}{L_{0}}\right)^{4}$ \\
4 & $\alpha_{4}=\frac{D^{2} E A}{m_{d}\left(\tilde{m}+C_{a}^{\text {pot }}\right) \omega_{n, 1}^{2}}\left(\frac{\pi}{L_{0}}\right)^{4}$ & $\beta_{4}=\alpha_{4}$ & $\gamma_{4}=\alpha_{5}$ \\
5 & $\alpha_{5}=\frac{9}{4} \frac{D^{2} E A}{m_{d}\left(\tilde{m}+C_{a}^{p o t}\right) \omega_{n, 1}^{2}}\left(\frac{\pi}{L_{0}}\right)^{4}$ & $\beta_{5}=\frac{1}{4} \frac{D^{2} E A}{m_{d}\left(\tilde{m}+C_{a}^{p o t}\right) \omega_{n, 1}^{2}}\left(\frac{2 \pi}{L_{0}}\right)^{4}$ & $\gamma_{5}=\frac{1}{4} \frac{D^{2} E A}{m_{d}\left(\tilde{m}+C_{a}^{\text {pot }}\right) \omega_{n, 1}^{2}}\left(\frac{3 \pi}{L_{0}}\right)^{4}$ \\
6 & - & $\gamma_{3}$ & - \\
\hline \hline
\end{tabular}

Fonte: Adaptada de Franzini e Mazzilli (2016).

Como análise de resultado, considere a Equação $8.17 \mathrm{com} \gamma=0$ (isto é, força de tração $\bar{T}_{t}$ e constante ao longo da estrutura) e com $E I=0$ (comportamento de cabo), a primeira frequência natural não amortecida é:

$$
\omega_{n, 1}=\frac{\pi}{L_{0}} \sqrt{\frac{\bar{T}_{t}}{m_{d}\left(\tilde{m}+C_{a}^{p o t}\right)}}
$$

A Equação 8.18 corresponde, de fato, à solução analítica da primeira frequência natural não amortecida de uma corda horizontal de massa linear $m_{d}\left(\tilde{m}+C_{a}^{p o t}\right)=m_{l}+m_{a}^{p o t}$ e com tração $\bar{T}_{t}$.

Antes da apresentação das metodologias de solução numérica e de análise, cumpre salientar ao leitor que as funções de interpolação $\psi_{k}(\xi)$ empregadas neste capítulo não correspondem aos modos de vibrar da estrutura representada na Figura 92(a). No entanto e seguindo o que já fora adotado no capítulo 7 , as quantidades $\tilde{a}_{k}$ são chamadas de séries temporais de amplitude modal. Essa nomenclatura é um abuso de linguagem, dado que $\tilde{a}_{k}$ não são, strito senso, os termos que multiplicam o k-ésimo modo de vibrar de sorte a recompor a configuração deformada instantânea.

Uma vez definido o modelo matemático, esta seção apresenta as metodologias de solução numérica das equações de movimento adimensionais e de análise dos resultados. As Equações 8.13 foram numericamente integradas utilizando o método de Runge-Kutta por meio da função ode45 do MATLAB ${ }^{\circledR}$. O tempo máximo de simulação numérica foi $\tau_{\max }=12000$ e o passo de tempo adotado foi $\Delta \tau=0,10$.

Os parâmetros de massa, rigidez, tração no topo e excitação de suporte foram os mesmos adotados nos experimentos descritos no capítulo 7 (ver Tabela 3). Dois conjuntos de simulação foram realizados, sendo o primeiro conduzido com vistas ao estudo da resposta à excitação de suporte com frequência adimensional $n=\Omega / \omega_{n, 1} \approx 2$ e amplitude 
$A_{t} / L_{0}=1 \%$ (o mesmo valor empregado na campanha experimental analisada no capítulo 7), induzindo, portanto a ressonância paramétrica principal com o primeiro modo de vibrar. No segundo conjunto, os valores característicos das séries temporais de amplitude modal pós-críticas ${ }^{1} \hat{A}_{k}=\max \left\{\tilde{a}_{k}(\tau>6000)\right\}$ foram calculadas como funções dos parâmetros que governam a excitação paramétrica e exibidas na forma de mapas de cores. O conjunto de resultados analisados contempla, ainda, os espectros de amplitude calculados a partir das séries temporais de amplitude modal.

A metodologia de simulação numérica ainda envolve a definição dos coeficientes hidrodinâmicos de massa adicional potencial $C_{a}^{\text {pot }}$ e de arrasto médio $\bar{C}_{D}$. Neste texto, esses valores foram definidos como $C_{a}^{p o t}=1$ e $\bar{C}_{D}=1,20$ como são tipicamente encontrados nos códigos de projeto e análise usados na engenharia oceânica. Conforme mencionado na revisão bibliográfica conduzida na seção 3.2, esses coeficientes dependem da amplitude de oscilação da estrutura, representada pelo número de Keulegan-Carpenter $(K C)$, o que incluiria uma segunda fonte de não-linearidade ao modelo matemático em estudo. O trabalho de Franzini et al. (2016) traz uma série de estudos numéricos acerca da sensibilidade da resposta de um cilindro flexível sujeito à excitação paramétrica com relação aos coeficientes de massa adicional e de arrasto médio.

A apresentação da metodologia de simulação numérica é encerrada com a discussão do cálculo das integrais ao longo do comprimento do modelo que aparecem nas Equações 8.13, 8.14 e 8.15. Para cada instante de tempo adimensional $\tau$, o modelo foi discretizado em 200 elementos e a função $f(\xi, \tau)=\sum_{k=1}^{3} \dot{\tilde{a}}_{k}(\tau) \psi_{k}(\xi)$ foi avaliada nesse domínio discreto. Assim e, novamente, para cada instante de tempo adimensional, a integral $\int_{0}^{1} f(\xi, \tau) \mid f(\xi, \tau) d \xi$ foi calculada utilizando o método dos trapézios.

Apresentadas as metodologias de solução numérica e de análise, incia-se, neste ponto, a análise dos resultados. A Figura 92 apresenta as séries temporais de amplitude modal para os três primeiros modos de vibrar, além de algumas seções transversais do espaço de fase.

Como mostra a Figura 92(a), a série temporal de amplitude modal $\tilde{a}_{1}(\tau)$ é livre de modulação de amplitude e com valor característico $\hat{A}_{1} \approx 1,8$. Seu espectro de amplitude é de banda estreita, com frequência dominante igual a 1 , ou seja, na frequência natural do primeiro modo da estrutura e correspondente à metade da frequência da excitação paramétrica.

A comparação entre as séries temporais de amplitude modal associada ao primeiro modo de vibrar obtidas a partir do modelo matemático discutido neste capítulo e aquela experimentalmente obtida e apresentada na Figura 66(c) indica uma notável semelhança no que diz respeito à assinatura em frequência, com espectro de amplitude de banda

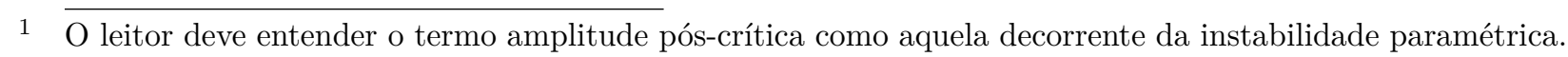
Note, ainda, que caso o modelo fosse linear, a resposta pós-crítica seria ilimitada. 
Figura 92 - Séries temporais de amplitude modal adimensional $n=2, A_{t} / L_{0}=1 \%$.
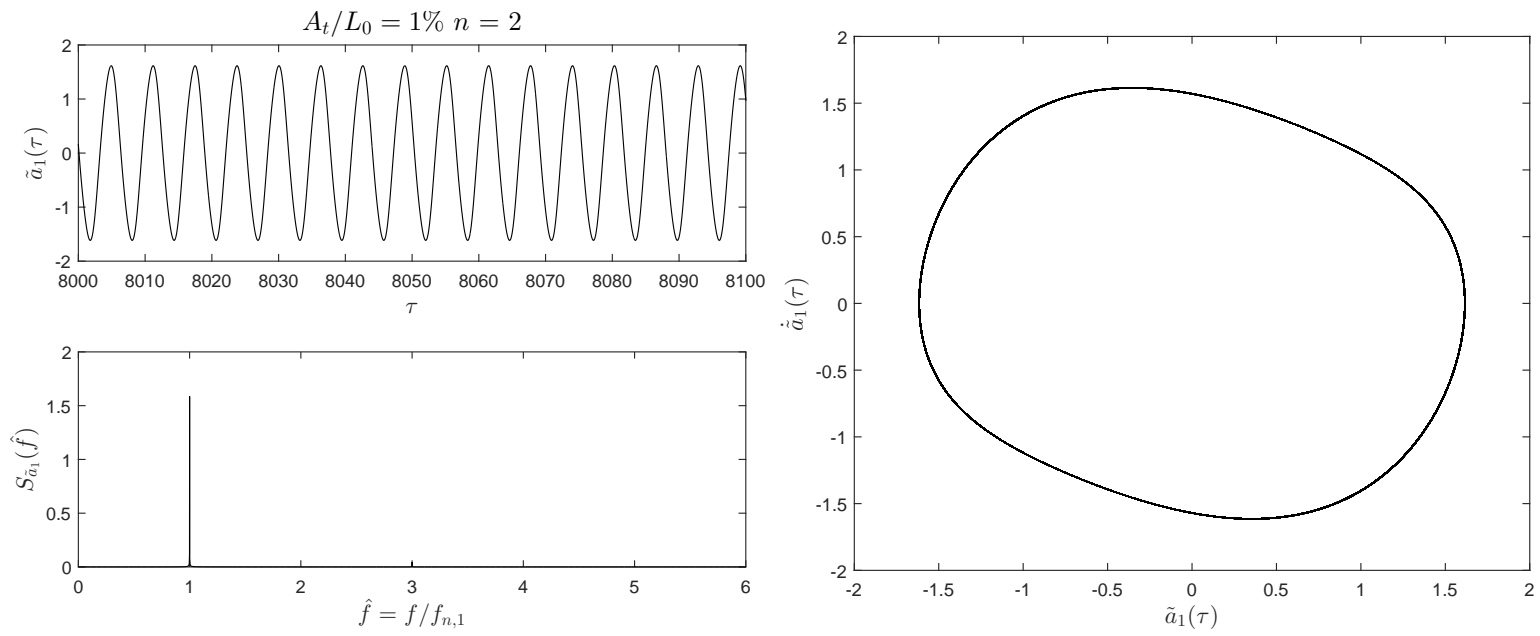

(a) $\tilde{a}_{1}(\tau)$.

(b) Seção transversal $\tilde{a}_{1}(\tau) \times \dot{\tilde{a}}_{1}(\tau)$ do espaço de fases.
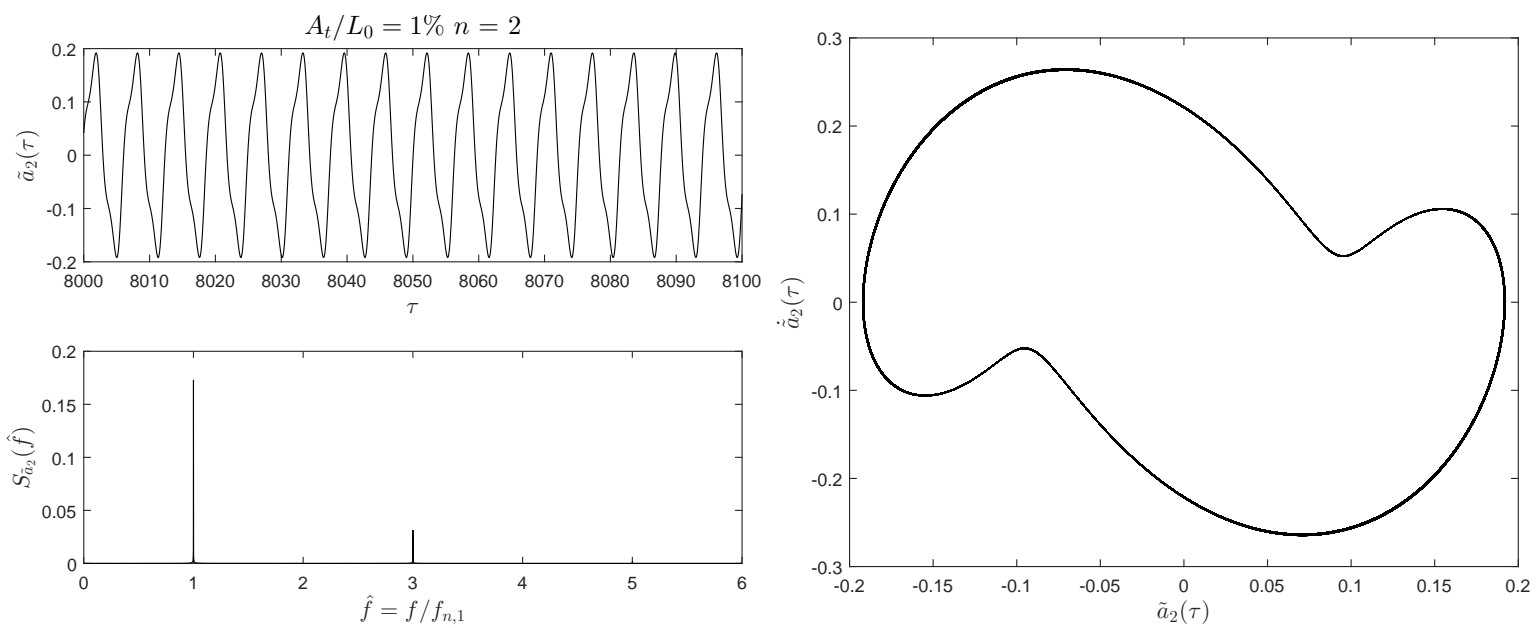

(c) $\tilde{a}_{2}(\tau)$.

(d) Seção transversal $\tilde{a}_{2}(\tau) \times \dot{\tilde{a}}_{2}(\tau)$ do espaço de fases.
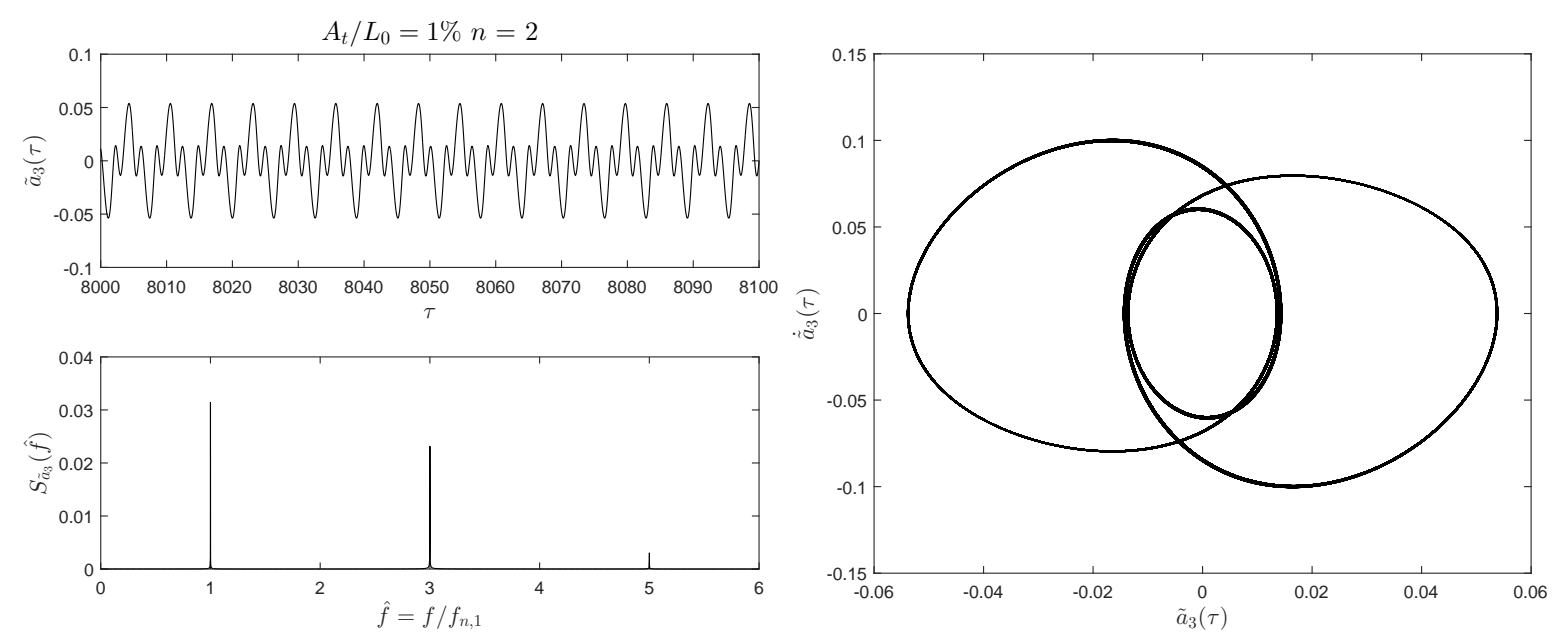

(e) $\tilde{a}_{3}(\tau)$.

(f) Seção transversal $\tilde{a}_{3}(\tau) \times \dot{\tilde{a}}_{3}(\tau)$ do espaço de fases.

Fonte: Adaptada de Franzini e Mazzilli (2016). 
estreita e frequência dominante igual àquela do primeiro modo de vibrar. Um outro aspecto semelhante é a ausência de modulação de amplitude nas resposta $\tilde{a}_{1}(\tau)$.

Já o valor característico da série temporal amplitude de resposta modal associada ao primeiro modo experimentalmente obtida e mostrada na Figura 66(c) é cerca de 35\% daquela proveniente a partir do modelo de ordem reduzida que é objeto desta seção. Dentre as possíveis explicações para as diferenças, podem ser destacados aspectos não considerados na modelagem como, por exemplo, o caráter tridimensional da resposta do modelo ensaiado em laboratório e alguns aspectos do carregamento hidrodinâmico. Esse último tópico, em particular, merece uma discussão mais aprofundada.

Em decorrência da instabilidade paramétrica, o cilindro movimenta-se com relação ao fluido, o que acaba por induzir um escoamento oscilatório ao redor de cada seção transversal da estrutura. Dependendo de sua amplitude, esse escoamento oscilatório pode estar associado à liberação de vórtices que acaba por induzir uma outra classe de vibrações induzidas pelo escoamento aqui nomeadas vibrações induzidas pelo escoamento oscilatório. Esse fenômeno, também denominado de Vortex Self Induced Vibration (VSIV), já foi objeto de estudos envolvendo cilindros rígidos montados em apoio elástico e sujeitos a escoamento oscilatórios (ver Sumer e Fredsøe (1988)), cilindros flexíveis em oscilação forçada (Fu et al. (2014)) ou em cilindros flexíveis montados em catenária submetidos a movimentos impostos ao topo (Rateiro et al. (2013) e Pesce et al. (2017)). Como o carregamento hidrodinâmico é aqui modelado por meio da fórmula de Morison, o fenômeno de VSIV não é capturado pelo modelo numérico.

Retomando a análise da Figura 92, discute-se a série temporal referente ao segundo modo de vibrar. Como mostram as Figuras 92(c) e 92(d), existe resposta no segundo modo de vibrar mesmo em uma condição de ressonância paramétrica com o primeiro modo natural. O valor máximo da série temporal $\tilde{a}_{2}(\tau)$ é próximo a 0,20 (cerca de nove vezes inferior àquele obtido para $\tilde{a}_{1}(\tau)$ ), enquanto que seu espectro de amplitude é composto das frequências $f / f_{n, 1}=1$ e $f / f_{n, 1}=3$. Já o resultado experimental apresentado na seção 7.2, Figura $67(\mathrm{c})$, mostra que $\tilde{a}_{2}(\tau)$ tem valor máximo próximo a 0,50 e com frequência dominante igual a $f / f_{n, 1}=2$, a mesma frequência da excitação de suporte.

Por sua vez, a Figura 92(e) indica que a série temporal de amplitude modal associada ao terceiro modo possui valor máximo próximo a 0,05 e é composta de três frequências, a saber $f / f_{n, 1}=1, f / f_{n, 1}=3$ e $f / f_{n, 1}=5$. Já o resultado experimental apresentado na Figura 67(c) também indica que essa série temporal tem valor máximo significativamente inferior àquele associado ao primeiro modo, porém com a presença das frequências $f / f_{n, 1}=2$ e $f / f_{n, 1}=4$ em sua assinatura em frequência.

A Figura 93 mostra exemplos de configurações deformadas instantâneas obtidas da regeneração da resposta $u\left(\tau, z / L_{0}\right)$ a partir das séries temporais de amplitude modal e das funções de interpolação adotadas no método de Galerkin. Nessa figura, é claramente visível 
Figura 93 - Configurações deformadas instantâneas. Os marcadores indicam os máximos deslocamentos observados.

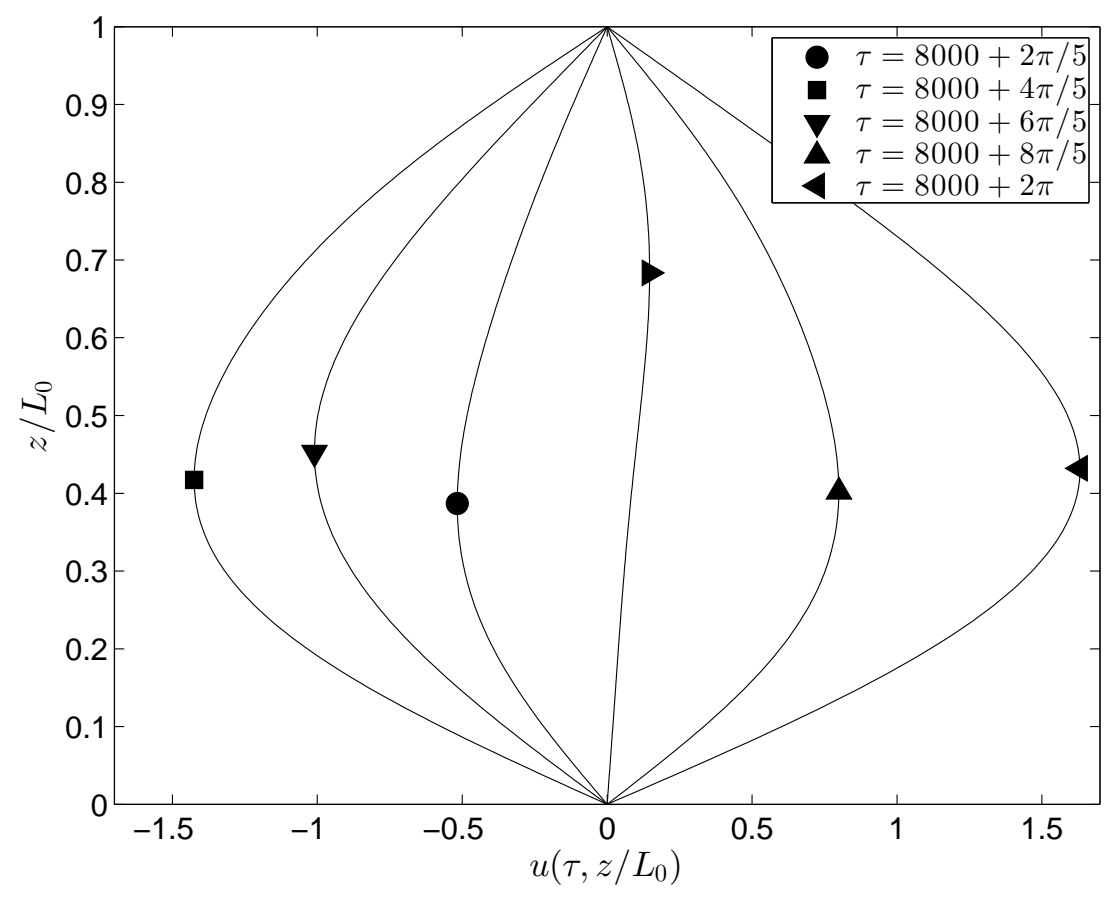

Fonte: Extraída de Franzini e Mazzilli (2016).

que a posição de máximo deslocamento ao longo do modelo depende do instante de tempo. Ressalta-se que esse resultado não seria obtido caso o MOR construído considerasse um único modo.

À título de comparação, a Figura 94 apresenta as séries temporais $\tilde{a}_{1}(\tau)$ e $\tilde{a}_{2}(\tau)$ obtidas a partir da projeção da Equação 8.3 em um único modo de vibrar (ou seja, $k=1$ ou $k=2$ ). Considerando a série temporal $\tilde{a}_{1}(\tau)$, a Figura 94(a) mostra que um MOR com um único modo é suficiente para representar a resposta no primeiro modo de vibrar. Por outro lado, a resposta no segundo modo, embora semelhante àquela obtida quando do uso do MOR com três graus de liberdade em termos de valor máximo, é significativamente distinta em termos de espectro de amplitude. Enquanto que o modelo multimodal leva a uma resposta composta das frequências $f / f_{n, 1}=1$ e $f / f_{n, 1}=3$ (ver Figura $92(\mathrm{c})$ ), a Figura 94(b) revela que a resposta obtida a partir do MOR unimodal tem como única frequência $f / f_{n, 1}=2$.

É interessante, ainda, estudar a resposta estrutural a uma excitação de suporte com uma frequência ligeiramente distinta daquela da instabilidade paramétrica principal com o primeiro modo. Essa investigação é agora conduzida por meio de simulações considerando $n=2,15$, ou seja, uma dessintonia de $0,15 / 2=7,5 \%$.

A Figura 95 ilustra as séries temporais de amplitude modal com os correspondentes espectros de amplitude, além de seções transversais do espaço de fase. Dos pontos de vista 
Figura 94 - Exemplos de séries temporais de amplitude modal - MOR unimodal.
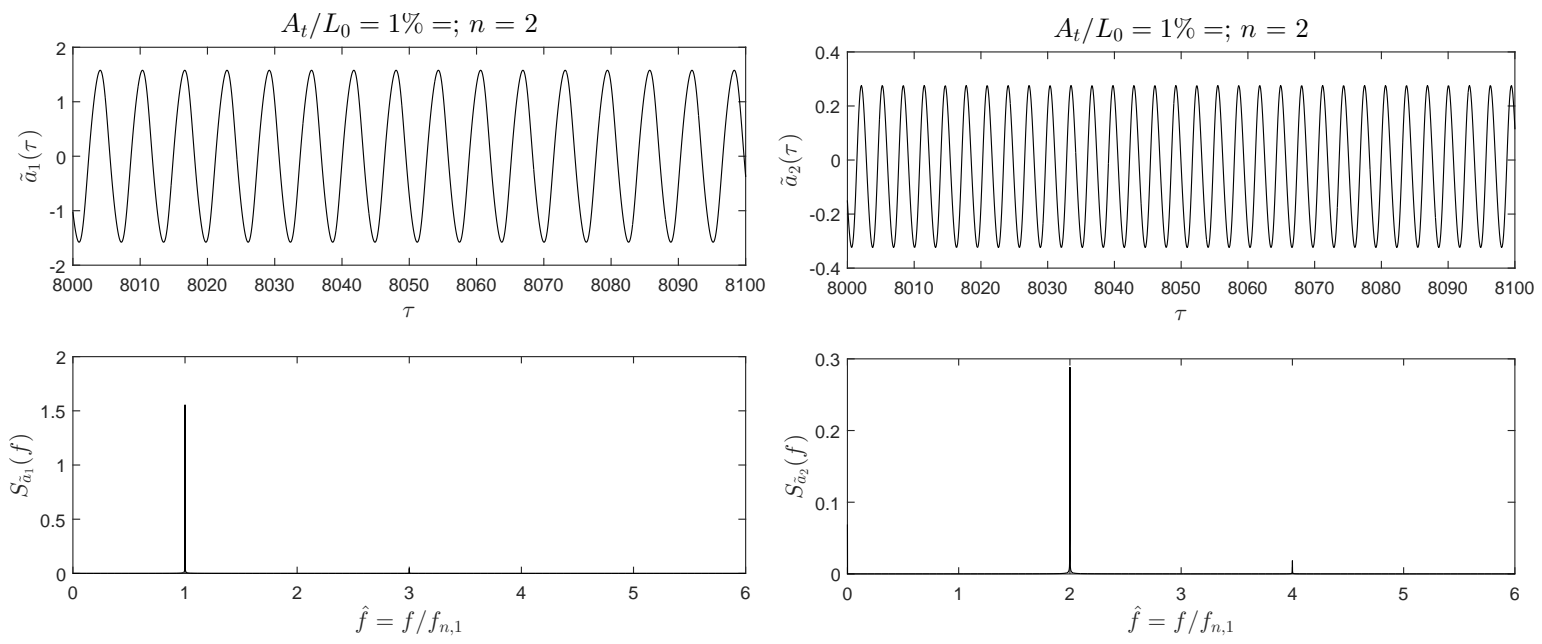

(a) $\tilde{a}_{1}(\tau)$.

(b) $\tilde{a}_{2}(\tau)$.

Fonte: Adaptada de Franzini e Mazzilli (2016).

qualitativo e de assinatura em frequência, o aspecto das respostas é o mesmo obtido na Figura 92 por ocasião do caso com excitação de suporte definida por $n=2$, porém com uma redução bastante significativa nos máximos valores de resposta.

Como mostrado, uma pequena variação na frequência da excitação de suporte pode resultar na diminuição significativa das amplitudes pós-críticas de oscilação. Essa sensibilidade do problema de excitação paramétrica já pôde ser notada quando da análise do diagrama de Strutt (ver Figura 3(b)), em especial quando a amplitude da excitação paramétrica é pequena. Assim, é interessante avaliar qual o valor característico pós-crítico das séries temporais de amplitude modal para diferentes valores de amplitude e frequência do movimento imposto (ou seja, os parâmetros de controle do problema).

A Figura 96 ilustra as curvas de amplitudes pós-críticas ${ }^{2}$ como funções da amplitude do movimento prescrito ao topo (normalizado pelo comprimento indeformado do cilindro) e da frequência adimensional $n=\Omega / \omega_{n, 1}$. Além desses mapas, a amplitude pós-crítica é exibida na mesma figura como funções de $\epsilon_{k}$ e de $\Omega / \omega_{n, k}$, correspondendo à amplitude da excitação paramétrica nas equações modais de movimento (ver Equações 8.13, 8.14 e 8.15) e à relação entre a frequência do movimento imposto e a frequência natural do $k$-ésimo modo de vibrar.

As Figuras 96(a), 96(c) e 96(e) apresentam os mapas de amplitude pós-críticas como funções de $A_{t} / L_{0}$ e de $n=\Omega / \omega_{n, 1}$. Como a rigidez flexional do modelo em estudo é bastante baixa, a frequência natural varia linearmente com o número do modo e de acordo com a análise experimental conduzida no capítulo 7 , justificando a existência

2 Como mencionado anteriormente nesta seção, aqui a amplitude pós-crítica corresponde ao máximo valor da série temporal de amplitude modal obtido considerando $\tau>6000$. 
Figura 95 - Séries temporais de amplitude modal adimensional. $n=2,15, A_{t} / L_{0}=1 \%$.
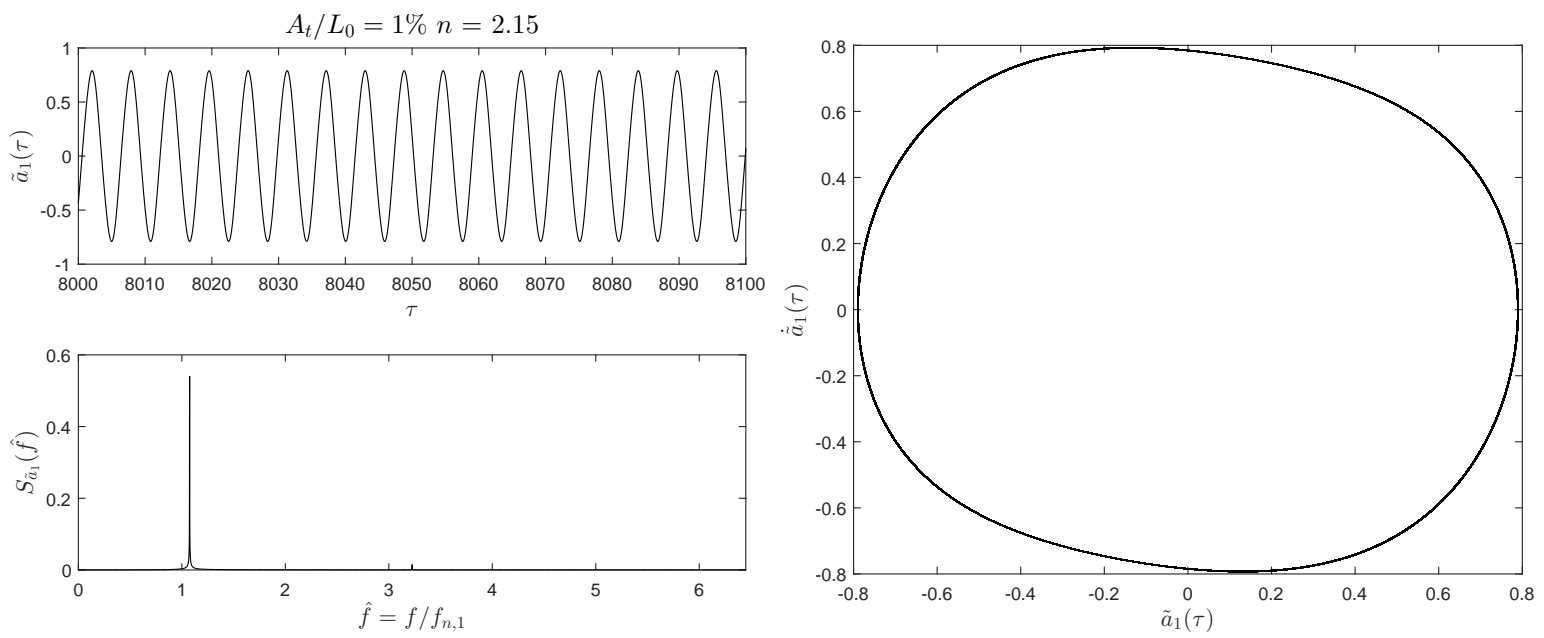

(a) $\tilde{a}_{1}(\tau)$ e espectro de amplitude.

(b) Seção transversal $\tilde{a}_{1}(\tau) \times \dot{\tilde{a}}_{1}(\tau)$ do espaço de fases.
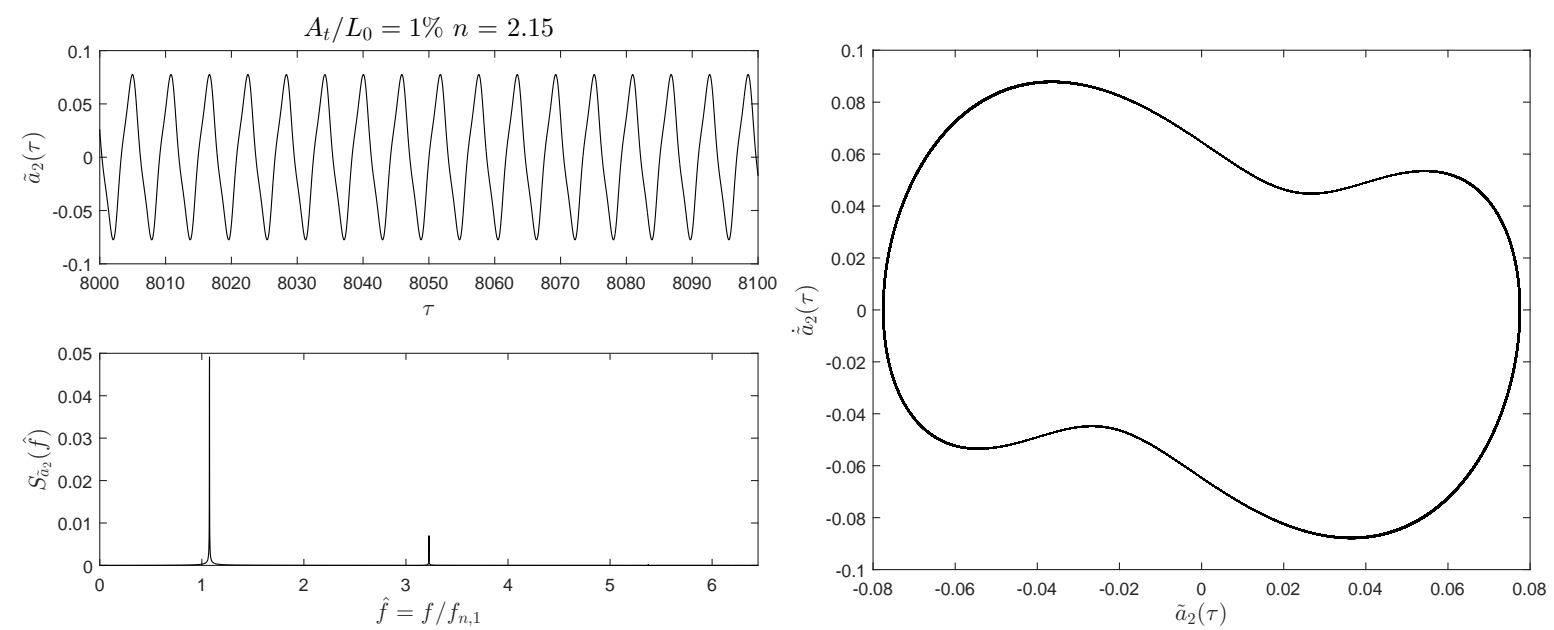

(d) Seção transversal $\tilde{a}_{2}(\tau) \times \dot{\tilde{a}}_{2}(\tau)$ do espaço (c) $\tilde{a}_{2}(\tau)$ e espectro de amplitude. de fases.
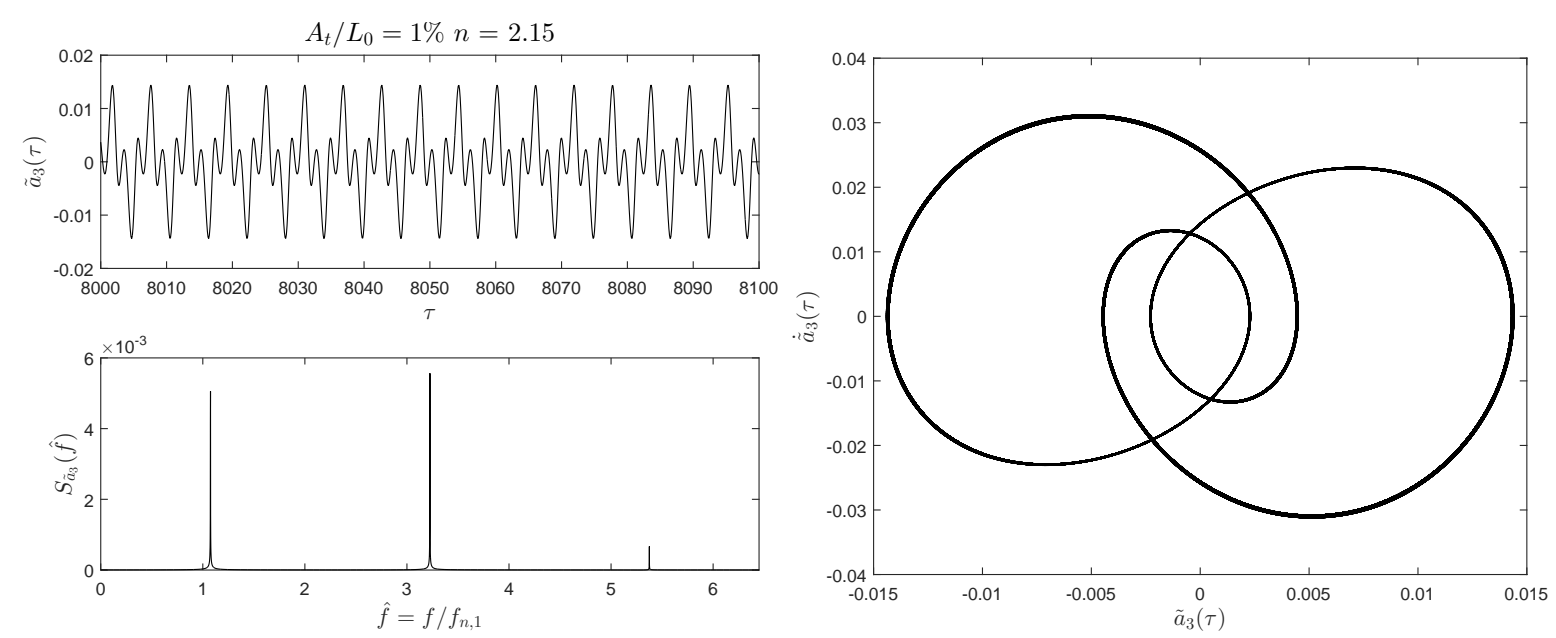

(e) $\tilde{a}_{3}(\tau)$ e espectro de amplitude.

(f) Seção transversal $\tilde{a}_{3}(\tau) \times \dot{\tilde{a}}_{3}(\tau)$ do espaço de fases.

Fonte: Adaptada de Franzini e Mazzilli (2016). 


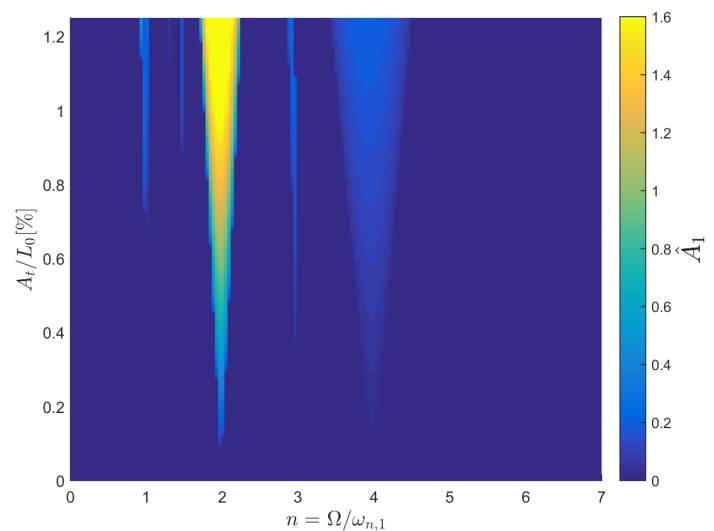

(a) $\hat{A}_{1}\left(A_{t} / L_{0}, n\right)$.

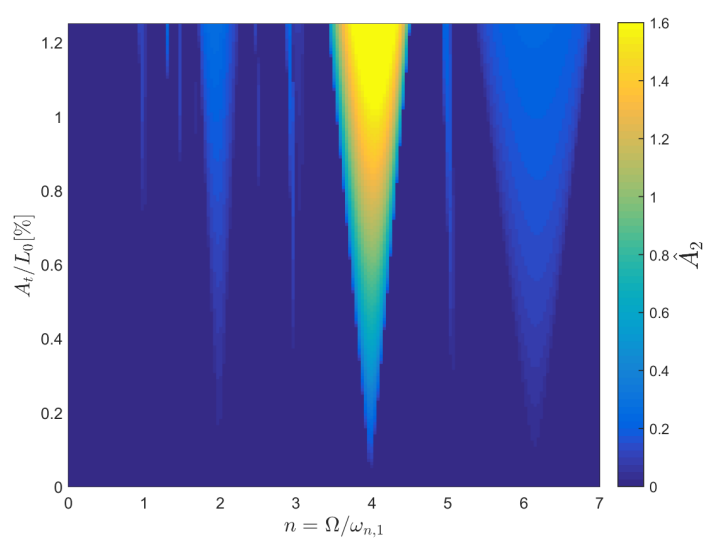

(c) $\hat{A}_{2}\left(A_{t} / L_{0}, n\right)$.

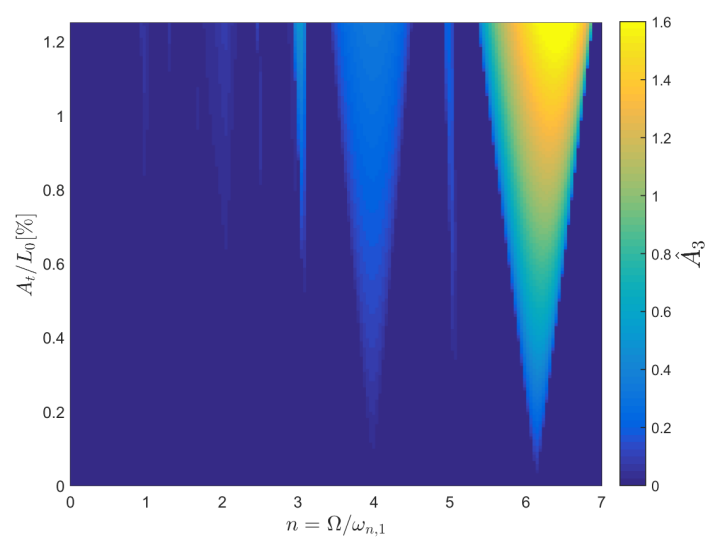

(e) $\hat{A}_{3}\left(A_{t} / L_{0}, n\right)$.

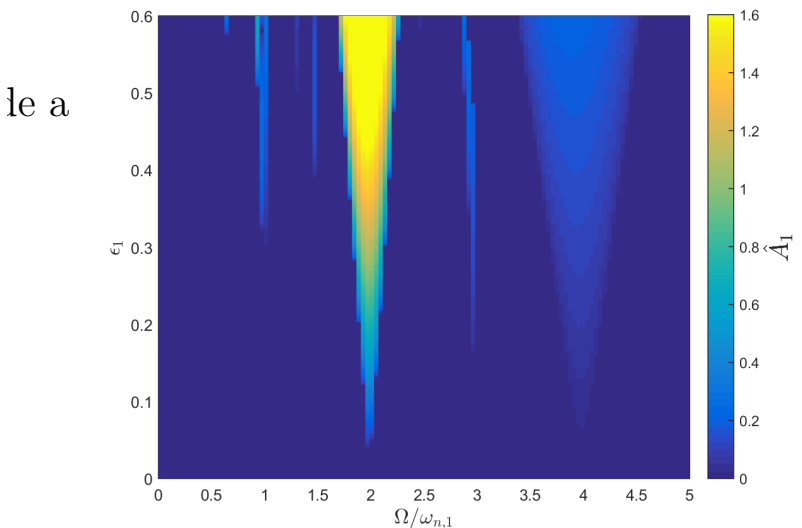

(b) $\hat{A}_{1}\left(\epsilon_{1}, n=\frac{\Omega}{\omega_{n, 1}}\right)$.

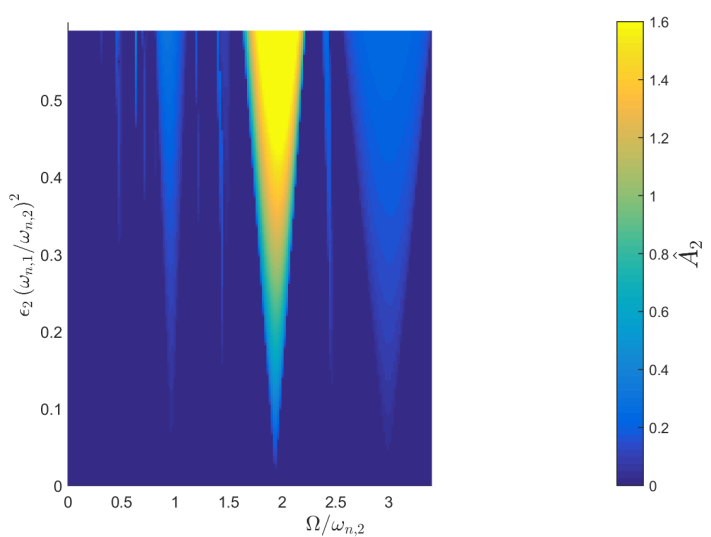

(d) $\hat{A}_{2}\left(\epsilon_{2}\left(\frac{\omega_{n, 1}}{\omega_{n, 2}}\right)^{2}, \frac{\Omega}{\omega_{n, 2}}\right)$.
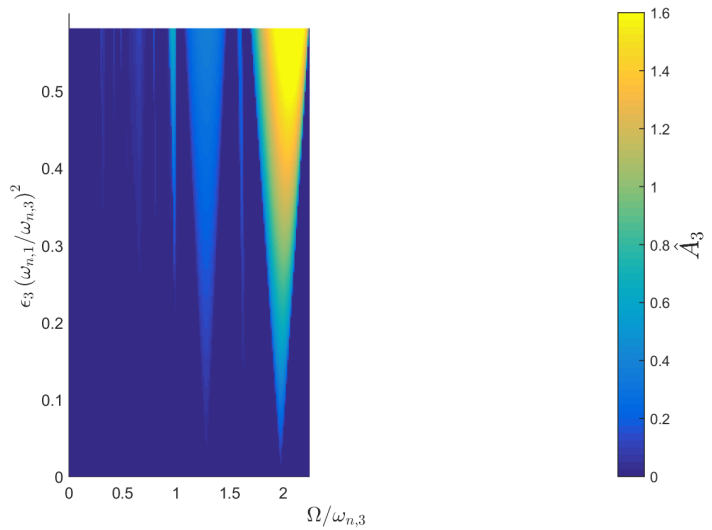

Fonte: Adaptada de Franzini e Mazzilli (2016). 
de regiões no plano de parâmetros de controle $\left(A_{t} / L_{0} ; \Omega / \omega_{n, 1}\right)$ originadas em valores de abscissas próximas ao dobro da frequência natural do modo em estudo e que possuem as maiores amplitudes características de oscilação. A existência de respostas limitadas mesmo na condição de instabilidade paramétrica principal está associada ao amortecimento hidrodinâmico não-linear, em concordância com as conclusões previamente apresentadas em Patel e Park (1991).

É claramente visível nas Figuras 96(a), 96(c) e 96(e) a existência de outras regiões de respostas em regime estacionário além daquela originada em uma frequência correspondente ao dobro de uma frequência natural. Nota-se, dentro da região de respostas apreciáveis, o aumento das respostas modais com o aumento do movimento imposto. Por fim, cumpre ressaltar que as Figuras 96(a), 96(c) e 96(e) não são representações do diagrama de Strutt, uma vez que esse diagrama define apenas o plano de parâmetros de controle da instabilidade paramétrica em regiões caracterizadas por soluções limitadas ou ilimitadas.

Os mapas de cores apresentados representam a compilação de uma série de resultados, sendo relevantes para análises qualitativas da resposta, embora aspectos quantitativos demandem informações por vezes inacessíveis por essa forma de apresentação de resultados. A Figura 97 mostra a variação do valor característico da série temporal de amplitude modal pós-crítica como função da amplitude da excitação paramétrica associada a cada modo e para uma frequência de excitação paramétrica igual ao dobro da frequência natural do modo considerado. Essa figura claramente revela que o crescimento de $\hat{A}_{k}$ é não linear com o valor de $\epsilon_{k}\left(\omega_{n, 1} / \omega_{n, k}\right)$.

Figura 97 - Valores característicos das séries temporais de amplitude modal como funções de $\epsilon_{k}\left(\omega_{1} / \omega_{n, k}\right)^{2}$ para $\Omega / \omega_{n, k}=2$.

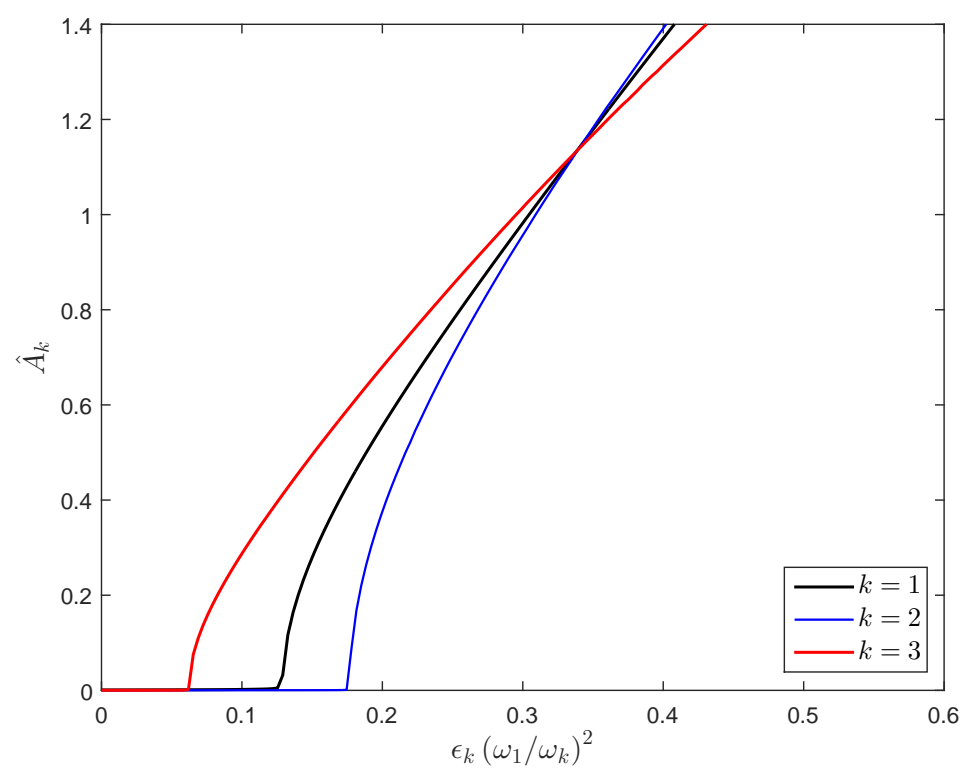

Fonte: Adaptada de Franzini e Mazzilli (2016).

Já a Figura 98 ilustra as curvas de resposta em frequência para um particular valor 
de amplitude de excitação paramétrica igual a $1 \%$ do valor do comprimento indeformado do cilindro. Embora alguma resposta modal de pequeno valor característico (tipicamente inferior a 0,4$)$ seja observada, as respostas mais significativas ocorrem em uma estreita banda ao redor de $\Omega / \omega_{n, k}=2$, ou seja, na instabilidade paramétrica principal com o correspondente modo de vibrar. Nota-se, ainda, que a banda de frequências na qual as maiores respostas são observadas não é distribuída de maneira simétrica com relação a $\Omega / \omega_{n, k}=2$.

Figura 98 - Curvas de resposta em frequência para $A_{t} / L_{0}=1 \%$.

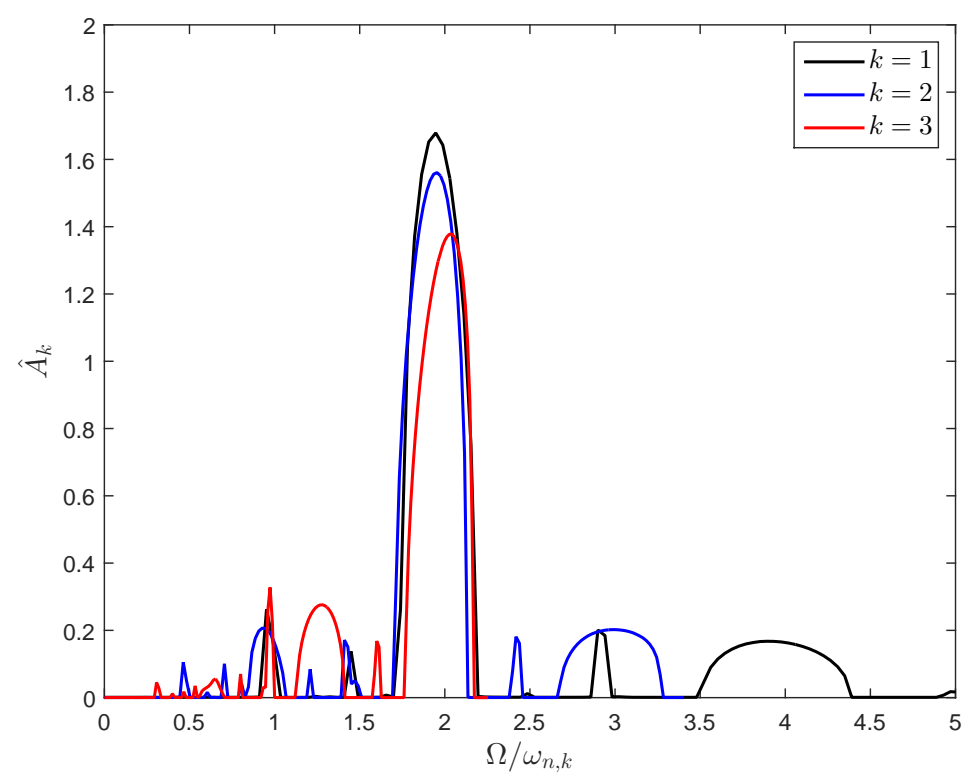

Fonte: Adaptada de Franzini e Mazzilli (2016).

\subsection{Contribuições à modelagem do fenômeno de VIV}

Esta seção tem como objetivo apresentar duas contribuições do autor acerca da modelagem matemática dos fenômenos de VIV em cilindros rígidos montados em apoio elástico e está dividida em duas subseções. A subseção 8.2.1 traz uma comparação entre os resultados numéricos obtidos a partir dos modelos de ordem reduzida propostos por Facchinetti, de Langre e Biolley (2004) e por Ogink e Metrikine (2010), ambos válidos para condição VIV-1gl. Já a subseção 8.2.2 apresenta a derivação de um modelo de ordem reduzida para a condição VIV-2gl.

\subsubsection{Comparação entre os modelos de ordem reduzida propostos por Facchi- netti, de Langre e Biolley (2004) e por Ogink e Metrikine (2010)}

A comparação entre os modelos de ordem reduzida é feita por meio da comparação com dados experimentais apresentados em Franzini et al. (2012a). Os principais parâmetros 
desses experimentos estão apresentados na Tabela 8. Já os modelos de ordem reduzida com abordagem via wake-oscillators foram simulados, em um primeiro momento, utilizando os seus coeficientes originais, já apresentados na Tabela 2.

Tabela 8 - Propriedades do arranjo experimental descrito em Franzini et al. (2012a).

\begin{tabular}{c|c}
\hline \hline Parâmetro & Valor \\
\hline \hline$m^{*}$ & 2,6 \\
$L / D$ & 15 \\
$\zeta_{y}$ & $7 \times 10^{-4}$ \\
$D$ & $44,45 \mathrm{~mm}$ \\
$f_{n, y}$ & $0,62 \mathrm{~Hz}$ \\
\hline \hline
\end{tabular}

Fonte: Adaptada de Franzini e Bunzel (2018).

As Equações 4.25 e 4.26 (modelo de Ogink e Metrikine (2010)) e 4.284 .29 (modelo de Facchinetti, de Langre e Biolley (2004)) foram numericamente integradas utilizando o método de Runge-Kutta implementado na função ode45 do MATLAB ${ }^{\circledR}$. Em ambos os modelos, o passo de tempo utilizado na integração numérica foi $\Delta \tau=0,001$ e as simulações duraram $\tau_{\max }=800$.

A Figura 99 apresenta as curvas de amplitude característica de oscilação obtidas experimentalmente e a partir das simulações numéricas. A análise dessa figura mostra que o modelo de Ogink e Metrikine (2010) apresenta notável aderência com os resultados experimentais. Essa aderência refere-se tanto à caracterização da máxima resposta ao VIV quanto com relação ao valor de velocidade reduzida no qual ele ocorre. Do ponto de vista de distinções entre os resultados experimentais e aqueles numericamente obtidos a partir da integração numérica do modelo proposto por Ogink e Metrikine (2010), podem ser apontadas a antecipação do início e do fim do lower branch nos resultados numéricos. O leitor nota, ainda, que as amplitudes características de oscilação no lower branch são similares.

Já a correlação experimental dos resultados obtidos a partir do modelo proposto em Facchinetti, de Langre e Biolley (2004) foi bastante insatisfatória. Embora o modelo tenha previsto de maneira bastante aderente a velocidade reduzida na qual o pico de resposta é observado, esse último valor é próximo a $\hat{A}_{y}=0,30$, significativamente abaixo da medida experimental. Note, ainda, que o modelo proposto por Facchinetti, de Langre e Biolley (2004) não permite identificar o lower branch.

Ogink e Metrikine (2010) já notaram que o modelo proposto por Facchinetti, de Langre e Biolley (2004) não se mostrou capaz de recuperar aspectos quantitativos da curva de resposta ao VIV. Cabe, neste ponto, indagar sobre qual as origens para os comportamentos tão distintos observados. Como visto na subseção 4.1.5, os modelos em 
Figura 99 - Comparação entre os modelos de ordem reduzida e dados experimentais.

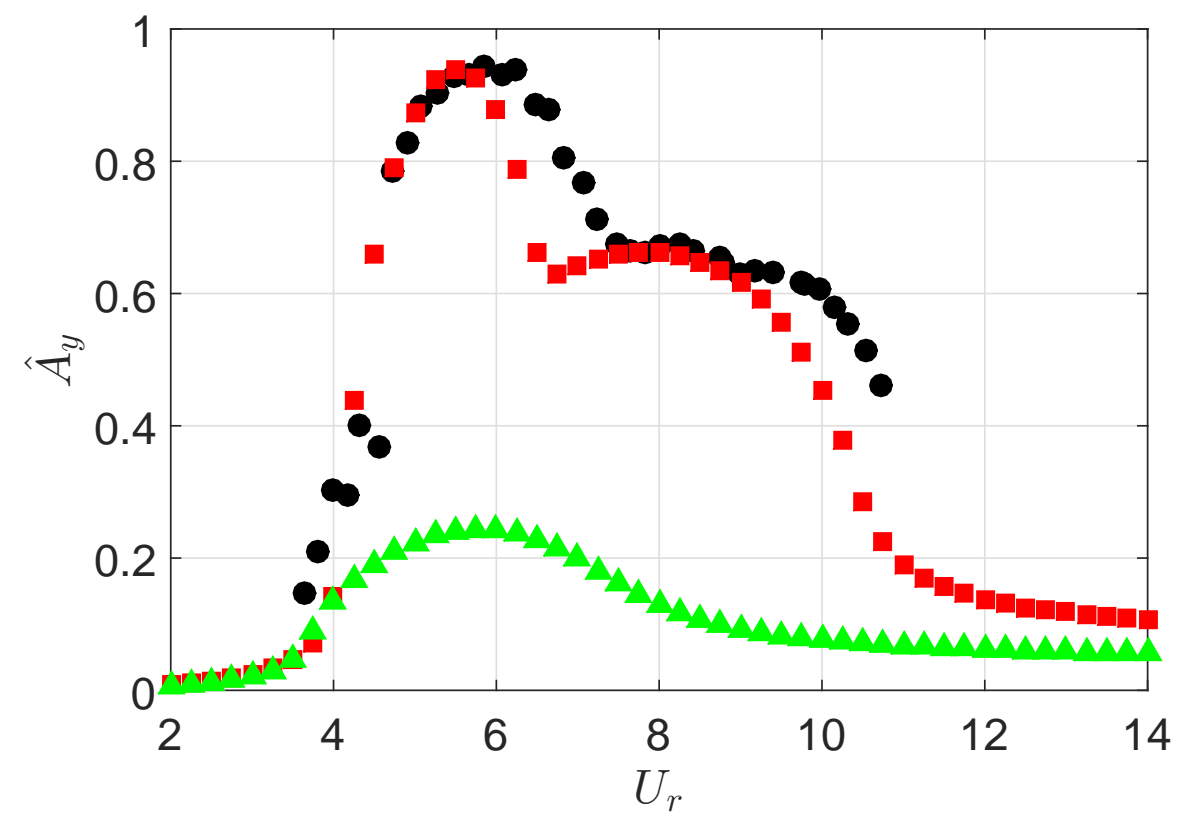

- Franzini et al. (2012)

- Ogink e Metrikine (2010) Facchinetti et al. (2004)

Fonte: Elaborada pelo autor.

tela apresentam duas diferenças, a saber, o uso de diferentes calibrações para os coeficientes $A_{y}$ e $\epsilon_{y}$ e a hipótese adotada por Facchinetti, de Langre e Biolley (2004) que torna unitário o termo $\sqrt{1+\left(\frac{2 \pi \dot{y}}{U_{r}}\right)^{2}}$ que aparece na Equação 11.20.

Visando investigar o efeito de calibração dos parâmetros $A_{y}$ e $\epsilon_{y}$, este texto nomeia como "Facchinetti et al. (2004) - mod" o modelo proposto por Facchinetti, de Langre e Biolley (2004) e dado pelas Equações 4.28 4.29, porém utilizando a mesma calibração proposta por Ogink e Metrikine (2010). A Figura 100 ilustra a comparação entre os modelos propostos por Ogink e Metrikine (2010), Facchinetti, de Langre e Biolley (2004) e o modelo de Facchinetti, de Langre e Biolley (2004) modificado.

Como mostra a Figura 100, uma justificativa para as baixas amplitudes características de oscilação obtidas a partir do modelo proposto por Facchinetti, de Langre e Biolley (2004) reside na calibração dos coeficientes $A_{y}$ e $\epsilon_{y}$. Dessa forma, a hipótese acerca da magnitude da velocidade de translação do cilindro face à velocidade do escoamento incidente mostrou ser válida para o caso em estudo.

Sob a ótica do estudo numérico por meio da integração numérica das equações de movimento, a presença do termo $\sqrt{1+\left(\frac{2 \pi \dot{y}}{U_{r}}\right)^{2}}$ não acarreta em dificuldades de implementação ou custo computacionais apreciáveis. No entanto, em um estudo de caráter analítico baseado no método das múltiplas escalas ou em uma abordagem via variedades invariantes com foco na obtenção dos modos não-lineares, esse termo pode trazer alguma complexidade de manipulação, de sorte que a modificação sobre o modelo de Facchinetti, 
Figura 100 - Comparação entre os modelos de ordem reduzida e dados experimentais.

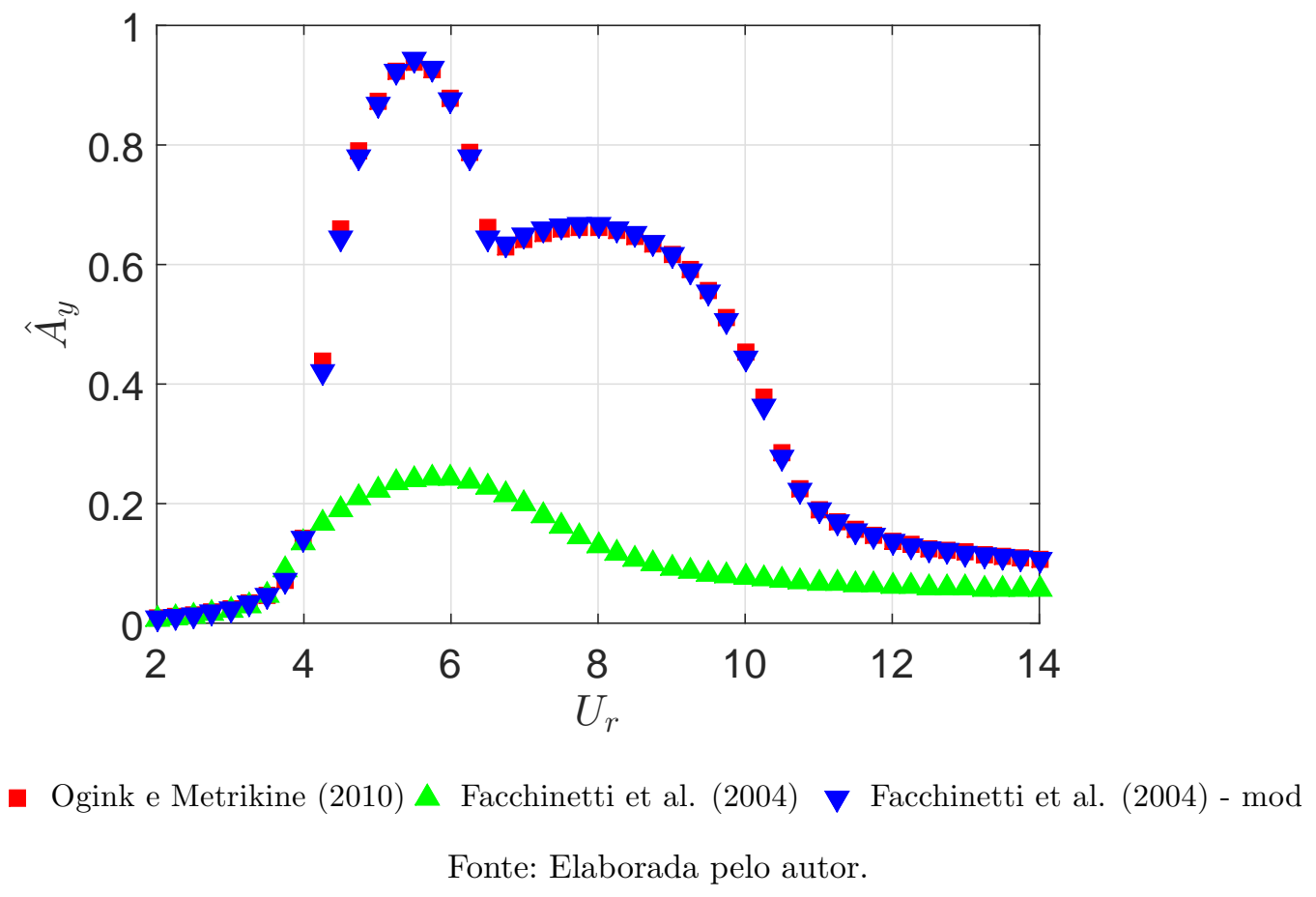

de Langre e Biolley (2004) aqui proposta pode ser interessante.

\subsubsection{Um novo modelo fenomenológico para VIV-2gI}

Cabe, no início desta subseção, uma discussão acerca do trabalho de Postnikov, Pavlovskaia e Wiercigroch (2017). Nesse artigo, os autores propõem um modelo de ordem reduzida para a condição VIV-2gl que, com uma abordagem ligeiramente distinta daquela aqui descrita, obtém as mesmas equações para o sistema hidro-elástico. A abordagem apresentada em Postnikov, Pavlovskaia e Wiercigroch (2017) descreve, de maneira vetorial as forças hidrodinâmicas decorrentes do fenômeno de VIV. Já a dedução apresentada no âmbito deste texto calcula explicitamente cada componente destes esforços.

Uma outra distinção é feita no tocante à calibração dos coeficientes do modelo. Enquanto Postnikov, Pavlovskaia e Wiercigroch (2017) empregam valores que não variam com a velocidade reduzida, aqui esses parâmetros são selecionados dependendo do ramo de resposta. Antes da dedução do modelo e da discussão de sua calibração, é importante ressaltar que esta formulação foi apresentada em Franzini e Bunzel (2018) ${ }^{3}$. Salienta-se, também, que o artigo Franzini e Bunzel (2018) foi submetido no final do mês de julho de 2017, enquanto que o trabalho Postnikov, Pavlovskaia e Wiercigroch (2017) foi publicado no mesmo mês. Essas datas indicam que o desenvolvimento do modelo de ordem reduzida que é objeto desta subseção foi feito de maneira praticamente concomitante pelos dois 
grupos de pesquisa.

Feita a contextualização temporal e a distinção com relação a um trabalho existente na literatura, parte-se para a dedução do equacionamento apresentado em Franzini e Bunzel (2018). A formulação aqui descrita adapta a metodologia desenvolvida em Facchinetti, de Langre e Biolley (2004) e posteriormente revisitada em Ogink e Metrikine (2010) para a condição VIV-2gl.

A Figura 101 ilustra o problema que é abordado nesta seção. O cilindro rígido tem massa $M$, diâmetro $D$, comprimento $L$ e está montado em um apoio elástico linear com liberdade de movimentação nas direções in-line e cross-wise (coordenadas generalizadas $X$ e $Y$ respectivamente). As restaurações nas direções in-line e cross-wise são, respectivamente, $k_{x}$ e $k_{y}$ enquanto que as constantes de amortecimento nessas mesmas direções valem $c_{x} \mathrm{e}$ $c_{y}$. Os deslocamentos $X$ e $Y$ são supostos tais que não excitem não-linearidades nas forças restauradoras.

Figura 101 - Representação esquemática - fenômeno de VIV com dois graus de liberdade para a estrutura.

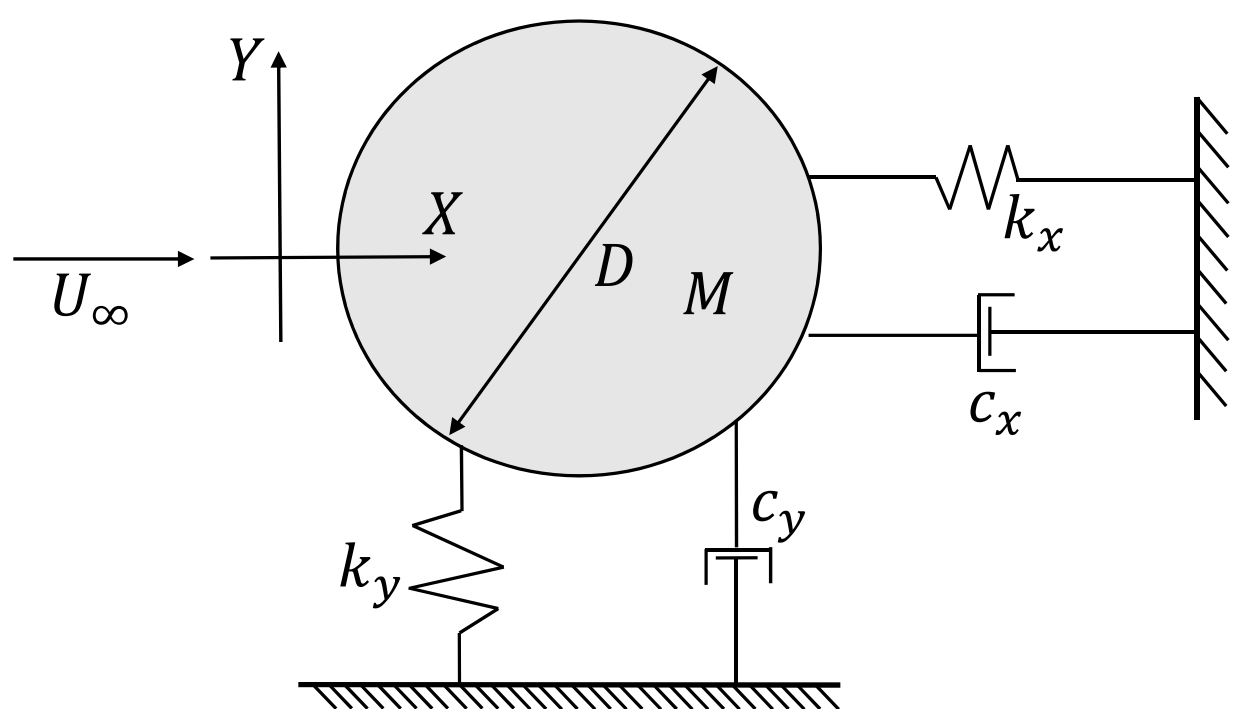

Fonte: Adaptada de Franzini e Bunzel (2018).

Os esforços hidrodinâmicos atuantes no cilindro são avaliados tomando como base a velocidade relativa entre o fluido e o corpo e assumindo que os coeficientes de força são aqueles observados em um cilindro fixo. O coeficiente de sustentação continua associado a uma variável $q_{y}$, proveniente da solução de uma equação de van der Pol.

Já o coeficiente de arrasto é composto de uma parcela média $\bar{C}_{D}^{0}$ somada a uma parcela oscilatória $C_{D}^{o s c}$ que, por sua vez, está associada a uma segunda variável advinda 
de uma equação de van der Pol $q_{x}$. O modelo matemático de quatro graus de liberdade (deslocamentos do cilindro $Y$ e $X$ e duas variáveis descritivas dos esforços hidrodinâmicos $q_{x}$ e $\left.q_{y}\right)$ é dado pelas Equações ${ }^{4}$ 8.19, 8.20, 8.21 e 8.22 .

$$
\begin{aligned}
& \left(M+m_{a}^{p o t}\right) \frac{d^{2} Y}{d t^{2}}+c_{y} \frac{d Y}{d t}+k_{y} Y=\frac{1}{2} \rho U_{\infty}^{2} D L C_{y, v} \\
& \frac{d^{2} q_{y}}{d t^{2}}+\epsilon_{y} \omega_{f}\left(q_{y}^{2}-1\right) \frac{d q_{y}}{d t}+\omega_{f}^{2} q_{y}=\frac{A_{y}}{D} \frac{d^{2} Y}{d t^{2}} \\
& \left(M+m_{a}^{p o t}\right) \frac{d^{2} X}{d t^{2}}+c_{x} \frac{d X}{d t}+k_{x} X=\frac{1}{2} \rho U_{\infty}^{2} D L C_{x, v} \\
& \frac{d^{2} q_{x}}{d t^{2}}+\epsilon_{x} \omega_{f}\left(q_{x}^{2}-1\right) \frac{d q_{x}}{d t}+\left(2 \omega_{f}\right)^{2} q_{x}=\frac{A_{x}}{D} \frac{d^{2} X}{d t^{2}}
\end{aligned}
$$

Note que a equação de van der Pol associada à variável $q_{x}$ e que tem relação com a parcela oscilatória do coeficiente de arrasto possui frequência natural linear $2 \omega_{f}$. Esse resultado busca emular o clássico comportamento observado em um cilindro fixo, no qual a frequência da parcela oscilatória da força de arrasto pulsa com o dobro da frequência de emissão de vórtices $\omega_{f}=2 \pi f_{f}$.

Adicionalmente às definições feitas na Equação 4.10 quando da apresentação dos modelos de ordem reduzida para a condição VIV-1gl, considere as seguintes quantidades:

$$
\omega_{n, x}=\sqrt{\frac{k_{x}}{M+m_{a}^{p o t}}}, \zeta_{x}=\frac{c_{x}}{2\left(M+m_{a}^{p o t}\right) \omega_{n, x}}, x=\frac{X}{D}, \quad f^{*}=\frac{\omega_{n, x}}{\omega_{n, y}}
$$

Note que $\omega_{n, x}$ corresponde à frequência natural na direção in-line considerando o cilindro imerso em água parada e que $f^{*}$ está relacionado à relação entre os coeficientes de rigidez nas direções in-line e cross-wise. Para o cálculo dos esforços hidrodinâmicos, considere a Figura 102.

Relembrando que $(\dot{)})$ indica a derivada com relação ao tempo adimensional $\tau=t \omega_{n, y}$, as seguintes relações são facilmente extraídas da Figura 102.

$$
\begin{aligned}
& U=\sqrt{\left(U_{\infty}-\frac{d X}{d t}\right)^{2}+\left(\frac{d Y}{d t}\right)^{2}}=U_{\infty} \sqrt{1-\frac{4 \pi}{U_{r}} \dot{x}+\left(\frac{2 \pi}{U_{r}}\right)^{2}\left(\dot{x}^{2}+\dot{y}^{2}\right)} \\
& \sin \beta=\frac{-\frac{d Y}{d t}}{U}=-\frac{2 \pi \dot{y}}{U_{r} \sqrt{1-\frac{4 \pi}{U_{r}} \dot{x}+\left(\frac{2 \pi}{U_{r}}\right)^{2}\left(\dot{x}^{2}+\dot{y}^{2}\right)}} \\
& \cos \beta=\frac{U_{\infty}-\frac{d X}{d t}}{U}=\frac{1-\frac{2 \pi}{U_{r}} \dot{x}}{\sqrt{1-\frac{4 \pi}{U_{r}} \dot{x}+\left(\frac{2 \pi}{U_{r}}\right)^{2}\left(\dot{x}^{2}+\dot{y}^{2}\right)}}
\end{aligned}
$$

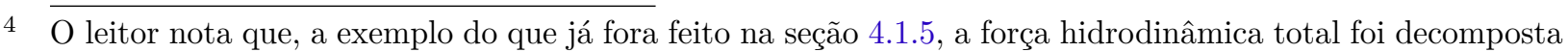
em um termo associado ao escoamento potencial e um termo viscoso associado à emissão de vórtices. Nas Equações 8.19 e 8.21, o termo decorrente do escoamento potencial já está incluso no lado esquerdo. 
Figura 102 - Representação esquemática das forças hidrodinâmicas atuando em um cilindro sujeito ao VIV-2gl.

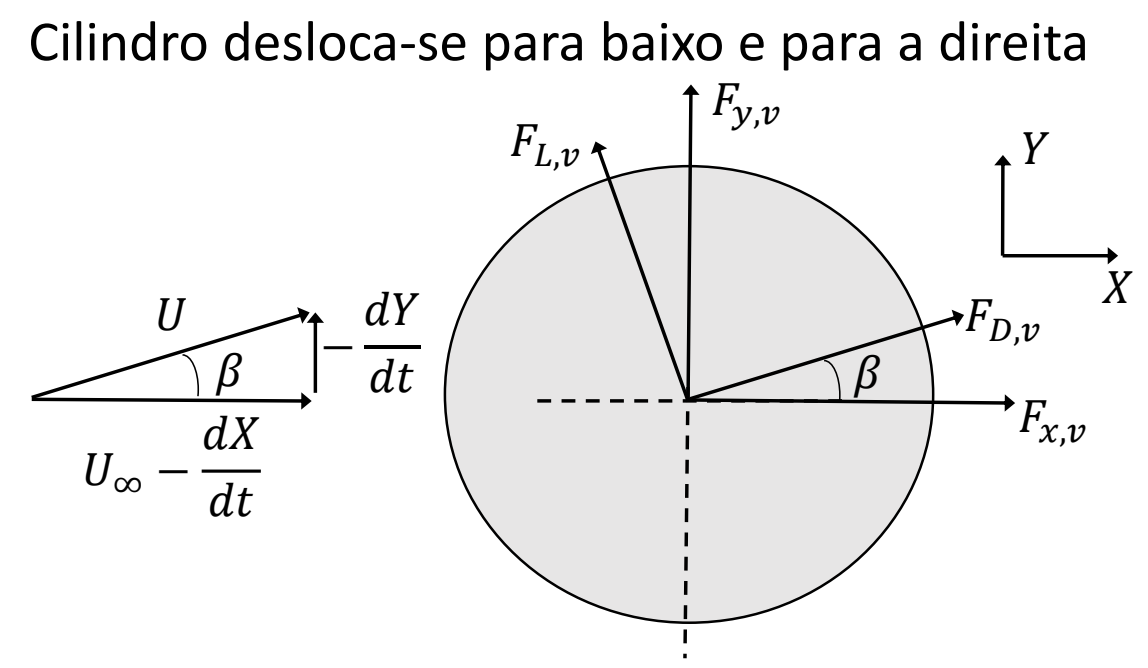

Fonte: Adaptado de Franzini e Bunzel (2018).

Segundo a metodologia aqui adotada, as forças de arrasto $F_{D, v}$ e de sustentação $F_{L, v}$ associadas à emissão de vórtices são baseadas na velocidade relativa entre fluido e o cilindro $U$. De posse desse resultado e procedendo a decomposição dessas forças nas direções in-line e cross-wise, as Equações 8.27, 8.28, 8.29 e 8.30 são obtidas.

$$
\begin{aligned}
& F_{D, v}=\frac{1}{2} \rho U^{2} D L C_{D, v} \\
& F_{L, v}=\frac{1}{2} \rho U^{2} D L C_{L, v} \\
& F_{y, v}=\frac{1}{2} \rho U_{\infty}^{2} D L C_{y, v}=F_{L, v} \cos \beta+F_{D, v} \sin \beta \\
& F_{x, v}=\frac{1}{2} \rho U_{\infty}^{2} D L C_{x, v}=-F_{L, v} \sin \beta+F_{D, v} \cos \beta
\end{aligned}
$$

A partir dos esforços hidrodinâmicas, os coeficientes de força nas direções in-line $C_{x, v}$ e cross-wise $C_{y, v}$ são escritos como:

$$
\begin{aligned}
C_{x, v} & =\left(\frac{U}{U_{\infty}}\right)^{2}\left(C_{D, v} \cos \beta-C_{L, v} \sin \beta\right) \\
C_{y, v} & =\left(\frac{U}{U_{\infty}}\right)^{2}\left(C_{D, v} \sin \beta+C_{L, v} \cos \beta\right)
\end{aligned}
$$

Cabe, agora, relacionar os coeficientes de arrasto e de sustentação associados à emissão de vórtices com as variáveis que representam a esteira vorticosa. Conforme mencionado no início desta seção, o coeficiente $C_{L, v}$ é análogo àquele já discutido na seção 
4.1.5. Já o coeficiente de arrasto $C_{D, v}$ é dado pela soma de um valor médio $\bar{C}_{D}^{0}$ somado a uma parcela oscilatória, esta sim associada a uma variável de esteira $q_{x}$. Matematicamente, essas relações são descritas pelas Equações 8.33 e 8.34 .

$$
\begin{aligned}
& C_{D, v}=\bar{C}_{D}^{0}+C_{D}^{o s c}=\bar{C}_{D}^{0}+\frac{q_{x}}{\hat{q}_{x}} \hat{C}_{D}^{0} \\
& C_{L, v}=\frac{q_{y}}{\hat{q}_{y}} \hat{C}_{L}^{0}
\end{aligned}
$$

onde $\hat{C}_{D}^{0}$ é a amplitude de oscilação da força de arrasto observada em um cilindro fixo.

O modelo matemático final é obtido substituindo-se as Equações 8.24, 8.25, 8.26, 8.31, 8.32, 8.33 e 8.34 nas equações de movimento do cilindro 8.19 e 8.21. Tais substituições levam ao modelo matemático adimensional dado pelas Equações 8.35, 8.36, 8.37 e 8.38.

$$
\begin{aligned}
& \ddot{y}+2 \zeta_{y} \dot{y}+y=\frac{1}{2 \pi^{3}} \frac{U_{r}^{2}}{\left(m^{*}+C_{a}\right)} C_{y, v} \\
& \ddot{q}_{y}+\epsilon_{y} S t U_{r}\left(q_{y}^{2}-1\right) \dot{q}_{y}+\left(S t U_{r}\right)^{2} q_{y}=A_{y} \ddot{y} \\
& \ddot{x}+2 \zeta_{x} f^{*} \dot{x}+\left(f^{*}\right)^{2} x=\frac{1}{2 \pi^{3}} \frac{U_{r}^{2}}{\left(m^{*}+C_{a}\right)} C_{x, v} \\
& \ddot{q}_{x}+\epsilon_{x} S t U_{r}\left(q_{x}^{2}-1\right) \dot{q}_{x}+\left(2 S t U_{r}\right)^{2} q_{x}=A_{x} \ddot{x}
\end{aligned}
$$

Uma vez obtido o sistema de equações diferenciais que governa a dinâmica do sistema hidro-elástico, é necessária a calibração os coeficientes $\epsilon_{x}, \epsilon_{y}, A_{x}$ e $A_{y}$. Seguindo a ideia de Ogink e Metrikine (2010), dois conjuntos de calibração são propostos, sendo um para o super upper branch e outro para o lower branch. Para a condição VIV-2gl, a transição entre os ramos de resposta mencionados foi selecionada como ocorrendo em $U_{r}=8$.

Como em Ogink e Metrikine (2010), os valores do coeficiente de arrasto médio e da amplitude do coeficiente de sustentação, ambos obtidos para o problema do escoamento ao redor de um cilindro, valem $\bar{C}_{D}^{0}=1,1856$ e $\hat{C}_{L}^{0}=0,3842$. Como visto na subseção 4.1.3, a presença de oscilações na direção in-line desloca o valor de velocidade reduzida no qual a máxima amplitude de oscilação é obtida para $U_{r} \approx 8$. No modelo de ordem reduzida aqui desenvolvido, esse deslocamento no valor da velocidade reduzida é refletido em uma diminuição do número de Strouhal para $S t=0,17$. O leitor relembra, neste ponto, de que a movimentação do cilindro afeta a esteira vorticosa, de sorte que é esperada alguma mudança nos adimensionais que definem o escoamento.

Os resultados numéricos são comparados com aqueles da campanha experimental descrita em Franzini et al. (2012a) para a condição VIV-2gl e cujos dados são encontrados ${ }^{5}$

5 Cumpre ressaltar que o artigo Franzini et al. (2012a) traz resultados experimentais para as condições VIV-1gl e VIV-2gl. 
na Tabela 8. Em um primeiro momento, discutem-se os parâmetros selecionados para o intervalo $U_{r}<8$. Utilizando $\epsilon_{y}=0,0045 e^{0,228 m^{*}}$ e $\epsilon_{x}=0,6$, os mesmos valores adotados por Srinil e Zanganeh (2012) para todos os valores de velocidade reduzida, resta o estudo da influência dos parâmetros $A_{x}$ e $A_{y}$. Já para $U_{r} \geq 8$, foram simuladas combinações dos parâmetros $\epsilon_{x}, \epsilon_{y}, A_{x}$ e $A_{y}$. A Tabela 9 traz o conjunto de simulações conduzidas como forma de definição dos parâmetros do modelo de ordem reduzida aqui obtido.

Tabela 9 - Estudo de sensibilidade do modelo desenvolvimento com relação aos parâmetros de calibração,

\begin{tabular}{c|cc|cccc}
\hline \hline \multirow{2}{*}{ Simulação } & \multicolumn{3}{|c}{$U_{r}<8$} & \multicolumn{4}{c}{$U_{r} \geq 8$} \\
\cline { 2 - 7 } & $A_{x}$ & $A_{y}$ & $\epsilon_{x}$ & $\epsilon_{y}$ & $A_{x}$ & $A_{y}$ \\
\hline \hline Sim1 & 12 & 2 & 0,7 & 0,7 & 12 & 12 \\
\hline Sim2 & 8 & 2 & 0,7 & 0,7 & 12 & 12 \\
\hline Sim3 & 14 & 2 & 0,7 & 0,7 & 12 & 12 \\
\hline Sim4 & 12 & 4 & 0,7 & 0,7 & 12 & 12 \\
\hline Sim5 & 12 & 2 & 0,5 & 0,5 & 12 & 12 \\
\hline Sim6 & 12 & 2 & 0,9 & 0,9 & 12 & 12 \\
\hline Sim7 & 12 & 2 & 0,7 & 0,7 & 10 & 10 \\
\hline Sim8 & 12 & 2 & 0,7 & 0,7 & 14 & 14 \\
\hline \hline
\end{tabular}

Fonte: Adaptada de Franzini e Bunzel (2018).

A Figura 103 apresenta as curvas $\hat{A}_{y}\left(U_{r}\right)$ e $\hat{A}_{x}\left(U_{r}\right)$ obtidas a partir das simulações descritas na Tabela 9. Para $U_{r}<8$ (grupo estudado nas simulações Sim1, Sim2, Sim3 e Sim4), a Figura 103 mostra uma notável aderência entre os resultados obtidos considerando as simulações Sim1, Sim2 e Sim3. Tal fato mostra que, para $U_{r}<8$, mudanças no parâmetro $A_{x}$ não promovem mudanças significativas na curva de resposta. Por outro lado, a simulação Sim4, conduzida considerando $A_{y}=4$, é aquela onde as respostas nas direções cross-wise e in-line são mais amplificadas.

Dando continuidade ao estudo de sensibilidade, considere agora a calibração para $U_{r} \geq 8$ e que está associada às simulações Sim1, Sim5, Sim6, Sim7 e Sim8. Visando diminuir o número de possibilidades de calibração, este texto adota $\epsilon_{x}=\epsilon_{y}$ e $A_{y}=A_{x}$. Cumpre ressaltar que a simulação Sim1 adota, para o lower branch observado na condição VIV-2gl, os mesmos valores propostos por Ogink e Metrikine (2010) para o caso VIV-1gl.

Na Figura 103, os parâmetros definidos na Sim1 levam a resultados com notável aderência com os dados experimentais até o início da dessincronização ocorrido em $U_{r} \approx 10$. Na simulação Sim7, caracterizada por um decréscimo nos valores de $A_{y}=A_{x}$ para 10 , a dessincronização é bem representada. No entanto, como os experimentos não foram conduzidos até um decréscimo total da curva de amplitude de resposta, por questão de segurança, adota-se como modelo mais representativo aquele definido pela simulação Sim1, embora as simulações Sim5, Sim6 e Sim7 também ofereçam resultados bastante aderentes 
Figura 103 - Estudo de sensibilidade da resposta do modelo obtido com relação aos parâmetros de calibração. Condição VIV-2gl.

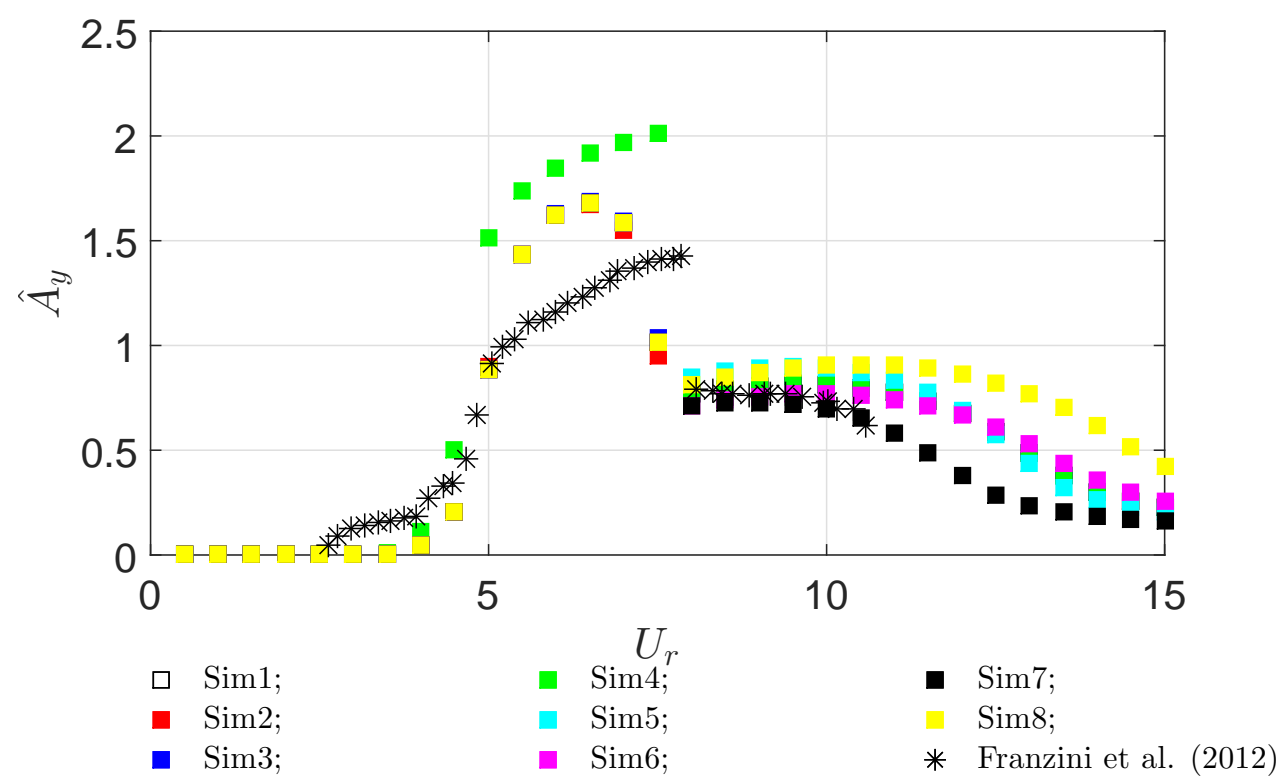

(a) $\hat{A}_{y}\left(U_{r}\right)$.

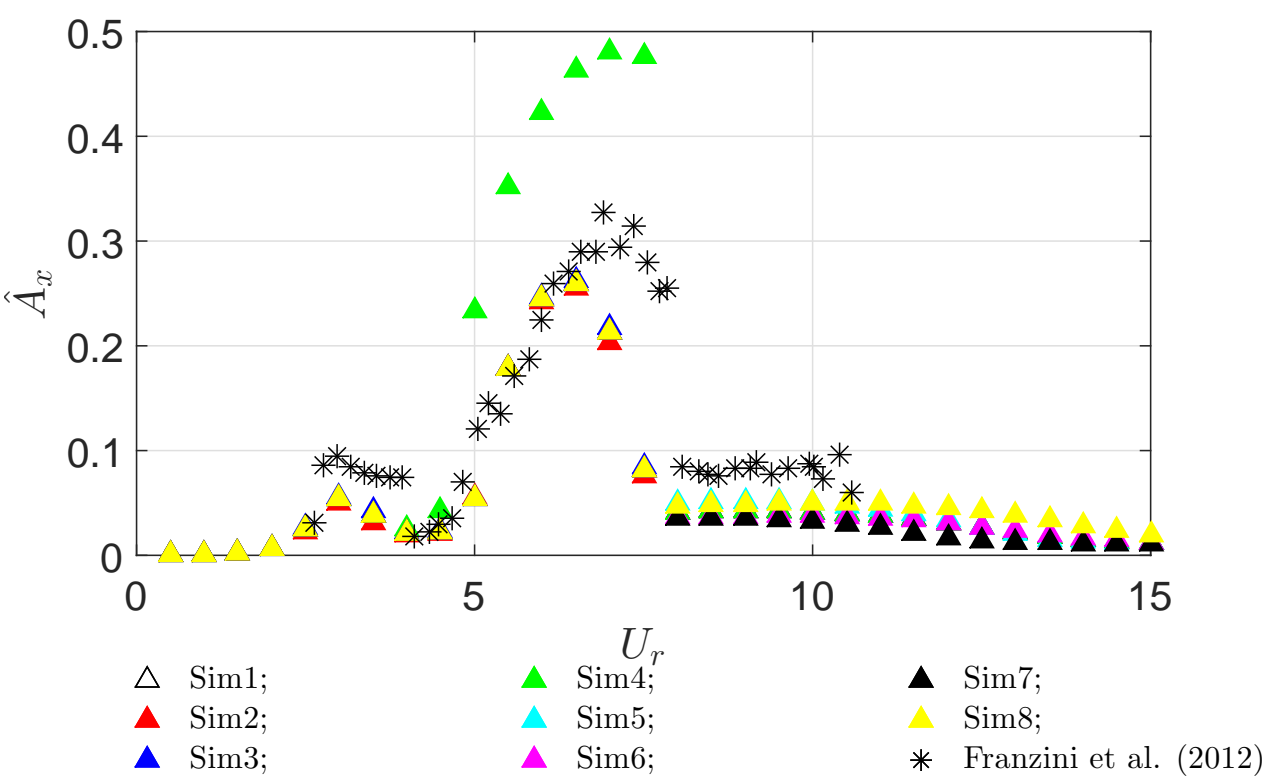

(b) $\hat{A}_{x}\left(U_{r}\right)$.

Fonte: Adaptada de Franzini e Bunzel (2018).

aos experimentais. Outra razão para a escolha de parâmetros Sim1 é que os coeficientes obtidos para o lower branch são aderentes com aqueles da condição VIV-1gl.

A discussão acima mostrou que mudanças nos parâmetros $\epsilon_{x}=\epsilon_{y}$ não acarretam em mudanças significativas na curva de amplitude característica de oscilação. Já o aumento de $A_{x}=A_{y}$ para 14 (Sim8) levou a um alargamento da faixa de velocidades reduzidas nas quais $\hat{A}_{y}>0,50$. Os resultados das simulações Sim7 e Sim8 indicam que a largura do 
lower branch pode ser alterada por meio da variação de $A_{x}=A_{y}$.

Como o leitor pôde aqui notar, a calibração considerou apenas um valor do parâmetro de massa-amortecimento e um particular intervalo de número de Reynolds. Como será visto na seção subsequente, o autor do texto pretende inserir esforços na melhoria do procedimento de calibração dos coeficientes dos wake-oscillators, incluindo a dependência desses com outros parâmetros característicos do VIV.

\subsection{Considerações finais do capítulo e perspectivas de continuidade da pesquisa}

Este capítulo apresentou as contribuições do autor no tema de modelagem matemática e simulação do problema de excitação paramétrica em um cilindro flexível, vertical submerso e do fenômeno de VIV em cilindros rígidos montados em apoios elásticos.

Iniciando as considerações finais pelas contribuições relacionadas à excitação paramétrica, um modelo matemático foi obtido a partir de uma equação de movimento não-linear de uma viga bi-apoiada submetida à movimento vertical harmônico imposto ao seu apoio superior. Essas não-linearidades decorrem da consideração da extensibilidade da estrutura e também do amortecimento hidrodinâmico e quadrático na velocidade.

O foco principal da investigação descrita na seção 8.1 foi para uma condição onde a frequência do movimento imposto ao topo era próxima a duas vezes a primeira frequência natural, correspondendo à instabilidade paramétrica principal com o primeiro modo, de sorte que esse deve ser o modo predominante na resposta. Dessa forma, um modelo de ordem reduzida com um pequeno número de modos é aceitável como ferramenta de análise do problema.

A partir da equação de movimento da estrutura como meio contínuo, um modelo de ordem reduzida de três graus de liberdade foi obtido a partir do uso conjunto da separação de variáveis e da posterior aplicação do método de Galerkin. Esse procedimento gerou um sistema de três equações diferenciais ordinárias não-lineares e que possui como incógnitas as amplitudes modais ${ }^{6}$.

A integração numérica do modelo matemático não-linear e com três graus de liberdade mostrou algum acoplamento entre as séries temporais de amplitude modal. Embora não tenha sido verificada grande influência da consideração de um número maior de modos na resposta do modo parametricamente excitado, algumas diferenças no tocante ao conteúdo espectral foram apontadas.

Mapas de amplitude pós-crítica também foram construídos. Esses mapas mostram

6 O leitor é relembrado que, embora este texto use a terminologia série temporal de amplitude modal, a função de interpolação usada no método de Galerkin não corresponde aos modos de vibrar. 
qual o valor característico das séries temporais de amplitude modal como funções da amplitude e e da frequência da excitação paramétrica (e suas contrapartes adimensionais). Como esperado, uma região nesse plano de parâmetros de controle originada próximo à frequência de excitação paramétrica correspondente ao dobro da frequência natural não amortecida do $k$-ésimo modo de vibrar é aquela que apresenta as amplitudes características de oscilação mais significativas. Em virtude dos acoplamentos decorrentes das não-linearidades, os mapas de amplitude pós-crítica são dotadas de outras regiões de resposta não nulas, porém bastante inferiores àquelas associadas à região principal.

Cumpre ressaltar que esses mapas não devem ser confundidos com extensões do diagrama de Strutt, uma vez que enquanto os últimos delimitam o plano de parâmetros de controle em regiões de solução limitada ou ilimitada. Os mapas de amplitude pós-crítica apresentam valores característicos de séries temporais de amplitude modal limitadas, mesmo onde o diagrama de Strutt prevê soluções ilimitadas. Essa limitação das amplitudes é decorrente das não-linearidades existentes no modelo matemático, em particular do amortecimento hidrodinâmico quadrático na velocidade, em concordância com o trabalho de Patel e Park (1991).

Como forma de continuidade da pesquisa no problema de excitação paramétrica de um cilindro flexível vertical, é importante apontar para o estudo de sensibilidade da resposta com relação à função de projeção adotada no método de Galerkin. Um primeiro fruto científico desse estudo está publicada na forma do artigo Vernizzi, Franzini e Lenci (2019), que aborda o problema estudado na seção 8.1 por meio do uso de funções "quaseBessel" no método de Galerkin. Esse último artigo foi escrito pelo doutorando Guilherme Jorge Vernizzi Lopes, orientando do autor deste texto e em co-autoria com o Prof. Stefano Lenci $^{7}$, da Università Politecnica delle Marche, Itália. Uma versão mais completa desse trabalho está sendo preparada para submissão em periódico indexado.

No tocante à continuidade das pesquisas relacionadas à modelagem matemática do fenômeno de VIV, algumas atividades estão em curso por ocasião da redação deste texto. A primeira iniciativa envolve a obtenção dos modos não-lineares de vibração do sistema hidro-elástico associado à condição VIV-1gl. Nessa iniciativa e partindo do modelo de ordem reduzida proposto em Ogink e Metrikine (2010) e posteriormente utilizando o método de obtenção das variedades invariantes descrito em Shaw e Pierre (1993), o trabalho de Vernizzi e Franzini (2019) traz os osciladores modais relativos ao problema. Por meio da integração numérica dos osciladores modais e da regeneração das coordenadas físicas originais (a saber, o deslocamento do cilindro e a variável descritiva da esteira), os autores discutem os resultados obtidos com aqueles oriundos da integração numérica do modelo proposto em Ogink e Metrikine (2010). A pesquisa iniciada em Vernizzi e Franzini

7 O Prof. Lenci será supervisor do doutorando Guilherme Vernizzi durante seu período de doutoradosanduíche. 
(2019) terá continuidade por ocasião do intercâmbio do doutorando Guilherme Vernizzi junto ao grupo do Prof. Lenci.

Uma outra atividade de modelagem matemática referente ao fenômeno de VIV diz respeito à procura por novas formas de calibração dos wake-oscillators. Essa atividade já está em curso em uma parceria com a Profa. Victoria Kurushina, da Industrial University of Tyumen, Russia. A Profa. Kurushina empregou durante seu doutorado uma série de procedimentos de otimização visando a calibração dos coeficientes empíricos de alguns modelos de ordem reduzida. A pesquisa em colaboração com o autor deste texto já resultou no artigo apresentado em conferência internacional Kurushina et al. (2019). Nesse primeiro artigo, o conjunto de coeficientes empíricos é válido para toda a faixa de velocidades reduzidas, embora discussões recentes tenham indicado um caminho para a proposição de dois conjuntos de coeficientes, um válido para o upper branch e outro para o lower branch, segundo a sugestão de Ogink e Metrikine (2010) e os resultados obtidos no âmbito do presente texto de síntese.

Ainda discutindo formas de melhoria na calibração dos wake-oscillators, técnicas heurísticas como, por exemplo, o algoritmo genético podem ser aplicadas a partir dos modelos matemáticos e de resultados experimentais. Tendo em vista os diversos grupos da EPUSP atuantes no tema com foco na análise experimental, as novas metodologias de calibração podem envolver não somente as curvas de amplitude de oscilação (encontradas com certa facilidade na literatura) mas também as séries temporais de deslocamento e de força. Em particular, a diferença de fase entre as séries temporais de força e de deslocamento pode ser empregada como forma de definir a transição upper branch $\leftrightarrow$ lower branch, como demonstram as evidências experimentais apresentadas em Khalak e Williamson (1999).

Também é importante considerar nos procedimentos de calibração dos wakeoscillators outros parâmetros que governam o fenômeno de VIV como, por exemplo, o parâmetro de massa reduzida $m^{*}$, a velocidade reduzida, a relação entre os valores de rigidez nas direções in-line e cross-wise e o número de Reynolds. Enquanto o primeiro desses parâmetros governa aspectos qualitativos da curva de resposta, o número de Reynolds mostrou ser de grande importância quando o regime de escoamento é caracterizado pela transição para turbulência nas camadas cisalhantes; ver discussão na subseção 4.1.2. Aqui, novos experimentos devem ser conduzidos, em particular para atingir números de Reynolds $R e \approx 10^{5}$.

Uma última atividade de pesquisa em curso e que dá continuidade aos estudos descritos no âmbito deste capítulo versa sobre o uso de wake-oscillators como forma de representar o problema de solicitação combinada de VIV e de excitação paramétrica. Esse é o tema da dissertação de mestrado do aluno Michel Freitas, orientado pelo autor deste texto. Em sua pesquisa, o mestrando fará uso dos modelos de ordem reduzida propostos em Ogink 
e Metrikine (2010) (VIV-1gl) e aquele descrito na subseção 8.2.2 (VIV-2gl) devidamente adaptados para incluir a variação temporal da rigidez. Por meio de simulações numéricas e correlações com os resultados experimentais apresentados na subseção 7.3.2, o mestrando poderá inferir acerca da representatividade dos wake-oscillators para a modelagem do problema de solicitação combinada e para a qual os modelos de ordem reduzida não foram calibrados ${ }^{8}$.

Cumpre aqui ressaltar que o estudo experimental dos efeitos concomitantes de excitação paramétrica e do fenômeno de VIV em cilindros rígidos montados em base elástica não é uma tarefa trivial. Para tanto, é necessário um sistema de controle em malha fechada de sorte a acrescer uma força que atua no cilindro e que seja, a cada instante de tempo, linearmente proporcional ao seu deslocamento. A variação temporal da constante de proporcionalidade é o termo que induziria experimentalmente a excitação paramétrica. Assim, além da concepção desse sistema, seria necessária toda a implementação de uma lei de controle com inúmeros testes de validação do sistema.

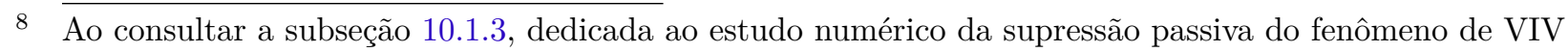
por meio de um NVA rotativo, o leitor nota que as séries temporais de deslocamento do cilindro obtidas por meio dos wake-oscillators podem guardar notáveis semelhanças com aquelas obtidas a partir de um modelo de maior hierarquia, mesmo para uma condição distinta daquela de calibração. 


\section{Supressão passiva de excitação paramétrica}

Como mostrado na seção 5.3, a supressão passiva de vibrações decorrentes da excitação paramétrica constitui uma lacuna de conhecimento. Este capítulo é baseado no trabalho ${ }^{1}$ Franzini, Campedelli e Mazzilli (2018) e foi originado do Auxílio à Pesquisa Regular apoiado pela FAPESP e já mencionado na seção 2.2.

Este capítulo está organizado em cinco seções. A seção 9.1 apresenta o problema a ser estudado e o correspondente modelo matemático. Seguindo, a seção 9.1 é dedicada à apresentação das metodologias de solução numérica e de análise de resultados. A discussão dos resultados é objeto da seção 9.3. Um estudo analítico baseado em um método de perturbação é conduzido na seção 9.4 e, por fim, a seção 9.5 traz as considerações finais do capítulo juntamente com perspectivas de continuidade das pesquisas no tema.

\subsection{Modelagem matemática do problema de supressão passiva}

A Figura 104 ilustra o problema de supressão investigado neste capítulo. O cilindro rígido possui massa por unidade de comprimento $M$ e está montado em um apoio elástico de rigidez $k(t)=\bar{k}+\Delta k \sin \Omega t$ e constante de amortecimento $c$, ambos por unidade de comprimento. Esse cilindro tem liberdade de oscilação na direção indicada pela coordenada generalizada $Y$. Um NVA rotativo de raio $r$, massa e constante de amortecimento linear por unidade de comprimento $m$ e $c_{\theta}$ respectivamente é acoplado ao cilindro. A aceleração gravitacional é perpendicular ao plano onde os movimentos são desenvolvidos, de sorte que não há variação da energia potencial gravitacional.

Por questão de conveniência, as equações de movimento do problema são obtidas por meio das equações de Euler-Lagrange. As coordenadas generalizadas empregadas para a descrição do sistema mecânico são o deslocamento do cilindro $Y$ e a posição angular do supressor $\theta$.

Sendo $O$ o ponto do cilindro no qual o NVA está acoplado, e $(\mathbf{m}-\mathbf{O})$ o vetor que define a posição da extremidade livre da barra, a velocidade da massa $m$ é dada por:

$$
\mathbf{v}_{\mathbf{m}}=\mathbf{v}_{\mathbf{O}}+\frac{d \theta}{d t} \mathbf{k} \times(\mathbf{m}-\mathbf{O})=\left(\frac{d Y}{d t}-\frac{d \theta}{d t} r \sin \theta\right) \mathbf{j}-\frac{d \theta}{d t} r \cos \theta \mathbf{i}
$$

1 A aluna Giovanna Ribeiro Campedelli desenvolveu sua IC no problema abordado neste capítulo e sob orientação do autor deste texto. 
Figura 104 - Representação esquemática do problema. Cilindro rígido sujeito à excitação paramétrica dotado de um NVA rotativo. O versor i é horizontal e orientado da esquerda para a direita.

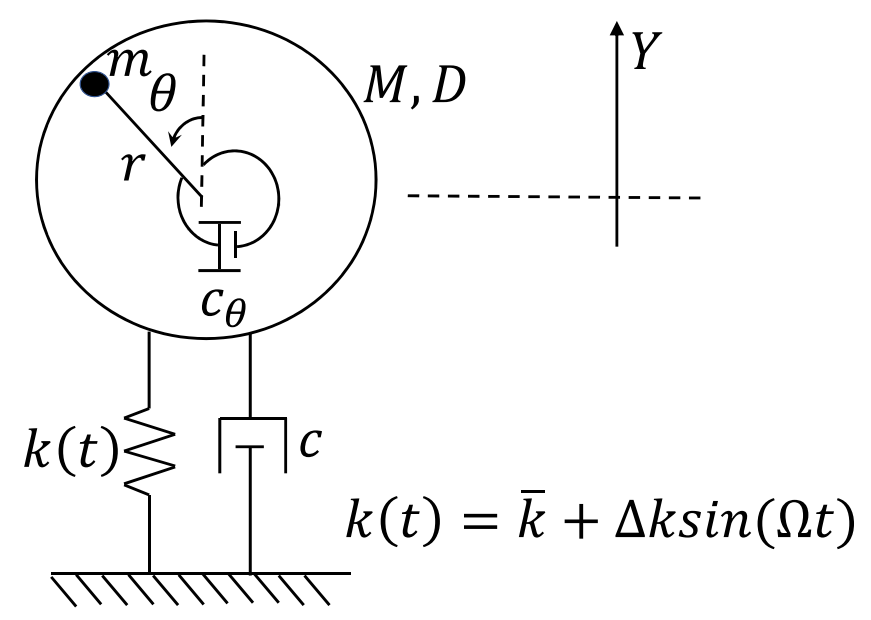

Fonte: Elaborada pelo autor.

A energia cinética do sistema é escrita na forma da Equação 9.2.

$$
T=\frac{1}{2} m \mathbf{v}_{\mathbf{m}} \cdot \mathbf{v}_{\mathbf{m}}+\frac{1}{2} M \mathbf{v}_{\mathbf{O}} \cdot \mathbf{v}_{\mathbf{O}}=\frac{1}{2}(M+m)\left(\frac{d Y}{d t}\right)^{2}+\frac{1}{2} m r^{2}\left(\frac{d \theta}{d t}\right)^{2}-m r \frac{d Y}{d t} \frac{d \theta}{d t} \sin \theta
$$

As Equações de Euler-Lagrange para esse problema são:

$$
\frac{d}{d t}\left(\frac{d T}{d\left(\frac{d q_{k}}{d t}\right)}\right)-\frac{d T}{d q_{k}}=Q_{q_{k}} ; \quad q_{k}=Y, \theta
$$

sendo $Q_{q_{k}}$ as forças generalizadas não conservativas. Note que não há energia potencial, uma vez que a força na mola depende explicitamente do tempo. Matematicamente, essas forças são escritas como:

$$
Q_{Y}=-k(t) Y-c \frac{d Y}{d t} ; Q_{\theta}=-c_{\theta} \frac{d \theta}{d t}
$$

Levando as expressões 9.4 na Equação 9.3, as equações de movimento são escritas na forma dimensional por meio das Equações 9.5 e 9.6. 


$$
\begin{aligned}
& (M+m) \frac{d^{2} Y}{d t^{2}}-m r \sin \theta \frac{d^{2} \theta}{d t^{2}}-m r \cos \theta\left(\frac{d \theta}{d t}\right)^{2}+c \frac{d Y}{d t}+ \\
& +(\bar{k}+\Delta k \sin (\Omega t)) y=0 \\
& m r^{2} \frac{d^{2} \theta}{d t^{2}}-m r \sin \theta \frac{d^{2} Y}{d t^{2}}+c_{\theta} \frac{d \theta}{d t}=0
\end{aligned}
$$

Visando uma maior generalidade das análises, o modelo matemático é escrito na forma adimensional. Para tanto, define-se o tempo adimensional ${ }^{2} \tau=\omega_{n, y}$, com $\omega_{n, y}^{2}=\frac{\bar{k}}{M+m}$. Além disso, consideram-se as seguintes quantidades adimensionais:

$$
\begin{aligned}
& y=\frac{Y}{D}, \hat{m}=\frac{m}{M}, \hat{r}=\frac{r}{D}, \zeta_{y}=\frac{c}{2(M+m) \omega_{n, y}}, \zeta_{\theta}=\frac{c_{\theta}}{2 m r^{2} \omega_{n, y}} \\
& \beta_{1}=\hat{r} \frac{\hat{m}}{1+\hat{m}}, \beta_{2}=2 \zeta_{y}, \beta_{3}=2 \zeta_{\theta}, \delta=\frac{\Delta k}{\bar{k}}, n=\frac{\Omega}{\omega_{n, y}}
\end{aligned}
$$

É claro ao leitor que o parâmetro $\hat{m}$ representa a relação entre a massa do supressor e a massa da estrutura a ser controlada (estrutural principal) e que, portanto, deve ser um parâmetro pequeno (por exemplo, inferior a 15\%). A substituição das quantidades dadas na Equação 9.7 nas Equações. 9.5 e 9.6 leva às seguintes equações de movimento adimensionais:

$$
\begin{aligned}
& \ddot{y}-\beta_{1} \sin \theta \ddot{\theta}-\beta_{1} \cos \theta \dot{\theta}^{2}+\beta_{2} \dot{y}+(1+\delta \sin n \tau) y=0 \\
& \ddot{\theta}-\frac{1}{\hat{r}} \sin \theta \ddot{y}+\beta_{3} \dot{\theta}=0
\end{aligned}
$$

onde ( ) representa a derivada com relação a $\tau$.

\subsection{Metodologias de simulação e de análise}

As Equações 9.8 e 9.9 foram integradas numericamente por meio do método de Runge-Kutta (função ode45 do MATLAB ${ }^{\circledR}$ ) utilizando como passo de tempo $\Delta \tau=0,001$ durante $\tau_{\max }=800$. Tendo em vista que o modelo matemático dado pelas Equações 9.8 and 9.9 é caracterizado por um grande número de parâmetros, foco foi dado na análise da influência que os parâmetros que definem o supressor (a saber, seu raio, massa e amortecimento) apresentam na resposta do cilindro. Esses parâmetros são representados, respectivamente, pelos adimensionais $\hat{r}, \hat{m}$ e $\zeta_{\theta}$.

2 Note que $\omega_{n, y}$ é a frequência natural não amortecida no caso onde o supressor não tem liberdade de oscilação. 
Todas as simulações foram realizadas empregando o seguinte conjunto de condições inciais: $y(0)=0,1, \theta(0)=\pi / 6, \dot{y}(0)=\dot{\theta}(0)=0$. Uma única condição de excitação paramétrica foi estudada, a saber: $\delta=0,10$ e $n=2$. Note que a excitação paramétrica com $n=2$ é um cenário bastante favorável ao aparecimento de uma resposta ilimitada do cilindro, uma vez que ele é a nascente da região de instabilidade paramétrica principal da equação de Mathieu não amortecida (ver o diagrama de Strutt apresentado na Figura 3(b)). Já a taxa de amortecimento do cilindro foi estipulada em $\zeta_{y}=0,01$, um valor bastante baixo de sorte a promover a instabilidade paramétrica com $n=2$. Cumpre ressaltar que, dada a não-linearidade do modelo matemático, atratores distintos podem ser obtidos dependendo das condições iniciais utilizadas. Embora interessante, o estudo da sensibilidade da resposta às condições inciais não faz parte das análises aqui descritas.

As séries temporais foram analisadas por meio de dois procedimentos. O primeiro é baseado na Transformada de Fourier Discreta (TFD), o que permite obter o espectro de amplitude clássico. Tendo em vista a adimensionalização adotada, a frequência $\hat{\omega}$ indicada nos espectros corresponde à frequência de oscilação dividida pela frequência de referência $\omega_{n, y}$.

A outra técnica de análise espectral empregada foi a Transformada de Hilbert-Huang (HHT). Essa técnica de análise de sinais no domínio tempo-frequência foi introduzida em Huang et al. (1998) e é bastante apropriada para sinais não-estacionários provenientes de sistemas não-lineares. O grupo de pesquisa no qual o autor do texto está inserido já faz uso da HHT no contexto de VIV como pode ser visto em diversas publicações como, por exemplo, Pesce, Fujarra e Kubota (2006), Franzini et al. (2008, 2011, 2015) e Gonçalves et al. (2012).

Além das séries temporais, considera-se também a energia dissipada no amortecedor do NVA nas discussões deste capítulo. A potência instantânea dissipada nesse elemento é dada pela Equação 9.10. Já a potência fornecida $P_{G}$ corresponde à parcela da força restauradora associada à variação temporal da rigidez e é escrita na forma da Equação 9.11.

$$
\begin{aligned}
& P_{D}=-c_{\theta}\left(\frac{d \theta}{d t}\right)^{2} \\
& P_{G}=-(\Delta k \sin (\Omega t) Y) \frac{d Y}{d t}
\end{aligned}
$$

A eficiência da supressão $\eta$ é aqui medida por meio da relação entre a energia dissipada no amortecedor do NVA e a energia fornecida, ambas considerando toda a simulação numérica. Matematicamente, a eficiência é escrita por meio da Equação 9.12. Levando os adimensionais deduzidos na Equação 9.7, a eficiência $\eta$ é dada pela Equação 9.13 . 


$$
\eta=2\left(\frac{\hat{m}}{1+\hat{m}}\right) \frac{1}{\delta} \hat{r}_{0}^{2} \zeta_{\theta} \frac{\int_{0}^{T_{\max }} P_{0}^{\tau_{\max }} \dot{\theta}^{2} d \tau}{\int_{0}^{\max }(\sin n t) y \dot{y} d \tau}
$$

\subsection{Resultados e discussões}

O primeiro resultado a ser mostrado nesta seção corresponde a dois parâmetros estatísticos da resposta do cilindro. A grandeza $y_{s t d}$ corresponde ao desvio padrão da série de deslocamentos $y(\tau)$, porém considerando somente $\tau>\tau_{\text {max }} / 2$ de sorte a evitar o regime transitório inicial. Por sua vez $\max \{y\}$ corresponde ao máximo valor da resposta do cilindro, considerando toda a simulação.

A Figura 105 apresenta as variações de $y_{\text {std }}$ e de $\max \{y\}$ como funções dos adimensionais $\hat{r}$ e $\hat{m}$. O aspecto mais importante evidenciado pela Figura 105 é o fato de que, mesmo em um cenário onde $n=2$ (e, portanto, são esperadas respostas ilimitadas da estrutura principal), o cilindro apresenta uma resposta finita. Esse fato demonstra que o supressor estudado é capaz de limitar as oscilações oriundas da instabilidade paramétrica. Além da capacidade de limitar as respostas da estrutura principal, os pontos brancos nos mapas apresentados nas Figuras 105(a) e 105(c) revelam respostas com desvio padrão praticamente nulo, indicando a mitigação completa do caráter oscilatório da resposta do cilindro. Esse resultado será abordado com maiores detalhes ainda nesta seção.

Um outro aspecto bastante interessante e, de certo ponto, contra-intuitivo em primeira vista é o fato de que o aumento do amortecimento do supressor $\zeta_{\theta}$ não necessariamente leva à diminuição das oscilações do cilindro,representadas por $y_{s t d}$. Ao contrário, a comparação das Figuras 105(a), 105(c) e 105(e) mostra que as menores amplitudes de oscilação (marcadas em azul escuro) são observadas para a menor taxa de amortecimento do supressor estudada. No entanto, como visto na seção 5.1, o aumento na taxa de amortecimento de um absorvedor do tipo TMD não reduz a amplitude de oscilação da estrutura principal se ela estiver submetida a um carregamento de frequência igual a sua frequência natural antes da incorporação do TMD.

No tocante aos máximos deslocamentos do cilindro, novamente o efeito do amortecimento do NVA é contra-intuitivo em primeira análise. As regiões marcadas em laranja (correspondentes a $\max \{y\} \approx 0,50$ ) avançam sobre as regiões de pequenos valores de $\max \{y\}$ conforme o amortecimento é aumentado de $\zeta_{\theta}=0,05$ (Figura 105(b)) para $\zeta_{\theta}=0,15$ (Figura 105(f)). 
Figura 105 - Variação de $y_{\text {std }}$ e de $\max \{y\}$ como função de $\hat{r}$ e $\hat{m}$.

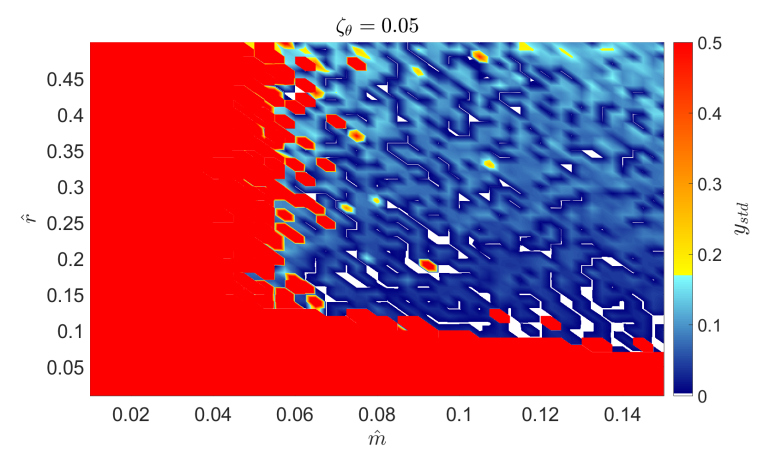

(a) $y_{s t d}(\hat{m} ; \hat{r}), \zeta_{\theta}=0,05$.

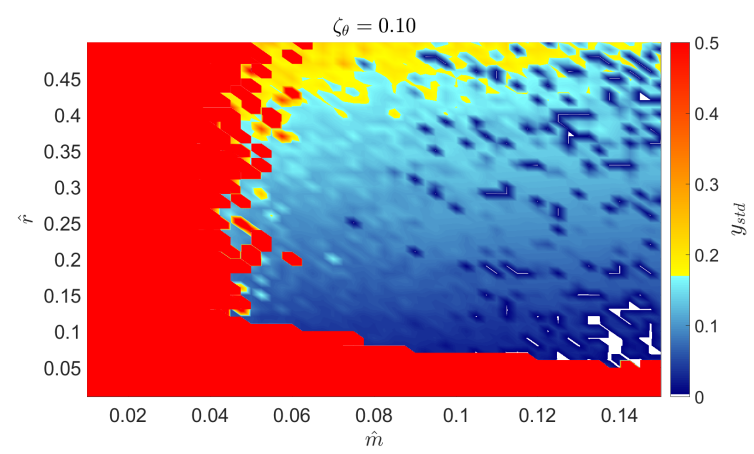

(c) $y_{s t d}(\hat{m} ; \hat{r}), \zeta_{\theta}=0,10$.

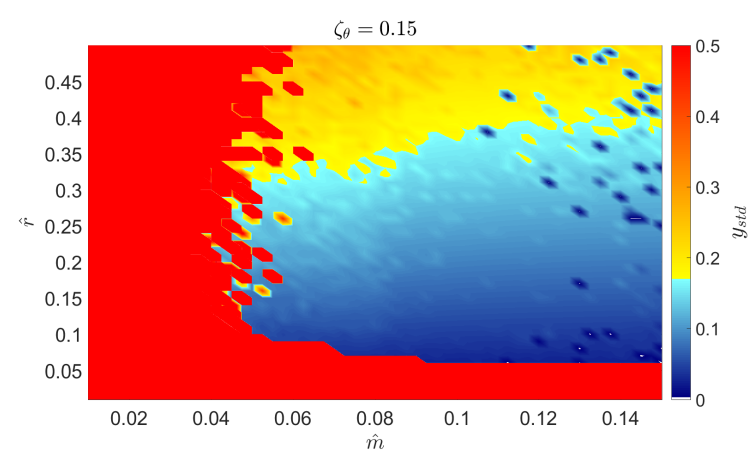

(e) $y_{s t d}(\hat{m} ; \hat{r}), \zeta_{\theta}=0,15$.

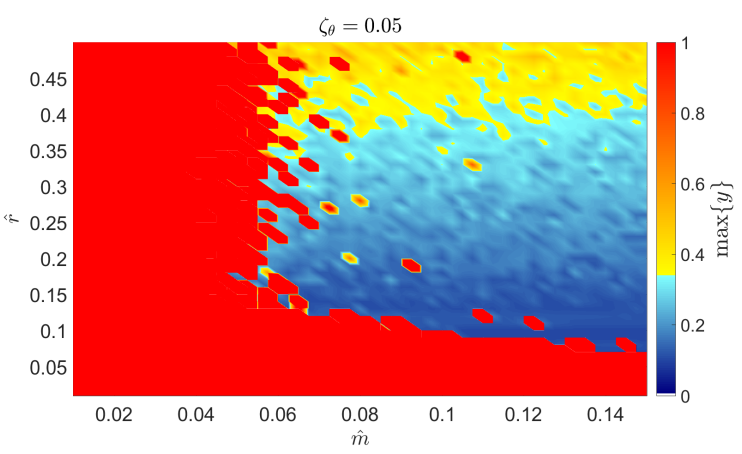

(b) $\max \{y\}(\hat{m} ; \hat{r}), \zeta_{\theta}=0,05$.

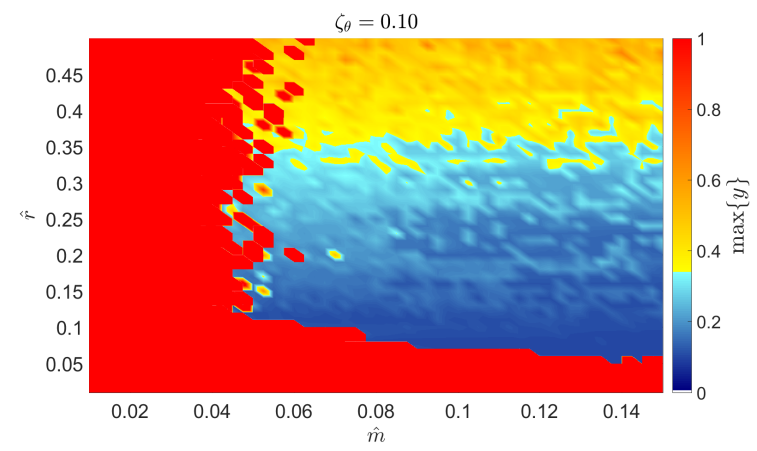

(d) $\max \{y\}(\hat{m} ; \hat{r}), \zeta_{\theta}=0,10$.

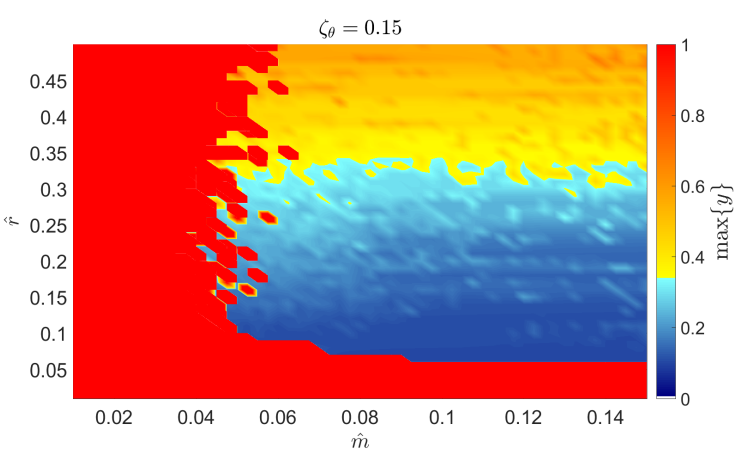

(f) $\max \{y\}(\hat{m} ; \hat{r}), \zeta_{\theta}=0,15$.

Fonte: Extraída de Franzini, Campedelli e Mazzilli (2018).

Cabe, neste ponto, uma discussão acerca de quais os valores dos parâmetros no espaço de controle $\left(\hat{m} ; \hat{r} ; \zeta_{\theta}\right)$ devem ser escolhidos em um eventual projeto de dispositivo. Embora o decréscimo da taxa de amortecimento do NVA tenha ocasionado menores amplitudes de oscilação no cilindro, o valor $y_{s t d}$ exibe um comportamento semelhante a uma distribuição fractal no plano de parâmetros $(\hat{m} ; \hat{r})$ quando $\zeta_{\theta}=0,05$. Essa distribuição indica uma baixa robustez do sistema, o que pode ser indesejável em uma aplicação tecnológica. Já o aumento da taxa de amortecimento do NVA, embora possa levar a um aumento da amplitude de resposta do cilindro $^{3}$, apresenta uma distribuição $y_{\text {std }}(\hat{m} ; \hat{r})$

3 O leitor deve lembrar que a amplitude da resposta está relacionada ao seu desvio padrão. 
muito mais suave.

Embora de interesse prático, a Figura 105 não fornece nenhum aspecto qualitativo da resposta. Para tanto, são construídas as Figuras 106, 107 e 108, que reproduzem os mapas $y_{s t d}(\hat{m} ; \hat{r})$ já apresentados anteriormente em conjunto com exemplos de séries temporais $y(\tau)$ obtidos para particulares pontos do plano de parâmetros de controle $(\hat{m} ; \hat{r})$. Cumpre ressaltar que os mesmos pares $(\hat{m} ; \hat{r})$ são identificados nessas três figuras.

Figura $106-y_{s t d}(\hat{m} ; \hat{r})$ e exemplos qualitativos da resposta do cilindro $y(\tau) \cdot \zeta_{\theta}=0,05$.

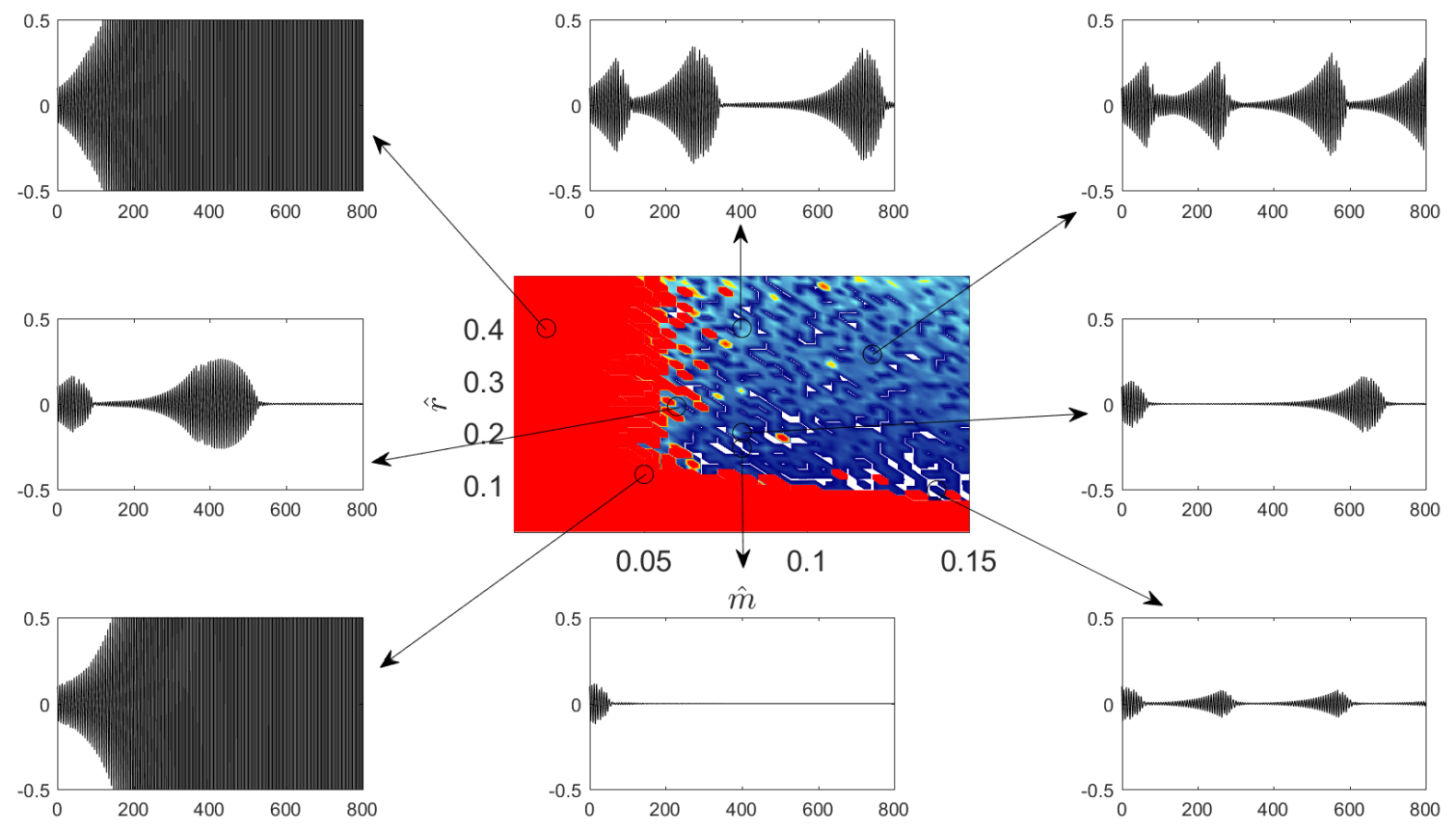

Fonte: Extraída de Franzini, Campedelli e Mazzilli (2018).

A análise das Figuras 106, 107 e 108 revela a existência de diversos tipos de resposta para o cilindro. O primeiro tipo contempla as respostas ilimitadas (ver, por exemplo, a série temporal $y(\tau)$ obtida a partir da simulação numérica com $\hat{m}=0,02, \hat{r}=0,40$ e $\left.\zeta_{\theta}=0,05\right)$ e no qual a amplitude de resposta do cilindro tende ao infinito. Por questão de visualização dos mapas de cores, essas respostas estão identificadas em vermelho nos mapas $y_{s t d}(\hat{m} ; \hat{r})$. Neste capítulo, as respostas ilimitadas são identificadas pela sigla "RI".

Um segundo tipo de resposta observada é aquele no qual o cilindro oscila com uma amplitude finita e praticamente invariante no tempo como, por exemplo, aquela obtida a partir de $\hat{m}=0,12, \hat{r}=0,35$ e $\zeta_{\theta}=0,15$. Esse tipo de resposta é identificado pela sigla "RAC" - Resposta com amplitude constante. Uma terceira classe de respostas é aquela onde as respostas do cilindro também são finitas, porém caracterizadas por importantes modulações em amplitude (respostas do tipo "RMA"). Um exemplo dessa classe é obtido considerando $\hat{m}=0,12, \hat{r}=0,35$ e $\zeta_{\theta}=0,05$.

As respostas que ilustram a supressão completa ("SC", na nomenclatura aqui 
Figura $107-y_{\text {std }}(\hat{m} ; \hat{r})$ e exemplos qualitativos da resposta do cilindro $y(\tau) . \zeta_{\theta}=0,10$.

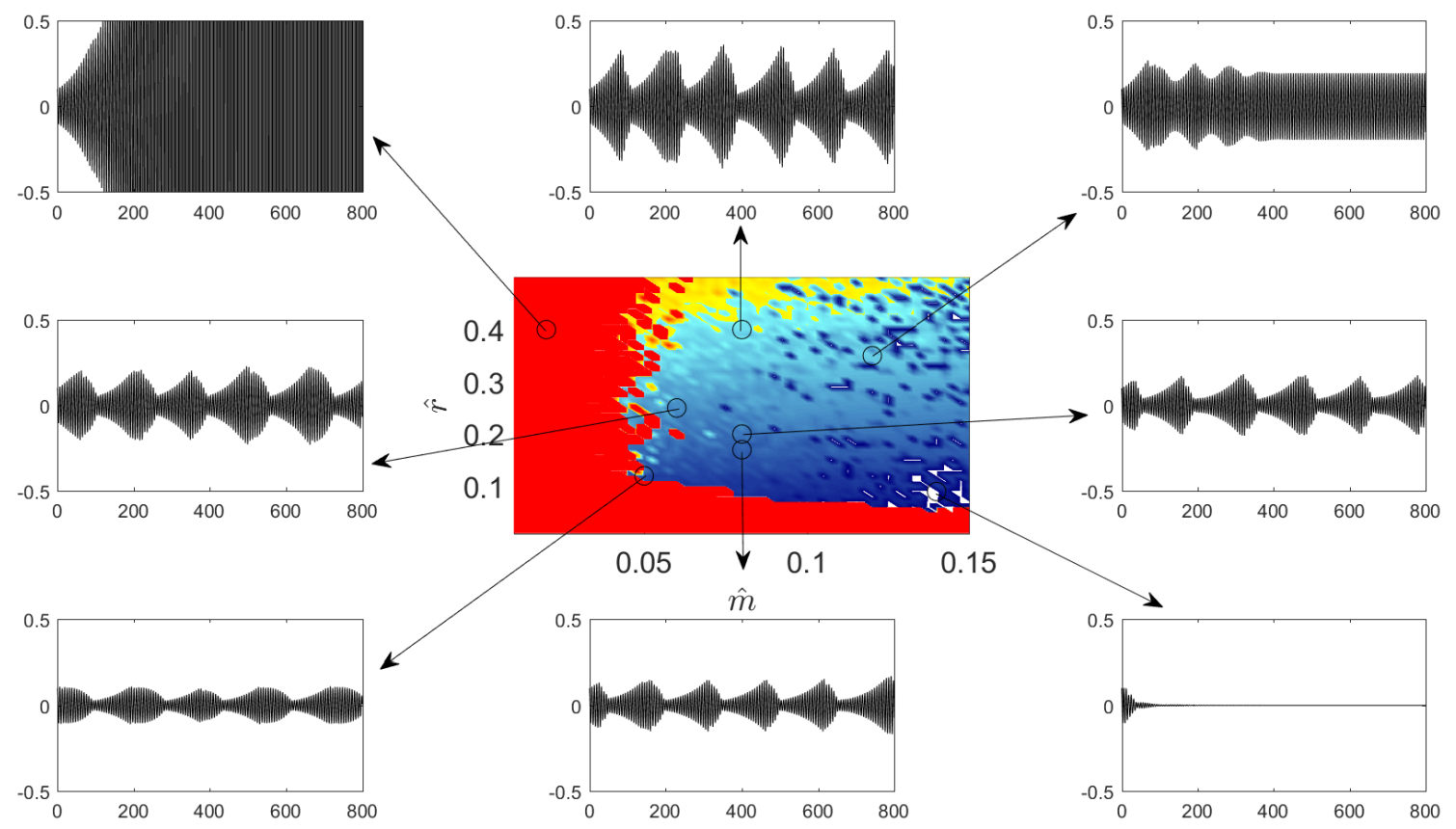

Fonte: Extraído de Franzini, Campedelli e Mazzilli (2018).

Figura $108-y_{\text {std }}(\hat{m} ; \hat{r})$ e exemplos qualitativos da resposta do cilindro $y(\tau) . \zeta_{\theta}=0,15$.

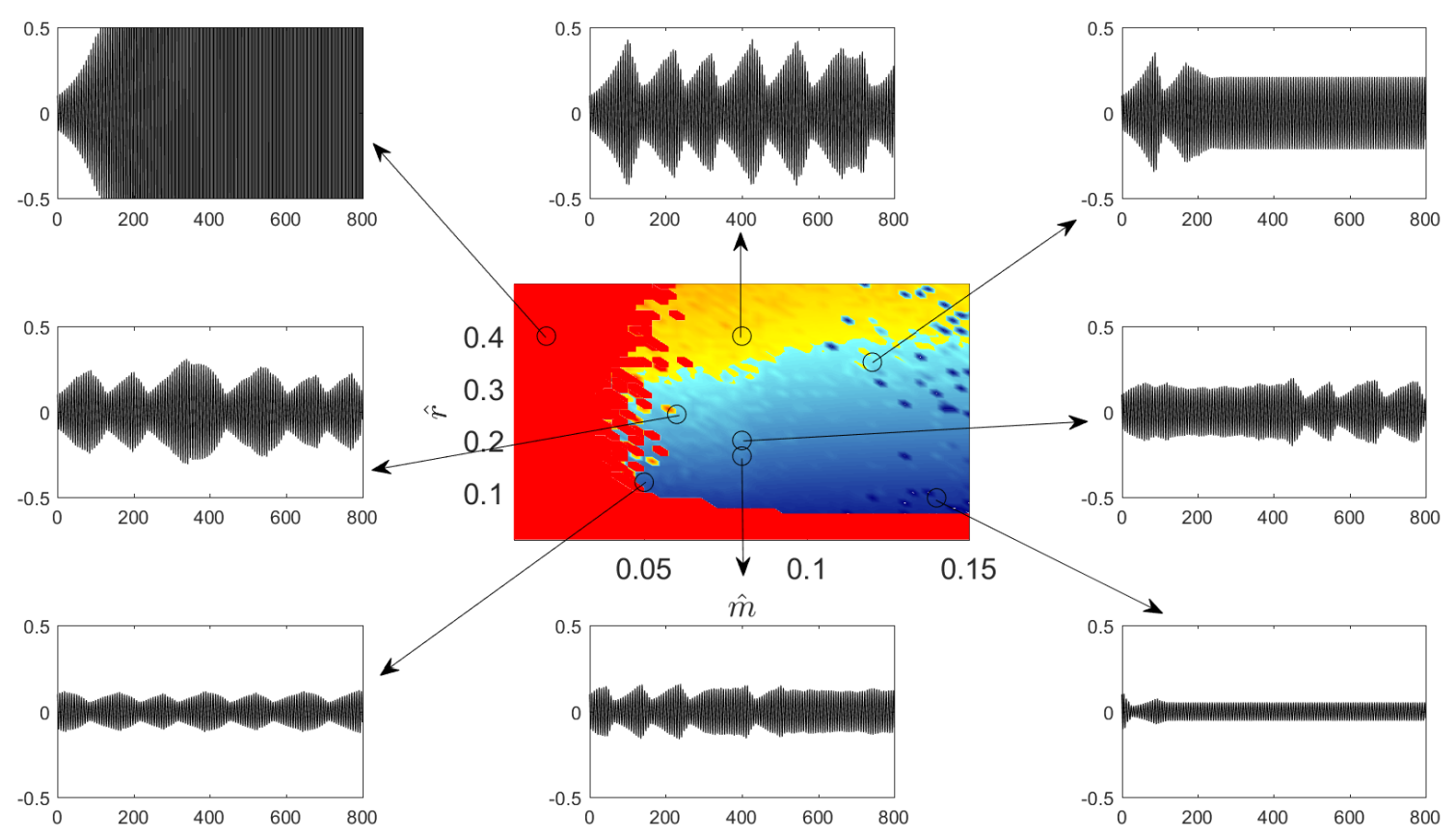

Fonte: Extraída de Franzini, Campedelli e Mazzilli (2018).

adotada) como, por exemplo, aquela obtida com $\hat{m}=0,08, \hat{r}=0,17$ e $\zeta_{\theta}=0,05$ são caracterizadas por amplitudes de resposta do cilindro próximas a zero ${ }^{4}$. Já o quinto tipo

$4 \overline{\text { Mais precisamente, inferiores a } y_{\text {std }}=10^{-4}}$, ou seja, três ordens de magnitude menores do que a condição 
de resposta é aqui denominada de mista ("RM"), onde existe uma intermitência entre os regimes de respostas com e sem modulação de amplitude. Um exemplo de resposta mista é aquela obtida para $\hat{m}=0,08, \hat{r}=0,20$ e $\zeta_{\theta}=0,15$. Os diferentes tipos de resposta identificados nas Figuras 106, 107 e 108 são exibidos na Tabela 10.

Tabela 10 - Diferentes tipos de resposta do cilindro para valores selecionados de $\hat{m}, \hat{r}$ e $\zeta_{\theta}$.

\begin{tabular}{|c|c|c|c|c|c|}
\hline$\overline{\hat{m}}$ & $\overline{\bar{r}}$ & $\overline{\text { Resposta }}$ & $\overline{\bar{m}}$ & $\overline{\overline{\hat{r}}}$ & Resposta \\
\hline 0,02 & 0,40 & $\begin{array}{l}\zeta_{\theta}=0,05: " \mathrm{RI} " \\
\zeta_{\theta}=0,10: " \mathrm{RI} " \\
\zeta_{\theta}=0,15: " \mathrm{RI} "\end{array}$ & 0,06 & 0,25 & $\begin{array}{l}\zeta_{\theta}=0,05: \text { "RMA" } \\
\zeta_{\theta}=0,10: \text { "RMA" } \\
\zeta_{\theta}=0,15: \text { "RMA" }\end{array}$ \\
\hline 0,05 & 0,12 & $\begin{array}{c}\zeta_{\theta}=0,05: \text { "RI" } \\
\zeta_{\theta}=0,10: \text { "RMA" } \\
\zeta_{\theta}=0,15: \text { "RMA" }\end{array}$ & 0,08 & 0,17 & $\begin{array}{c}\zeta_{\theta}=0,05: " \mathrm{SC} " \\
\zeta_{\theta}=0,10: " \mathrm{RMA} " \\
\zeta_{\theta}=0,15: " \mathrm{RM} "\end{array}$ \\
\hline 0,14 & 0,09 & $\begin{array}{c}\zeta_{\theta}=0,05: \text { "RMA" } \\
\zeta_{\theta}=0,10: \text { "SC" } \\
\zeta_{\theta}=0,15: \text { "RAC" }\end{array}$ & 0,08 & 0,20 & $\begin{array}{c}\zeta_{\theta}=0,05: \text { "RMA" } \\
\zeta_{\theta}=0,10: \text { "RAC" } \\
\zeta_{\theta}=0,15: \text { "RM" }\end{array}$ \\
\hline 0,12 & 0,35 & $\begin{array}{l}\zeta_{\theta}=0,05: \text { "RMA" } \\
\zeta_{\theta}=0,10: \text { "RAC" } \\
\zeta_{\theta}=0,15: \text { "RAC" }\end{array}$ & 0,08 & 0,40 & $\begin{array}{l}\zeta_{\theta}=0,05: \text { "RMA" } \\
\zeta_{\theta}=0,10: \text { "RMA" } \\
\zeta_{\theta}=0,15: \text { "RMA" }\end{array}$ \\
\hline
\end{tabular}

Fonte: Adaptada de Franzini, Campedelli e Mazzilli (2018).

Apresentada a variedade de respostas estruturais como funções dos parâmetros que definem o supressor, este texto passa a analisar algumas das séries temporais identificadas na Tabela 10. Essas análises contemplam as respostas do cilindro e do supressor $(y(\tau)$, $\theta(\tau)$ e $\dot{\theta}(\tau)$ ), bem como os espectros de amplitude e de Hilbert-Huang calculados a partir da série temporal de deslocamento do cilindro.

A Figura 109 ilustra as respostas do cilindro e do NVA obtidas para a condição em que $\hat{m}=0,12, \hat{r}=0,35$ e $\zeta_{\theta}=0,05$. O primeiro resultado e que chama a atenção é a capacidade do NVA rotativo em limitar a amplitude da resposta mesmo em um cenário de excitação paramétrica com $n=2$, isso é, favorecendo a instabilidade paramétrica principal $^{5}$.

A Figura 109(a) mostra a série temporal $y(\tau)$ é caracterizada por dois regimes intermitentes sendo um deles de crescimento da resposta e o outro de supressão das oscilações do cilindro. Essa intermitência entre os regimes induz a presença de importantes modulações de amplitude na resposta do cilindro, caracterizando uma resposta do tipo "RMA". Do ponto de vista de assinatura em frequência, tanto o espectro de amplitude obtido via TFD (Figura 109(a)) quanto o espectro de Hilbert-Huang (Figura 109(c)) indicam que o cilindro oscila com frequência próxima da sua frequência de referência inicial de deslocamento do cilindro.

5 Ao retornar à seção 3.1, o leitor relembra que um sistema de um grau de liberdade sujeito à instabilidade paramétrica apresenta respostas ilimitadas. 
Figura 109 - Séries temporais e análises espectrais. $\hat{m}=0,12, \hat{r}=0,35$ e $\zeta_{\theta}=0,05$.
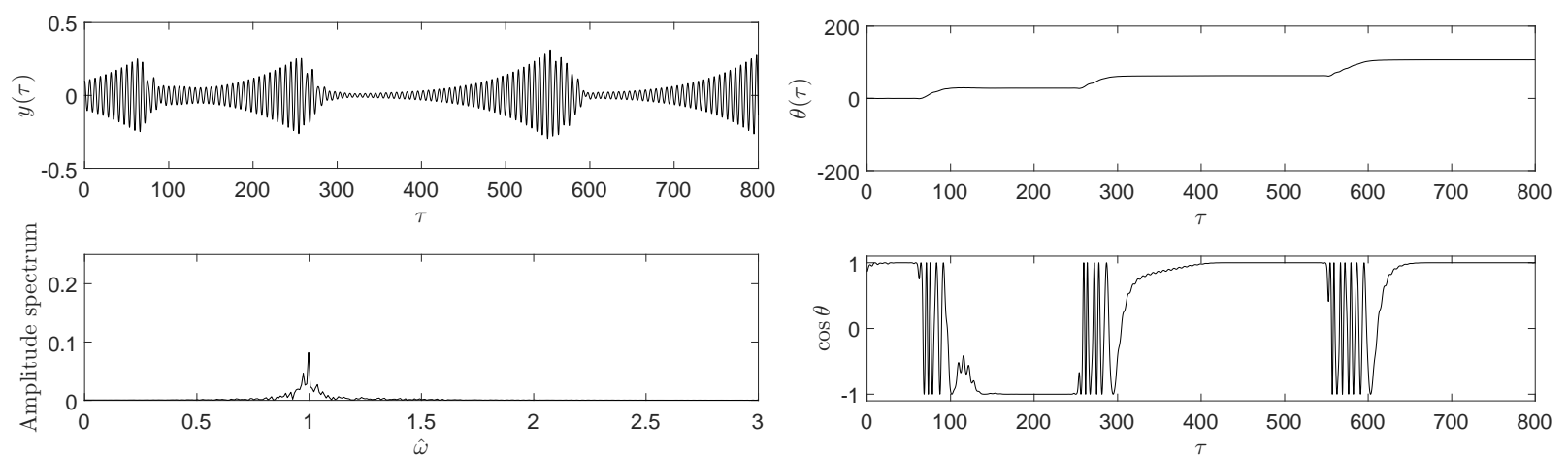

(a) $y(\tau)$.

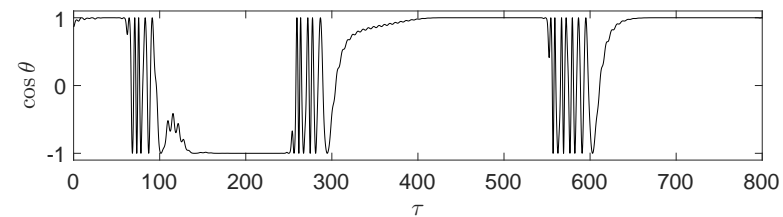

(b) $\theta(\tau)$.
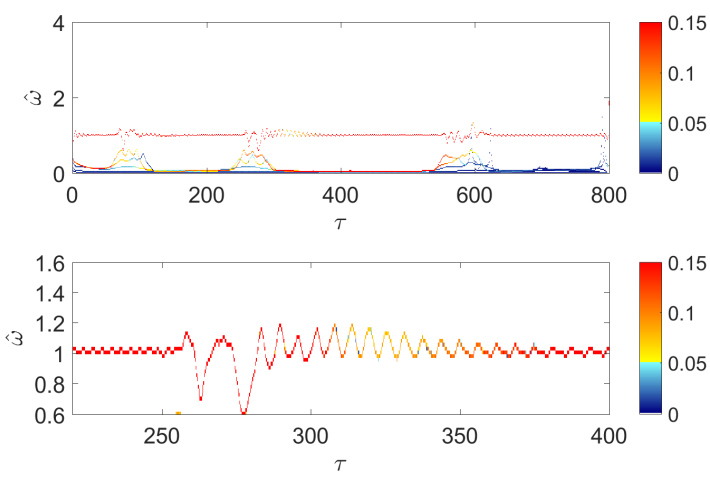

(c) Espectro de Hilbert-Huang de $y(\tau)$.

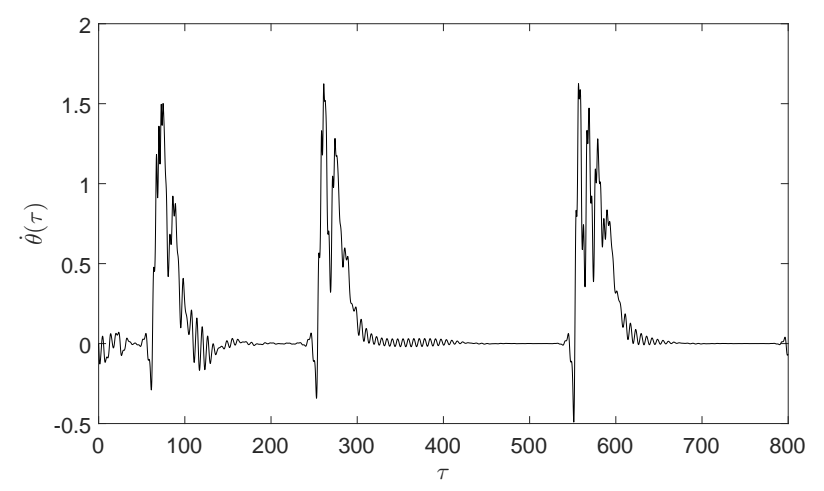

(d) $\dot{\theta}(\tau)$.

Fonte: Extraída de Franzini, Campedelli e Mazzilli (2018).

$\omega_{n, y}$. No entanto, o espectro de Hilbert-Huang revela alguma modulação na frequência instantânea de vibração quando da transição entre os regime supra-citados.

Um aspecto bastante interessante pode ser notado comparando as séries temporais $y(\tau)$ (Figura 109(a)) e $\theta(\tau)$ (Figura 109(b)). Durante os intervalos de tempo que caracterizam o regime de crescimento da resposta do cilindro ${ }^{6}$, o supressor permanece em um ângulo fixo tal que $\cos \theta= \pm 1$. Uma vez que um valor máximo de resposta é atingido, tem início o regime de supressão.

Durante o regime de supressão, o NVA rotaciona com velocidade angular praticamente constante e igual a $\omega_{r}=1$. Tendo em vista que o regime de supressão ocorre por curtos intervalos de tempo, a sua discussão é mais facilmente observada notando o crescimento praticamente linear da posição angular $\theta(\tau)$ na Figura 109(b). A rotação do NVA promove a dissipação de energia junto ao seu amortecedor, o que configura o mecanismo TET e acaba por diminuir a resposta da estrutura principal. O regime de supressão é cessado quando o deslocamento do cilindro atinge um valor mínimo, dando início a um novo ciclo de crescimento da resposta.

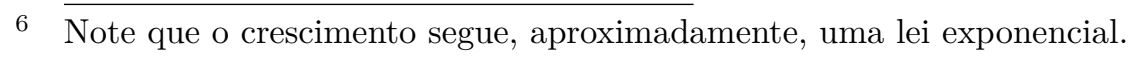


O regime de crescimento da resposta pode ser facilmente explicável. Note que, nesse regime, $\dot{\theta}=\ddot{\theta} \approx 0$ e que $\cos \theta= \pm 1$, ou seja, $\sin \theta=0$. Levando esses resultados na Equação 9.8, chega-se $a^{7}$ :

$$
\ddot{y}+\beta_{2} \dot{y}+(1+\delta \sin n \tau) y=0
$$

que é a equação de Mathieu amortecida. Para valores pequenos de amortecimento estrutural (caso do sistema aqui estudado), uma excitação paramétrica de pequena amplitude e com frequência adimensional $n=2$ leva a soluções ilimitadas, com crescimento da amplitude seguindo uma solução exponencial.

A Figura 110 traz os resultados obtidos a partir de uma combinação de parâmetros do supressor que leva à supressão completa (resposta tipo "SC") da resposta do cilindro. Como mostra a Figura 110(b), a posição do NVA após a supressão completa é tal que $\cos \theta \approx 0$. Por sua vez, o espectro de Hilbert-Huang apresentado na Figura 110(c) mostra que, durante o intervalo de tempo $0<\tau<60$ e no qual ocorre a supressão, a frequência instantânea de oscilação do cilindro apresenta importantes modulações, podendo atingir até $\hat{\omega}=0,70$.

Um exemplo de resposta do cilindro do tipo "RAC" é apresentado na Figura 111. A série temporal $y(\tau)$ ilustrada na Figura 111(a) mostra a existência de ligeiras modulações em amplitude para $\tau<320$ e uma resposta com amplitude constante para os instantes acima desse. Nota-se, ainda, a presença de um espectro de amplitude de banda estreita e centrado em um valor ligeiramente superior a $\hat{\omega}=1$.

Ainda para essa condição, a resposta angular do supressor, ilustrada na Figura 111(b) guarda algumas diferenças quando comparadas ao caso onde a resposta do cilindro apresenta modulações em amplitude (ver Figura 109(b)). Para $\tau<320$, a Figura 111(b) possui comportamento semelhante àquele apresentado na Figura 109(b), embora os regimes de supressão não estejam associados a valores de velocidade angular tão bem definidos quanto aquelas observadas em uma resposta do tipo "RMA".

Já para $\tau>320$, quando a resposta do cilindro passa a exibir uma amplitude praticamente constante, as Figuras 111(b) e 111(d) mostram que a resposta do supressor possui caráter oscilatório com amplitude e frequência bem definidas. Mais ainda, a oscilação do supressor se dá em torno de um valor médio próximo àquele correspondente a $\cos \theta= \pm 1$, ou seja, alinhado com a direção de movimento do cilindro (ver representação esquemática na Figura 104). Por sua vez, o espectro de Hilbert-Huang apresentado na Figura 112(c) revela uma frequência de oscilação com pouca variação temporal (ainda menos intensa do que aquela observada na Figura 110(c) e correspondente a uma resposta do tipo "RAM") e próxima a $\hat{\omega}=1$.

7 É trivial notar que a inserção desses mesmos resultados na Equação 9.9 resulta em uma condição trivialmente satisfeita 
Figura 110 - Séries temporais e análises espectrais. $\hat{m}=0,08, \hat{r}=0,17$ e $\zeta_{\theta}=0,05$.
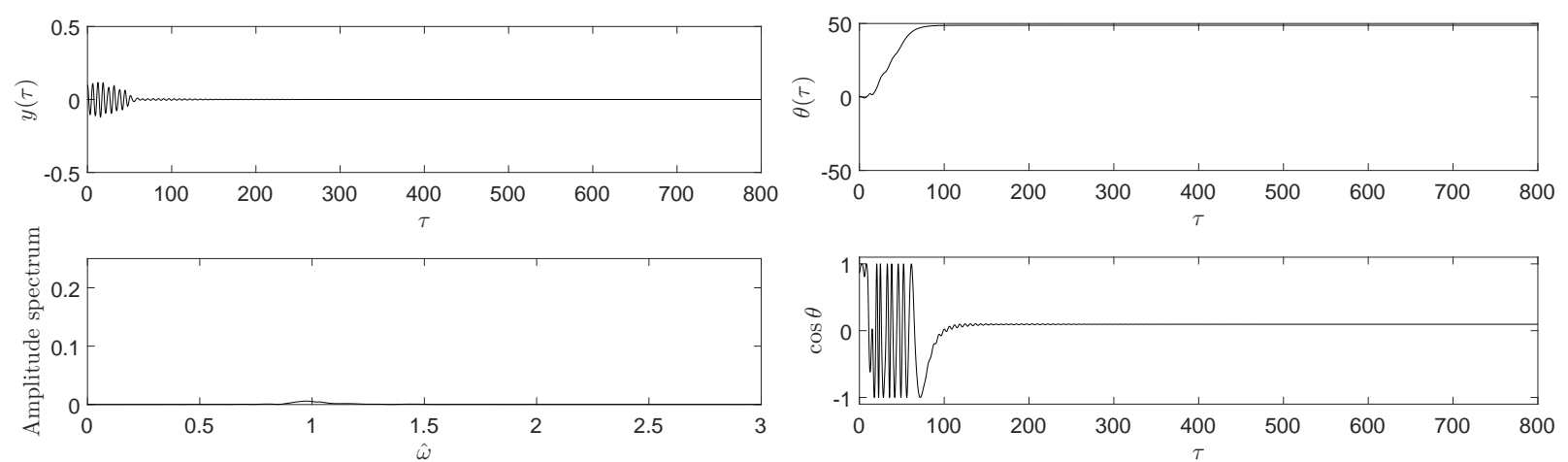

(a) $y(\tau)$.

(b) $\theta(\tau)$.
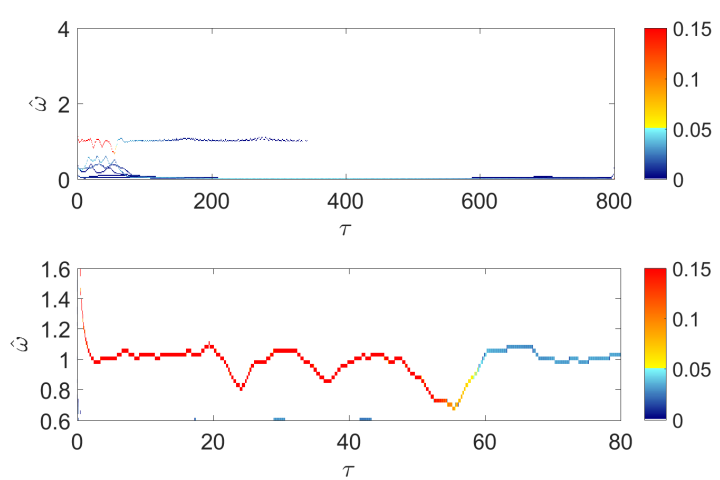

(c) Espectro de Hilbert-Huang de $y(\tau)$.

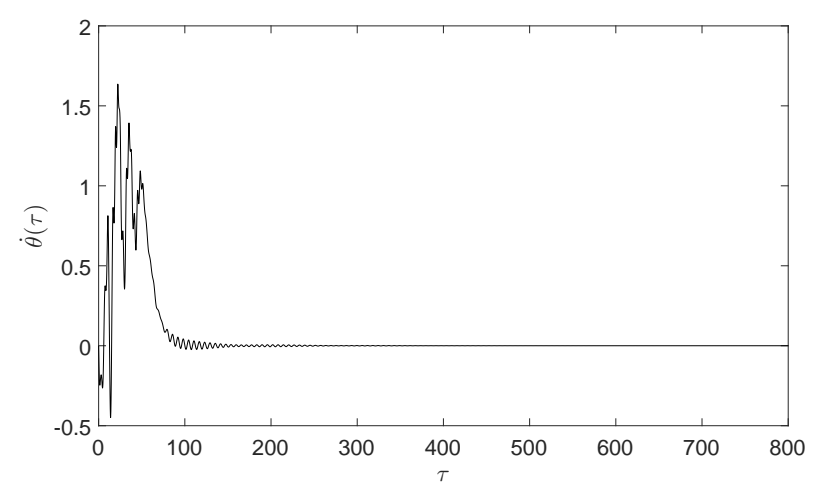

(d) $\dot{\theta}(\tau)$.

Fonte: Extraída de Franzini, Campedelli e Mazzilli (2018).

Um exemplo de resposta do tipo "RM" é ilustrado na Figura 112. Embora a série temporal apresentada na Figura 112(a) seja bastante semelhante àquela classificada como sendo do tipo "RAC" (ver Figura 111(a)) com apenas uma inversão entre um regime de resposta modulada em amplitude precedida por um outro de amplitude praticamente constante. O movimento do supressor, por sua vez, guarda importantes diferenças.

Enquanto para a resposta do tipo "RAC" a série temporal $\theta(\tau)$ apresenta comportamento harmônico bem definido no intervalo de tempo onde a resposta do cilindro é livre de modulação em amplitude, a Figura 112(b) claramente revela a falta de padrão na resposta do supressor, em particular no intervalo $\tau<400$ e onde a resposta do cilindro tem amplitude praticamente constante. Já o espectro de Hilbert-Huang apresentado na Figura 112(c) indica que a frequência de oscilação apresentou pequena variação temporal em torno de $\hat{\omega}=1$.

Além das análises associadas às séries temporais de deslocamento do cilindro e do supressor, é interessante calcular a eficiência da supressão passiva no que diz respeito à energia dissipada no amortecedor associado ao NVA. A Figura 113 traz a variação da eficiência de supressão $|\eta|$ como funções dos parâmetros de massa e de raio do supressor 
Figura 111 - Séries temporais e análises espectrais. $\hat{m}=0,12, \hat{r}=0,35$ e $\zeta_{\theta}=0,10$.
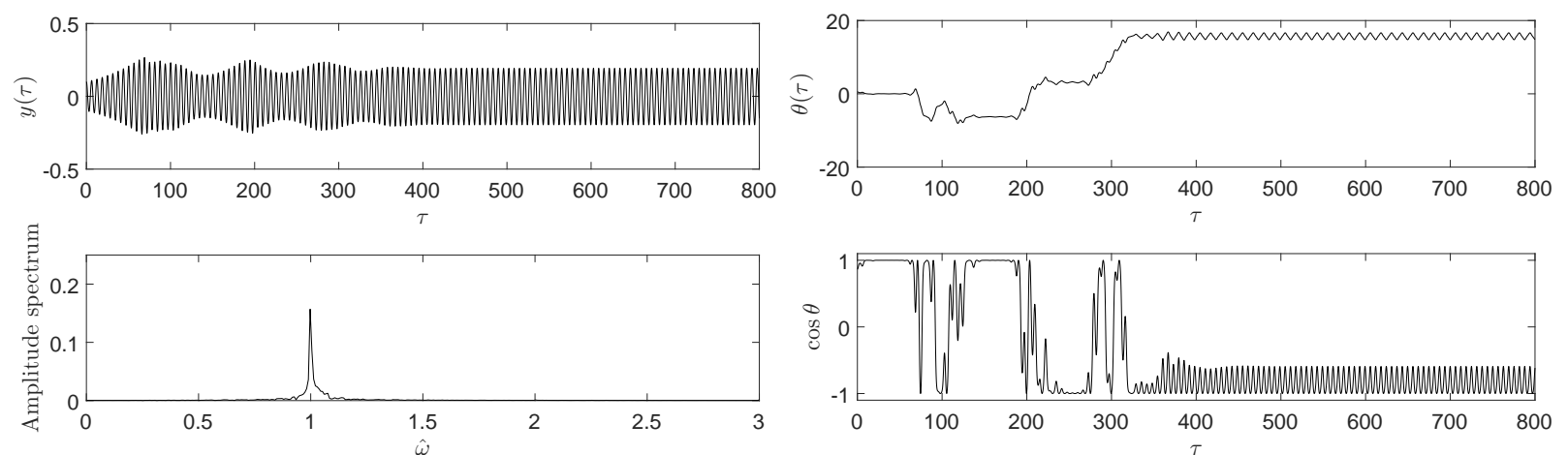

(a) $y(\tau)$.

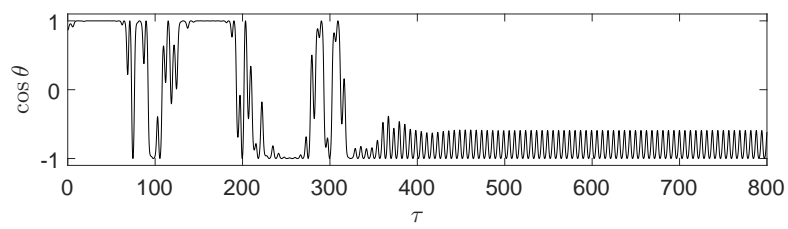

(b) $\theta(\tau)$.
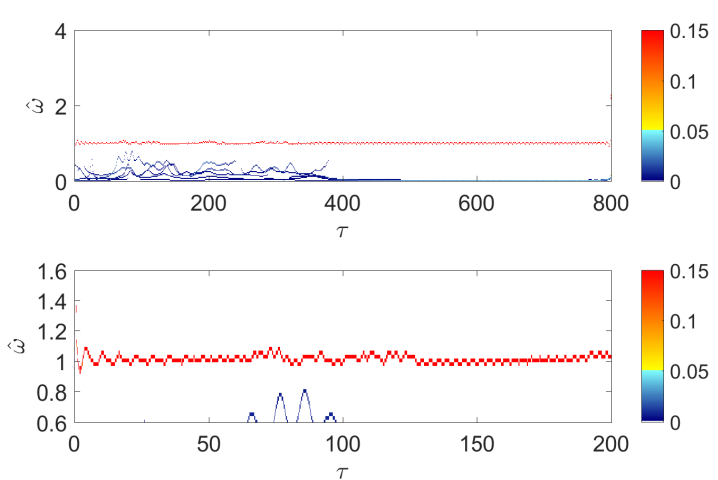

(c) Espectro de Hilbert-Huang de $y(\tau)$.

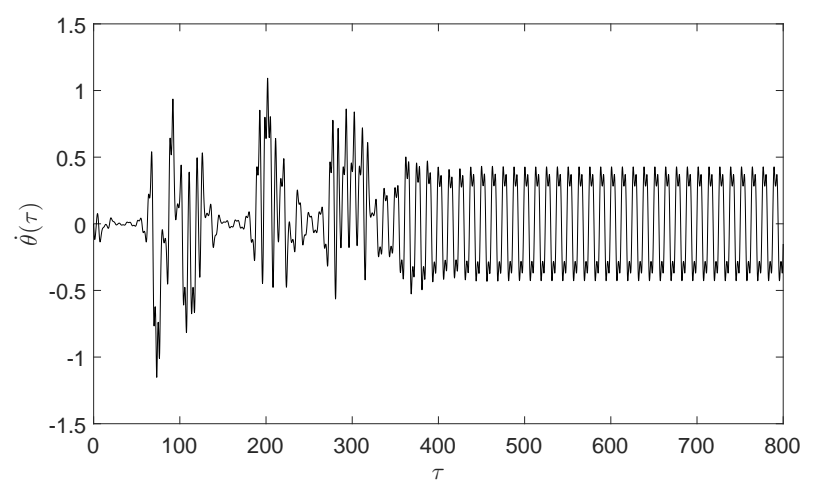

(d) $\dot{\theta}(\tau)$.

Fonte: Extraída de Franzini, Campedelli e Mazzilli (2018).

e para $\zeta_{\theta}=0,05, \zeta_{\theta}=0,10$ e $\zeta_{\theta}=0,15$. Esses três valores de taxa de amortecimento do supressor têm como característica uma região de baixa eficiência (marcada em branco nos mapas) para valores de $\hat{m}$ e $\hat{r}$ pequenos. De fato, nessa região, os mapas apresentados na Figura 105 apresentam zonas marcadas em vermelho e que correspondem aos casos onde o cilindro apresenta uma resposta do tipo "RI".

Ao contrário do que, à primeira vista é intuitivo, as regiões de maior eficiência de supressão (indicadas pela cor vermelha nos mapas da Figura 113) são diminuídas com o aumento da taxa de amortecimento do supressor $\zeta_{\theta}$. A comparação entre os mapas das Figuras 113(a) e 113(c) revela, ainda, que o aumento na taxa de amortecimento do supressor suaviza a distribuição de eficiência de supressor como funções dos parâmetros $\hat{r}$ e $\hat{m}$, em concordância com os mapas ilustrados na Figura 105.

Como mostrado nesta seção, os resultados numéricos demonstram a capacidade de supressão de vibrações decorrentes da excitação paramétrica por meio de um NVA rotativo. Dentre os diversos tipos de resposta, algumas configurações de massa e raio do supressor promovem respostas da estrutura principal caracterizadas por modulações em amplitude que, por sua vez, estão associadas à rotação do NVA com velocidade aproximadamente 
Figura 112 - Séries temporais e análises espectrais. $\hat{m}=0,08, \hat{r}=0,20$ e $\zeta_{\theta}=0,15$.
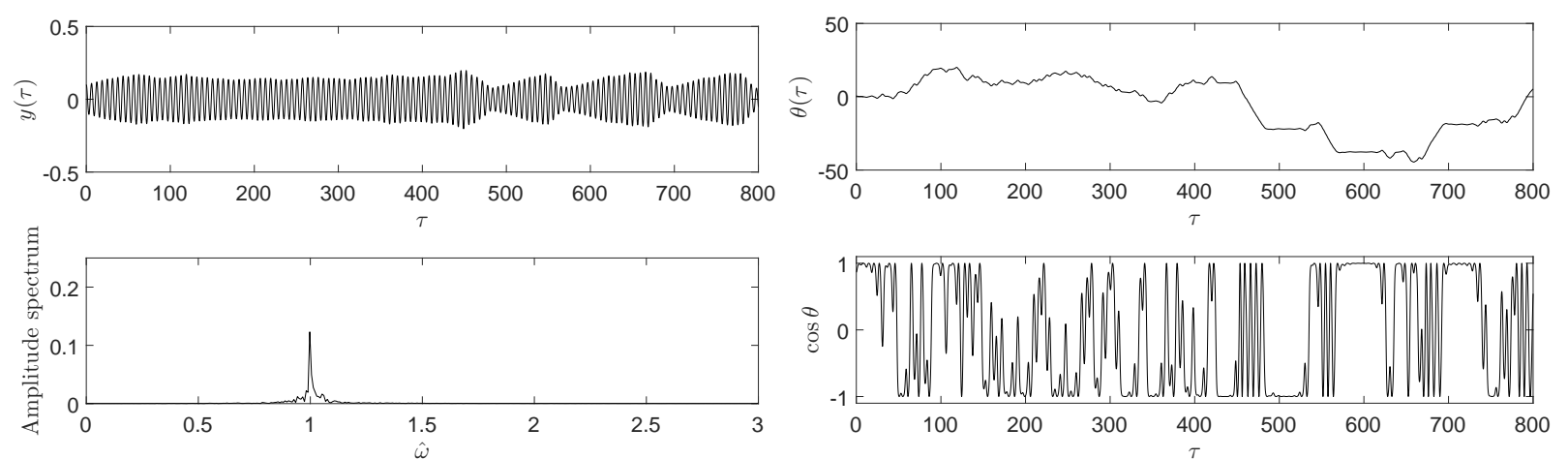

(a) $y(\tau)$.

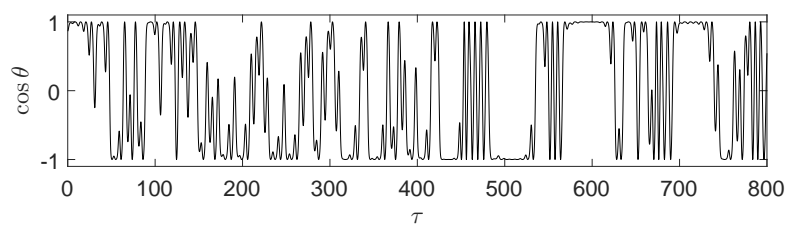

(b) $\theta(\tau)$.
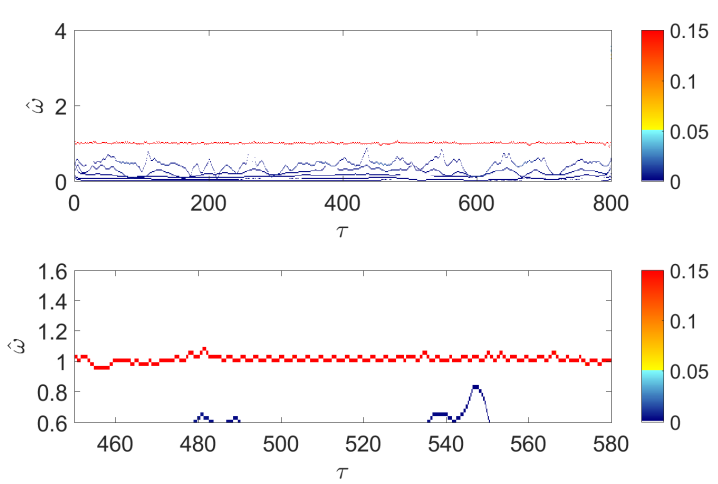

(c) Espectro de Hilbert-Huang de $y(\tau)$.

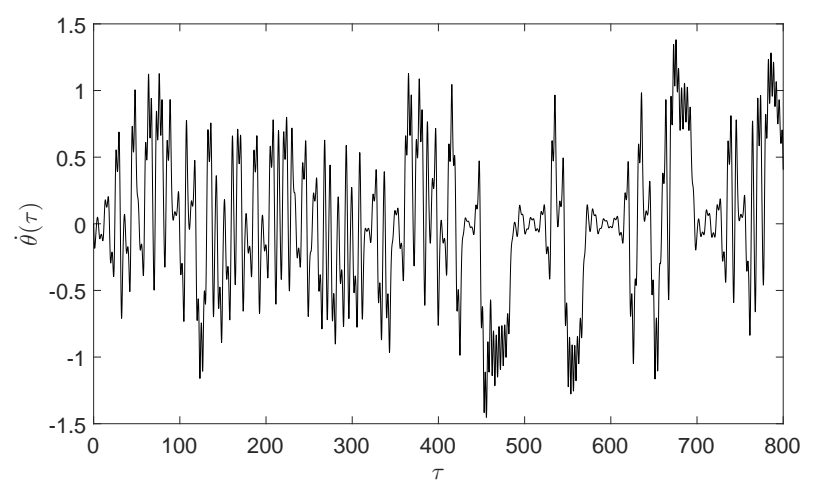

(d) $\dot{\theta}(\tau)$.

Fonte: Extraída de Franzini, Campedelli e Mazzilli (2018).

constante durante alguns intervalos de tempo, seguidos por outros onde a sua posição angular é praticamente constante. A seção subsequente busca analisar esse comportamento por meio de um método assintótico de perturbação.

\subsection{Estudo analítico baseado em um método de perturbação}

O estudo analítico aqui descrito é conduzido por meio do método complexificaçãomédia, já mencionado na revisão bibliográfica conduzida na seção 5.2. Considere que o adimensional $\beta_{1}$ seja o parâmetro de perturbação $\epsilon$. De fato, $\beta_{1}$ é da ordem do produto entre $\hat{r}$ e $\hat{m}$. Considere, ainda, $\delta=\epsilon \hat{\delta}$ e $\beta_{2}=\epsilon \lambda_{2}$ como formas alternativas de escrever a amplitude da excitação paramétrica e a taxa de amortecimento do cilindro. Como em Sigalov et al. (2012), adota-se que $\ddot{y}=-y+O(\epsilon)$, de sorte que as equações adimensionais de movimento (Equações 9.8 e 9.9) são reescritas pelas Equações ${ }^{8} 9.15$ e 9.16.

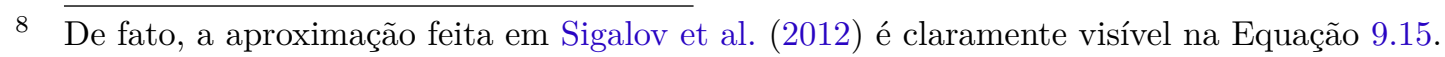


Figura 113 - Variação de $|\eta|$ como função de $\hat{r}$ e $\hat{m}$.

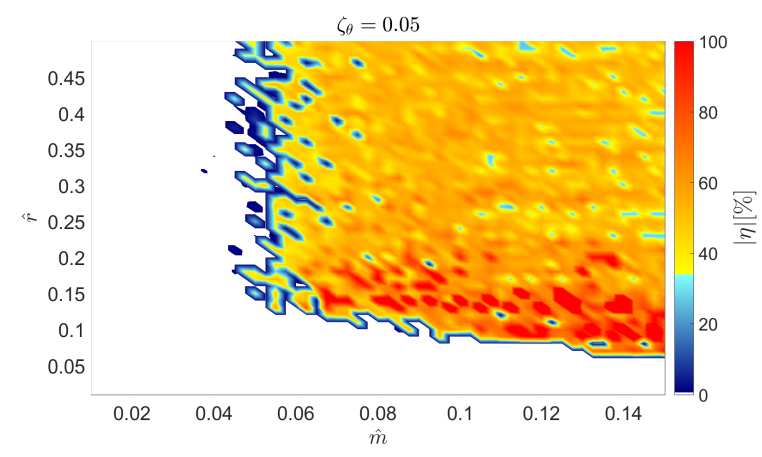

(a) $\zeta_{\theta}=0,05$.

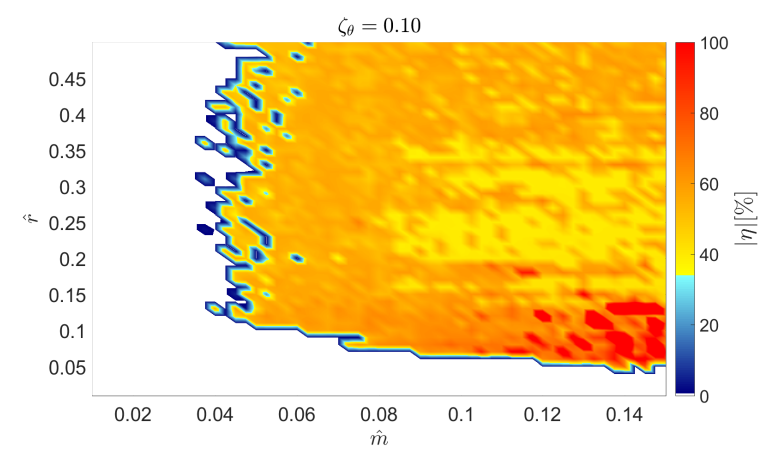

(b) $\zeta_{\theta}=0,10$.

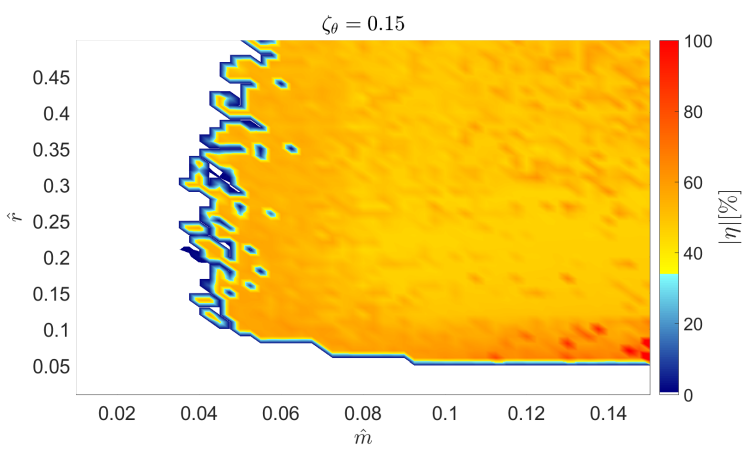

(c) $\zeta_{\theta}=0,15$.

Fonte: Extraída de Franzini, Campedelli e Mazzilli (2018).

$$
\begin{array}{r}
\ddot{y}+\epsilon \lambda_{2} \dot{y}+y=\epsilon\left(\sin \theta \ddot{\theta}+\cos \theta \dot{\theta}^{2}-\hat{\delta} y \sin n \tau\right) \\
\ddot{\theta}+\beta_{3} \dot{\theta}=-\frac{1}{\hat{r}} \sin \theta y+O(\epsilon)
\end{array}
$$

Cabe aqui ressaltar que a adoção da simplificação envolvendo o deslocamento y e a aceleração $\ddot{y}$ é comum na análise assintótica de estruturas dotadas de um NVA rotativo. Como um exemplo, destaca-se que Blanchard et al. (2016) adotaram um procedimento semelhante para o contexto de VIV. Caso essa hipótese não fosse adotada, a matriz de massa não-linear existente no sistema dado pelas Equações 9.8 e 9.9 seria não diagonal, o que complicaria sobremaneira o tratamento analítico. O leitor interessado nesse último caso é direcionado ao trabalho de Benarous e Gendelman (2016).

O método de complexificação é feito considerando a troca de variáveis identificada na Equação 9.17, sendo $i=\sqrt{-1}$. Como visto na seção 9.3, durante o regime de supressão em uma resposta do tipo "RMA", o NVA tem uma velocidade angular praticamente constante e igual a 1, o que justifica a proposição da aproximação dada pela Equação 9.18. 


$$
\begin{array}{r}
\phi e^{i \tau}=\dot{y}+i y \\
\theta=\tau+\psi
\end{array}
$$

Nas Equações 9.17 e $9.18, \phi=\phi(\tau)$ e $\psi=\psi(\tau)$ são, respectivamente, a amplitude complexa de vibração e a defasagem real, ambas variando lentamente com relação à escala de tempo rápida do problema. A existência de uma escala lenta de tempo é particularmente notável na Figura 110(a) que mostra que, para cada ciclo de supressão-crescimento da resposta, existe um grande número de oscilações do cilindro.

Levando as Equações 9.17 e 9.18 nas Equações 9.15 e 9.16 e transformando as funções trigonométricas em exponenciais complexas, as seguintes expressões são obtidas:

$$
\begin{aligned}
& \dot{\phi}+\epsilon \frac{\lambda_{2}}{2} \phi=\epsilon e^{-i \tau}(1+\psi)^{2} \cos (\tau+\psi)+\epsilon \frac{i}{2} \hat{\delta} \phi \sin 2 \tau-\epsilon \frac{i}{2} e^{-2 i \tau} \hat{\delta} \epsilon \phi^{*} \sin 2 \tau+ \\
& +\epsilon e^{-i \tau} \ddot{\psi} \sin (\tau+\psi)-\epsilon \frac{\lambda_{2}}{2} \phi^{*} e^{-i 2 \tau} \\
& \ddot{\psi}+(1+\dot{\psi}) \beta_{3}=-\frac{i}{2 \hat{r}}\left(-\phi e^{i \tau}+\phi^{*} e^{-i \tau}\right) \sin (\tau+\psi)+O(\epsilon)
\end{aligned}
$$

onde ( )* representa o complexo conjugado.

Como tanto a amplitude complexa quanto a fase real ( $\phi$ e $\psi$, respectivamente) variam lentamente com relação à escala rápida, o lado direito das Equações 9.19 e 9.20 é substituído por seus valores médios em um ciclo da escala rápida e que tem período $\bar{\tau}=2 \pi$, resultando nas Equações 9.21 e 9.22. Esse procedimento é semelhante a outros métodos de média como, por exemplo, o método de Krylov-Bogoliubov (ver Nayfeh (1973)). Neste ponto, o leitor percebe a justificativa para a nomenclatura complexificação-média, comumente adotada para esse método de perturbação.

$$
\begin{aligned}
& \dot{\phi}+\epsilon \frac{\lambda_{2}}{2} \phi=\frac{\epsilon}{2}\left(-\frac{\hat{\delta}}{2} \phi^{*}+e^{i \psi}\left[\left(1+\dot{\psi}^{2}\right)-i \ddot{\psi}\right]\right) \\
& \ddot{\psi}+(1+\dot{\psi}) \beta_{3}=-\frac{1}{4 \hat{r}}\left(\phi e^{-i \psi}+\phi^{*} e^{i \psi}\right)+O(\epsilon)
\end{aligned}
$$

As Equações 9.21 e 9.22 são discutidas por meio do método das múltiplas escalas (ver, por exemplo, Bender e Orszag (1978) e Nayfeh e Mook (1979)). Nesse método, são assumidas as seguintes expansões assintóticas para $\phi$ e $\psi$ :

$$
\begin{aligned}
& \phi(\tau)=\phi_{0}\left(\tau_{0}, \tau_{1}\right)+\epsilon \phi_{1}\left(\tau_{0}, \tau_{1}\right) \\
& \psi(\tau)=\psi_{0}\left(\tau_{0}, \tau_{1}\right)+\epsilon \psi_{1}\left(\tau_{0}, \tau_{1}\right)
\end{aligned}
$$


onde as duas escalas de tempo são $\tau_{0}=\epsilon^{0} \tau=\tau$ e $\tau_{1}=\epsilon \tau$. Definindo a família de operadores diferenciais $D_{k}^{m}$ como na Equação 9.25 , as derivadas com relação a $\tau$ são escritas na forma das Equações 9.26 e 9.27.

$$
\begin{aligned}
& D_{k}^{m}()=\frac{\partial^{m}}{\partial \tau_{k}^{m}}() \\
& \dot{(})=\frac{\partial()}{\partial \tau_{0}}+\epsilon \frac{\partial()}{\partial \tau_{1}}+O\left(\epsilon^{2}\right)=D_{0}()+\epsilon D_{1}()+O\left(\epsilon^{2}\right) \\
& \ddot{(})=D_{0}^{2}()+2 D_{1} D_{0}()+O\left(\epsilon^{2}\right)
\end{aligned}
$$

Substituindo as definições dadas pelas Equações 9.23, 9.24, 9.25, 9.26 e 9.27 nas Equações 9.21 e 9.22 e coletando os termos de ordem $\epsilon^{0}$, as seguintes equações são obtidas:

$$
\begin{aligned}
& D_{0} \phi_{0}=0 \\
& D_{0}^{2} \psi_{0}+\beta_{3}\left(1+D_{0} \psi_{0}\right)=-\frac{1}{4 \hat{r}}\left(\phi e^{-i \psi_{0}}+\phi^{*} e^{i \psi_{0}}\right)
\end{aligned}
$$

A Equação 9.28 é facilmente resolvida como $\phi_{0}=\phi_{0}\left(\tau_{1}\right)$ que, por sua vez, pode ser escrito na forma polar como $\phi_{0}\left(\tau_{1}\right)=N e^{i \alpha} \operatorname{com} N=N\left(\tau_{1}\right)>0$ e $\alpha=\alpha\left(\tau_{1}\right)$. Com essas definições, a Equação 9.29 passa a ser escrita na forma da Equação 9.30.

$$
D_{0}^{2} \psi_{0}+\beta_{3}\left(1+D_{0} \psi_{0}\right)=-\frac{N}{2 \hat{r}} \cos \left(\psi_{0}-\alpha\right)
$$

Estuda-se, agora, os pontos de equilíbrio da Equação 9.30. Definindo $x_{1}=\psi_{0}$, $x_{2}=D_{0} \psi_{0}$ e $\mathbf{x}=\left\{\begin{array}{ll}x_{1} & x_{2}\end{array}\right\}^{t}$, a Equação 9.30 passa a ser escrita como o seguinte sistema de equações diferenciais de primeira ordem:

$$
D_{o} \mathbf{x}=\left\{\begin{array}{c}
x_{2} \\
-\frac{N}{2 \hat{r}} \cos \left(x_{1}-\alpha\right)-\beta_{3}\left(1+x_{2}\right)
\end{array}\right\}=\left\{\begin{array}{c}
f_{1}\left(x_{1}, x_{2}\right) \\
f_{2}\left(x_{1}, x_{2}\right)
\end{array}\right\}
$$

É trivial notar que os pontos de equilíbrio da Equação 9.31 são $x_{2}=D_{0} \psi_{0}=0$ e as seguintes quantidades.

$$
\begin{aligned}
\cos (\gamma-\alpha) & =-\frac{2 \beta_{3} \hat{r}}{N} \\
\gamma & =\lim _{\tau_{0} \rightarrow \infty} x_{1}
\end{aligned}
$$

Segundo Sigalov et al. (2012) e Gendelman e Alloni (2015), os pontos de equilíbrio das equações de ordem 1 (escala rápida) definem as chamadas slow invariant manifolds 
(SIM) do problema. Ainda segundo essas duas últimas referências, as equações de ordem $\epsilon$ (primeira escala lenta) governam a evolução da resposta sobre a SIM.

Como $\beta_{3}, \hat{r}$ e $N$ são não-negativos, a Equação 9.32 exige que $\cos (\gamma-\alpha)<0$. O estudo da estabilidade dos pontos de equilíbrio prossegue com o cálculo do polinômio característico da matriz Jacobiana da Equação 9.31 e de suas raízes, dados pelas Equações 9.34 e 9.35 respectivamente.

$$
\begin{aligned}
& \lambda^{2}+\beta_{3} \lambda-\frac{N}{2 \hat{r}} \sin (\gamma-\alpha) \\
& \lambda=\frac{-\beta_{3} \pm \beta_{3} \sqrt{1+\frac{2 N}{\beta_{3}^{2} \hat{r}} \sin (\gamma-\alpha)}}{2}
\end{aligned}
$$

Os pontos de equilíbrio são assintoticamente estáveis (no sentido Lyapunov) se $1+\frac{2 N}{\beta_{3}^{2} \hat{r}} \sin (\gamma-\alpha)<0$. Isso é garantido se $\sin (\gamma-\alpha)<0$ ou, de maneira equivalente, se $\sin (\alpha-\gamma)>0$. O leitor nota que a SIM, dada pelas Equações 9.32 e 9.33 apresenta dois ramos sendo apenas um deles estável.

Em sequência, discute-se um exemplo de resposta do tipo "RMA" já apresentado na seção anterior por meio da confrontação dos resultados numéricos com aqueles oriundos do método analítico discutido na presente seção. Considere as séries temporais ilustradas na Figura 114 e obtidas a partir da simulação numérica considerando $\hat{m}=0,06, \hat{r}=0,25$ e $\zeta_{\theta}=0,15$, levando a $\beta_{1}=\epsilon=0,014$. As duas retas verticais limitam o trecho que será analisado (regime de supressão) e para o qual a aproximação dada pela Equação 9.18 é válida.

Figura 114 - Séries temporais de resposta do cilindro e do supressor. $\hat{m}=0,06, \hat{r}=0,25$ e $\zeta_{\theta}=0,15$.

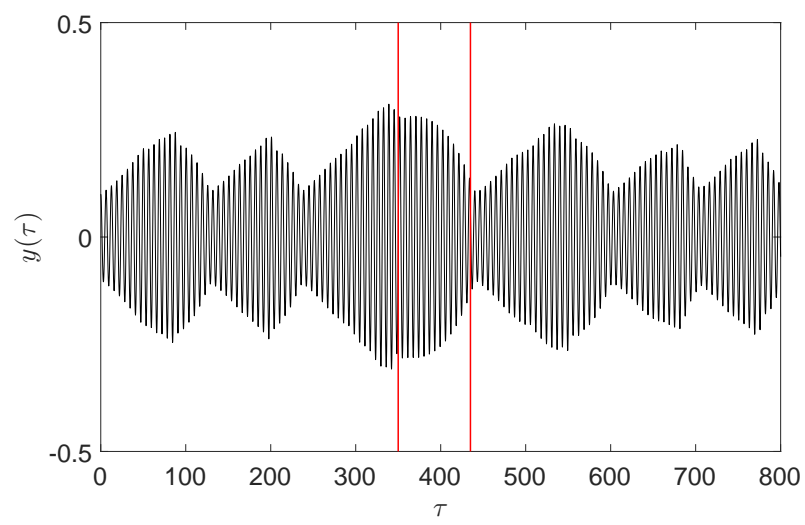

(a) $y(\tau)$.

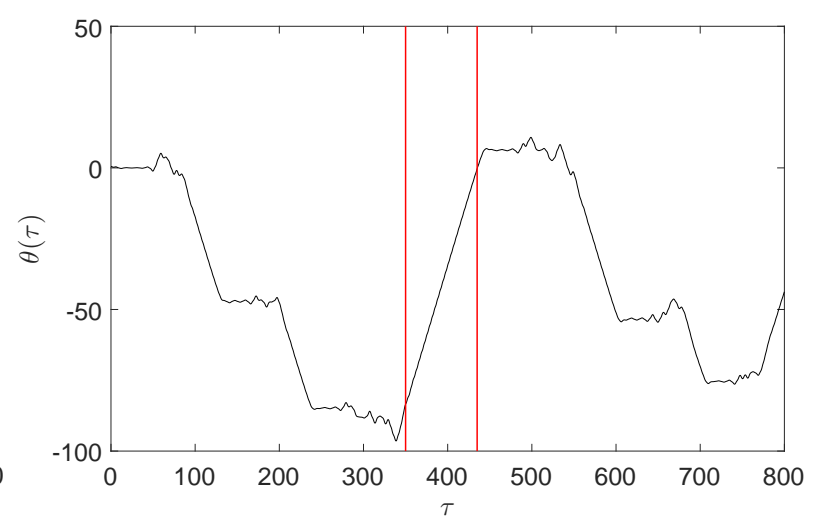

(b) $\theta(\tau)$.

Fonte: Extraída de Franzini, Campedelli e Mazzilli (2018).

A partir das séries temporais $y(\tau), \dot{y}(\tau)$ e $\theta(\tau)$ obtidas pela integração numérica 
das equações de movimento, a forma polar da amplitude complexa $\phi(\tau)=(\dot{y}+i y) e^{-i \tau}$ e a função $\psi(\tau)$ foram calculadas ${ }^{9}$ como (ver Equações 9.17 e 9.18):

$$
\begin{aligned}
& \phi(\tau)=\tilde{N}(\tau) e^{i \tilde{a}(\tau)} \\
& \psi(\tau)=\theta(\tau)-\tau
\end{aligned}
$$

Para essa particular configuração do supressor, a SIM pode ser calculada a partir da Equação 9.32 e é exibida na Figura 115. Essa figura mostra, ainda, os ramos estável e instável da SIM. A partir da análise da Equação 9.17, nota-se que a menor amplitude $N$ pertencente à SIM é $2 \beta_{3} \hat{r}=0,15$. Como o parâmetro $\beta_{3}$ está ligado à taxa de amortecimento do NVA (ver Equação 9.7), nota-se que o aumento dessa grandeza aumenta a menor amplitude de resposta possível na SIM.

Figura 115 - Apresentação da SIM para o caso onde o supressor é definido por $\hat{m}=0,06$, $\hat{r}=0,25$ e $\zeta_{\theta}=0,15$.

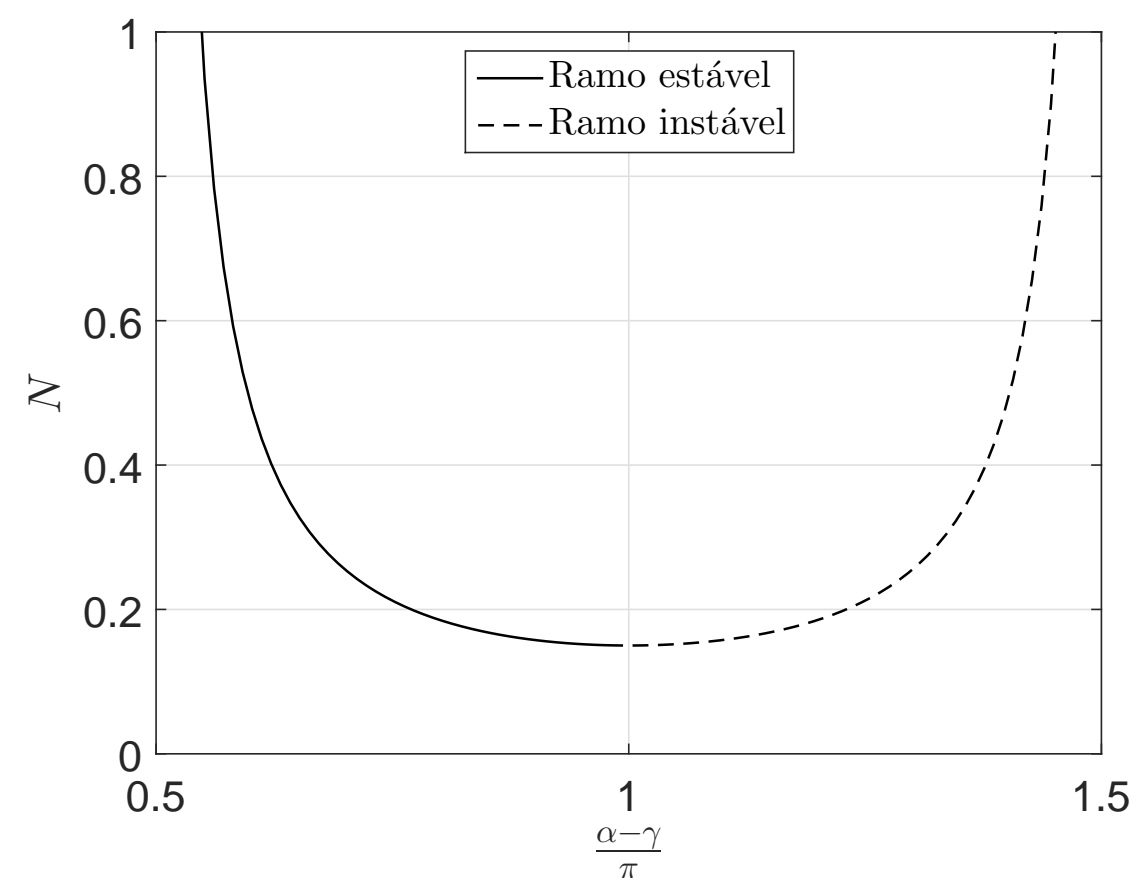

Fonte: Elaborada pelo autor.

A Figura 116 mostra a série temporal da diferença de fase $\tilde{a}-\psi$, destacando o trecho analisado entre duas retas identificadas com a cor vermelha. A inspeção dessa figura mostra que, durante praticamente todo o trecho analisado, a defasagem $\tilde{a}-\psi$ é praticamente constante. Sob o prisma do conceito de sincronização definido em Pikovsky, Rosenblum e Kurths (2001) e já utilizado no capítulo 7 quando da análise experimental

9 Note que as funções $\tilde{N}(\tau)$ e $\tilde{a}(\tau)$ não devem ser confundidas com os termos $N\left(\tau_{1}\right)$ e $a\left(\tau_{1}\right)$ resultantes da análise assintótica. 
do fenômeno de VIV, a pouca variação da diferença de fase $\tilde{a}-\psi$ revela, ao menos do ponto de vista qualitativo, a sincronização entre o movimento do cilindro (definido por $\tilde{\alpha}(\tau)$ ) e a resposta do NVA (governada por $\psi(\tau)$ ).

Figura 116 - Série temporal da defasagem $\tilde{\alpha}-\psi \cdot \hat{m}=0,06, \hat{r}=0,25$ e $\zeta_{\theta}=0,15$.
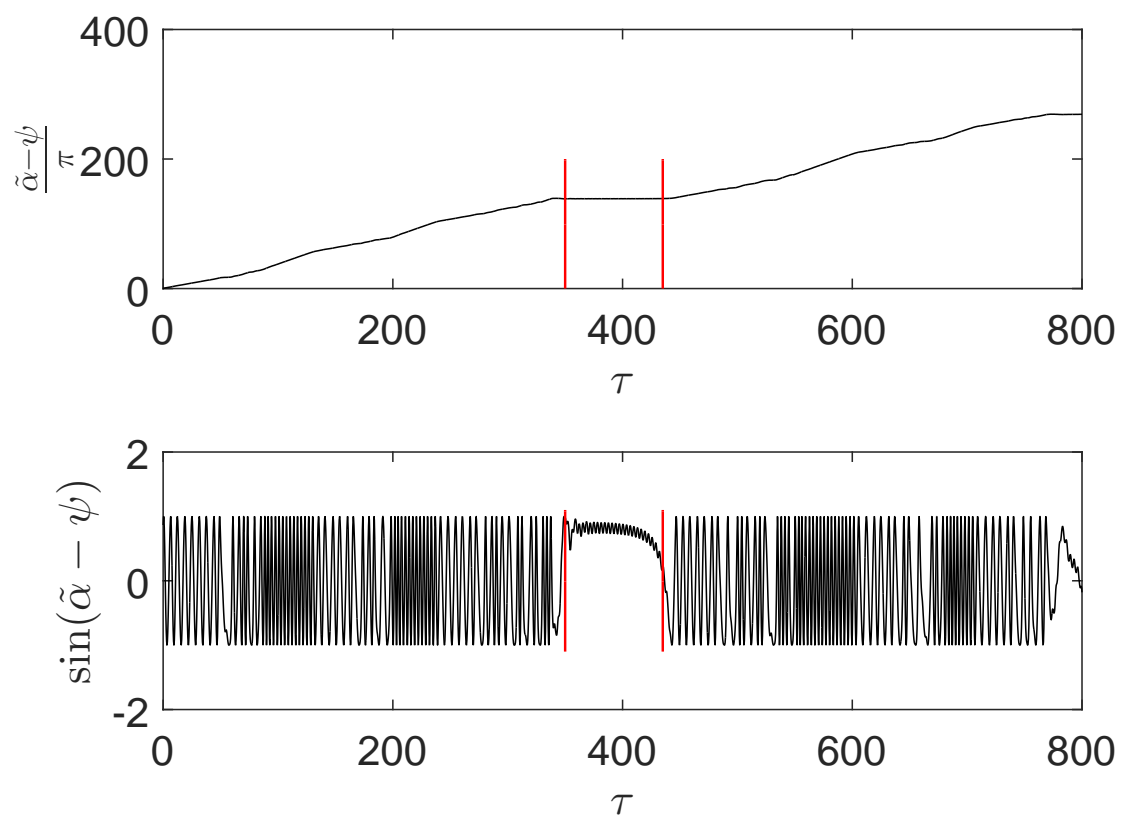

Fonte: Elaborada pelo autor.

Por fim, a Figura 117 ilustra a trajetória ${ }^{10}$ da resposta numericamente obtida sobre a SIM. Como pode ser notado nessa figura, o regime de supressão é caracterizado pela captura da resposta do sistema composto do cilindro e do supressor na SIM.

Com a diminuição da amplitude $\tilde{N}$ decorrente da atuação do NVA, a resposta do escapa da SIM, dando origem ao regime de crescimento. Em concordância com outros trabalhos que empregam NVAs rotativos como supressores passivos, pode-se afirmar que o funcionamento do NVA é, no caso da resposta do tipo "RMA" aqui obtida, caracterizada por uma ressonância $n: \hat{\omega}: \omega_{r}=2: 1: 1$ onde a resposta do cilindro $\hat{\omega}$ é metade daquela da excitação paramétrica e igual à frequência típica de rotação do NVA.

\subsection{Considerações finais do capítulo e perspectivas de continuidade da pesquisa}

Este capítulo focou na análise numérica do problema de supressão passiva de vibrações decorrentes da excitação paramétrica por meio de um absorvedor não-linear de vibração rotativo. Tomando por base a revisão bibliográfica conduzida, essa abordagem

10 Convém ressaltar ao leitor que uma análise similar foi conduzida em Blanchard et al. (2016) para o fenômeno VIV-1gl. 
Figura 117 - Comparação entre a resposta e a SIM. $\hat{m}=0,06, \hat{r}=0,25$ e $\zeta_{\theta}=0,15$.

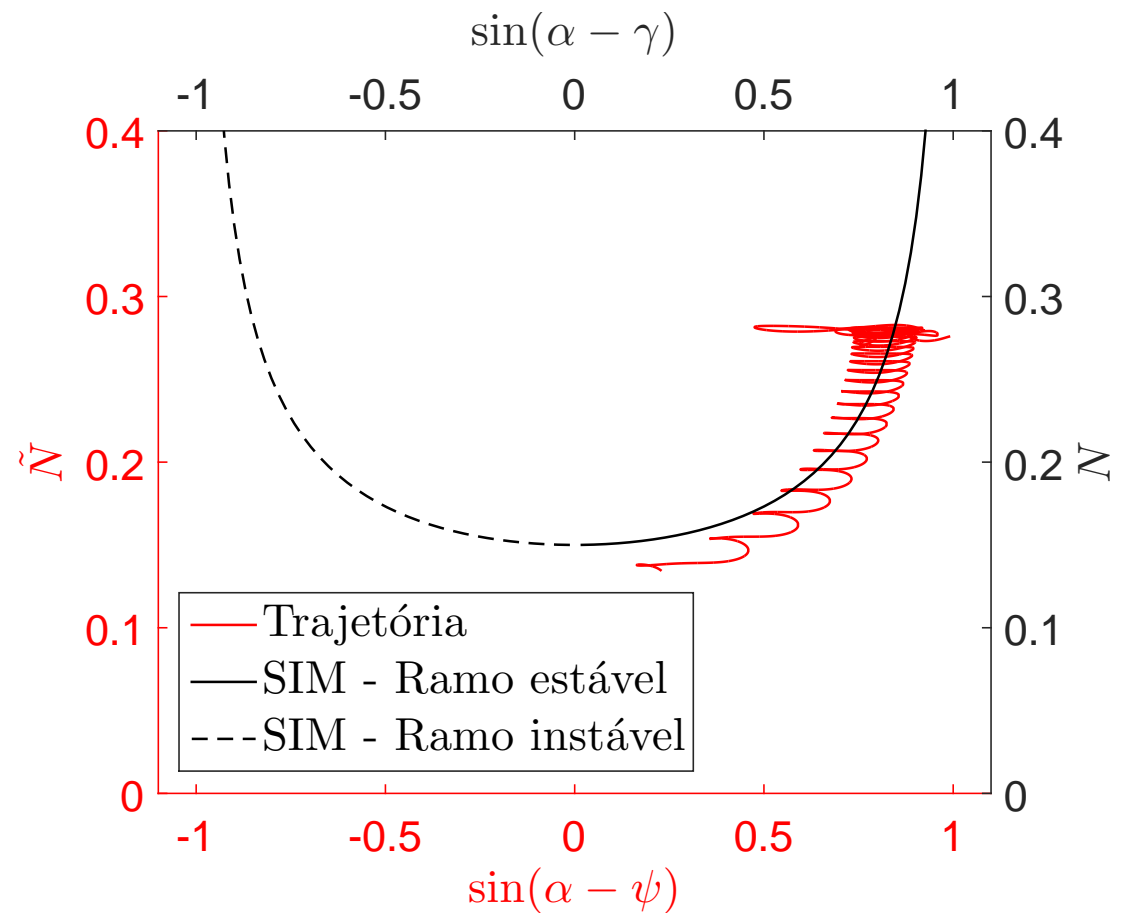

Fonte: Adaptada de Franzini, Campedelli e Mazzilli (2018).

não foi encontrada na literatura e configura uma contribuição do autor deste texto ao estado-da-arte no tema de mitigação de vibrações por meio de NVAs.

Em particular, foi analisado o caso em que a amplitude de variação de rigidez é $10 \%$ do seu valor médio e onde a frequência da excitação paramétrica é o dobro da frequência natural não amortecida associada ao problema autônomo, ou seja, aquele onde não há variação de rigidez. O principal resultado obtido foi que o NVA rotativo é capaz de limitar a resposta da estrutura controlada mesmo no cenário de instabilidade paramétrica principal e no qual o cilindro (estrutura principal a ser controlada) sem o supressor apresenta respostas ilimitadas.

Foram construídos mapas mostrando o desvio padrão da resposta do cilindro como função dos parâmetros que definem o NVA (a saber, sua massa, raio e amortecimento). Dentre os cenários estudados, aquele com a menor taxa de amortecimento do supressor foi o que exibiu a maior capacidade de supressão. Nesse caso, o comportamento do desvio padrão da série temporal do cilindro como função da massa e do raio do apresentou um caráter fractal, ou seja, houve uma erosão no plano de parâmetros de controle. Esse caráter pode não ser interessante quando do projeto de um dispositivo com vistas a uma aplicação tecnológica. O aumento da taxa de amortecimento do supressor, embora leve a um aumento da resposta da estrutural principal, diminui a erosão supra-citada.

Estudos paramétricos obtidos a partir da variação da massa, do raio e da constante de amortecimento do supressor (representadas pelos parâmetros adimensionais $\hat{m}, \hat{r}$ e $\zeta_{\theta}$ 
respectivamente) mostraram a existência de diversos tipos de resposta estrutural, a saber: respostas com modulação de amplitude ("RMA"), respostas com amplitude constante ("RAC"), respostas com supressão completa ("SC") e respostas mistas ("RM").

Em particular, as respostas do tipo "RMA" foram investigadas mais a fundo e são definidas por dois regimes intermitentes. No regime de supressão, o NVA rotaciona com velocidade aproximadamente constante, o que promove a TET. Já no regime de crescimento da resposta, o supressor está em uma posição angular praticamente constante e alinhado com a direção do movimento da estrutura principal. Nesse último regime, a equação de movimento associada ao supressor é trivialmente satisfeita, restando como modelo matemático para a resposta do cilindro a equação de Mathieu amortecida.

O estudo analítico conduzido por meio de um método de perturbação sobre o regime de supressão de uma resposta do tipo "RMA" possibilitou identificar que esse regime é caracterizado pela captura da resposta do sistema em uma slow invariant manifold (SIM) definida por uma ressonância $2: 1: 1$. Como não foi encontrado um ponto fixo sobre a SIM, a resposta do sistema composto do cilindro e do NVA escapa da SIM, o que dá origem ao regime de crescimento.

A condução dos estudos numéricos aqui apresentados abriram frente para diversas ramificações nessa linha de pesquisa. Uma delas consiste do uso de métodos assintóticos de perturbação como ferramentas auxiliares para analisar os diversos tipos de respostas obtidos. Uma segunda frente de trabalhos para a continuidade da pesquisa foca no estudo da sensibilidade da resposta no que diz respeito às condições iniciais. Esse estudo é motivado por indícios de respostas caóticas em outros trabalhos da literatura que usam NVAs rotativos como supressores passivos de vibração para problemas distintos daquele que é objeto do presente capítulo (ver, por exemplo, Gendelman e Alloni (2015) e Blanchard et al. (2016)).

Também do ponto de vista numérico, pretende-se investigar o problema combinado de supressão passiva e aproveitamento de energia. Em particular e em virtude de algumas características da resposta do NVA como, por exemplo, rotação com velocidade praticamente constante, existe potencial aplicação para conversão de energia a partir de efeitos eletromagnéticos. Nesse caso, a dinâmica do circuito elétrico deve ser incorporada ao modelo matemático. Cumpre ressaltar que o estudo combinado de supressão passiva por meio de um NVA e de aproveitamento de energia é tema candente na literatura. Como exemplo, tem-se o trabalho de Pennisi et al. (2018) e que foca em uma fonte de excitação distinta da excitação paramétrica.

Por fim, pretende-se conduzir estudos experimentais relacionados à supressão passiva de vibrações decorrentes da excitação paramétrica. Em um primeiro momento, esses estudos serão conduzidos utilizando um cilindro flexível sujeito a movimento vertical imposto ao topo por meio de um arranjo semelhante àquele que foi objeto da seção 7.2. 
Embora de natureza distinta do modelo de corpo rígido montado em base elástica investigado no presente capítulo, o arranjo com modelo flexível é de mais fácil construção. Nesse caso, um ou mais supressores podem ser empregados simultaneamente e montados também externamente ao modelo, o que facilita sobremaneira a construção do arranjo experimental. Do ponto de vista de modelo matemático, a montagem do NVA externamente ao corpo flexível indica que a distância entre a massa do supressor e o eixo do cilindro é superior ao raio do último. Cumpre ressaltar que estudos numéricos do problema de supressão passiva de excitação paramétrica em um cabo vertical são o objeto de estudos na aluna do Technische Univeristät Darmstadt Pauline Kölb, que desenvolverá seu trabalho de conclusão de curso sob orientação do autor do presente texto ao longo do primeiro semestre de 2019. Pretende-se que a aluna adapte o modelo matemático descrito na seção 8.1 para a condução de sua pesquisa.

De maneira análoga àquela mencionada na seção 8.3 quando da apresentação de estudos experimentais envolvendo a coexistência dos fenômenos VIV-1gl e VIV-2gl com a excitação paramétrica, os estudos com cilindros rígidos montados em base elástica de rigidez dependente do tempo podem ser conduzidos desde que exista um dispositivo capaz de impor essa modulação de rigidez. Um possível dispositivo para essa tarefa é aquele onde as molas e amortecedores físicos são substituídos por atuadores eletromecânicos capazes de imporem forças proporcionais ao deslocamento e à velocidade do corpo.

No entanto, é importante enfatizar que tais sistemas são bastante complexos e demandam a implementação de sistemas de controle e inúmeros testes. Um exemplo de dispositivo que emula molas e amortecedores por meio de atuadores eletromecânicos é o virtual damper-spring ( $\left.\mathrm{V}_{\mathrm{CK}}\right)$, utilizado em Lee e Bernitsas (2011) para condução de experimentos de VIV, porém sem considerar o efeito de excitação paramétrica. 


\section{Supressão passiva de vibrações induzidas pelo escoamento}

Este capítulo foca na apresentação de contribuições atinentes à supressão passiva dos fenômenos de VIV e de galloping por meio de um NVA rotativo. Em particular, busca-se identificar a influência dos parâmetros que caracterizam o supressor (a saber, seu raio, sua massa e sua constante de amortecimento) na sua capacidade de mitigação dos fenômenos que são o objeto do presente capítulo.

Este capítulo está organizado em três seções. A seção 10.1 foca no problema de supressão do fenômeno de VIV em cilindros rígidos montados em apoio elástico com um e dois graus de liberdade e emprega o conceito de wake-oscillators como modelos de ordem reduzida para o carregamento hidrodinâmico. Por sua vez, a seção 10.2 discute a mitigação do galloping em um prisma rígido, de seção transversal quadrada e montado em apoio elástico unidirecional (a saber, a direção cross-wise). Nessa seção, a modelagem matemática do carregamento decorrente da interação fluido-estrutura emprega a hipótese quase-estática já discutida na seção 4.2. Finalmente, a seção 10.3 apresenta as considerações finais deste capítulo bem como propostas para a continuidade das pesquisas aqui descritas.

\subsection{Supressão passiva do fenômeno de VIV}

A presente seção tem como objetivo a análise numérica da supressão passiva, via NVA rotativo, do fenômeno de VIV em cilindros rígidos montados em base elástica. Os esforços decorrentes da interação fluido-estrutura são modelados por meio do conceito de wake-oscillators. Como pode ser visto ao longo desta seção, o supressor estudado mostra-se mais eficiente para a condição VIV-1gl do que para VIV-2gl.

Além desse resultado principal, são discutidas as curvas de amplitude característica de oscilação do cilindro como funções da massa, do raio e da taxa de amortecimento do NVA rotativo para toda a faixa de velocidades reduzidas característica do lock-in. Como mencionado na revisão bibliográfica apresentada na seção 5.2, praticamente não existem estudos que foquem na supressão passiva do fenômeno de VIV por meio de NVAs cobrindo toda a região de lock-in, o que confere inovação à pesquisa aqui apresentada. Mais ainda, o uso de wake-oscillators como metodologia para modelagem do carregamento permite, com relativa facilidade, o estudo da sensibilidade da resposta do sistema hidro-elástico com relação aos parâmetros que definem o NVA, o que constitui outro ganho de conhecimento com relação à literatura. 
Os resultados apresentados nesta seção foram obtidos pela pós-graduanda Tatiana Ueno no âmbito de sua dissertação de mestrado (ver Ueno (2019)) e constam em Ueno e Franzini (2019), artigo submetido para apreciação do comitê científico do International Journal of Non-Linear Mechanics. Os resultados do artigo submetido para o referido periódico indexado complementam aqueles apresentados em Ueno, Sato e Franzini (2018), trabalho publicado na 9th International Symposium on Fluid-Structure Interactions, FlowSound Interactions, Flow-Induced Vibration \& Noise.

Esta seção está organizada em três subseções, sendo que a subseção 10.1.1 é dedicada à apresentação dos modelos matemáticos do problema de supressão passiva das condições VIV-1gl e VIV-2gl. A subseção 10.1.2 traz as metodologias de simulação e de análise de resultados. Por fim, os resultados são apresentados e discutidos na subseção 10.1.3.

\subsubsection{Modelagem matemática do problema de supressão passiva}

O problema investigado nesta seção é apresentado de forma esquemática na Figura 118. Essa figura ilustra um cilindro rígido de massa $M$, comprimento imerso $L$ e diâmetro externo $D$ e que é dotado de um NVA rotativo de massa $m$, raio $r$ e constante de amortecimento $c_{\theta}$. O cilindro está imerso em um fluido de massa específica $\rho$ e caracterizado por uma velocidade incidente $U_{\infty}$.

Na condição esquematizada na Figura 118(a), o cilindro tem liberdade de oscilação somente na direção cross-wise e está montado em um apoio de rigidez e constante de amortecimento lineares de valores $k_{y}$ e $c_{y}$ respectivamente. Já na condição VIV-2gl, ilustrada na Figura 118(b), a rigidez e a constante de amortecimento na direção in-line ( $k_{x}$ e $c_{x}$, respectivamente) caracterizam o apoio em conjunto com grandezas $k_{y}$ e $c_{y}$.

Figura 118 - Representações esquemáticas do problema em estudo.

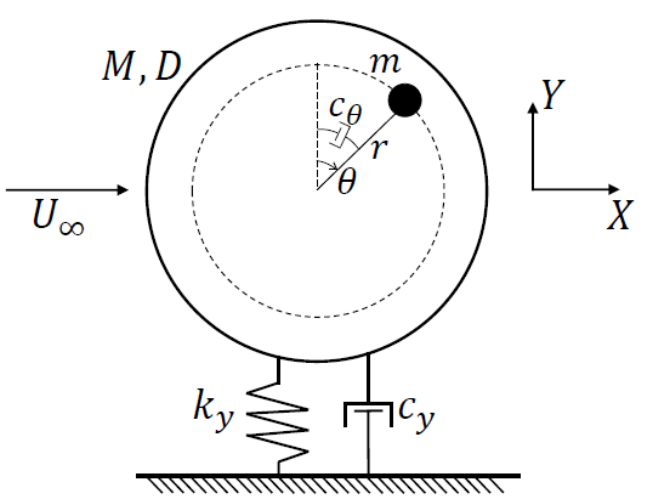

(a) VIV-1gl.

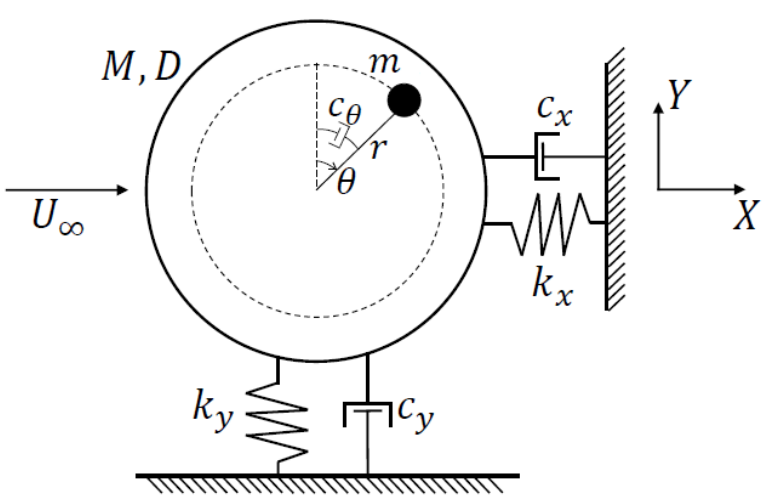

(b) VIV-2gl.

Fonte: Adaptada de Ueno (2019).

Este texto apresenta as equações de movimento em suas formas finais, de sorte que as deduções completas podem ser encontradas em Ueno (2019). Para a condição VIV-1gl, o 
carregamento foi considerado empregando o modelo descrito em Ogink e Metrikine (2010) (ver também subseção 4.1.5), levando às seguintes equações de movimento:

$$
\begin{aligned}
& \left(M+m+m_{a}^{p o t}\right) \frac{d^{2} Y}{d t^{2}}-m r \sin \theta \frac{d^{2} \theta}{d t^{2}}-m r \cos \theta\left(\frac{d \theta}{d t}\right)^{2}+c_{y} \frac{d Y}{d t}+k_{y} Y= \\
& =\frac{1}{2} \rho U_{\infty}^{2} D L C_{y, v} \\
& m r^{2} \frac{d^{2} \theta}{d t^{2}}-m r \sin \theta \frac{d^{2} Y}{d t^{2}}+c_{\theta} \frac{d \theta}{d t}=0 \\
& \frac{d^{2} q_{y}}{d t^{2}}+\varepsilon_{y} \omega_{f}\left(q_{y}^{2}-1\right) \frac{d q_{y}}{d t}+\omega_{f}^{2} q_{y}=\frac{A_{y}}{D} \frac{d^{2} Y}{d t^{2}}
\end{aligned}
$$

Visando uma maior generalidade, as Equações 10.1, 10.2 e 10.3 são reescritas na forma adimensional. Para tanto, as seguintes grandezas são definidas:

$$
\begin{aligned}
& y=\frac{Y}{D} ; \quad \zeta_{y}=\frac{c_{y}}{2\left(M+m+m_{a}^{p o t}\right) \omega_{n, y}} ; \quad m^{*}=\frac{(M+m)}{m_{d}}=\frac{4(M+m)}{\rho \pi D^{2} L} ; \\
& \hat{m}=\frac{m}{M} ; \quad \hat{r}=\frac{r}{D} ; \quad \zeta_{\theta}=\frac{c_{\theta}}{2 m r^{2} \omega_{n, y}} ; \quad C_{a}^{p o t}=\frac{4 m_{a}^{p o t}}{\rho \pi D^{2} L} ; \\
& U_{r}=\frac{U_{\infty}}{f_{n, y} D} ; \quad S t=\frac{f_{f} D}{U_{\infty}} ; \quad \tau=\omega_{n, y} t
\end{aligned}
$$

onde $\omega_{n, y}=\sqrt{\frac{k_{y}}{M+m+m_{a}^{p o t}}}$ é a frequência natural do cilindro imerso em água parada e dotado de uma massa interna igual à massa do NVA, porém sem que ela tenha deslocamento relativo com relação ao cilindro.

Definindo $(\dot{\text { ) }}$ como a derivada com relação ao tempo adimensional $\tau$ e levando as quantidades definidas na Equação 10.4 nas Equações 10.1, 10.2 e 10.3, o problema de supressão passiva da condição VIV-1gl via NVA rotativo é descrito, em sua forma adimensional, pelo seguinte sistema de equações diferenciais ordinárias:

$$
\begin{aligned}
& \ddot{y}-\left(\frac{\hat{m}}{1+\hat{m}}\right)\left(\frac{m^{*}}{C_{a}^{p o t}+m^{*}}\right) \hat{r}\left[\sin \theta \ddot{\theta}+\cos \theta \dot{\theta}^{2}\right]+2 \zeta_{y} \dot{y}+y= \\
& =\frac{U_{r}^{2}}{2 \pi^{3}\left(C_{a}^{p o t}+m^{*}\right)} \sqrt{1+\left(\frac{2 \pi}{U_{r}} \dot{y}\right)^{2}}\left(\frac{C_{L}^{0}}{\hat{q}_{y}} q_{y}-\frac{2 \pi}{U_{r}} C_{D} \dot{y}\right) \\
& \ddot{\theta}-\frac{1}{\hat{r}} \sin \theta \ddot{y}+2 \zeta_{\theta} \dot{\theta}=0 \\
& \ddot{q}_{y}+\varepsilon_{y} S t U_{r}\left(q_{y}^{2}-1\right) \dot{q}_{y}+\left(S t U_{r}\right)^{2} q_{y}=A_{y} \ddot{y}
\end{aligned}
$$

Já a condição VIV-2gl considera o modelo descrito em Franzini e Bunzel (2018), já apresentado na subseção 8.2.2, como alternativa para cálculo do carregamento hidrodinâmico. Também empregando as equações de Euler-Lagrange como descrito em Ueno (2019), 
é possível mostrar que o problema de supressão passiva da condição VIV-2gl é governado pelas seguintes equações:

$$
\begin{aligned}
& \left(M+m+m_{a}^{p o t}\right) \frac{d^{2} Y}{d t^{2}}-m r\left[\sin \theta \frac{d^{2} \theta}{d t^{2}}+\cos \theta\left(\frac{d \theta}{d t}\right)^{2}\right]+c_{y} \frac{d Y}{d t}+k_{y} Y= \\
& =\frac{1}{2} \rho U_{\infty}^{2} D L C_{y, v} \\
& \left(M+m+m_{a}^{p o t}\right) \frac{d^{2} X}{d t^{2}}+m r\left[\cos \theta \frac{d^{2} \theta}{d t^{2}}-\sin \theta\left(\frac{d \theta}{d t}\right)^{2}\right]+c_{x} \frac{d X}{d t}+k_{x} X= \\
& =\frac{1}{2} \rho U_{\infty}^{2} D L C_{x, v} \\
& m r^{2} \frac{d^{2} \theta}{d t^{2}}+m r \cos \theta \frac{d^{2} X}{d t^{2}}-m r \sin \theta \frac{d^{2} Y}{d t^{2}}+c_{\theta} \frac{d \theta}{d t}=0 \\
& \frac{d^{2} q_{y}}{d t^{2}}+\varepsilon_{y} \omega_{f}\left(q_{y}^{2}-1\right) \frac{d q_{y}}{d t}+\omega_{f}^{2} q_{y}=\frac{A_{y}}{D} \frac{d^{2} Y}{d t^{2}} \\
& \frac{d^{2} q_{x}}{d t^{2}}+\varepsilon_{x} \omega_{f}\left(q_{x}^{2}-1\right) \frac{d q_{x}}{d t}+\left(2 \omega_{f}\right)^{2} q_{x}=\frac{A_{x}}{D} \frac{d^{2} X}{d t^{2}}
\end{aligned}
$$

Novamente e, tendo em vista a maior generalidade das análises, opta-se pelo estudo de um modelo matemático escrito em sua forma adimensional. Para tanto, considere as seguintes quantidades em adição àquelas apresentadas Equação 10.4.

$$
x=\frac{X}{D} ; \quad \zeta_{x}=\frac{c_{x}}{2\left(M+m+m_{a}^{p o t}\right) \omega_{n, x}} ; \quad f^{*}=\frac{\omega_{n, x}}{\omega_{n, y}}
$$

com $\omega_{n, x}=\sqrt{\frac{k_{x}}{M+m+m_{a}^{p o t}}}$. O leitor logo nota que $f^{*}$ representa uma relação entre os valores de rigidez nas direções cross-wise e in-line.

Levando os adimensionais definidos nas Equações 10.4 e 10.13 nas Equações 10.8, 10.9, 10.10, 10.11 e 10.12, o seguinte modelo matemático adimensional é obtido: 


$$
\begin{aligned}
& \ddot{y}-\left(\frac{\hat{m}}{1+\hat{m}}\right)\left(\frac{m^{*}}{C_{a}^{p o t}+m^{*}}\right) \hat{r}\left[\sin \theta \ddot{\theta}+\cos \theta \dot{\theta}^{2}\right]+2 \zeta_{y} \dot{y}+y= \\
& =\frac{U_{r}}{2 \pi^{3}\left(C_{a}^{p o t}+m^{*}\right)} \sqrt{1-\frac{4 \pi}{U_{r}} \dot{x}+\left(\frac{2 \pi}{U_{r}}\right)^{2}\left(\dot{x}^{2}+\dot{y}^{2}\right)} \\
& {\left[\left(U_{r}-2 \pi \dot{x}\right) \frac{\hat{C}_{L}^{0}}{\hat{q}_{y}} q_{y}-2 \pi \dot{y}\left(\bar{C}_{D}^{0}+\frac{\hat{C}_{D}^{0}}{\hat{q}_{x}} q_{x}\right)\right]} \\
& \ddot{x}+\left(\frac{\hat{m}}{1+\hat{m}}\right)\left(\frac{m^{*}}{C_{a}^{p o t}+m^{*}}\right) \hat{r}\left[\cos \theta \ddot{\theta}-\sin \theta \dot{\theta}^{2}\right]+2 \zeta_{x} f^{*} \dot{x}+\left(f^{*}\right)^{2} x= \\
& =\frac{U_{r}}{2 \pi^{3}\left(C_{a}^{p o t}+m^{*}\right)} \sqrt{1-\frac{4 \pi}{U_{r}} \dot{x}+\left(\frac{2 \pi}{U_{r}}\right)^{2}\left(\dot{x}^{2}+\dot{y}^{2}\right)} \\
& {\left[\left(U_{r}-2 \pi \dot{x}\right)\left(\bar{C}_{D}^{0}+\frac{\hat{C}_{D}^{0}}{\hat{q}_{x}} q_{x}\right)+2 \pi \dot{y}\left(\frac{\hat{C}_{L}^{0}}{\hat{q}_{y}} q_{y}\right)\right]} \\
& \ddot{\theta}-\frac{1}{\hat{r}}(\sin \theta \ddot{y}-\cos \theta \ddot{x})+2 \zeta_{\theta} \dot{\theta}=0 \\
& \ddot{q}_{y}+\varepsilon_{y} S t U_{r}\left(q_{y}^{2}-1\right) \dot{q}_{y}+\left(S t U_{r}\right)^{2} q_{y}=A_{y} \ddot{y} \\
& \ddot{q}_{x}+\varepsilon_{x} S t U_{r}\left(q_{x}^{2}-1\right) \dot{q}_{x}+\left(2 S t U_{r}\right)^{2} q_{x}=A_{x} \ddot{x}
\end{aligned}
$$

\subsubsection{Metodologias de simulação e de análise}

As Equações 10.5, 10.5 e 10.5 (descritivas da supressão passiva do fenômeno VIV-1gl) ou 10.14, 10.15, 10.16, 10.17 e 10.18 (referentes à condição VIV-2gl) foram numericamente integradas utilizando o método de Runge-Kutta implementado na função ode45 do MATLAB ${ }^{\circledR}$. As simulações foram realizadas durante $\tau_{\max }=800$ e com passo de integração $\Delta \tau=0,01$. Em todas as simulações, a condição inicial não trivial associada ao supressor foi $\theta(0)=\pi / 6$. A outra condição inicial não trivial adotada foi $q_{y}(0)=0,1$ (VIV-1gl) ou $q_{y}(0)=0,01$ (VIV-2gl). Como já mencionado na seção 9.2, a não-linearidade dos modelos matemáticos indica uma possível dependência da resposta às condições iniciais. Embora interessante, tal estudo não foi aqui conduzido, ficando como uma sugestão de trabalhos futuros.

Os valores empíricos que aparecem nas abordagens via wake-oscillators foram empregados segundo a Tabela 11. Cumpre ressaltar que a transição do upper branch para o lower branch existente na condição VIV-1gl foi definida como ocorrendo em $U_{r}=6,5$.

Os valores do parâmetro de massa reduzida e da taxa de amortecimento estrutural foram, respectivamente, $m^{*}=2,6$ e $\zeta_{y}=\zeta_{x}=8 \times 10^{-4}$, os mesmos empregados na campanha experimental descrita em Franzini et al. (2012a). Nesses experimentos, o cilindro estava sujeito somente à ação da interação fluido-estrutura, sem qualquer forma de supressão.

Como mencionado, um dos ganhos de conhecimento com relação à literatura existente reside no estudo do problema de supressão do VIV para diversos valores de 
Tabela 11 - Valores dos parâmetros do modelo apresentado em Franzini e Bunzel (2018).

\begin{tabular}{|c|c|c|c|c|c|}
\hline \multicolumn{3}{|c|}{ VIV-1gl } & \multicolumn{3}{|c|}{ VIV-2gl } \\
\hline $\begin{array}{l}\epsilon_{y} \\
A_{y}\end{array}$ & $\begin{array}{c}0,05 \\
4\end{array}$ & $U_{r}<6,5$ & $\begin{array}{l}\epsilon_{y} \\
\epsilon_{x} \\
A_{y} \\
A_{x}\end{array}$ & $\begin{array}{c}0,0045 e^{0,228 m^{*}} \\
0,6 \\
2 \\
12\end{array}$ & $U_{r}<8$ \\
\hline$A_{y}$ & $\begin{array}{l}0,7 \\
12\end{array}$ & $U_{r} \geq 6,5$ & $\begin{array}{l}\epsilon_{y} \\
\epsilon_{x} \\
A_{y} \\
A_{x}\end{array}$ & $\begin{array}{l}0,7 \\
0,7 \\
12 \\
12 \\
\end{array}$ & $U_{r} \geq 8$ \\
\hline $\begin{array}{c}\hat{C}_{L}^{0} \\
\bar{C}_{D}^{0} \\
S t\end{array}$ & $\begin{array}{l}0,3842 \\
1,1856 \\
0,1932\end{array}$ & $0 \leq U_{r} \leq 15$ & $\begin{array}{l}\hat{C}_{I}^{c} \\
\bar{C}_{I}^{0} \\
\hat{C}_{L}^{0} \\
S t\end{array}$ & $\begin{array}{c}0,3842 \\
1,1856 \\
0,2 \\
0,17\end{array}$ & $0 \leq U_{r} \leq 15$ \\
\hline
\end{tabular}

Fonte: Adaptada de Franzini e Bunzel (2018).

velocidade reduzida que caracterizam o regime de lock-in. Assim, as simulações numéricas foram conduzidas no intervalo $2 \leq U_{r} \leq 14$, com incrementos de 0,1 . As amplitudes características de oscilação nas direções in-line e cross-wise ( $\hat{A}_{x}$ e $\hat{A}_{y}$ respectivamente) foram calculadas como:

$$
\begin{aligned}
& \hat{A}_{x}=\sqrt{2}(x-\bar{x})_{s t d} \\
& \hat{A}_{y}=\sqrt{2}(y)_{s t d}
\end{aligned}
$$

onde o subscrito ( ) std denota o desvio padrão da correspondente série temporal considerando apenas $\tau>$ 400. Tal consideração evita incluir eventuais transitórios iniciais na redução dos resultados. Note que a multiplicação do desvio padrão da série temporal por $\sqrt{2}$ fornece a amplitude de um sinal harmônico e monocromático. Como é visto na próxima subseção, algumas respostas do cilindro certamente não podem ser enquadradas como possuindo essas características.

Relembrando que um dos objetivos desta seção é identificar a influência de cada parâmetro que define o NVA rotativo na sua capacidade de supressão, é interessante que a condução das simulações numéricas seja feita de maneira sistemática. Para tanto, foram conduzidos três grupos de simulação, nos quais apenas um parâmetro varia enquanto os outros dois são mantidos constantes. Além desses três grupos, uma configuração de referência ("Sim-0") arbitrada como sendo definida por $\hat{m}=0,05, \hat{r}=0,50$ e $\zeta_{\theta}=0,10$ foi estudada. A Tabela 12 traz os parâmetros do NVA utilizados nas diversas simulações conduzidas.

Visando quantificar a eficiência do NVA, a presente seção faz uso de um métrica, 
Tabela 12 - Valores numéricos dos parâmetros que definem o NVA rotativo.

\begin{tabular}{c|c|c|c|c|c}
\hline \hline \multicolumn{2}{c|}{$\begin{array}{c}\text { Grupo 1 } \\
\hat{r}=0,50\end{array}$} & \multicolumn{2}{c|}{$\begin{array}{c}\text { Grupo 2 } \\
\hat{m}=0,05\end{array}$} & \multicolumn{2}{c}{$\begin{array}{c}\text { Grupo 3 } \\
\hat{m}=0,05\end{array}$} \\
\multicolumn{2}{c|}{$\zeta_{\theta}=0,10$} & \multicolumn{2}{c}{$\zeta_{\theta}=0,10$} & \multicolumn{2}{r}{$=0,50$} \\
\hline \hline Sim & $\hat{m}$ & Sim & $\hat{r}$ & Sim & $\zeta_{\theta}$ \\
\hline \hline G1-Sim1 & 0,03 & G2-Sim1 & 0,40 & G3-Sim1 & 0,20 \\
G1-Sim2 & 0,07 & G2-Sim2 & 0,30 & G3-Sim2 & 0,15 \\
G1-Sim3 & 0,10 & G2-Sim3 & 0,20 & G3-Sim3 & 0,08 \\
G1-Sim4 & 0,12 & G2-Sim4 & 0,10 & G3-Sim4 & 0,05 \\
G1-Sim5 & 0,15 & & & G3-Sim5 & 0,01 \\
\hline \hline
\end{tabular}

Fonte: Adaptada de Ueno (2019).

aqui chamada critério $\hat{S}$, dada pela Equação 10.21 .

$$
\hat{S}\left(U_{r}\right)=1-\frac{\hat{A}_{y, N V A}\left(U_{r}\right)}{\hat{A}_{y, 0}\left(U_{r}\right)}
$$

onde $\hat{A}_{y, N V A}$ e $\hat{A}_{y, 0}$ correspondem, respectivamente, às amplitudes características de oscilação do cilindro dotado do NVA e do cilindro sujeito à excitação somente pelo VIV (condição "VIV puro") para cada velocidade reduzida. Note que tanto $\hat{A}_{y, N V A}$ quanto $\hat{A}_{y, 0}$ consideram apenas as oscilações na direção cross-wise.

Embora a presente seção foque apenas na discussão da eficiência de supressão com base no critério $\hat{S}$, Ueno (2019) traz outros dois critérios denominados pela autora como critérios $S$ e $S^{*}$ e que são baseado na relação entre as áreas abaixo da curva $\hat{A}_{y}\left(U_{r}\right)$ e na relação entre as máximas amplitudes características de oscilação. Cumpre ressaltar que os critérios $S$ e $S^{*}$ foram propostos originalmente em Freire, Korkischko e Meneghini (2011) no contexto supressão passiva do fenômeno de VIV empregando strakes. Ao contrário do critério $\hat{S}$, os critérios $S$ e $S^{*}$ resumem, em um único valor, o comportamento do sistema para todo o intervalo de velocidades reduzidas estudado.

De maneira análoga àquela feita na seção ${ }^{1}$ 9.2, parte da análise dos resultados é feita por meio de mapas mostrando a variação do critério $\hat{S}$ como função dos parâmetros de controle $\hat{m}$ e $\hat{r}$ para alguns valores selecionados de velocidade reduzida e de taxa de amortecimento do NVA. Juntamente aos mapas, séries temporais de deslocamento do cilindro e do NVA são exibidas como forma de complementar as análises. Os pontos no plano de parâmetros de controle para os quais as séries temporais são apresentadas junto aos mapas estão explicitados na Tabela 13.

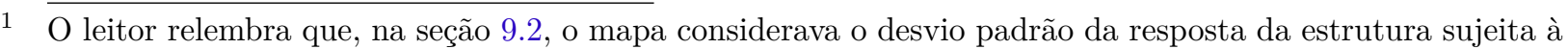
excitação paramétrica. Como naquela seção a resposta do sistema sem o supressor era ilimitada, o critério $\hat{S}$ não poderia ser definido. 
Tabela 13 - Pontos no plano de parâmetros de controle para os quais as séries temporais $y(\tau)$ e $\theta(\tau)$ são exibidas juntamente aos mapas $\hat{S}(\hat{m} ; \hat{r})$.

\begin{tabular}{c|c}
\hline \hline$\hat{m}$ & $\hat{r}$ \\
\hline \hline 0,07 & 0,37 \\
0,015 & 0,35 \\
0,05 & 0,10 \\
0,09 & 0,27 \\
0,13 & 0,17 \\
0,13 & 0,42 \\
0,14 & 0,50 \\
0,10 & 0,40 \\
\hline \hline
\end{tabular}

Fonte: Adaptada de Ueno (2019).

Finalizada a apresentação das metodologias de análise e de simulação, a próxima subseção apresenta os resultados e as correspondentes discussões.

\subsubsection{Resultados e discussões}

Visando uma maior facilidade de compreensão, esta subseção discute os resultados de maneira sistemática. Em um primeiro momento, as curvas de amplitude característica de oscilação como funções da velocidade reduzida obtidas a partir das simulações numéricas dos três grupos mencionados na Tabela 12 são discutidas para as condições VIV-1gl e VIV-2gl. Em conjunto com essas curvas, exemplos de séries temporais são fornecidos como forma de enriquecer as análises.

Já em um segundo momento, mapas mostrando a variação do critério $\hat{S}$ no plano de parâmetros de controle $(\hat{m} ; \hat{r})$ são exibidos para três valores de velocidades reduzidas (a saber, $U_{r}=6,2, U_{r}=7,9$ e $U_{r}=9,2$ ) e dois valores de taxa de amortecimento do NVA, $\zeta_{\theta}=0,05$ e $\zeta_{\theta}=0,20$. Em conjunto com esses mapas, exemplos de séries temporais de deslocamento do cilindro e do NVA são exibidos com vistas ao melhor entendimento da dinâmica do sistema hidro-elástico em estudo.

A Figura 119 traz as curvas de amplitude característica de oscilação como funções da velocidade reduzida obtidas a partir das simulações do Grupo 1. Considerando a condição VIV-1gl, a Figura 119(a) claramente mostra que o aumento no valor do parâmetro $\hat{m}$ leva tanto à redução da máxima amplitude característica quanto a um estreitamento do lower branch.

Ainda considerando a condição VIV-1gl e tomando como exemplo a simulação G1Sim5 (correspondendo a $\hat{m}=0,15$, o maior valor aqui investigado), a máxima amplitude característica de oscilação cai de $\hat{A}_{y} \approx 0,94$ na condição "VIV puro" para $\hat{A}_{y} \approx 0,80$. Já o lower branch, que está compreendido entre $6 \leq U_{r} \leq 9,5$ e é caracterizado por $\hat{A}_{y} \approx 0,60$ 
na condição "VIV puro", passa a ter amplitude característica de oscilação $\hat{A}_{y} \approx 0,50 \mathrm{e}$ encerra-se em $U_{r}=8,5$.

A Figura 119(a) ainda guarda alguns aspectos interessantes acerca do comportamento do sistema hidro-elástico. Além da capacidade do NVA em mitigar as vibrações ser monotônica com a variação do parâmetro $\hat{m}$, observa-se que as curvas de resposta obtidas a partir da condição onde o cilindro é dotado do supressor coincidem com a resposta obtida para a condição "VIV puro" para $U_{r}>10,5$. Mais ainda, comportamentos irregulares das curvas $\hat{A}_{y}\left(U_{r}\right)$ podem ser notados em $U_{r} \approx 6,2$ e no intervalo $8,5 \leq U_{r} \leq 10,5$.

Figura 119 - Influência do parâmetro $\hat{m}$ nas curvas de amplitudes características de oscilação. Simulações pertencentes ao Grupo 1 e caracterizadas por $\hat{r}=0,50$ e $\zeta_{\theta}=0,10$. G1-Sim1: $\hat{m}=0,03$, G1-Sim2: $\hat{m}=0,07$, G1-Sim3: $\hat{m}=0,10$, G1-Sim4: $\hat{m}=0,12$ e G1-Sim5: $\hat{m}=0,15$.

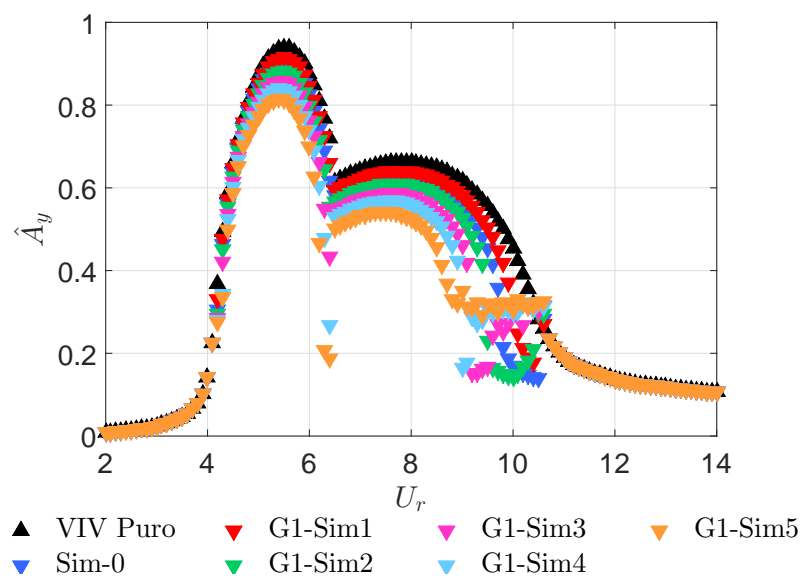

(a) $\hat{A}_{y}\left(U_{r}\right)$. VIV-1gl.

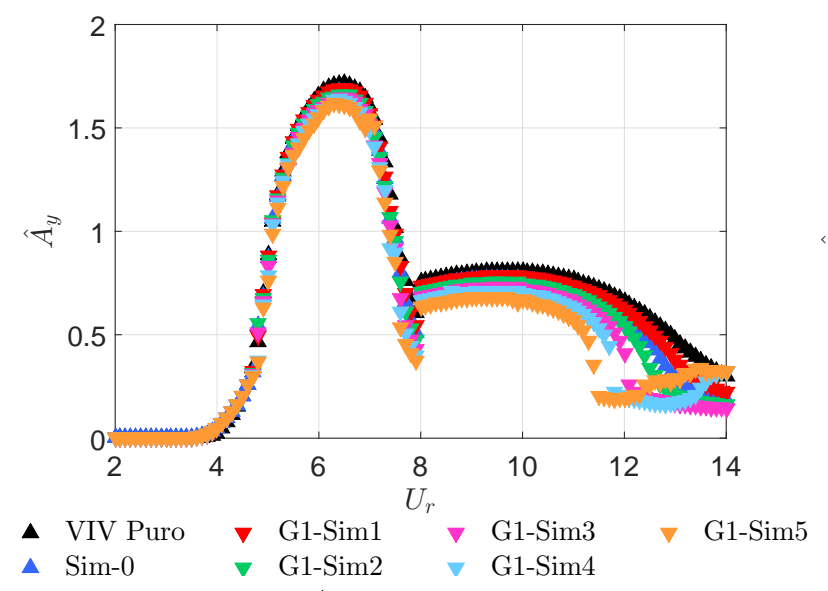

(b) $\hat{A}_{y}\left(U_{r}\right)$. VIV-2gl.

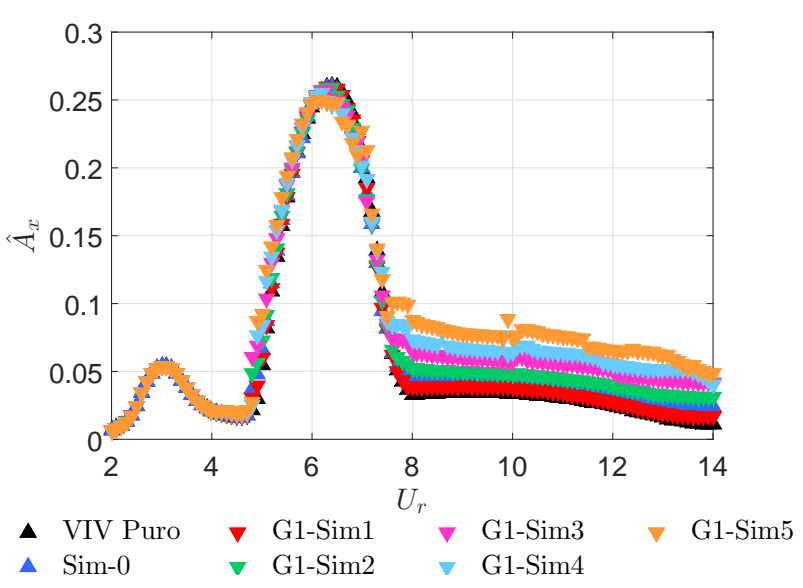

(c) $\hat{A}_{x}\left(U_{r}\right)$. VIV-2gl.

Fonte: Extraída de Ueno (2019).

As discussões segundo por meio do estudo das curvas $\hat{A}_{y}\left(U_{r}\right)$ obtidas a partir das simulações numéricas pertencentes ao Grupo G1, porém focando na condição VIV-2gl. Como mostra a Figura 119(b), o NVA rotativo pouco diminui as amplitudes características 
de oscilação na direção cross-wise no intervalo de velocidades reduzidas compreendido entre 2 e 8. Embora tal diminuição seja pequena comparada àquela observada para a condição VIV-1gl, o aumento da massa do supressor mais uma vez é benéfico no sentido de mitigação de oscilações. Ainda analisando a Figura 119(b), existe um ligeiro decréscimo nos valores de $\hat{A}_{y}$ com o aumento da massa do supressor no intervalo $8 \leq U_{r} \leq 11$, correspondendo ao lower branch e ao início da dessincronização. O leitor nota que, embora exista um pequeno decréscimo nas amplitudes características de oscilação na direção cross-wise, a Figura 119 (c) revela um pronunciado aumento nos valores de $\hat{A}_{x}$ para velocidades reduzidas acima de $U_{r} \approx 7,5$.

A Figura 120 traz os resultados obtidos a partir das simulações numéricas referentes ao Grupo 2 definido na Tabela 12. Discutindo inicialmente os resultados atinentes à configuração VIV-1gl, a Figura 120(a) revela que a resposta do sistema hidro-elástico composto do cilindro, do NVA e do fluido (representado pela variável de esteira) é menos sensível à variação do raio do supressor do que de sua massa. Essa pouca sensibilidade à variação no parâmetro $\hat{r}$ é notável próximo ao pico de amplitude, que atinge um valor mínimo próximo a $\hat{A}_{y}=0,90$ para todas as simulações do Grupo. Constituindo um resultado análogo àquele observado nas análises dos resultados numéricos pertencentes ao Grupo 1, o aumento do raio do supressor promove um estreitamento do intervalo de lock-in.

As Figuras 120(b) e 120(c) apresentam, respectivamente, as curvas de amplitude característica de oscilação do cilindro nas direções cross-wise e in-line como funções da velocidade reduzida referentes. De maneira similar àquela observada para a condição VIV-1gl, essas figuras revelam que a variação do raio não tem impacto significativo na supressão do fenômeno VIV-2gl. Em particular, a Figura 120(b) indica que a supressão passiva é visível apenas para $U_{r} \geq 13$, intervalo no qual a resposta estrutural ao fenômeno já é caracterizada por uma amplitude bastante baixa.

As últimas curvas de amplitude característica de oscilação do cilindro como funções da velocidade reduzida a serem discutidas são aquelas obtidas a partir das simulações pertencentes ao Grupo 3. Esse grupo de simulações foi conduzido visando identificar a influência da taxa de amortecimento do NVA $\zeta_{\theta}$ na sua capacidade de supressão e tem seus resultados ilustrados na Figura 121.

A Figura 121(a) mostra a curva $\hat{A}_{y}\left(U_{r}\right)$ para a condição VIV-1gl. Embora a variação do parâmetro $\zeta_{\theta}$ tenha levado ao decréscimo mais pronunciado das amplitudes características de oscilação do cilindro do que aquele decorrente na variação do raio do NVA, essa variação é inferior àquela observada na Figura 119 obtida por ocasião da análise das simulações do Grupo 1. Como pode ser notado na Figura 121(a), o aumento na taxa de amortecimento do NVA promove um ligeiro decréscimo na máxima amplitude característica de oscilação. Esse decréscimo é mais pronunciado para velocidades reduzidas 
Figura 120 - Simulações pertencentes ao Grupo 2 e caracterizadas por $\hat{m}=0,05$ e $\zeta_{\theta}=0,10$. G2-Sim1: $\hat{r}=0,40$, G2-Sim2: $\hat{r}=0,30$, G2-Sim3: $\hat{r}=0,20$ e G2-Sim4: $\hat{r}=0,10$.

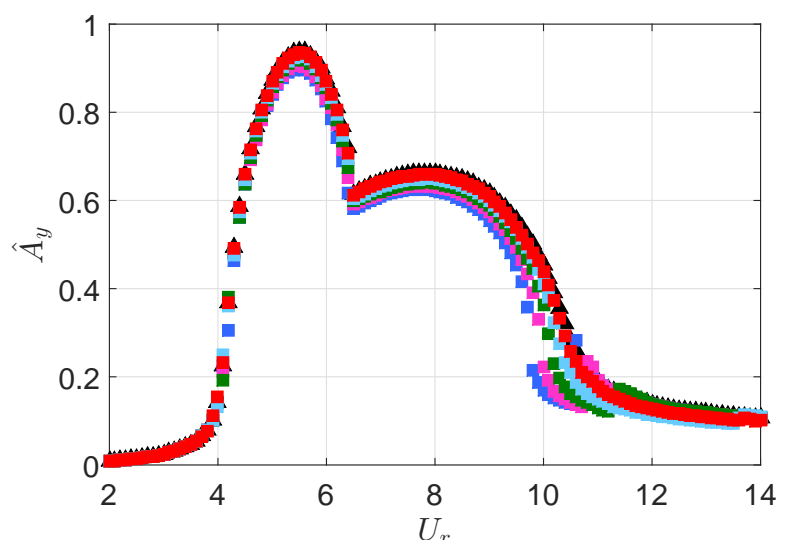
- VIV Puro
- G2-Sim1
- G2-Sim3
- Sim-0
- G2-Sim2
- G2-Sim4

(a) $\hat{A}_{y}\left(U_{r}\right)$. VIV-1gl.

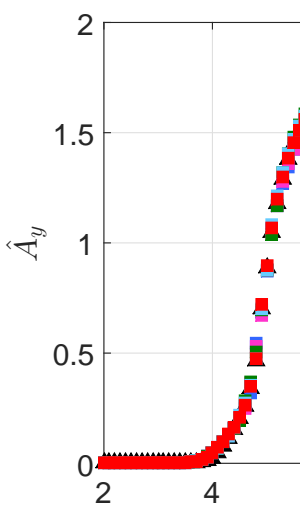

- VIV Puro

- $\quad$ Sim-0

(b) $\hat{A}_{y}\left(U_{r}\right)$. VIV-2gl.

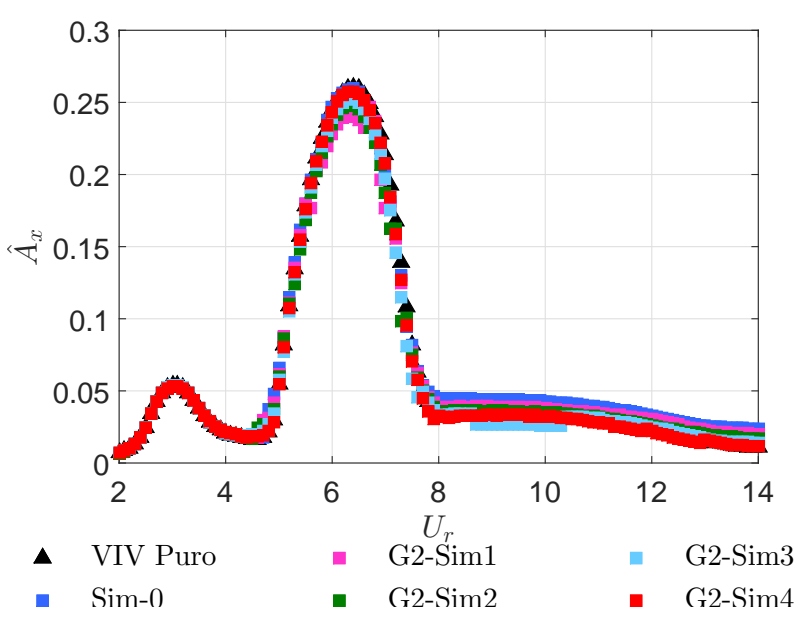

(c) $\hat{A}_{x}\left(U_{r}\right)$. VIV-2gl.

Fonte: Extraída de Ueno (2019).

típicas do lower branch. A mesma figura mostra, ainda, que o intervalo de velocidades reduzidas que define o lower branch é diminuído conforme o parâmetro $\zeta_{\theta}$ aumenta.

Ainda considerando as simulações numéricas relativas ao Grupo 3, as Figuras 121(b) e 121(c) apresentam os resultados atinentes à condição VIV-2gl. A exemplo do que já foi observado nas simulações pertencentes aos demais grupos, a variação da taxa de amortecimento do NVA só tem impacto nas curvas de amplitude característica de oscilação para velocidades reduzidas superiores a 12, ou seja, em condições nas quais o fenômeno de VIV já é menos significativo.

Como forma de complementar os comentários tecidos a partir das curvas de amplitude característica de oscilação como funções da velocidade reduzida, seguem alguns exemplos selecionados de séries temporais. Por questão de concisão desta seção, apenas 
Figura 121 - Simulações pertencentes ao Grupo 3 e caracterizadas por $\hat{m}=0,05$ e $\hat{r}=0,50$. G3-Sim1: $\zeta_{\theta}=0,20$, G3-Sim2: $\zeta_{\theta}=0,15$, G3-Sim3: $\zeta_{\theta}=0,08$, G3-Sim4: $\zeta_{\theta}=0,05$ e G3-Sim5: $\zeta_{\theta}=0,01$.

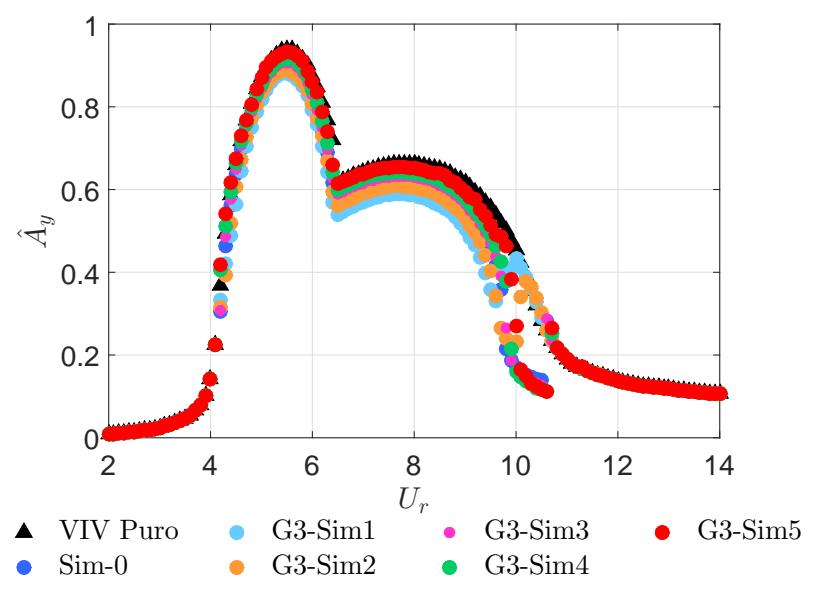

(a) $\hat{A}_{y}\left(U_{r}\right)$. VIV-1gl.

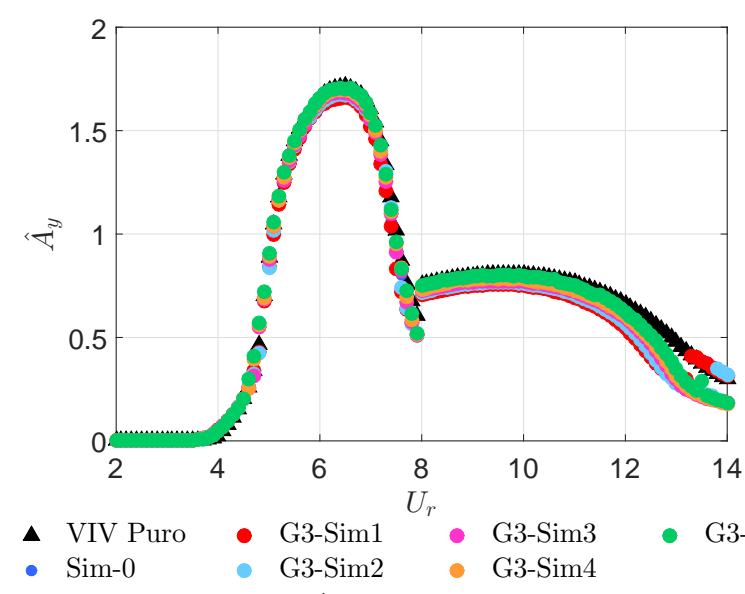

(b) $\hat{A}_{y}\left(U_{r}\right)$. VIV-2gl.

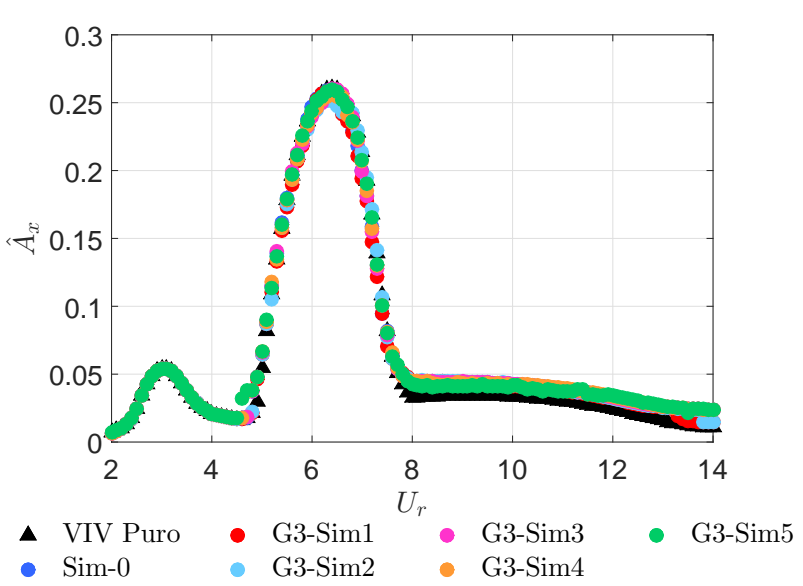

(c) $\hat{A}_{x}\left(U_{r}\right)$. VIV-2gl.

Fonte: Extraída de Ueno (2019).

os resultados atinentes à simulação G1-Sim5 são discutidos, uma vez que eles já trazem aspectos representativos da dinâmica do sistema hidro-elástico. O leitor interessado em mais exemplos de séries temporais é convidado à leitura da dissertação de Ueno (2019).

A Figura 122 traz as séries temporais $y(\tau)^{2}, q_{y}(\tau)$ e $\theta(\tau)$. Note que, no caso das séries temporais de deslocamento do cilindro e da variável de esteira, os espectros de amplitude também são exibidos.

Por meio da análise das séries temporais apresentadas nas Figuras 122(a) e 122(b), é possível notar que as respostas do cilindro e da variável de esteira são caracterizadas por uma amplitude estacionária (ou, utilizando a nomenclatura introduzida na seção 9.3, são respostas do tipo "RAC") e com espectro de amplitude definido por uma única

2 Ao longo desta subseção, as linhas horizontais tracejadas e coloridas em vermelho indicam a amplitude característica de oscilação obtida para a condição "VIV puro". 
Figura 122 - Exemplos de séries temporais obtidas para a condição VIV-1gl. Simulação G1-Sim5 e $U_{r}=6$.
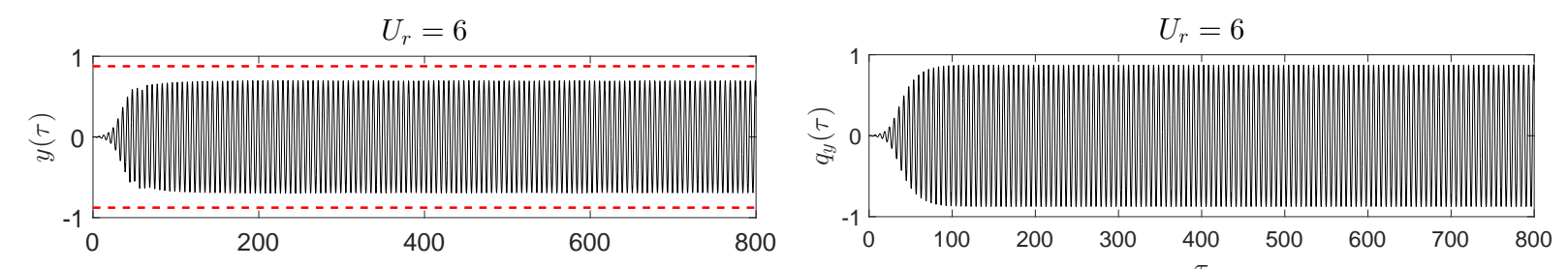

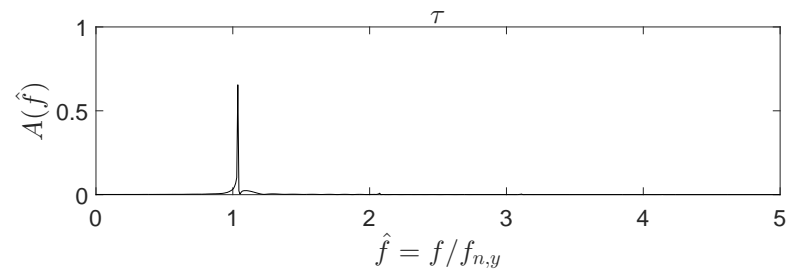

(a) $y(\tau)$ e espectro de amplitude.

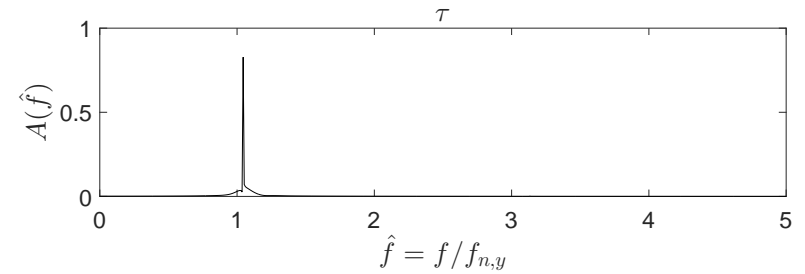

(b) $q_{y}(\tau)$ e espectro de amplitude.

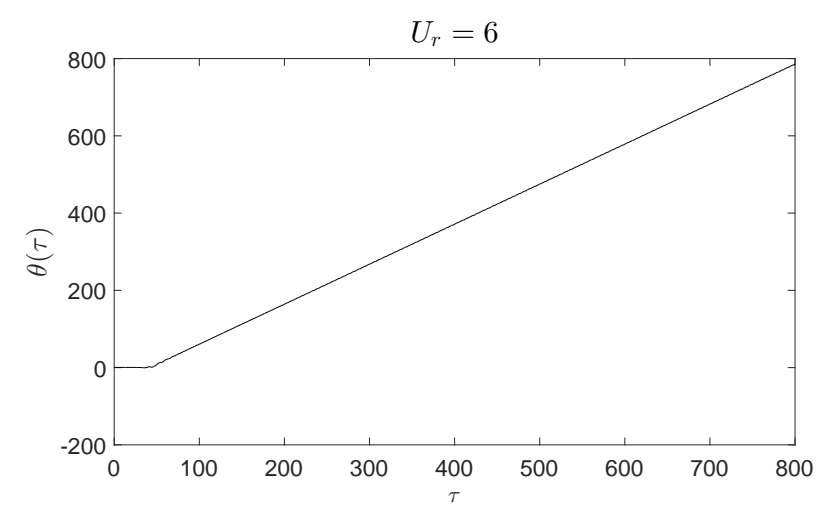

(c) $\theta(\tau)$.

Fonte: Adaptada de Ueno (2019).

frequência $\hat{f}=f / f_{n, y} \approx 1$. O leitor percebe na Figura 122(a) um decréscimo da amplitude característica de oscilação em comparação com a condição "VIV puro".

Já a série temporal $\theta(\tau)$ ilustrada na Figura 122(c) é caracterizada por uma velocidade angular característica praticamente e próxima a $\omega_{r}=1$. Essa condição na qual os valores das frequências de oscilação do cilindro, da variável de esteira e da velocidade angular característica são próximos define uma ressonância $1: 1: 1$ e compõe um cenário bastante favorável para o mecanismo TET.

A Figura 123 apresenta as séries temporais obtidas para a condição VIV-1gl e considerando velocidade reduzida $U_{r}=8,7$. A análise da série temporal $y(\tau)$ apresentada na Figura 123(a) já revela uma interessante característica do wake-oscillator aqui utilizado. Mesmo sabendo que os modelos de ordem reduzida baseados no conceito de wake-oscillator são calibrados para a condição na qual a resposta do cilindro é ditada apenas pelo fenômeno de VIV (o que leva, portanto, a respostas com amplitude estacionária), a comparação da série temporal ilustrada na Figura 123(a) com aquela obtida por Blanchard et al. (2016) utilizando um modelo de maior hierarquia baseado em DFC e já apresentada na Figura 43 
revela uma notável similaridade entre as abordagens. Cumpre ressaltar que Blanchard et al. (2016) não apresentam os resultados como função da velocidade reduzida e sim como função do número de Reynolds, de sorte que não é possível a correlação direta com os resultados aqui apresentados.

Figura 123 - Exemplos de séries temporais obtidas para a condição VIV-1gl. Simulação G1-Sim5 e $U_{r}=8,7$.
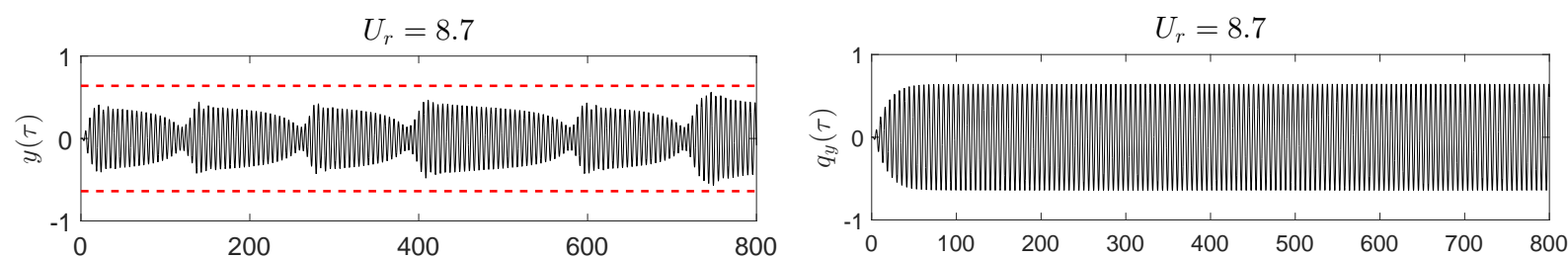

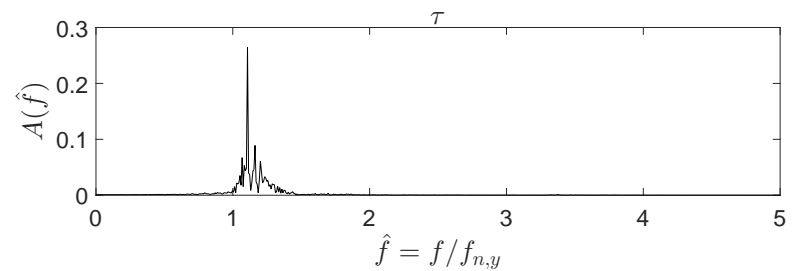

(a) $y(\tau)$ e espectro de amplitude.

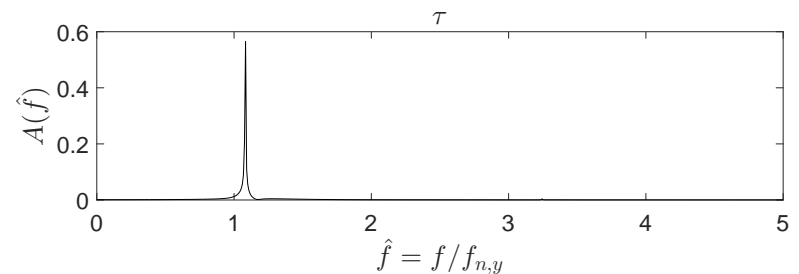

(b) $q_{y}(\tau)$ e espectro de amplitude.

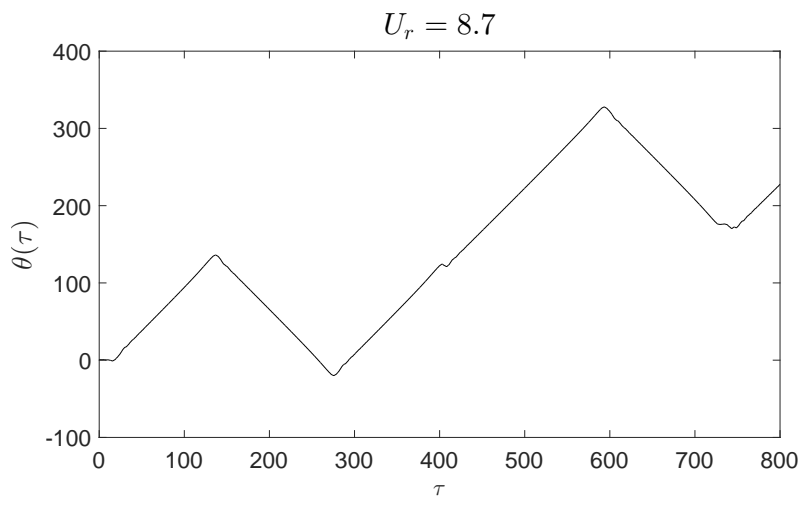

(c) $\theta(\tau)$.

Fonte: Adaptada de Ueno (2019).

Como mostram as Figuras 123(a) e 123(b), enquanto a resposta do cilindro é caracterizada por ciclos de crescimento e de supressão (resposta do tipo "RMA") muito similares àqueles obtidos por Blanchard et al. (2016), a resposta da variável $q_{y}$ é praticamente livre de modulações. No tocante aos espectros de amplitude calculados a partir de $y(\tau)$ e de $q_{y}(\tau)$, ambos tem praticamente a mesma frequência dominante $\hat{f}_{d} / f_{n, y} \approx 1$, embora exista um certo alargamento na banda espectral no caso da resposta do cilindro.

Focando na análise da série temporal de deslocamento do NVA apresentada na Figura 123(c), nota-se que, concomitante aos trechos onde existe supressão das oscilações do cilindro, o NVA responde com velocidade angular $\omega_{r} \approx 1$. O leitor nota, ainda, a inversão no sentido da rotação do existente em alguns instantes de tempo.

De maneira análoga àquela observada na supressão passiva de excitação paramétrica 
e seguindo os comentários tecidos em Blanchard et al. (2016), o comportamento do tipo "RAC" está associado às seguidas captura e escape da resposta por uma ressonância $1: 1: 1$ que, por sua vez, está relacionada a uma SIM. Note que, neste texto, não foi obtida a SIM para o modelo matemático de três graus de liberdade. Esse trabalho é deixado como sugestão de continuidade da pesquisa.

As séries temporais obtidas a partir da simulação numérica da condição VIV-1gl e velocidade reduzida $U_{r}=10$ são exibidas na Figura 124. A Figura 124(a) indica que a série temporal de deslocamento do cilindro é caracterizada por intensas modulações em amplitude, porém sem redução de seu valor máximo quando comparado ao caso onde a estrutural principal é solicitada somente pelo fenômeno de interação fluido-estrutura. Nota-se, ainda, a presença de duas frequências com valores de amplitude comparáveis. A menor dessas frequências coincide com a frequência dominante obtida a partir da série temporal $q_{y}(\tau)$; ver Figura 124(b). A Figura 124(c) mostra a série temporal $\theta(\tau)$, revelando a inexistência de um padrão de resposta do NVA, de sorte que a ressonância $1: 1: 1$ não é atingida e justificando assim a baixa eficiência do dispositivo supressor.

Figura 124 - Exemplo de séries temporais obtidas para a condição VIV-1gl. Condição G1-Sim5 e $U_{r}=10$.

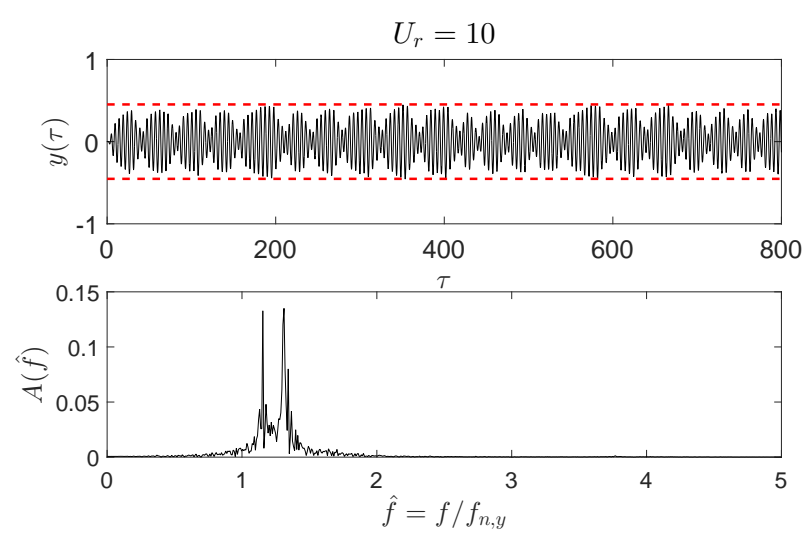

(a) $y(\tau)$ e espectro de amplitude.
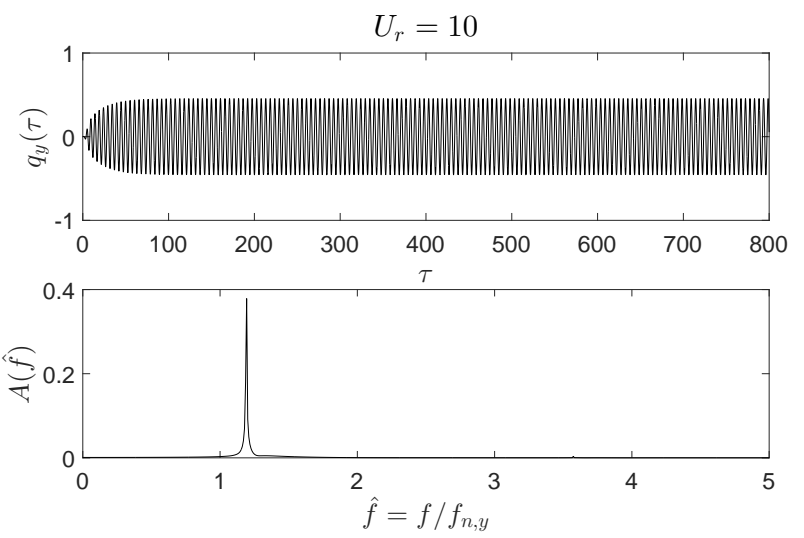

(b) $q_{y}(\tau)$ e espectro de amplitude.

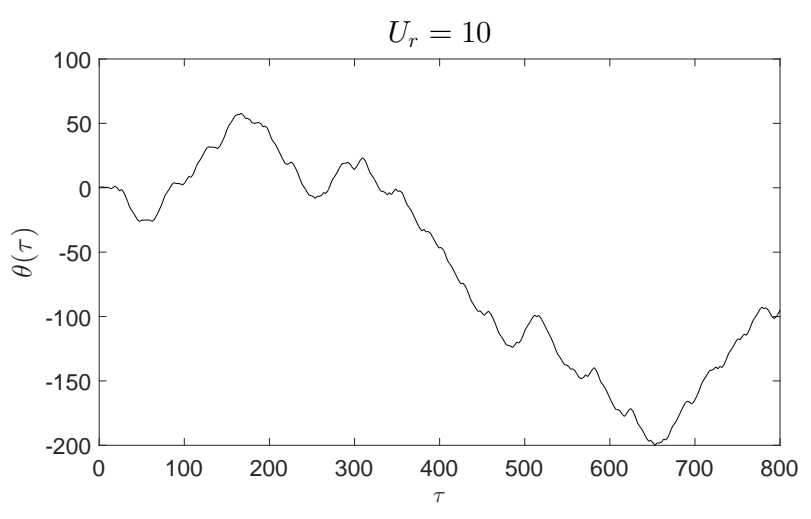

(c) $\theta(\tau)$.

Fonte: Adaptada de Ueno (2019). 
Analisam-se, neste ponto do texto, exemplos de séries temporais obtidas a partir da condição VIV-2gl e relacionadas à simulação G1-Sim5³. A Figura 125 ilustra as séries temporais de deslocamentos nas direções cross-wise e in-line, as trajetórias no plano horizontal e a série temporal de deslocamento do NVA obtidas para velocidade reduzida $U_{r}=6$.

Figura 125 - Exemplo de séries temporais obtidas para a condição VIV-2gl. Condição G1-Sim5 e $U_{r}=6$.

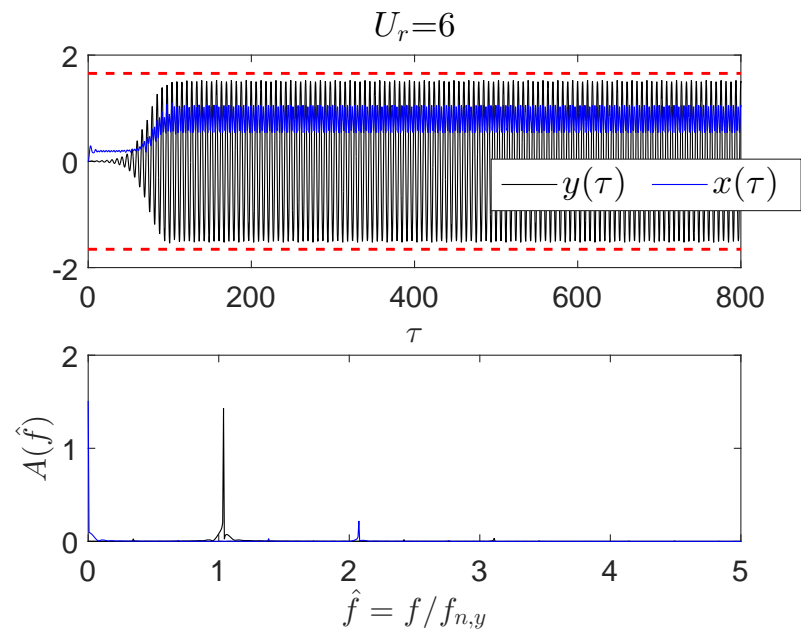

(a) $y(\tau), x(\tau)$ e espectros de amplitude.

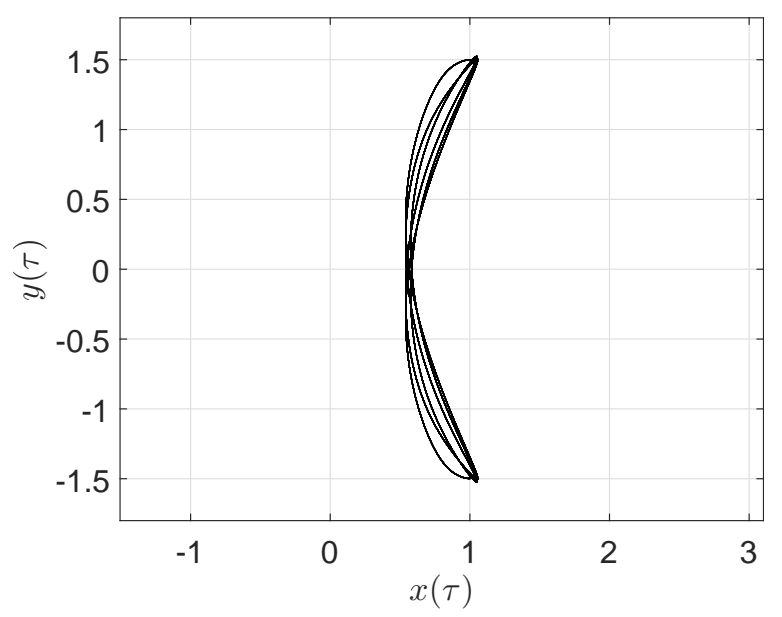

(b) Trajetória no plano horizontal.

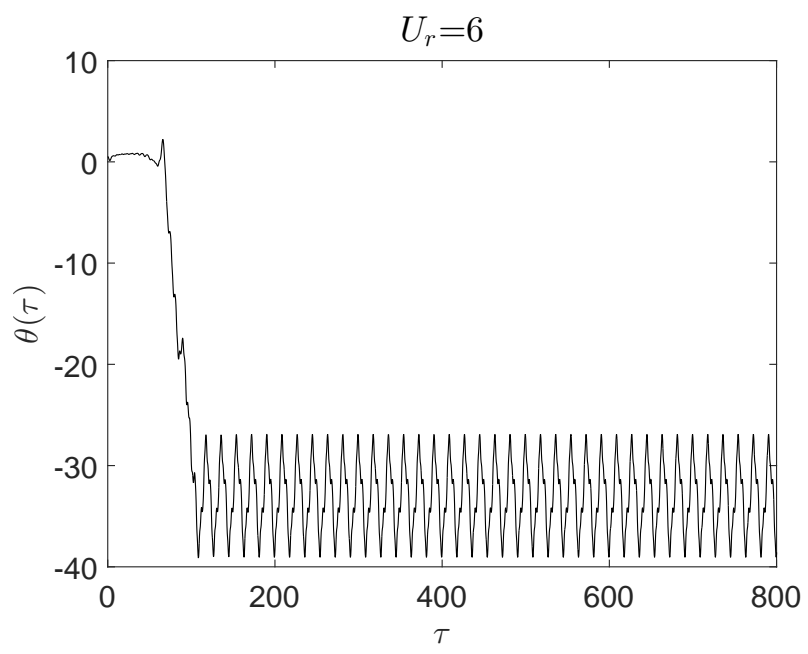

(c) $\theta(\tau)$.

Fonte: Adaptada de Ueno (2019).

Como mostra a Figura 125(a), as séries temporais $y(\tau)$ e $x(\tau)$ permanecem com amplitude constante mesmo na presença do NVA rotativo. Os espectros de amplitude mostrados na mesma figura também trazem os resultados classicamente encontrados no problema de VIV-2gl nos quais os valores de rigidez são os mesmos nas direções cross-wise e in-line. Ambos os espectros são de banda estreita e com frequência dominante $\hat{f}=1$

3 Novamente, fica o convite à leitura da dissertação de Ueno (2019) para mais exemplos de séries temporais. 
(série $y(\tau)$ ) ou $\hat{f}=2$ ( série $^{4} x(\tau)$ ). Embora as séries temporais de resposta do cilindro guardem semelhanças qualitativas com aquelas obtidas a partir da condição "VIV puro", a presença do NVA rotativo promove a redução na amplitude característica de oscilação na direção cross-wise e também uma perda de repetitividade na trajetória no plano horizontal (ver Figura 125(b)), que deixa de ter o seu clássico formato em forma de "oito".

Já a série temporal de deslocamento do NVA mostrada na Figura 125(c) apresenta um comportamento oscilatório com amplitude estacionária. Comparando o resultado apresentado na Figura 125(c) com aquele da Figura 122(c) obtida para a mesma velocidade reduzida mas para a condição VIV-1gl, nota-se que a introdução de um grau de liberdade faz com que a resposta do NVA deixe de ser caracterizada por uma rotação com velocidade angular $\omega_{r}$ próxima a 1 passe a ser oscilatória com amplitude constante. Como mencionado anteriormente, a resposta do NVA caracterizada por $\omega_{r} \approx 1$ configura um cenário favorável à supressão passiva.

A Figura 126 também ilustra exemplos de séries temporais obtidas a partir da simulação numérica da condição G1-Sim5 para o problema VIV-2gl, porém considerando $U_{r}=10$. Como mostrado na Figura 126(a), o espectro de amplitude calculado a partir de $x(\tau)$ tem como frequência de oscilação dominante um valor ligeiramente superior a $\hat{f}=1$ (o mesmo resultado obtido a partir do espectro de amplitude de $y(\tau)$ ), resultado contrário àquele apresentado na Figura 125(a) . Essa diferença de conteúdo espectral é refletida na Figura 126(b), que mostra que trajetória no plano horizontal deixa de ser caracterizada pelo clássico formato de "oito".

A série temporal de deslocamento do NVA $\theta(\tau)$ apresenta uma importante diferença quando comparada com aquela obtida para a condição VIV-1gl e ilustrada na Figura 124(b). Para a condição VIV2-gl, a velocidade angular do NVA é praticamente constante e ligeiramente superior a $\omega_{r}=1$ (em módulo) ao longo de quase toda a simulação, o mesmo valor da frequências dominante de oscilação do cilindro na direção cross-wise.

A análise dos resultados segue com a discussão dos mapas ilustrativos da variação do critério $\hat{S}$ no plano de parâmetros de controle $(\hat{m} ; \hat{r})$. Esses mapas estão parametrizados segundo dois valores de taxa de amortecimento do NVA $\left(\zeta_{\theta}=0,05\right.$ e $\left.\zeta_{\theta}=0,20\right)$ e três valores de velocidade reduzida que abrangem a máxima resposta para a condição VIV-2gl $\left(U_{r}=6,4\right)$, o início e o fim do lower branch $\left(U_{r}=7,9\right.$ e $U_{r}=9,2$ respectivamente). Para a construção dos mapas, o domínio $0<\hat{m} \leq 0,15 \times 0<\hat{r} \leq 0,50$ foi discretizado utilizando uma malha de dimensão $71 \times 50$. Além dos mapas, exemplos de séries temporais $y(\tau)$ e $\theta(\tau)$ são mostrados como forma de aprofundar as discussões.

A Figura 127 mostra o mapa $\hat{S}(\hat{m} ; \hat{r})$ obtido para a condição VIV-1gl e caracterizada

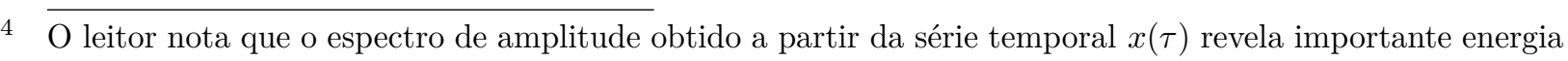
na frequência nula, o que corresponde ao deslocamento médio (estático) do cilindro na direção in-line. Para efeito de análise dinâmica, essa frequência não deve ser discutida. 
Figura 126 - Exemplo de séries temporais obtidas para a condição VIV-2gl. Condição G1-Sim5 e $U_{r}=10$.

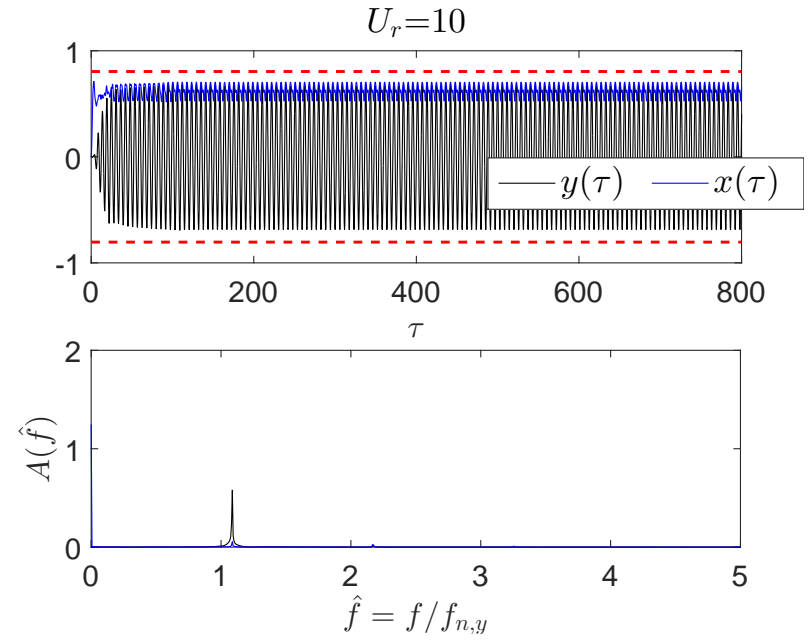

(a) $y(\tau), x(\tau)$ e espectros de amplitude.

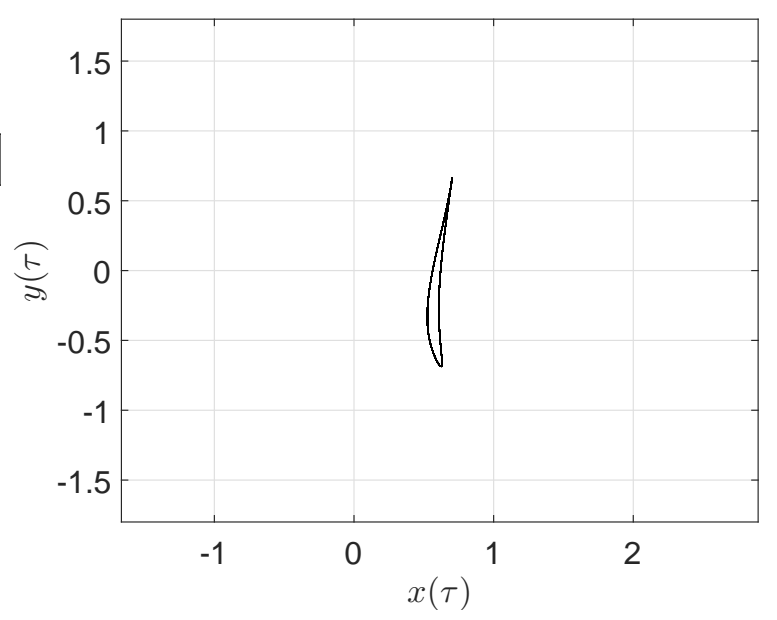

(b) Trajetória no plano horizontal.

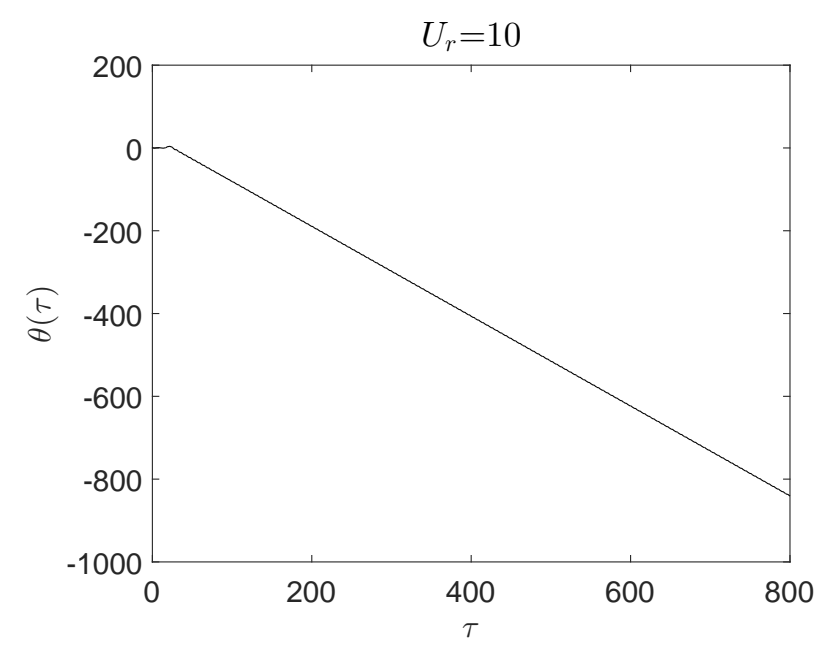

(c) $\theta(\tau)$.

Fonte: Adaptada de Ueno (2019).

por $\zeta_{\theta}=0,05$ e $U_{r}=6,4$. Esse mapa é exibido em conjunto com as séries temporais de deslocamento do cilindro na Figura 127(a) e do supressor na Figura 127(b). Como visto na Figura $127($ a), a região do plano $(\hat{m} ; \hat{r})$ onde o parâmetro $\hat{S}$ é superior a $30 \%$ está restrita a valores de $\hat{m}$ maiores do que 0,10 e de $\hat{r}$ acima de 0,40 . As demais regiões, coloridas em azul, apresentam baixa eficiência do supressor, contemplando valores do parâmetro $S^{*}$ inferiores a 0,20 .

Ainda considerando a Figura 127(a), o leitor nota que o máximo valor do critério $\hat{S}$ é próximo a 0,80 e que as séries temporais de deslocamento do cilindro são todas caracterizadas por uma amplitude estacionária. Em particular, a série $y(\tau)$ obtida para $\hat{m}=0,14$ e $\hat{r}=0,50$ é caracterizada por uma amplitude estacionária, atingida após um transitório inicial, inferior à metade daquela obtida na condição VIV puro. 
Figura 127 - Variação do critério $\hat{S}$ como função dos parâmetros $\hat{m}$ e $\hat{r}$. Condição VIV-1gl, $\zeta_{\theta}=0,05$ e $U_{r}=6,4$.
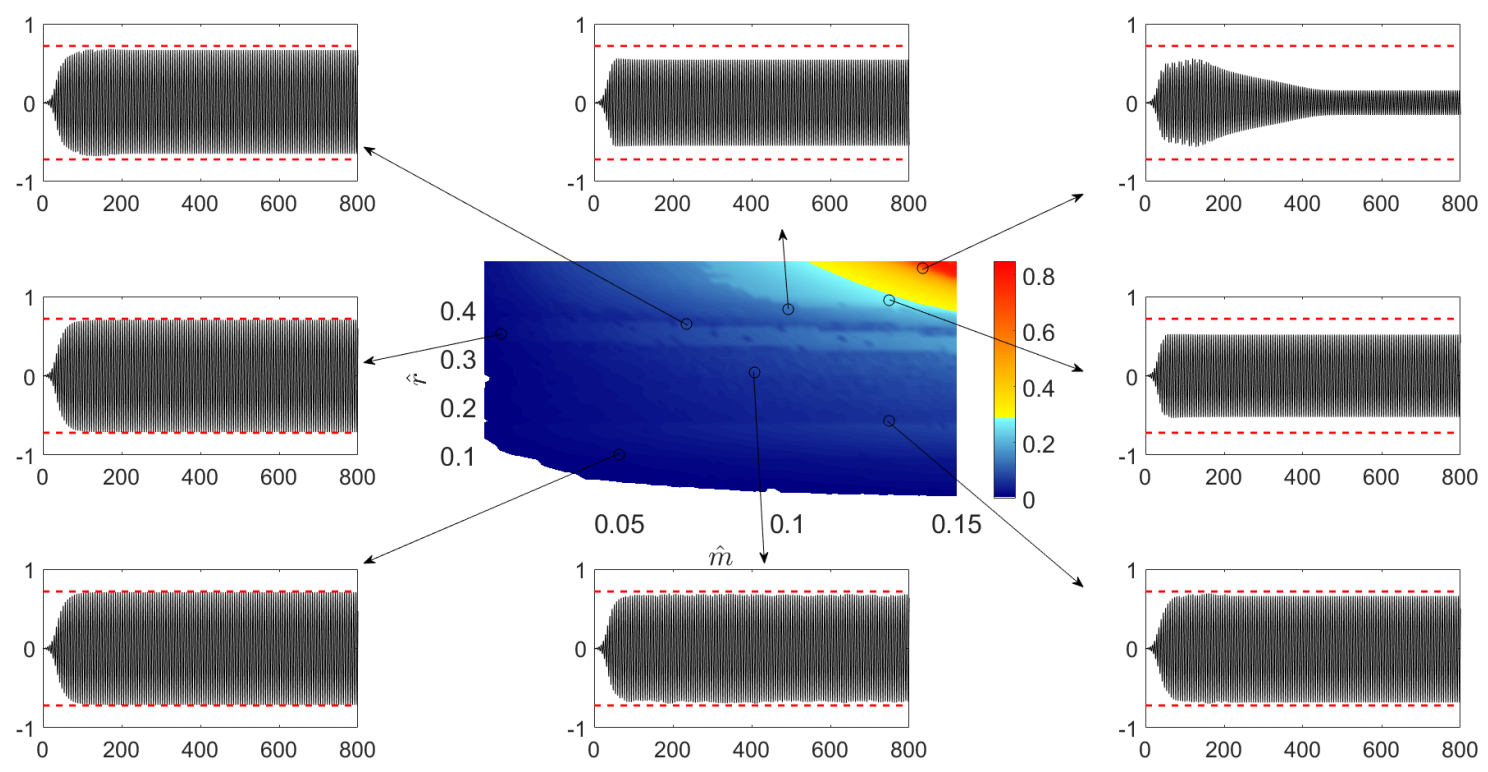

(a) $\hat{S}(\hat{m} ; \hat{r})$ e séries temporais $y(\tau)$.
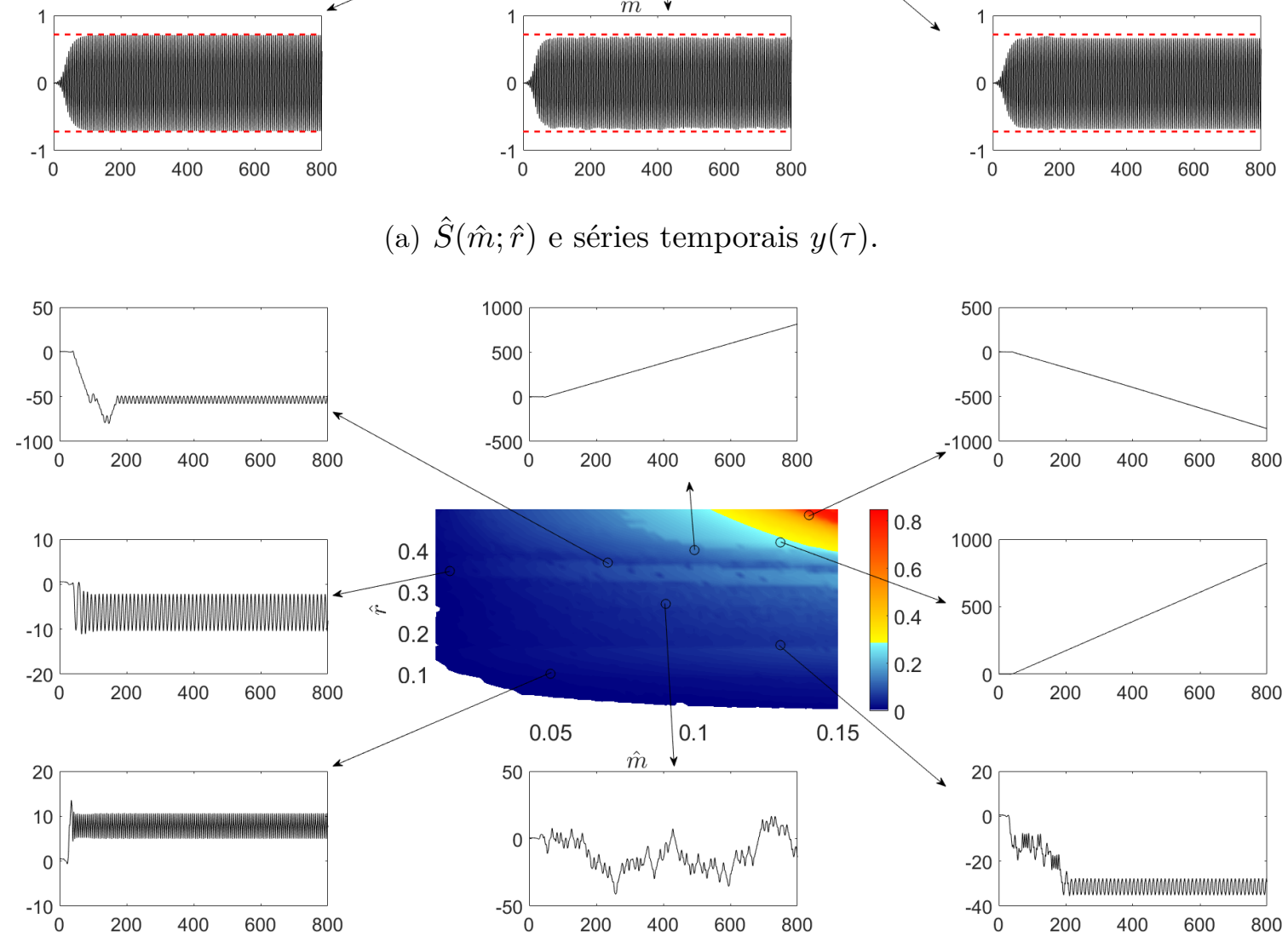

(b) $\hat{S}(\hat{m} ; \hat{r})$ e séries temporais $\theta(\tau)$.

Fonte: Extraída de Ueno (2019).

Analisando o mesmo mapa $\hat{S}(\hat{m} ; \hat{r})$ porém em conjunto com as séries temporais de deslocamento do NVA (ver Figura 127(b)), é possível correlacionar condições com boa capacidade de supressão com respostas do NVA caracterizadas por uma linha praticamente reta, caracterizando uma velocidade angular típica de rotação constante e próxima a $\omega_{r}=1$. Outros exemplos de resposta do NVA encontradas incluem respostas oscilatórias com amplitude constante e uma resposta sem padrão aparente. 
A Figura 128 também ilustra o mapa $\hat{S}(\hat{m} ; \hat{r})$ obtido para $U_{r}=6,4$ e $\zeta_{\theta}=0,05$, porém referente à condição VIV-2gl. A inclusão de um grau de liberdade adicional para o cilindro traz algumas diferenças com relação ao mapa obtido para o fenômeno VIV-1gl. Como mostra a Figura 128(a), o máximo valor do critério $\hat{S}$ é significativamente inferior na condição VIV-2gl do que no caso onde apenas oscilações na direção cross-wise são permitidas ao cilindro. Visando quantificar essa comparação, é claro ao leitor que $\max \{\hat{S}\} \approx 0,04$ para a condição VIV-2gl enquanto, para a condição VIV-1gl, $\max \{\hat{S}\} \approx 0,80$; ver Figura 127.

Um segundo aspecto que pode ser destacado no mapa $\hat{S}(\hat{m} ; \hat{r})$ apresentado na Figura 128 é sua maior erosão quando comparado àquele obtido a partir da condição VIV-1gl e apresentado na Figura 127. Em particular nas fronteiras da região com valores de $\hat{S} \approx 0,02$ (regiões coloridas em amarelo e laranja), existem alguns pontos isolados nessas cores imerso em regiões de baixa supressão ou mesmo amplificação das respostas (ver regiões coloridas em azul). Nesse sentido, o mapa da Figura 128 guarda mais semelhanças com aquele obtido no problema de supressão passiva de excitação paramétrica (ver, por exemplo, a Figura 105(a) na seção 9.3), embora a erosão do plano de parâmetros de controle seja maior no problema explorado no capítulo 9 deste texto.

Ainda considerando a condição VIV-2gl e o mapa $\hat{S}(\hat{m} ; \hat{r})$ obtido considerando $\zeta_{\theta}=0,05$ e $U_{r}=6,4$, as Figuras 128(b) e 128(b) mostram, respectivamente, que as séries temporais de deslocamento do cilindro são caracterizadas por uma amplitude estacionária e que todas as séries temporais de deslocamento do NVA são apresentam respostas oscilatórias, também em regime estacionário. Nota-se, portanto, que a ressonância $1: 1: 1$ não foi atingida nas simulações ilustradas na Figura 128, corroborando a conjectura de que a supressão passiva é mais eficiente quando a dinâmica do sistema hidro-elástico é capturada nessa ressonância.

A discussão dos mapas $\hat{S}(\hat{m} ; \hat{r})$ segue ainda considerando $U_{r}=6,4$, porém com um aumento da taxa de amortecimento do NVA para $\zeta_{\theta}=0,20$. A Figura 129 apresenta o mapa correspondente à condição VIV-1gl, de onde é possível notar dois aspectos ${ }^{5}$ de interesse no projeto de um dispositivo desta natureza. O primeiro aspecto é o aumento da área no plano de parâmetros de controle $(\hat{m} ; \hat{r})$ na qual $\hat{S} \geq 0,50$ em comparação ao mapa apresentado na Figura 127. O segundo aspecto é que, embora a área onde uma maior eficiência de supressão seja obtida, o máximo valor do critério $\hat{S}$ é diminuído quando a taxa de amortecimento do NVA passou de $\zeta_{\theta}=0,05$ para $\zeta_{\theta}=0,20$.

É interessante ressaltar também que, ao contrário do mapa obtido considerando $\zeta_{\theta}=0,05$, a Figura 129 revela a existência de uma região no plano de parâmetros de controle $(\hat{m} ; \hat{r})$ colorida em laranja escuro e na qual a supressão é maximizada. O leitor

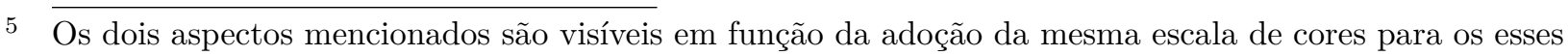
dois mapas. 
Figura 128 - Variação do critério $\hat{S}$ como função dos parâmetros $\hat{m}$ e $\hat{r}$. Condição VIV-2gl, $\zeta_{\theta}=0,05$ e $U_{r}=6,4$.
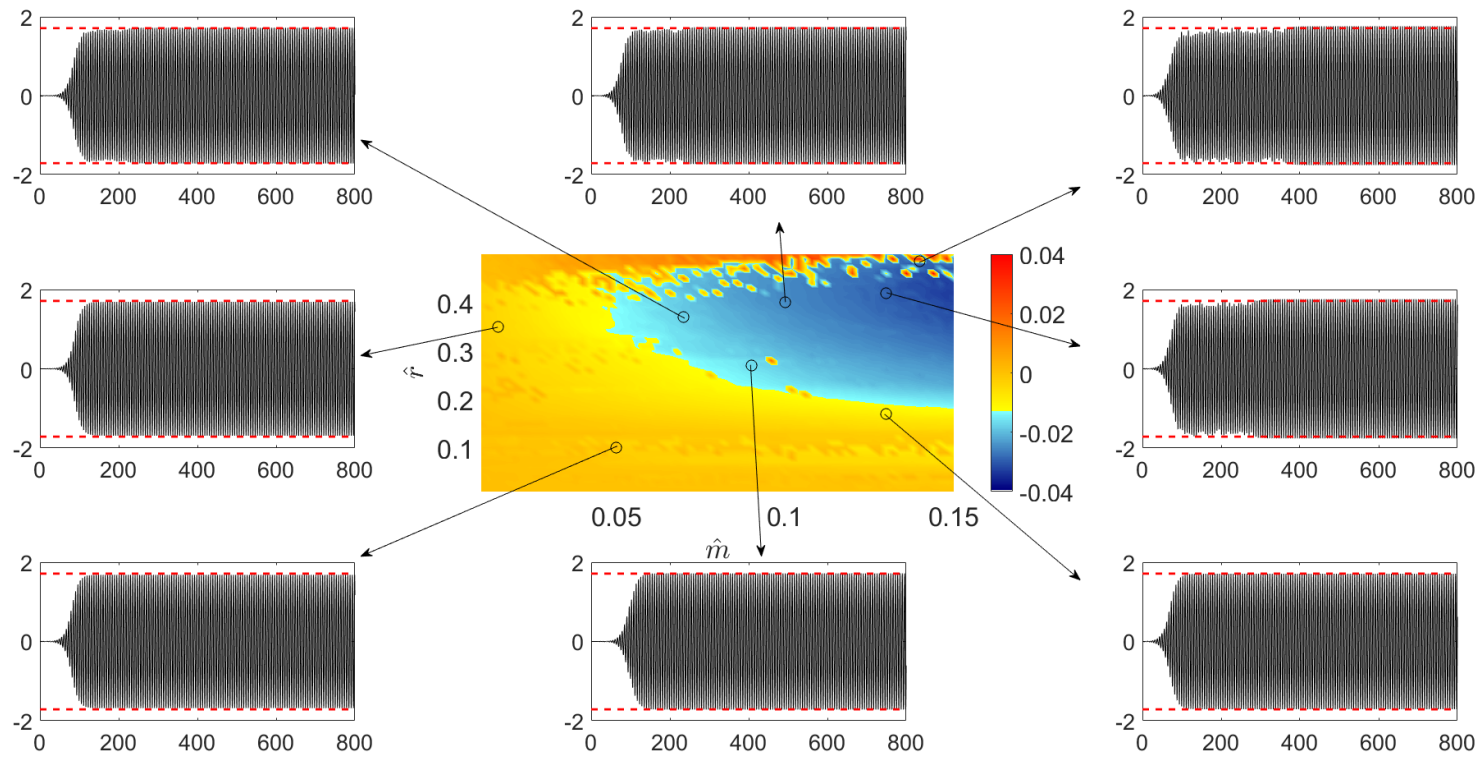

(a) $\hat{S}(\hat{m} ; \hat{r})$ e séries temporais $y(\tau)$.
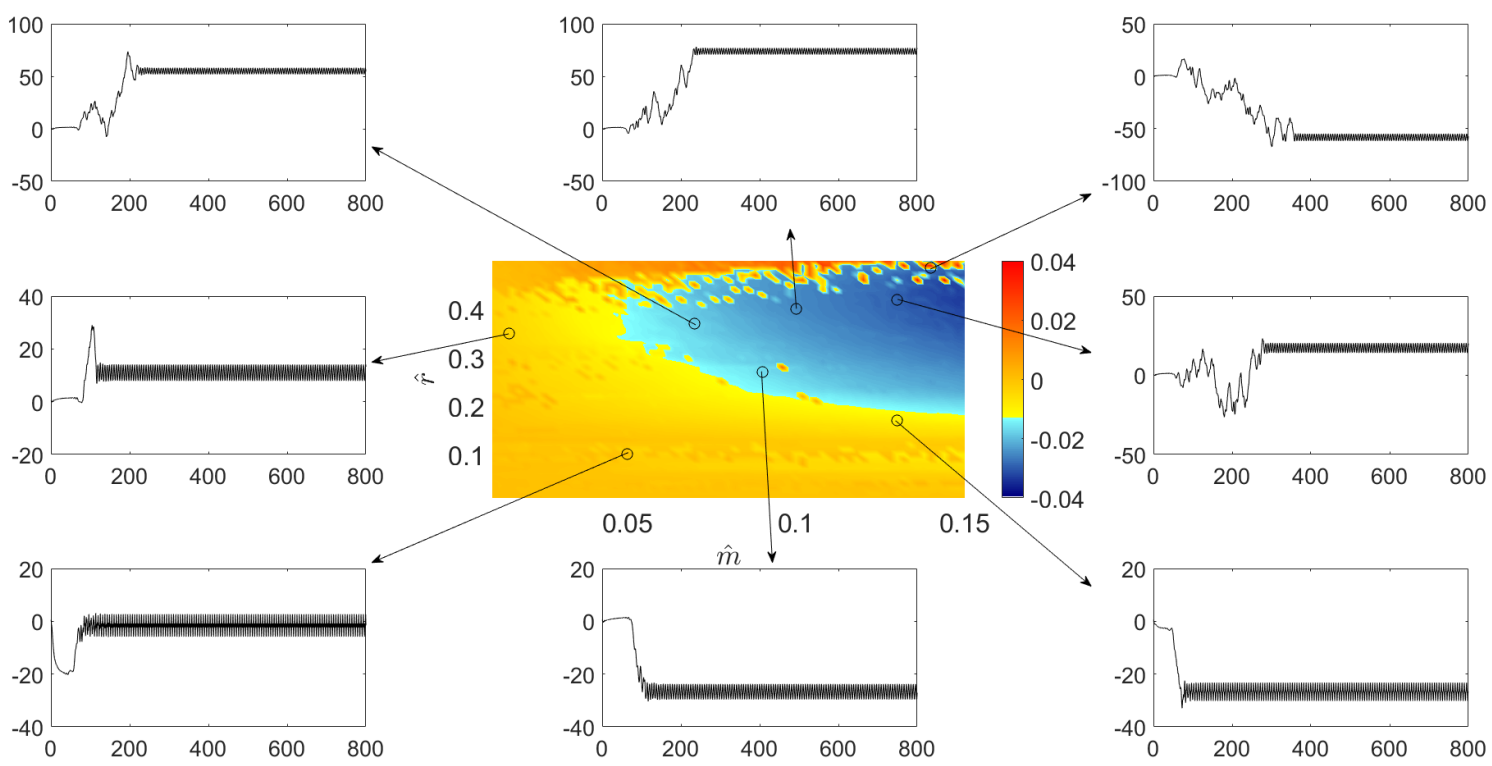

(b) $\hat{S}(\hat{m} ; \hat{r})$ e séries temporais $\theta(\tau)$.

Fonte: Extraída de Ueno (2019).

nota que as séries temporais $y(\tau)$ obtidas para $(\hat{m} ; \hat{r})=(0,10 ; 0,40)$ e $(\hat{m} ; \hat{r})=(0,13 ; 0,41)$ e exibidas na Figura 129(a) apresentam valores máximos inferiores àqueles obtidos quando a taxa de amortecimento do NVA é $\zeta_{\theta}=0,05$ e ilustrados na Figura 127(a).

Sob a ótica do tamanho da região no plano $(\hat{m} ; \hat{r})$ onde a supressão é eficiente, o aumento na taxa de amortecimento do NVA mostra-se benéfico. Por outro lado, tal aumento levou a uma diminuição no máximo valor do critério $\hat{S}$ obtido. Considerando 
Figura 129 - Variação do critério $\hat{S}$ como função dos parâmetros $\hat{m}$ e $\hat{r}$. Condição VIV-1gl, $\zeta_{\theta}=0,20$ e $U_{r}=6,4$.
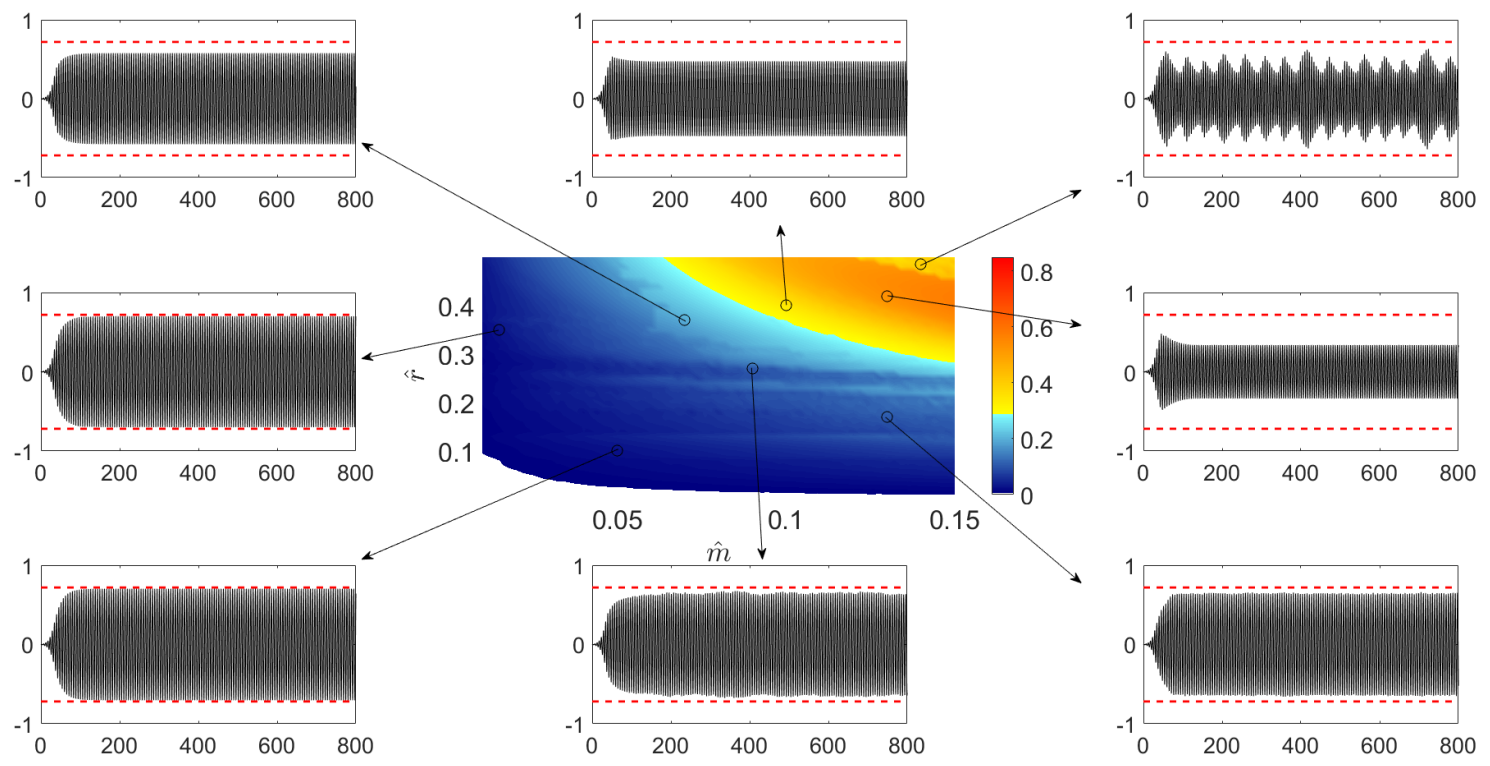

(a) $\hat{S}(\hat{m} ; \hat{r})$ e séries temporais $y(\tau)$.
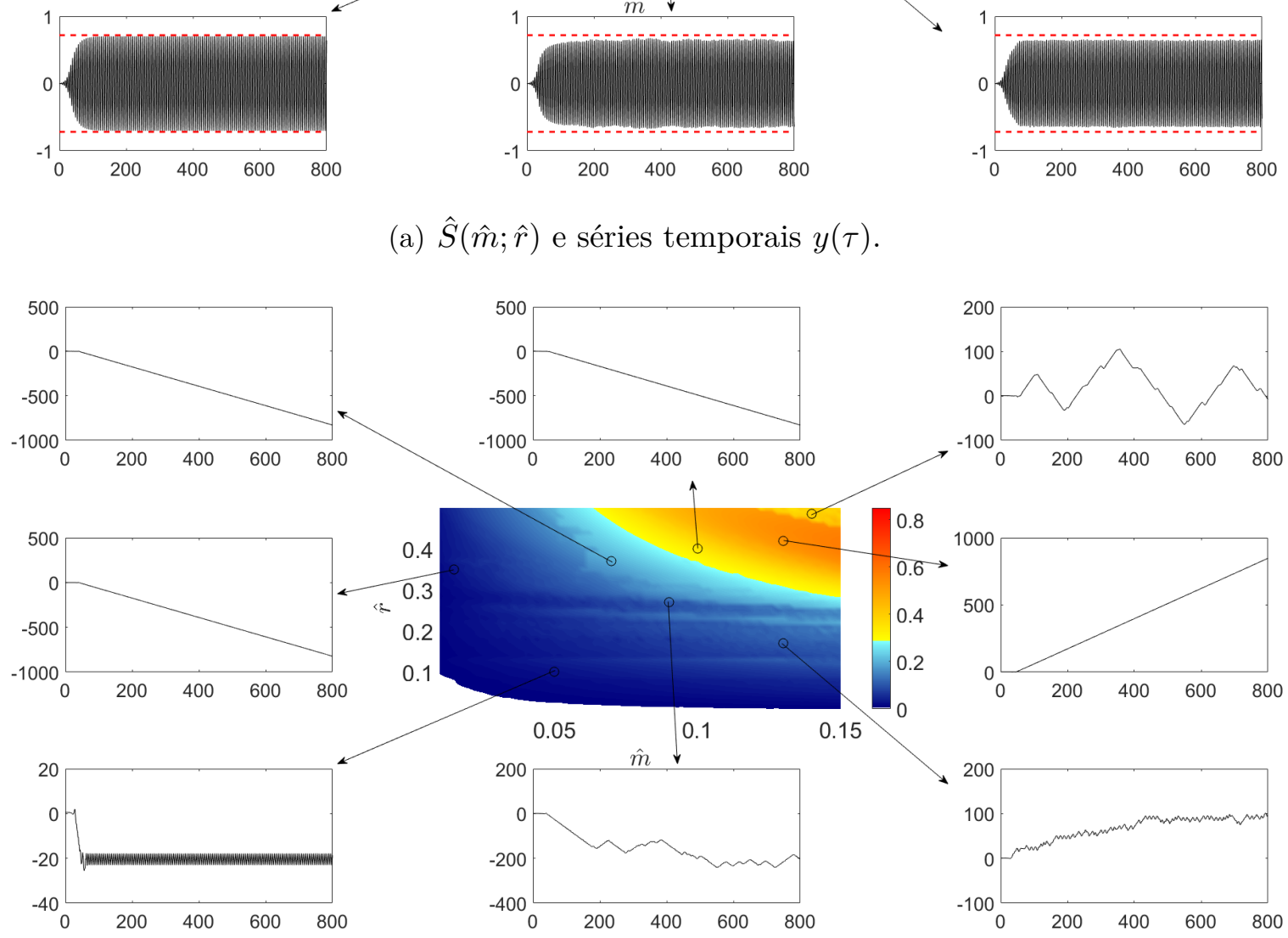

(b) $\hat{S}(\hat{m} ; \hat{r})$ e séries temporais $\theta(\tau)$.

Fonte: Extraída de Ueno (2019).

$(\hat{m} ; \hat{r})=(0,14 ; 0,50)$, a comparação entre os mapas apresentados nas Figuras 127(a) e 129(a) claramente mostra tanto o aumento no valor característico de $y(\tau)$ com o aumento no valor de $\zeta_{\theta}$ quanto a passagem de uma solução com amplitude estacionária para uma solução do tipo "RMA"6.

A discussão dos efeitos do aumento da taxa de amortecimento do NVA na capacidade

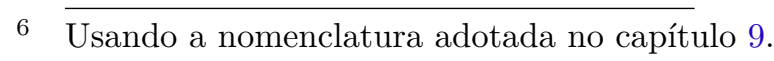


de supressão do fenômeno VIV-1gl em velocidade reduzida $U_{r}=6,4$ é encerrada pela análise das séries temporais de deslocamento do supressor. Comparando as Figuras 127(b) e 129(b), o leitor nota que o aumento no valor de $\zeta_{\theta}$ levou ao surgimento de um maior número de condições onde a resposta do NVA é caracterizada por uma velocidade de rotação $\omega_{r} \approx 1$, um cenário mais favorável à captura na ressonância $1: 1: 1$.

A comparação entre as Figuras 127(b) e 129(b) mostra, ainda, que a resposta do NVA obtida para o caso com $(\hat{m} ; \hat{r})=(0,14 ; 0,50)$ deixa de ser caracterizada por uma resposta do NVA com $\omega_{r} \approx 1$ e passa a ser definida por trechos alternados onde a ressonância $1: 1$ : 1 é atingida. Mais ainda, o caráter modulado da resposta do cilindro obtida para $\hat{m}=0,14, \hat{r}=0,50$ e $\zeta_{\theta}=0,20$ possui íntima relação com os diversos trechos observados na correspondente série temporal $\theta(\tau)$.

A análise dos mapas $\hat{S}(\hat{m} ; \hat{r})$ obtidos considerando $U_{r}=6,4$ é finalizada com a apresentação e discussão dos resultados referentes à condição VIV2-gl e para $\zeta_{\theta}=0,20$, cuja mapa é apresentado na Figura 130. Em comparação com o mesmo mapa obtido para $\zeta_{\theta}=0,05$ (ver Figura 128), percebe-se que o aumento na taxa de amortecimento do NVA foi bastante benéfica como forma de mitigação do fenômeno. Para um valor de taxa de amortecimento do NVA $\zeta_{\theta}=0,20$, a Figura 130 revela uma região compreendida definida por $0,03 \leq \hat{m} \leq 0,15 \times 0,40 \leq \hat{r} \leq 0,50$ na qual o critério $\hat{S}$ excede 0,05 , valor superior ao máximo encontrado na Figura 128.

O leitor nota, no entanto, que a supressão passiva continua mais eficiente para a condição VIV-1gl considerando os mesmos valores de velocidade reduzida e taxa de amortecimento do NVA. Essa afirmação pode ser feita notando que, na Figura 129 obtida para a condição VIV-1gl, o máximo valor do critério $\hat{S}$ é superior a 0,50 enquanto que $\max \{\hat{S}\} \approx 0,10$ para a condição VIV-2gl. Já no tocante aos aspectos qualitativos das respostas do cilindro e do supressor, as Figuras 130(a) e 130(b) mostram que as séries temporais $y(\tau)$ são todas caracterizadas por uma resposta com amplitude estacionária enquanto que as séries temporais de deslocamento do NVA contemplam um regime caracterizado por oscilações com amplitude estacionária. Esse padrão observado para a taxa de amortecimento $\zeta_{\theta}=0,20$ é bastante similar àquele obtido para $\zeta_{\theta}=0,05 \mathrm{e}$ ilustrado na Figura 128.

Discutem-se, a partir de agora, os mapas obtidos para uma condição de velocidade reduzida $U_{r}=7,9$, correspondendo ao fim do lower branch para a condição VIV-1gl. A Figura 131 traz o mapa $\hat{S}(\hat{m} ; \hat{r})$ calculado considerando a taxa de amortecimento do NVA $\zeta_{\theta}=0,05$ e para a condição VIV-1gl. Como mostrado na Figura 131, o máximo valor do critério $\hat{S}$ é próximo a 0,10 , valor significativamente menor do que o obtido para $U_{r}=6,4$. Note, no entanto, que uma extensa região do plano de parâmetros $(\hat{m} ; \hat{r})$ apresenta valores do critério de supressão superiores à metade do máximo encontrado.

Do ponto de vista qualitativo, as séries temporais $y(\tau)$ mostradas na Figura 131(a) 
Figura 130 - Variação do critério $\hat{S}$ como função dos parâmetros $\hat{m}$ e $\hat{r}$. Condição VIV-2gl, $\zeta_{\theta}=0,20$ e $U_{r}=6,4$.
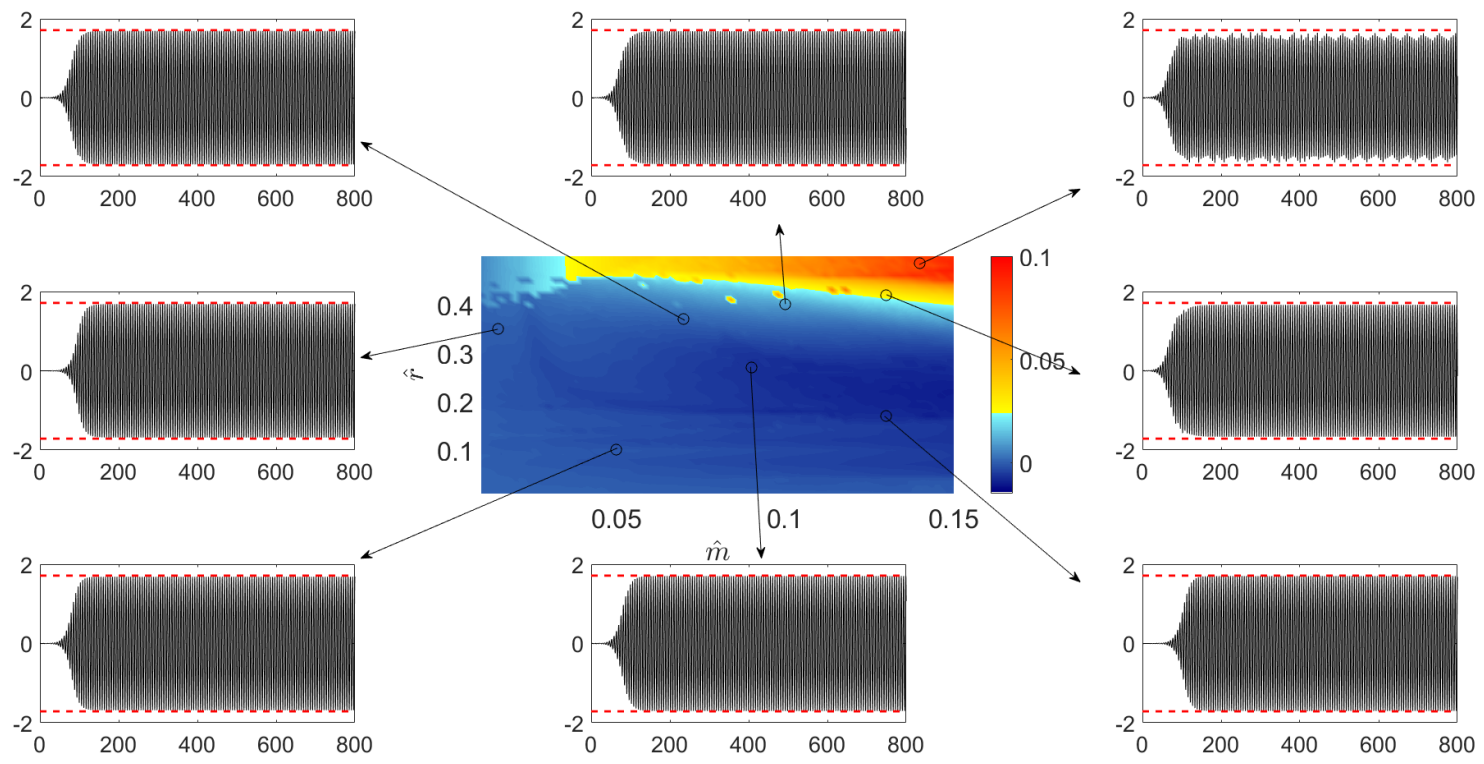

(a) $\hat{S}(\hat{m} ; \hat{r})$ e séries temporais $y(\tau)$.
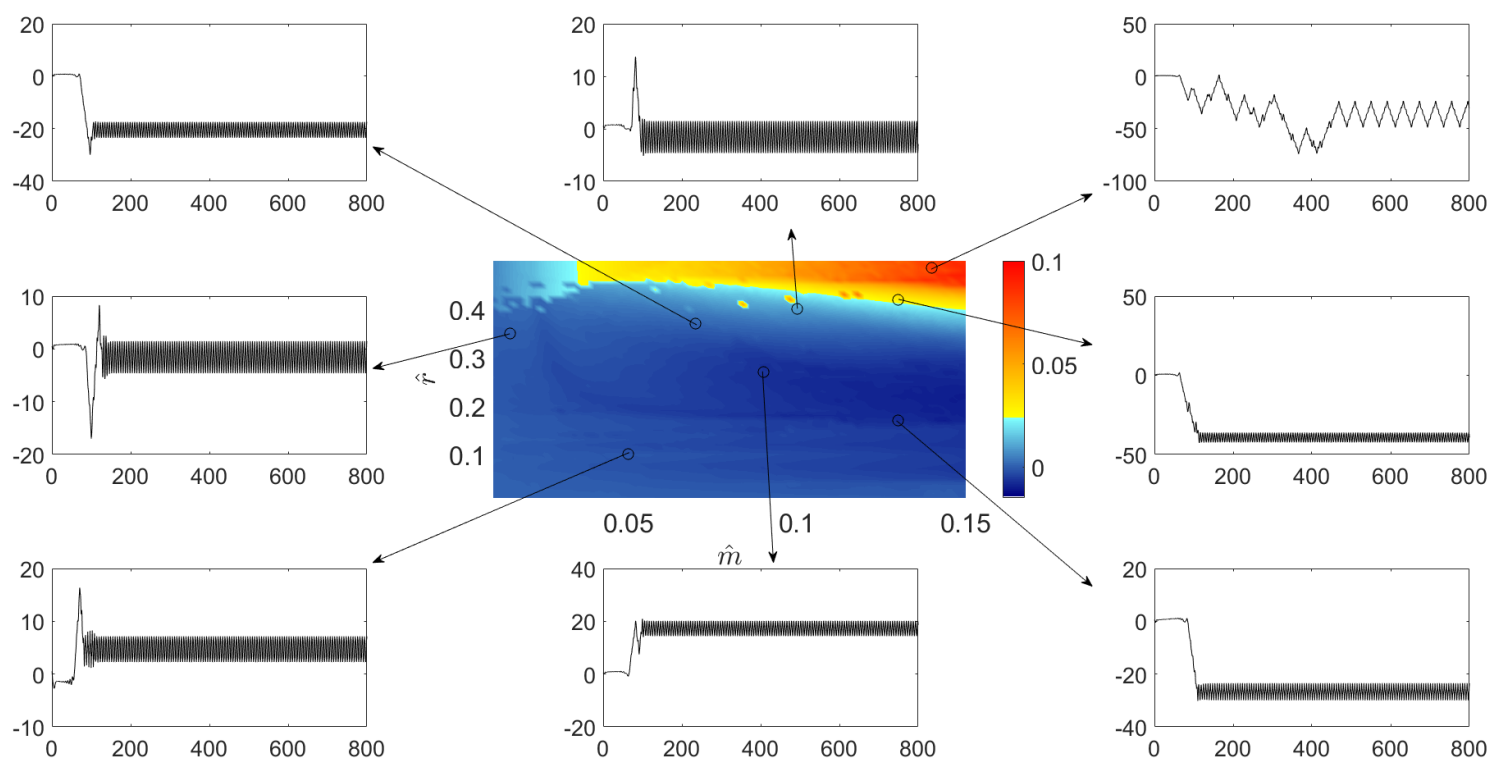

(b) $\hat{S}(\hat{m} ; \hat{r})$ e séries temporais $\theta(\tau)$.

Fonte: Extraída de Ueno (2019).

apresentam respostas com amplitudes estacionárias. Já as séries temporais de deslocamento do NVA, apresentadas na Figura 131(b), revelam três condições nas quais o NVA tem velocidade angular próxima a $\omega_{r}=1$ ao longo de toda a simulação. Além desse tipo de regime, são encontradas tanto respostas oscilatórias com amplitude estacionária quanto respostas sem padrão definido.

A Figura 132 apresenta o mapa $\hat{S}(\hat{m} ; \hat{r})$ ainda considerando $U_{r}=7,9$ e $\zeta_{\theta}=0,05$, 
Figura 131 - Variação do critério $\hat{S}$ como função dos parâmetros $\hat{m}$ e $\hat{r}$. Condição VIV-1gl, $\zeta_{\theta}=0,05$ e $U_{r}=7,9$.
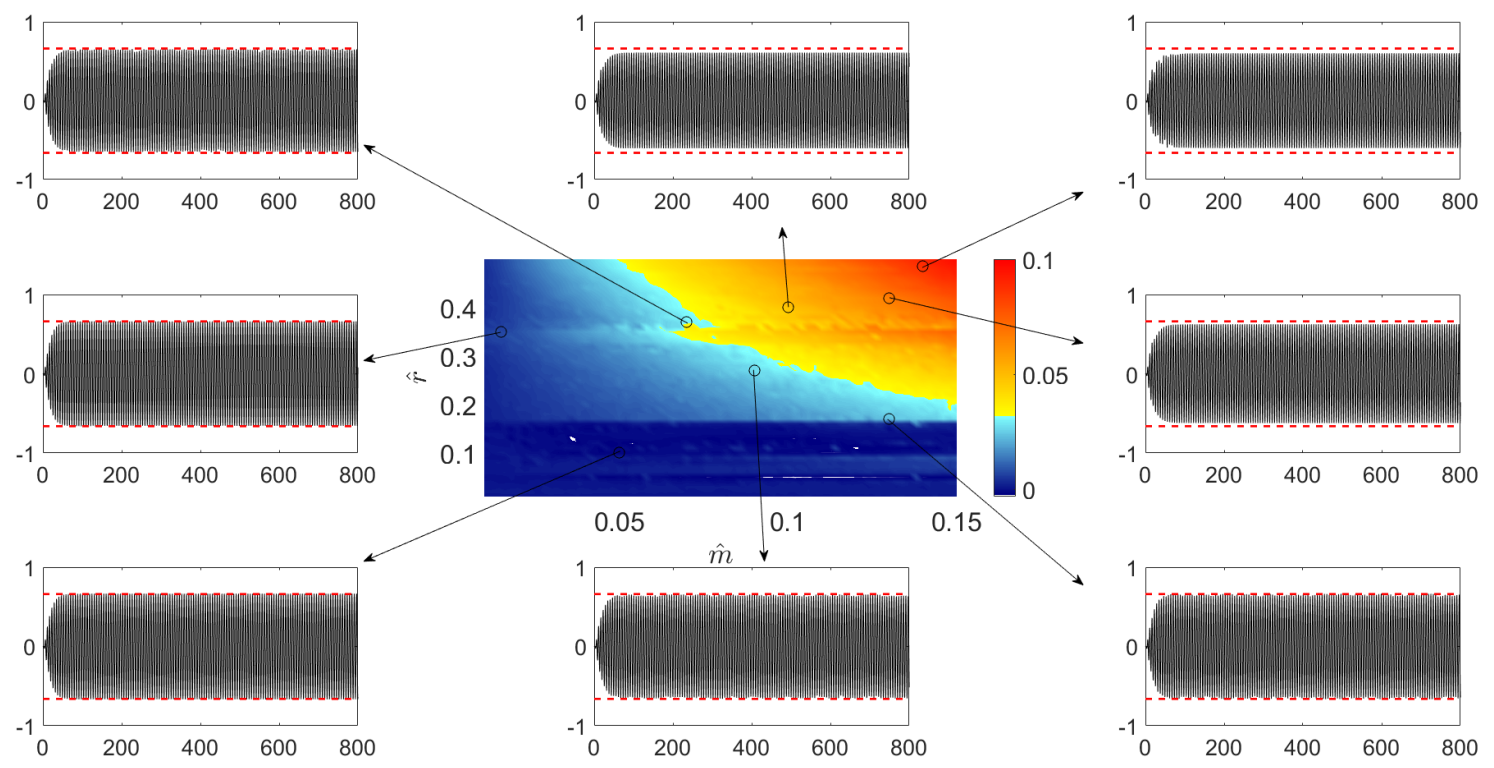

(a) $\hat{S}(\hat{m} ; \hat{r})$ e séries temporais $y(\tau)$.
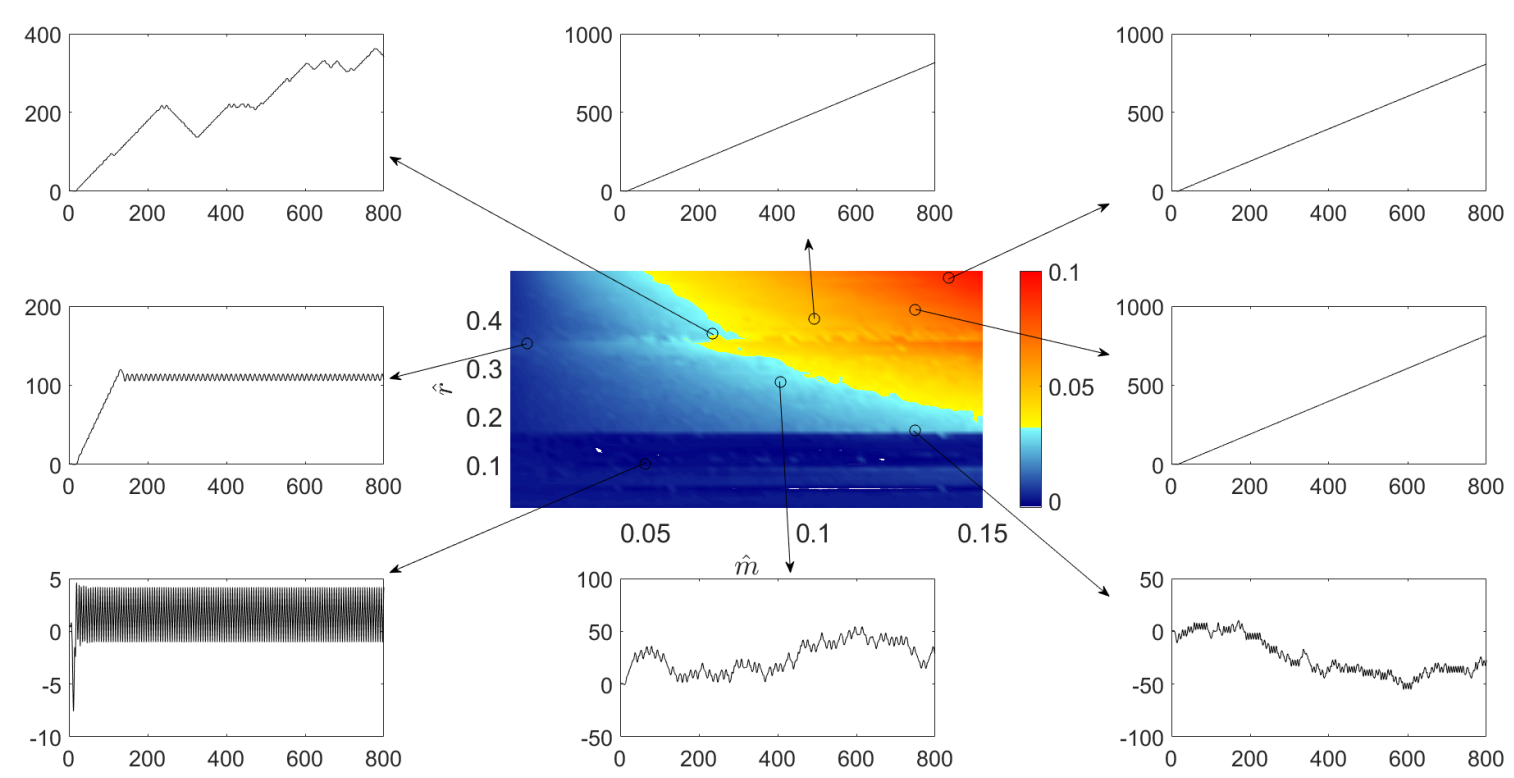

(b) $\hat{S}(\hat{m} ; \hat{r})$ e séries temporais $\theta(\tau)$.

Fonte: Extraída de Ueno (2019).

porém para a condição VIV-2gl. Um primeiro resultado que pode ser pontuado é a maior eficiência de supressão para a condição VIV-2gl, ao contrário do que fora observado quando da análise do caso definido por $U_{r}=6,4$. Comparando os mapas das Figuras 131 e 132, o máximo valor de $\hat{S}$ passa de 0,10 para 0,40 quando o cilindro passa a ter liberdade de oscilação na direção in-line.

Ao contrário dos demais casos analisados até este ponto, o mapa $\hat{S}(\hat{m} ; \hat{r})$ apresentado 
Figura 132 - Variação do critério $\hat{S}$ como função dos parâmetros $\hat{m}$ e $\hat{r}$. Condição VIV-2gl, $\zeta_{\theta}=0,05$ e $U_{r}=7,9$.
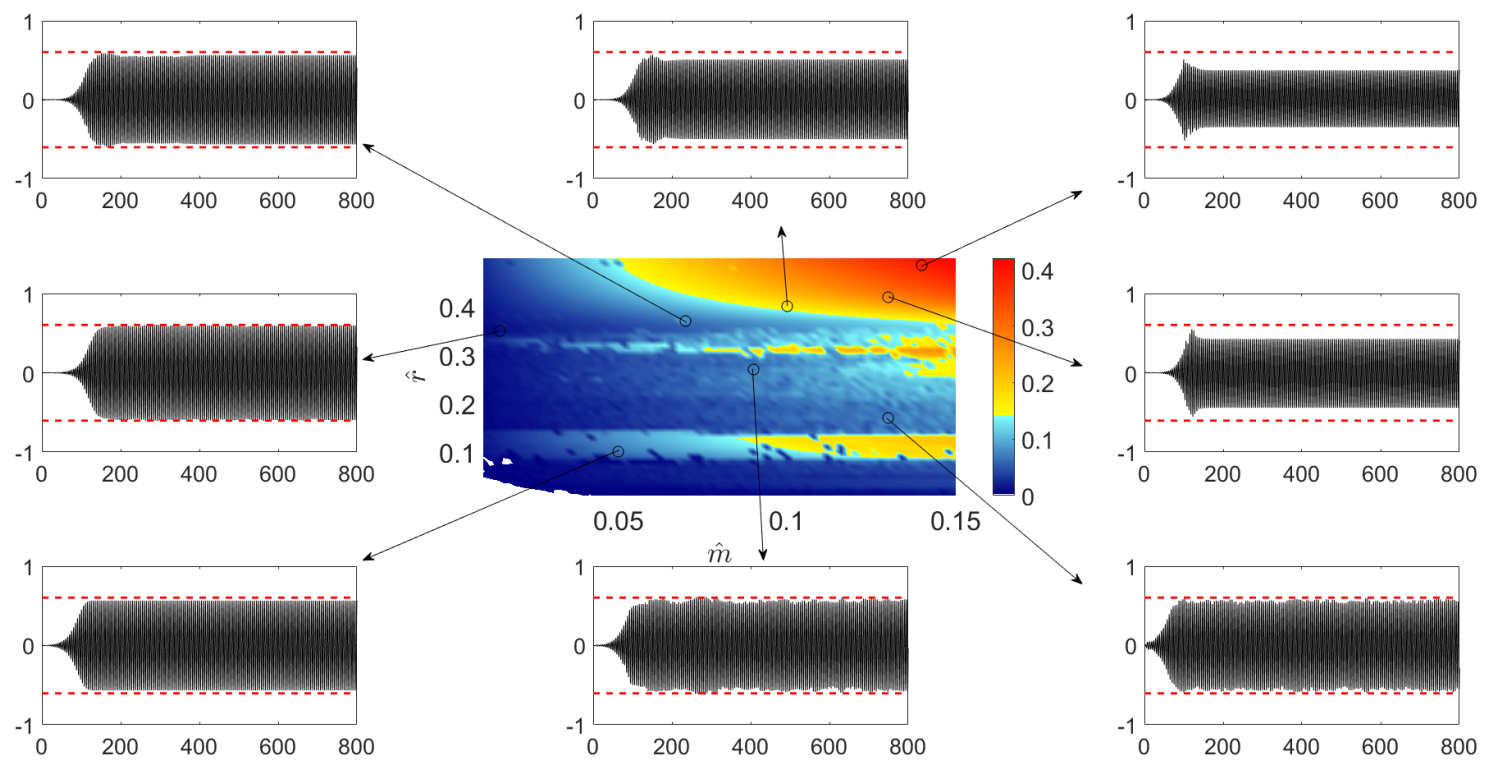

(a) $\hat{S}(\hat{m} ; \hat{r})$ e séries temporais $y(\tau)$.
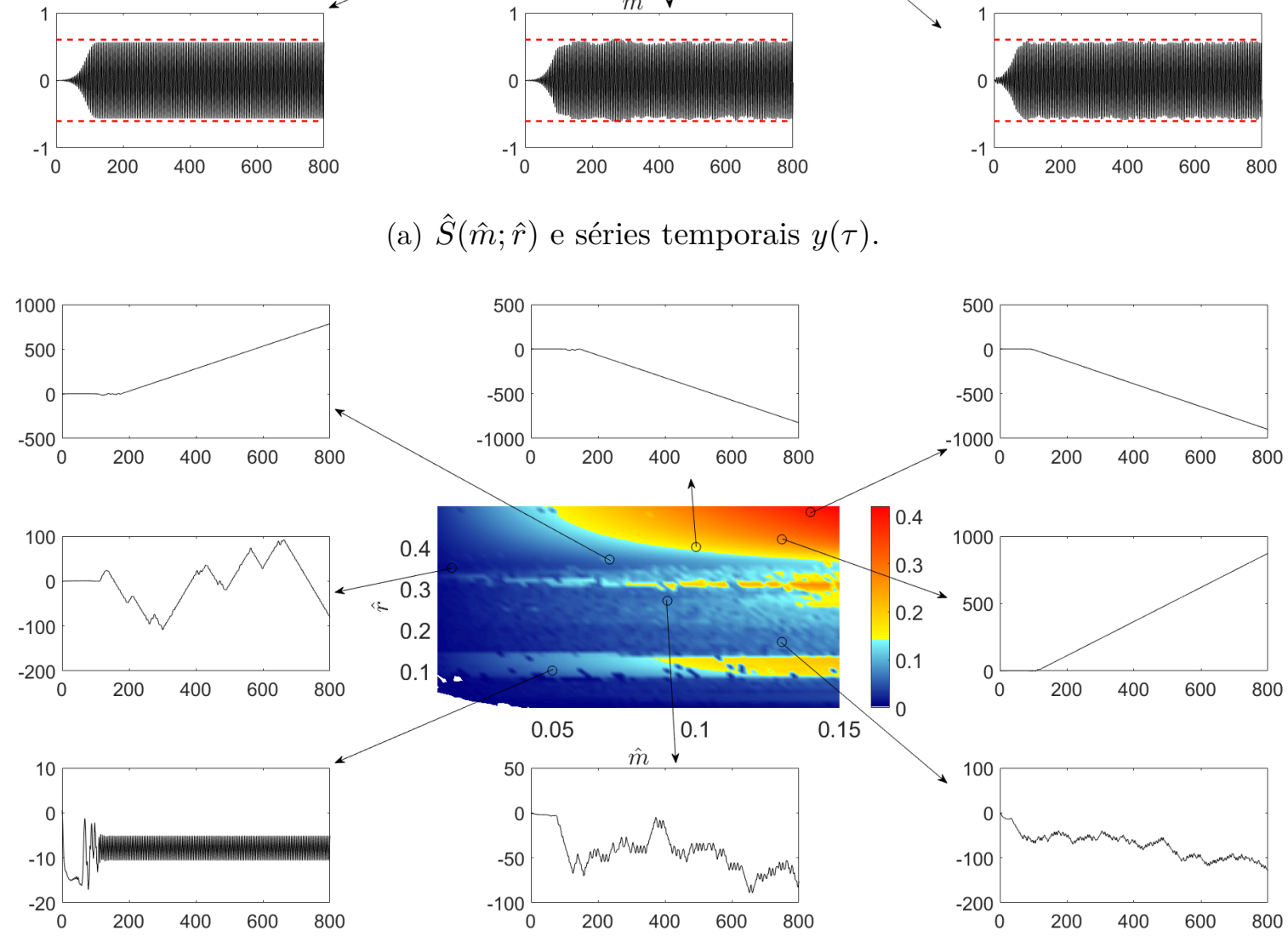

(b) $\hat{S}(\hat{m} ; \hat{r})$ e séries temporais $\theta(\tau)$.

Fonte: Extraída de Ueno (2019).

na Figura 132 apresenta regiões desconexas onde o parâmetro $\hat{S}$ é maior ou igual à metade do valor seu máximo obtido; ver regiões coloridas em laranja ou vermelho. O leitor nota a presença de três regiões de interesse para a supressão no plano de parâmetros de controle $(\hat{m} ; \hat{r})$, sendo a mais extensa aquela que abrange $\hat{r} \geq 0,40$ e $\hat{m} \geq 0,05$. As outras regiões de interesse para a supressão passiva são menos extensas e localizadas em $\hat{m} \geq 0,13 \times 0,15 \leq \hat{r} \leq 0,30$ e em $0,10 \leq \hat{m} \leq 0,15 \times 0,10 \leq \hat{r} \leq 0,15$. 
O leitor nota, ainda, que o plano de parâmetros de controle apresenta uma maior erosão (no que diz respeito ao critério $\hat{S}$ ) do que quando apenas oscilações cross-wise eram permitidas ao cilindro. Do ponto de vista tecnológico, como já mencionado na seção 9.2 por ocasião do estudo da supressão passiva da excitação paramétrica, essa erosão é indesejável, uma vez que pequenas e incontroláveis variações nos parâmetros de controle podem levar a resultados bastante distintos.

Discutindo agora as séries temporais de deslocamento do cilindro apresentadas na Figura 132(a), é possível notar que todas as séries ilustradas são caracterizadas por uma amplitude estacionária. Em particular, a condição com $\hat{m}=0,14$ e $\hat{r}=0,50$ configura um caso bastante interessante do ponto de vista de supressão, uma vez que ele leva a um decréscimo apreciável da amplitude de resposta da estrutura principal sem com isso apresentar respostas moduladas em amplitude. Por sua vez, as séries temporais de resposta do NVA apresentadas na Figura 132(b) novamente mostram que as condições onde a supressão é mais efetiva são aquelas nas quais o NVA tem sua resposta caracterizada por uma velocidade angular praticamente constante e igual à unidade.

A Figura 133 mostra o mapa $\hat{S}(\hat{m} ; \hat{r})$ obtido a partir das simulações numéricas $\operatorname{com} \zeta_{\theta}=0,20$ e $U_{r}=7,9$ para a condição VIV-1gl. Comparando esse mapa com aquele apresentado na Figura 131 e obtido para a mesma condição de velocidade reduzida porém $\operatorname{com} \zeta_{\theta}=0,05$, é possível notar que o aumento na taxa de amortecimento do NVA promoveu um importante ganho em sua capacidade de supressão. Enquanto o mapa $\hat{S}(\hat{m} ; \hat{r})$ obtido para $\zeta_{\theta}=0,05$ tem seu valor máximo próximo a 0,10, a Figura 133 claramente mostra que $\max \{\hat{S}\} \approx 0,40$ se $\zeta_{\theta}=0,20$, além de uma região colorida em amarelo, vermelho e laranja onde o critério $\hat{S}$ excede 0,20 . Mais ainda e configurando um resultando análogo àquele já obtido para velocidade reduzida $U_{r}=6,4$ e já apresentado na Figura 129, o mapa apresentado na Figura 133 tem uma região bem definida no plano de parâmetros de controle $(\hat{m} ; \hat{r})$ e na qual a eficiência da supressão passiva, se tomada com base no parâmetro $\hat{S}$, é maximizada.

Como mostrado na Figura 133(a), as correspondentes séries temporais de deslocamento do cilindro são caracterizadas por amplitudes estacionárias, salvo o caso definido por $(\hat{m} ; \hat{r})=(0,14 ; 0,50)$ e no qual a resposta é enquadrada como do tipo "RMA". Novamente, a correlação entre as respostas do cilindro e do NVA (essas apresentadas na Figura 133(b)) mostra que a mitigação de vibrações está relacionada à rotação do NVA com velocidade angular $\omega_{r} \approx 1$. Mesmo a simulação $\operatorname{com}(\hat{m} ; \hat{r})=(0,14 ; 0,50)$ e que leva a uma resposta do cilindro com importantes modulações em amplitude tem, em seu regime de supressão, velocidades angulares características do NVA próximas a $\omega_{r}=1$. De maneira análoga aos demais casos aqui descritos, diferentes classes de respostas do NVA são obtidas e abrangem aquelas com velocidade angular constante (seja ao longo de toda a simulação ou em alguns trechos), aquelas caracterizadas por oscilações com amplitude estacionária 
Figura 133 - Variação do critério $\hat{S}$ como função dos parâmetros $\hat{m}$ e $\hat{r}$. Condição VIV-1gl, $\zeta_{\theta}=0,20$ e $U_{r}=7,9$.
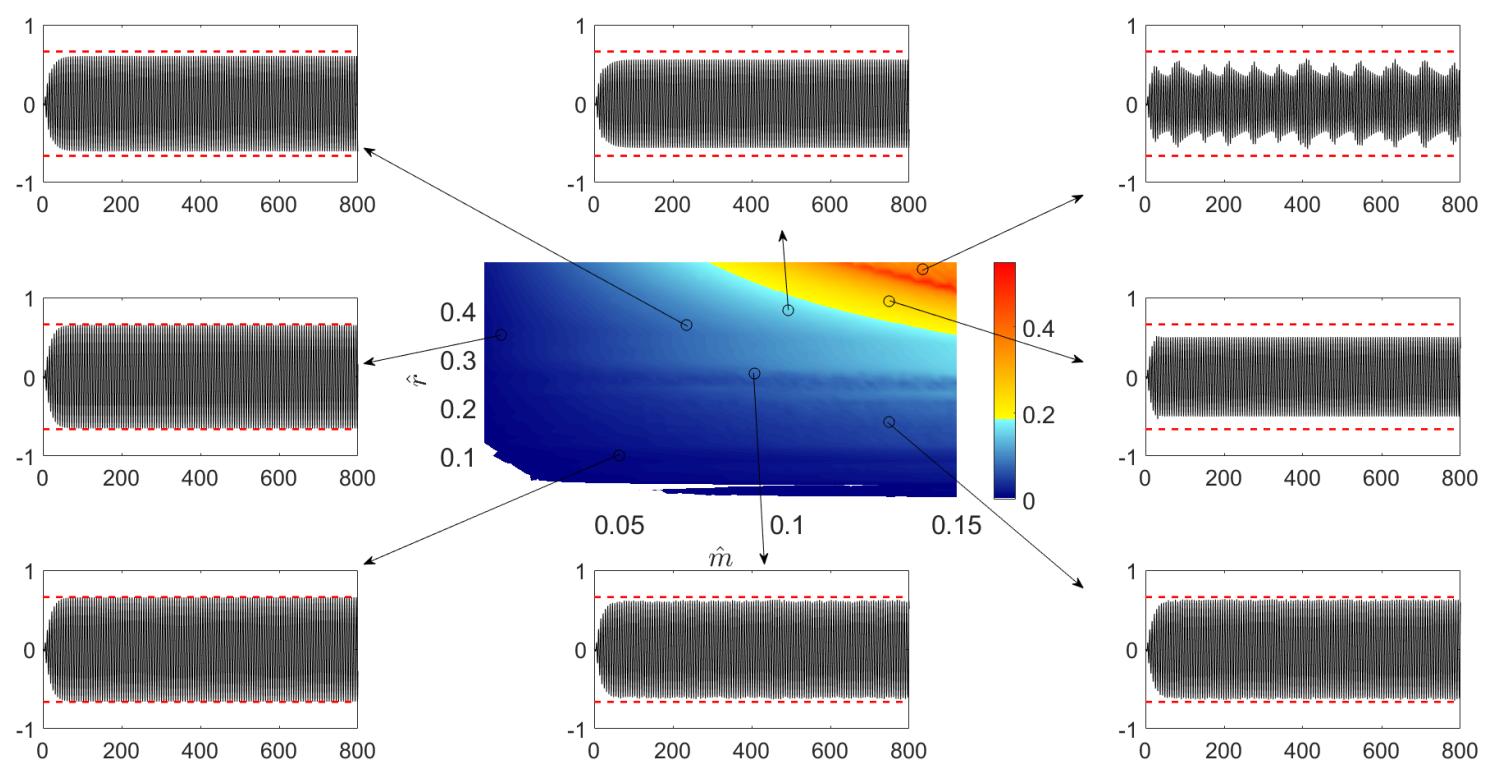

(a) $\hat{S}(\hat{m} ; \hat{r})$ e séries temporais $y(\tau)$.
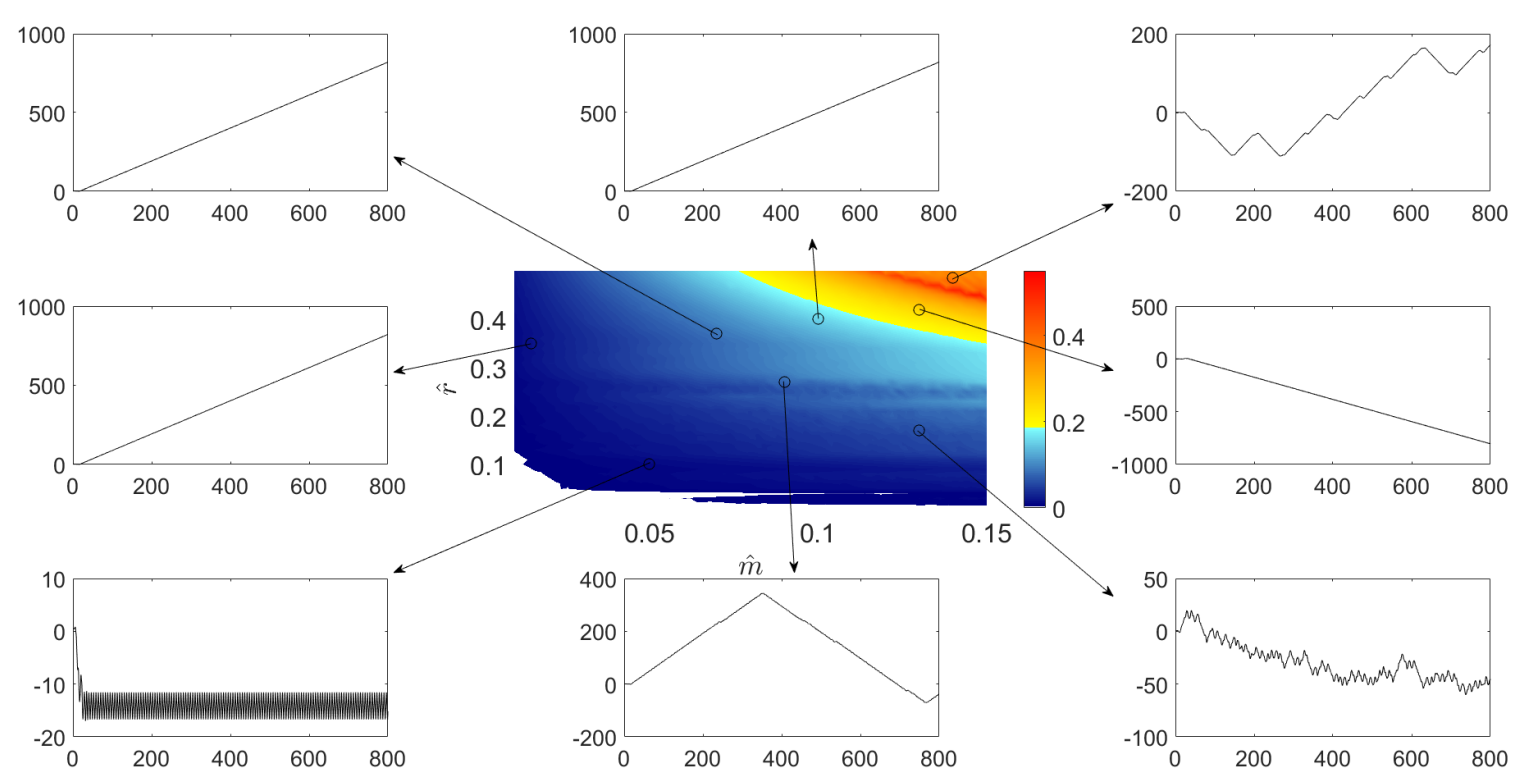

(b) $\hat{S}(\hat{m} ; \hat{r})$ e séries temporais $\theta(\tau)$.

Fonte: Extraída de Ueno (2019).

ou mesmo respostas sem padrão definido.

A Figura 134 traz o mapa $\hat{S}(\hat{m} ; \hat{r})$ ainda considerando a taxa de amortecimento do NVA como $\zeta_{\theta}=0,20$ e velocidade reduzida $U_{r}=7,9$, porém para a condição VIV2gl. Essa figura revela uma extensa área no plano de parâmetros $(\hat{m} ; \hat{r})$ definida por $0,07 \leq \hat{m} \leq 0,15 \times 0,30 \leq \hat{r} \leq 0,50$ na qual $\hat{S} \geq 0,20$. Nota-se, ainda, a existência de uma segunda e estreita área colorida em amarelo definida por $\hat{m} \geq 0,15$ e $\hat{r} \approx 0,10$ na qual o 
parâmetro $\hat{S}$ assume valores próximos a 0,20 .

Figura 134 - Variação do critério $\hat{S}$ como função dos parâmetros $\hat{m}$ e $\hat{r}$. Condição VIV-2gl, $\zeta_{\theta}=0,20$ e $U_{r}=7,9$.
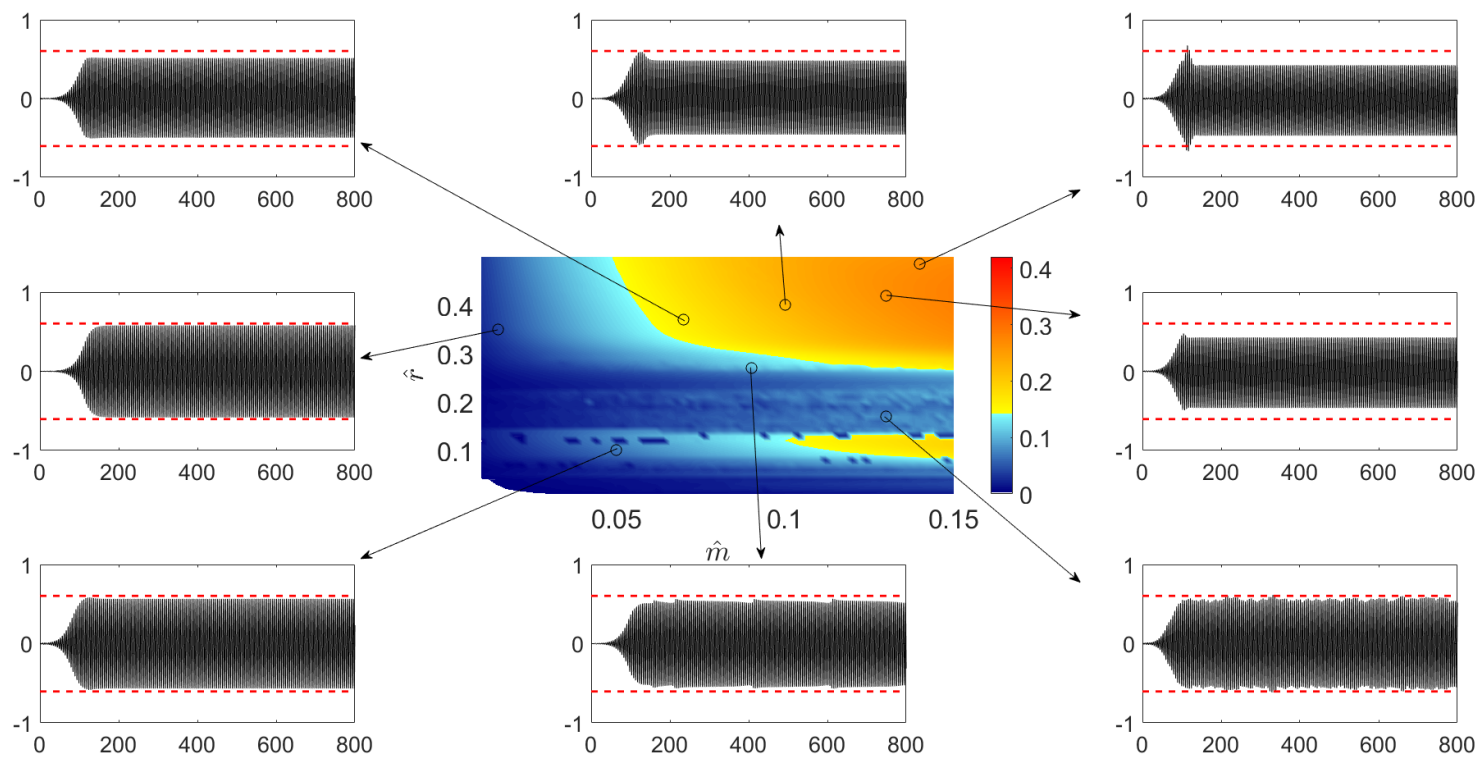

(a) $\hat{S}(\hat{m} ; \hat{r})$ e séries temporais $y(\tau)$.
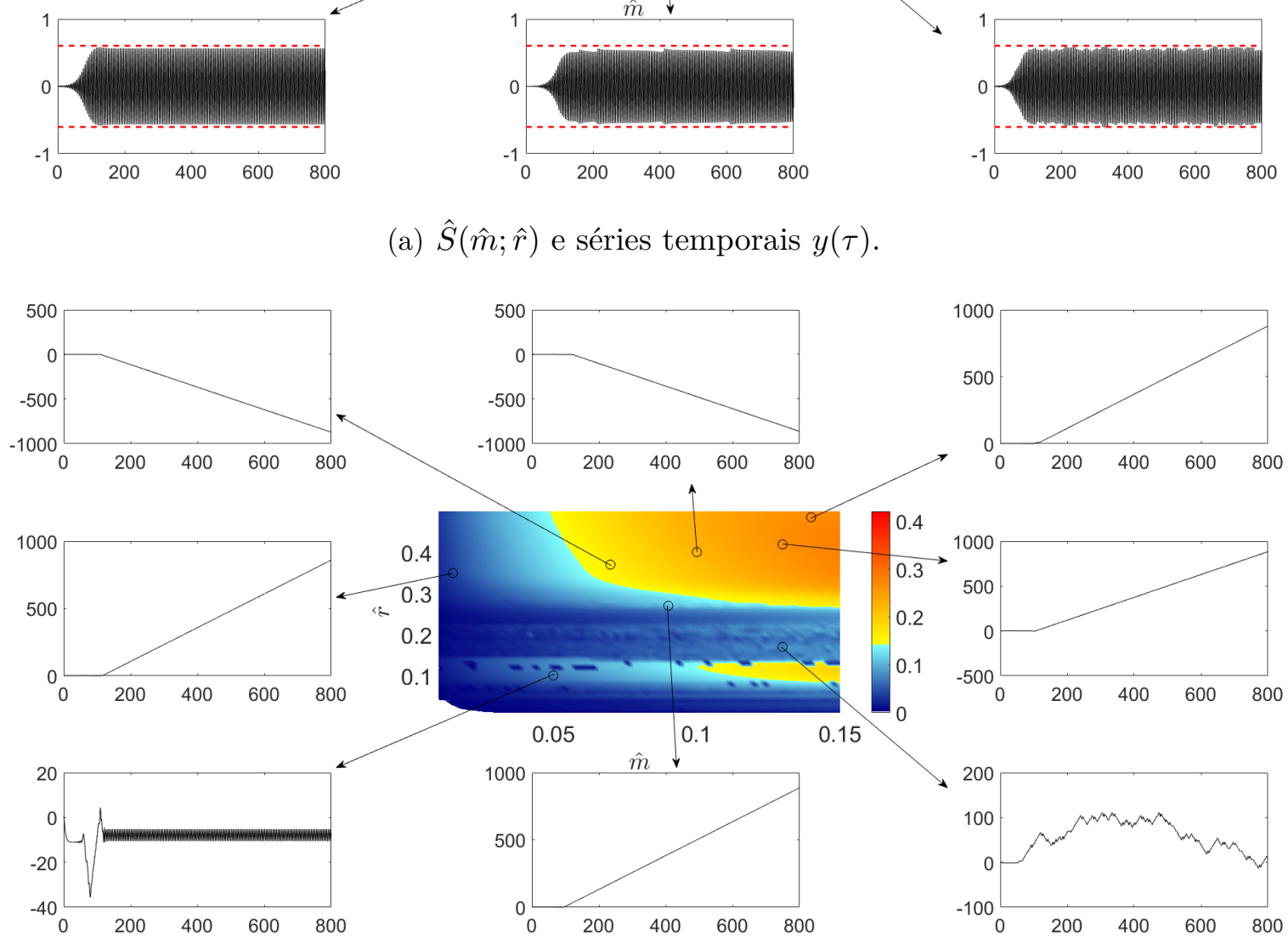

(b) $\hat{S}(\hat{m} ; \hat{r})$ e séries temporais $\theta(\tau)$.

Fonte: Extraída de Ueno (2019).

Comparando os mapas apresentados nas Figuras 132 e 134, ambos obtidos para a condição VIV-2gl e $U_{r}=7,9$, é possível notar que o acréscimo na taxa de amortecimento do NVA reduz o máximo valor do parâmetro $\hat{S}$ obtido. Percebe-se também que a região do plano $(\hat{m} ; \hat{r})$ próxima a $\hat{r} \approx 0,3$ e que era caracterizada por uma grande erosão (ver Figura 132) deixa de existir quando $\zeta_{\theta}=0,20$, formando a já discutida extensa região do 
plano $(\hat{m} ; \hat{r})$ que é contínua e caracterizada por $\hat{S} \geq 0,20$.

Do ponto de vista qualitativo, as séries temporais de deslocamento do cilindro apresentadas na Figura 134(a) são semelhantes àquelas obtidas considerando a taxa de amortecimento do NVA como $\zeta_{\theta}=0,05$ e caracterizadas por respostas com amplitude estacionária. Já a análise das séries temporais $\theta(\tau)$ exibidas na Figura 134(b) indicam que o aumento no valor de $\zeta_{\theta}$ promove um aumento no número de casos onde a velocidade angular é praticamente constante e igual a $\omega_{r}=1$.

A última condição de velocidade reduzida a ser discutida na forma do mapa $\hat{S}(\hat{m} ; \hat{r})$ é $U_{r}=9,2$, correspondendo ao final do lower branch para a condição VIV1-gl. A Figura 135 apresenta o referido mapa obtido a partir de simulações numéricas conduzidas com a taxa de amortecimento do NVA igual a 0,05 e para a condição VIV-1gl.

Segundo o mapa apresentado na Figura 135, a maior porção do plano de parâmetros de controle $(\hat{m} ; \hat{r})$ está relacionada a valores do parâmetro $\hat{S} \approx 0$, com apenas uma pequena região caracterizadas por altos valores de massa e de raio do NVA apresentando $\hat{S} \geq 0,6$ (ver regiões em coloridas em vermelho). Note, na Figura 135(a), que a série temporal $y(\tau)$ obtida para $(\hat{m} ; \hat{r})=(0,14 ; 0,50)$ é do tipo "RMA" e tem seu máximo valor significativamente inferior àquele obtido na condição onde o cilindro não é dotado do supressor.

A Figura 135(b) traz as séries temporais de deslocamento do NVA para obtidas para a condição VIV-1gl com taxa de amortecimento do NVA $\zeta_{\theta}=0,05$ e velocidade reduzida $U_{r}=9,2$. Ainda considerando o caso $(\hat{m} ; \hat{r})=(0,14 ; 0,50)$, a série temporal $\theta(\tau)$ é caracterizada por sua velocidade angular $\omega_{r} \approx 1$ ao longo de toda a simulação. No entanto, este comportamento da resposta do NVA não foi observado em conjunto com respostas do tipo "RMA", podendo ser estudo de investigações futuras.

Cabe, neste ponto, uma analogia com a discussão conduzida na seção 9.4 por ocasião da análise do problema de supressão passiva por meio de uma análise assintótica. Naquela seção, demonstrou-se que a resposta do tipo "RMA" estava associada à captura e escape da SIM e, portanto, da ressonância $2: 1: 1$. Durante a supressão passiva da excitação paramétrica e a consequente captura na SIM, o supressor é, por vezes, caracterizado por rotacionar com velocidade angular $\omega_{r} \approx 1$. Já o escape da SIM levava o supressor a permanecer com sua posição angular praticamente invariante no tempo.

A Figura 136 também apresenta o mapa $\hat{S}(\hat{m} ; \hat{r})$ obtido considerando $\zeta_{\theta}=0,05$, porém para a condição VIV-2gl. Comparando esse mapa com aquele obtido para o mesmo valor de taxa de amortecimento do NVA e para a condição VIV-1gl (ver Figura 135), nota-se que a presença de oscilações do cilindro na direção in-line leva o critério $\hat{S}$ a apresentar valores máximos próximos a 0,10 , bastante inferiores ao valor máximo obtido para a condição VIV-1gl. A Figura 136 ainda mostra uma região colorida em azul escuro e compreendida no intervalo $0,15 \leq \hat{r} \leq 0,20$ e para praticamente todos os valores de massa 
Figura 135 - Variação do critério $\hat{S}$ como função dos parâmetros $\hat{m}$ e $\hat{r}$. Condição VIV-1gl, $\zeta_{\theta}=0,05$ e $U_{r}=9,2$.
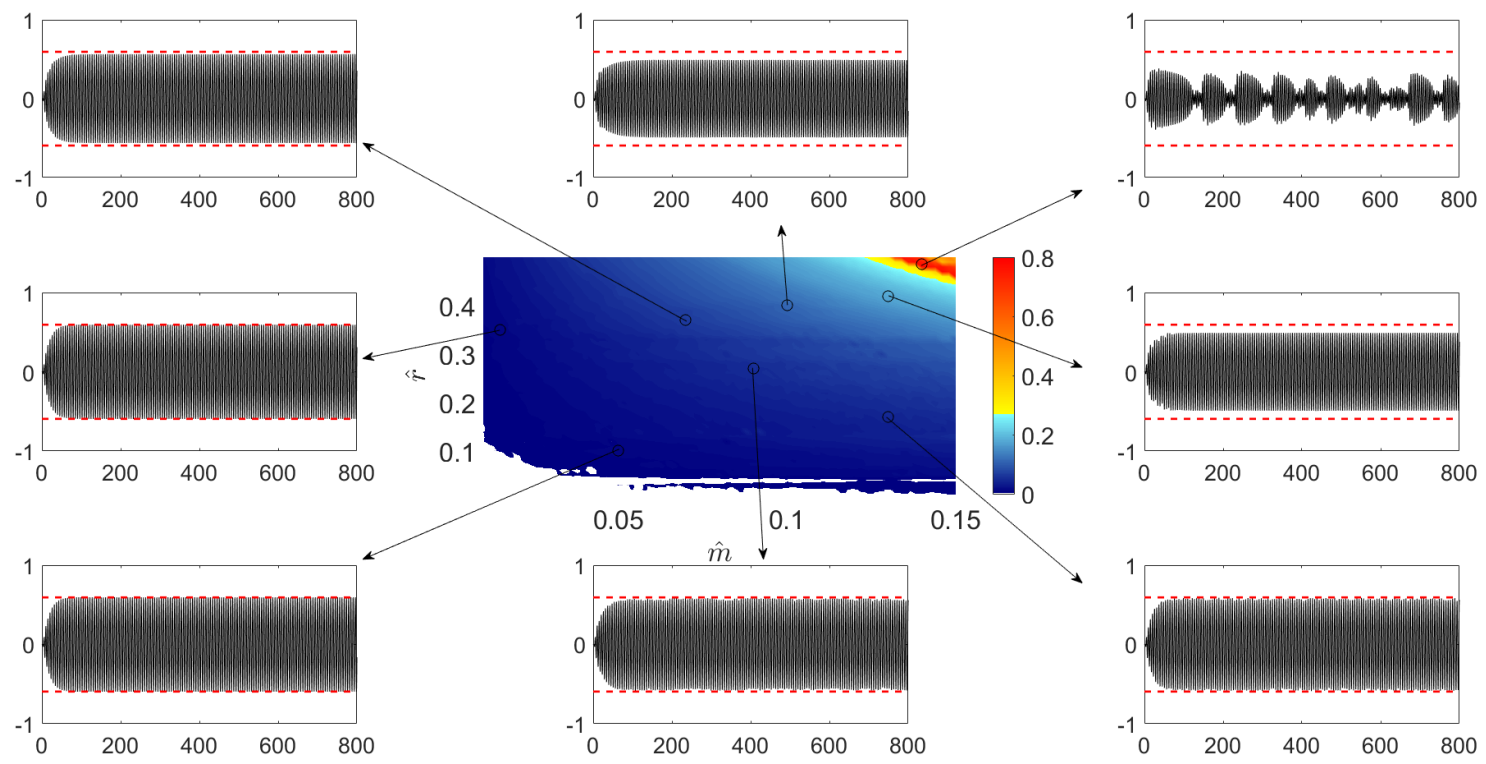

(a) $\hat{S}(\hat{m} ; \hat{r})$ e séries temporais $y(\tau)$.
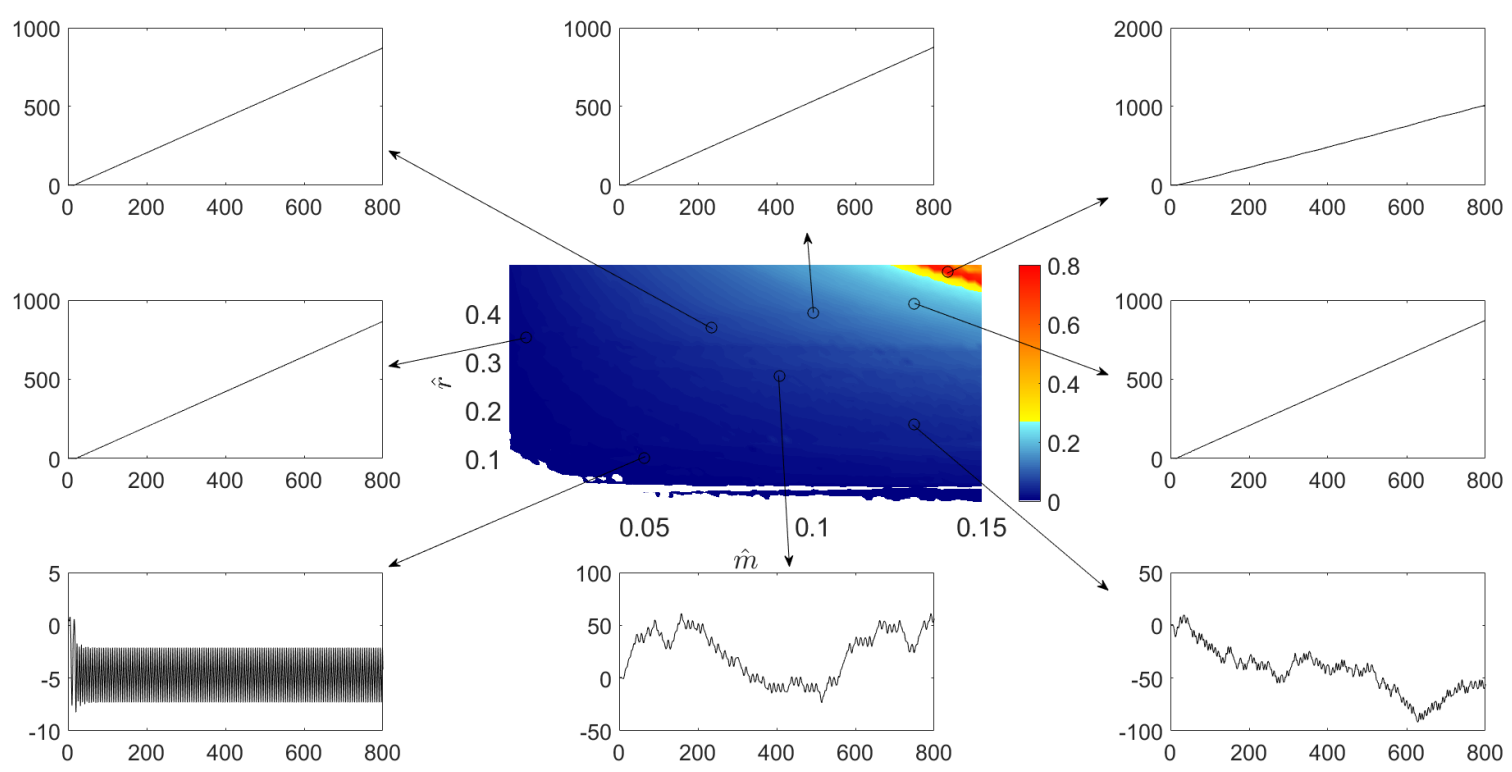

(b) $\hat{S}(\hat{m} ; \hat{r})$ e séries temporais $\theta(\tau)$.

Fonte: Extraída de Ueno (2019).

do NVA onde existe uma amplificação das oscilações na direção cross-wise.

Do ponto de vista qualitativo das respostas do cilindro e do NVA, a Figura 136(a) indica que as séries temporais $y(\tau)$ possuem um aspecto bastante regular, embora uma pequena modulação em amplitude possa ser notada nos casos com $(\hat{m} ; \hat{r})=(0,14 ; 0,50)$ e $(\hat{m} ; \hat{r})=(0,13 ; 0,42)$. Já as respostas do supressor ilustradas na Figura 136(b) são, em sua maioria, desprovidas de um padrão regular. Como exceções a esse comportamento 
Figura 136 - Variação do critério $\hat{S}$ como função dos parâmetros $\hat{m}$ e $\hat{r}$. Condição VIV-2gl, $\zeta_{\theta}=0,05$ e $U_{r}=9,2$.
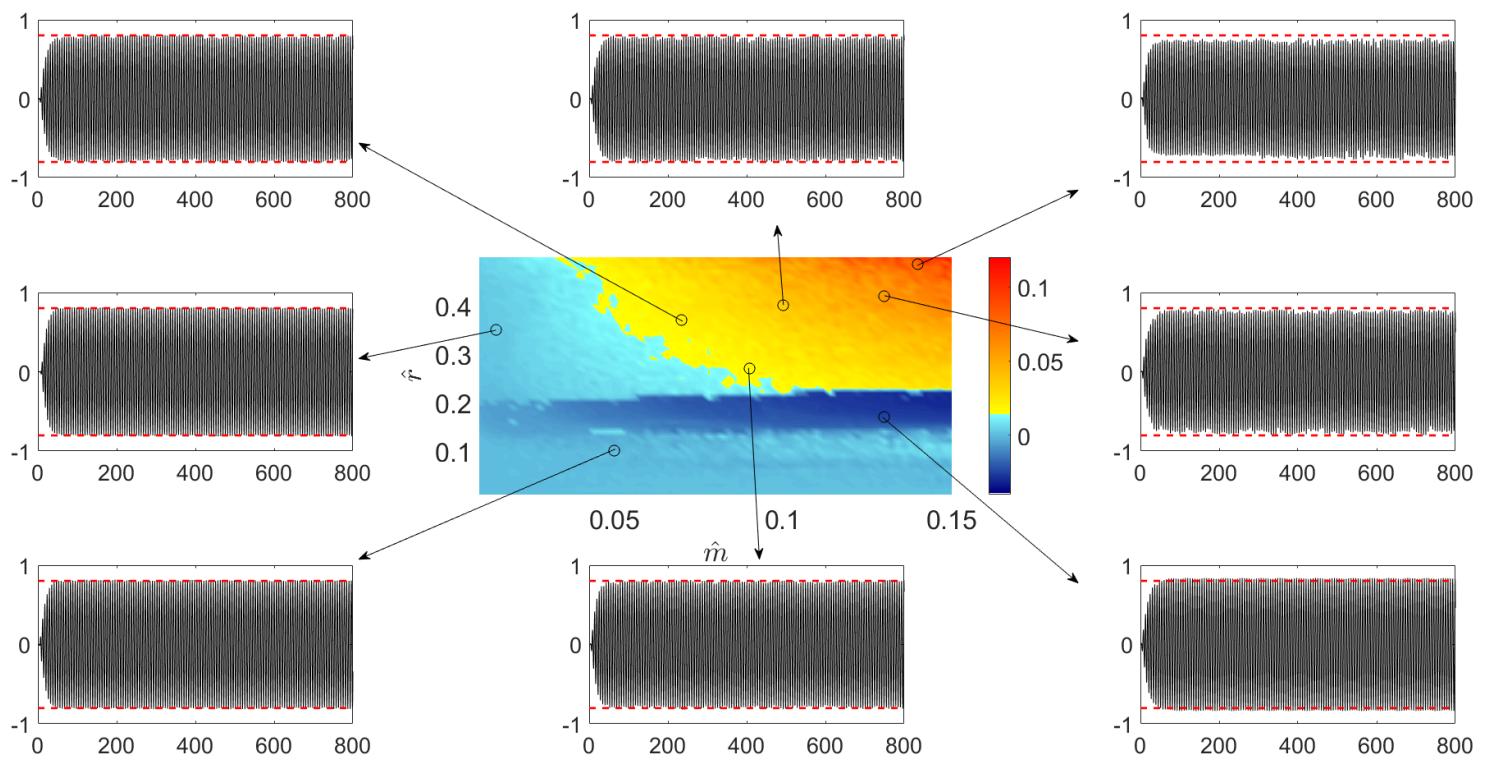

(a) $\hat{S}(\hat{m} ; \hat{r})$ e séries temporais $y(\tau)$.
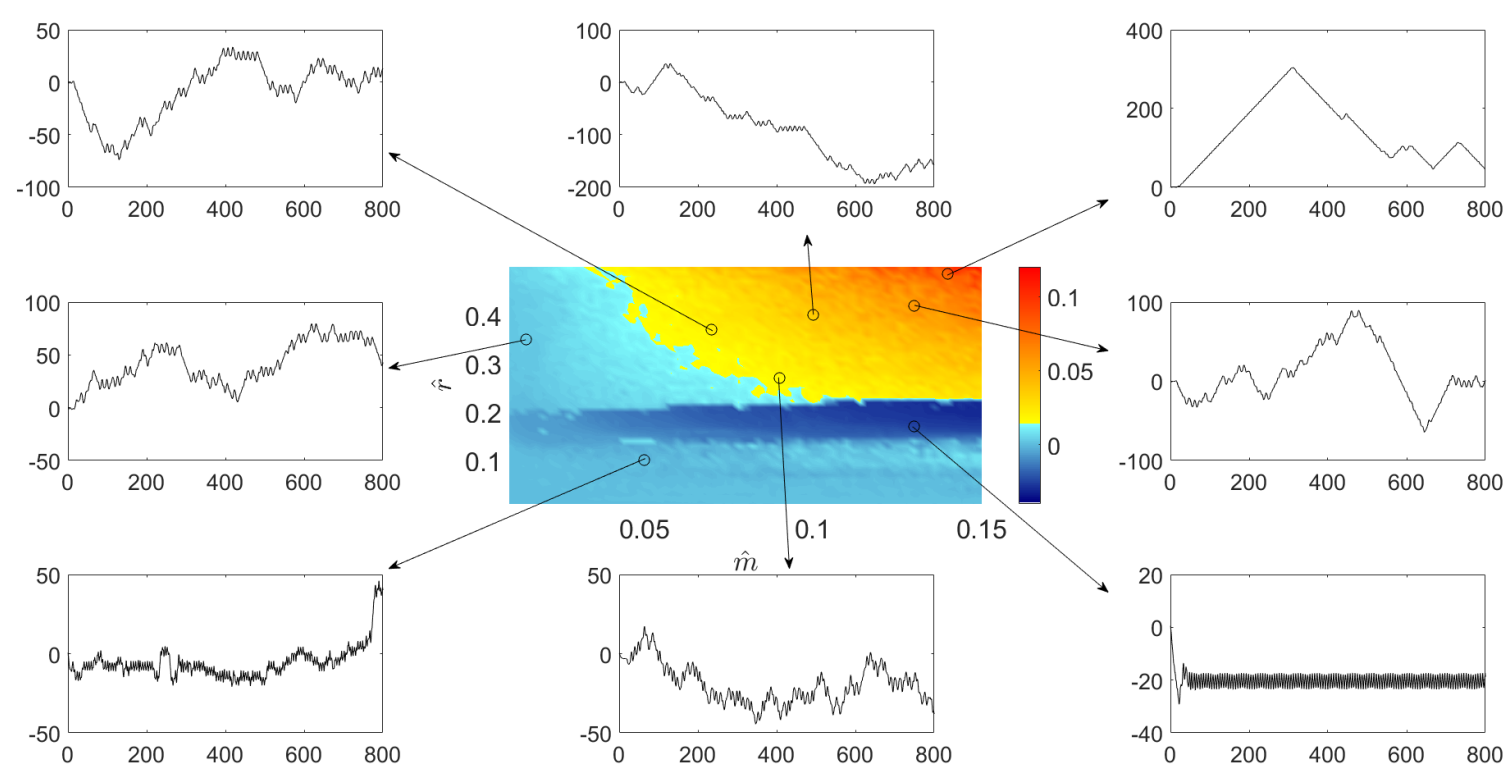

(b) $\hat{S}(\hat{m} ; \hat{r})$ e séries temporais $\theta(\tau)$.

Fonte: Extraída de Ueno (2019).

sem padrão, destacam-se a condição dada por $(\hat{m} ; \hat{r})=(0,14 ; 0,50)$ e na qual existem trechos bem definidos de rotação com velocidade aproximadamente constante e aquela caracterizada por $(\hat{m} ; \hat{r})=(0,13 ; 0,17)$ e na qual o NVA tem uma resposta oscilatória.

As discussões têm prosseguimento com a análise das simulações referentes ao valor de taxa de amortecimento do NVA $\zeta_{\theta}=0,20$, velocidade reduzida $U_{r}=9,2$ e a condição VIV-1gl. Como mostra a Figura 137, a elevação da taxa de amortecimento do supressor 
aumenta a região do plano de parâmetros de controle onde $\hat{S} \geq 0,40$ em comparação com o mapa obtido considerando $\zeta_{\theta}=0,05$ e mostrado na Figura 135. No entanto, esse aumento é acompanhado de uma redução no máximo valor obtido para o critério $\hat{S}$ de cerca de 0,80 para 0,60. Note, ainda, a região colorida em vermelho e que corresponde à maximização do critério $\hat{S}$ (ao menos no intervalo de parâmetros considerado). De fato, o surgimento de uma região do plano $(\hat{m} ; \hat{r})$ onde a supressão é maximizada já foi obtido para a condição de velocidade reduzida $U_{r}=6,4$; ver Figura 129.

A análise das séries temporais $y(\tau)$ mostradas na Figura 137(a) guarda aspectos interessantes. Considerando $(\hat{m} ; \hat{r})=(0,10 ; 0,40)$, ponto interno à região de maximização de $\hat{S}$, a série temporal de resposta do cilindro decai até atingir uma resposta com amplitude estacionária (resposta do tipo "RAC") significativamente inferior àquela obtida no caso onde o cilindro não é dotado do NVA. Já as combinações $(\hat{m} ; \hat{r})=(0,13 ; 0,42)$ e $(\hat{m} ; \hat{r})=$ $(0,14 ; 0,50)$ levam ao surgimento de respostas do cilindro com importantes modulações em amplitude. Considerando a resposta do NVA apresentada na Figura 137(b), o leitor nota que o caso onde a supressão é mais eficiente está relacionado a uma série temporal $\theta(\tau)$ caracterizada por $\omega_{r} \approx 1$.

O último mapa discutido nesta subseção é aquele obtido para a condição VIV-2gl, sob velocidade reduzida $U_{r}=9,2$ e taxa de amortecimento do NVA $\zeta_{\theta}=0,20$. Esse mapa é apresentado na Figura 138 e revela que o valor máximo atingido pelo parâmetro $\hat{S}$ é próximo a 0,30. Comparando os mapas apresentados nas Figuras 136 e 138, é possível notar que o aumento da taxa de amortecimento do NVA de $\zeta_{\theta}=0,05$ para $\zeta_{\theta}=0,20$, além de aumentar o máximo valor do critério $\hat{S}$, elimina a região do plano de parâmetros $(\hat{m} ; \hat{r})$ onde existia amplificação das respostas do cilindro.

A Figura 138(a) traz, além do mapa $\hat{S}(\hat{m} ; \hat{r})$, exemplos de séries temporais de deslocamento do cilindro. Todas as séries temporais $y(\tau)$ ilustradas são do tipo "RAC" e, a exemplo do que já fora objeto de discussão desta subseção, as séries temporais de resposta do NVA contemplam rotações com $\omega_{r} \approx 1$ (ao longo de toda a simulação ou em trechos), respostas oscilatórias com amplitude estacionária e séries $\theta(\tau)$ sem padrão definido. Constituindo um resultado também já explorado neste texto, a condição de maior supressão e que leva a uma resposta do cilindro com amplitude estacionária está relacionada à rotação do NVA com velocidade angular praticamente unitária.

A análise dos mapas $\hat{S}(\hat{m} ; \hat{r})$ encerra a discussão sobre a supressão passiva do fenômeno de VIV por meio de um NVA rotativo. A seção subsequente é dedicada ao estudo numérico do problema de mitigação do fenômeno de galloping por meio de um NVA rotativo. 
Figura 137 - Variação do critério $\hat{S}$ como função dos parâmetros $\hat{m}$ e $\hat{r}$. Condição VIV-1gl, $\zeta_{\theta}=0,20$ e $U_{r}=9,2$.
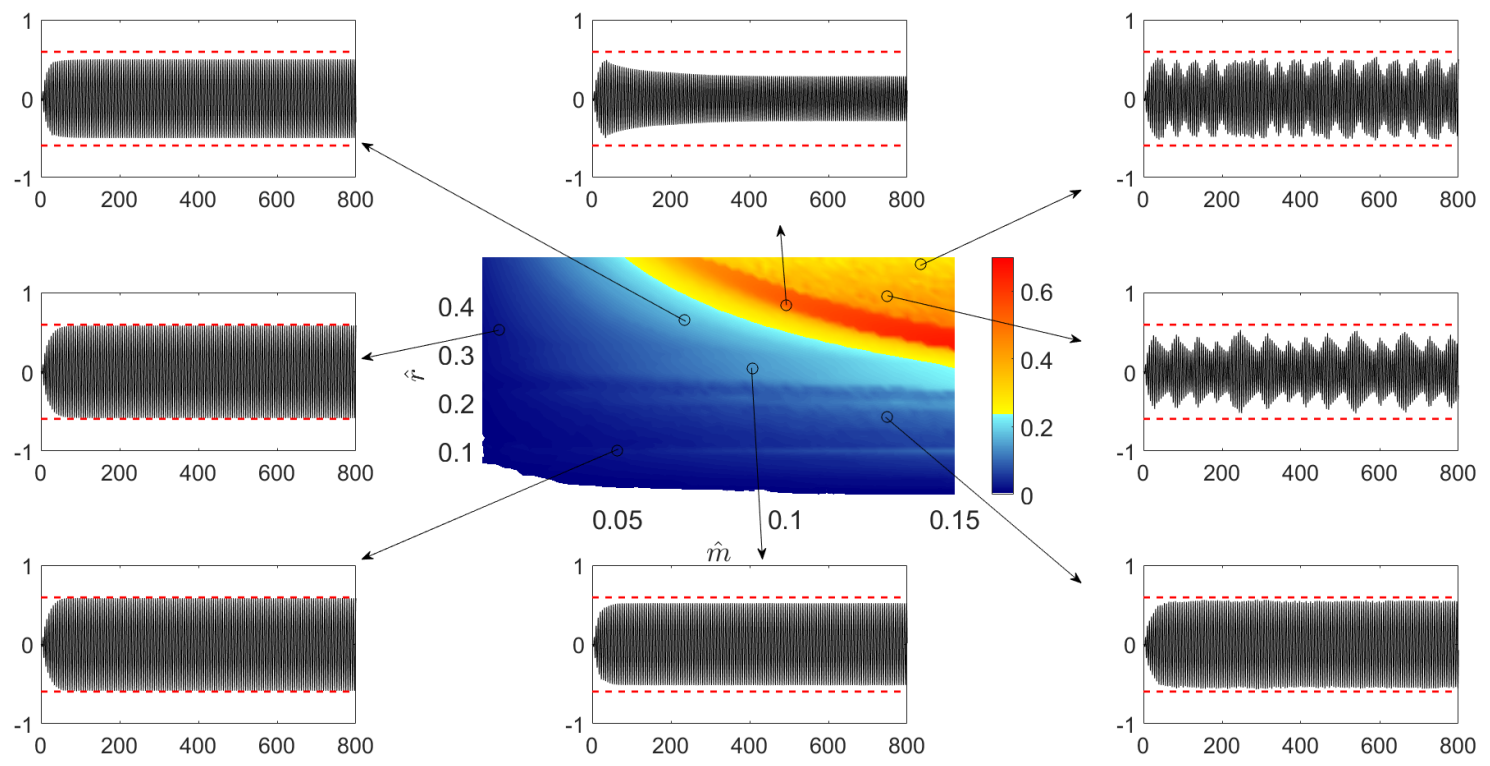

(a) $\hat{S}(\hat{m} ; \hat{r})$ e séries temporais $y(\tau)$.
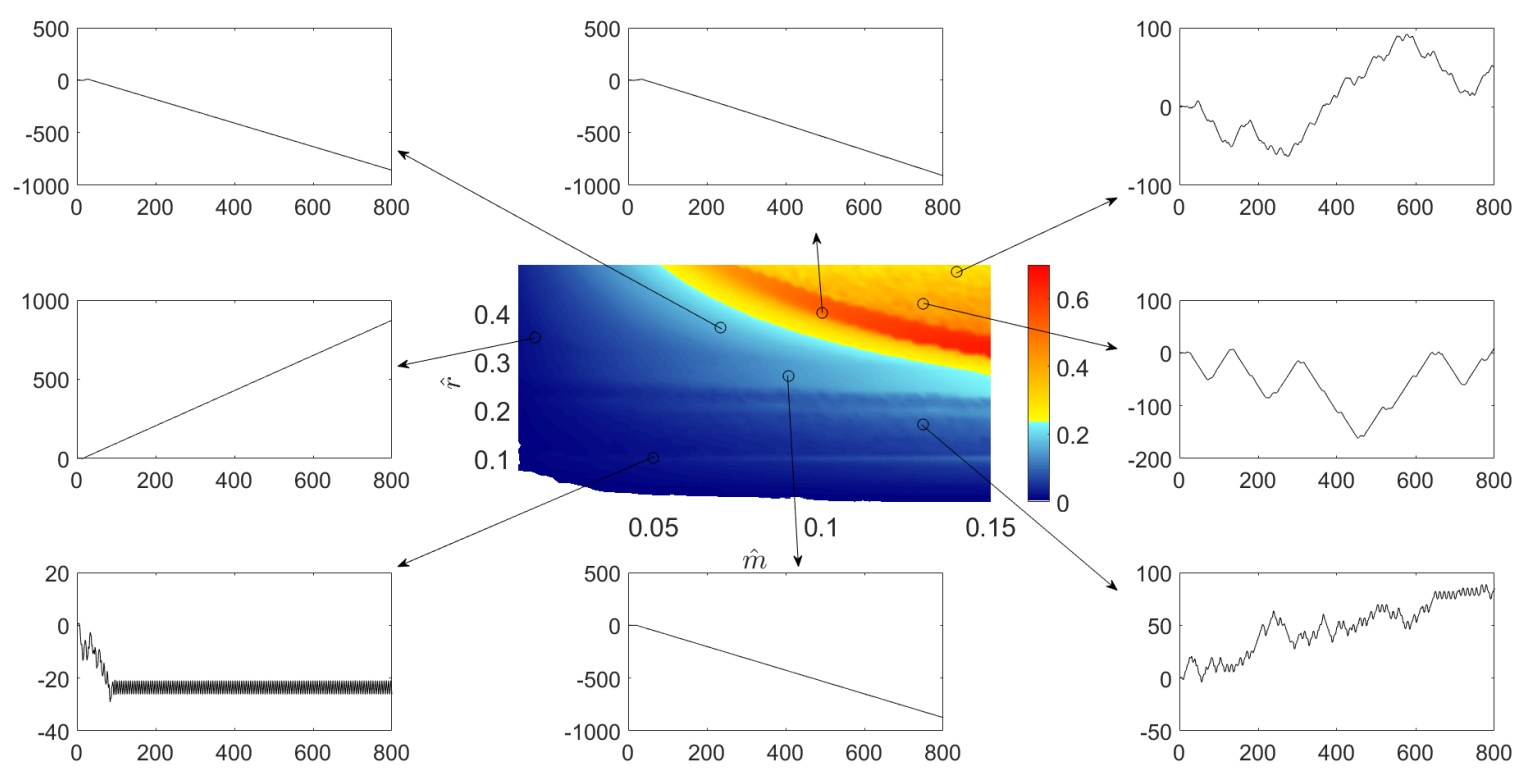

(b) $\hat{S}(\hat{m} ; \hat{r})$ e séries temporais $\theta(\tau)$.

Fonte: Extraída de Ueno (2019).

\subsection{Supressão passiva do fenômeno de galloping}

Os resultados apresentados nesta seção fazem parte da pesquisa conduzida pelo autor deste texto no âmbito do projeto de pesquisa relacionado ao cumprimento de um período como pesquisador visitante junto à PolyMTL, conforme já mencionado na seção 2.2. Além disso, é importante ressaltar que o tema desta seção foi objeto de pesquisa da 
Figura 138 - Variação do critério $\hat{S}$ como função dos parâmetros $\hat{m}$ e $\hat{r}$. Condição VIV-2gl, $\zeta_{\theta}=0,20$ e $U_{r}=9,2$.
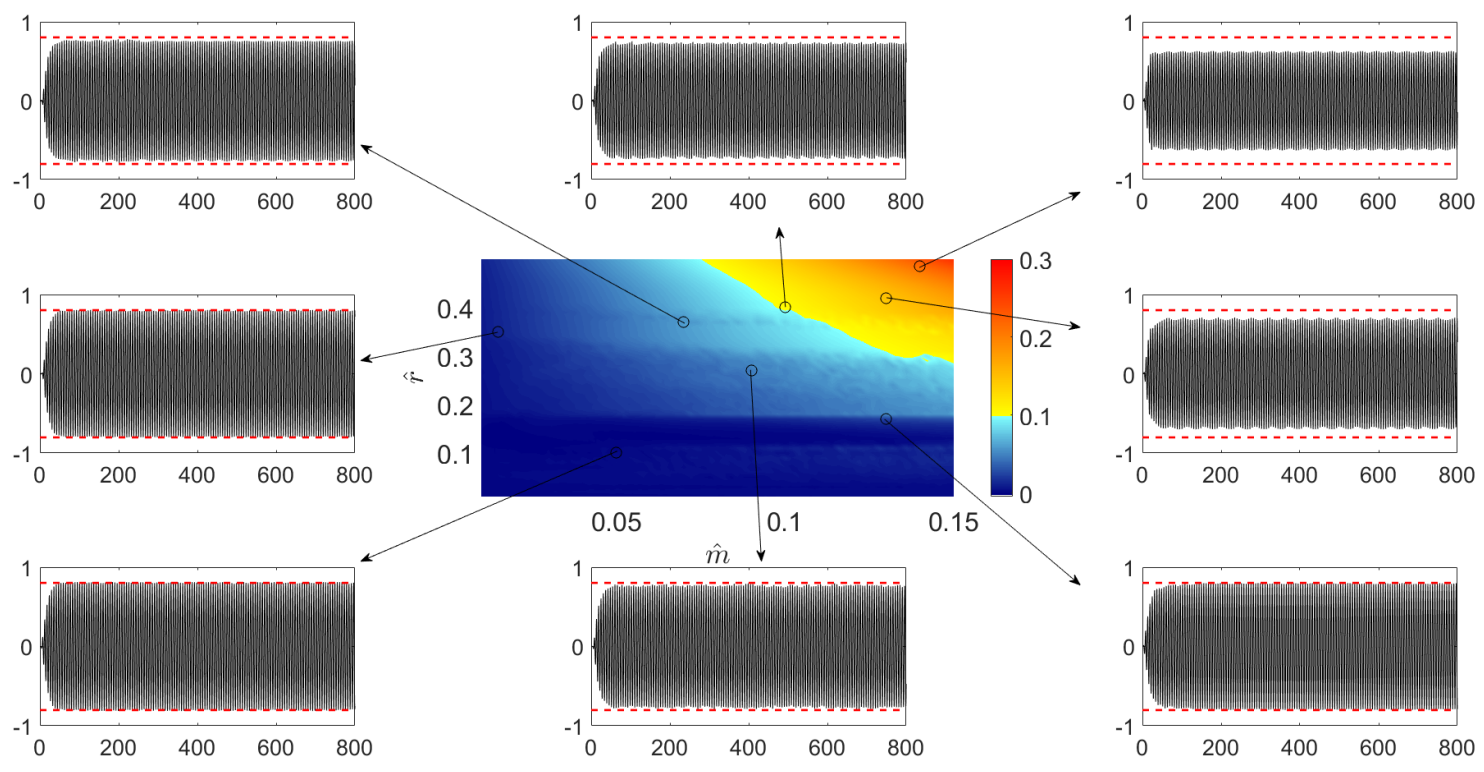

(a) $\hat{S}(\hat{m} ; \hat{r})$ e séries temporais $y(\tau)$.
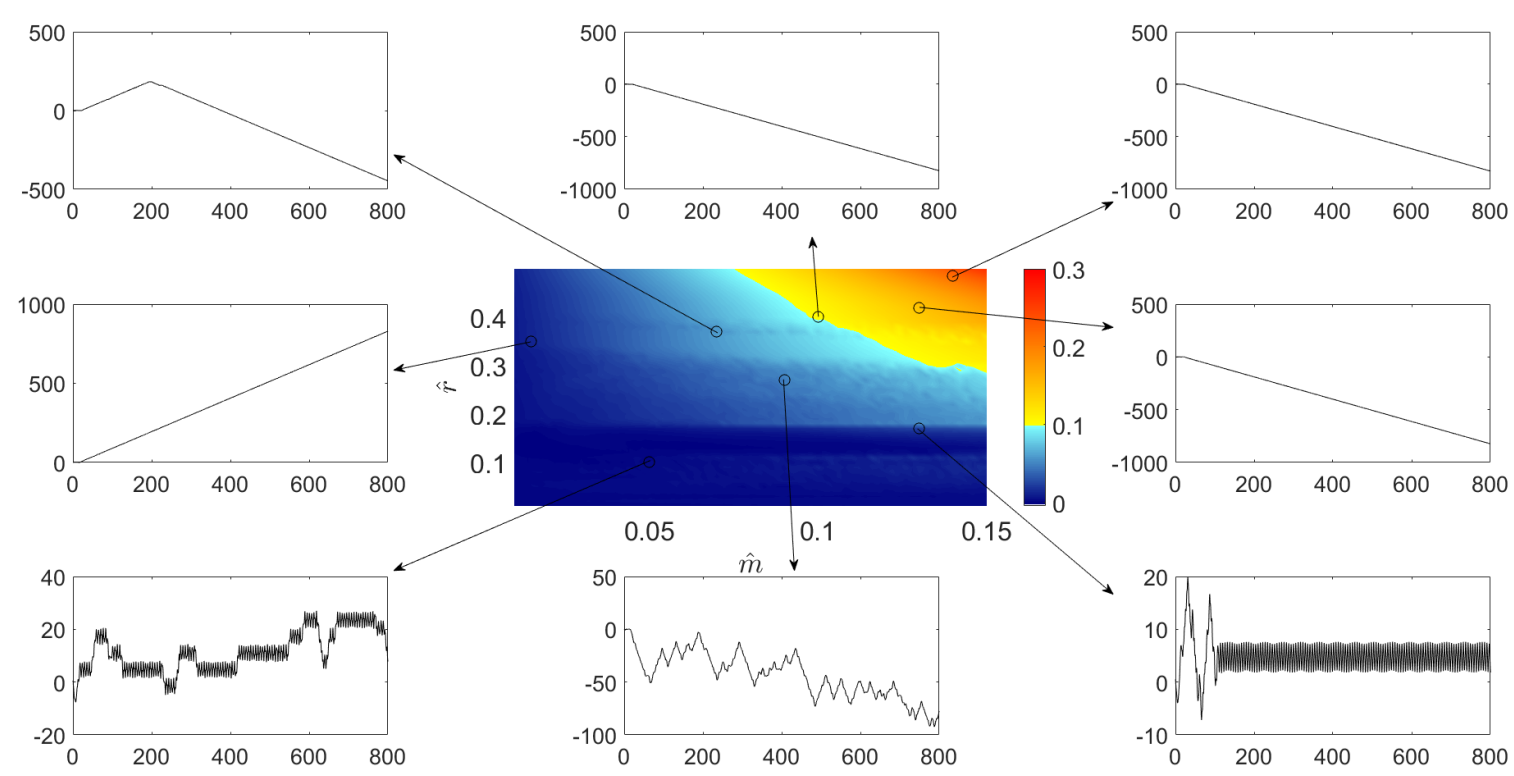

(b) $\hat{S}(\hat{m} ; \hat{r})$ e séries temporais $\theta(\tau)$.

Fonte: Extraída de Ueno (2019).

aluna Bianca Teixeira no âmbito de sua iniciação científica, modalidade pré-mestrado. Cumpre salientar ainda que os resultados numéricos aqui discutidos expandem aqueles apresentados em Teixeira, Franzini e Gosselin (2018), artigo publicado nos anais do 9th International Symposium on Fluid-Structure Interactions, Flow-Sound Interactions, Flow-Induced Vibration \& Noise. .

Do ponto de vista de organização, esta seção é dividida em três subseções. A 
subseção 10.2.1 apresenta a obtenção dos modelos matemáticos descritivos do problema em tela. As metodologias de simulação e de análise numérica são detalhadas na subseção 10.2.2 enquanto que os resultados numéricos são discutidos na subseção 10.2.3.

\subsubsection{Modelagem matemática do problema de supressão passiva}

Considere o problema bidimensional de um corpo prismático caracterizado por massa, rigidez e amortecimento (todos por unidade de comprimento) $M, k_{y}$ and $c_{y}$ respectivamente. O NVA rotativo possui massa por unidade de comprimento $m$ e a haste imponderável tem comprimento $r$. Este elemento rotativo é conectado ao corpo prismático (estrutural principal) por meio de um amortecedor linear de constante $c_{\theta}$, também por unidade de comprimento. A Figura 139 apresenta uma representação esquemática do problema físico aqui estudado.

Figura 139 - Representação esquemática do problema de supressão passiva utilizando um NVA rotativo.

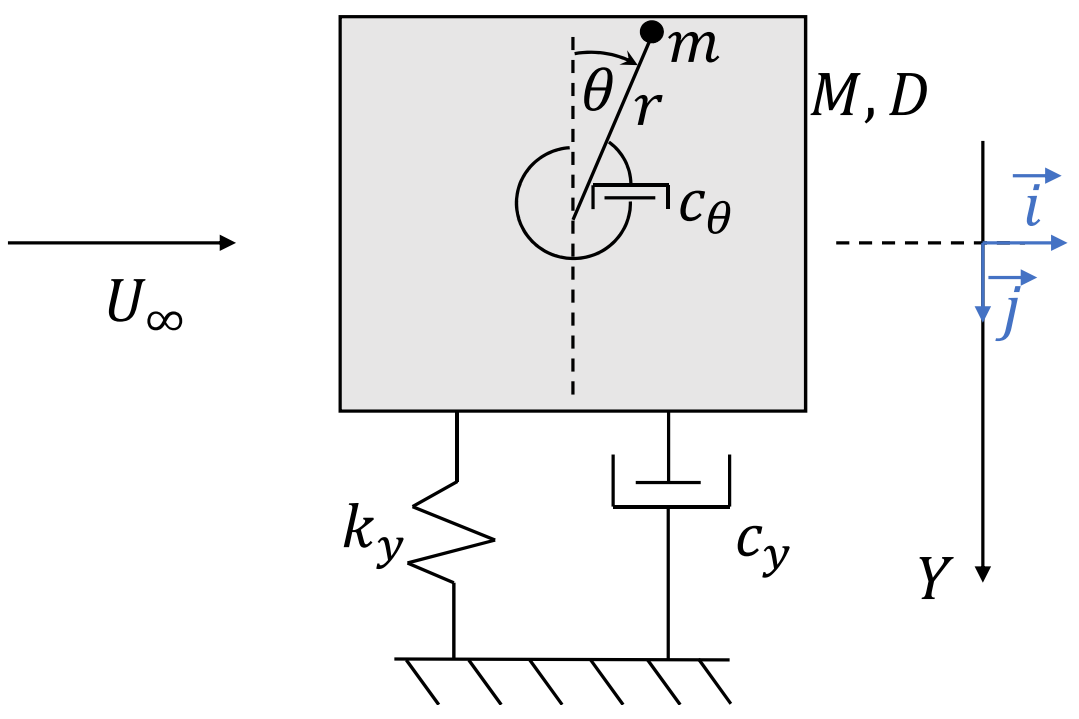

Fonte: Elaborada pelo autor.

As equações de movimento foram obtidas por meio do formalismo lagrangiano. Considere que $O$ seja o ponto de conexão do prisma à haste rígida que compõe o supressor, que a velocidade da correnteza incidente seja $\mathbf{U}_{\infty}=U_{\infty} \mathbf{i}$ e que $\mathbf{m}-\mathbf{O}$ seja o vetor posição da massa $m$. A velocidade da massa $m$ é dada por:

$$
\mathbf{v}_{\mathbf{m}}=\mathbf{v}_{\mathbf{O}}+\frac{d \theta}{d t} \mathbf{k} \times(\mathbf{m}-\mathbf{O})=\left(\frac{d \theta}{d t} r \cos \theta\right) \mathbf{i}+\left(\frac{d Y}{d t}+\frac{d \theta}{d t} r \sin \theta\right) \mathbf{j}
$$


As expressões das energia cinética e potencial do sistema são dadas, respectivamente, pelas Equações 10.23 e 10.24.

$$
\begin{aligned}
& T=\frac{1}{2} M \mathbf{v}_{\mathbf{O}} \cdot \mathbf{v}_{\mathbf{O}}+\frac{1}{2} m \mathbf{v}_{\mathbf{m}} \cdot \mathbf{v}_{\mathbf{m}}= \\
& =\frac{1}{2}(M+m)\left(\frac{d Y}{d t}\right)^{2}+\frac{1}{2} m r^{2}\left(\frac{d \theta}{d t}\right)^{2}-m \frac{d Y}{d t} \frac{d \theta}{d t} r \sin \theta \\
& V=\frac{1}{2} k_{y} Y^{2}
\end{aligned}
$$

Já as forças generalizadas não conservativas associadas às coordenadas generalizadas $Y$ e $\theta$ são:

$$
\begin{aligned}
Q_{Y} & =\frac{1}{2} \rho D U_{\infty}^{2} C_{y}-c_{y} \frac{d Y}{d t} \\
Q_{\theta} & =-c_{\theta} \frac{d \theta}{d t}
\end{aligned}
$$

sendo $C_{y}$ o coeficiente de força aerodinâmica dado pela Equação 4.52. Como em Parkinson e Smith (1964), o coeficiente de força $C_{y}$ é definido na forma de um polinômio de sétimo grau no ângulo de ataque $\alpha$.

De posse das expressões das energias cinética e potencial, bem como das forças generalizadas não conservativas, as equações de movimento são escritas na forma das Equações 10.27 e 10.28 após algumas manipulações algébricas.

$$
\begin{aligned}
& (M+m) \frac{d^{2} Y}{d t^{2}}+m r\left[\sin \theta \frac{d^{2} \theta}{d t^{2}}+\cos \theta\left(\frac{d \theta}{d t}\right)^{2}\right]+c_{y} \frac{d Y}{d t}+k_{y} Y=\frac{1}{2} \rho U_{\infty}^{2} D C_{y} \\
& m r^{2} \frac{d^{2} \theta}{d t^{2}}+m r \sin \theta \frac{d^{2} Y}{d t^{2}}+c_{\theta} \frac{d \theta}{d t}=0
\end{aligned}
$$

Tendo em vista uma maior generalização das análises, é interessante reescrever as equações de movimento na forma adimensional. Para tanto, considere os seguintes parâmetros:

$$
\begin{aligned}
& y=\frac{Y}{D}, \hat{r}=\frac{r}{D}, \tau=t \omega_{n, y}=t \sqrt{\frac{k_{y}}{M+m}}, \zeta_{y}=\frac{c_{y}}{2(M+m) \omega_{n, y}}, \zeta_{\theta}=\frac{c_{\theta}}{2 m r^{2} \omega_{n, y}} \\
& U_{r}=\frac{U_{\infty}}{\omega_{n, y} D}, \hat{m}=\frac{m}{M}, m^{*}=\frac{M+m}{\rho D^{2}}
\end{aligned}
$$

Considerando os parâmetros acima descritos, as equações de movimento 10.27 e 10.28 são escritas na forma adimensional como: 


$$
\begin{aligned}
& \ddot{y}+\frac{\hat{m}}{1+\hat{m}} \hat{r}\left(\sin \theta \ddot{\theta}+\cos \theta \dot{\theta}^{2}\right)+2 \zeta_{y} \dot{y}+y=\frac{U_{r}^{2}}{2 m^{*}} \sum_{k=1}^{7}\left(a_{k}\left(\frac{\dot{y}}{U_{r}}\right)^{k}\right) \\
& \ddot{\theta}+\frac{1}{\hat{r}} \sin \theta \ddot{y}+2 \zeta_{\theta} \dot{\theta}=0
\end{aligned}
$$

onde ( ) indica a derivada com relação ao tempo adimensional $\tau$.

\subsubsection{Metodologias de simulação e de análise}

As Equações 10.30 e 10.31 foram numericamente integradas utilizando o método de Runge-Kutta disponível na função ode45 do ambiente MATLAB ${ }^{\circledR}$. As simulações tiveram tempo de integração total $\tau_{\max }=5000$ e passo de integração $\Delta \tau=0,01$. Como é visto na subseção 10.2.3, o tempo máximo de simulação aqui adotado garante a existência de uma resposta com amplitude estacionária para a condição onde o prisma é sujeito apenas à ação do galloping, ou seja, sem a presença do supressor. As condições iniciais adotadas foram $y(0)=0,05, \theta(0)=\pi / 6$ e $\dot{y}(0)=\dot{\theta}(0)=0$.

A exemplo do que fora discutido na seção 9.2 e na subseção 10.1.2, o caráter não-linear do modelo matemático pode fazer com que a resposta seja sensível às condições iniciais empregadas na integração numérica. No entanto, esse estudo de sensibilidade não faz parte do presente texto, sendo objeto de uma proposta de continuidade da pesquisa.

Como mencionado, o principal objetivo deste capítulo é a identificação da influência dos parâmetros que definem o NVA rotativo (supressor) na sua capacidade de mitigação das oscilações da estrutura principal (prisma). Para tanto e seguindo uma estrutura semelhante àquela feita para o estudo da supressão passiva do VIV (ver subseção 10.1.3), três grupos de simulação foram estudados. Em cada grupo, dois parâmetros do NVA são mantidos constantes e o terceiro é variado em um certo intervalo.

Dentre os resultados obtidos, destacam-se o desvio padrão da série temporal de deslocamento do prisma $y_{s t d}$ calculado considerando apenas os instantes de tempo superiores a $\tau_{\max } / 2$ como função da velocidade reduzida $U_{r}$, os espectros de amplitude calculados por meio da aplicação da TFD à série temporal de deslocamento ${ }^{7}$ do prisma via função fft do MATLAB ${ }^{\circledR}$ e mapas mostrando a eficiência da supressão como funções dos parâmetros que caracterizam o NVA. Como forma de complementar as análises, exemplos de séries temporais de resposta do prisma e do supressor $(y(\tau)$ e $\theta(\tau)$ respectivamente) são exibidos e discutidos.

Além das curvas $y_{s t d}\left(U_{r}\right)$, este texto aborda a variação de um critério de eficiência do supressor como função da velocidade reduzida. A exemplo do que já foi conduzido na

7 De maneira consistente ao cálculo da grandeza $y_{s t d}$, os espectros de amplitude também consideram os instantes de tempo $\tau>\tau_{\max } / 2$. 
seção anterior, um critério $\hat{S}$ é proposto para cada velocidade reduzida e leva em conta a relação entre os valores do desvio padrão (calculados apenas considerando $\tau>\tau_{\max } / 2$ ) relativos às condições com e sem supressor (esta última aqui nomeada como $y_{s t d, 0}$ ) na forma da Equação 10.32, de onde o leitor claramente nota que valores de $\hat{S}$ próximos a 1 indicam cenários mais favoráveis à supressão.

$$
\hat{S}\left(U_{r}\right)=1-\frac{y_{s t d}\left(U_{r}\right)}{y_{s t d, 0}\left(U_{r}\right)}
$$

Os parâmetros geométricos e inerciais do prisma utilizados nas simulações numéricas correspondem àqueles que caracterizam o modelo experimentalmente ensaiado no túnel de vento da PolyMTL. O modelo ensaiado era um prisma de seção transversal quadrada feito em madeira balsa. A escolha por parâmetros coincidentes com aqueles do experimento possibilitará uma futura correlação numérico-experimental. A Tabela 14 traz os parâmetros relativos à campanha experimental conduzida.

Tabela 14 - Parâmetros do arranjo experimental utilizado no túnel de vento da PolyMTL.

\begin{tabular}{cc||cc}
\hline \hline \multicolumn{2}{c}{$\begin{array}{c}\text { Grandezas } \\
\text { dimensionais }\end{array}$} & \multicolumn{2}{c}{$\begin{array}{c}\text { Grandezas } \\
\text { adimensionais }\end{array}$} \\
\hline \hline Dimensão da seção & $5,08 \mathrm{~cm}$ & $\begin{array}{c}\text { Taxa de amortecimento } \\
\text { estrutural } \zeta_{y}\end{array}$ & $0,9 \%$ \\
transversal $D$ & $58 \mathrm{~cm}$ & Razão de aspecto $L / D$ & 11,41 \\
Comprimento do prisma $L$ & & & \\
Rigidez equivalente $k_{y}$ & $360,13 \mathrm{~N} / \mathrm{m}$ & & \\
Massa total oscilante $M_{t}$ & $1,03 \mathrm{~kg}$ & & \\
Frequência natural & $18,70 \mathrm{rad} / \mathrm{s}$ & & \\
não amortecida $\omega_{n, y}$ & & & \\
\hline \hline
\end{tabular}

Fonte: Elaborada pelo autor.

Cabe, aqui, destacar um aspecto de nomenclatura. O valor da frequência natural não amortecida relatado na Tabela 14 foi obtido por meio de ensaios de decaimento (vibração livre) na ausência do supressor, porém com uma massa interna próxima àquela que o caracteriza mas sem liberdade de movimento com relação ao prisma.

Também visando uma maior facilidade de correlação experimental, os estudos numéricos consideram um ângulo de ataque inicial $\alpha_{0}=10^{\circ}$, como ilustrado na Figura 140. Essa configuração foi estudada por conta do fato que, embora a curva $C_{y}(\alpha)$ apresentada em Parkinson e Smith (1964) indique que o prisma sem o supressor e orientado a $0^{\circ}$ tenha uma velocidade crítica para o galloping, oscilações auto-excitadas não foram observado experimentalmente. Assim, foi conferida uma rotação inicial ao prisma de sorte a promover o fenômeno de galloping. No momento da redação deste texto, os dados experimentais estão sendo analisados, de sorte que ainda não há uma explicação para a estabilidade 
assintótica do equilíbrio trivial verificada experimentalmente no caso onde o escoamento incidente era perpendicular a uma das faces do prisma.

Figura 140 - Representação esquemática da orientação do prisma estudada numericamente e experimentalmente.

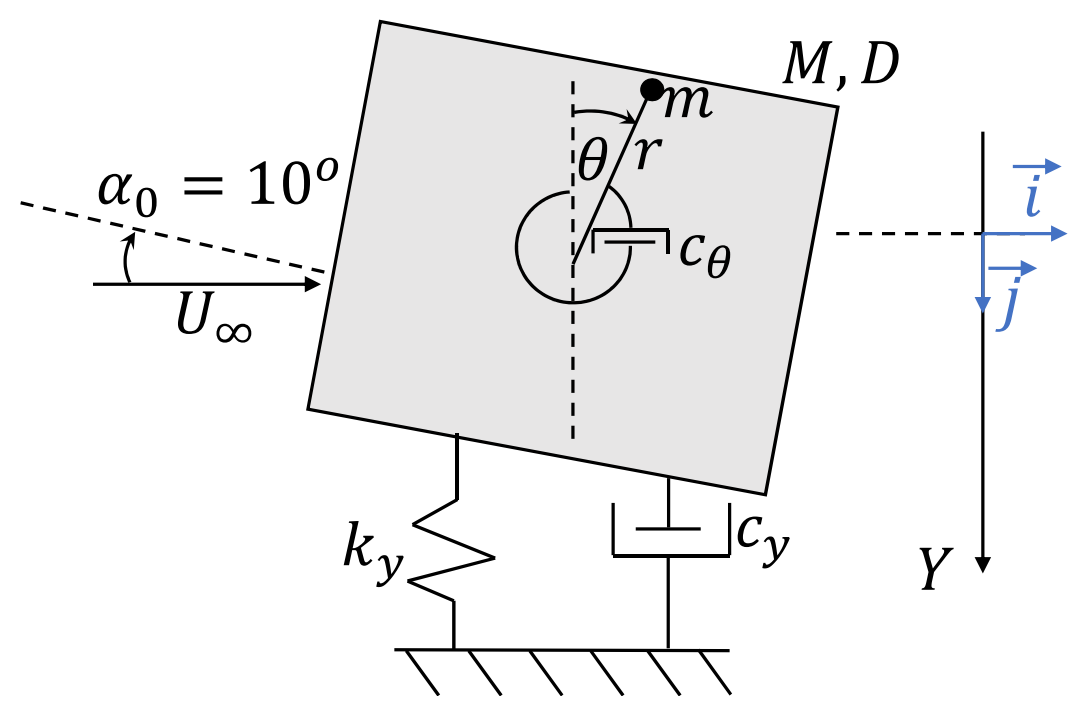

Fonte: Elaborada pelo autor.

O cálculo dos coeficientes que descrevem a função $C_{y}(\alpha)$ e necessários para o modelo matemático envolveram a adaptação dos dados apresentados ${ }^{8}$ em Parkinson e Smith (1964). Para tanto, considera-se uma translação de $10^{\circ}$ no eixo das abscissas, de sorte posicionar a nova origem do ângulo de ataque $\alpha$ segundo o arranjo apresentado na Figura 140. Os coeficientes da função $C_{y}(\alpha)$ que leva em conta o ângulo de ataque inicial $\alpha_{0}=10^{\circ}$ são $a_{0}=0,2962, a_{1}=4,5756, a_{2}=41,6651, a_{3}=-203,4283, a_{4}=-5,6746 \times 10^{3}$, $a_{5}=-3,2048 \times 10^{4}, a_{6}=-7,3182 \times 10^{4}$ e $a_{7}=-5,9900 \times 10^{4}$. Como esperado, a rotação de $10^{\circ}$ do prisma promove uma força constante na direção cross-wise e associada ao termo $a_{0}$. A Figura 141 ilustra a variação do coeficiente de força $C_{y}$ com o ângulo de ataque $\alpha$ para as condições com $\alpha_{0}=0^{\circ}$ (a mesma condição estudada em Parkinson e Smith (1964)) e $\alpha_{0}=10^{\circ}$.

A massa oscilante por unidade de comprimento do prisma é $M=M_{t} / L=1,78$ $\mathrm{kg} / \mathrm{m}$. Assumindo a massa específica do ar como $\rho=1,20 \mathrm{~kg} / \mathrm{m}^{3}$, tem-se $M / \rho D^{2} \approx 570$. Como a massa do supressor empregado era inferior a $m=10 \mathrm{~g}$, as simulações numéricas aqui descritas são todas caracterizadas por $m^{*}=570$. A taxa de amortecimento estrutural

8 O leitor lembra que o trabalho de Parkinson e Smith (1964) tratou do problema onde não havia ângulo de ataque inicial. 
Figura 141 - Variação do coeficiente de força $C_{y}(\alpha)$ com o ângulo de ataque $\alpha$.

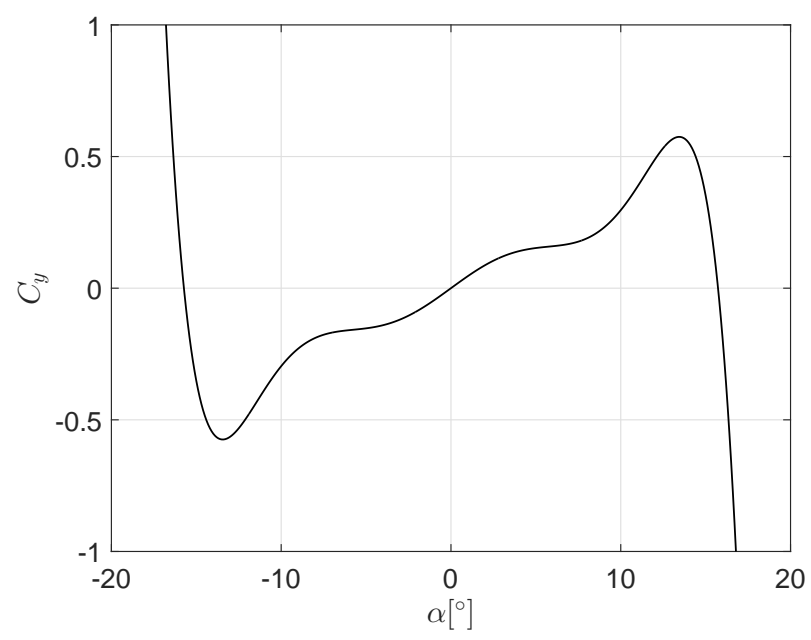

(a) $\alpha_{0}=0^{\circ}$

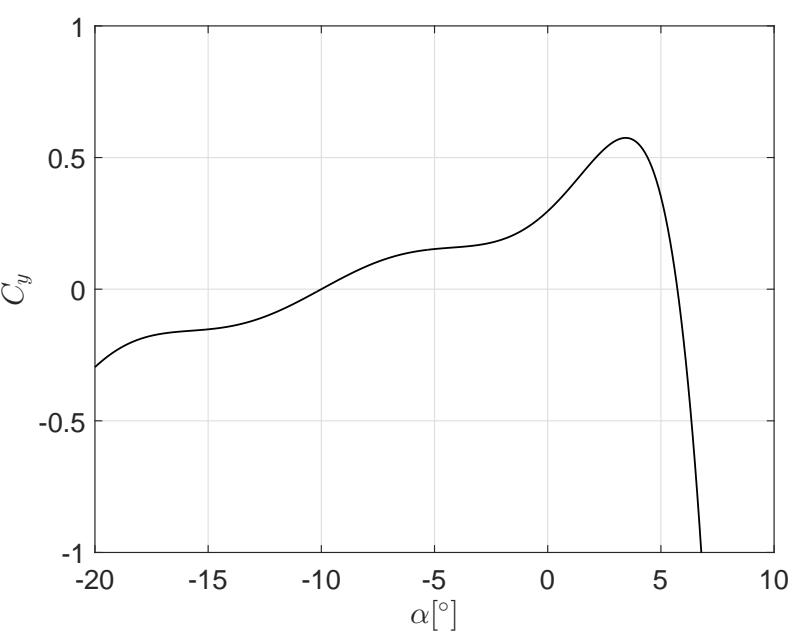

(b) $\alpha_{0}=10^{\circ}$

Fonte: Elaborada pelo autor.

utilizada nas simulações numéricas foi $\zeta_{y}=0,9 \%$, o mesmo valor experimentalmente obtido.

A exemplo do que foi conduzido nas análises dos problemas de supressão passiva de excitação paramétrica (ver capítulo 9) e de VIV (seção 10.1), mapas mostrando a eficiência do NVA como funções de seus parâmetros de controle também são exibidos. Em particular, os mapas apresentados na presente seção focam na variação da grandeza $\hat{S}$ como funções dos parâmetros de massa e de comprimento do NVA ( $\hat{m}$ e $\hat{r}$, respectivamente) para valores selecionados de velocidade reduzida e de taxa de amortecimento do NVA. Juntamente aos mapas $\hat{S}(\hat{m} ; \hat{r})$, séries temporais de deslocamento do prisma e do supressor são apresentadas para os pontos no plano de parâmetros de controle $(\hat{m} ; \hat{r})$ descritos na Tabela 15.

Tabela 15 - Pontos no plano de parâmetros de controle para os quais as séries temporais $y(\tau)$ e $\theta(\tau)$ são exibidas juntamente aos mapas $\hat{S}(\hat{m} ; \hat{r})$.

\begin{tabular}{c|c}
\hline \hline$\hat{m}$ & $\hat{r}$ \\
\hline \hline 0,02 & 0,45 \\
0,05 & 0,27 \\
0,06 & 0,11 \\
0,08 & 0,03 \\
0,13 & 0,08 \\
0,14 & 0,23 \\
0,13 & 0,44 \\
0,08 & 0,46 \\
\hline \hline
\end{tabular}

Fonte: Elaborada pelo autor. 
A próxima subseção apresenta os resultados numéricos relativos à sensibilidade da resposta do sistema composto do prisma e do NVA com relação aos parâmetros de massa, raio e amortecimento do supressor.

\subsubsection{Resultados e discussões}

Esta subseção tem início com a apresentação dos resultados numéricos referentes à condição na qual o prisma não está dotado do NVA rotativo. A Figura 142 traz como resultados relativos a esta condição a curva $y_{s t d}\left(U_{r}\right)$ e exemplos de séries temporais de deslocamento do prisma.

Figura 142 - Resultados numéricos referentes à condição onde o prisma não está dotado do supressor.

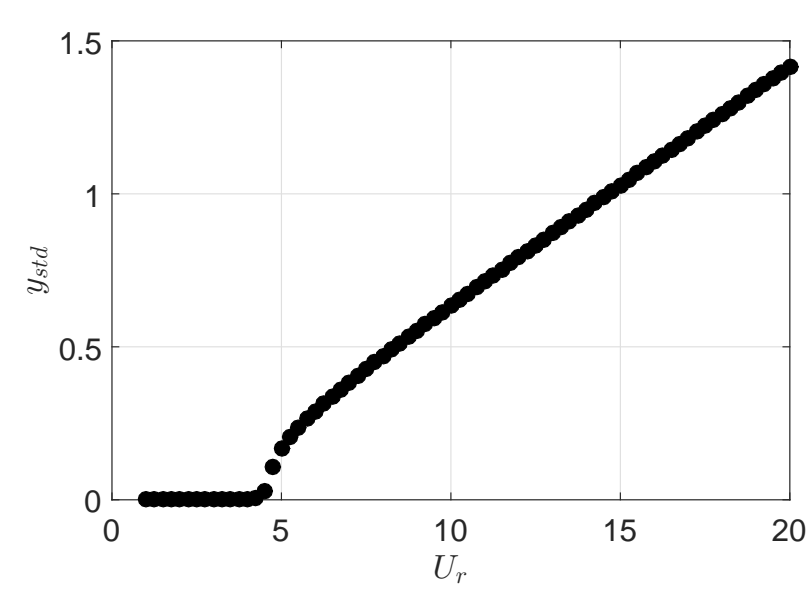

(a) $y_{s t d}\left(U_{r}\right)$.
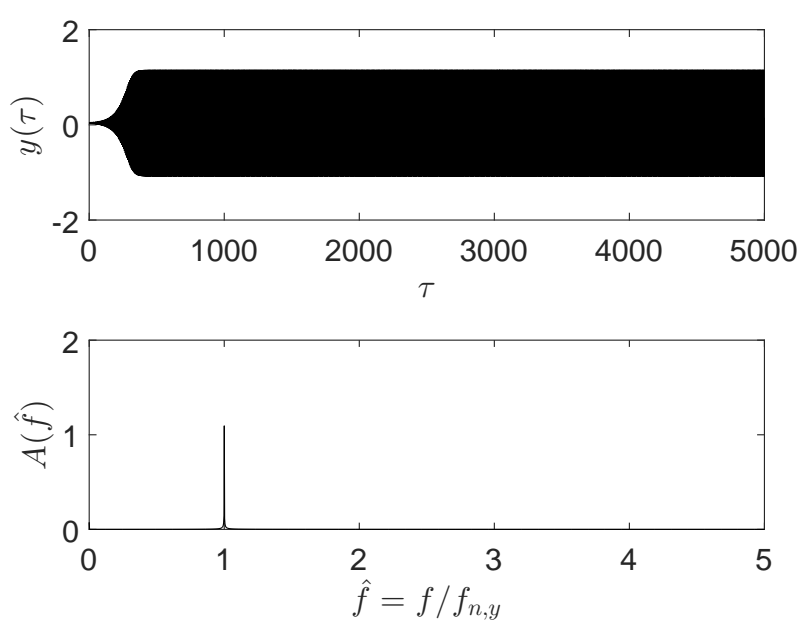

(c) $U_{r}=12$.
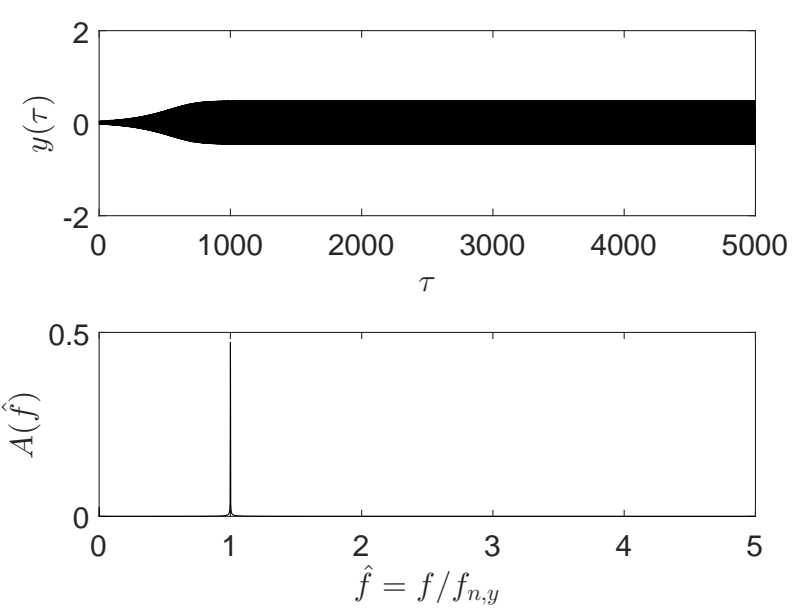

(b) $U_{r}=6,5$.
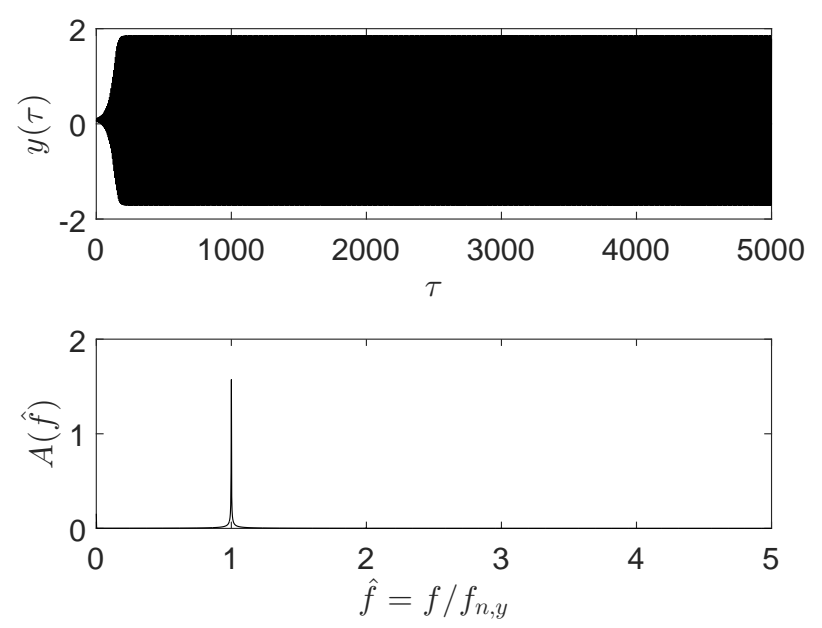

(d) $U_{r}=18$.

Fonte: Elaborada pelo autor.

A Figura 142(a) apresenta a variação do desvio padrão da resposta do prisma $y_{\text {std }}$ como função da velocidade reduzida $U_{r}$. Essa figura mostra que a resposta do sistema sem o supressor é caracterizada por uma velocidade reduzida a partir da qual as respostas 
do prisma não são amortecidas (ou seja, a velocidade reduzida crítica para o fenômeno de galloping) $U_{r}^{c} \approx 4,5$ e por um crescimento praticamente linear da grandeza $y_{s t d}$ com a velocidade reduzida, atingindo $y_{s t d} \approx 1,40$ para $U_{r}=20$. Já as séries temporais ilustradas nas Figuras 142(b), 142(c) e 142(d) indicam a presença de oscilações com resposta estacionária e caracterizadas por um espectro de amplitude de banda estreita e com frequência dominante $\hat{f}=f / f_{n, y}=1$. Como mencionado na subseção anterior, existe uma componente média de deslocamento associada ao termo $a_{0}$ empregado na descrição do coeficiente de força aerodinâmica. Tal componente é melhor identificada na Figura 142(d).

A discussão dos resultados numéricos do sistema dotado do NVA rotativo foca, em um primeiro momento, nos efeitos da massa do supressor representada pelo parâmetro adimensional $\hat{m}$. Para tanto, foram conduzidos estudos numéricos com valores fixos do raio e da taxa de amortecimento do supressor, a saber, $\hat{r}=0,40$ e $\zeta_{\theta}=0,05$ e diversos valores de massa ${ }^{9}$ do NVA no intervalo $0,03 \leq \hat{m} \leq 0,15$. Os resultados relativos a esse conjunto de simulações numéricas são apresentados na Figura 143.

Figura 143 - Influência da massa do supressor na curva de resposta do prisma como função da velocidade reduzida. $\hat{r}=0,40$ e $\zeta_{\theta}=0,05$.

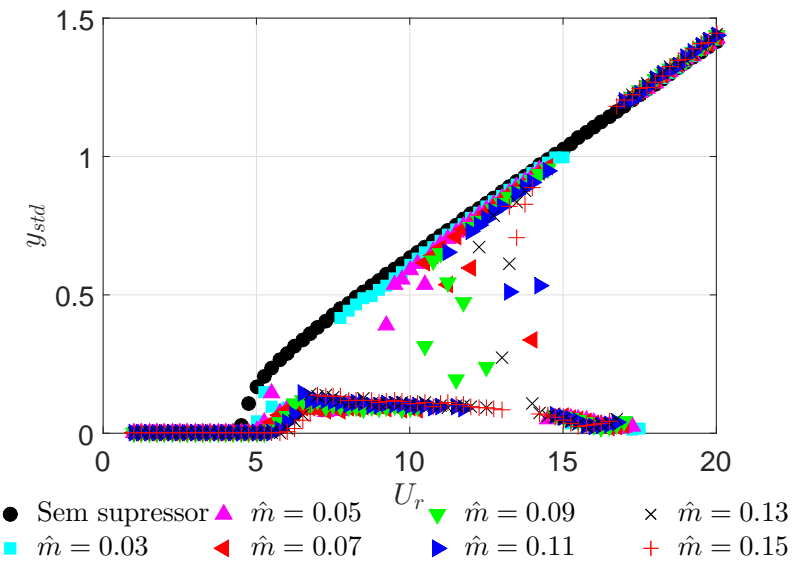

(a) Desvio padrão da resposta do prisma como função da velocidade reduzida.

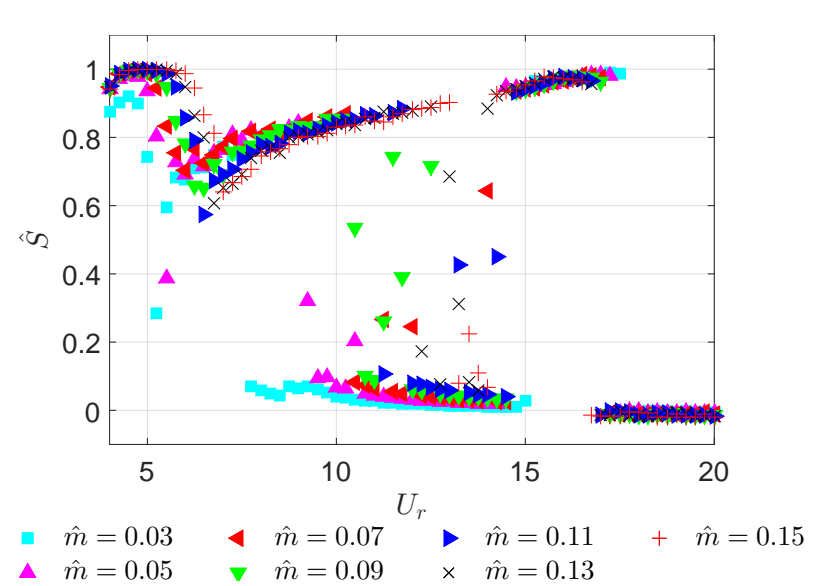

(b) Valores numéricos do critério $\hat{S}$ como função da velocidade reduzida.

Fonte: Elaborada pelo autor.

Considerando a curva $y_{s t d}\left(U_{r}\right)$ apresentada na Figura 143(a), a presença do NVA rotativo apresenta dois aspectos de interesse para a supressão de vibrações. O primeiro deles é o aumento da velocidade reduzida crítica para o fenômeno de galloping com o aumento do valor do parâmetro $\hat{m}$. O segundo aspecto é a existência de quatro grandes comportamentos da curva $y_{s t d}\left(U_{r}\right)$ de acordo com o intervalo de velocidade reduzida.

Esses comportamentos são explicitados, inicialmente, considerando a curva referente ao parâmetro $\hat{m}=0,03$. O primeiro comportamento ocorre para velocidades reduzidas

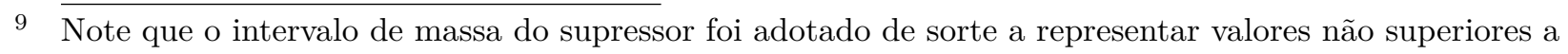
$15 \%$ da massa da estrutura principal. 
entre $U_{r} \approx 5$ e $U_{r}=8$, onde o supressor mostra ser capaz de reduzir significativamente as amplitudes de oscilação do prisma. Como mostrado na Figura 143(b), o parâmetro $\hat{S}$ cresce de 0,30 para 0,80 no mencionado intervalo de velocidades reduzidas.

Já para $8 \leq U_{r} \leq 15$ e ainda considerando $\hat{m}=0,03$, a Figura 143 (b) exibe um pronunciado decréscimo do parâmetro $\hat{S}$ para valores próximos a zero, indicando que os desvios padrão das séries temporais de deslocamento do prisma com ou sem supressor são praticamente idênticos (ver também a Figura 143(a)).

O terceiro comportamento observado para o caso onde $\hat{m}=0,03$ tem início em $U_{r}=15$ e se estende até $U_{r}=17,5$. Nesse terceiro comportamento, o supressor recupera sua capacidade de mitigação das respostas da estrutura principal, levando a uma supressão quase que total das vibrações, ou seja, $\hat{S} \approx 1$. Por fim, o quarto regime é observado no intervalo $17,5 \leq U_{r} \leq 20$, onde as respostas do prisma dotado de um supressor excedem aquelas obtidas na condição sem o supressor de uma pequena quantidade. Tal resultado pode ser confirmado atentando para os valores ligeiramente abaixo de 0 na Figura 143(b).

Uma vez discutidos os quatro comportamentos observados para o caso de menor valor do parâmetro de massa do supressor $\hat{m}$, a análise dos demais casos é facilitada. Como mostram as Figuras 143(a) e 143(b), embora ainda existam os comportamentos mencionados, o aumento no valor de $\hat{m}$ faz com que os saltos entre os regimes de alta supressão para aqueles onde há uma aderência notável com a curva referente ao prisma sem o supressor sejam mais raros. Note, por exemplo, que o supressor caracterizado por $\hat{m}=0,15$ é capaz de promover respostas do prisma com valores de $\hat{S}$ superiores a $0,60 \mathrm{em}$ praticamente todas as velocidades reduzidas contidas no intervalo entre $U_{r}=6$ e $U_{r}=17$, embora alguma redução de sua capacidade de mitigação seja observada em $12 \leq U_{r} \leq 14$. Também é notável a dispersão das curvas $y_{s t d}\left(U_{r}\right)$ no intervalo $10 \leq U_{r} \leq 15$ para valores de massa do NVA no intervalo $0,05 \leq \hat{m} \leq 0,13$.

Focando agora na curva $\hat{S}\left(U_{r}\right)$ apresentada na Figura 143(b), nota-se que a capacidade de supressão do NVA caracterizado por $\hat{m}=0,13$ e $\hat{m}=0,15$ é quantificada como sendo superior a $\hat{S} \approx 0,60$ para praticamente todas as velocidades reduzidas entre 7 e 17 . A Figura 143(b) revela, ainda, que os valores numéricos do critério $\hat{S}$ são praticamente os mesmos para $\hat{m}=0,13$ e $\hat{m}=0,15$. Esse último resultado pode ser relevante quando da adoção de uma solução tecnológica, uma vez que é desejável que a massa do supressor seja a menor possível.

Agora, muda-se o foco das discussões para a influência do raio do supressor na dinâmica do sistema definido pelo prisma dotado do NVA e sujeito às oscilações decorrentes do galloping. Tais discussões são conduzidas por meio de simulações numéricas onde tanto a massa quanto a taxa de amortecimento do supressor são constantes de valores $\hat{m}=0,08$ e $\zeta_{\theta}=0,05$. Já o raio do supressor varia entre $\hat{r}=0,03$ e $\hat{r}=0,45$, indicando que ele é 
posicionado internamente à estrutura principal ${ }^{10}$ e não está em contato com o fluido. A Figura 144 traz as variações do desvio padrão das respostas em deslocamento do prisma e também dos valores do critério $\hat{S}$ com a velocidade reduzida.

Figura 144 - Influência do raio do supressor na curva de resposta do prisma como função da velocidade reduzida. $\hat{m}=0,08$ e $\zeta_{\theta}=0,05$.

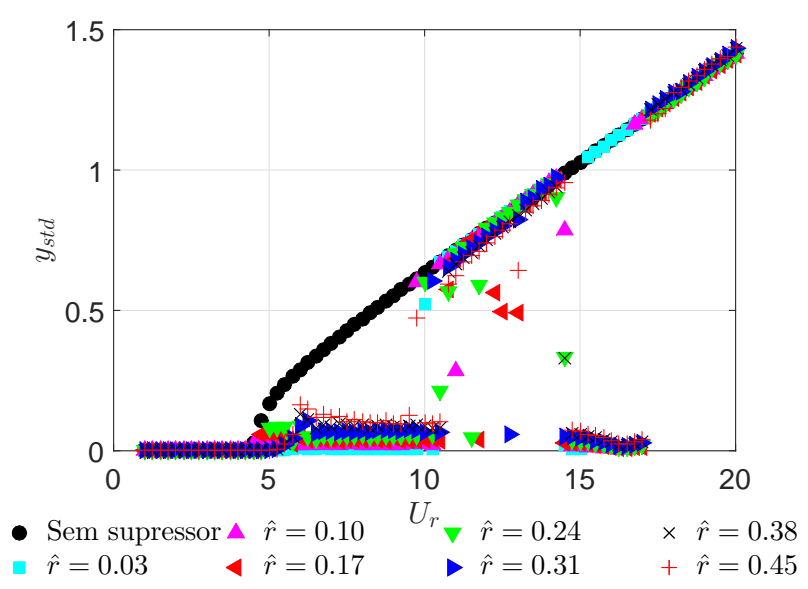

(a) Desvio padrão da resposta do prisma como função da velocidade reduzida.

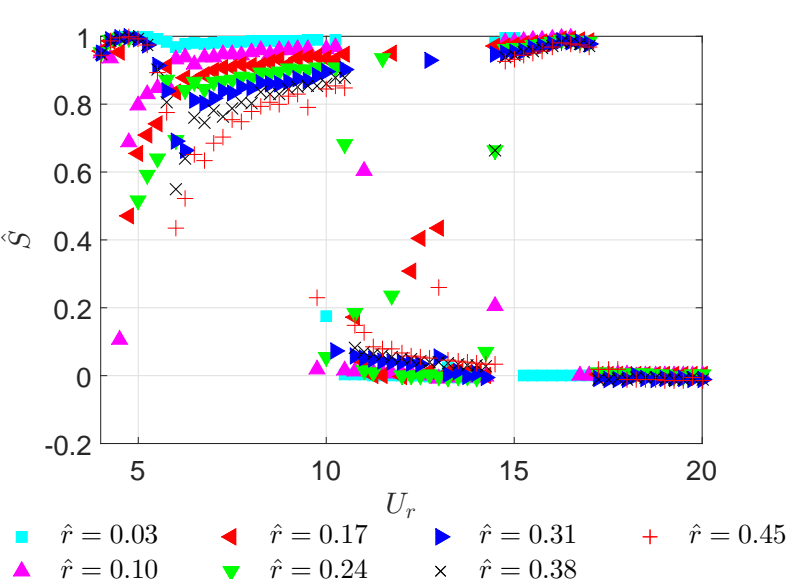

(b) Valores numéricos do critério $\hat{S}$ como função da velocidade reduzida.

Fonte: Elaborada pelo autor.

A Figura 144(a) revela a capacidade do supressor em reduzir as amplitudes de oscilação do prisma no intervalo $5 \leq U_{r} \leq 10$ para todos os valores do parâmetro $\hat{r}$. Note que existe uma dispersão dos resultados do desvio padrão da resposta do prisma entre $U_{r}=10$ e $U_{r}=15$ para valores de raio do supressor superiores a $\hat{r}=0,10$. É interessante notar que a Figura 143(a) também já havia exibido dispersão da curva $y_{s t d}\left(U_{r}\right)$ para $10 \leq U_{r} \leq 15$.

Discutindo, agora, a variação do parâmetro $\hat{S}$ com a velocidade reduzida (ver Figura 144(b)), é possível notar que a diminuição do raio do supressor aumenta a sua eficiência no intervalo de velocidades reduzidas $5 \leq U_{r} \leq 10$. Já entre $U_{r}=10$ e $U_{r}=15$, o parâmetro $\hat{S}$ experimenta um abrupto decréscimo para valores próximos a 0 para todos os valores de massa do supressor simulados.

Cabe, neste ponto, uma discussão acerca dos resultados obtidos com $\hat{r}=0,03$. Embora esse valor de massa do supressor promova a maior capacidade de supressão no intervalo $5 \leq U_{r} \leq 10$, não é observada uma recuperação de sua eficiência após a abrupta queda no valor do parâmetro de supressão $\hat{S}$ ocorrida em $U_{r} \approx 10$.

A Figura 145 traz as curvas que ilustram as variações do desvio padrão da série

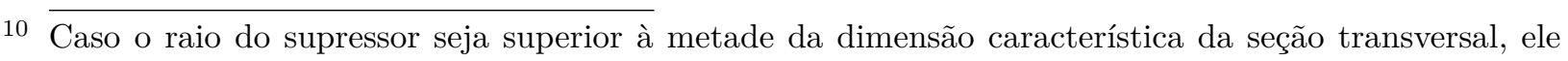
não é mais posicionado internamente à estrutura estando, portanto, em contato com o meio fluído. No entanto, uma possível solução tecnológica para cabos poderia adotar algumas seções com maior dimensão característica visando acomodar um supressor com $\hat{r}>0,50$. 
temporal de deslocamento do prisma e do parâmetro $\hat{S}$ com a velocidade reduzida, ambas parametrizadas na taxa de amortecimento do NVA $\zeta_{\theta}$. Tais estudos consideram os parâmetros de massa e de raio do NVA iguais a $\hat{m}=0,08$ e $\hat{r}=0,40$.

Figura 145 - Influência da taxa de amortecimento do supressor na curva de resposta do prisma como função da velocidade reduzida. $\hat{m}=0,08$ e $\hat{r}=0,40$.

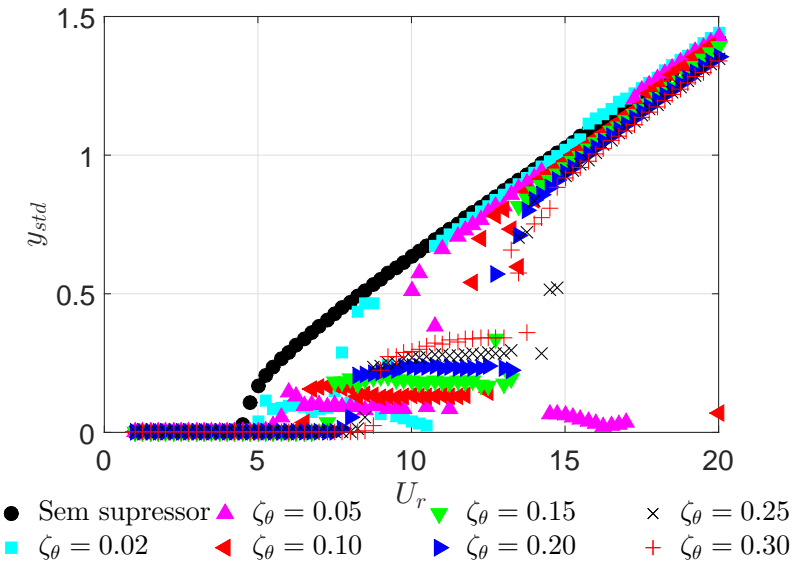

(a) Desvio padrão da resposta do prisma como função da velocidade reduzida.

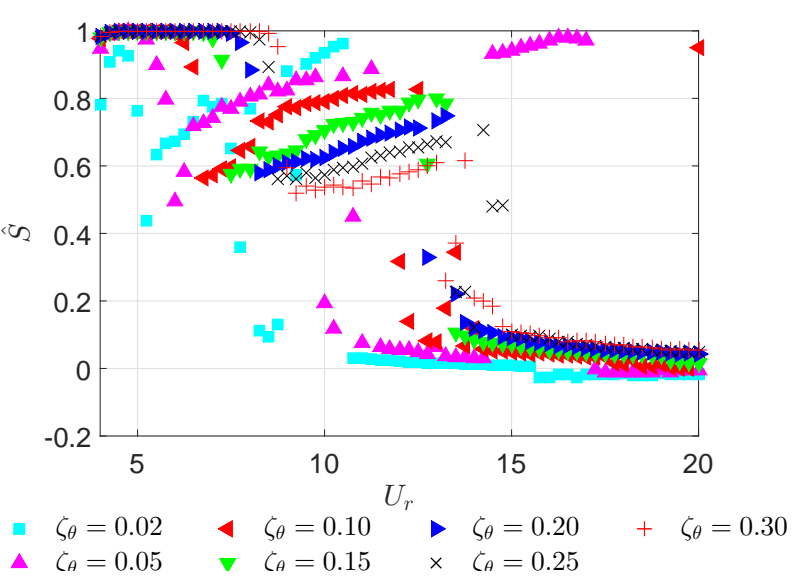

(b) Valores numéricos do critério $\hat{S}$ como função da velocidade reduzida.

Fonte: Elaborada pelo autor.

Como pode ser visto na Figura 145(a), diferenças na capacidade de supressão do NVA decorrentes da variação da sua taxa de amortecimento são encontradas no intervalo $5 \leq U_{r} \leq 15$. Com exceção de algumas simulações obtidas com $\zeta_{\theta}=0,05$, existe uma perda de eficiência do NVA para velocidades reduzidas superiores a 15 .

Já a variação do critério $\hat{S}$ como função da velocidade reduzida, apresentada na Figura 145(b), torna mais claro alguns aspectos já visíveis na Figura 145(a). No intervalo $5 \leq U_{r} \leq 10$ o aumento da taxa de amortecimento do NVA promove um decréscimo em sua capacidade de supressão mensurada pelo critério $\hat{S}$. Nesse mesmo intervalo de velocidades reduzidas, embora a condição $\operatorname{com} \zeta_{\theta}=0,02$ seja a mais eficiente, ela apresenta a maior dispersão de resultados, incluindo alguns pontos onde $\hat{S}$ é próximo a 0 . Nesse sentido, uma aplicação tecnológica sugerida seria aquela onde $\zeta_{\theta}=0,10$, capaz de operar com valores numéricos do critério $\hat{S}$ acima de 0,60 para $5 \leq U_{r} \leq 10$ e sem mudanças bruscas de seus valores dentro do intervalo de velocidades reduzidas mencionado. Considerando velocidades reduzidas superiores a 15, com exceção das simulações conduzidas com a taxa de amortecimento do NVA igual a 0,05 , o critério $\hat{S}$ apresenta valores inferiores a 0,10 .

O leitor nota que, embora as Figuras 143, 144 e 145 mostrem alguns efeitos dos parâmetros que definem o NVA na sua capacidade de supressão, nenhuma informação acerca dos aspectos qualitativos das séries temporais pôde ser delas extraída. A discussão de tais aspectos é feita agora por meio da apresentação de exemplos selecionados ${ }^{11}$ de

11 Fica claro aqui que a análise de todas as séries temporais aumentaria sobremaneira o texto. Assim, 
séries temporais.

A Figura 146 traz uma comparação das séries temporais obtidas para velocidade reduzida $U_{r}=6,5$ e considerando os casos nos quais o prisma não está dotado do NVA e também aqueles onde supressor tem massa definida por $\hat{m}=0,05$ ou $\hat{m}=0,13$. Visando uma direta comparação com os resultados da Figura 143, o raio e a taxa de amortecimento do supressor são considerados como $\hat{r}=0,40$ e $\zeta_{\theta}=0,05$.

A condição no qual o prisma oscila apenas em decorrência do fenômeno de galloping é apresentada na Figura 146(a), de onde é possível notar que sua série temporal de deslocamento é caracterizada por uma amplitude estacionária e igual a 0,50. Já seu espectro de amplitude é caracterizado por uma banda bastante estreita e centrada em $\hat{f}=f / f_{n, y}=1$.

Considerando agora os resultados obtidos com o NVA definido por $\hat{m}=0,05$, a Figura 146(b) indica que a resposta do prisma é caracterizada por importantes modulações em amplitude. O leitor prontamente nota que esse tipo de resposta já foi observado na seção 9.3 por ocasião da análise da supressão passiva de vibrações oriundas da excitação paramétrica e também na Figura 123(a), apresentada na subseção anterior. Adotando a nomenclatura já empregada neste texto, a supressão passiva do galloping pode, portanto, envolver respostas moduladas em amplitude ("RMA") nas quais regimes de supressão da resposta são seguidos por regimes de crescimento da mesma, configurando um outro resultado análogo àquele obtido na seção 9.3.

Ainda analisando a condição de velocidade reduzida $U_{r}=6,5$, porém aumentando a massa do supressor de sorte que $\hat{m}=0,13$, a Figura 146(c) indica uma resposta com amplitude constante ${ }^{12}$ igual a 0,10 , valor significativamente inferior àquele observado na simulação sem o supressor e apresentada na Figura 146(a). Para esse último valor de massa do NVA e de forma distinta do que foi observado na seção 9.3, a Figura 146(e) mostra que a resposta do supressor é caracterizada por uma velocidade angular constante $\omega_{r}=0,10$.

Visando uma melhor análise da resposta do tipo "RMA" obtida na Figura 146(b), a Figura 147 reapresenta as séries temporais de deslocamento do prisma e do NVA para o caso definido por $\hat{m}=0,05, \hat{r}=0,40, \zeta_{\theta}=0,05$ e $U_{r}=6,5$, porém diminuindo o intervalo de tempo exibido de sorte a ilustrar dois ciclos de supressão passiva.

Como mostra a Figura 147(a), o regime de crescimento da resposta pode ser subdividido em dois trechos. No primeiro trecho, localizado entre $1500<\tau<1600$ no primeiro ciclo de crescimento e entre $1900<\tau<2100$ no segundo ciclo, o NVA tem uma resposta caracterizada por uma rotação angular bastante lenta até atingir uma posição angular tal que $\cos \theta= \pm 1$. Essa posição angular corresponde a $\theta=0$ ou $\theta=\pi$,

12 Seguindo a nomenclatura introduzida na seção 9.3, "RAC". 
Figura 146 - Exemplos de séries temporais. Supressor caracterizado por $\hat{r}=0,40$ e $\zeta_{\theta}=$ 0,05. $U_{r}=6,5$.
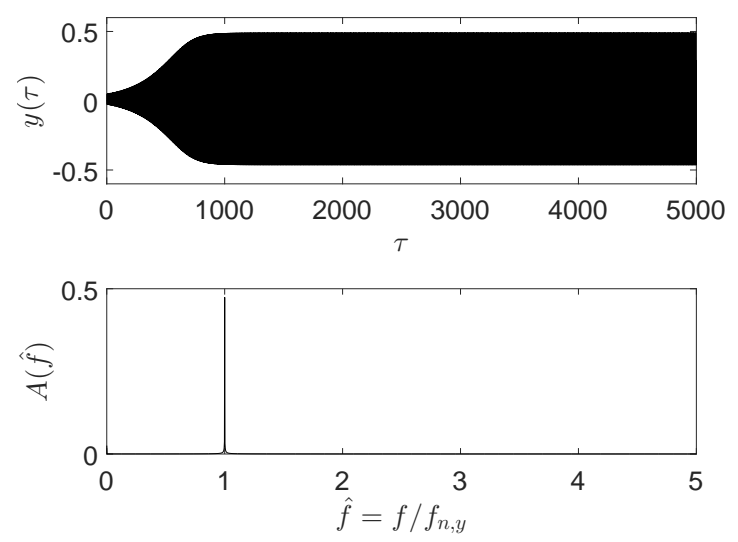

(a) Resposta do prisma. Condição sem supressor.
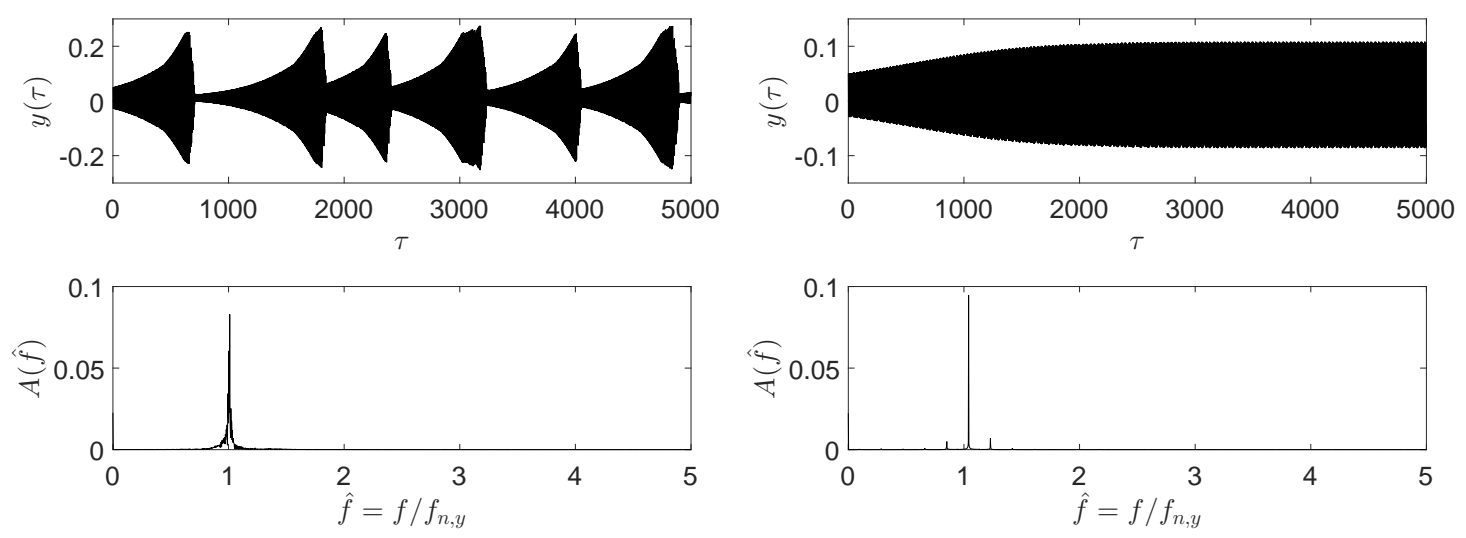

(b) Resposta do prisma. $\hat{m}=0,05$.

(c) Resposta do prisma. $\hat{m}=0,13$.
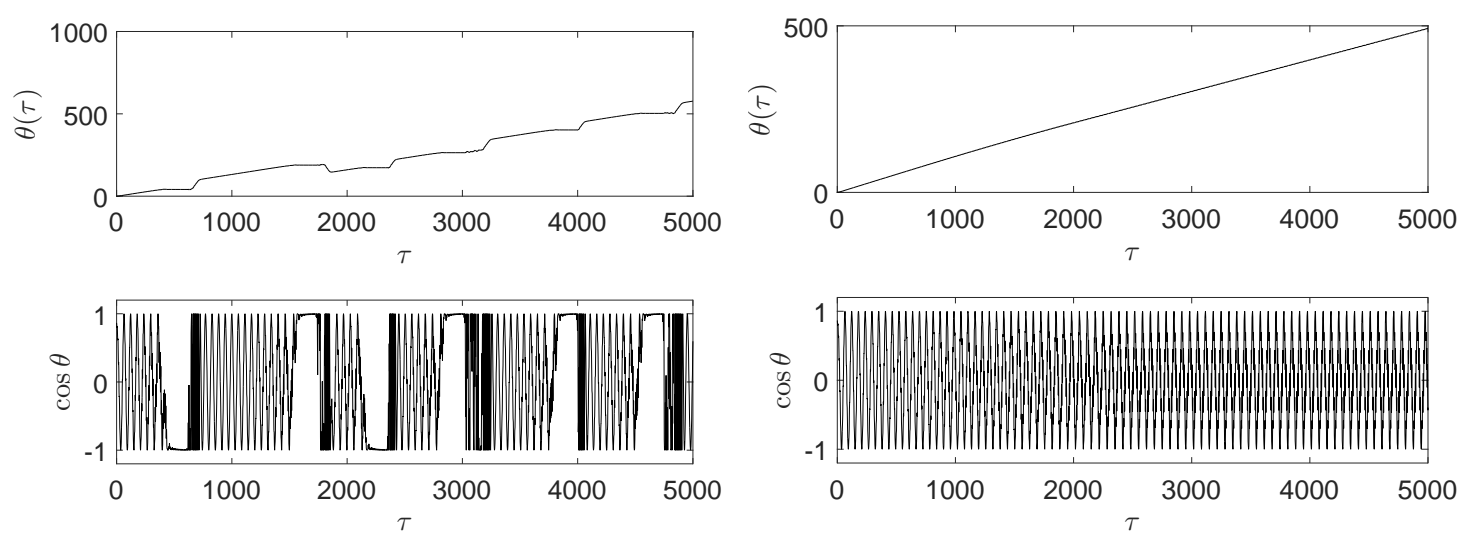

(d) Resposta do NVA. $\hat{m}=0,05$.

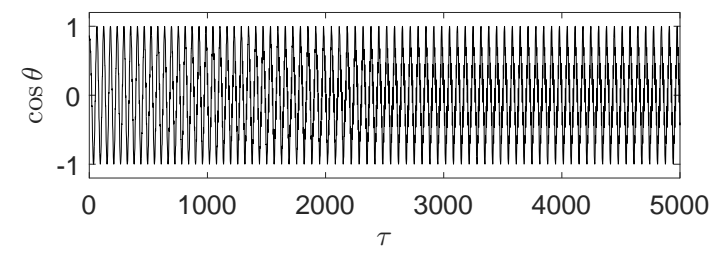

(e) Resposta do NVA. $\hat{m}=0,13$.

Fonte: Elaborada pelo autor.

configurando, portanto, que o NVA está alinhado com a direção de movimento do prisma; ver Figura 139.

Ao atingir a posição $\theta=0$ ou $\theta=\pi$, a Figura 147(b) mostra um ligeiro aumento na taxa de crescimento da resposta do prisma. Esse acréscimo está ligado ao fato de que, 
Figura 147 - Detalhe das séries temporais de resposta. $\hat{m}=0,05, \hat{r}=0,40, \zeta_{\theta}=0,05$ e $U_{r}=6,5$.
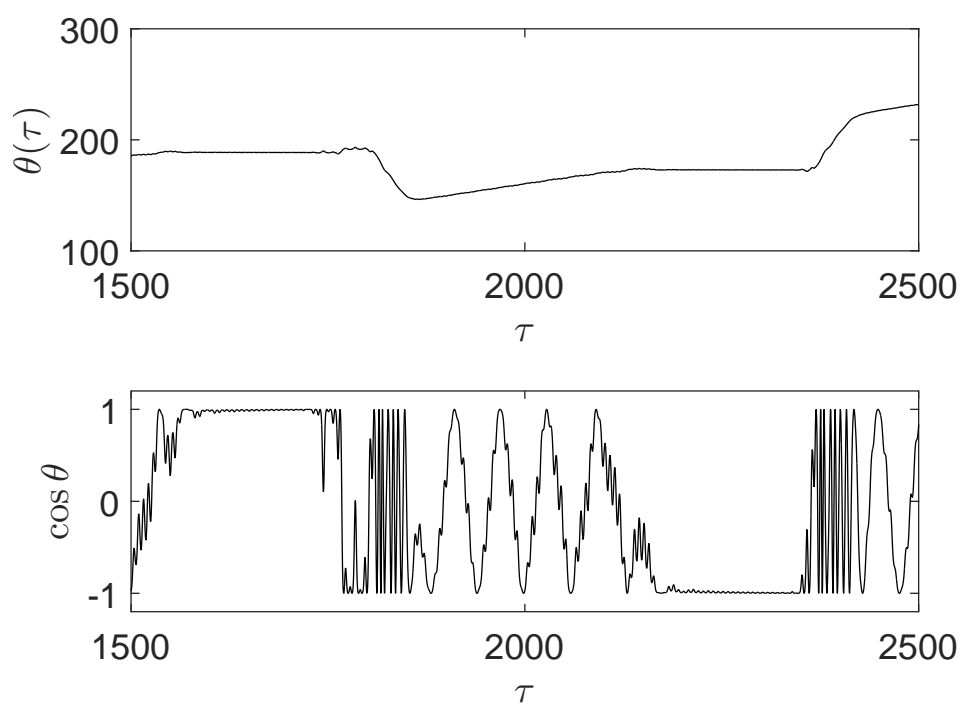

(a) $\theta(\tau)$ e $\cos \theta$.
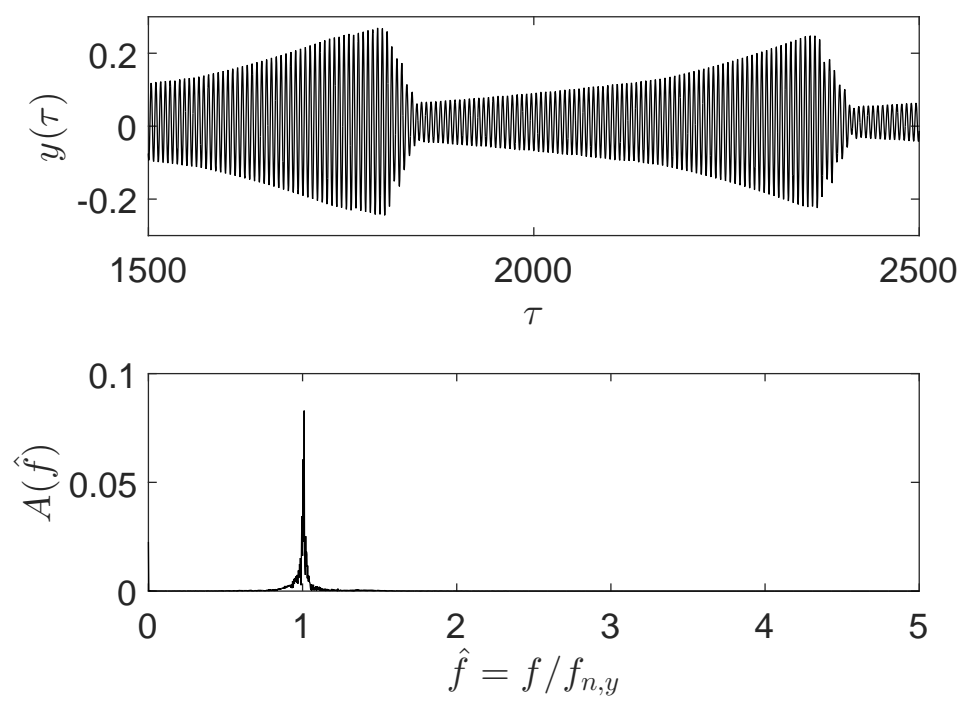

(b) $y(\tau)$ e espectro de amplitude.

Fonte: Elaborada pelo autor.

com o NVA com velocidade angular praticamente nula, não há dissipação de energia. O crescimento da resposta do prisma segue até que ele rotacione com velocidade angular característica $\omega_{r} \approx 1$ e, por meio do mecanismo TET e da captura em uma ressonância 1 : 1 caracterizada pela frequência de oscilação do prisma sendo próxima da velocidade angular do NVA.

A exemplo do que já fora conduzido na seção 9.3 por ocasião da análise do problema de supressão passiva da excitação paramétrica, discute-se agora uma explicação para o regime de crescimento da série temporal apresentado na Figura 147(b). Durante o regime de crescimento, a resposta do NVA é bastante lenta (primeiro trecho) ou mesmo de velocidade 
e aceleração nulas (segundo trecho). Desta forma, pode-se assumir que $\dot{\theta} \approx \ddot{\theta} \approx 0$ e que, como $\cos \theta= \pm 1, \sin \theta=0$. Levando estes resultados nas Equações 10.30 e 10.31, nota-se que essa última equação é trivialmente satisfeita e que:

$$
\ddot{y}+2 \zeta_{y} \dot{y}+y=\frac{U_{r}^{2}}{2 m^{*}} \sum_{k=1}^{7}\left(a_{k}\left(\frac{\dot{y}}{U_{r}}\right)^{k}\right)
$$

O leitor nota que a Equação 10.33 é a equação de movimento adimensional de um corpo prismático submetido somente ao fenômeno de galloping. Como o foco desta seção reside nos casos com velocidade reduzida acima da velocidade reduzida crítica para o fenômeno, existe um crescimento da resposta até que o NVA inicie seu movimento, dando início ao regime de supressão.

A Figura 148 traz as séries temporais de resposta do prisma para a condição de velocidade reduzida $U_{r}=12$ e os mesmos valores de massa do NVA estudados na Figura 146. Retornando à Figura 143, o leitor nota que essa velocidade reduzida está no intervalo no qual existe uma grande dispersão da curva $y_{s t d}\left(U_{r}\right)$ apresentada na Figura 143.

Como mostra a Figura 148(a), a resposta do prisma sem o NVA tem uma amplitude estacionária de valor 1,16 e um espectro de amplitude de banda estreita com um pico em $\hat{f}=f / f_{n, y}=1$. Para a condição onde o supressor tem massa correspondente à $\hat{m}=0,05$, as Figuras 148(b) e 148(d) mostram que a resposta do prisma é praticamente livre de modulação em amplitude e que a série temporal de posição angular do NVA não apresenta um padrão bem definido. Essa ausência de padrão na série temporal $\theta(\tau)$ faz com que praticamente não ocorra o mecanismo TET, de sorte que a amplitude de resposta estacionária do prisma com NVA seja próxima daquela onde o supressor não é considerado.

Já a resposta obtida considerando $\hat{m}=0,13$ é bastante distinta e merece uma análise detalhada. Como mostrado na Figura 148(c), a série temporal $y(\tau)$ pode, em primeira análise, ser enquadrada como do tipo "RMA". No entanto, cabe uma análise mais detalhada dessa série temporal. A Figura 149(a) apresenta a referida série temporal, porém detalhando o intervalo $1500 \leq \tau \leq 2500$.

De maneira distinta daquela observada na Figura 147(a) na qual uma resposta do prisma também do é tipo "RMA" e na qual o NVA posições angulares constantes durante certos intervalos de tempo, a Figura 149(a) indica que o NVA responde com velocidade angular não nula ao longo dos ciclos de crescimento e de supressão da resposta do prisma. Note, no entanto, que a série temporal $\cos \theta$ revela que, durante certos intervalos correspondentes aos regimes de supressão da resposta do prisma, existe um aumento da velocidade angular do NVA. Já no tocante à série temporal ilustrada na Figura 149(b), observa-se um comportamento qualitativamente menos regular do que aquele revelado pela Figura 147(b). Essa irregularidade é refletida no alargamento da banda observada no espectro de amplitude, embora a frequência dominante ainda permaneça $\hat{f}=f / f_{n, 1}=1$. 
Figura 148 - Exemplos de séries temporais. Supressor caracterizado por $\hat{r}=0,40$ e $\zeta_{\theta}=$ $0,05 . U_{r}=12$.
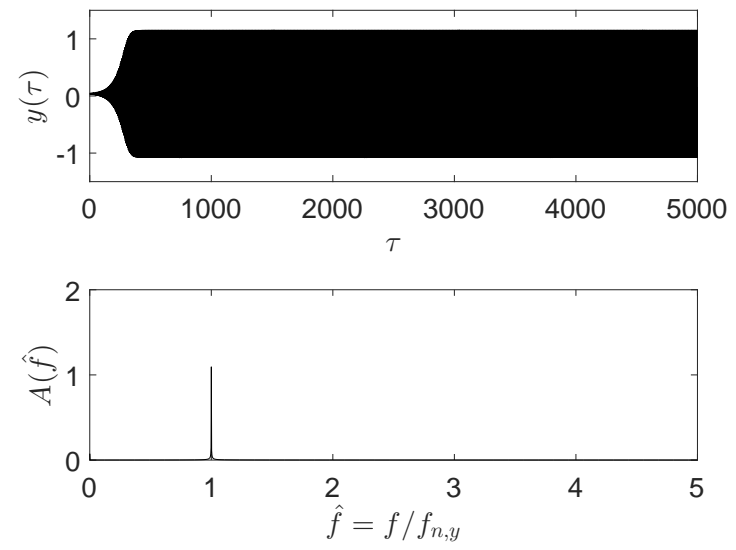

(a) Resposta do prisma. Condição sem supressor.
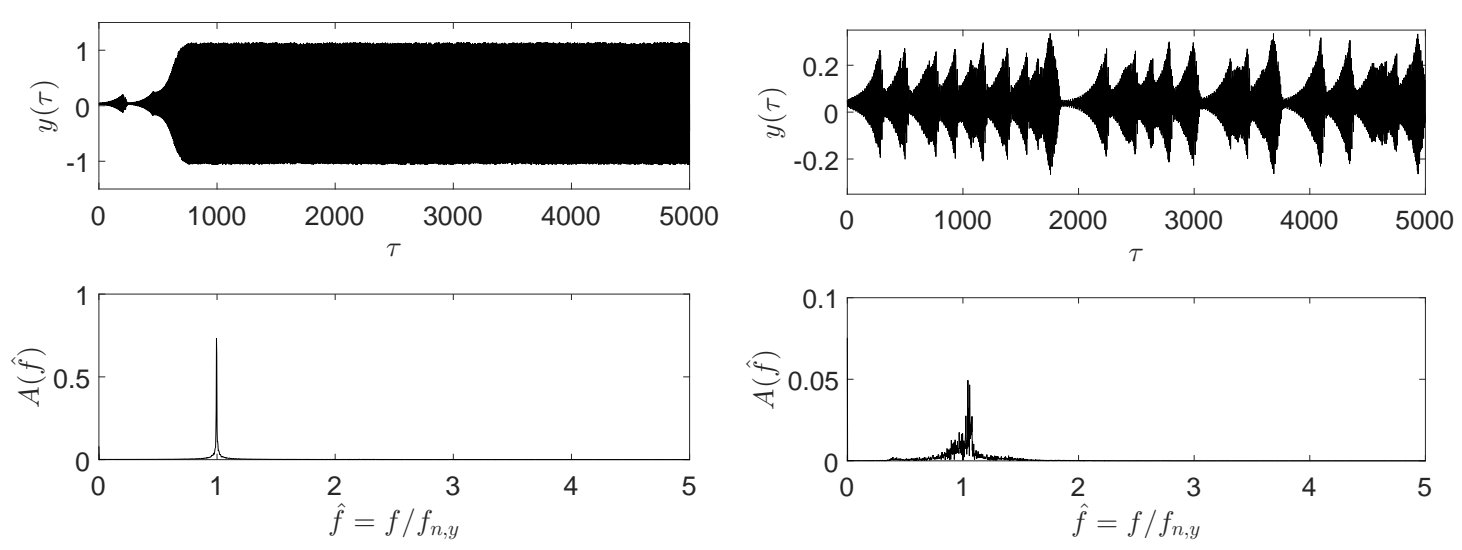

(b) Resposta do prisma. $\hat{m}=0,05$.

(c) Resposta do prisma. $\hat{m}=0,13$.
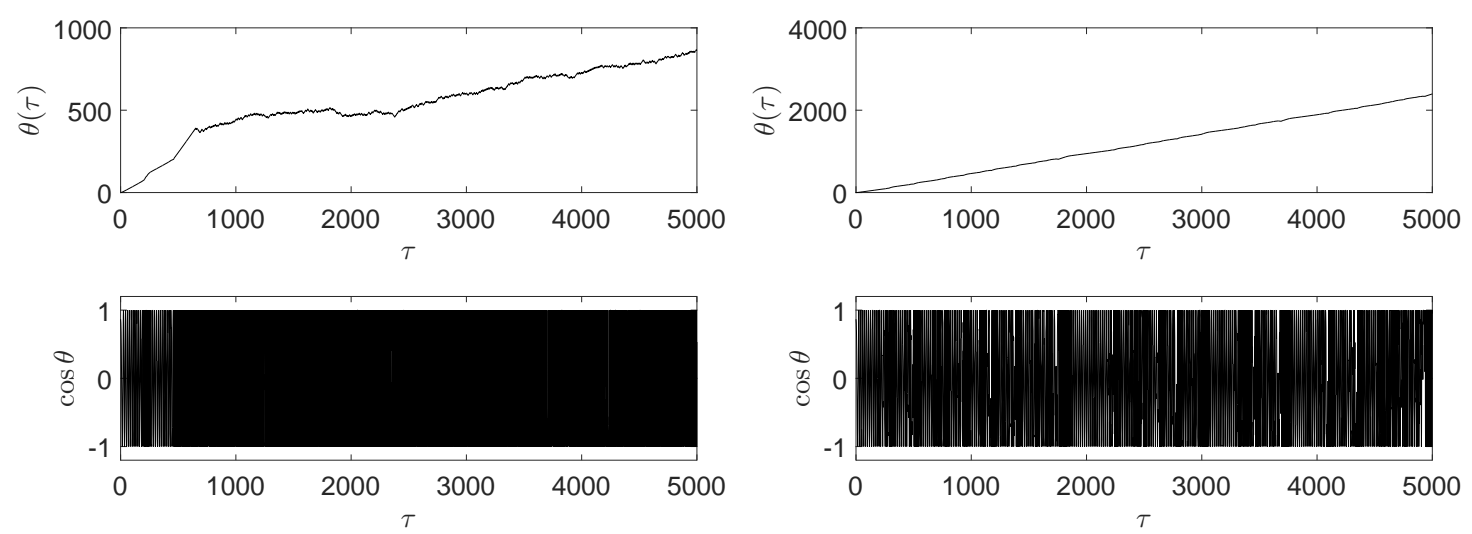

(d) Resposta do NVA. $\hat{m}=0,05$.

(e) Resposta do NVA. $\hat{m}=0,13$.

Fonte: Elaborada pelo autor.

O estudo de sensibilidade da resposta do sistema composto do prisma e do NVA é, por ora, concluído com a apresentação das séries temporais da Figura 150. Essas séries temporais foram obtidas para o valor de velocidade reduzida $U_{r}=18$, raio e taxa de amortecimento do supressor iguais a $\hat{r}=0,40$ e $\zeta_{\theta}=0,05$ respectivamente e dois valores 
Figura 149 - Detalhe das séries temporais de resposta. $\hat{m}=0,13, \hat{r}=0,40, \zeta_{\theta}=0,05$ e $U_{r}=12$.
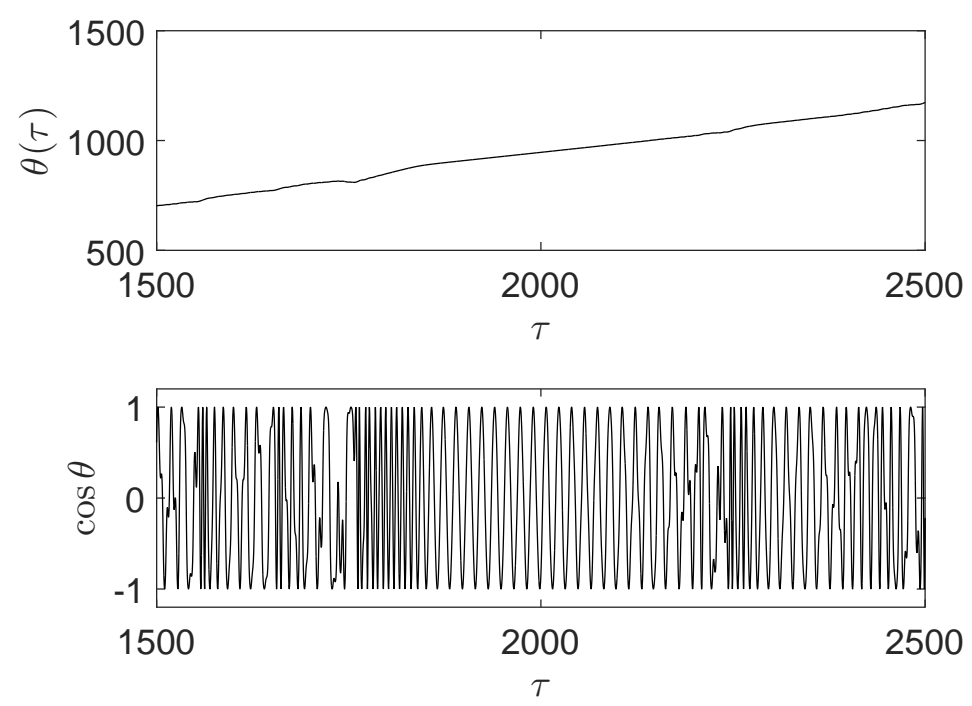

(a) $\theta(\tau)$ e $\cos \theta$.
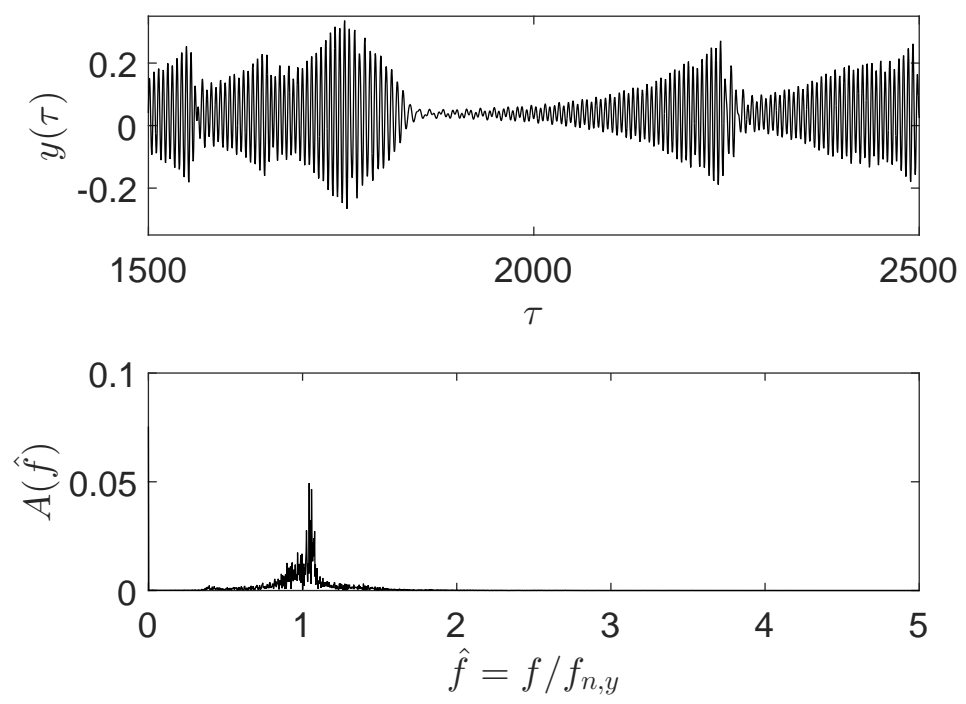

(b) $y(\tau)$ e espectro de amplitude.

Fonte: Elaborada pelo autor.

de massa do supressor, $\hat{m}=0,05$ e $\hat{m}=0,13$. O leitor nota que tais valores de $\hat{r}$ e $\zeta_{\theta}$ são os mesmos empregados na construção da Figura 143.

As Figuras 150(a), 150(b) e 150(d) indicam que a presença do NVA pouco afeta a resposta do prisma ao carregamento decorrente da interação fluido-estrutura com velocidade reduzida $U_{r}=18$. Já as respostas do NVA apresentadas nas Figuras 150(c) e 150(e) são caracterizadas como sendo oscilatórias em torno de um valor médio não nulo e com amplitude constante.

A discussão da capacidade do NVA em suprimir oscilações decorrentes do galloping segue com a apresentação de mapas mostrando a variação do critério $\hat{S}$ como funções dos 
Figura 150 - Exemplos de séries temporais. Supressor caracterizado por $\hat{r}=0,40$ e $\zeta_{\theta}=$ $0,05 . U_{r}=18$.
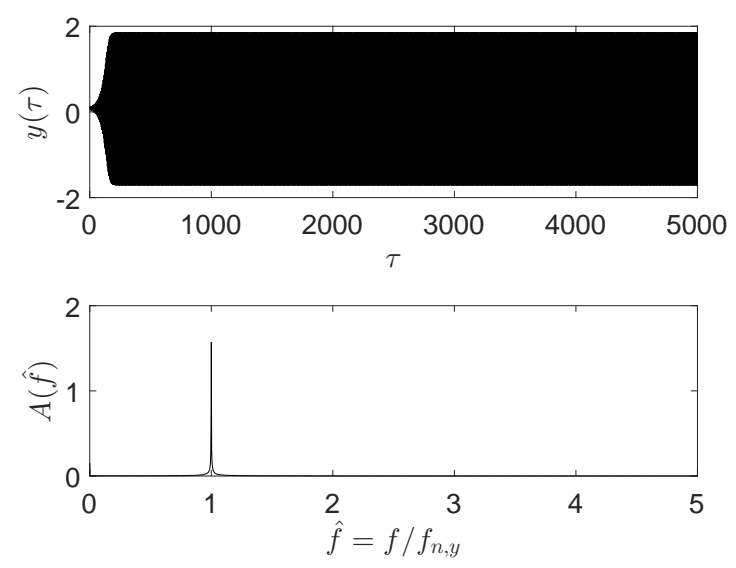

(a) Resposta do prisma. Condição sem supressor.
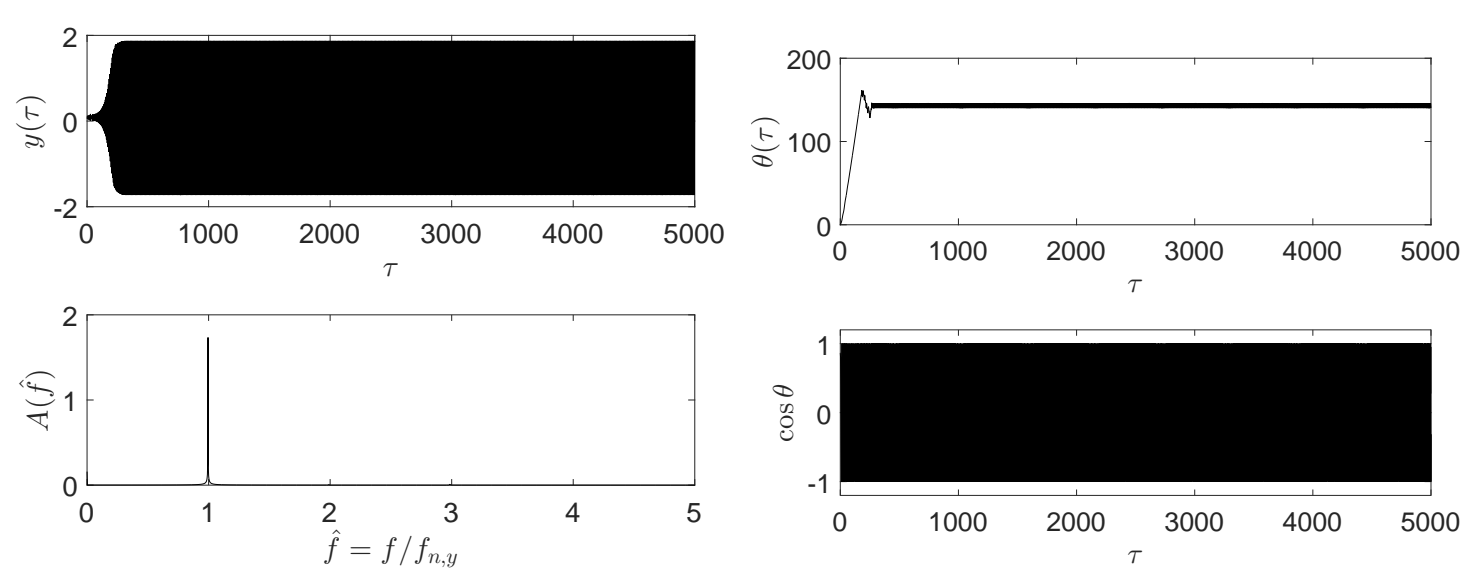

(b) Resposta do prisma. $\hat{m}=0,05$.

(c) Resposta do prisma. $\hat{m}=0,05$.
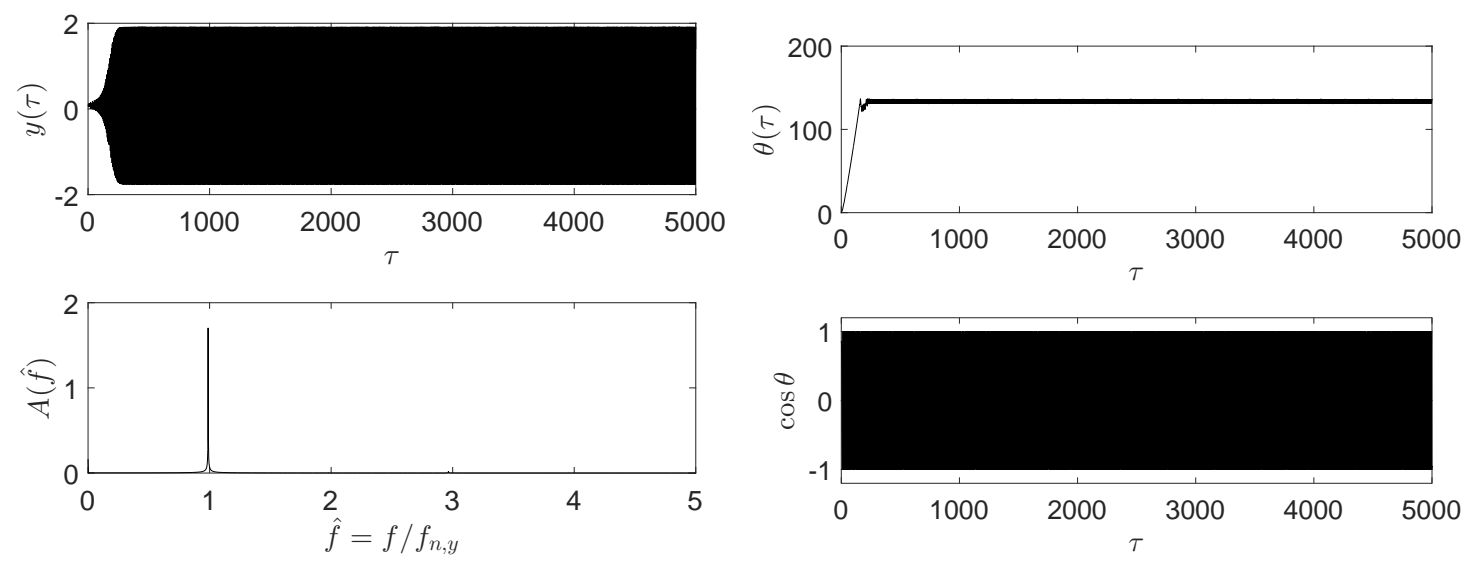

(d) Resposta do NVA. $\hat{m}=0,13$.

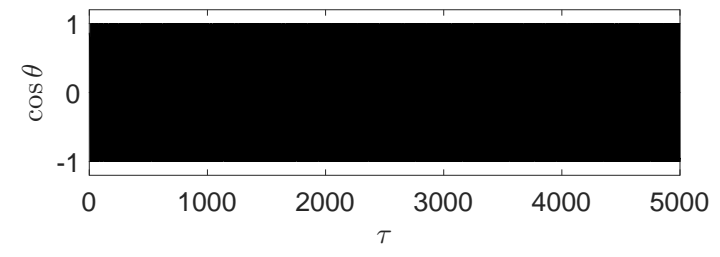

(e) Resposta do NVA. $\hat{m}=0,13$.

Fonte: Elaborada pelo autor.

parâmetros adimensionais $\hat{m}$ e $\hat{r}$ para valores selecionados de taxa de amortecimento do NVA e de velocidade reduzida. Em particular, os mapas aqui apresentados contemplam três valores de velocidades reduzidas, $U_{r}=6,5, U_{r}=12$ e $U_{r}=18$ e dois valores de taxa 
de amortecimento do NVA, a saber $\zeta_{\theta}=0,05$ e $\zeta_{\theta}=0,20$.

A Figura 151 traz o mapa $\hat{S}(\hat{m} ; \hat{r})$ obtido a partir das simulações numérica com velocidade reduzida $U_{r}=6,5$ e taxa de amortecimento do NVA $\zeta_{\theta}=0,05$ em conjunto com exemplos ${ }^{13}$ de séries temporais de resposta do prisma e do supressor. Como mostrado na Figura 151(a), a supressão passiva é bastante eficiente para $U_{r}=6,5$ e $\zeta_{\theta}=0,05$, sendo caracterizada por $\hat{S} \geq 0,7$ (regiões coloridas em laranja ou vermelho) para a maior parte dos valores no plano $(\hat{m} ; \hat{r})$ aqui estudados. Note que, para valores do parâmetro de massa $\hat{m} \leq 0,02$ ou para $\hat{r} \leq 0,02$, o critério $\hat{S}$ assume valores muito baixos, correspondendo à região colorida em azul. Essa mesma figura mostra, ainda, que as respostas dos prisma podem ser dos tipos "RMA" ou "RAC". É interessante ressaltar a série temporal $y(\tau)$ obtida para $\hat{m}=0,08$ e $\hat{r}=0,46$ que, embora caracterizada por modulações em amplitude, é distinta de outras respostas do tipo "RMA".

As séries temporais de resposta do NVA apresentadas na Figura 151(b) complementam a análise da resposta do sistema. Enquanto as respostas do tipo "RAC" têm a série temporal de deslocamento do NVA caracterizadas velocidade angular praticamente constante próximas a $\omega_{r}=0,1$. s afirmação pode ser notada inspecionando as séries temporais $\theta(\tau)$ obtidas para $(\hat{m} ; \hat{r})=(0,14 ; 0,23)$ e $(\hat{m} ; \hat{r})=(0,13 ; 0,44)$. Já para as respostas do prisma do tipo "RMA", as séries temporais $\theta(\tau)$ alternam entre regimes com velocidades angulares pequenas ou nulas com regimes nos quais existem trechos caracterizados por velocidade angular praticamente constante e igual a $\omega_{r}=1$. Esses últimos regimes correspondem àqueles onde a resposta do cilindro é diminuída em decorrência da captura em uma ressonância $1: 1$.

A Figura 152 traz o mapa $\hat{S}(\hat{m} ; \hat{r})$ também considerando a velocidade reduzida como sendo igual a 6,5 , porém a taxa de amortecimento do NVA foi aumentada para $\zeta_{\theta}=0,20$. O leitor prontamente nota algumas diferenças interessantes decorrentes do aumento da taxa de amortecimento do supressor.

Como pode ser visto na Figura 152(a), existe uma região colorida em vermelho aproximadamente definida por $0,04 \leq \hat{m} \leq 0,15 \times 0,17 \leq \hat{r} \leq 0,50$ e na qual existe uma alta capacidade de mitigação. Mais ainda, alguns pontos chegam a apresentar uma resposta caracterizada por supressão completa ${ }^{14}$ (resposta do tipo "SC", usando a nomenclatura introduzida na seção 9.3). Cumpre ressaltar que o mapa apresentado na Figura 151 já apresentava uma região colorida em vermelho, porém o aumento no valor de $\zeta_{\theta}$ promoveu tanto um aumento dessa região quanto uma diminuição das respostas do prisma.

Adicionalmente, a Figura 152(a) ainda mostra que o aumento no valor de $\zeta_{\theta}$ acabou por suavizar o mapa $\hat{S}(\hat{m} ; \hat{r})$. Por fim, cumpre ressaltar que existe uma região colorida

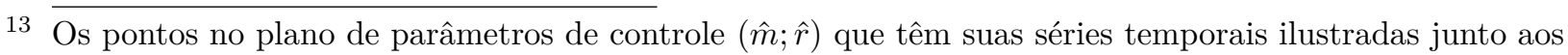
mapas estão apresentados na Tabela 15.

14 Sendo mais preciso, essas respostas são da ordem de $10^{-2}$. 
Figura 151 - Variação do critério $\hat{S}$ como função dos parâmetros $\hat{m}$ e $\hat{r} \cdot \zeta_{\theta}=0,05$ e $U_{r}=6,5 . y_{s t d, 0}=0,34$.

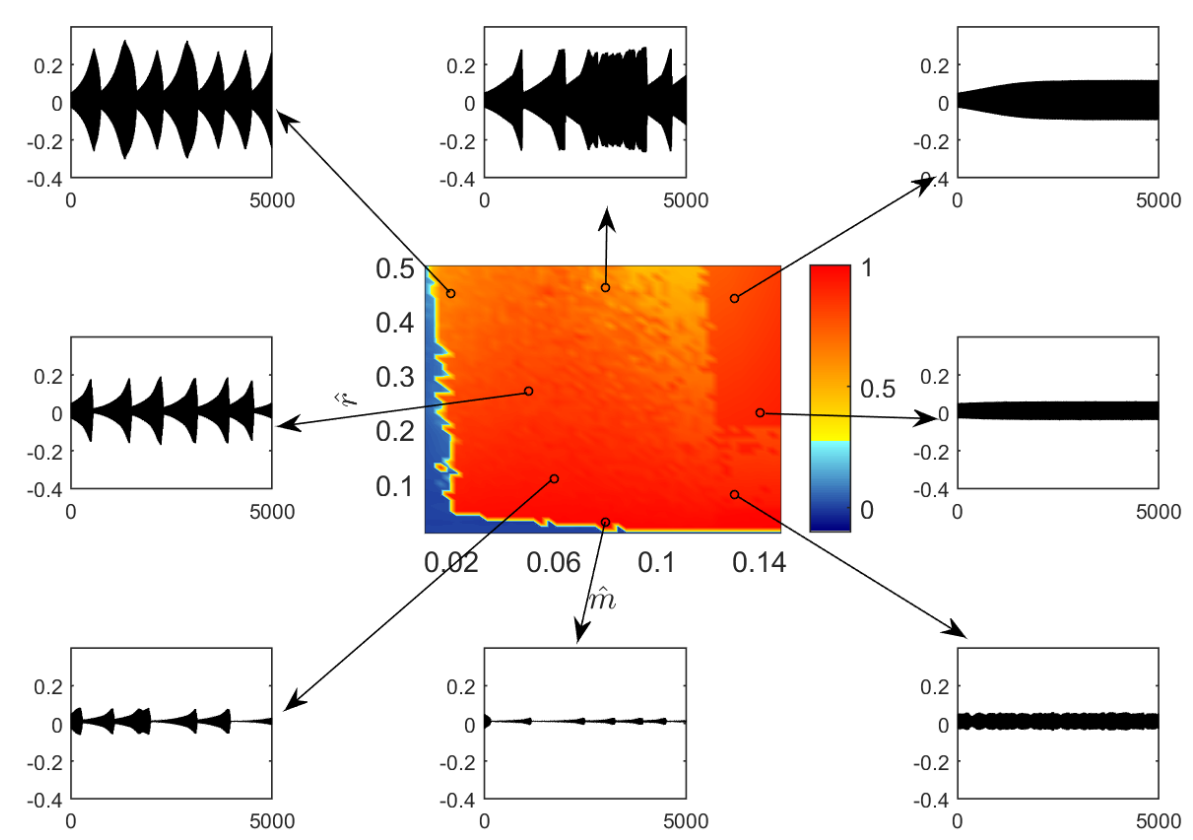

(a) $\hat{S}(\hat{m} ; \hat{r})$ e séries temporais $y(\tau)$.

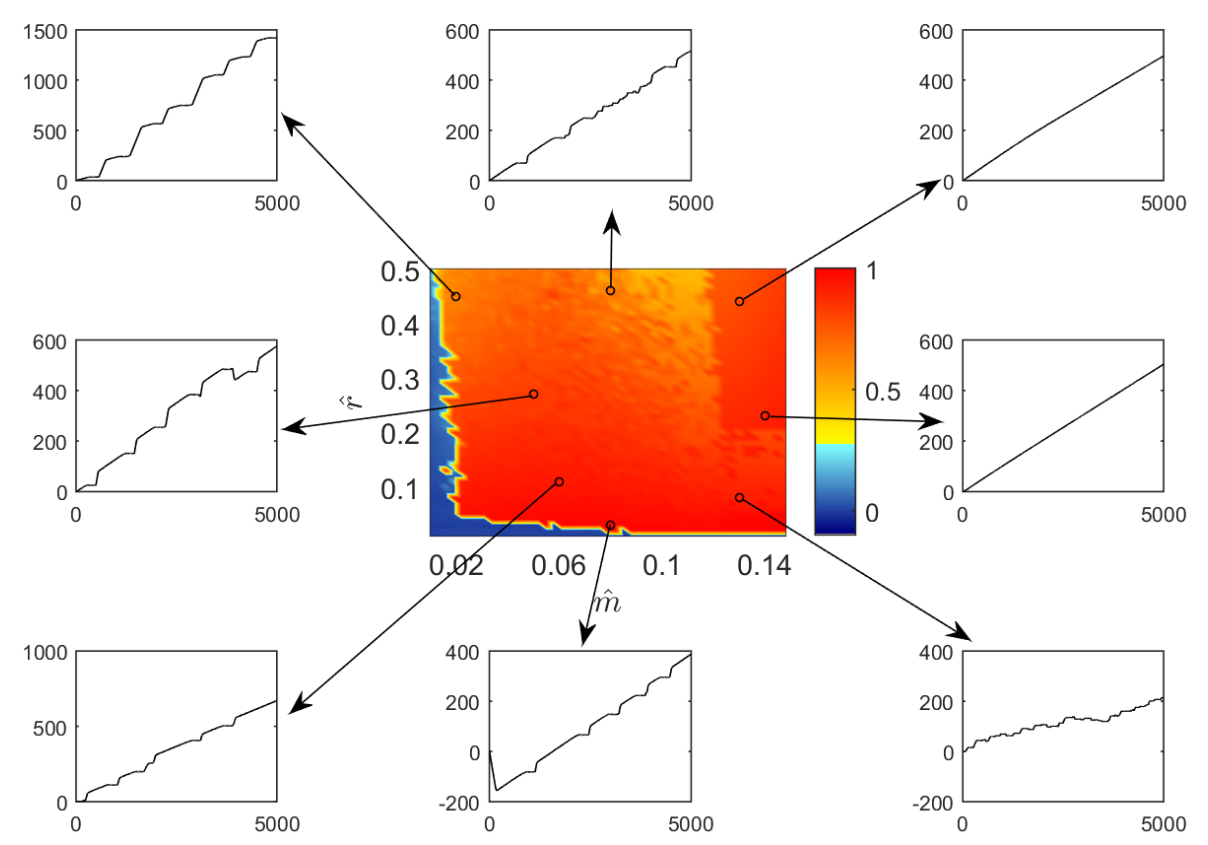

(b) $\hat{S}(\hat{m} ; \hat{r})$ e séries temporais $\theta(\tau)$.

Fonte: Elaborada pelo autor.

em azul claro compreendida no sub-espaço $0,01 \leq \hat{m} \leq 0,03 \times 0,40 \leq \hat{r} \leq 0,50$ na qual o aumento na taxa de amortecimento do NVA foi prejudicial no que diz respeito à diminuição das amplitudes de oscilação do prisma. 
Figura 152 - Variação do critério $\hat{S}$ como função dos parâmetros $\hat{m}$ e $\hat{r} \cdot \zeta_{\theta}=0,20$ e $U_{r}=6,5 . y_{s t d, 0}=0,34$.

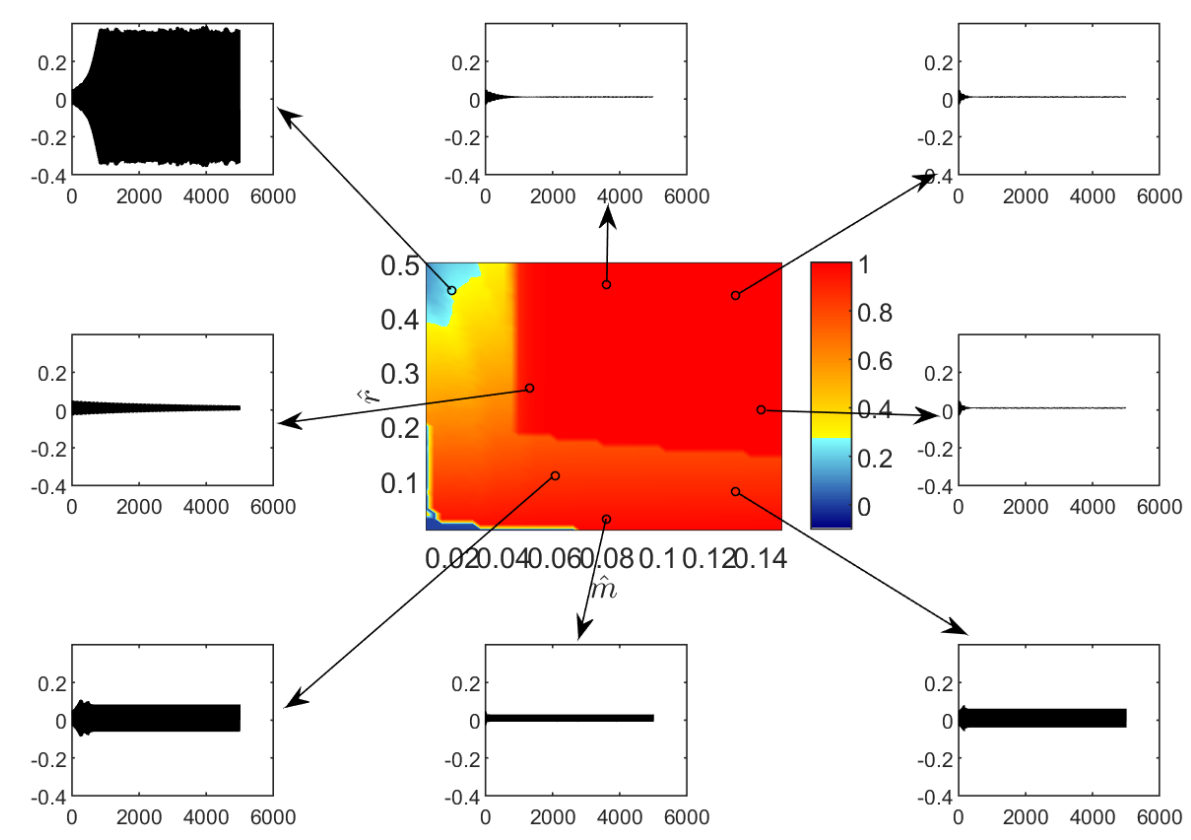

(a) $\hat{S}(\hat{m} ; \hat{r})$ e séries temporais $y(\tau)$.

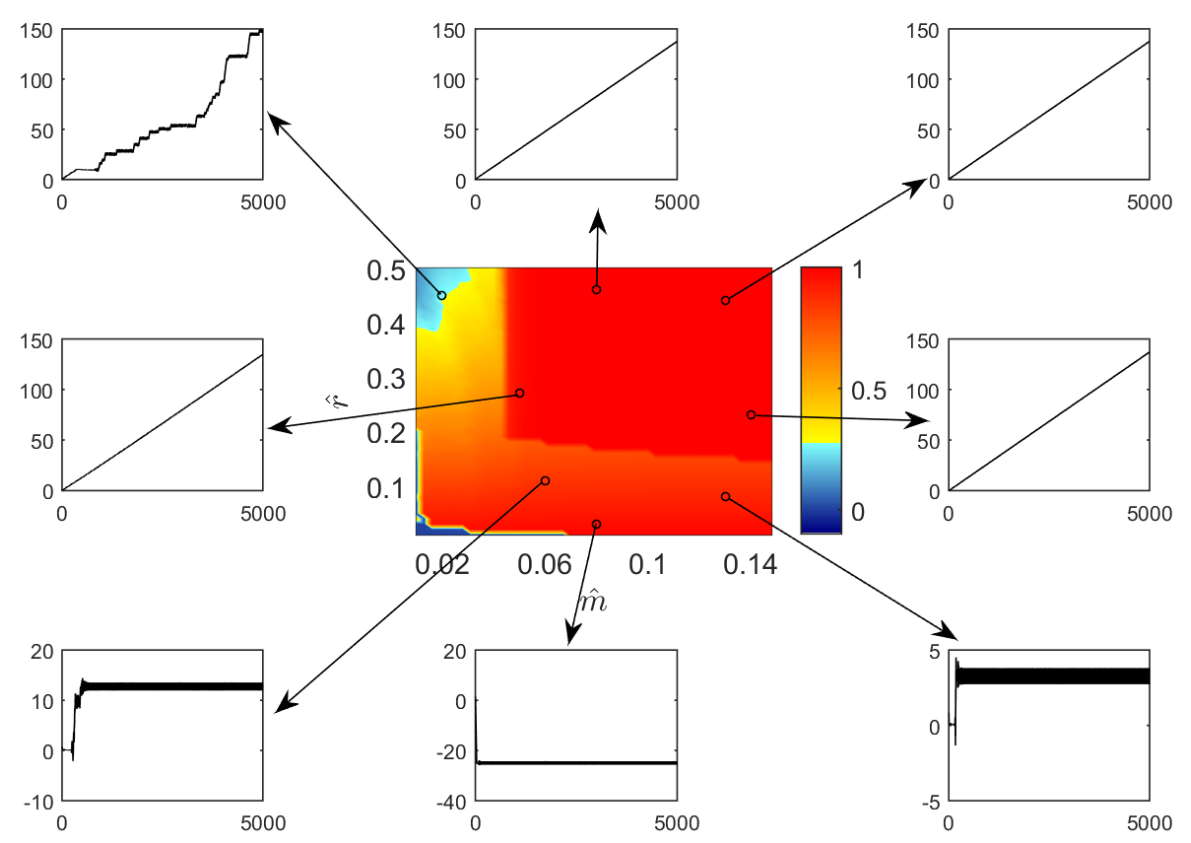

(b) $\hat{S}(\hat{m} ; \hat{r})$ e séries temporais $\theta(\tau)$.

Fonte: Elaborada pelo autor.

As séries temporais $\theta(\tau)$ ilustradas na Figura 152(b) podem ser caracterizadas por rotação com velocidade angular praticamente constante mas bastante abaixo daquela que caracteriza a ressonância $1: 1$, por respostas oscilatórias com amplitude constante 
e correspondendo a respostas do prisma do tipo "RAC", ou mesmo uma resposta sem padrão definido.

A análise dos mapas $\hat{S}(\hat{m} ; \hat{r})$ segue com a discussão dos resultados obtidos para velocidade reduzida $U_{r}=12$ e taxa de amortecimento do NVA $\zeta_{\theta}=0,05$. Cabe aqui relembrar o leitor que as Figuras 143, 144 e 145 mostram que a resposta do sistema é bastante sensível aos parâmetros de controle nessa velocidade reduzida.

Ao contrário do que foi observado na Figura 151 obtida para velocidade reduzida $U_{r}=6,5$ e o mesmo valor de taxa de amortecimento do NVA, existe uma erosão intensa do plano de parâmetros de controle $(\hat{m} ; \hat{r})$. Essa erosão, já vista no problema de supressão passiva de excitação paramétrica (ver Figura 106), é representa por uma mescla de regiões de alta supressão (coloridas em vermelho) com outras de baixa supressão e coloridas em azul. Sob a ótica de uma aplicação tecnológica, a erosão do plano de parâmetros certamente é indesejável, uma vez que não é interessante a ocorrência de mudanças bruscas de respostas de acordo com pequenas e inevitáveis variações nos parâmetros que definem o NVA.

Do ponto de vista qualitativo da resposta do prisma, a Figura 153(a) revela a presença de respostas dos tipos "RAC" e "RMA". Além desses exemplos, as séries temporais obtidas para $(\hat{m}, \hat{r})=(0,13 ; 0,08)$ e $(\hat{m}, \hat{r})=(0,08 ; 0,46)$ mostram a transição entre uma resposta do tipo "RMA" para outra do tipo "RAC" com uma amplitude significativamente superior. Note, ainda, que o tempo de simulação necessário para esta transição pode superar $\tau=4000$. O leitor nota, por meio da análise das séries temporais $\theta(\tau)$ apresentadas na Figura 153(b), que a transição de respostas do prisma "RMA" $\rightarrow$ "RAC" são acompanhadas de mudanças nas correspondentes resposta do NVA.

A Figura 154 traz o mapa $\hat{S}(\hat{m} ; \hat{r})$ obtido também para velocidade reduzida $U_{r}=12$, porém com taxa de amortecimento do NVA $\zeta_{\theta}=0,20$. Configurando um resultado análogo àquele apresentado na Figura 107 por ocasião da análise da supressão passiva da excitação paramétrica, o aumento da taxa de amortecimento do NVA é responsável por uma significativa redução na erosão do plano de parâmetros de controle $(\hat{m} ; \hat{r})$. Comparando as Figuras 153(a) e 154(a), é possível notar que o aumento da taxa de amortecimento do NVA, além de diminuir a erosão mencionada, aumenta a região do plano $(\hat{m} ; \hat{r})$ onde o parâmetro $\hat{S} \geq 0,6$, o que indubitavelmente é benéfico no sentido de supressão passiva.

Por fim, os últimos mapas aqui analisados foram obtidos a partir de simulações numéricas considerando velocidade reduzida $U_{r}=18$. Retornando às Figuras 144(a), 145(a) e 146(a), é possível notar que essa velocidade reduzida é caracterizada por valores baixos do parâmetro $\hat{S}$, de sorte que praticamente não há distinção entre as curvas $y_{s t d}\left(U_{r}\right)$ obtidas para a maioria das simulações.

Considerando, em um primeiro momento, as simulações conduzidas com taxa 
Figura 153 - Variação do critério $\hat{S}$ como função dos parâmetros $\hat{m}$ e $\hat{r} \cdot \zeta_{\theta}=0,05$ e $U_{r}=12$.

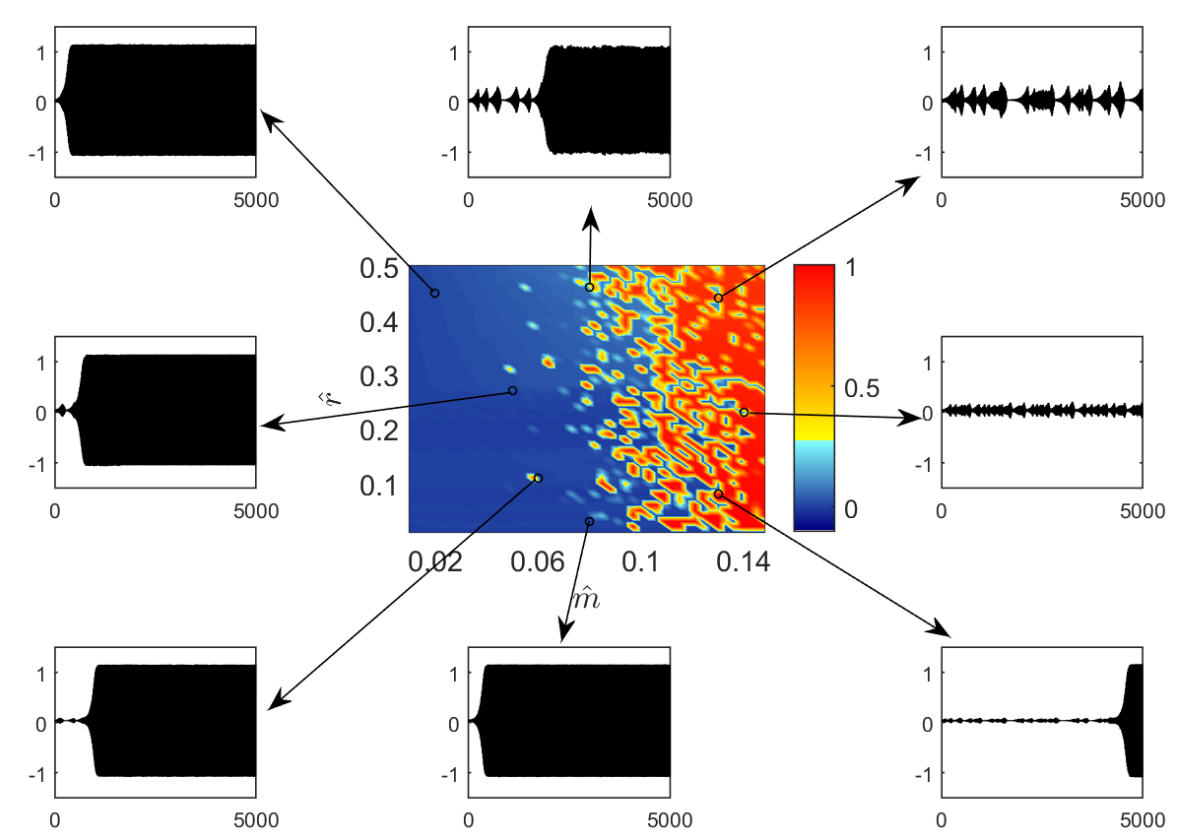

(a) $\hat{S}(\hat{m} ; \hat{r})$ e séries temporais $y(\tau)$.

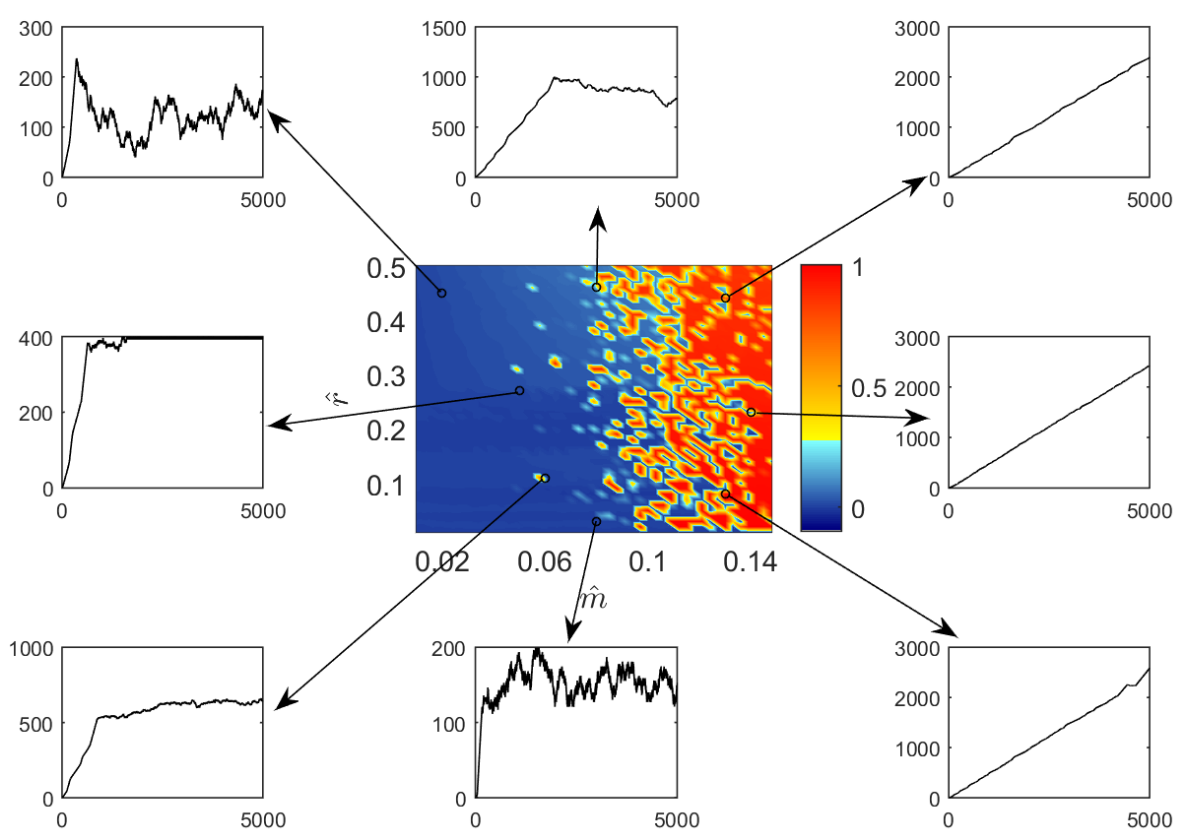

(b) $\hat{S}(\hat{m} ; \hat{r})$ e séries temporais $\theta(\tau)$.

Fonte: Elaborada pelo autor.

de amortecimento do NVA igual a $\zeta_{\theta}=0,05$, a Figura 155 reafirma a incapacidade do dispositivo em mitigar as oscilações decorrentes do galloping. Por sua vez, a Figura 156 indica que um aumento da da taxa de amortecimento do supressor para $\zeta_{\theta}=0,20$ promove 
Figura 154 - Variação do critério $\hat{S}$ como função dos parâmetros $\hat{m}$ e $\hat{r} \cdot \zeta_{\theta}=0,20$ e $U_{r}=12$.

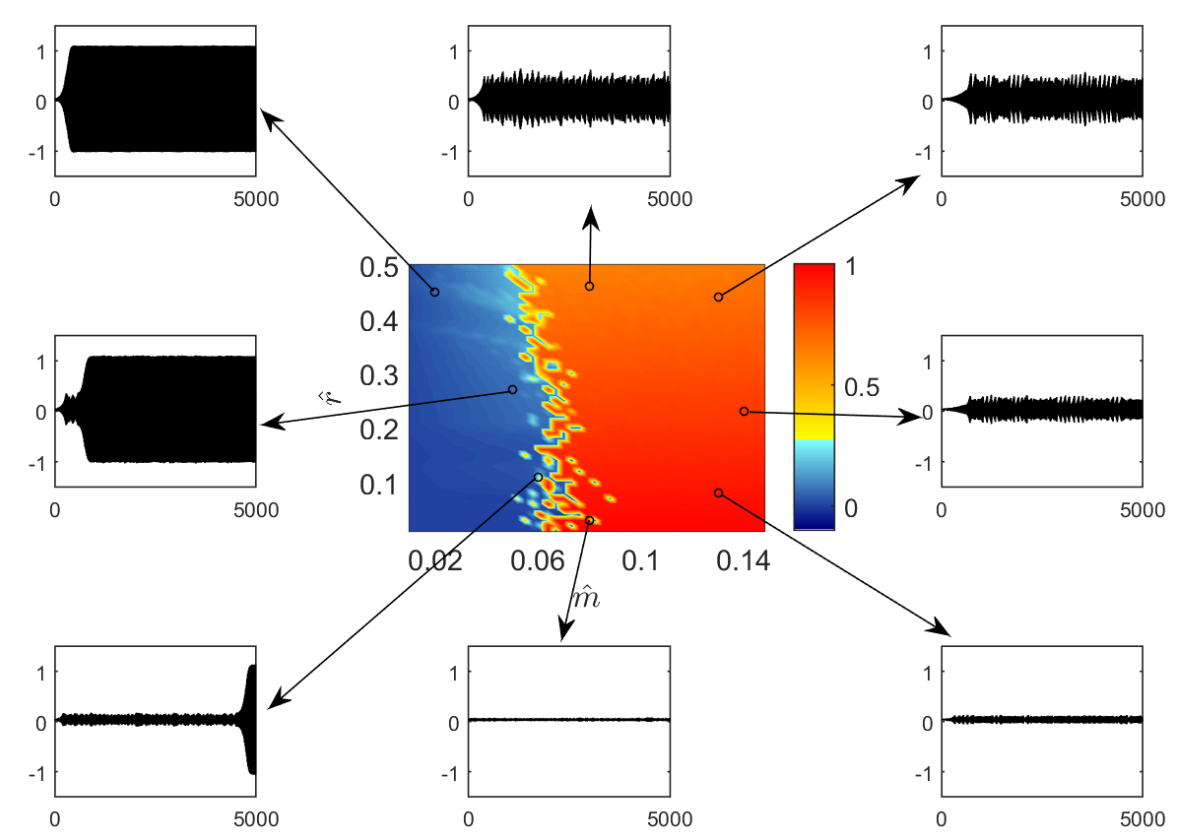

(a) $\hat{S}(\hat{m} ; \hat{r})$ e séries temporais $y(\tau)$.

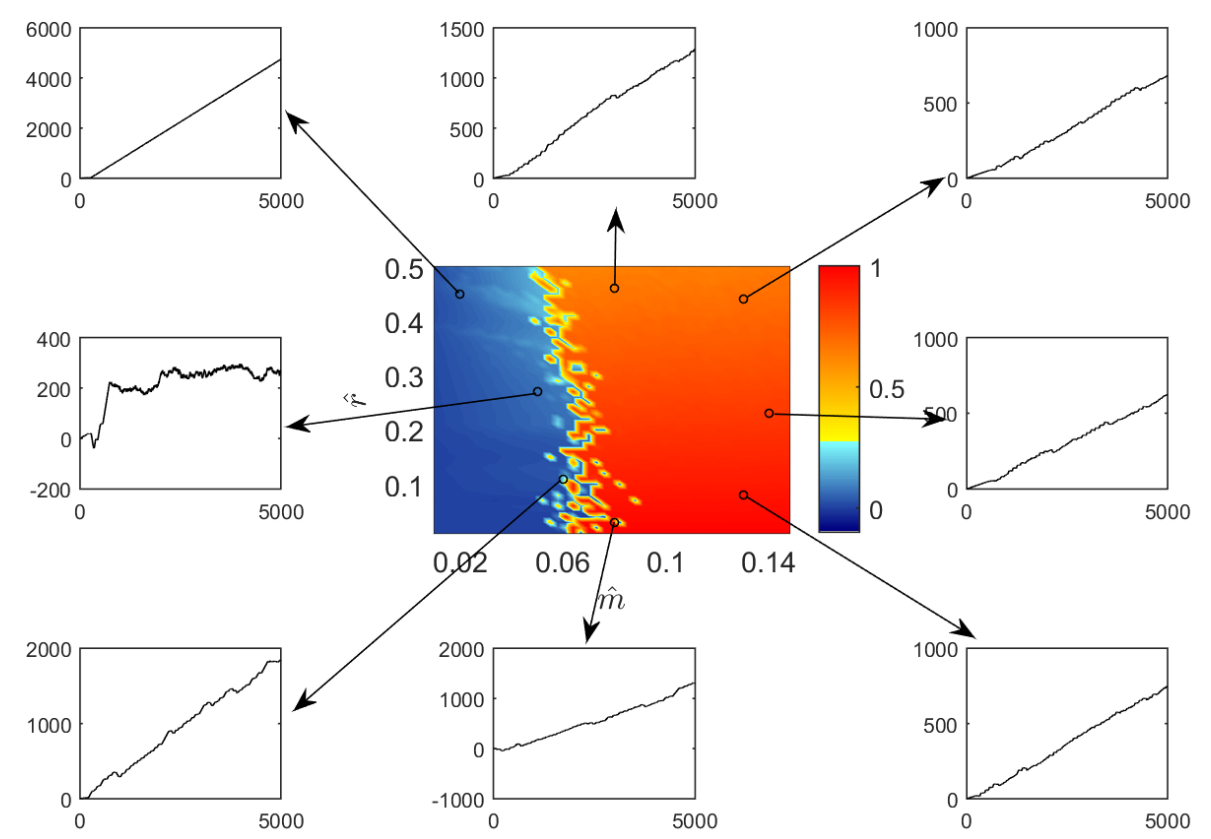

(b) $\hat{S}(\hat{m} ; \hat{r})$ e séries temporais $\theta(\tau)$.

Fonte: Elaborada pelo autor.

o aparecimento de alguns pontos no plano $(\hat{m} ; \hat{r})$ nos quais a supressão passiva tem alguma eficiência. Note, no entanto, que esses pontos estão bastante esparsos, configurando novamente a erosão do plano de parâmetros de controle. 
Figura 155 - Variação do critério $\hat{S}$ como função dos parâmetros $\hat{m}$ e $\hat{r} \cdot \zeta_{\theta}=0,05$ e $U_{r}=18$.

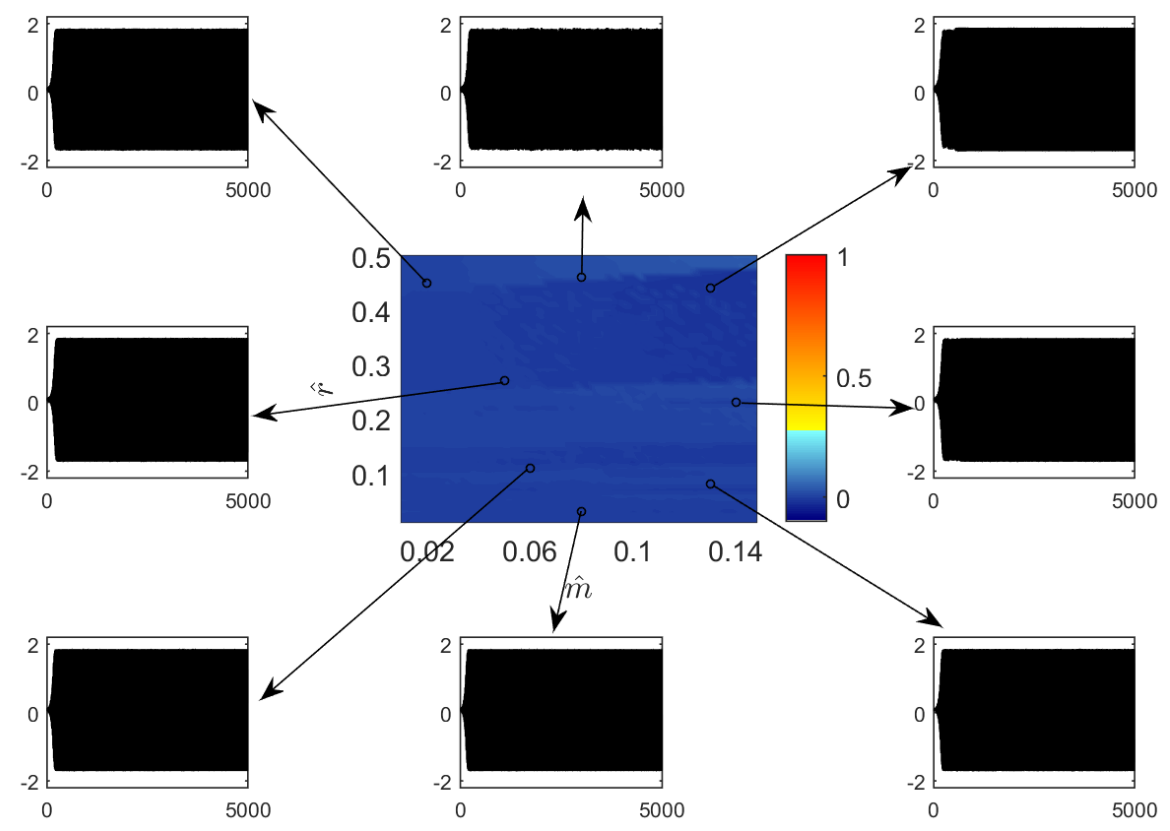

(a) $\hat{S}(\hat{m} ; \hat{r})$ e séries temporais $y(\tau)$.

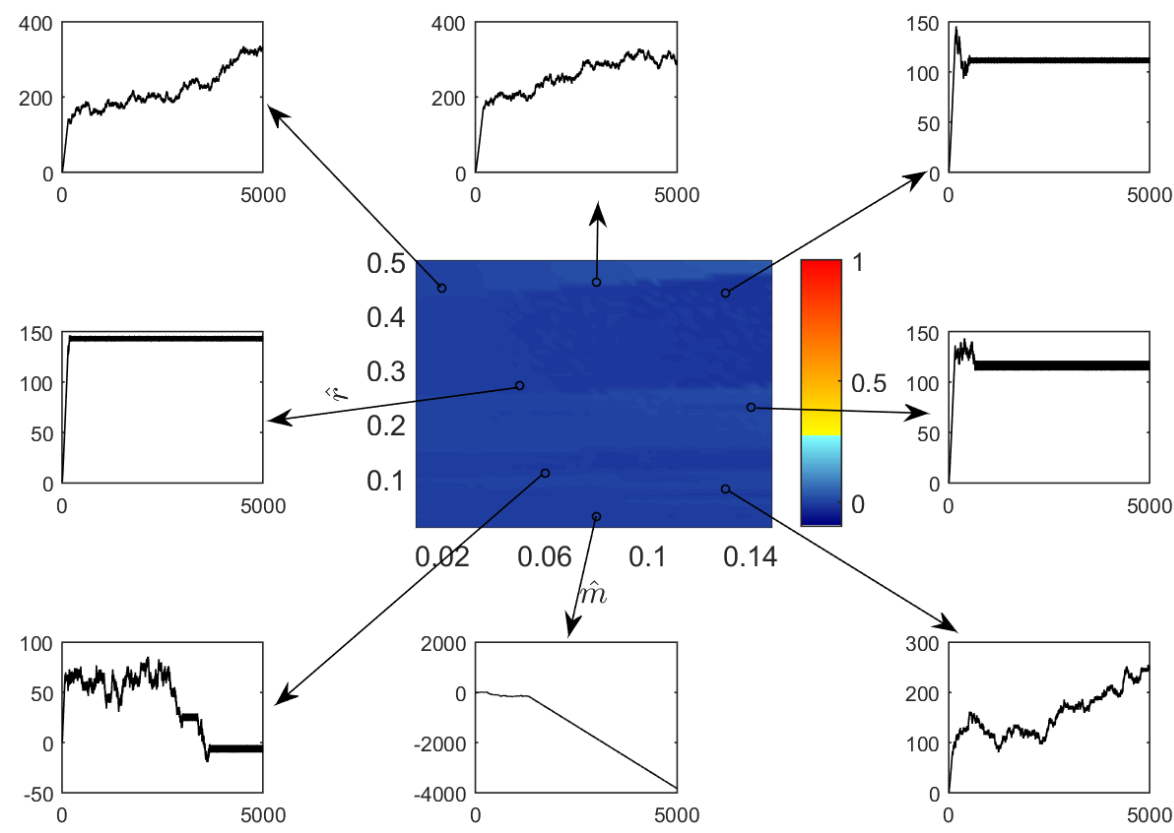

(b) $\hat{S}(\hat{m} ; \hat{r})$ e séries temporais $\theta(\tau)$.

Fonte: Elaborada pelo autor.

Ainda considerando a Figura 156, cabe ressaltar alguns aspectos das séries temporais $y(\tau)$ e $\theta(\tau)$. Como pode ser visto na Figura 156(a), as séries temporais $y(\tau)$ obtidas a partir das simulações com $(\hat{m} ; \hat{r})=(0,14 ; 0,23)$ e $(\hat{m} ; \hat{r})=(0,13 ; 0,44)$ são caracterizadas 
Figura 156 - Variação do critério $\hat{S}$ como função dos parâmetros $\hat{m}$ e $\hat{r} \cdot \zeta_{\theta}=0,20$ e $U_{r}=18$.

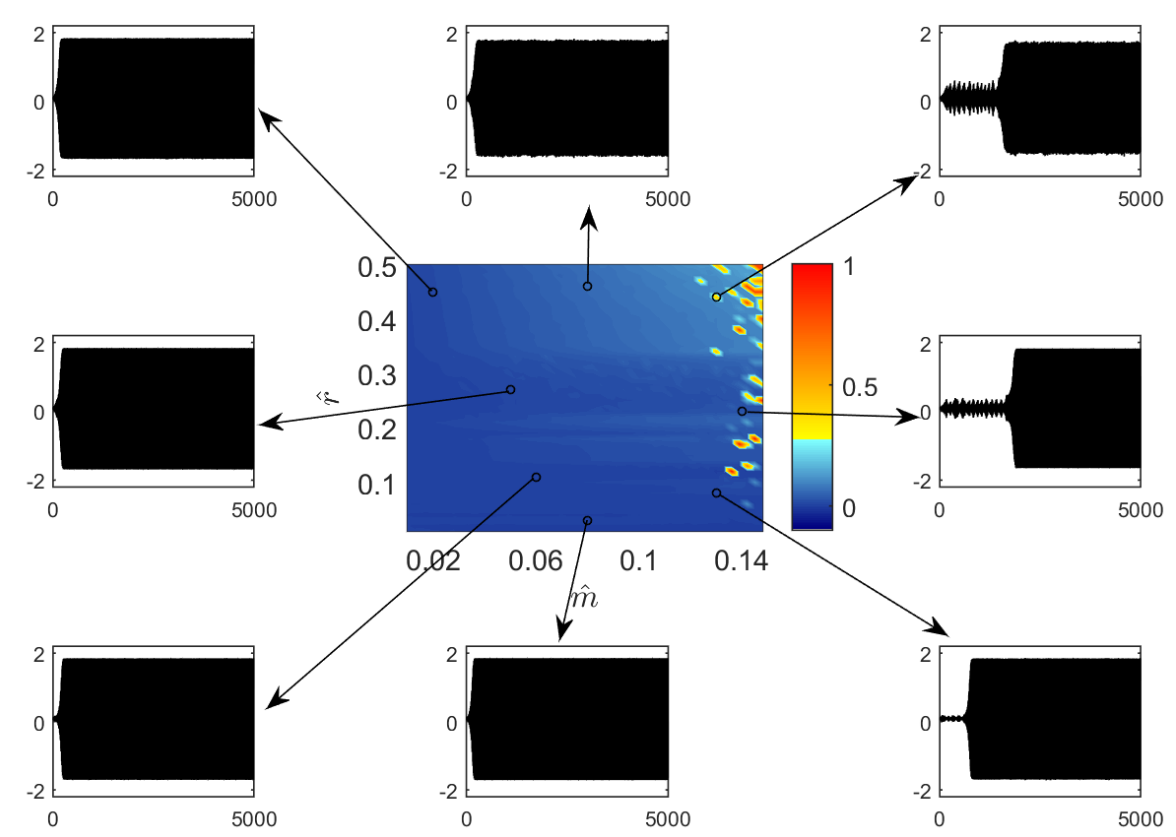

(a) $\hat{S}(\hat{m} ; \hat{r})$ e séries temporais $y(\tau)$.

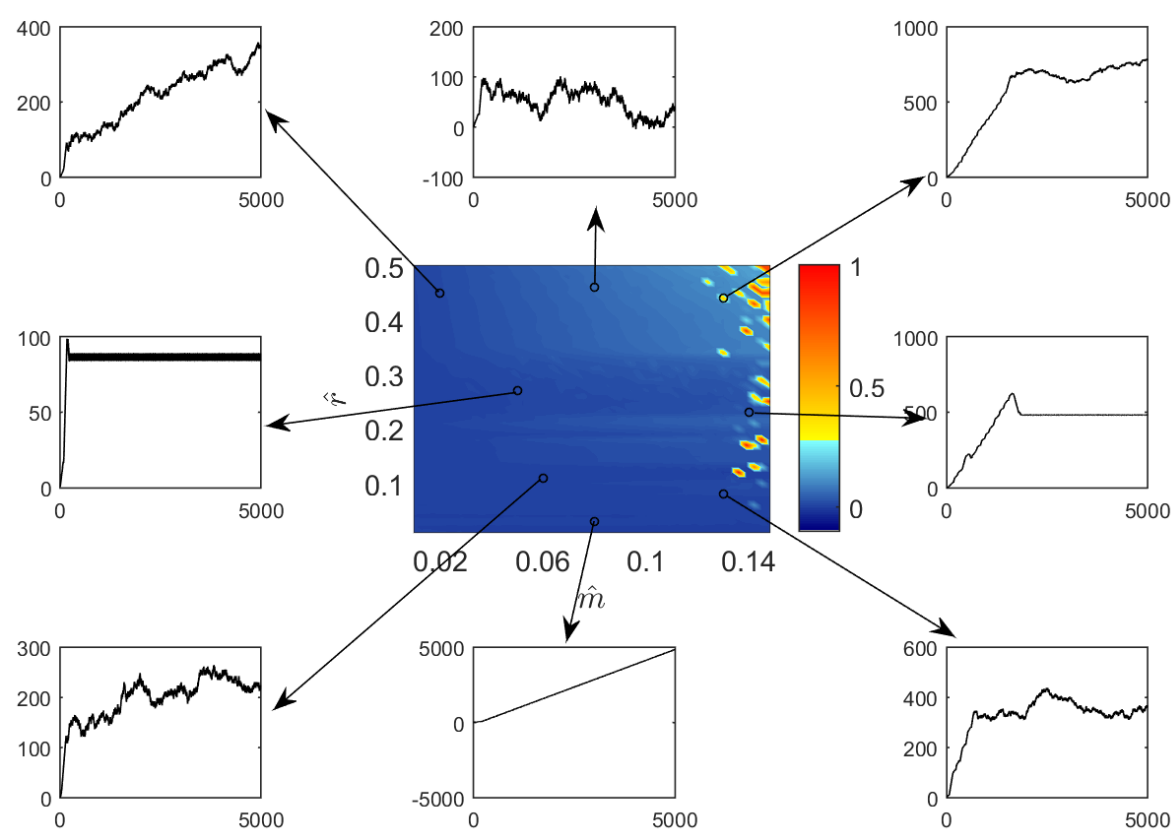

(b) $\hat{S}(\hat{m} ; \hat{r})$ e séries temporais $\theta(\tau)$.

Fonte: Elaborada pelo autor.

por dois regimes. Durante um certo intervalo de tempo, a resposta da estrutura principal é significativamente suprimida. Em sequência e após a mudança de regime, a série temporal de deslocamento do prisma volta a ser caracterizada por um amplitude estacionária e com 
valor próximo daquele obtido quando da ausência do NVA.

\subsection{Considerações finais do capítulo e perspectivas de continui- dade da pesquisa}

O presente capítulo apresentou estudos numéricos relativos à supressão passiva dos fenômenos de VIV e de galloping por meio de um NVA rotativo. Em particular, buscou-se investigar a influência dos parâmetros que definem o supressor (a saber, sua massa, raio e taxa de amortecimento) na sua capacidade de supressão. De maneira geral, os resultados aqui mostrados indicam que o dispositivo que foi objeto de estudo deste capítulo é capaz de mitigar as oscilações decorrentes dos referidos fenômenos.

O estudo acerca da supressão passiva do fenômeno de VIV contemplou apenas cilindros rígidos montados em base elástica com um e dois graus de liberdade e fazem parte da pesquisa da mestranda Tatiana Ueno, orientada do autor deste texto. Na ocasião de redação do presente texto, os resultados aqui apresentados constam de um artigo científico em apreciação por parte do comitê científico de um periódico indexado.

Os carregamentos decorrentes da interação fluido-estrutura foram modelados empregando os wake-oscillators descritos nas subseções 4.1 .5 (condição VIV-1gl) e 8.2.2 (VIV-2gl). Os parâmetros de massa e de amortecimento da estrutura principal (ou seja, o cilindro) foram escolhidos como $m^{*}=2,6$ e $\zeta_{y}=0,008$, os mesmos utilizados nos experimentos sem o supressor apresentados em Franzini et al. (2012a).

Para a condição VIV-1gl, a massa do NVA mostrou ser o parâmetro de maior influência em sua capacidade de supressão. Mais ainda, quanto maior o valor desse parâmetro (representado pelo adimensional $\hat{m}$ ), maior a redução de amplitudes de vibração no upper branch e no lower branch. Cumpre ressaltar que, como apontado na seção 5.3 , estudos que focam na supressão passiva do VIV por meio de um NVA rotativo e considerando todo o intervalo de velocidades reduzidas no qual o lock-in é observado são pouco encontrados na literatura e configuram uma contribuição da pesquisa liderada pelo autor do texto ao estado-da-arte.

Embora a massa do supressor tenha se mostrado um parâmetro relevante para a supressão passiva da condição VIV-2gl, essa última condição teve sua mitigação bem menos pronunciada do que aquela obtida para a condição VIV-1gl. De maneira mais específica, o NVA rotativo promoveu alguma redução de amplitude característica de oscilação apenas para velocidades reduzidas que não correspondiam àquelas de máxima resposta. Como também mostrado na seção 5.3, não existem estudos pregressos que focam no uso de NVA rotativo como supressor passivo do fenômeno VIV-2gl, o que confere originalidade à pesquisa em tela. 
Além de curvas mostrando a variação da amplitude característica de oscilação do cilindro na direção cross-wise como função da velocidade reduzida, a seção 10.1 trouxe mapas que ilustram a variação de um critério quantitativo de supressão como função da massa e do raio do supressor para valores selecionados de velocidade reduzida e taxa de amortecimento do NVA. Para a condição VIV-1gl, tais mapas não foram caracterizados por erosão do plano de parâmetros de controle, ou seja, pequenas mudanças na massa e o no raio do NVA não promoveram mudanças significativas na resposta. O leitor nota que esse resultado não foi obtido para o problema de supressão passiva de excitação paramétrica com pequena taxa de amortecimento do NVA; ver seção 9.3. Já para a condição VIV-2gl, os mapas mostraram uma maior erosão do plano $(\hat{m} ; \hat{r})$, embora inferior àquela observada no problema estudado na seção 9.3. Essa erosão foi diminuída com o aumento da taxa de amortecimento do NVA.

A metodologia de análise também envolveu a discussão de algumas séries temporais de respostas numericamente obtidas. De maneira análoga àquela observada para o problema de supressão passiva de excitação paramétrica, foram obtidas respostas do cilindro caracterizadas tanto por modulações em amplitude quanto por amplitudes estacionárias (respostas dos tipos "RMA" e "RAC", respectivamente). As respostas do cilindro do tipo "RMA" estão associadas a séries temporais de deslocamento do NVA com velocidade constante em certos trechos, podendo ou não ocorrer inversão no sentido de rotação.

Em particular, durante o regime de supressão de uma resposta do tipo "RMA", a rotação do NVA é próxima das frequências de oscilação do cilindro e da variável que representa a esteira vorticosa. Esse resultado configura uma ressonância 1: 1: 1 e é um cenário bastante favorável ao mecanismo TET. Algumas respostas do tipo "RAC" também caracterizaram-se por uma ressonância $1: 1: 1$, porém com a velocidade angular do NVA permanecendo constante ao longo de toda a simulação. Cumpre ressaltar, ainda, que embora os wake-oscillators envolvam parâmetros calibrados experimentalmente a partir de experimentos sem qualquer supressor (o que leva a respostas com amplitude estacionária), algumas das séries temporais aqui mostradas exibiram notável aderência com outras obtidas na literatura a partir de modelos de maior hierarquia baseados em técnicas de DFC.

Como mencionado, este capítulo também analisou o problema de supressão passiva do fenômeno de galloping por meio de um NVA rotativo, outra lacuna de conhecimento identificada na subseção 5.3. Cumpre ressaltar que esses estudos numéricos relativos fazem parte de um projeto conduzido em conjunto com o grupo de pesquisa do Professor Frédérick Gosselin (École Polytechnique de Montréal - PolyMTL), com apoio financeiro do Fond de Recherche du Québec e com a colaboração da orientada de graduação Bianca Teixeira. Embora dando continuidade a um artigo previamente publicado em conferência internacional, a seção 10.2 trouxe resultados inéditos. 
Analogamente ao que foi conduzido para o problema de supressão passiva do fenômeno de VIV, estudos sistemáticos visando analisar a influência dos parâmetros que definem o NVA na sua capacidade supressora foram conduzidos para diversos valores de velocidade reduzida. Ao contrário do que foi observado para o fenômeno de VIV, o supressor estudado mostrou ser amplamente capaz de mitigar as oscilações de um prisma (estrutura principal) decorrentes do fenômeno de galloping, podendo levar a respostas com amplitude inferior a $20 \%$ daquelas obtidas para o sistema sem o dispositivo. No entanto, para velocidades reduzidas superiores a 15, a capacidade de supressão do NVA foi cessada para praticamente todas as condições aqui simuladas.

A capacidade de supressão do NVA rotativo mostrou ser fortemente dependente da velocidade reduzida. Em particular, para velocidades reduzidas entre 8 e 12, observouse uma significativa dispersão dos resultados obtidos a partir das diversas combinações de parâmetros do supressor investigadas. Essa dependência foi confirmada a partir da erosão do mapa que relaciona um critério quantitativo de eficiência da supressão com os parâmetros de massa e de raio do NVA obtido para velocidade reduzida igual a 12 . A erosão do plano de parâmetros de controle já havia sido relatada na seção 9.3 e dedicada ao problema de supressão passiva da excitação paramétrica. Configurando um resultado análogo àquele obtido na seção 9.3 e também para o problema envolvendo supressão do fenômeno de VIV, o aumento na taxa de amortecimento do NVA foi responsável por uma significativa diminuição da erosão mencionada.

A exemplo do que foi obtido para o problema de supressão passiva do fenômeno de VIV, as séries temporais de resposta do prisma também foram dos tipos "RMA" ou "RAC". Em alguns dos exemplos de resposta do tipo "RMA" ilustrados, a resposta do NVA envolveu trechos nos quais a velocidade angular era próxima a $\omega_{r}=1$ nos regimes onde há supressão de vibração, configurando uma ressonância $1: 1$. Outros exemplos mostraram mitigação de vibração da estrutura principal sob condições onde o NVA rotaciona com velocidade angular constante distinta de $\omega_{r}=1$, configurando um resultado não observado quando da análise dos demais problemas de supressão passiva que foram objeto deste texto.

Como o leitor pôde notar, as pesquisas aqui descritas e conduzidas em conjunto com orientadas do autor do texto auxiliariam no entendimento de algumas das lacunas de conhecimento identificadas na seção 5.3. No entanto, é possível elencar uma série de perspectivas de continuidade da pesquisa que foi objeto deste capítulo.

Algumas iniciativas em curso envolvem o uso de um NVA translativo como supressor passivo do fenômeno de VIV. Também utilizando o conceito de wake-oscillators como ferramenta de modelagem do carregamento hidrodinâmico, a mestranda Tatiana Ueno realizou uma série de simulações que mostram que esse tipo de NVA também é capaz de reduzir as amplitudes de vibração decorrentes do fenômeno VIV-1gl. Esses resultados serão 
publicados em breve à comunidade científica na forma de um artigo de conferência ou de periódico. Outra pesquisa em curso e conduzida pelo aluno de iniciação científica Vitor Maciel é aquela na qual verificar-se-á a eficácia de um NVA rotativo como supressor de vibrações induzidas pelo escoamento interno. Convém ressaltar que essa última pesquisa está em caráter incipiente quando da redação do presente texto.

Outra importante linha de trabalho atualmente em curso envolve a análise dos experimentos conduzidos no túnel de vento da PolyMTL. Até a data da redação deste texto, algumas análises preliminares já foram concluídas, revelando que, de fato, o NVA rotativo é capaz de suprimir o fenômeno de galloping. Um artigo científico a ser submetido a periódico indexado está sendo composto.

Além das pesquisas em curso, uma série de outras investigações estão planejadas. A primeira delas é a condução de estudos experimentais dos problemas que foram objeto deste capítulo, o que permitiria ajudar a preencher mais uma lacuna de conhecimento identificada na seção 5.3. Mesmo com a base de dados dos ensaios conduzidos na PolyMTL, esses novos experimentos podem ser repetidos nas instalações disponíveis na EPUSP, em particular no canal de água recirculante do Núcleo de Dinâmica e Fluidos (NDF) (o que levaria a uma diminuição do parâmetro de massa $m^{*}$ ) ou mesmo no túnel de vento do IPT. Tais experimentos podem incluir outras geometrias para a seção transversal. Como metodologia a ser seguida para a condução de experimentos com vistas à supressão do galloping, fica a sugestão da condução de ensaios prévios com os corpos prismáticos fixos visando a obtenção experimental da curva $C_{y}(\alpha)$ visando alimentar o modelo numérico aqui desenvolvido.

Experimentos envolvendo a supressão passiva do fenômeno de VIV também são de grande importância, uma vez tais dados não são fartamente encontrados na literatura e proverão uma base de dados experimental para correlação com os resultados numéricos aqui apresentados. Tais experimentos podem ser conduzidos tanto no canal de água recirculante do NDF quanto no tanque de reboques do IPT. A diferença entre esses dois laboratórios reside tanto na dimensão do modelo a ser estudado, quanto no fato de que o canal de água recirculante permitir ensaios com a duração desejada.

Como sugestão de metodologia de ensaios de supressão passiva dos fenômenos de VIV-1gl e VIV-2gl, sugere-se manter um único valor do parâmetro de massa reduzida $m^{*}$, o que permitirá um estudo mais aprofundado da influência dos parâmetros que definem o NVA rotativo. Para a condição VIV-2gl, fica a sugestão do estudo da supressão passiva considerando diversas relações entre os valores de rigidez nas direções in-line e cross-wise. É importante ressaltar que a existência de uma rica base de dados experimentais no tema pode conferir ao grupo de pesquisa mais um reconhecimento da comunidade científica com relação à qualidade da pesquisa desenvolvida na EPUSP.

Além dos estudos experimentais relacionados à supressão passiva dos fenômenos 
de VIV e de galloping, estudos numéricos baseados em modelos numéricos de maior hierarquia (técnicas de DFC) são ferramentas interessantes à análise do problema, uma vez que eles permitem acessar parâmetros de difícil mensuração experimental. Por fim, estudos analíticos baseados em métodos de perturbação como aquele apresentado na seção 9.4 podem ser conduzidas sobre os modelos matemáticos que foram objeto de estudo deste capítulo. Cumpre ressaltar que os estudos experimentais de supressão passiva do fenômeno de VIV, com a posterior correlação com estudos numérico-analíticos fazem parte da pesquisa que será desenvolvida pelo aluno Giovanni Aiosa do Amaral em sua vindoura tese de doutorado. 


\section{Aproveitamento de energia a partir do fenômeno de VIV}

Embora existam uma série de estudos com foco na condição VIV-1gl, a revisão bibliográfica apresentada no capítulo 6 identificou que discussões com foco no aproveitamento de energia a partir do VIV-2gl não foram encontradas na literatura. De fato, a seção 6.2 aponta essa como uma das lacunas a serem preenchidas no tema. Além da lacuna de conhecimento identificada, o aproveitamento de energia a partir da condição VIV-2gl ${ }^{1}$ tende a ser mais vantajoso do que aquela relacionada à condição VIV-1gl, uma vez que a presença de oscilações na direção in-line amplifica a resposta estrutural na condição cross-wise.

Uma primeira verificação de que a condição VIV-2gl constitui um cenário mais favorável ao aproveitamento de energia via efeito piezoelétrico do que a condição VIV-1gl é o trabalho ${ }^{2}$ de Bunzel e Franzini (2017). Nesse último trabalho, os autores utilizaram o modelo fenomenológico de Srinil e Zanganeh (2012) para a condição VIV-2gl, além de considerar apenas um conjunto de parâmetros que definem o circuito piezoelétrico.

O foco deste capítulo é na condução de um estudo numérico mais aprofundado acerca do aproveitamento de energia via efeito piezoelétrico a partir do fenômeno de VIV em cilindros rígidos montados em base elástica com um ou dois graus de liberdade. É aqui demonstrado que a condição VIV-2gl é, de fato, um cenário mais favorável ao aproveitamento de energia do que a condição VIV-1gl. Também são mostrados estudos de sensibilidade da resposta do sistema sólido-fluido-elétrico com relação à variação dos parâmetros que definem os circuitos de coleta de energia.

Este capítulo apresenta os resultados do artigo Franzini e Bunzel (2018), publicado no Journal of Fluids and Structures, e está estruturado da seguinte forma. A seção 11.1 apresenta a obtenção dos modelos matemáticos, enquanto que a seção 11.2 traz as metodologias empregadas para a realização das simulações numéricas e para a análise de resultados que, por sua vez, são discutidos na seção 11.3. As considerações finais e propostas de continuidade da pesquisa no tema são tecidas na seção 11.4.

1 O leitor pode retornar à subseção 4.1 .3 para uma revisão bibliográfica acerca da condição VIV-2gl. Nessa subseção, o leitor relembra que a presença de oscilações na direção in-line estão intimamente relacionadas com o parâmetro de massa reduzida $m^{*}$.

2 O aluno Lucas de Oliveira Bunzel realizou sua iniciação científica por 18 meses e seu projeto de formatura por outros 18 meses sob orientação do autor deste texto. Tanto sua iniciação científica quanto seu projeto de formatura focaram no aproveitamento de energia a partir do fenômeno de VIV em cilindros rígidos montados em apoio elástico e utilizando wake-oscillators na modelagem do carregamento. 


\subsection{Modelagem matemática}

A Figura 157 traz representações esquemáticas dos modelos físicos que são objeto de estudo deste capítulo. A Figura 157(a) mostra um cilindro rígido, de massa $M$, diâmetro $D$ e comprimento $L$, montado em um apoio elástico unidirecional de rigidez linear $k_{y}$, constante de amortecimento $c_{y}$. Esse apoio elástico está associado a um circuito piezoelétrico de capacitância $C_{P, y}$, resistência elétrica $R_{y}$ e termo de acoplamento eletromecânico $\theta_{y}$.

Já a Figura 157(b) apresenta um cilindro rígido análogo àquele já definido nesta seção e montado em um apoio elástico com liberdade de oscilação simultânea nas direções cross-wise e in-line. Para a direção cross-wise, o apoio elástico e o circuito piezoelétrico têm as mesmas definições apresentadas na Figura 157(a). Por sua vez, a vinculação na in-line é caracterizada por sua rigidez $k_{x}$ e constante de amortecimento $c_{x}$. Ainda para essa última direção, o circuito de coleta de energia tem capacitância $C_{P, x}$, resistência $R_{x} \mathrm{e}$ termo de acoplamento eletromecânico $\theta_{x}$. Para as duas condições, VIV-1gl e VIV-2gl, o cilindro está imerso em um fluido de massa específica $\rho$ e sujeito a uma correnteza uniforme e invariante no tempo dada por $U_{\infty}$.

Figura 157 - Representações esquemáticas.
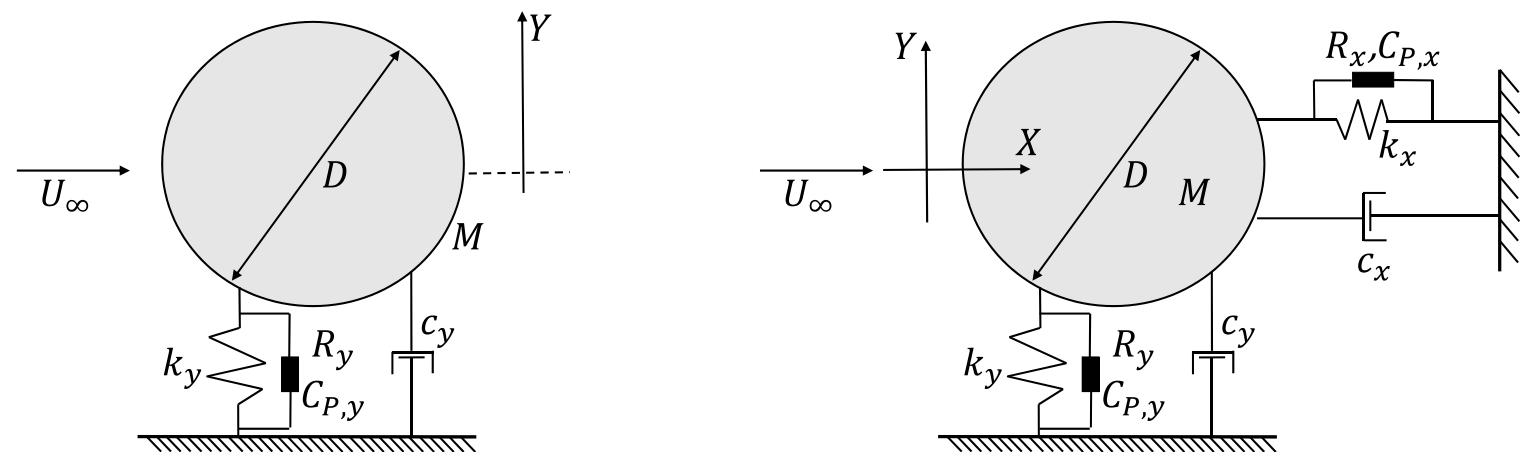

(a) Condição VIV-1gl. Apoio elástico com um (b) Condição VIV-2gl. Cada apoio elástico está circuito de coleta de energia. associado a um circuito de coleta de energia.

Fonte: Extraída de Franzini e Bunzel (2018).

Em Franzini e Bunzel (2018), as equações de movimento do sistema sólido-fluidoelétrico são apresentadas diretamente, sendo que tanto a equação que rege a dinâmica do circuito piezoelétrico quanto o seu acoplamento com a equação descritiva do movimento do cilindro são adotadas segundo Mehmood et al. (2013). No âmbito do presente texto e de maneira complementar aos trabalhos de Mehmood et al. (2013) e Franzini e Bunzel (2018), os modelos matemáticos são deduzidos com base no princípio de Hamilton estendido e com consideração do efeito piezoelétrico.

Conforme Erturk e Inman (2011), as equações de Euler-Lagrange para um sistema 
sólido-fluido-elétrico são dadas por:

$$
\frac{d}{d t}\left(\frac{\partial T}{\partial \dot{q}_{k}}\right)-\frac{\partial T}{\partial q_{k}}+\frac{\partial U}{\partial q_{k}}-\frac{\partial W_{i e}}{\partial q_{k}}=Q_{k}
$$

onde $T$ é a energia cinética, $U$ a energia potencial mecânica, $W_{i e}$ a energia elétrica interna e $Q_{k}$ é a força generalizada não conservativa associada à coordenada generalizada $q_{k}$.

Como o apoio elástico é dotado do efeito piezoelétrico, a equação constitutiva linear que resulta na força não depende apenas do deslocamento, mas também de alguma grandeza elétrica. Aqui, adapta-se a equação constitutiva ${ }^{3}$ apresentada em Lossouarn, Deü e Aucejo (2015) para uma mola rotacional piezoelétrica. No presente trabalho, a carga elétrica no elemento piezoelétrico associado à direção cross-wise ${ }^{4} \tilde{q}_{y}$ e a força elástica exercida pelo apoio sobre o cilindro $F_{\text {elast }, y}$ são dadas por:

$$
\begin{aligned}
& F_{\text {elast }, y}=k_{y} Y-\theta_{y} V_{y} \\
& \tilde{q}_{y}=\theta_{y} Y+C_{P, y} V_{y}
\end{aligned}
$$

sendo $V_{y}$ a tensão elétrica obtida no circuito piezoelétrico associado à direção cross-wise.

Em um primeiro momento desta seção, o foco é na obtenção do modelo matemático descritivo do problema representado na Figura 157(a). Nesse problema, duas coordenadas generalizadas $^{5}$ são o deslocamento do cilindro $Y$ e a tensão elétrica no circuito de coleta de energia $V_{y}$, de sorte que as Equações 11.4, 11.5, 11.6, 11.7 e 11.8 são verdadeiras.

$$
\begin{aligned}
& T=\frac{1}{2} M\left(\frac{d Y}{d t}\right)^{2} \\
& U=\frac{1}{2} F_{e l, y} Y=\frac{1}{2}\left(k_{y} Y^{2}-\theta_{y} V_{y} Y\right) \\
& W_{i e}=\frac{1}{2} \tilde{q}_{y} V_{y}=\frac{1}{2}\left(\theta_{y} V_{y} Y+C_{P, y} V_{y}^{2}\right) \\
& Q_{Y}=-m_{a}^{p o t} \frac{d^{2} Y}{d t^{2}}+\frac{1}{2} \rho U_{\infty}^{2} D L C_{y, v}-c_{y} \frac{d Y}{d t} \\
& Q_{V_{y}}=Q_{y}
\end{aligned}
$$

sendo $Q_{y}$ a carga elétrica no resistor $R_{y}$. Realizando as derivadas necessárias à Equação de Euler-Lagrange, as equações de movimento obtidas são:

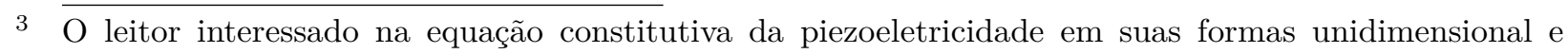
tridimensional deve consultar o livro de Erturk e Inman (2011).

4 A mesma forma de equação constitutiva é adotada para a direção in-line, bastando trocar o índice $y$ por $x$ e o deslocamento $Y$.

5 Como o leitor vê ainda nesta seção, a consideração do wake-oscillator acrescenta uma nova coordenada generalizada ao modelo matemático. 


$$
\begin{aligned}
& \left(M+m_{f}\right) \frac{d^{2} Y}{d t^{2}}+c_{y} \frac{d Y}{d t}+k_{y} Y-\theta_{y} V_{y}=\frac{1}{2} \rho U_{\infty}^{2} D L C_{y, v} \\
& -\theta_{y} Y-C_{P, y} V=Q_{y}
\end{aligned}
$$

O modelo matemático referente ao sistema sólido-fluido-elétrico representativo da coleta de energia a partir do fenômeno VIV-1gl via efeito piezoelétrico é concluído lembrando que o coeficiente de força $C_{y, v}$ é calculado por meio do modelo fenomenológico de Ogink e Metrikine (2010), o que confere um grau de liberdade adicional ao sistema. Além dessa consideração, a Equação 11.10 é derivada com relação ao tempo. Conduzindo esses procedimentos e lembrando que $V_{y}=R_{y} \frac{d Q_{y}}{d t}$, o seguinte modelo matemático dimensional é obtido:

$$
\begin{aligned}
& \left(M+m_{a}^{p o t}\right) \frac{d^{2} Y}{d t^{2}}+c_{y} \frac{d Y}{d t}+k_{y} Y-\theta_{y} V_{y}=\frac{1}{2} \rho U_{\infty}^{2} D L C_{y, v} \\
& \frac{d^{2} q_{y}}{d t^{2}}+\epsilon_{y} \omega_{f}\left(q_{y}^{2}-1\right) \frac{d q_{y}}{d t}+\omega_{f}^{2} q_{y}=\frac{A_{y}}{D} \frac{d^{2} Y}{d t^{2}} \\
& C_{P, y} \frac{d V_{y}}{d t}+\frac{V_{y}}{R_{y}}+\theta_{y} \frac{d Y}{d t}=0
\end{aligned}
$$

Assim como nos capítulo anteriores e tendo em vista a maior generalidade das análises, os modelos matemáticos referentes à dinâmica do sistema sólido-fluido-elétrico são escritos em suas versões adimensionais. Para tanto, considere as seguintes grandezas :

$$
\begin{aligned}
& \zeta_{y}=\frac{c_{y}}{2\left(M+m_{a}^{p o t}\right) \omega_{n, y}}, U_{r}=\frac{U_{\infty}}{f_{n, y} D}, S t=\frac{\omega_{f} D}{2 \pi U_{\infty}}, \quad y=\frac{Y}{D}, \quad \tau=\omega_{n, y} t, \quad v_{y}=\frac{V_{y}}{V_{0}} \\
& m^{*}=\frac{M}{m_{d}}, \quad C_{a}^{p o t}=\frac{m_{a}^{p o t}}{m_{d}}, \quad \sigma_{2, y}=\frac{1}{C_{P, y} R_{y} \omega_{n, y}}, \quad \sigma_{1, y}=\frac{\theta_{y}^{2}}{C_{P, y}\left(M+m_{a}^{p o t}\right) \omega_{n, y}^{2}}
\end{aligned}
$$

onde $\omega_{n, y}=\sqrt{\frac{k_{y}}{M+m_{a}^{p o t}}}$ é a frequência natural na direção cross-wise, $V_{0}=\frac{\left(M+m_{a}^{\text {pot }}\right) \omega_{n, y}^{2} D}{\theta_{y}}$ é uma tensão elétrica de referência e $m_{d}=\rho \pi D^{2} L / 4$ é a massa de fluido deslocada pelo cilindro. Definindo ( ) como a derivada com relação ao tempo adimensional $\tau$ e levando a Equação 11.14 nas Equações 11.11, 11.12 e 11.13, as Equações 11.15, 11.16 e 11.17 são obtidas e representam a dinâmica do sistema sólido-fluido-elétrico em sua forma adimensional.

$$
\begin{aligned}
& \ddot{y}+2 \zeta_{y} \dot{y}+y-v_{y}=\frac{1}{2 \pi^{3}} \frac{U_{r}^{2}}{\left(m^{*}+C_{a}^{p o t}\right)} C_{y, v} \\
& \ddot{q}_{y}+\epsilon_{y} S t U_{r}\left(q_{y}^{2}-1\right) \dot{q}_{y}+\left(S t U_{r}\right)^{2} q_{y}=A_{y} \ddot{y} \\
& \dot{v}_{y}+\sigma_{2, y} v_{y}+\sigma_{1, y} \dot{y}=0
\end{aligned}
$$


No modelo de Ogink e Metrikine $(2010)^{6}$, o coeficiente de força hidrodinâmica na direção cross-wise e que está associado ao fenômeno de VIV, $C_{y, v}$, vale:

$$
C_{y, v}=\left(\frac{U}{U_{\infty}}\right)^{2}\left(C_{L, v} \cos \beta+C_{D, v} \sin \beta\right)=\left(C_{L, v}-\frac{C_{D, v} 2 \pi \dot{y}}{U_{r}}\right) \sqrt{1+\left(\frac{2 \pi \dot{y}}{U_{r}}\right)^{2}}
$$

sendo $C_{L, v}$ e $C_{D, v}$ os coeficientes de sustentação e de arrasto observados no problema do escoamento ao redor de um cilindro fixo. O coeficiente $C_{L, v}$ pode ser escrito como função da variável representativa da $q_{y}$ por meio da Equação 11.19.

$$
C_{L, v}=\frac{q_{y}}{\hat{q}_{y}} \hat{C}_{L}^{0}
$$

onde $\hat{C}_{L}^{0}$ é a amplitude da força de sustentação observada no escoamento ao redor de um cilindro fixo. Levando as Equações 11.18 e 11.19 na Equação 11.15, o modelo matemático descritivo da coleta de energia por meio do circuito piezoelétrico representado na Figura 157(a) é dado pelas Equações 11.20, 11.21 e 11.22.

$$
\begin{aligned}
& \ddot{y}+2 \zeta_{y} \dot{y}+y-v_{y}=\frac{1}{2 \pi^{3}} \frac{U_{r}^{2}}{\left(m^{*}+C_{a}^{p o t}\right)}\left[\left(\frac{q_{y}}{\hat{q}_{y}} \hat{C}_{L}^{0}-\frac{C_{D, v} 2 \pi \dot{y}}{U_{r}}\right) \sqrt{1+\left(\frac{2 \pi \dot{y}}{U_{r}}\right)^{2}}\right] \\
& \ddot{q}_{y}+\epsilon_{y} S t U_{r}\left(q_{y}^{2}-1\right) \dot{q}_{y}+\left(S t U_{r}\right)^{2} q_{y}=A_{y} \ddot{y} \\
& \dot{v}_{y}+\sigma_{2, y} v_{y}+\sigma_{1, y} \dot{y}=0
\end{aligned}
$$

A potência elétrica obtida no circuito de coleta de energia $\left(P_{e l, y}\right)$ é dada, em sua forma dimensional, pela Equação 11.23. Esta potência elétrica será adimensionalizada pelo fluxo de densidade de energia cinética ao longo da área frontal do cilindro, como na Equação 11.24.

$$
\begin{aligned}
& P_{e l, y}=\frac{V_{y}^{2}}{R_{y}} \\
& \eta_{e l, y}=\frac{P_{e l, y}}{1 / 2 \rho U_{\infty}^{3} D L}=\frac{4 \pi^{4}}{U_{r}^{3}} \frac{\sigma_{2, y}}{\sigma_{1, y}}\left(m^{*}+C_{a}^{p o t}\right)
\end{aligned}
$$

O leitor nota que o termo $\eta_{e l, y}$ pode ser interpretado como uma medida de eficiência da coleta de energia, sendo proposto de forma análoga àquela apresentada em Grouthier et al. (2014) para adimensionalizar a potência dissipada no amortecedor de um apoio que recebe um cilindro sujeito ao fenômeno de VIV. Neste capítulo, apenas as principais passagens são reapresentadas com vistas à sua compreensão e concisão. 
Uma vez obtido o modelo matemático representativo do problema esquematizado na Figura 157(a), o foco passa a ser na obtenção das equações de movimento do sistema sólidofluido-elétrico quando o cilindro é montado em arranjo elástico com dois graus de liberdade, sendo que ambas as molas piezoelétricas estão associadas a circuitos elétricos independentes. Nessa configuração, além das coordenadas generalizadas referentes existentes para o problema já estudado na presente seção, o deslocamento do cilindro na direção in-line, a tensão elétrica obtida no circuito piezoelétrico associado a essa direção e a carga elétrica no correspondente resistor devem ser consideradas. Os termos necessários para uso da Equação 11.1 são:

$$
\begin{aligned}
& T=\frac{1}{2} M\left[\left(\frac{d X}{d t}\right)^{2}+\left(\frac{d Y}{d t}\right)^{2}\right] \\
& U=\frac{1}{2} F_{e l, y} Y+\frac{1}{2} F_{e l, x} X=\frac{1}{2}\left(k_{y} Y^{2}-\theta_{y} V_{y} Y\right)+\frac{1}{2}\left(k_{x} X^{2}-\theta_{x} V_{x} X\right) \\
& W_{i e}=\frac{1}{2} q_{y} V_{y}+\frac{1}{2} q_{x} V_{x}=\frac{1}{2}\left(\theta_{y} V_{y} Y+C_{P, y} V_{y}^{2}\right)+\frac{1}{2}\left(\theta_{x} V_{x} X+C_{P, x} V_{x}^{2}\right) \\
& Q_{Y}=-m_{a}^{p o t} \frac{d^{2} Y}{d t^{2}}+\frac{1}{2} \rho U_{\infty}^{2} D L C_{y, v}-c_{y} \frac{d Y}{d t} \\
& Q_{X}=-m_{a}^{p o t} \frac{d^{2} X}{d t^{2}}+\frac{1}{2} \rho U_{\infty}^{2} D L C_{x, v}-c_{y} \frac{d X}{d t} \\
& Q_{V_{y}}=Q_{y} \\
& Q_{V_{x}}=Q_{x}
\end{aligned}
$$

Em particular, a Equação 11.26 indica que as oscilações do cilindro são pequenas, de sorte que as forças elásticas sejam lineares e desacopladas entre si. Levando as Equações 11.25, 11.26, 11.27, 11.28, 11.29, 11.30 e 11.31 na expressão do princípio de Hamilton estendido (Equação 11.1), as seguintes expressões são obtidas:

$$
\begin{aligned}
& \left(M+m_{a}^{p o t}\right) \frac{d^{2} Y}{d t^{2}}+c_{y} \frac{d Y}{d t}+k_{y} Y-\theta_{y} V_{y}=\frac{1}{2} \rho U_{\infty}^{2} D L C_{y, v} \\
& \left(M+m_{a}^{p o t}\right) \frac{d^{2} X}{d t^{2}}+c_{x} \frac{d X}{d t}+k_{x} X-\theta_{x} V_{x}=\frac{1}{2} \rho U_{\infty}^{2} D L C_{x, v} \\
& -C_{P, y} V_{y}-\theta_{y} Y=Q_{y} \\
& -C_{P, x} V_{x}-\theta_{y} Y=Q_{x}
\end{aligned}
$$

De maneira análoga àquela conduzida para a análise do aproveitamento de energia a partir da condição VIV-1gl, as Equações 11.34 e 11.35 são derivadas com relação ao tempo. Por sua vez, os coeficientes de força associados à emissão de vórtices são calculados com base no modelo já detalhado na subseção 8.2.2 deste texto. Incorporando essas considerações, o modelo matemático é apresentado em sua forma dimensional por meio das Equações 11.36, 11.37, 11.38, 11.39, 11.40 e 11.41. 


$$
\begin{aligned}
& \left(M+m_{a}^{p o t}\right) \frac{d^{2} Y}{d t^{2}}+c_{y} \frac{d Y}{d t}+k_{y} Y-\theta_{y} V_{y}=\frac{1}{2} \rho U_{\infty}^{2} D L C_{y, v} \\
& \frac{d^{2} q_{y}}{d t^{2}}+\epsilon_{y} \omega_{f}\left(q_{y}^{2}-1\right) \frac{d q_{y}}{d t}+\omega_{f}^{2} q_{y}=\frac{A_{y}}{D} \frac{d^{2} Y}{d t^{2}} \\
& \left(M+m_{a}^{p o t}\right) \frac{d^{2} X}{d t^{2}}+c_{x} \frac{d X}{d t}+k_{x} X-\theta_{x} V_{x}=\frac{1}{2} \rho U_{\infty}^{2} D L C_{x, v} \\
& \frac{d^{2} q_{x}}{d t^{2}}+\epsilon_{x} \omega_{f}\left(q_{x}^{2}-1\right) \frac{d q_{x}}{d t}+\left(2 \omega_{f}\right)^{2} q_{x}=\frac{A_{x}}{D} \frac{d^{2} X}{d t^{2}} \\
& C_{P, y} \frac{d V_{y}}{d t}+\frac{V_{y}}{R_{y}}+\theta_{y} \frac{d Y}{d t}=0 \\
& C_{P, x} \frac{d V_{x}}{d t}+\frac{V_{x}}{R_{x}}+\theta_{x} \frac{d X}{d t}=0
\end{aligned}
$$

Para a obtenção do modelo matemático em sua versão adimensional, considere as seguintes quantidades em adição aos parâmetros dados na Equação 11.14:

$$
\begin{aligned}
& \omega_{n, x}=\sqrt{\frac{k_{x}}{M+m_{a}^{p o t}}}, \zeta_{x}=\frac{c_{x}}{2\left(M+m_{a}^{p o t}\right) \omega_{n, x}}, x=\frac{X}{D}, \quad v_{x}=\frac{V_{x}}{V_{0}} \\
& \sigma_{2, x}=\frac{1}{C_{P, x} R_{x} \omega_{n, x}}, \quad \sigma_{1, x}=\frac{\theta_{x}^{2}}{C_{P, x}\left(M+m_{a}^{p o t}\right) \omega_{n, x}^{2}}, \quad f^{*}=\frac{\omega_{n, x}}{\omega_{n, y}}, \quad \theta^{*}=\frac{\theta_{x}}{\theta_{y}}
\end{aligned}
$$

Substituindo as quantidades definidas na Equação 11.43 nas Equações 11.36, 11.37, 11.38, 11.39, 11.40 e 11.41, a forma final e adimensional do modelo matemático para a coleta de energia a partir do fenômeno VIV-2gl e considerando o efeito piezoelétrico é:

$$
\begin{aligned}
& \ddot{y}+2 \zeta_{y} \dot{y}+y-v_{y}=\frac{1}{2 \pi^{3}} \frac{U_{r}^{2}}{\left(m^{*}+C_{a}^{p o t}\right)} C_{y, v} \\
& \ddot{q}_{y}+\epsilon_{y} S t U_{r}\left(q_{y}^{2}-1\right) \dot{q}_{y}+\left(S t U_{r}\right)^{2} q_{y}=A_{y} \ddot{y} \\
& \ddot{x}+2 \zeta_{x} f^{*} \dot{x}+\left(f^{*}\right)^{2} x-\theta^{*} v_{x}=\frac{1}{2 \pi^{3}} \frac{U_{r}^{2}}{\left(m^{*}+C_{a}^{p o t}\right)} C_{x, v} \\
& \ddot{q}_{x}+\epsilon_{x} S t U_{r}\left(q_{x}^{2}-1\right) \dot{q}_{x}+\left(2 S t U_{r}\right)^{2} q_{x}=A_{x} \ddot{x} \\
& \dot{v}_{y}+\sigma_{2, y} v_{y}+\sigma_{1, y} \dot{y}=0 \\
& \dot{v}_{x}+f^{*} \sigma_{2, x} v_{x}+\frac{\sigma_{1, x}}{\theta^{*}}\left(f^{*}\right)^{2} \dot{x}=0
\end{aligned}
$$

onde os coeficientes $C_{y, v}$ e $C_{x, v}$ já foram obtidos na subseção 8.2.2 e são aqui reapresentados nas Equações 11.50 - 11.56 apenas visando o melhor entendimento do presente capítulo. 


$$
\begin{aligned}
& C_{x, v}=\left(\frac{U}{U_{\infty}}\right)^{2}\left(C_{D, v} \cos \beta-C_{L, v} \sin \beta\right) \\
& C_{y, v}=\left(\frac{U}{U_{\infty}}\right)^{2}\left(C_{D, v} \sin \beta+C_{L, v} \cos \beta\right) \\
& C_{D, v}=\bar{C}_{D}^{0}+C_{D}^{o s c}=\bar{C}_{D}^{0}+\frac{q_{x}}{\hat{q}_{x}} \hat{C}_{D}^{0} \\
& C_{L, v}=\frac{q_{y}}{\hat{q}_{y}} \hat{C}_{L}^{0} \\
& U=\sqrt{\left(U_{\infty}-\frac{d X}{d t}\right)^{2}+\left(\frac{d Y}{d t}\right)^{2}}=U_{\infty} \sqrt{1-\frac{4 \pi}{U_{r}} \dot{x}}+\left(\frac{2 \pi}{U_{r}}\right)^{2}\left(\dot{x}^{2}+\dot{y}^{2}\right) \\
& \sin \beta=\frac{-\frac{d Y}{d t}}{U}=-\frac{2 \pi \dot{y}}{U_{r} \sqrt{1-\frac{4 \pi}{U_{r}} \dot{x}+\left(\frac{2 \pi}{U_{r}}\right)^{2}\left(\dot{x}^{2}+\dot{y}^{2}\right)}} \\
& \cos \beta=\frac{1-\frac{2 \pi}{U_{r}} \dot{x}}{U}=\frac{U_{\infty}-\frac{d X}{d t}}{\sqrt{1-\frac{4 \pi}{U_{r}} \dot{x}+\left(\frac{2 \pi}{U_{r}}\right)^{2}\left(\dot{x}^{2}+\dot{y}^{2}\right)}}
\end{aligned}
$$

A potência elétrica extraída no circuito associado à mola na direção in-line $P_{e l, x} \mathrm{e}$ a eficiência associada são dadas, respectivamente, pela Equações 11.57 e 11.58.

$$
\begin{aligned}
& P_{e l, x}=\frac{V_{x}^{2}}{R_{x}} \\
& \eta_{e l, x}=\frac{4 \pi^{4}}{U_{r}^{3}} \frac{\left(\theta^{*}\right)^{2}}{f^{*}} \frac{\sigma_{2, x}}{\sigma_{1, x}}\left(m^{*}+C_{a}\right) v_{x}^{2}
\end{aligned}
$$

\subsection{Metodologias de simulação numérica e de análise}

Os modelos matemáticos adimensionais para os problemas de aproveitamento de energia a partir do VIV e por meio do efeito piezoelétrico (Equações 11.20, 11.21 e 11.22 para a condição VIV-1gl e 11.44, 11.45, 11.46, 11.47, 11.48 e 11.49 para VIV-2gl) foram numericamente integrados utilizando o método de Runge-Kutta implementado na função ode45 do MATLAB ${ }^{\circledR}$. O passo de tempo adotado na integração numérica foi $\Delta \tau=0,01 \mathrm{e}$ somente uma condição inicial foi assumida como não trivial, a saber $q_{y}(0)=0,10$. Todas as simulações tiveram duração $\tau_{\max }=800$.

Visando desconsiderar o efeito decorrente de um regime transitório inicial, respostas em regime permanente são aqui consideradas como aquelas associadas a valores de tempo adimensional tais que $\tau>\tau_{\max } / 2$. Como em Franzini et al. (2009) e Franzini et al. (2013), os valores característico de oscilação nas direções cross-wise e in-line $\left(\hat{A}_{y}\right.$ e $\hat{A}_{x}$, respectivamente) foram calculados considerando a média dos $10 \%$ dos maiores extremos. Cumpre ressaltar que essa estatística referente à direção in-line foi calculada removendo, a priori, o valor médio da resposta $x(\tau)$. 
O objetivo das simulações aqui apresentadas é avaliar a potência elétrica que poderia ser obtida via efeito piezoelétrico considerando o arranjo experimental apresentado em Franzini et al. (2012a) e cujos parâmetros de maior interesse estão apresentados na Tabela 16. Nesse último trabalho, não houve qualquer consideração do efeito piezoelétrico.

Tabela 16 - Propriedades do arranjo experimental descrito em Franzini et al. (2012a).

\begin{tabular}{c|c}
\hline \hline Parâmetro & Valor \\
\hline \hline$m^{*}$ & 2,6 \\
$L / D$ & 15 \\
$\zeta_{y}=\zeta_{x}$ & $7 \times 10^{-4}$ \\
$D$ & $44,45 \mathrm{~mm}$ \\
$f_{n, y}=f_{n, x}$ & $0,62 \mathrm{~Hz}$ \\
\hline \hline
\end{tabular}

Fonte: Adaptada de Franzini e Bunzel (2018).

Embora o modelo matemático permita, as análises aqui conduzidas focam nos casos onde as características das molas piezoelétricas independem da direção, de sorte que $f^{*}=1=\theta^{*}, \sigma_{1, x}=\sigma_{1, y}=\sigma_{1}$ e $\sigma_{2, x}=\sigma_{2, y}=\sigma_{2}$. Em um primeiro conjunto de simulações, as propriedades do circuito elétrico foram as mesmas adotadas em Mehmood et al. (2013), a saber $C_{P, x}=C_{P, y}=C_{P}=120 \mathrm{nF}, R_{x}=R_{y}=100 \mathrm{k} \Omega$ e $\theta_{x}=\theta_{y}=1,55 \times 10^{-3} \mathrm{~N} / \mathrm{V}$. Esses parâmetros, combinados com os dados da Tabela 16 levam a $\sigma_{1}=0,34$ e $\sigma_{2}=21,4$.

Para cada direção (in-line ou cross-wise), A coleta de energia é aqui avaliada por meio de dois parâmetros. O primeiro é o valor médio da eficiência da coleta de energia considerando apenas o regime permanente $\left(\bar{\eta}_{e l, x}\right.$ ou $\left.\bar{\eta}_{e l, x}\right)$. O segundo parâmetro corresponde ao root-mean square, também considerando apenas o regime permanente, da tensão elétrica adimensional $\left(v_{x, r m s}\right.$ ou $\left.v_{x, r m s}\right)$. Essas grandezas são avaliadas como funções da velocidade reduzida para todo o intervalo de lock-in, resultado pouco apresentado na literatura.

Como já mencionado neste capítulo, os esforços hidrodinâmicos foram calculados segundo os modelos baseados em wake-oscillators de Ogink e Metrikine (2010) (condição VIV-1gl) e aquele descrito na subseção 8.2.2 para a condição VIV-2gl. Os parâmetros dos modelos de ordem reduzida são aqueles apresentados na Tabela 17.

\subsection{Resultados e discussões}

A Figura 158 mostra as amplitudes características de oscilação $\hat{A}_{y}$ como funções da velocidade reduzida para as condições VIV-1gl e VIV-2gl. Não surpreende o fato de que, embora pequeno, o aproveitamento de energia promova um decréscimo nas amplitudes de resposta do cilindro quando em comparação com o caso onde não há qualquer atuação do efeito piezoelétrico (condição "VIV puro"). Essa redução deve-se à conversão de parte da energia mecânica em energia elétrica. 
Tabela 17 - Parâmetros dos modelos de ordem reduzida.

\begin{tabular}{|c|c|c|c|c|c|}
\hline \multicolumn{3}{|c|}{$\overline{\text { VIV-1gl }}$} & \multicolumn{3}{|c|}{ VIV-2gl } \\
\hline$A_{y}$ & $\begin{array}{c}0,05 \\
4\end{array}$ & $U_{r}<6,5$ & $\begin{array}{l}\epsilon_{y} \\
\epsilon_{x} \\
A_{y} \\
A_{x}\end{array}$ & $\begin{array}{c}045 e^{0,228 m^{*}} \\
0,6 \\
2 \\
12\end{array}$ & $U_{r}<8$ \\
\hline$A_{y}$ & 0,7 & $U_{r} \geq 6,5$ & $\begin{array}{l}\epsilon_{y} \\
\epsilon_{x} \\
A_{y} \\
A_{x}\end{array}$ & $\begin{array}{l}0,7 \\
0,7 \\
12 \\
12\end{array}$ & $U_{r} \geq 8$ \\
\hline $\begin{array}{l}\hat{C}_{L}^{0} \\
\bar{C}_{D}^{0} \\
S t\end{array}$ & $\begin{array}{l}0,3842 \\
1,1856 \\
0,1932\end{array}$ & $0 \leq U_{r} \leq 15$ & $\begin{array}{l}\hat{C}_{I}^{0} \\
\bar{C}_{L}^{0} \\
\hat{C}_{L}^{0} \\
S t\end{array}$ & $\begin{array}{c}0,3842 \\
1,1856 \\
0,2 \\
0,17\end{array}$ & $0 \leq U_{r} \leq 15$ \\
\hline
\end{tabular}

Fonte: Adaptada de Franzini e Bunzel (2018).

A Figura 159 ilustra alguns exemplos de séries temporais de deslocamento, os correspondentes espectros de amplitude e trajetórias no plano horizontal para um particular valor de velocidade reduzida $U_{r}=6$. As Figuras 159(a), 159(b), 159 (c) e 159(d) corroboram o resultado apresentado na Figura 158 de que ocorre uma pequena redução de nas amplitudes de oscilação quando o efeito piezoelétrico é incorporado ao sistema. No entanto, é claramente exibido que, do ponto de vista qualitativo, não há mudanças apreciáveis no aspecto da resposta do cilindro, dada por oscilações com amplitude constante e com espectros de amplitude de banda estreita. Já as notáveis similaridades nas trajetórias no plano horizontal indicadas nas Figuras 159(e) e 159(f) revelam que a diferença de fase entre as séries temporais $x(\tau)$ e $y(\tau)$ é pouco afetada pelo presença do material piezoelétrico.

A variação do valor rms da tensão elétrica adimensional com a velocidade é mostrada na Figura 160. Considerando inicialmente a condição VIV-1gl, além da esperada similaridade de forma com a curva de amplitude de oscilação, o máximo valor obtido é $\max \left\{v_{y, r m s}\right\} \approx 0,01$ e ocorre na velocidade reduzida $U_{r}=5,5$. Já no intervalo $6,5<U_{r}<9$, obtém-se um valor próximo a $v_{y, r m s}=0,007$.

Como mencionado, a condição VIV-2gl permite que a coleta de energia seja realizada feita por meio dos circuitos elétricos associados às direções cross-wise e in-line. A análise da Figura 160 mostra que, quando a condição VIV-2gl é considerada, o valor rms da tensão elétrica obtido no circuito associado à direção cross-wise é praticamente o dobro daquele resultante da condição VIV-1gl. Outro aspecto importante é que, ao contrário do observado para a condição VIV1-gl, a presença de oscilações in-line mantém a tensão elétrica obtida no circuito associado à direção cross-wise em um valor aproximado de 0,01 para $8<U_{r}<12$. O leitor nota, neste ponto, uma dupla vantagem da condição VIV-2gl 
Figura 158 - Amplitudes características de oscilação. Condições "VIV puro" (marcadores vazios) e considerando o efeito piezoelétrico com $\sigma_{1}=0,34$ e $\sigma_{2}=21,4$ (marcadores preenchidos).

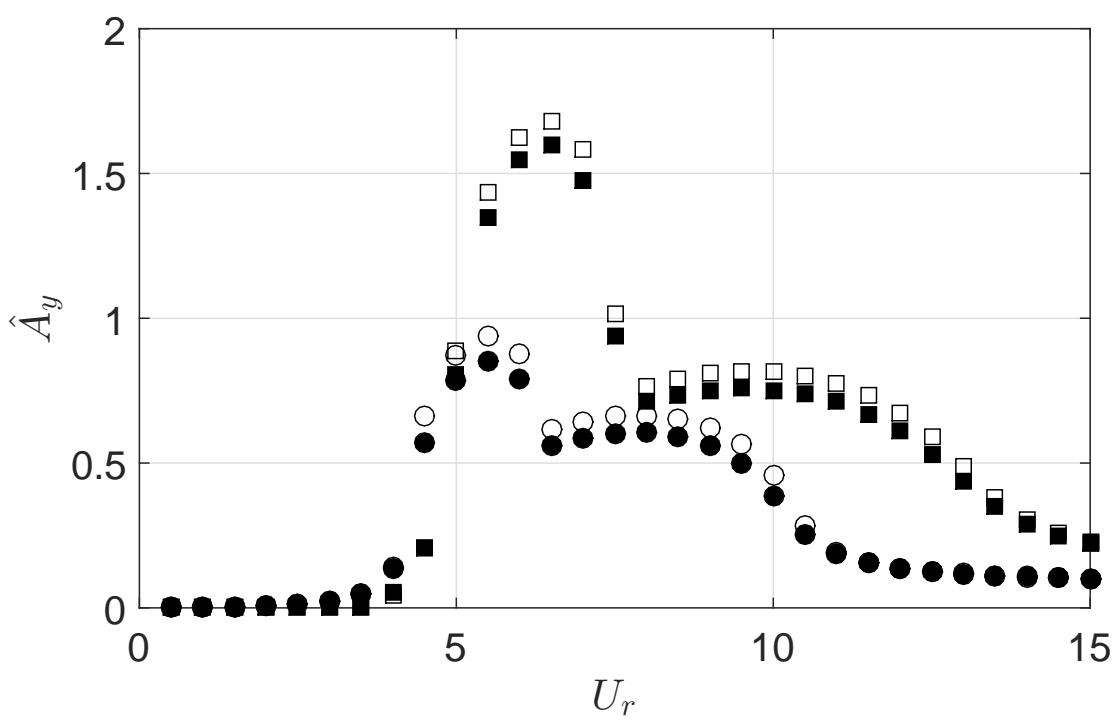

- Piezo - VIV-1gl; O VIV-1gl; ■ Piezo - VIV-2gl; $\square$ VIV=2gl

(a) Direção cross-wise.

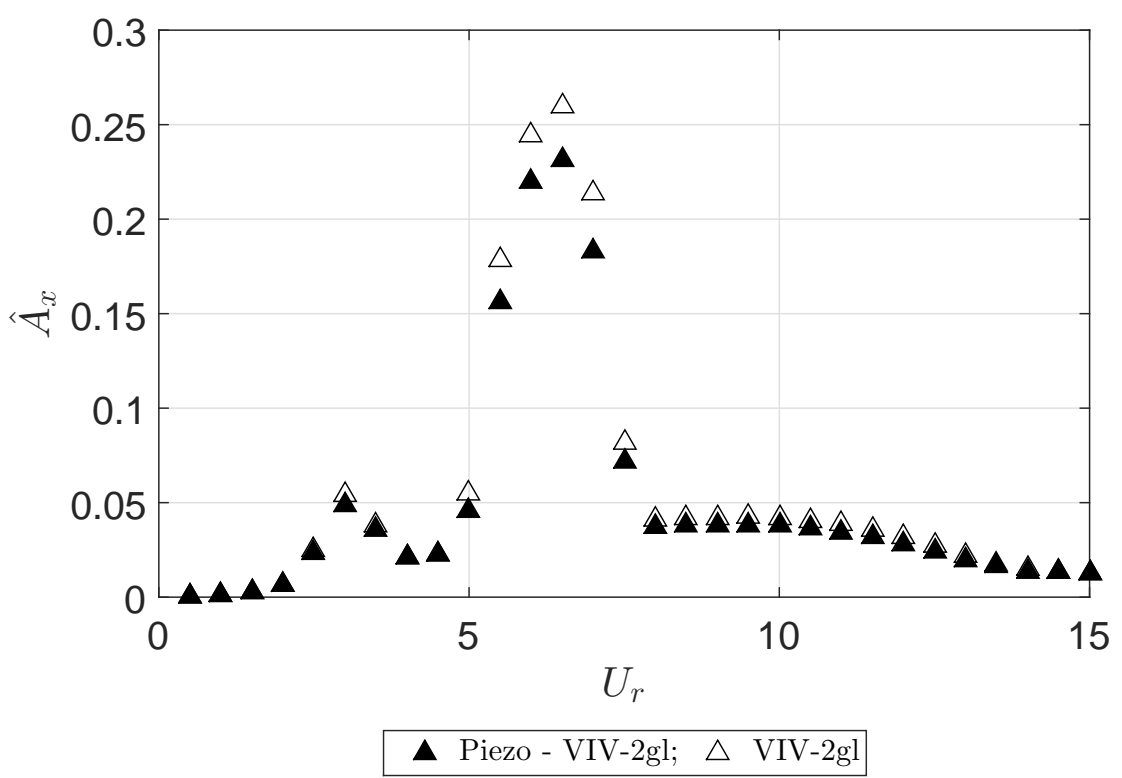

(b) Direção in-line.

Fonte: Adaptada de Franzini e Bunzel (2018).

sobre a VIV-1gl em termos de aproveitamento de energia, a saber, o aumento no máximo valor rms da tensão elétrica e a manutenção de valores não nulos para uma faixa maior de velocidades reduzidas.

A Figura 160 mostra, ainda, o valor rms da tensão elétrica obtida no circuito elétrico associado à direção in-line. Nota-se que seu valor máximo é ligeiramente superior a $v_{x, r m s}=$ 
Figura 159 - Séries temporais de deslocamento, espectros de amplitude e trajetórias no plano horizontal. $U_{r}=6$.
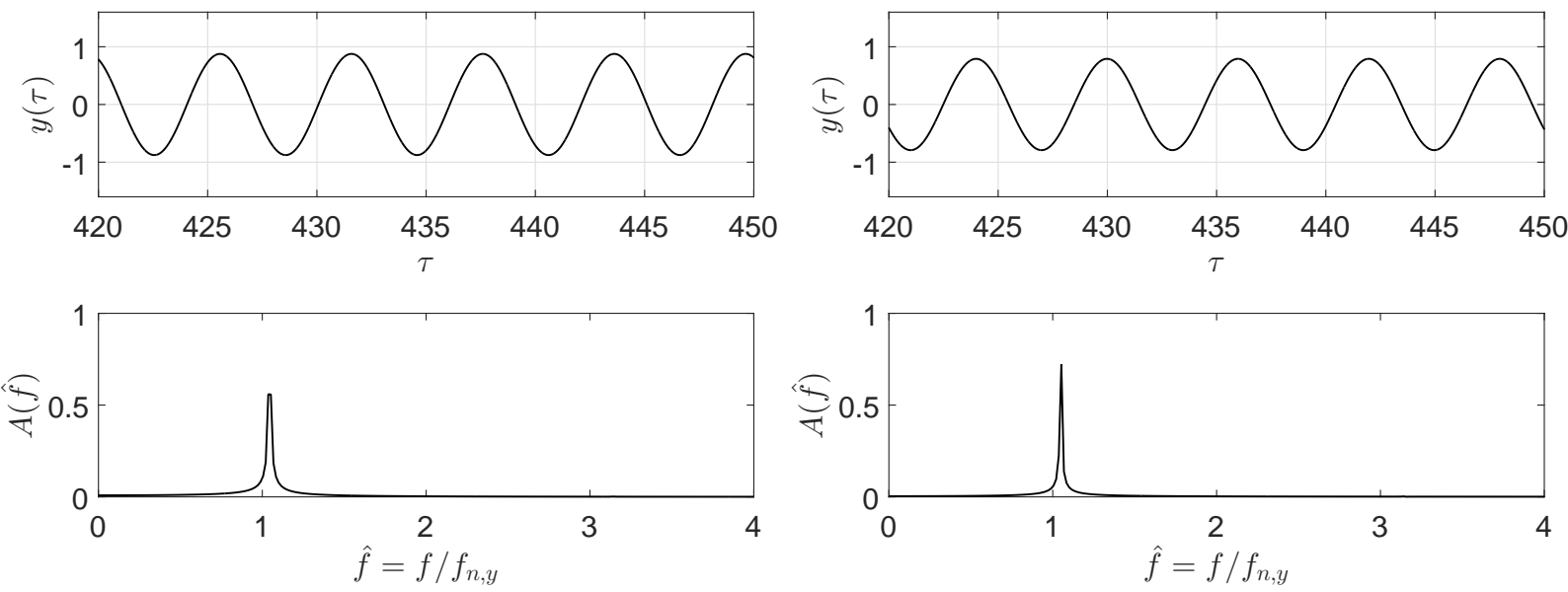

(a) VIV-1gl. Condição "VIV puro"

(b) VIV-1gl. $\sigma_{1}=0,34$ e $\sigma_{2}=21,4$.
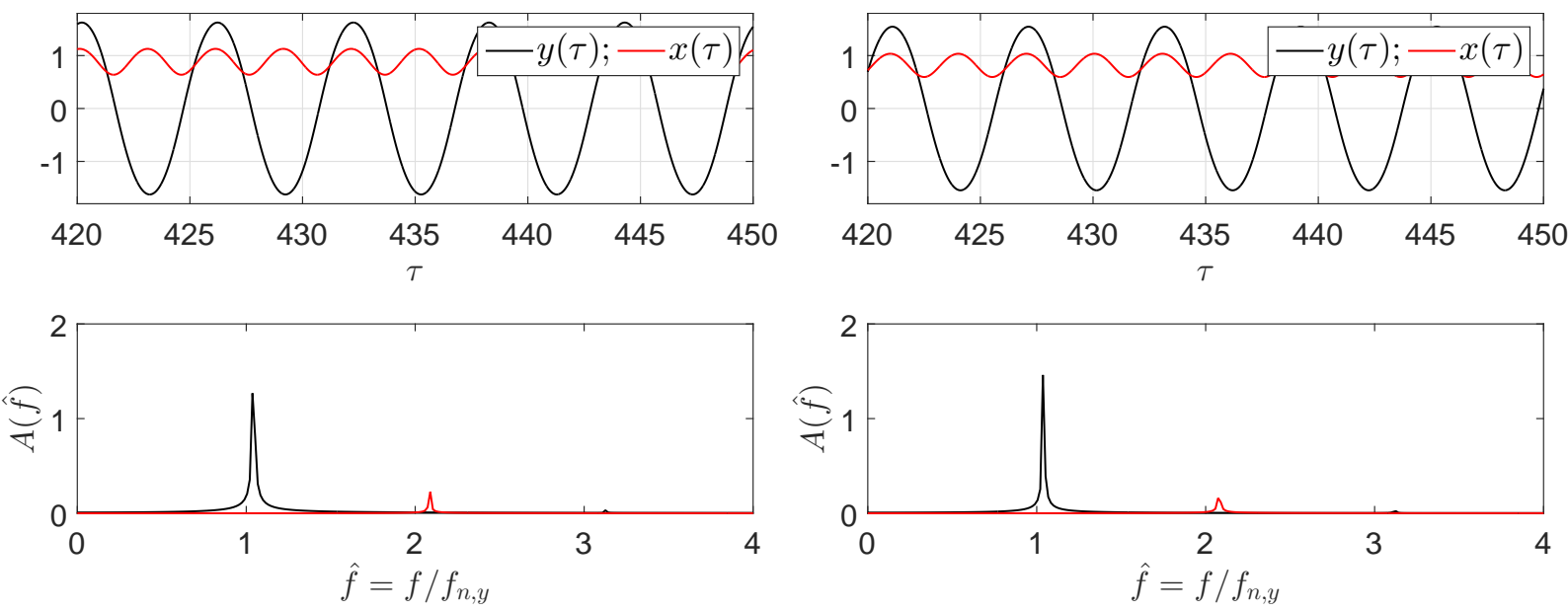

(c) VIV-2gl. Condição "VIV puro".

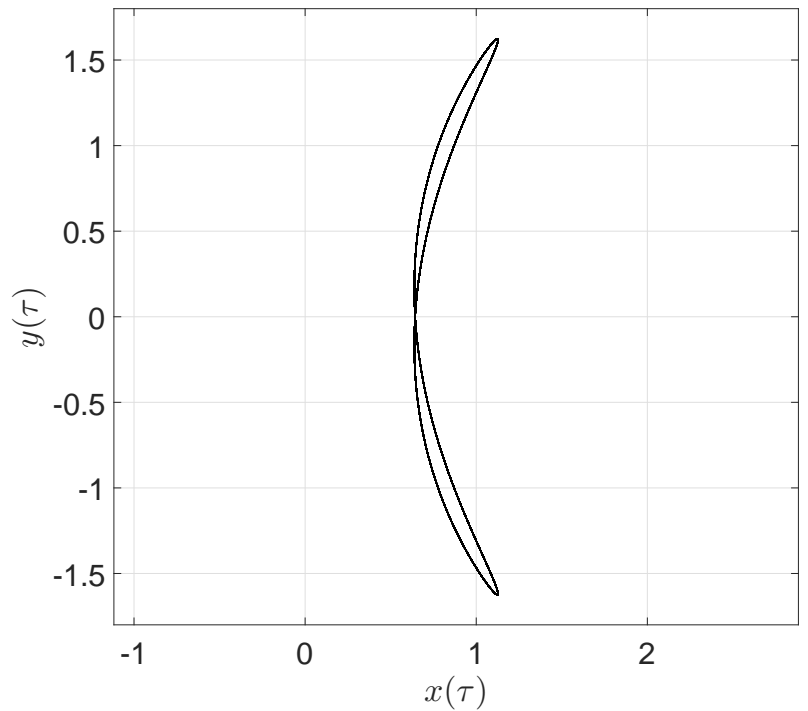

(d) VIV-2gl. $\sigma_{1}=0,34$ e $\sigma_{2}=21,4$.

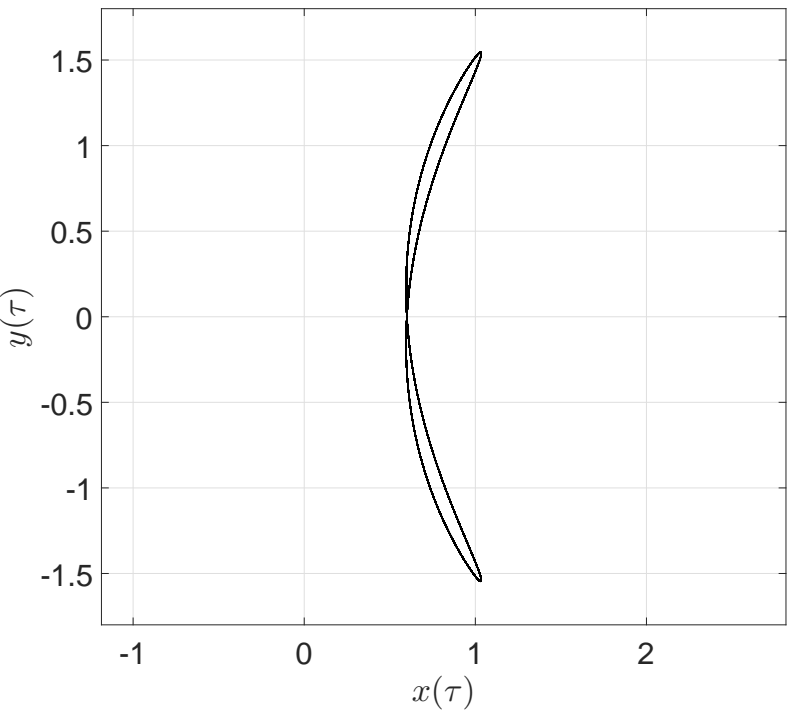

(e) Trajetórias no plano horizontal. Condição (f) Trajetórias no plano horizontal. $\sigma_{1}=0,34$ and "VIV puro". $\sigma_{2}=21,4$.

Fonte: Adaptada de Franzini e Bunzel (2018). 
0,005, sendo verificada em uma estreita faixa de velocidades reduzidas compreendida entre $U_{r}=5$ e $U_{r}=8$. Dessa forma, afirma-se que a maior vantagem do aproveitamento de energia via efeito piezoelétrico a partir do VIV reside no fato do incremento da tensão elétrica associada à direção cross-wise e não da possibilidade da coleta de energia a partir de dois circuitos independentes.

Figura 160 - Tensão elétrica adimensional (rms). $\sigma_{1}=0,34$ e $\sigma_{2}=21,4$.

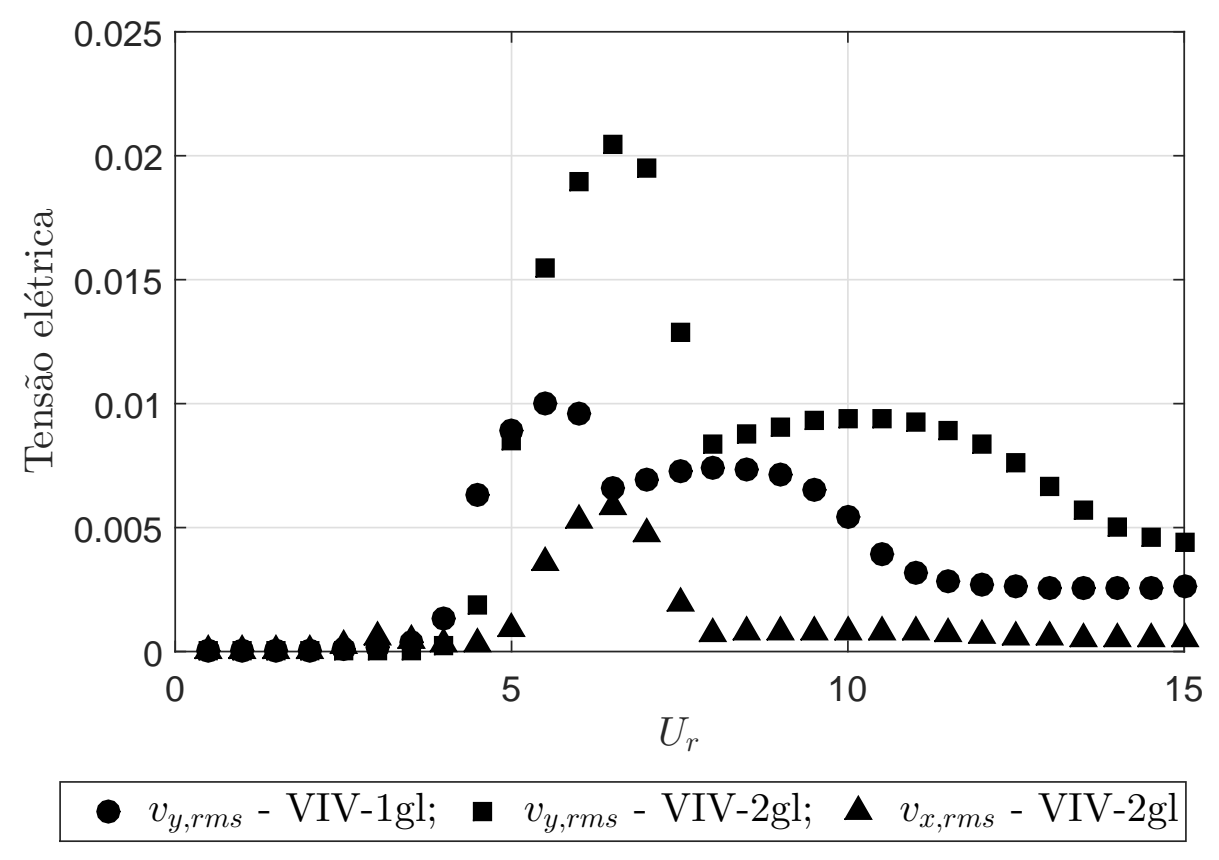

Fonte: Adaptada de Franzini e Bunzel (2018).

A exemplo do que foi feito para a resposta do cilindro, a Figura 161 ilustra as séries temporais de tensão elétrica adimensional para a condição de velocidade reduzida $U_{r}=6$. Tanto as séries $v_{x}(\tau)$ quanto $v_{y}(\tau)$ apresentam respostas praticamente livres de modulação em amplitude. A comparação entre as Figuras 161(a) e 161(b) reafirma a maior tensão elétrica obtida no circuito associado à direção cross-wise. Por sua vez, a tensão elétrica $v_{x}(\tau)$ pulsa com praticamente o dobro da frequência de oscilação de $v_{y}(\tau)$, constituindo um resultado análogo àquele observado para as séries temporais de deslocamento do cilindro.

No contexto de aproveitamento de energia, é interessante o cálculo de sua eficiência. Ao contrário de alguns trabalhos mencionados no capítulo 6 nos quais a eficiência considera apenas a energia dissipada no amortecedor, aqui essa grandeza é calculada com base em uma forma prontamente útil de energia, a saber, energia elétrica. A Figura 162 mostra a variação da eficiência da coleta de energia como função da velocidade reduzida.

Um primeiro resultado revelado pela Figura 162 é que o aproveitamento de energia a partir do VIV é eficiente apenas no intervalo de velocidades reduzidas próximo ao pico de resposta, embora a tensão elétrica seja obtida até $U_{r}=12$ quando da condição VIV-2gl. Essa baixa eficiência deve-se ao fato de que $\eta_{e l, y}$ é proporcional a $1 / U_{r}^{3}$ (ver Equação 
Figura 161 - Séries temporais de tensão elétrica adimensional. $\sigma_{1}=0,34, \sigma_{2}=21,4 \mathrm{e}$ $U_{r}=6$.

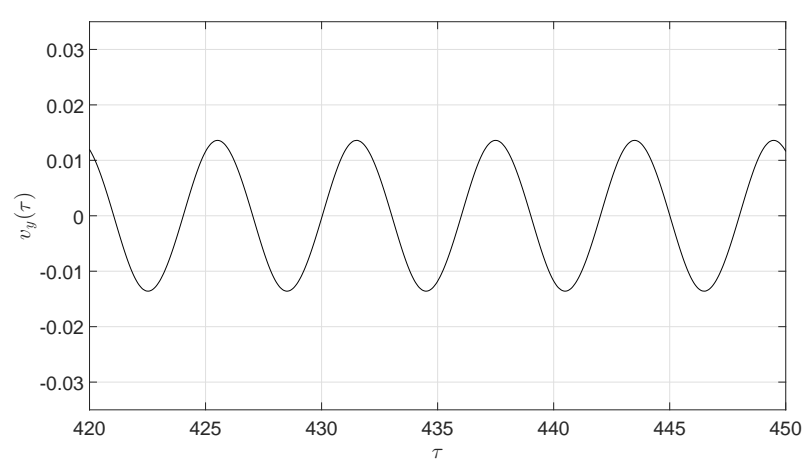

(a) VIV-1gl.

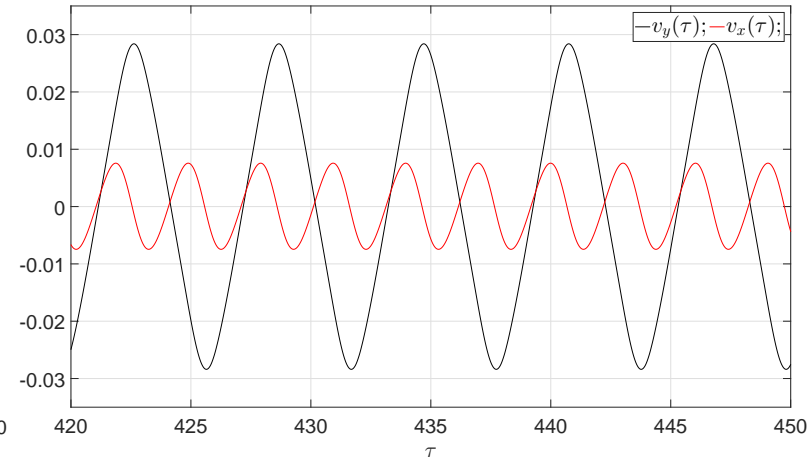

(b) VIV-2gl.

Fonte: Extraída de Franzini e Bunzel (2018).

11.24).

Note, ainda, que a máxima eficiência de coleta de energia a partir da condição VIV-1gl é $\max \left\{\bar{\eta}_{e l, y}\right\} \approx 5 \%$, ocorrendo em velocidade reduzida próxima a 5. Já quando a condição VIV-2gl é considerada, $\max \left\{\bar{\eta}_{e l, y}\right\} \approx 15 \%$ e ocorre em uma velocidade reduzida superior. Já a máxima eficiência de coleta de energia no circuito associado à direção in-line é próxima a $\max \left\{\bar{\eta}_{e l, x}\right\} \approx 1 \%$. Para efeitos de comparação, a eficiência da coleta de energia do dispositivo VIVACE é de $22 \%$, valor próximo àquele obtido por Grouthier et al. (2014) para a máxima eficiência considerando a potência dissipada no amortecedor.

Figura 162 - Eficiência do aproveitamento de energia. $\sigma_{1}=0,34, \sigma_{2}=21,4$.

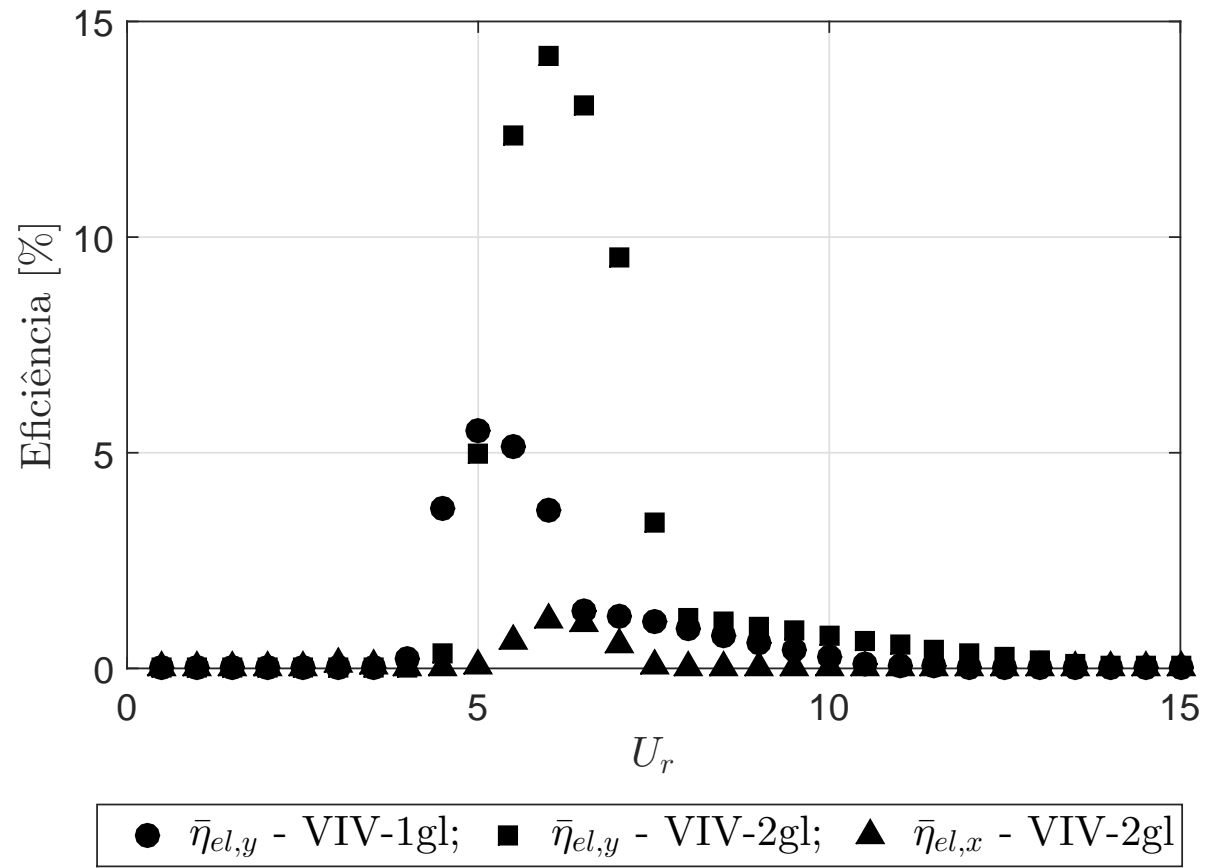

Fonte: Adaptada de Franzini e Bunzel (2018). 
Como mencionado, esta seção visa a investigação numérica acerca do aproveitamento de energia que seria possível caso o experimento descrito em Franzini et al. (2012a) fosse dotado de molas piezoelétricas. Dessa forma, é natural o interesse em saber qual a potência elétrica extraída como função da velocidade de escoamento incidente. Esse resultado é exibido na Figura 163, de onde é possível notar que a máxima potência elétrica média obtida é $\bar{P}_{e l, y}=11 \mathrm{~mW}$ e está associada à condição VIV-2gl, um valor cerca de quatro vezes superior àquele obtido quando o cilindro é restrito a oscilar apenas na direção cross-wise e cujo valor é $\bar{P}_{e l, y}=2,6 \mathrm{~mW}$.

Figura 163 - Média temporal da potência elétrica obtida no circuito associado à direção cross-wise.

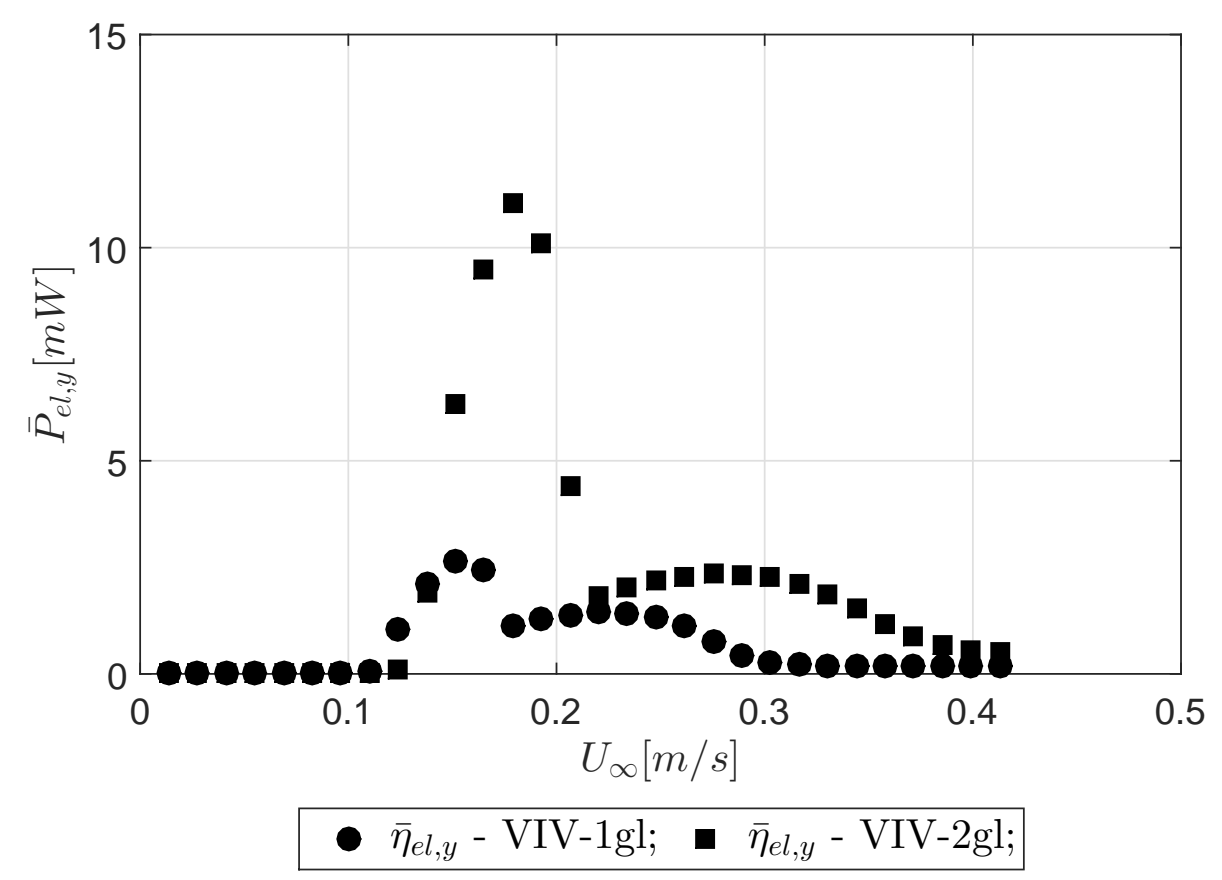

Fonte: Adaptada de Franzini e Bunzel (2018).

Até este ponto, a análise conduzida focou em um determinado par de parâmetros adimensionais $\sigma_{1}$ e $\sigma_{2}$. Agora, conduz-se um estudo numérico de sensibilidade da resposta do sistema sólido-fluido-elétrico com relação a essas quantidades adimensionais e para uma única velocidade reduzida, a saber $U_{r}=6$. O estudo de sensibilidade foi conduzido por meio de mapas de cores mostrando diversas grandezas como funções de $\sigma_{1}$ e $\sigma_{2}$, discretizados nos intervalos $0,07<\sigma_{1}<1,35$ and $4,28<\sigma_{2}<107$ utilizando uma malha de dimensão $20 \times 20$. A Figura 164 ilustra as variações de $\hat{A}_{y}, \bar{\eta}_{e l, y}$ e $\bar{P}_{e l, y}$ como funções de $\sigma_{1}$ e $\sigma_{2}$. Tendo em vista as diferenças observadas nos resultados obtidos a partir das condições VIV-1gl e VIV-2gl, as escalas não são mantidas as mesmas.

As Figuras 164(a) e 164(b) apresentam a variação da amplitude característica de oscilação na direção cross-wise. Essas figuras mostram que a grandeza $\hat{A}_{y}$ é alterada de maneira significativa nos intervalos $\sigma_{2}<20$ e $\sigma_{1}>0,4$. Como mostram as Figuras 
Figura 164 - Estudo de sensibilidade e curvas de nível. $U_{r}=6$.

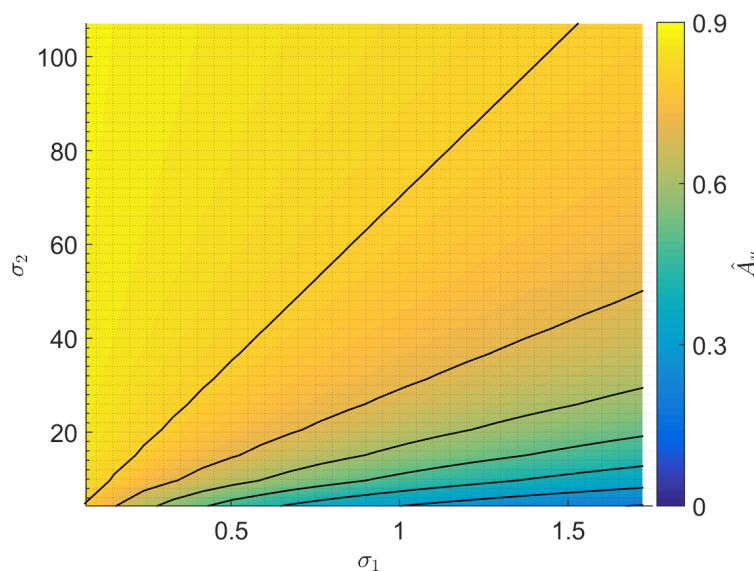

(a) $\hat{A}_{y}\left(\sigma_{1} ; \sigma_{2}\right)$. VIV-1gl.

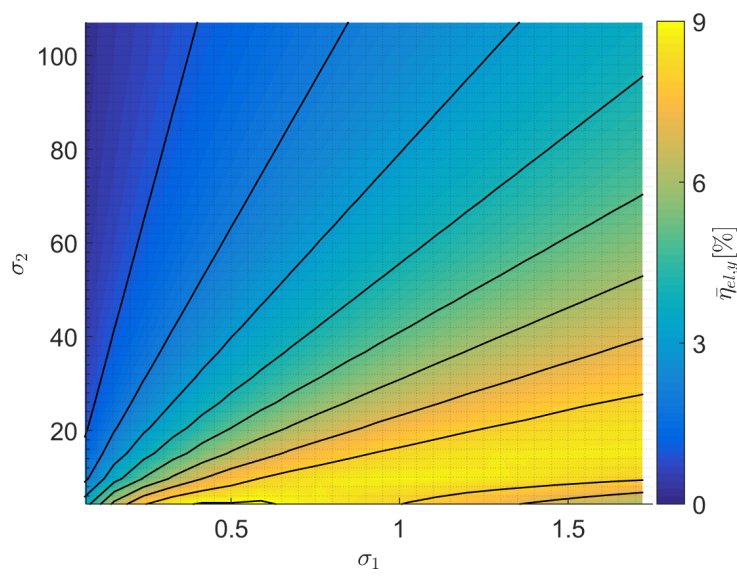

(c) $\bar{\eta}_{e l, y}\left(\sigma_{1} ; \sigma_{2}\right)$. VIV-1gl.

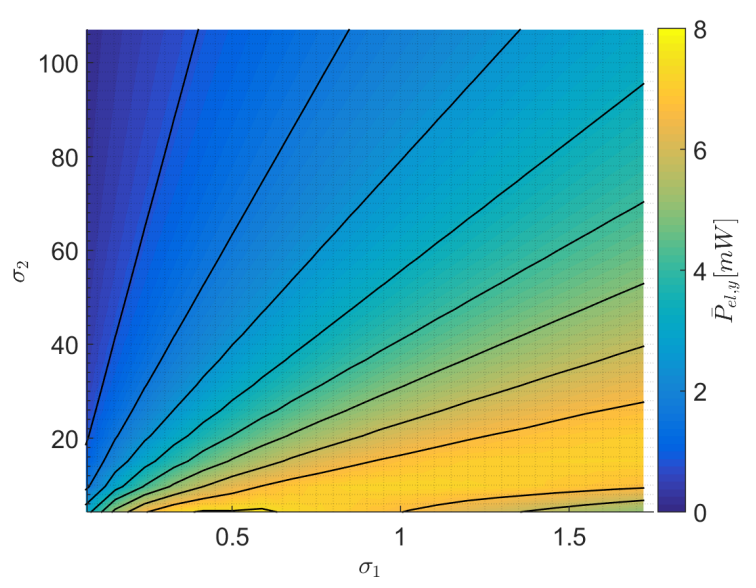

(e) $\bar{P}_{e l, y}\left(\sigma_{1} ; \sigma_{2}\right)$. VIV-1gl.

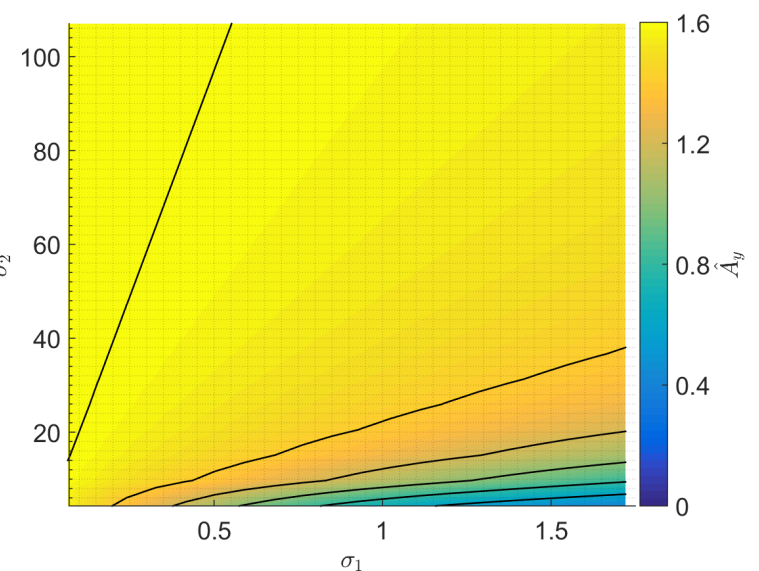

(b) $\hat{A}_{y}\left(\sigma_{1} ; \sigma_{2}\right)$. VIV-2gl.

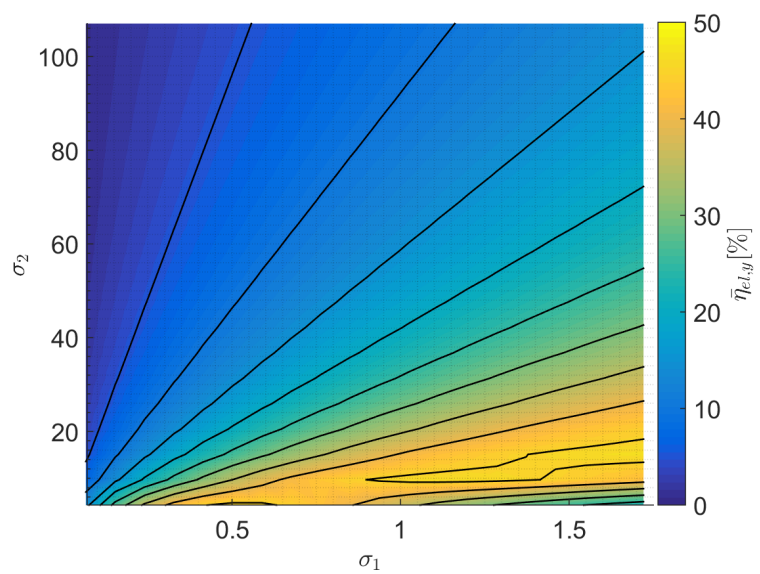

(d) $\bar{\eta}_{e l, y}\left(\sigma_{1} ; \sigma_{2}\right)$. VIV-2gl.

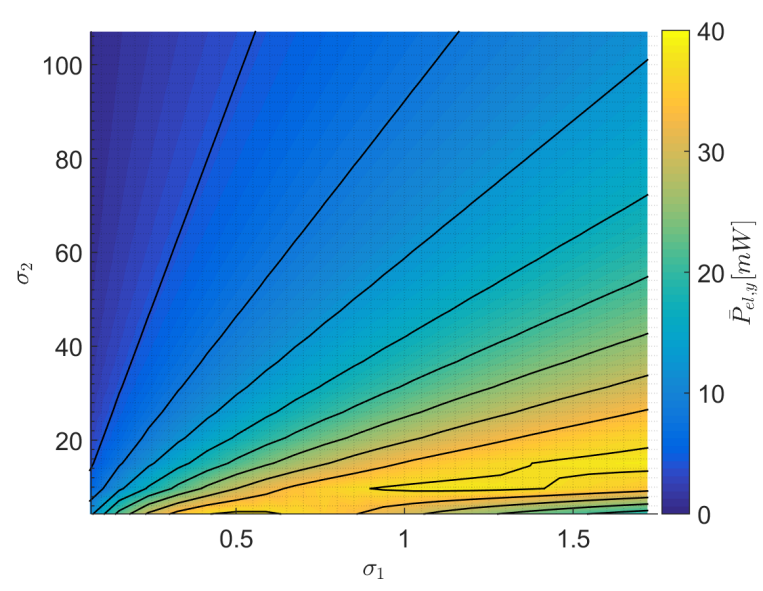

(f) $\bar{P}_{e l, y}\left(\sigma_{1} ; \sigma_{2}\right)$. VIV-2gl.

Fonte: Adaptada de Franzini e Bunzel (2018).

164(c), 164(d), 164(e) e 164(f), na região do plano de parâmetros de controle $\left(\sigma_{1} ; \sigma_{2}\right)$ onde a amplitude característica de oscilação apresenta um significativo decréscimo existe um 
pronunciado aumento da eficiência do aproveitamento de energia e da potência elétrica extraída. De fato, a redução das amplitudes de oscilação do cilindro está intimamente à maior energia extraída do sistema sólido-fluido-elétrico.

A Figura 165 mostra a variação da eficiência do aproveitamento de energia como função de $\sigma_{1}$ para $\sigma_{2}=20,5$ fixo e considerando $U_{r}=6$. Considerando a condição VIV-1gl, não há variação significativa na eficiência para $\sigma_{1}>0,70$. Por outro lado, existe uma tendência crescente do aumento da eficiência do aproveitamento de energia com $\sigma_{2}$ para a condição VIV-2gl com a possível existência de um valor ótimo $\sigma_{2}^{\text {oti }}$ para o qual a eficiência é máxima.

O leitor nota, ainda, que os valores de $\sigma_{1}$ e $\sigma_{2}$ adotados nas primeiras análises conduzidas nesta seção não correspondem à máxima eficiência de coleta de energia. Tomando como comparação a Figura 162 e que considera $\sigma_{1}=0,34$ e $\sigma_{2}=21,4$, as máximas eficiências de coleta de energia são $\bar{\eta}_{e l, y}=5 \%$ (VIV-1gl) e $\bar{\eta}_{e l, y}=15 \%$ (VIV$2 \mathrm{gl}$ ). Em especial para a condição VIV-2gl, a eficiência pode ser aumentada em $5 \%$ se o parâmetro $\sigma_{1}$ for adotado como 0,50 . Isso pode ser conseguido por meio de uma redução na capacitância do circuito na direção cross-wise utilizado nas análises conduzidas no início desta seção (o que aumenta tanto $\sigma_{1}$ quanto $\sigma_{2}$; ver Equação 11.14) e um aumento na resistência elétrica desse circuito (que promoverá uma redução em $\sigma_{2}$ para atingir o valor aqui investigado).

Figura 165 - Variação de $\bar{\eta}_{e l, y}$ com o parâmetro $\sigma_{1}$. $U_{r}=6$ and $\sigma_{2}=20,5$.

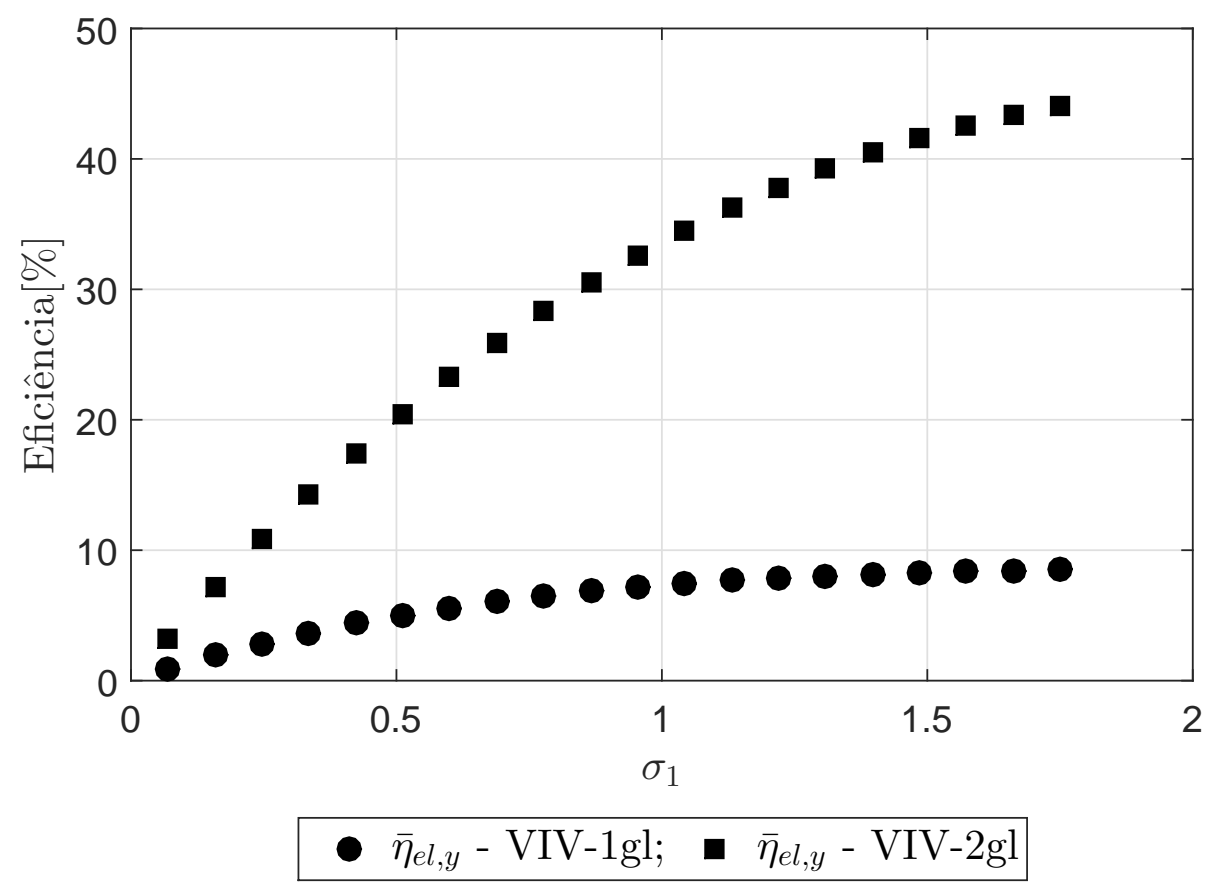

Fonte: Adaptada de Franzini e Bunzel (2018). 


\subsection{Considerações finais do capítulo e perspectivas de continui- dade da pesquisa}

Este capítulo apresentou um estudo numérico do aproveitamento de energia a partir do fenômeno de VIV. Um cilindro rígido foi montado em um arranjo de molas piezoelétricas e o carregamento hidrodinâmico foi modelado por meio do conceito de wake-oscillator. Tanto as condições VIV-1gl quanto VIV-2gl foram investigadas. Os estudos aqui descritos foram conduzidos com a apoio de um aluno de graduação orientado do autor deste texto e suscitou a publicação de um artigo em conferência internacional e um segundo artigo, agora em periódico indexado.

Embora a condição VIV-1gl já tenha sido objeto de estudos por parte da literatura, estudos com foco na condição VIV-2gl não haviam sido conduzidos, a menos do conhecimento do autor do presente texto, e é a principal contribuição da pesquisa descrita neste capítulo. Em um primeiro momento, avaliou-se a resposta do sistema sólido-fluido-elétrico para um dado conjunto de parâmetros que representam, do ponto de vista de propriedades mecânicas, um experimento conduzido anteriormente sem qualquer consideração do efeito piezoelétrico. Os dados do circuito elétrico foram extraídos de um artigo da literatura. Esse primeiro estudo mostrou que o aproveitamento de energia a partir da condição VIV-2gl apresenta uma eficiência cerca de três vezes superior àquela referente ao caso onde o cilindro pode oscilar apenas em uma direção, reiterando uma contribuição da pesquisa aqui descrita acerca da importância de considerar oscilações na direção in-line.

Um segundo estudo, agora focado na influência dos parâmetros que governam o circuito piezoelétrico, mostrou que o caso que foi objeto de estudo do capítulo não correspondia à configuração ótima no sentido de maximização da eficiência do aproveitamento de energia. Nesse sentido, uma proposta de continuidade da pesquisa no tema aqui abordado diz respeito à definição de um conjunto de parâmetros que caracterizam o material piezoelétrico de sorte a maximizar a coleta de energia a partir do fenômeno de VIV em cilindros rígidos e elasticamente apoiados. Complementando os estudos aqui conduzidos, essa otimização poderia contemplar não apenas um particular valor de velocidade reduzida, mas sim todo o intervalo de lock-in. Dentre as alternativas, esse procedimento de otimização poderia ser conduzido por meio do uso do algoritmo genético.

Uma segunda proposta de continuidade da pesquisa contempla a construção de modelos de ordem reduzida, com posterior simulação numérica, do aproveitamento de energia a partir do VIV de um cilindro flexível e dotado de uma alma composta de lâminas piezoelétricas. Essa proposta está sendo conduzida pela mestranda do LMO Letícia Siqueira Madi sob orientação Prof. Dr. Celso Pupo Pesce. A pesquisa da mestranda já originou um primeiro fruto científico na forma do trabalho Madi, Pesce e Franzini (2019), onde apenas oscilações na direção cross-wise são consideradas. Uma possível expansão que pode 
ser realizada tanto pela mesma mestranda quanto por outro membro do LMO, seria a consideração de oscilações simultâneas nas direções cross-wise e in-line, o que, segundo as análises conduzidas neste capítulo para cilindros rígidos montados em apoios elásticos, aumenta de maneira significativa a eficiência do aproveitamento de energia.

Ainda considerando o fenômeno de VIV, foco pode ser investido na modelagem matemática do problema considerando o efeito eletromagnético como forma de conversão de energia. Como visto na revisão bibliográfica apresentada no capítulo 6, embora existam investigações experimentais nesse tema, modelos matemáticos de ordem reduzida com o uso de wake-oscillators podem ser alternativas interessantes no que toca à otimização do parâmetros que governam o sistema sólido-fluido-elétrico com vistas à maximização da eficiência do aproveitamento de energia.

Focando em temas com caráter mais teórico e considerando outros fenômenos de vibração induzida pelo escoamento, os problemas de aproveitamento de energia levam a modelos matemáticos não-lineares que podem ser estudados por meio de técnicas usualmente empregadas pela comunidade de mecânica teórica e aplicada como, por exemplo, os modos não-lineares e métodos assintóticos de perturbação. Essa abordagem seria uma forma de conectar um campo de caráter mais abstrato da dinâmica das estruturas com um problema tecnológico.

Por fim e também constituindo uma proposta comum a diversos fenômenos de vibrações induzidas pelo escoamento está o uso de simulações numéricas com modelos de maior hierarquia baseados em técnicas de DFC com vistas à confrontação com os modelos de ordem reduzida e também a realização estudos experimentais em canal de água recirculante, tanque de reboque ou túnel de vento. Cumpre ressaltar que o projeto de mestrado da Enga. Madi contempla estudos experimentais acerca do aproveitamento de energia.

Ao terminar a leitura deste capítulo, o leitor nota que existe a possibilidade (a menos do ponto de vista teórico) de construir um dispositivo para realizar o aproveitamento de energia a partir do VIV via efeito piezoelétrico. Mais ainda, ao concluir a leitura do capítulo anterior, o leitor percebe que ao acoplar um NVA a uma estrutura principal, as oscilações dessa última estrutura são mitigadas em decorrência de movimentos na sub-estrutura instalada.

Assim, surge um interesse natural em realizar o aproveitamento de energia não a partir de oscilações da estrutura principal, mas sim daquelas existentes no dispositivo supressor. Essa ideia configura uma nova linha de pesquisa na qual o docente pretende inserir esforços e é melhor detalhada nas considerações finais deste texto de síntese descritas no capítulo subsequente. 


\section{Considerações finais}

Este texto apresentou tópicos de pesquisa em problemas de vibrações induzidas pelo escoamento (VIE) e de excitação paramétrica abordados pelo autor desde seu ingresso como docente do Departamento de Engenharia de Estruturas e Geotécnica da Escola Politécnica da Universidade de São Paulo (PEF/EPUSP). Dois fenômenos de VIE foram objetos de estudo, a saber, as vibrações induzidas pela emissão de vórtices e o galloping translacional.

Os mencionados problemas de dinâmica das estruturas foram abordados dos pontos de vista de modelagem matemática e de análise experimental, além de estudos numéricos com foco em supressão passiva por meio de absorvedores não-lineares de vibração. O texto também contemplou estudos numéricos acerca do aproveitamento de energia a partir do fenômeno de vibrações induzidas pela emissão de vórtices (VIV) por meio do efeito piezoelétrico.

Do ponto de vista das contribuições à análise experimental dos problemas em tela, a pesquisa descrita no capítulo 7 ajudou a preencher algumas lacunas de conhecimento identificadas na revisão bibliográfica apresentada nos capítulos 3 e 4 . Tais lacunas envolvem resultados experimentais do problema de excitação paramétrica em cilindros flexíveis submersos, novas metodologias de análise experimental para redução de resultados acerca da dinâmica de um cilindro flexível sujeito ao fenômeno de VIV e estudos experimentais com foco nos efeitos combinados de VIV e de excitação paramétrica em cilindros flexíveis.

Dentre os principais resultados no capítulo 7, destacam-se a proposição de uma metodologia para análise experimental da resposta de um cilindro flexível ao fenômenos aqui investigados, a análise experimental com base em diagramas de Strutt modais para o problema de excitação paramétrica em um cilindro flexível, a verificação experimental de que os valores característicos de amplitude calculados a partir das séries temporais de amplitude modal apresentam boa aderência se a velocidade reduzida modal é utilizada e que a resposta de um cilindro flexível à solicitação combinada dos fenômenos de VIV e de excitação paramétrica pode ser bastante amplificada se comparada apenas ao caso onde o fenômeno de VIV atua. Em particular, as amplitudes de oscilação medidas ao longo do cilindro podem ser dobradas no caso onde o VIV excita o lock-in com o primeiro modo de vibrar na direção cross-wise de maneira concomitante com a instabilidade paramétrica principal nesse mesmo modo.

Cumpre ressaltar que algumas das técnicas de análise experimental desenvolvidas pelo autor deste texto e apresentadas no capítulo 7 foram aplicadas por outros pesquisadores com interesse em vibrações induzidas pelo escoamento, auxiliando-os na redução dos 
resultados publicados em suas teses de doutorado. É importante salientar, ainda, que tais técnicas apresentam caráter bastante geral, podendo ser aplicadas ou adaptadas para a análise experimental de dinâmica das estruturas de quaisquer natureza, não apenas decorrentes de problemas de interação fluido-estrutura.

Finalmente, é importante destacar que a base de dados experimental aqui parcialmente analisada é bastante rara de ser encontrada, em particular no tocante aos resultados envolvendo a solicitação combinada de VIV e de excitação paramétrica. Assim, além dos paradigmas experimentais já descritos no capítulo 7 e que podem servir como base de comparação para códigos numéricos, novas e futuras análises poderão dar ainda mais visibilidade ao grupo de pesquisa.

No que toca à modelagem matemática, o capítulo 8 trouxe um modelo de ordem reduzida (MOR) com três graus de liberdade (a saber, as amplitudes modais dos três primeiros modos) para o estudo da determinação numérica da resposta pós-crítica ao fenômeno de excitação paramétrica, ajudando assim a preencher uma das lacunas de conhecimento identificadas no capítulo 3. Além da obtenção das maiores respostas nas vizinhanças da instabilidade paramétrica principal, respostas pós-críticas também foram observadas para outras frequências de excitação paramétrica.

Do ponto de vista de modelagem matemática do fenômeno de VIV, a principal contribuição apresentada no capítulo 8 foi a proposição de um wake-oscillator para a condição na qual um cilindro rígido montado em apoio elástico que permite oscilações no plano horizontal (condição aqui denominada VIV-2gl) é submetido ao referido fenômeno. Embora com desenvolvimento praticamente concomitante a um outro trabalho publicado na literatura, a pesquisa aqui introduziu a dependência dos coeficientes de calibração com a velocidade reduzida. Esse modelo baseado em wake-oscillators já foi aplicado com sucesso na análise do problema de aproveitamento de energia a partir do fenômeno de VIV, além de estar sendo empregado como ferramenta para modelagem do problema de solicitação conjunta pelo fenômenos de VIV e de escoamento interno em um projeto envolvendo a indústria e também em alguns projetos de pesquisa em desenvolvimento no grupo do LMO.

Os capítulos 9 e 10 foram originados a partir de projetos de pesquisa apoiados por órgão de fomento e tiveram como foco o estudo numérico da supressão passiva dos fenômenos de VIV, galloping e excitação paramétrica utilizando absorvedores nãolineares de vibração (NVA) rotativos. Como mencionado no capítulo 5, existem lacunas de conhecimento no tema e que estão sendo entendidas com o auxílio da pesquisa conduzida pelo autor deste texto.

Dentre as conclusões obtidas nos capítulos 9 e 10, podem ser apontado o fato de que o NVA rotativo pode ser bastante eficiente na mitigação dos fenômenos de galloping e de excitação paramétrica. Em particular para o fenômeno de excitação paramétrica, algumas 
configurações levaram à supressão completa de vibrações, mesmo em uma condição onde a estrutura principal sem o supressor experimentava respostas ilimitadas.

Ainda considerando a supressão passiva dos fenômenos de excitação paramétrica e de galloping, os mapas construídos mostraram erosão no plano de parâmetros de controle que definem o NVA. Por sua vez, a supressão passiva do fenômeno de VIV mostrou-se menos pronunciada do que para os outros fenômenos aqui investigados. Em particular para a condição VIV-2gl, o NVA estudado não promoveu reduções de amplitude de resposta tão significativas como aquelas encontradas para os fenômenos de excitação paramétrica e de galloping. Ainda para o fenômenos de VIV, a erosão do plano de parâmetros de controle que definem o NVA foi significativamente menor do que nos demais fenômenos aqui estudados.

A linha de pesquisa de supressão passiva via NVA dos problemas de excitação paramétrica e de vibrações induzidas pelo escoamento foi iniciada pelo autor tanto nos âmbitos do LMO quanto do PEF. Trata-se de uma iniciativa bastante recente, mas que já tem como impactos a formação de uma aluna de graduação na modalidade pré-mestrado, duas alunas de graduação que desenvolveram suas iniciações científicas no tema e de uma mestranda que concluirá sua dissertação no primeiro semestre de 2019.

Além da nucleação de uma linha de pesquisa, o tema possibilitou ao autor a condução de um período como pesquisador visitante junto à École Polytechnique de Montréal com apoio financeiro de uma agência canadense. É esperado que o autor deste texto receba dois alunos estrangeiros para atuar nos temas descritos neste parágrafo, sendo um doutorando da École Polytechnique de Montréal e uma aluna da Technischen Universität Darmstadt para o desenvolvimento de seu projeto de formatura. Assim, esta linha de pesquisa pode vir a contribuir com os interesses do PEF, da EPUSP e da Universidade no sentido de internacionalização de suas atividades.

O capítulo 11 apresentou um estudo numérico acerca do aproveitamento de energia a partir do fenômeno de VIV. Buscando preencher uma das lacunas identificadas no capítulo 6, verificou-se que a consideração de oscilações na direção in-line (ou seja, oscilações na direção da correnteza incidente) é de grande interesse para o aproveitamento de energia. Em decorrência das pequenas amplitudes de oscilação na direção in-line, a potência elétrica obtida neste circuito via efeito piezoelétrico é significativamente menor do que aquela observada no circuito associado à direção cross-wise. No entanto, o aumento das oscilações na direção cross-wise ocasionado pela presença do grau de liberdade associado à direção in-line levou a um pronunciado aumento na potência elétrica nesse circuito quando comparada à condição onde o cilindro era restrito a oscilações na direção cross-wise (VIV-1gl).

O principal impacto da pesquisa conduzida no capítulo 11 nos grupos do LMO e do $\mathrm{PEF}$ foi a formação de um aluno de graduação com forte viés de pesquisa. Tendo conduzido 
sua iniciação científica e projeto de formatura sob orientação do autor, foi possível dar ampla noção da carreira científica ao estudante. Além disso, auxiliou na nucleação de um grupo de alunos orientados pelo autor deste texto e que desenvolveu um conjunto de projetos de iniciação científica no tema. Atualmente, o grupo do LMO tem uma mestranda desenvolvendo sua dissertação no tema de aproveitamento de energia a partir do fenômeno de VIV em cilindros flexíveis.

Além das contribuições aqui apresentadas, é importante enfatizar que o autor pretende continuar a inserir esforços de pesquisa nos problemas descritos no âmbito deste texto. Os próximos parágrafos pontuarão as propostas de continuidade da pesquisa, nomeando os orientados do autor deste texto que estão envolvidos.

Do ponto de vista de modelagem matemática dos fenômenos de VIV e de excitação paramétrica, o doutorando Guilherme Vernizzi já tem atuado no estudo de uso de funções de projeção baseadas em modos não-lineares como alternativa às funções senoidais para a obtenção de modelos de ordem reduzida após a aplicação do método de Galerkin. Espera-se que ao final de sua pesquisa seja possível pontuar os benefícios que o uso de funções mais ricas apresentam na construção de modelos de ordem reduzida. Além desses estudos, o Eng. Vernizzi tem estudado formas de analisar o VIV por meio de modos não-lineares de vibração obtidos por meio de variedades invariantes. O doutorando embarcará ainda no primeiro semestre de 2019 para cumprir um período de um ano junto ao grupo do Prof. Stefano Lenci, onde a aplicação de modos não-lineares como ferramenta de modelagem e análise do VIV em cilindros flexíveis será aprofundada.

O mestrando Michel Freitas iniciou sua pesquisa no ano de 2018 e empregará os wake-oscillators como modelos de ordem reduzida para o estudo do fenômeno de VIV combinado ao de excitação paramétrica em cilindros rígidos montados em apoio elástico e também em cilindros flexíveis. Espera-se que sua dissertação indique os efeitos qualitativos e quantitativos capturados pela adoção ad-hoc dos wake-oscillators na modelagem do problema combinado. Em particular, pretende-se correlacionar os resultados a serem obtidos numericamente com aqueles provenientes dos experimentos analisados no capítulo 7.

Uma outra proposta de continuidade de pesquisa e que ainda não tem alunos definidos envolve a consideração da dependência de outros parâmetros como, por exemplo, o parâmetro de massa reduzida $m^{*}$, o número de Reynolds e a velocidade reduzida na definição dos coeficientes empíricos dos wake-oscillators. Um primeiro esforço nesse sentido está em curso em uma pesquisa conduzida em conjunto com a professora Victoria Kurushina, da Industrial University of Tyumen. Outro aspecto interessante a se estudar no tocante ao uso de wake-oscillators para a condição VIV-2gl diz respeito à incorporação dos efeitos de valores distintos de rigidez nas direções in-line e cross-wise nos coeficientes empíricos do modelo de ordem reduzida. 
Visando preencher as lacunas apresentadas no capítulo 5, pretende-se que o hoje mestrando Giovanni do Amaral dedique parte de sua futura pesquisa de doutorado na condução de experimentos com foco na supressão passiva dos fenômenos de VIE por meio de NVAs. Além dos dados experimentais e das correlações numéricas com os simuladores já desenvolvidos pela mestranda Tatiana Ueno, o futuro doutorando também fará estudos com base em métodos de perturbação semelhantes àquele empregado no capítulo 9. É importante ressaltar ainda que é de interesse do autor do texto e do futuro doutorando que ele desenvolva parte de sua pesquisa no exterior.

Neste ponto, cabe propor uma uma nova linha de pesquisa (ao menos dentro dos grupos do LMO e do PEF) e na qual o docente tenciona investir esforços de pesquisa. Como mencionado visto nos capítulos 9 e 10, o uso de NVAs rotativos como supressores de excitação paramétrica, do VIV e do galloping pode levar a respostas do supressor caracterizadas por velocidades angulares constantes. Esse comportamento do NVA pode vir a ser utilizado como alternativa para a coleta de energia, caso acoplado a uma bobina imersa em um campo magnético.

Nesse cenário de estudos do efeito combinado de supressão passiva e aproveitamento de energia, é necessária a consideração da dinâmica do circuito elétrico nas equações de movimento do conjunto composto da estrutura principal, do supressor, do circuito de coleta de energia e do fluido (no caso do estudo numérico do fenômeno de VIV por meio de modelos de ordem reduzida baseados no conceito de wake-oscillators). Uma outra alternativa que faz parte da mesma linha de pesquisa é o uso de um NVA translativo dotado de uma imã que se move em relação a uma bobina. Além dos estudos numéricos nos problemas de concomitante supressão passiva e aproveitamento de energia, investigações experimentais são, indubitavelmente, interessantes.

A apresentação das perspectivas de trabalhos futuros nos temas que foram aqui descritos e a proposição de uma nova linha de pesquisa na qual o docente tenciona atuar encerram este texto, que buscou tanto fornecer uma visão integrada de parte das atividades de pesquisa conduzidas pelo docente quanto pontuar suas contribuições ao estado-da-arte e aos grupos do LMO e do PEF. 


\section{Referências}

AKAYDIN, H. D.; ELVIN, N.; ANDREOPOULOS. The performance of a self-excited fluidic energy harvester. Smart Material and Structures, v. 21, p. 1-13, 2012.

ALSUWAIYAN, A. S.; SHAW, S. W. Non-synchronous and localized responses of systems of identical centrifugal pendulum vibration absorbers. Arabian Journal for Science and Engineering, v. 39, n. 12, p. 9205-9217, 2014.

ANDERSON Jr., J. D. Fundamentals of Aerodynamics. [S.l.]: McGraw-Hill, 2011.

ANDRIANNE, T.; ARYOPUTRO, R. P.; LAURENT, P.; COLSON, G.; AMANDOLèSE, X.; HéMON, P. Energy harvesting from different aeroelastic instabilities of a square cylinder. Journal of Wind Engineering \& Industrial Aerodynamics, v. 172, p. 164-169, 2018.

ANTOINE, G. O.; de LANGRE, E.; MICHELIN, S. Optimal energy harvesting from vortex-induced vibrations of cables. Philosophical Transactions of the Royal Society A, v. 472 , p. $1-18,2016$.

ARANHA, J. A. P. Weak three dimensionality of a flow around a slender cylinder: the Ginzburg-Landau equation. Journal of the Brazilian Society of Mechanical Sciences and Engineering, XXVI, n. 4, p. 355-367, 2004.

ARIONFARD, H.; NISHI, Y. Experimental investigation of a drag assisted vortex-induced vibration energy converter. Journal of Fluids and Structures, v. 68, p. 48-57, 2017.

ASSI, G. R. S. Mechanisms for flow-induced vibration of interfering bluff bodies. Tese (Doutorado) — Imperial College London, 2009.

BARRERO-GIL, A.; ALONSO, G.; SANZ-ANDRES, A. Energy harvesting from transverse galloping. Journal of Sound and Vibration, v. 329, p. 2873-2883, 2010.

BENAROUS, N.; GENDELMAN, O. V. Nonlinear energy sink with combined nonlinearities: Enhanced mitigation of vibrations and amplitude locking phenomenon. Journal of Mechanical Engineering Science, v. 230(1), p. 21-33, 2016.

BENDER, C. M.; ORSZAG, S. A. Advanced Mathematical Methods for Scientists and Engineers. [S.l.]: McGraw-Hill, 1978.

BERNITSAS, M. M.; BEN-SIMOS, Y.; RAGHAVAN, K.; GARCIA, E. M. H. The VIVACE converter: model tests at high damping and Reynolds number around $10^{5}$. In: Proceedings of OMAE2006 - International Conference on Offshore Mechanics and Artic Engineering. [S.l.: s.n.], 2006.

BERNITSAS, M. M.; RAGHAVAN, K.; BEN-SIMOS, Y.; GARCIA, E. M. H. VIVACE (Vortex Induced Vibration Aquatic Clean Energy): A new concept in generation of clean and renewable energy from fluid flow. In: Proceedings of OMAE2006 - International Conference on Offshore Mechanics and Artic Engineering. [S.l.: s.n.], 2006. 
BERNITSAS, M. M.; RAGHAVAN, K.; DUCHENE, G. Induced separation and vorticity using roughness in VIV of circular cylinders at $8 \times 10^{3}<R e<2.0 \times 10^{5}$. In: Proceedings of OMAE2008 - International Conference on Offshore Mechanics and Artic Engineering. [S.l.: s.n.], 2008.

BLANCHARD, A. B.; GENDELMAN, O. V.; BERGMAN, L. A.; VAKAKIS, A. F. Capture into a slow-invariant-manifold in the fluid-structure dynamics of a sprung cylinder with a nonlinear rotator. Journal of Fluids and Structures, v. 63, p. 155-173, 2016.

BLEVINS, R. Flow-Induced Vibration. [S.l.]: Krieger, 2001.

BLEVINS, R. D.; COUGHRAN, C. S. Experimental investigation of vortex-induced vibration in one and two dimensions with variable mass, damping, and Reynolds number. Journal of Fluids Engineering, v. 131, p. 101202-1 - 101202-7, 2009.

BUNZEL, L. O.; FRANZINI, G. R. Numerical studies on piezoelectric energy harvesting from vortex-induced vibrations considering cross-wise and in-line oscillations. In:

Proceedings of the 9th European Nonlinear Dynamics Conference - ENOC2017. [S.l.: s.n.], 2017.

CHANDRASEKARAN, S.; CHANDAK, N. R.; ANUPAM, G. Stability analysis of TLP theters. Ocean Engineering, v. 33, p. 471-482, 2006.

CHAO, C.-P.; LEE, C.-T.; SHAW, S. W. Non-unison dynamics of multiple centrifugal pendulum vibration absorbers. Journal of Sound and Vibration, v. 204, n. 5, p. 769-794, 1997.

CHAPLIN, J. R.; BEARMAN, P. W.; CHENG, Y.; FONTAINE, E.; GRAHAM, J. M. R.; HERFJORD, K.; HUARTE, F. J. H.; ISHERWOOD, M.; LAMBRACOS, K.; LARSEN, C. M.; MENEGHINI, J. R.; MOE, G.; PATTENDEN, R.; TRIANTAFYLLOU, M. S.; WILLDEN, R. H. J. Blind predictions of laboratory measurements of Vortex-Induced Vibrations of a tension riser. Jounal of Fluids and Structures, v. 21, p. 25-40, 2005.

CHAPlin, J. R.; BEARMAN, P. W.; HUARTE, F. J. H.; PATTENDEN, R. J. Laboratory measurements of Vortex-Induced Vibrations of a vertical tension riser in a stepped current. Jounal of Fluids and Structures, v. 21, p. 3-24, 2005.

CICOLIN, M. M.; ASSI, G. R. S. Laboratory-scale investigation of the Ventilated-Trousers device acting as a suppressor of vortex-induced vibrations. Ocean Engineering, v. 142, p. 411-418, 2017.

CLOUGH, R. W.; PENZIEN, J. Dynamics of Structures. [S.l.]: Berkeley California, 2003.

CUNHA, L. D. Vibração Induzida por Vórtices: Análise Crítica de Modelos

Fenomenológicos. Dissertação (Mestrado) — Escola Politécnica da Universidade de São Paulo, 2005.

DAHL, J. M.; HOVER, F. S.; TRIANTAFYLlOU, M. S.; OAKLEY, O. H. Dual ressonance in vortex-induced vibrations at subcritical and supercritical Reynolds numbers. Journal of Fluid Mechanics, v. 643, p. 395-424, 2010.

DAI, H. L.; ABDELKEFI, A.; WANG, L. Theoretical modeling and nonlinear analysis of piezoelectric energy harvesting from vortex-induced vibrations. Journal of Intelligent Material Systems and Structures, v. 25, n. 14, p. 1861-1874, 2014. 
DAI, H. L.; ABDELKEFI, A.; WANG, L. Usefulness of passive non-linear energy sinks in controlling galloping vibrations. International Journal of Non-Linear Mechanics, v. 81, p. 83-94, 2016.

DAI, H. L.; ABDELKEFI, A.; WANG, L. Vortex-induced vibrations mitigation through a nonlinear energy sink. Communications in Nonlinear Science and Numerical Simulation, v. 42, p. 22-36, 2017.

de PAUlA, A. S.; INMAN, D. J.; SAVI, M. A. Energy harvesting in a nonlinear piezomagneto elastic beam subjected to random excitation. Mechanical Systems and Signal Processing, v. 54-55, p. 405-416, 2015.

Defensor Filho, W. A. Investigação experimental de vibrações induzidas por escoamento em cilindros flexíveis com rigidez ortotrópica. Dissertação (Mestrado) - Escola Politécnica da Universidade de São Paulo, 2018.

Defensor Filho, W. A.; PESCE, C. P.; FRANZINI, G. R. Investigation of the high energy mode branch in flexible cylinders VIV: A novel recursive experimental analysis methodology. In: Proceedings of the 24th International Congress of Mechanical Engineering. [S.l.: s.n.], 2017.

Defensor Filho, W. A.; PESCE, C. P.; FRANZINI, G. R. An experimental investigation on vortex-induced vibrations of cantilevered flexible cylinders with orthotropic bending stiffness. In: Proceedings of the 9th International Symposium on Fluid-Structure Interactions, Flow-Sound Interactions, Flow-Induced Vibration \& Noise FSI2 \& FIV $+N$. [S.l.: s.n.], 2018.

Den HARTOG, J. P. Mechanical vibrations. [S.l.]: McGraw-Hill, 1956.

DHANWANI, M. A.; SARKAR, A.; PATNAIK, B. S. V. Lumped parameter models of vortex-induced vibration with application to the design of aquatic energy harvester. Journal of Fluids and Structures, v. 43, p. 302-324, 2013.

DOARé, O.; MICHELIN, S. Piezoelectric coupling in energy harvesting fluttering flexible plates: linear stability analysis and conversion efficiency. Journal of Fluids and Structures, v. 27, p. 1357-1375, 2011.

DONGYANG, C.; ABBAS, L. K.; GUOPING, W.; XIAOTING, R.; MARZOCCA, P. Numerical study of flow-induced vibrations of cylinders under the action of nonlinear energy sinks (ness). Nonlinear Dynamics, 2018.

ERTURK, A.; INMAN, D. J. A distributed parameter electromechanical model for cantilevered piezoelectric energy harvesters. Journal of Vibration and Accoustics, v. 130, p. 041002-1-41002-15, 2008.

ERTURK, A.; INMAN, D. J. An experimentally validated bimorph cantilever model for piezoelectric energy harvesting from base excitations. Smart Materials and Structures, v. 18, p. 1-18, 2009.

ERTURK, A.; INMAN, D. J. Piezoelectric energy harvesting. [S.l.]: John Wiley \& Sons, 2011. 
FACCHINETTI, M. L.; de LANGRE, E.; BIOLLEY, F. Coupling of structure and wake oscillators in vortex-induced vibrations. Journal of Fluids and Structures, v. 19, p. 123-140, 2004.

FERNANDES, A. C.; ARMANDEI, M. Low-head hydropower extraction based on torsional galloping. Renewable energy, v. 69, p. 447-452, 2014.

FRANZINI, G. R.; BUNZEL, L. O. A numerical investigation on piezoelectric energy harvesting from vortex-induced vibrations with one and two degrees of freedom. Journal of Fluids and Structures, v. 77, p. 196-212, 2018.

FRANZINI, G. R.; CAMPEDELLI, G. R.; MAZZILLI, C. E. N. A numerical investigation on passive suppression of the parametric instability phenomenon using a rotative non-linear vibration absorber. International Journal of Non-Linear Mechanics, v. 105, p. 249-260, 2018.

FRANZINI, G. R.; FUJARRA, A. L. C.; MENEGHINI, J. R.; KORKISCHKO, I.; FRANCISS, R. Experimental investigation of vortex-induced vibration on rigid, smooth and inclined cylinders. Journal of Fluids and Structures, v. 25, p. 742-750, 2009.

FRANZINI, G. R.; GONÇALVES, R. T.; MENEGHINI, J. R.; FUJARRA, A. L. C. Comparison between force measurements of one and two degrees-of-freedom VIV on cylinder with small and large mass ratio. In: Proceedings of the 10th FIV 2012 International Conference on Flow-Induced Vibrations Conference (E6 Flow-Induced Noise). [S.l.: s.n.], 2012.

FRANZINI, G. R.; GONÇALVES, R. T.; MENEGHINI, J. R.; FUJARRA, A. L. C. Experimental investigation into vortex-induced vibrations of yawed cylinders with one and two degrees-of-freedom. In: Proceedings of the 10th FIV 2012 - International Conference on Flow-Induced Vibrations Conference (ES Flow-Induced Noise). [S.l.: s.n.], 2012.

FRANZINI, G. R.; GONÇALVES, R. T.; MENEGHINI, J. R.; FUJARRA, A. L. C. One and two degrees-of-freedom vortex-induced vibration experiments with yawed cylinders. Journal of Fluids and Structures, v. 42, p. 401-420, 2013.

FRANZINI, G. R.; GONÇALVES, R. T.; PESCE, C. P.; FUJARRA, A. L. C.; MAZZILLI, C. E. N.; MENEGHINI, J. R.; MENDES, P. Vortex-Induced Vibration experiments with a long semi-immersed flexible cylinder under tension modulation: Fourier transform and Hilbert-Huang spectral analyses. Journal of the Brazilian Society of Mechanical Sciences and Engineering, v. 37, n. 2, p. 589-599, 2015.

FRANZINI, G. R.; MAZZILLI, C. E. N. Non-linear reduced-order model for parametric excitation of vertical and immersed slender rod. International Journal of Non-linear Mechanics, v. 80, p. 29-39, 2016.

FRANZINI, G. R.; PEREIRA, A. A. P.; FUJARRA, A. L. C.; PESCE, C. P. Experiments on VIV under frequency modulation and at constant Reynolds number. In: Proceedings of OMAE 08 , 27th Int. Conference on Offshore Mechanics and Arctic Engineering. [S.l.: s.n.], 2008.

FRANZINI, G. R.; PESCE, C. P.; GONÇALVES, R. T.; FUJARRA, A. L. C.; PEREIRA, A. P. P. Analysis of multimodal vortex-induced vibrations using the hilbert-huang spectral 
analysis. In: Proceeding of the third Internation Conference on Hilbert-Huang Transform: Theory and Applications. [S.1.: s.n.], 2011.

FRANZINI, G. R.; PESCE, C. P.; GONÇALVES, R. T.; FUJARRA, A. L. C.; MENDES, P. Experimental investigations on Vortex-Induced Vibrations with a long flexible cylinder. Part I: modal-amplitude analysis with a vertical configuration. In: Proceedings of the 11th International Conference on Flow-Induced Vibration - FIV2016. [S.l.: s.n.], 2016.

FRANZINI, G. R.; PESCE, C. P.; GONÇALVES, R. T.; MENDES, P. Experimental investigations on Vortex-Induced Vibrations with a long flexible cylinder. Part II: effect of axial motion excitation in a vertical configuration. In: Proceedings of the 11th International Conference on Flow-Induced Vibration - FIV2016. [S.l.: s.n.], 2016.

FRANZINI, G. R.; PESCE, C. P.; GONÇALVES, R. T.; FUJARRA, A. L. C.; MENDES, P. An experimental investigation on concomitant Vortex-Induced Vibration and axial top-motion excitation with a long flexible cylinder in vertical configuration. Ocean Engineering, v. 156, p. 596-612, 2018.

FRANZINI, G. R.; PESCE, C. P.; SAlLES, R.; GONÇALVES, R. T.; FUJARRA, A. L. C.; MENDES, P. Experimental investigation with a vertical and flexible cylinder in water: response to top motion excitation and parametric resonance. In: Proceedings of the ASME 2014 33rd International Conference on Ocean, Offshore and Arctic Engineering OMAE2014. [S.l.: s.n.], 2014.

FRANZINI, G. R.; PESCE, C. P.; SAllES, R.; GONÇALVES, R. T.; FUJARRA, A. L. C.; MENDES, P. Experimental investigation with a vertical and flexible cylinder in water: response to top motion excitation and parametric resonance. Journal of Vibration and Acoustics, v. 137 (3), p. 031010-1 - 031010-12, 2015.

FRANZINI, G. R.; SANTOS, C. C. P.; MAZZILLI, C. E. N.; PESCE, C. P. Parametric excitation of an immersed, vertical and slender beam using reduced-order models: influence of hydrodynamic coefficients. Marine Systems $\&$ Ocean Technology, v. 11, p. 10-18, 2016.

FRANZINI, G. R.; SANTOS, R. C. S.; PESCE, C. A numerical study on piezoelectric energy harvesting by combining transverse galloping and parametric instability phenomena. Journal of Marine Science and Application, v. 16, p. 465-472, 2017.

FRANZINI, G. R.; SANTOS, R. C. S.; PESCE, C. P. Energy harvesting from transverse galloping enhanced by parametric excitation. In: Proceedings of the 11th International Conference on Flow-Induced Vibration - FIV2016. [S.l.: s.n.], 2016.

FREIRE, C. M.; KORKISCHKO, I.; MENEGHINI, J. R. Defining a parameter of effectiveness for the suppression of vortex-induced vibration. In: Proceedings of the ASME 2011 30th International Conference on Ocean, Offshore and Arctic Engineering OMAE2011. [S.l.: s.n.], 2011.

FREIRE, C. M.; MENEGHINI, J. R. Experimental investigation of VIV on a circular cylinder mounted on an articulated elastic base with two degrees-of-freedom. In: IUTAM Symposium on Bluff Bodies Wakes and Vortex-Induced Vibrations - BBVIV6. [S.l.: s.n.], 2010 . 
FU, S.; WANG, J.; BAARHOLM, R.; WU, J.; LARSEN, C. M. Features of vortex-induced vibration in oscillatory flow. Journal of Offshore Mechanics and Arctic Engineering, v. 136, p. 011801-1-011801-10, 2014.

FUJARRA, A.; PESCE, C.; FLEMMING, F.; WILliAMSON, C. Vortex-induced vibration of a flexible cantilever. Journal of Fluids and Structures, v. 15, p. 651-658, 2001.

FUJARRA, A. L. C. O Fenômeno de VIM em Plataformas Oceânicas. 2013. Tese de Livre Docência apresentada à Escola Politécnica de Universidade de São Paulo.

FUJARRA, A. L. C.; PESCE, C. P. Added mass of an elastically mounted rigid cylinder in water subjected to vortex-induced vibrations. In: Procedings of OMAE 02, 21th Int. Conference on Offshore Mechanics and Arctic Engineering. [S.l.: s.n.], 2002.

FURNES, G. K.; SØRENSEN. Flow induced vibrations mmodele by coupled non-linear oscillators. In: Proceedings of the Seventeenth (2007) International Offshore and Polar Engineering Conference - ISOPE200\%. [S.1.: s.n.], 2007.

GABBAI, R.; BENAROYA, H. An overview of modeling and experiments of vortex-induced vibration of circular cylinders. Journal of Sound and Vibration, v. 282, p. 575-616, 2005.

GABBAI, R.; BENAROYA, H. A first-principles derivation procedure for wake-body models in vortex-induced vibration: Proof-of-concept. Journal of Sound and Vibration, v. 312, p. 19-38, 2008.

GENDELMAN, O. V.; ALLONI, A. Dynamics of forced system with vibro-impact energy sink. Journal of Sound and Vibration, v. 358, p. 301-314, 2015.

GENDELMAN, O. V.; MANEVITCH, L. I.; VAKAKIS, A. F.; MCLOSKEY, R. Energy pumping in nonlinear mechanical oscillators: Part I-dynamics of the underlying hamiltonian systems. Journal of Applied Mechanics, v. 68, n. 1, p. 34-41, 2001.

GENDELMAN, O. V.; SIGALOV, G.; MANEVITCH, L. I.; MANE, M.; VAKAKIS, A. F.; BERGMAN, L. A. Dynamics of an eccentric rotational nonlinear energy sink. Journal of Applied Mechanics, v. 79, p. 0110121-0110129, 2012.

GERRARD, J. H. The mechanics of the formation region of vortices behind bluff bodies. Journal of Fluid Mechanics, v. 25, p. 401-413, 1966.

GONÇALVES, R. T. Vibrações Induzidas pela Emissão de Vórtices em Cilindros com Baixa Razão de Aspecto. Tese (Doutorado) - Escola Politécnica da Universidade de São Paulo, 2013.

GONÇALVES, R. T.; FRANZINI, G. R.; ROSETTI, G. F.; FUJARRA, A. L. C.; NISHIMOTO, K. Analysis methodology for vortex-induced motions (VIM) of a monocolumn platform applying the Hilbert-Huang transform method. Journal of Offshore Mechanics and Arctic Engineering, v. 113, p. 011103-1 -011103-7, 2012.

GROUTHIER, C.; MICHELIN, S.; BOURGUET, R.; MODARRES-SADEGHI, Y.; de LANGRE, E. On the efficiency of energy harvesting using vortex-induced vibrations of cables. Journal of Fluids and Structures, v. 49, p. 427-440, 2014. 
HARTLEN, R. T.; CURRIE, T. G. Lift-oscillator model of vortex-induced vibration. Journal of the Engineering Mechanics Division EM5, p. 577-591, 1970.

HéMON, P.; AMANDOLESE, X.; ANDRIANNE, T. Energy harvesting from galloping of prisms: A wind tunnel experiment. Journal of Fluids and Structures, v. 70, p. 390-402, 2017.

HOVER, F. S.; MILLER, S. N.; TRIANTAFYLLOU, M. S. Vortex-induced vibration of marine cables: Experiments using force feedback. Journal of Fluids and Structures, v. 11, p. 307-326, 1997.

HUANG, N. E.; SHEN, Z.; LONG, S. R.; WU, M. C.; SHIH, H. H.; ZHENG, Q.; YEN, N.; TUNG, C. C.; LIU, H. H. The empirical mode decomposition and the Hilbert spectrum for nonlinear and non-stationary time series analysis. Royal Society London, v. 454, p. 903-955, 1998.

HUANG, S.; KHORASANCHI, M.; HERFJORD, K. Drag amplification of long flexible riser models undergoing multi-mode VIV in uniform currents. Journal of Fluids and Structures, v. 27, p. 342-353, 2011.

HUERA-HUARTE, F. J.; BEARMAN, P. W. Wake structures and vortex-induced vibrations of a long flexible cylinder - part 1:dynamic response. Journal of Fluids and Structures, v. 25, p. 969-990, 2009.

HUERA-HUARTE, F. J.; BEARMAN, P. W. Wake structures and vortex-induced vibrations of a long flexible cylinder - part 2: Drag coefficients and vortex modes. Jounal of Fluids and Structures, v. 25, p. 991-1006, 2009.

ISSA, J. S.; SHAW, S. W. Synchronous and non-synchronous responses of systems with multiple identical nonlinear vibration absorbers. Journal of Sound and Vibration, v. 348, p. $105-125,2015$.

IWAN, W. D.; BLEVINS, R. D. A model for vortex-induced oscillation of structures. Journal of Applied Mechanics, v. 41, p. 581-586, 1974.

JAUVTIS, N.; WILLIAMSON, C. H. K. The effect of two degrees of freedom on vortex-induced vibration at low mass and damping. Journal of Fluid Mechanics, v. 509, p. 23-62, 2004.

KHALAK, A.; WILLIAMSON, C. H. K. Motions, forces and modes transitions in Vortex-Induced Vibration at low Reynolds number. Journal of Fluids and Structures, v. 13, p. 813-851, 1999.

KORKISCHKO, I.; MENEGHINI, J. R. Experimental investigation of flow-induced vibration on isolated and tandem circular cylinders fitted with strakes. Journal of Fluids and Structures, v. 26, p. 611-625, 2010.

KORKISCHKO, I.; MENEGHINI, J. R. Volumetric reconstruction of the mean flow around circular cylinders fitted with strakes. Experiments in fluids, v. 51, p. 1109-1121, 2011.

KOROTKIN, A. I. Added Masses of Ship Structures. [S.l.]: Springer, 2009. 
KURUSHINA, V.; PAVLOVSKAIA, E.; POSTNIKOV, A.; FRANZINI, G. R.; WIERCIGROCH, M. Modelling VIV of transversally oscillating rigid structures using nonlinear uid oscillators. In: Proceedings of the First International Nonlinear Dynamics Conference - NODYCON 2019. [S.l.: s.n.], 2019.

LEE, J. H.; BERNITSAS, M. M. High-damping, high-Reynolds VIV tests for energy harnessing using the VIVACE converter. Ocean Engineering, v. 38, p. 1697-1712, 2011.

LEE, Y. S.; VAKAKIS, A. F.; BERGMAN, L. A.; MCFARLAND, D. M.; KERSCHEN, G.; NUCERA, F.; TSAKIRTZIS, S.; PANAGOPOULOS, P. N. Passive non-linear targeted energy transfer and its applications to vibration absorption: a review. Journal of Multi-body Dynamics, v. 222, n. 77-134, 2008.

LOSSOUARN, B.; DEü, J. F.; AUCEJO, M. Multimodal vibration damping of a beam with a periodic array of piezoelectric patches connected to a passive electrical network. Smart Materials and Structures, v. 24, p. 1-14, 2015.

LUONGO, A.; ZULLI, D. Aeroelastic instability analysis of NES-controlled systems via a mixed multiple scale/harmonic balance method. Journal of Vibration and Control, v. 20(13), p. 1985-1998, 2014.

MADI, L. S.; PESCE, C. P.; FRANZINI, G. R. Flexible piezoelectric cantilever under vortex-induced vibrations. In: Proceedings of the XVIII International Symposium on Dynamic Problems of Mechanics (DINAME 2019). [S.l.: s.n.], 2019.

MALTA, E. B. Investigação experimental das vibrações induzidas pela emissão de vórtices em catenárias sujeitas a perfis de correnteza variável, ortogonais ao plano de lançamento. Tese (Doutorado) — Escola Politécnica da Universidade de São Paulo, 2015.

MAZZILLI, C. E. N.; ANDRé, J. C.; BUCALEM, M. L.; CIFú, S. Lições em Mecânica das Estruturas: Dinâmica. [S.l.]: Edgard Blucher LTDA, 2016.

MAZZILLI, C. E. N.; LENCI, S.; DEMEIO, L. Non-linear free vibrations of tensioned vertical risers. In: Proceedings of the 8th European Nonlinear Dynamics Conference ENOC2014. [S.1.: s.n.], 2014.

MAZZILLI, C. E. N.; SANCHES, C. T.; BARACHO NETO, O. G. P.; WIERCIGROCH, M.; KEBER, M. Non-linear modal analysis for beams subjected to axial loads: Analytical and finite-element solutions. International Journal of Non-linear Mechanics, v. 43, p. 551-561, 2008.

MEHMOOD, A.; ABDELKEFI, A.; HAJJ, A. A.; NAYFEH, A. H.; AKTHAR, I.; NUHAIT, A. O. Piezoelectric energy harvesting from vortex-induced vibrations of circular cylinder. Journal of Sound and Vibration, v. 332, p. 4656-4667, 2013.

MEHMOOD, A.; NAYFEH, A. H.; HAJJ, A. A. Effects of a non-linear energy sink (NES) on vortex-induced vibrations of a circular cylinder. Nonlinear Dynamics, v. 77, p. 667-680, 2014 .

MEIROVITCH, L. Methods of Analytical Dynamics. [S.l.]: Dover Publications, 2003.

MOROOKA, C. K.; TSUKADA, R. I. Experiments with a steel catenary riser model in a towing tank. Applied Ocean Research, v. 43, p. 244-255, 2013. 
MOTATO, E.; HARLS, A.; THEODOSSIADES, S.; MOHAMMADPOUR, M.; RAHNEJAT, H.; KELLY, P.; VAKAKIS, A. F.; MCFARLAND, D. M.; BERGMAN, L. A. Targeted energy transfer and modal energy redistribution in automotive drivetrains. Nonlinear Dynamics, v. 87, p. 169-190, 2017.

NAUDASCHER, E.; ROCKWELL, D. Flow-Induced Vibrations - an engineering guide. [S.l.]: Dover, 2005.

NAYFEH, A. H. Perturbation Methods. [S.l.]: John Wiley \& Sons, 1973.

NAYFEH, A. H.; MOOK, D. T. Nonlinear oscillations. [S.l.]: John Wiley \& Sons, 1979.

NORBERG, C. Flow around a circular cylinder: Aspects of fluctuating lift. Journal of Fluids and Structures, v. 15, p. 459-469, 2001.

NORBERG, C. Fluctuating lift on a circular cylinder: review and new measurements. Journal of Fluids and Structures, v. 17, p. 57-96, 2003.

NUCERA, F.; IACONO, F. L.; MCFARLAND, D. M.; BERGMAN, L. A.; VAKAKIS, A. F. Application of broadband nonlinear targeted energy transfers for seismic mitigation of a shear frame: Experimental results. Journal of Sound and Vibration, v. 313, p. 57-76, 2008.

NUCERA, F.; MCFARLAND, D. M.; BERGMAN, L. A.; VAKAKIS, A. F. Application of broad band nonlinear targeted energy transfers for seismic mitigation of a shear frame:computational results. Journal of Sound and Vibration, v. 329, p. 2973-2994, 2010.

OGINK, R. H. M.; METRIKINE, A. V. A wake oscillator with frequency dependent coupling for the modeling of vortex-induced vibration. Journal of Sound and Vibration, v. 329 , p. $5452-5473,2010$.

PAÏDOUSSIS, M. P. Fluid-Structure Interactions - slender structures and axial flow: Volume 1. [S.l.]: Academic Press, 1998.

PAÏDOUSSIS, M. P.; PRICE, S. J.; de LANGRE, E. Fluid-Structure Interactions Cross-Flow-Induced Instabilities. [S.1.]: Cambridge University Press, 2011.

PARKINSON, G. V.; SMITH, J. D. The square prism as an aeroelastic non-linear oscillator. The Quarterly Journal of Mechanics and Applied Mathematics, v. 17, 1964.

PARRA, P.; ARANHA, J. A. P. Vibrações Induzidas por Emissão de Vórtices: Modelo Fenomenológico e Experimentos. [S.1.], 1996.

PATEL, M. H.; PARK, H. I. Dynamics of tension leg platform tethers at low tension. Part I - Mathieu stability at large parameters. Marine Structures, v. 4, p. 257-273, 1991.

PENNISI, G. Contrôle passif de vibrations à laide d'absorbeurs non-linéaires: Étude théorique et investigations expérimentales. Tese (Doutorado) — Université Fédérale Toulouse Midi-Pyrénées, 2016.

PENNISI, G.; MANN, B. P.; NAClERIO, N.; STEPHAN, C.; MICHON, G. Design and experimental study of a Nonlinear Energy Sink coupled to an electromagnetic energy harvester. Journal of Sound and Vibration, v. 437, p. 340-357, 2018. 
PEREIRA, F. R. Investigação das vibrações induzidas pela emisse vórtices em modelos reduzidos de riser lançados em catenária. Tese (Doutorado) - Escola Politécnica da Universidade de São Paulo, 2014.

PESCE, C.; FUJARRA, A.; KUBOTA, L. The Hilbert-Huang spectral analysis method applied to VIV. In: Proceedings of the 25th International Conference on Offshore Mechanics and Artic Engineering OMAE2006, Hamburg, Germany. [S.1.: s.n.], 2006.

PESCE, C. P. Mecânica de cabos e tubos submersos lanos em "catenária": Uma abordagem analítica e experimental. 1997. Tese de Livre Docência apresentada à Escola Politécnica de Universidade de São Paulo.

PESCE, C. P. Riser Dynamics: experiments with small scale models. 2013. LabOceano - Ten-Years Anniversary Celebration Workshop. Disponível em: <https://www.researchgate.net/publication/279191667>.

PESCE, C. P.; FRANZINI, G. R.; FUJARRA, A. L. C.; GONÇALVES, R. T.; SALlES, R.; MENDES, P. Further experimental investigations on vortex-self induced vibrations (vsiv) with a small-scale catenary riser model. In: Proceedings of the 36th International Conference on Ocean, Offshore Mechanics and Artic Engineering - OMAE2017. [S.l.: s.n.], 2017.

PESCE, C. P.; FUJARRA, A. L. C. Vortex-induced vibrations and jump phenomenon: Experiments with a clamped flexible cylinder in water. International Journal of Offshore and Polar Engineering, v. 10, p. 26-33, 2000.

PESCE, C. P.; FUJARRA, A. L. C. The "super-upper branch" VIV response of flexible cylinders. In: 4th Bluff-Bodies Wakes and Vortex-Induced Vibrations Conference $B B V I V 4$. [S.l.: s.n.], 2005.

PESCE, C. P.; FUJARRA, A. L. C.; FRANZINI, G. R.; RATEIRO, F.; GONÇALVES, R. T.; SALLES, R. Dinâmica não-linear de risers: Experimentos Hidro-elásticos com cilindros flexiveis verticais em tanque de reboque IPT (Technical report in portuguese, restricted). [S.l.], 2013.

PESCE, C. P.; FUJARRA, A. L. C.; FRANZINI, G. R.; RATEIRO, F.; GONÇALVES, R. T.; SALLES, R. Dinâmica não-linear de risers: Experimentos Hidro-elásticos com Modelo Imerso de Riser em Catenária, Sujeito a Correnteza Uniforme e a Imposição de Movimentos Verticais no Topo (IPT) (Technical report in portuguese, restricted). [S.1.], 2013.

PIKOVSKY, A.; ROSENBLUM, M.; KURTHS, J. Synchronization - A Universal Concept in Nonlinear Sciences. [S.l.]: Cambridge University Press, 2001.

POSTNIKOV, A.; PAVLOVSKAIA, E.; WIERCIGROCH, M. 2dof cfd calibrated wake oscillator model to investigate vortex-induced vibrations. International Journal of Mechanical Sciences, v. 127, p. 176-190, 2017.

RAGHAVAN, K.; BERNITSAS, M. Experimental investigation of Reynolds number effect on Vortex Induced Vibration of rigid cylinder on elastic supports. Ocean Engineering, v. 38, p. 719-731, 2011. 
RAINEY, R. C. T. The dynamics of tethered platforms. Transactions of the Royal Institution of Naval Architects, p. 59-80, 1977.

RATEIRO, F.; FUJARRA, A. L. C.; PESCE, C. P.; GONÇALVES, R. T.; FRANZINI, G. R.; MENDES, P. Experimental investigations on vortex-induced vibrations with a long flexible cylinder. Part III: modal-amplitude analysis with a catenary configuration. In: Proceedings of the 11th International Conference on Flow-Induced Vibration. [S.1.: s.n.], 2016.

RATEIRO, F.; GONÇALVES, R. T.; PESCE, C. P.; FUJARRA, A. L. C.; FRANZINI, G. R.; MENDES, P. A model scale experimental investigation on vortex-self induced vibrations (VSIV) of catenary risers. In: Proceedings of the ASME2013 32th International Conference on Ocean, Offshore and Arctic Engineering-OMAE2013. [S.1.: s.n.], 2013.

RATEIRO, F.; PESCE, C. P.; GONÇALVES, R. T.; FRANZINI, G. R.; FUJARRA, A. L. C.; SALLES, R.; MENDES, P. Risers model tests: Scaling methodology and dynamic similarity. In: Proceedings of the The 22nd International Ocean and Polar Engineering Conference, ISOPE 2012. [S.1.: s.n.], 2012.

REGA, G.; LENCI, S. A global dynamics perspective for system safety from macro - to nanomechanics: Analysis, control, and design engineering. Applied Mechanics Review, v. 67 , p. $050802-1-050802-19,2015$.

SALLES, R.; PESCE, C. P. Experimental assessments of the added mass of flexible cylinders in water: the role of modal shape representation. In: Proceedings of the $A B C M$ XVII International Symposium on Dynamic Problems of Mechanics, DINAME2017-0021. [S.l.: s.n.], 2017.

SARPKAYA, T. In-line and transverse forces on cylinders in oscillatory flow at high Reynolds numbers. Journal of Ship Research, v. 21, 1977.

SHANG, J. K.; STONE, H. A.; SMITS, A. J. Vortex and structural dynamics of a flexible cylinder in cross-flow. Physics of Fluids, v. 26, p. 053605-1 - 0.53605-15, 2014.

SHAW, S. W.; PIERRE, C. Normal modes for non-linear vibratory systems. Journal of Sound and Vibration, v. 164, p. 85-124, 1993.

SHIROKY, I. B.; GENDELMAN, O. V. Essentially nonlinear vibration absorber in parametric excited system. Zeitschrift für Angewandte Mathematik und Mechanik, v. 88, 2008 .

SIGALOV, G.; GENDELMAN, O. V.; AL-Shudeifat, M. A.; MANEVITCH, L. I.; VAKAKIS, A. F.; BERGMAN, L. A. Resonance captures and targeted energy transfers in an inertially-coupled rotational nonlinear energy sink. Nonlinear Dynamics, v. 69, p. 1693-1704, 2012.

SILVEIRA, L. M. Y. Modelo Hidro-Elástico para Simular as Vibrações Induzidas por Vórtices em Cabos Submersos. Tese (Doutorado) - Escola Politécnica da Universidade de São Paulo, 2009.

SIMOS, A. N.; PESCE, C. P. Mathieu stability in the dynamics of TLP's tethers considering variable tension along the length. In: Transactions on the Built Enviroment, vol. 29. Originally presented at Offshore Brazil 1997. [S.l.: s.n.], 1997. 
SOARES, M. E. S. Excitação paramétrica em sistemas com um grau de liberdade (in Portuguese). Dissertação (Mestrado) - Escola Politécnica da Universidade de São Paulo, 1992.

SONG, J.; LU, L.; TENG, B.; PARK, H.; TANG, G.; WU, H. Laboratory tests of vortex-induced vibrations of a long flexible riser pipe subjected to uniform flow. Ocean Engineering, v. 38, p. 1308-1322, 2011.

SOTI, A. K.; THOMPSON, M. C.; SHERIDAN, J.; BHARDWAJ, R. Harnessing electrical power from vortex-induced vibrations of a circular cylinder. Journal of Fluids and Structures, v. 70, p. 360-373, 2017.

SRINIL, N.; ZANGANEH, H. Modelling of coupled cross-flow/in-line Vortex-Induced Vibrations using double Duffing and van der Pol oscillators. Ocean Engineering, v. 53, p. 83-97, 2012.

STAPPENBELT, B.; LALJI, F. Vortex-induced vibration super-upper branch boundaries. International Journal of Offshore and Polar Engineering, v. 18, p. 99-105, 2008.

SUMER, B. M.; FREDSØE, J. Transverse vibrations of an elastically mounted cylinder exposed to an oscillating flow. Journal of Offshore Mechanics and Arctic Engineering, v. 110, p. 387-394, 1988.

TANG, D. M.; DOWEL, E. H. Aeroelastic response and energy harvesting from a cantilevered piezoelectric laminated plate. Journal of Fluids and Structures, v. 76, p. 14-36, 2018.

TANG, L.; PAÏDOUSSIS, M. P.; JIANG, J. Cantilever flexible plates in axial flow: Energy transfer and the concept of flutter-mill. Journal of Sound and Vibration, v. 326, p. 263-276, 2009.

TEIXEIRA, B.; FRANZINI, G. R.; GOSSELIN, F. P. Passive suppression of transverse galloping using a non-linear energy sink. In: Proceedings of the 9th International Symposium on Fluid-Structure Interactions, Flow-Sound Interactions, Flow-Induced Vibration \&5 Noise FSI2 \&6 FIV+N. [S.l.: s.n.], 2018.

THOMPSON, J.; STEWART, H. Nonlinear Dynamics and Chaos. [S.l.]: John Wiley \& Sons, 1986.

THOMPSON, J. M. T. Dynamical Integrity: Three Decades of Progress from Macro to Nanomechanics, Ch. 1 in Global Nonlinear Dynamics for Engineering design and system safety. [S.l.]: Springer, 2019.

TUMKUR, R. K. R.; CALDERER, R.; MASUD, A.; PEARLSTEIN, A. J.; BERGMAN, L. A.; VAKAKIS, A. F. Computational study of vortex-induced vibration of a sprung rigid cylinder with a strongly nonlinear internal attachment. Journal of Fluids and Structures, v. 40, p. 214-232, 2013.

TUMKUR, R. K. R.; PEARLSTEIN, A. J.; MASUD, A.; GENDELMAN, O. V.; BLANCHARD, A. B.; BERGMAN, L. A.; VAKAKIS, A. F. Effect of an internal nonlinear rotational dissipative element on vortex shedding and vortex-induced vibration of a sprung circular cylinder. Journal of Fluid Mechanics, v. 828, p. 196-235, 2017. 
UENO, T. Supressão passiva de vibrações induzidas pela emissão de vórtices utilizando absorvedores não lineares de vibração: uma abordagem via modelos fenomenológicos. Dissertação (Mestrado) - Escola Politécnica da Universidade de São Paulo, 2019.

UENO, T.; FRANZINI, G. R. Numerical studies on passive suppression of one and two degrees-of-freedom vortex-induced vibrations using a rotative non-linear vibration absorber. International Journal of Non-Linear Mechanics (submitted), 2019.

UENO, T.; SATO, B. S.; FRANZINI, G. R. A numerical study of VIV suppression using a rotative NVA (non-linear vibration absorber) and a wake-oscillator model. In: Proceedings of the 9th International Symposium on Fluid-Structure Interactions, Flow-Sound Interactions, Flow-Induced Vibration \& Noise FSI2 \& FIV+N. [S.l.: s.n.], 2018.

VAKAKIS, A. F. Inducing passive Nonlinear Energy Sinks in vibrating systems. Journal of Vibration and Acoustics, v. 123, p. 324-332, 2001.

VAKAKIS, A. F. Intentional utilization of strong nonlinearity in structural dynamics. In: Proceedings of the X International Conference on Structural Dynamics, EURODYN $201 \%$. [S.l.: s.n.], 2017.

VAKAKIS, A. F. Passive nonlinear targeted energy transfer. Philosophical Transactions of the Royal Society A, v. 376, p. 1-15, 2018.

VAKAKIS, A. F.; GENDELMAN, O. V. Energy pumping in nonlinear mechanical oscillators: Part II - resonance capture. Journal of Applied Mechanics, v. 68, n. 1, p. 42-48, 2001.

VERNIZZI, G. J.; FRANZINI, G. R. Vortex-induced vibration analysis using invariant manifolds. In: Proceedings of the XVIII International Symposium on Dynamic Problems of Mechanics (DINAME 2019). [S.l.: s.n.], 2019.

VERNIZZI, G. J. L.; FRANZINI, G. R.; LENCI, S. A comparison between reduced-order models for a vertical riser undergoing parametric excitation. In: Proceedings of the Fourth International Conference on Recent Advances in Nonlinear Mechanics. [S.l.: s.n.], 2019.

VIEIRA, D. P. Estudo experimental das vibrações induzidas pela emissão de vórtices em cilindros flexíveis inclinados em rela à correnteza. Tese (Doutorado) - Escola Politécnica da Universidade de São Paulo, 2017.

VIKESTAD, K.; VANDIVER, J. K.; LARSEN, C. M. Addes mass and oscillation frequency for a circular cylinder subjected to vortex-induced vibrations and external disturbances. Journal of Fluids and Structures, v. 14, p. 1071-1088, Jan 2000.

WIERSCHEN, N. E.; HUBBARD, S. A.; LU, J.; FAHNESTOCK, L. A.; SPENCER Jr., B. L.; MCFARLAND, D. M.; QUINN, D. D.; VAKAKIS, A. F.; BERGMAN. Response attenuation in a large-scale structure subjected to blast excitation utilizing a system of essentially nonlinear vibration absorbers. Journal of Sound and Vibration, 2017.

WILLIAMSON, C. H. K.; ROSHKO, A. Vortex formation in the wake of an oscillating cylinder. Journal of Fluids and Structures, v. 2, p. 355-381, 1988.

WU, X.; GE, F.; HONG, Y. A review of recent studies on vortex-induced vibrations of long slender cylinders. Journal of Fluids and Structures, v. 28, p. 292-308, 2012. 
XIAO, Q.; ZHU, Q. A review on flow energy harversters based in flapping foils. Journal of Fluids and Structures, v. 46, p. 174-191, 2014.

XU, J.; HE, M.; BOSE, N. Vortex modes and vortex-induced vibration of a long, flexible riser. Ocean Engineering, v. 36, p. 456-467, 2009.

YANG, H.; XIAO, F.; XU, P. Parametric instability prediction in a top-tensioned riser in irregular waves. Ocean Engineering, v. 70, p. 39-50, 2013.

YANG, W.; AI, Z.; ZHANG, X.; CHANG, X.; GOU, R. Nonlinear dynamics of three-dimensional vortex-induced vibration prediction model for a flexible fluid-conveying pipe. International Journal of Mechanical Sciences, v. 138-139, p. 99-109, 2018.

YUAN, Y.; XUE, H.; TANG, W. A numerical investigation of Vortex-Induced Vibration response characteristics for long flexible cylinders with time-varying axial tension. Journal of Fluids and Structures, v. 77, p. 36-57, 2018.

ZDRAVKOVICH, M. M. Flow around circular cylinders Vol. 1: Fundamentals. [S.1.]: Oxford University Press, 2003.

ZDRAVKOVICH, M. M. Flow around circular cylinders Vol. 2:Applications. [S.l.]: Oxford University Press, 2003.

ZHOU, K.; XIONG, F. R.; JIANG, N. B.; DAI, H. L.; YAN, H.; WANG, L.; NI, Q. Nonlinear vibration control of a cantilevered fluid-conveying pipe using the idea of nonlinear energy sink. Nonlinear Dynamics, 2018. 


\section{A Produção científica associada a este texto}

O texto de síntese aqui apresentado é baseado, em partes, em artigos científicos publicados pelo autor tanto em anais de conferências quanto em periódicos indexados. Segue abaixo a lista de artigos diretamente relacionada ao texto.

- Artigos publicados em periódicos indexados ${ }^{1}$

1. Franzini, G.R.; Campedelli, G.R.; Mazzilli, C.E.N. "A numerical investigation on passive suppression of the parametric instability phenomenon using a rotative non-linear vibration absorber". International Journal of Non-Linear Mechanics, v. 105, p. 249-260, 2018.

2. Franzini, G.R.; Pesce, C.P. ; Gonçalves, R.T. ; Fujarra, A.L.C. ; Mendes, P. "An Experimental Investigation on Concomitant Vortex-Induced Vibration and Axial Top-Motion Excitation with a Long Flexible Cylinder in Vertical Configuration". Ocean Engineering, v. 156, 0. 596-612, 2018.

3. Franzini, G.R.; Bunzel, L.O. "A numerical investigation on piezoelectric energy harvesting from Vortex-Induced Vibrations with one and two degrees of freedom". Journal of Fluids and Structures, v. 77, p. 196-212, 2018.

4. Franzini, G.R.; Mazzilli, C.E.N. "Non-linear reduced-order model for parametric excitation analysis of an immersed vertical slender rod". International Journal of Non-Linear Mechanics, v. 80, p. 29-39, 2016.

5. Franzini, G.R.; Pesce, C.P.; Salles, R.; Gonçalves, R.T.; Fujarra, A.L.C.; Mendes, P. "Experimental analysis of a vertical and flexible cylinder in water: Response to top motion excitation and parametric resonance". Journal of Vibration and Acoustics, v. 137, p. 031010, 2015.

- Artigos completos, resumos ou resumos expandidos publicados em anais de conferências

1. Ueno, T.; Sato, B.S. ; Franzini, G.R. "A numerical study of VIV suppression using a rotative non-linear vibration absorber (NVA) and a wake-oscillator model". In: International Symposium on Fluid-Structure Interactions, FlowSound Interactions, Flow-Induced Vibration $\&$ Noise, 2018, Toronto. Proceedings of the 9th International Symposium on Fluid-Structure Interactions, Flow-Sound Interactions, Flow-Induced Vibration \& Noise, 2018.

1 Essa lista contém conexões que permitem ao leitor acessar versões digitais dos artigos a partir dos sítios dos periódicos na internet. 
2. Teixeira, B.; Franzini, G.R. ; Gosselin, F.P. "Passive suppression of transverse galloping using a non-linear energy sink". In: 9th International Symposium on Fluid-Structure Interactions, Flow-Sound Interactions, Flow-Induced Vibration $\&$ Noise, 2018, Toronto. Proceedings of the 9th International Symposium on Fluid-Structure Interactions, Flow-Sound Interactions, Flow-Induced Vibration \& Noise, 2018.

3. Bunzel, L.O.; Franzini, G.R. . "Numerical studies on piezoelectric energy harvesting from vortex-induced vibrations considering cross-wise and in-line oscillations". In: 9th European Nonlinear Dynamics Conference, 2017, Budapest. Proceedings of the 9th European Nonlinear Dynamics Conference, 2017.

4. Franzini, G.R.; Sato, B.S.; Campedelli, G.R. "Numerical analysis of a nonlinear energy sink (NES) for the parametric excitation of a submerged cylinder". In: 9th European Nonlinear Dynamics Conference, 2017, Budapest. Proceedings of the 9th European Nonlinear Dynamics Conference, 2017.

5. Franzini, G.R.; Pesce, C.P.; Gonçalves, R.T.; Fujarra, A.L.C.; Mendes, P. "Experimental Investigations on Vortex-Induced Vibrations with a long flexible cylinder. Part I: Modal-amplitude analysis with a vertical configuration". In: 11th International Conference on Flow-Induced Vibration, 2016, The Hagues. Proceedings of the 11th International Conference on Flow-Induced Vibration, 2016.

6. Franzini, G.R.; Pesce, C.P.; Gonçalves, R.T.; Fujarra, A.L.C.; Mendes, P. "Experimental investigations on Vortex-Induced Vibrations with a long flexible cylinder. Part II: effect of axial motion excitation in a vertical configuration". In: 11th International Conference on Flow-Induced Vibration, 2016, The Hagues. Proceedings of the 11th International Conference on Flow-Induced Vibration, 2016.

7. Franzini, G.R.; Pesce, C.P.; Salles, R. ; Gonçalves, R.T. ; Fujarra, A.L.C. ; Mendes, P. "Experimental analysis of a vertical and flexible cylinder in water: Response to top motion excitation and parametric resonance". In: ASME 2014 33rd International Conference on Ocean, Offshore and Arctic Engineering - OMAE2014, 2014, San Francisco. Proceedings of the 33rd International Conference on Ocean, Offshore and Artic Engineering, 2014. 


\section{B Análise assintótica da equação de van der Pol}

Considere a seguinte equação de van der Pol:

$$
\frac{d^{2} q_{y}}{d t^{2}}+\epsilon_{y} \omega_{f}\left(q_{y}^{2}-1\right) \frac{d q_{y}}{d t}+\omega_{f}^{2} q_{y}=0
$$

Definindo o tempo adimensional como $\tau=\omega_{f} t$ e adotando $(\dot{)})$ como a derivada com relação a $\tau$, a Equação B.1 é reescrita como:

$$
\ddot{q}_{y}+\epsilon_{y}\left(q_{y}^{2}-1\right) \dot{q}_{y}+q_{y}=0
$$

Este apêndice mostrará o desenvolvimento de uma solução assintótica para a Equação B.2, válida para $0<\epsilon_{y}<<1$. Este desenvolvimento é aqui feito utilizando o método das múltiplas escalas. Maiores detalhes e exemplos de aplicação do método podem ser encontrados nos livros-texto de Nayfeh (1973), Bender e Orszag (1978) e Nayfeh e Mook (1979).

Considere que a solução $q_{y}=q_{y}(\tau)$ seja da forma $q_{y}=q_{y 0}+\epsilon_{y} q_{y 1}$, com $q_{y 0}=$ $q_{y 0}\left(\tau_{0}, \tau_{1}\right)$ e $q_{y 1}=q_{y 1}\left(\tau_{0}, \tau_{1}\right)$. Justificando o nome do método, duas escalas de tempo são definidas, a saber $\tau_{0}=\epsilon_{y}^{0} \tau=\tau$ (escala rápida) e $\tau_{1}=\epsilon_{y} \tau$ (escala lenta). Note que as expansões aqui propostas podem ser corrigidas, bastando a inclusão termos da ordem de $\epsilon_{y}^{2}$

Define-se, ainda, uma família de operadores diferencias $D_{k}^{m}()=\partial^{m} / \partial \tau_{k}^{m}($ ). A partir dessa definição e da regra da cadeia, os seguintes resultados são obtidos:

$$
\begin{array}{r}
(\ddot{)})=D_{0}^{2}+\epsilon_{y} 2 D_{1} D_{0}()+O\left(\epsilon_{y}^{2}\right) \\
\dot{q}_{y}=D_{0} q_{y 0}+\epsilon_{y}\left(D_{0} q_{y 1}+D_{1} q_{y 0}\right)+O\left(\epsilon_{y}^{2}\right) \\
\ddot{q}_{y}=D_{0}^{2} q_{y 0}+\epsilon_{y}\left(D_{0}^{2} q_{y 1}+2 D_{1} D_{0} q_{y 0}\right)+O\left(\epsilon_{y}^{2}\right)
\end{array}
$$

O método segue com a substituição dos termos acima na Equação B.2. Em seguida, coletam-se os termos de mesma potência em $\epsilon_{y}$, dando origem às seguintes equações diferenciais ordinárias

$$
\begin{array}{r}
O(1): D_{0}^{2} q_{y 0}+q_{y 0}=0 \\
O\left(\epsilon_{y}\right): D_{0}^{2} q_{y 1}+q_{y 1}=-2 D_{1} D_{0} q_{y 0}-\left(q_{y 0}^{2} D_{0} q_{y 0}-D_{0} q_{y 0}\right)
\end{array}
$$


Note que a aplicação do método das múltiplas escalas à equação não-linear produziu um sistema de duas equações ordinárias lineares. Note, ainda, que a equação de $O\left(\epsilon_{y}\right)$ apresenta, em seu termo forçante, a solução da equação de $O(1)$. Caso a expansão considerasse termos com $O\left(\epsilon_{y}^{2}\right)$, a terceira equação apresentaria as soluções das escalas mais rápidas ordem em seu termo forçante.

Lançando mão da notação complexa, a solução da Equação B.6 é $q_{y 0}\left(\tau_{0}, \tau_{1}\right)=$ $A e^{i \tau_{0}}+A^{*} e^{-i \tau_{0}}=A e^{i \tau_{0}}+$ c.c., onde $A=A\left(\tau_{1}\right)$ e ( $)^{*}$ é o complexo conjugado de de uma grandeza qualquer e c.c indica o complexo conjugado do termo imediatamente à esquerda. A partir da solução $q_{y 0}$ e após algumas manipulações algébricas, as seguintes igualdades podem ser verificadas:

$$
\begin{array}{r}
D_{0} q_{y 0}=i A e^{i \tau_{0}}+c . c \\
q_{y 0}^{2} D_{0} q_{y 0}=i A^{3} e^{i 3 \tau_{0}}+i A^{2} A^{*} e^{i \tau_{0}}+c . c
\end{array}
$$

Levando os resultados acima na Equação B.7, responsável por governar a evolução do termo $q_{y 1}$, chega-se à Equação B.10.

$$
D_{0}^{2} q_{y 1}+q_{y 1}=-i\left(2 D_{1} A+A^{2} A^{*}-A\right) e^{i \tau_{0}}-i A^{3} e^{i 3 \tau_{0}}+\text { c.c. }
$$

Na Equação B.10, o termo forçante contém as frequências 1 e 3, sendo a primeira o termo ressonante. Esse termo, também chamado de secular, dá origem à soluções ilimitadas e deve ser removido da solução. Essa remoção é feita impondo:

$$
2 D_{1} A+A^{2} A^{*}-A=0
$$

Note que a Equação B.11 é uma equação diferencial complexa cuja incógnita na incógnita $A=A\left(\tau_{1}\right)$ e que pode ser resolvida escrevendo a amplitude complexa $A$ na forma polar como $A=A\left(\tau_{1}\right)=1 / 2 a e^{i \phi}$, com $0<a=a\left(\tau_{1}\right)$ e $\phi=\phi\left(\tau_{1}\right)$ números reais. Substituindo essa definição na Equação B.11 e separando as partes reais e imaginárias da equação resultante leva ao seguinte sistema:

$$
\begin{array}{r}
D_{1} a=\frac{a}{2}-\frac{a^{3}}{8} \\
a D_{1} \phi=0
\end{array}
$$

Os pontos fixos do sistema B.12 e B.13 são $a^{0}$ e $\phi^{0}$ tais que $D_{1} a=D_{1} \phi=0$. Dessa forma, é trivial demonstrar que $a^{0}=2$ é um ponto fixo não trivial e que $\phi^{0}$ independe 
de $\tau_{1}$. Tendo em vista o estudo da estabilidade do ponto fixo $a^{0}=2$, a Equação B.12 é linearizada em terno desse ponto, levando a:

$$
D_{1} a \approx\left(\frac{1}{2}-\frac{3}{8}\left(a^{0}\right)^{2}\right)\left(a-a^{0}\right)=-1(a-2)=2-a
$$

A trivial notar que a a solução da Equação B.14 tende a 2 para $\tau_{1} \rightarrow \infty$. Assim, essa solução não trivial é assintoticamente estável (no sentido Lyapunov). 